Andreas Hoffmann-0con,

Andrea De Vincenti, Norbert Grube (Hg.)

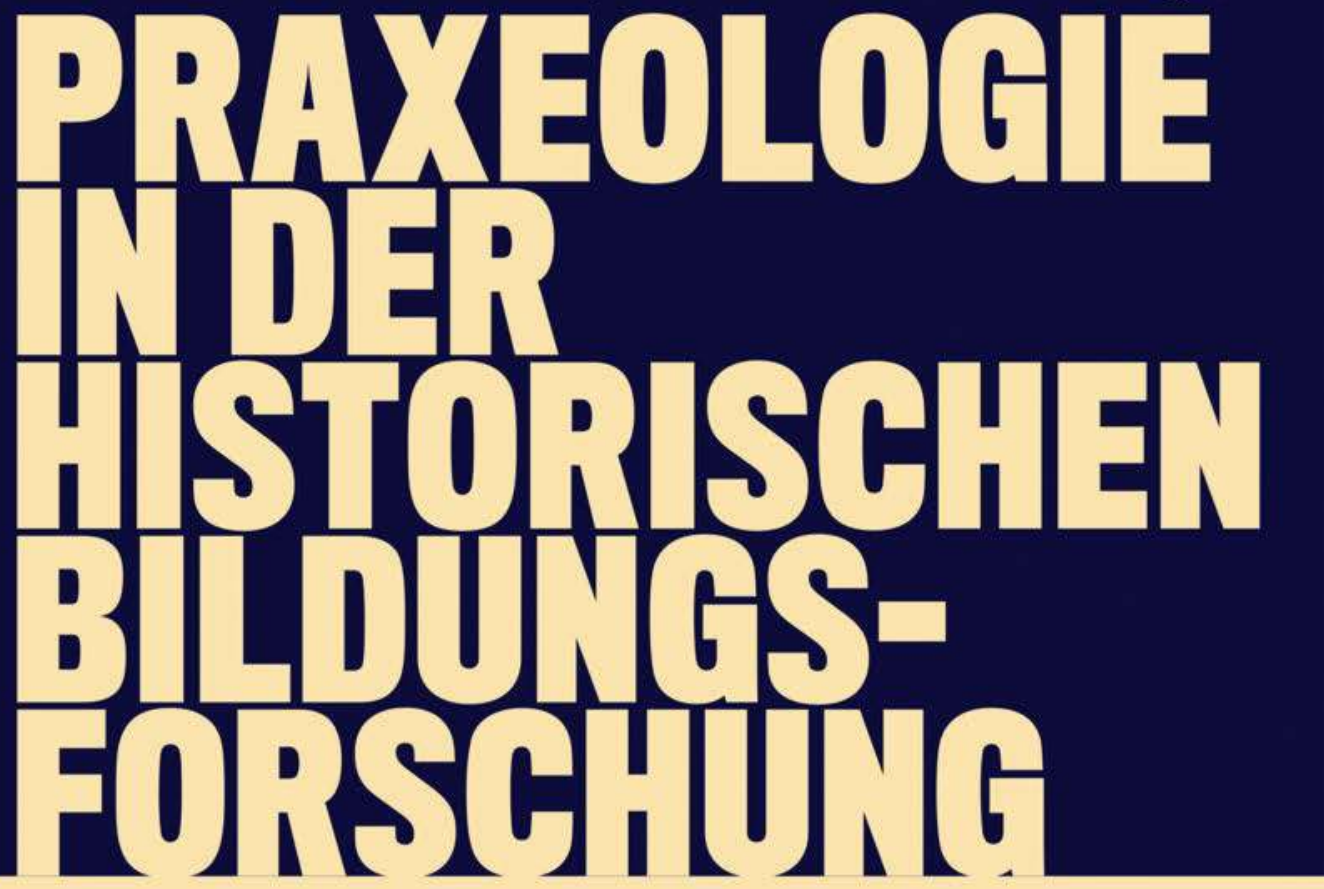

Möglichkeiten und Grenzen

eines Forschungsansatzes

[transcript] Pådagogik 
Andreas Hoffmann-Ocon, Andrea De Vincenti, Norbert Grube (Hg.)

Praxeologie in der Historischen Bildungsforschung 
Andreas Hoffmann-Ocon (Prof. Dr.), geb. 1969, leitet das Zentrum für Schulgeschichte (ZSG) der Pädagogischen Hochschule Zürich.

Andrea De Vincenti (Dr.), geb. 1977, lehrt und forscht am Zentrum für Schulgeschichte (ZSG) der Pädagogischen Hochschule Zürich.

Norbert Grube (Prof. Dr.), geb. 1969, lehrt und forscht am Zentrum für Schulgeschichte (ZSG) der Pädagogischen Hochschule Zürich. 
Andreas Hoffmann-Ocon, Andrea De Vincenti, Norbert Grube (Hg.)

\section{Praxeologie in der Historischen Bildungsforschung}

Möglichkeiten und Grenzen eines Forschungsansatzes

[transcript] 
Publiziert mit Unterstützung des Schweizerischen Nationalfonds zur Förderung wissenschaftlicher Forschung und der Pädagogischen Hochschule Zürich.

SCHWEIZERISCHER NATIONALFONDS

ZUR FÖRDERUNG DER WISSENSCHAFTLICHEN FORSCHUNG

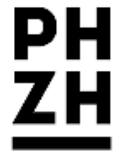

\section{Bibliografische Information der Deutschen Nationalbibliothek}

Die Deutsche Nationalbibliothek verzeichnet diese Publikation in der Deutschen Nationalbibliografie; detaillierte bibliografische Daten sind im Internet über http://dnb.d-nb.de abrufbar.

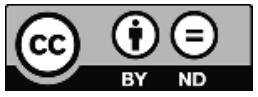

Dieses Werk ist lizenziert unter der Creative Commons Attribution-NoDerivatives 4.0 Lizenz (BY-ND). Diese Lizenz erlaubt unter Voraussetzung der Namensnennung des Urhebers die Vervielfältigung und Verbreitung des Materials in jedem Format oder Medium für beliebige Zwecke, auch kommerziell, gestattet aber keine Bearbeitung. (Lizenztext: https://creativecommons.org/licenses/by-nd/4.o/deed.de)

Um Genehmigungen für Adaptionen, Übersetzungen oder Derivate einzuholen, wenden Sie sich bitte an rights@transcript-publishing.com

Die Bedingungen der Creative-Commons-Lizenz gelten nur für Originalmaterial. Die Wiederverwendung von Material aus anderen Quellen (gekennzeichnet mit Quellenangabe) wie z.B. Schaubilder, Abbildungen, Fotos und Textauszüge erfordert ggf. weitere Nutzungsgenehmigungen durch den jeweiligen Rechteinhaber.

\section{() 2020 transcript Verlag, Bielefeld}

Umschlaggestaltung: Maria Arndt, Bielefeld

Korrektorat: Wolfgang Delseit, Köln

Satz: Francisco Bragança, Bielefeld

Druck: Majuskel Medienproduktion $\mathrm{GmbH}$, Wetzlar

Print-ISBN 978-3-8376-5374-8

PDF-ISBN 978-3-8394-5374-2

https://doi.org/10.14361/9783839453742

Gedruckt auf alterungsbeständigem Papier mit chlorfrei gebleichtem Zellstoff. Besuchen Sie uns im Internet: https://www.transcript-verlag.de Unsere aktuelle Vorschau finden Sie unter www.transcript-verlag.de/vorschau-download 


\section{Inhalt}

Möglichkeiten und Grenzen der Praxeologie in der Historischen Bildungsforschung

Einleitende Überlegungen zu einem facettenreichen Forschungsansatz

Andreas Hoffmann-Ocon/Andrea De Vincenti/Norbert Grube

I Orte - Akteure - Praktiken. Historische Fallanalysen zum Alltag und zu Krisenmomenten an Zürcher Lehrpersonenseminaren im 19. und 20. Jahrhundert

\section{Von Heizung und Hund}

Hauswarte an Zürcher Lehrerinnen- und Lehrerseminaren um 1900

Adrian Juen

Die "Seminarfamilie"

Nekrologe als Medium von Vergemeinschaftung

Jennifer Burri

81

Praktiken des Trinkens in Schülervereinen der Küsnachter

Seminaristen zu Beginn des 20. Jahrhunderts

Überlegungen zum Fokus auf Praktiken als Möglichkeit

einer radikalen Historisierung

Andrea De Vincenti

Kontrollregime und Eigensinn am Zürcher Lehrerseminar und an Erziehungsanstalten im späten 19. und frühen 20. Jahrhundert Analysen von Selbstzeugnissen und Archivquellen Norbert Grube

Praktiken der Eignungsabklärung von angehenden Zürcher Primarlehrpersonen (1940-1960)

Andreas Hoffmann-Ocon 


\section{Anleitungszusammenhänge. Interdisziplinäre Blicke auf Norm und Praxis des Lernens und Studierens}

Perspektiven einer bildungshistorischen Praxeologie

Studieren als Praxis

Sabine Reh/Kerrin Klinger

Fehler- und Strafpraktiken am Ende der Frühen Neuzeit am Beispiel von Schule und Unterricht in der Deutschschweiz

Rebekka Horlacher

"Da ist die Frage, ob man's steuern kann, seinen Körper«

Praxeologische Betrachtungen des Kindergartenalltags

Anja Sieber Egger/Gisela Unterweger

269

\section{Konzeptionelle Reflexionen und theoretische Ausblicke}

Registrieren oder Verstehen?

Überlegungen zur Rekonstruktion sozialer Wirklichkeit mittels

sozialer Handlung und/oder als Praxis

Christoph Maeder

Die normative Kraft des Praktischen

Bildungstheoretische Reflexion von zentralen Elementen der Buchbeiträge

Tomas Bascio 309

Verzeichnis der Autorinnen und Autoren 


\section{Möglichkeiten und Grenzen der Praxeologie in der Historischen Bildungsforschung \\ Einleitende Überlegungen zu einem facettenreichen Forschungsansatz}

Andreas Hoffmann-Ocon/Andrea De Vincenti/Norbert Grube

\section{Ausgangspunkte, Diskussionsanlässe und Ziele des Bandes}

Der aktuell zu verzeichnende Erfolg praxeologischer Ansätze und Perspektiven in geistes-, kultur- und sozialwissenschaftlichen Disziplinen kann als Indiz für einen "practice turn " verstanden werden; ${ }^{1}$ eine an Praktiken orientierte Neuausrichtung wissenschaftlicher Forschungsfelder weist neben grundlagenorientierten Fragen zur Krise von "grand theories« und generellen Überlegungen zu Sozial- und Erkenntnistheorien auch viele, teils widersprüchliche forschungspragmatische Facetten auf. Aus einer übergeordneten Perspektive betrachtet, ist die doppelte Absicht dieses Buches, vor dem Hintergrund verschiedener disziplinärer Forschungstraditionen anhand von Fallbeschreibungen und Erschliessungen auszuloten, welche Möglichkeiten der Praxeologie vor allem für den Zweig der Historischen Bildungsforschung, aber auch für die Bildungssoziologie und -ethnografie innewohnen, ohne aber die Limitierungen für den Erkenntniszusammenhang ausser Acht zu lassen. Dabei wird bewusst auf die Festschreibung eines >richtigen Verständnisses von Praxeologie verzichtet, um das Augenmerk stärker auf die in den einzelnen Beiträgen und die damit je nach Fragestellung und Quellenauswahl verbundenen praxeologischen Verständnis- und Anknüpfungsmöglichkeiten zu richten. An den unterschiedlichen Beiträgen, die Praxeologie teilweise eher als Heuristik, als Perspektive, teilweise aber auch als Thema oder methodische Implikation fassen, können die Facetten der Praxeologie sichtbar gemacht und diskutiert werden: Welche Aspekte praxeologischen Sehens und Denkens machen diesen Ansatz besonders interessant? Welchen ergänzenden, >neuen Erkenntniswert haben Deutungsverfahren, welche durch die Praxeologie nahegelegt werden? Verweist die konjunkturförmige Öffnung erziehungswissen- 
schaftlicher, historischer und bildungshistorischer Studien gegenüber der Praxeologie eher auf einen allgemeinen Trend in Kultur- und Sozialwissenschaften oder auf blinde Flecken bisheriger Forschungsperspektiven und -zugänge?

Gegenwärtig werden die Begriffe »Praktik«, »Praktiken«, »Praxis«, »Praxen« und »Praxeologie« in historisch angelegten Studien neben den Grossbegriffen "Diskurs«, »Struktur«, »Handeln« und »System« als zentrale Analysekategorien gehandelt, sodass von einer Praxeologisierung verschiedener disziplinärer Richtungen gesprochen werden kann. Die Bedeutungen dieser teils synonym, teils mehr oder weniger stark voneinander abgegrenzt verwendeten Begrifflichkeiten kann auch an dieser Stelle kaum abschliessend fixiert werden. Was eine einzelne Praktik ist, muss in jeder Forschungsarbeit wieder neu geklärt werden, welche Praktiken in der Summe eine Praxis formieren, die wiederum mit weiteren Praxen verflochten ist, ist Teil der Heuristik einzelner Studien. Fast reflexhaft wird denn auch mit der konzeptionellen Ausdehnung der Praxeologie auf weitere Themenbereiche und disziplinär bedingte Ansätze eine begriffliche "Unschärfe» beklagt. ${ }^{2}$ Studien zur (historischen) Praxeologie beginnen oder enden nicht selten mit dem Hinweis und Befund, dass Praxeologie keine Methode und kein Erklärungsmodell für konkrete historische Phänomene sei, sondern eine spezifische Perspektive auf vergangene Gegenstände, die menschliche Interaktionszusammenhänge auf kontingente Praxisformen zurückführt. ${ }^{3}$

Mit den in diesem Band versammelten Beiträgen lässt sich daher keine theoretische Fixierung der Praxeologie, aber der Prozess des gemeinsamen Nachdenkens über die >Unruhe< nachzeichnen, den der Begriff der Praxeologie im Feld der Historischen Bildungsforschung stiftet: Aus diesem Anlass veranstaltete im März 2018 das Zentrum für Schulgeschichte (ZSG) der Pädagogischen Hochschule Zürich (PHZH) einen Workshop mit dem Titel »Möglichkeiten und Grenzen der Praxeologie in der (Historischen) Bildungsforschung «. Die Arbeitstagung sollte eine vorläufige Bilanz aus Diskussionen und Überlegungen ziehen, welche die erste Phase des vom Schweizerischen Nationalfonds (SNF) unterstützten und von Mitarbeitenden des ZSG durchgeführten Projekts »Wissenschaft - Erziehung und Alltag. Orte und Praktiken der Zürcher Primarlehrer/-innenbildung in der ersten Hälfte des 20. Jahrhunderts« (Projektnummer 166008) ausgelöst hatte. In diesem Projekt stehen besonders das 1832 gegründete kantonale Lehrerseminar in Küsnacht, das 1869 etablierte Freie Evangelische Lehrerseminar Unterstrass, das seit 1878 existierende Lehrerinnenseminar an der Stadtzürcher Höheren Töchterschule und das ab 1942/43 seinen Betrieb aufnehmende Zürcher Oberseminar als Orte spezifischer Ausbildungskulturen für angehende Unterrichtende

2 Füssel 2015, S. 21 U. 23 (Zitat).

3 Welskopp 2017, S. 86. 
im Zentrum. ${ }^{4}$ Dabei werden die dem Seminar zugrundeliegenden verschiedenen wissenschaftlichen, fachlichen und praktischen/lokalen Wissen, die Abläufe im Unterrichtsalltag, Routinen und Rituale, z.B. Prüfungen, raumkonstituierende wie zugleich räumlich geprägte Interaktionen von Gruppen und Individuen fokussiert. ${ }^{5}$ Gibt es ein Bündel von bestimmten, ortsunabhängigen Praktiken, die das Seminar ausmachen, oder fallen ortsspezifische, widersprüchliche und lokal wiederum vielschichtige verschiedene Praktiken in den Blick?

Ein Meilenstein des Projekts bestand darin, forschungspraktische Fragen, methodische Reflexionen und erste inhaltliche Erkenntnisse mit grundsätzlichen Überlegungen zum Konzept der (historischen) Praxeologie zu verbinden. Zugleich ermöglichte der Austausch auf dem bildungshistorisch grundierten, jedoch interdisziplinär angelegten Workshop die Ergänzung und Vertiefung um Forschungsperspektiven von weiteren Expertinnen und Experten: aus der Erziehungs- und Geschichtswissenschaft vom Lehrstuhl für Historische Bildungsforschung und Steuerung des Bildungssystems an der Universität Zürich und von der Bibliothek für Bildungsgeschichtliche Forschung (BBF) Berlin des DIPF/Leibniz-Instituts für Bildungsforschung und Bildungsinformation sowie aus der Ethnologie/Ethnografie und Soziologie von dem ebenfalls an der PHZH angesiedelten "Zentrum Kindheiten in Schule und Gesellschaft«. Dort wurde das SNF-geförderte Forschungsprojekt »Kinder, die auffallen. Eine Ethnographie von Anerkennungsverhältnissen im Kindergarten« bearbeitet. Mit diesem vielperspektivischen Austausch war beabsichtigt, einen Beitrag zu forschungspraktischen Fragen im Zusammenhang mit praxeologischen Zugriffen auf heterogenes Quellenmaterial $\mathrm{zu}$ leisten und so die facettenreichen Möglichkeiten und Grenzen der Praxeologie zu diskutieren.

Die disziplinäre Zusammensetzung des Workshops mag zunächst willkürlich erscheinen. Doch scheint es gewinnbringend, multiperspektivisch praxeologische Herangehensweisen als sich gegenseitig ergänzend $\mathrm{zu}$ betrachten - sowohl mit disziplinär bedingten konzeptionellen Pfadabhängigkeiten als auch mit möglichen Schnittmengen. Denn ethnologische Ansätze werden seit Jahren in der Alltagsgeschichte und Historischen Anthropologie, aber auch in der Erziehungswissenschaft aufgegriffen, sodass praxeologische Zugänge in diesen Disziplinen stets auch über disziplinäre Grenzen hinausweisen, etwa indem sie über ein historisches Fundament verfügen. ${ }^{6}$

4 Zu den sich im 19. und 20. Jahrhundert ausdifferenzierenden Orten der Zürcher bzw. Deutschschweizer Lehrerinnen- und Lehrerbildung vgl. Hoffmann-Ocon 2015.

5 De Vincenti/Grube/Hoffmann-Ocon 2018a; De Vincenti/Grube/Hoffmann-Ocon 2018b; Hoffmann-Ocon 2017.

6 Breidenstein et al. 2013; Ulbricht 1994; Van Dülmen 1995, S. 407; Landwehr 2013, S. 7; Tanner 2012; jüngst im Überblick Müller 2018, S. 340. 
Dass eine solche disziplinäre Vielperspektivität durchaus ertragreich sein kann, zeigt etwa das Buch Das sowjetische Jahrhundert des Osteuropahistorikers Karl Schlögel, das sich einleitend dezidiert einem praxeologischen Ansatz verpflichtet. Mit der charakteristischen Herangehensweise der historischen Praxeologie, der archäologischen Spurensuche »nach einer untergegangenen Welt«, solle eine verschüttete Lebensform von Alltagspraktiken freigelegt und die gefundenen Mosaiksteinchen zusammengesetzt werden. ${ }^{7}$ Schlögel analysiert dabei nicht nur diverse schriftliche Quellen, die den sowjetischen Alltag prägten und die Bevölkerung ideologisch umzuformen suchten, wie etwa Kochbücher, Bibliotheksordnungen bzw. -kataloge, Statistiken, Fotodokumentationen, literarische oder publizistische Bestseller. Vielmehr besichtigte der Autor als jahrzehntelanger Kenner sowjetischer Landschaften und Städte zahlreiche Orte, Gebäude und Plätze. In dieser Mischung von Reisebericht und historischer Studie geht Schlögel kleinen Spuren von unscheinbar alltäglich gebrauchten oder auch symbolisch aufgeladenen Materialitäten, von Ritualen, wie den Paraden oder den Warteschlangen, von Routinen, Symbolen und Gewohnheiten nach - und damit also den Praktiken, welche die Sowjetunion als Lebensform konstituierten. ${ }^{8}$ So werden mit der von bis zu sieben Familien gleichzeitig genutzten Moskauer Stadtwohnung, der Kommunalka, Lebenspraktiken der nicht nur rational erfolgten Improvisation, der Rücksichtnahmen, stillschweigenden Regeln und zugleich der Durchsetzungsfähigkeit dargestellt. Die in der Kommunalka gelebte »Form der Kohabitation produzierte tatsächlich die ihr gemäßen Lebensweisen «. ${ }^{9}$ Mit vielfältigen ethnologisch-historischen Blicken auf Plätze, Dinge und Darstellungen spannt Schlögel ein weites Netz von ineinander verwobenen, sich teilweise widersprechenden und konfligierenden Praktiken auf - ohne sich in hermetischen Begriffsdefinitionen zu verlieren und einzuschliessen.

Auch die Erziehungswissenschaft hat die ethnologische Aufmerksamkeitsrichtung zur Erforschung sozialer Lebenswelten, Praktiken und institutioneller Verfahren aufgegriffen. So konstatiert etwa Breidenstein, dass »die Alltagspraxis gar nicht viel darüber wissen darf, wie sie es macht«, da »ein Zuviel an explizitem Wissen über die Praxis [...] deren Funktionieren [stört] [...] und das Handeln sins

7 Begrifflich bewegt sich Schlögel (2017) in der Nähe von Rahel Jaeggi (2014, S. 94 u. 106), die Lebensformen als ein Bündel bzw. Ensemble lebendiger Praktiken bzw. als eine gemeinsam geteilte Interpretation von Praktiken bestimmt.

8 Schlögel 2017, S. 20.

9 Ebd., S. 342f. Die Wohnpraktiken wurden auch durch die Materialität und soziale Konstituierung der Räume selbst hervorgebracht. Insbesondere die von allen Mitbewohnern genutzte Multifunktionsküche der Kommunalka, an deren Decke Fahrräder, Töpfe, Wannen und Pfannen hingen und in deren Ecken unzählige Haushaltsgeräte sich häuften, war ein »Konfliktfeld widerstreitender Auffassungen und Praktiken«. 
Stolpern« geraten lässt. ${ }^{10}$ Die zentrale Forschungsstrategie läge deshalb in der Beobachtung und Aufzeichnung der alltäglichen Praxis, um in einem weiteren deutenden Schritt immanente Regeln und Logiken der Praktiken zu rekonstruieren, die z.B. den Unterrichtsalltag konstituierten.

Der praxeologische Blick erschließt der Analyse eine eigene Ebene unterrichtlichen Handelns, indem er den schulischen Alltag als ein Bündel aufeinander bezogener, ineinander verschränkter sozialer Praktiken betrachtet, die es in ihrer Eigendynamik und in ihrem immanenten Funktionieren zu erkunden gilt. Diese Ebene der Praktiken liegt jenseits der Absichten, Deutungen und Entscheidungen der Akteure und auch jenseits individueller Verhaltensweisen. ${ }^{11}$

Der Zürcher Workshop und nun der vorliegende Band sollen kein >Einheitsverständnis` oder keine wissenschaftliche unité de doctrine von Praxeologie in der (Historischen) Bildungsforschung etablieren oder entsprechende Positionen sim Schützengraben der Theoriegefechte beziehen. Viel zu vielfältig wären mögliche theoretische Bezugspunkte und Rezeptionen von früheren Auseinandersetzungen mit Konzepten der Praxis oder der Praktiken, viel zu eklektisch hätte eine Zusammenführung von bereits Geschriebenem und Gedachtem daher auch ausfallen müssen. Vorstellungen von einer abschliessenden theoretisch-konzeptionellen Klärung des stets auch aus unterschiedlichen Perspektiven immer wieder neu diskutierten Ansatzes der Praxeologie würden eine Eindeutigkeit simulieren und die Vorstellung von einem konzeptionell-methodischen Baukasten nähren, der für verschiedenste Themen und Fragestellungen handhabbar sei. So könnten eher schematisch-schablonenhafte praxeologische Bezugnahmen gefördert werden, obwohl weiterhin interdisziplinär, aber auch historisch eine Vielfalt von innovativen Themen- und Fragestellungen ${ }^{12}$ mit teils neuen Quellen aufgeworfen werden, die das Potenzial hat, neue, bis dato eher marginalisierte Facetten dieses Konzepts zu extrapolieren. Weiterhin scheint doch die 15 Jahre alte Wahrnehmung von Andreas Reckwitz zutreffend, wonach es eine »bis ins Detail konsensual geteilte >Praxistheorie« nicht gebe, sondern eine gerade auch disziplinär mit unterschiedlichen Akzenten rezipierte theoretisch-konzeptionelle Vielfalt, die >Familienähnlichkeit beanspruchen könne. ${ }^{13}$ Das Bild von der "praxeologischen Theoriefamilie«, deren Grenzen angesichts interdisziplinärer praxeologischer Ansätze fliessend sind, rief zuletzt auch der Historiker Marian Füssel auf: wobei zur »Kernfamilie« gehörend die Schriften von Karl Marx, Pierre Bourdieu und Antho-

\footnotetext{
10 Breidenstein 2008, S. 207.

11 Ebd., S. 207.

12 Settele 2017; vgl. die Beiträge in Brendecke 2015.

13 Reckwitz 2003, S. 283; vgl. auch Freist 2015, S. 63.
} 
ny Giddens und als weitere Referenzen Werke von Luc Boltanski, Martin Heidegger, Michel Foucault, Michel de Certeau und Bruno Latour genannt werden. ${ }^{14}$

Ein wesentliches Ziel dieses Bandes ist es hingegen, beschreib- und (historisch) erschliessbare Merkmale von Praktiken in Bezug zur jeweils gewählten Forschungsperspektive und zum verwendeten empirischen Material zu thematisieren, zu untersuchen und zu diskutieren. Wenn Praktiken als an bestimmte Umstände, Orte, Kontexte und materielle Rahmungen gebunden gelten und sich überwiegend im Modus des durch jeweils implizites Wissen stabilisierten Gewohnten, Regelhaften, Ritualisierten und Selbstverständlichen vollziehen, somit »subjektunabhängige Handlungsmuster« darstellen, die allerdings »trotzdem nicht gänzlich übersubjektiv seien ", ${ }^{15}$ so sind die (historischen) Fälle auf diese Kennzeichen mit Abgrenzungs-, Verflechtungs- und Unschärfeproblematiken hin zu befragen. Der teilweise vermittelte Eindruck, mit dem aktuellen Trend praxeologischer Ansätze setze sich in den historisch arbeitenden Disziplinen ein methodologisches Bewusstsein und Wissen für Alltagskulturen nur zögerlich durch, ist ebenso auf seine >Inszenierung hin zu untersuchen, wie vergangene Wissensstände zur (mikrohistorischen) Erforschung des Alltäglichen wiederentdeckt werden können.

So zielt die hier präferierte praxeologische Beschäftigung darauf, den eigenen Erkenntnisprozess bei der Realisierung eines konkreten Forschungsvorhabens möglichst genau zu reflektieren - auch mit Blick auf disziplinär bereits gelegte Fundamente oder Vorläufer der Praxeologie - und somit auch Möglichkeiten und Grenzen aktueller praxeologischer Zugänge in der (Historischen) Bildungsforschung auszuloten. Dabei waren u.a. folgende Fragen leitend: Wie können neben bewussten auch unbewusste, nichtintentionale Handlungen in einer historischpraxeologischen Perspektive miterfasst werden, und wie lassen sich Quellen womöglich gegen etwaige Intentionen ihrer Verfasser analysieren ${ }^{16}$ Eignen sich bestimmte Dokumente und historische Quellen besonders für eine praxeologisch informierte Forschung? Welche Konsequenzen ergeben sich aus den unter der Prämisse der Praxeologie gemachten Setzungen? Was ist spezifisch für die praxeologische Perspektive? Was verliert man mit ihr aus den Augen?

Dazu wurden die Autorinnen und Autoren des Bandes aufgefordert, ihr jeweiliges Verständnis von Praxeologie, Praxis und Praktik in ihren Beiträgen offenzulegen und die Folgen dieser Prämissen für die eigene Forschungstätigkeit

14 Füssel 2015, S. 24.

15 Jaeggi 2014, S. 102 u. 126. Diese bzw. ähnliche Kennzeichen von Praktiken nennen etwa auch Freist 2015, S. 67, und Haasis/Rieske 2015a, S. 13f. u. 33. Die individuelle Kreativität im Umgang mit Praktiken betonen Reichardt 2015, S. 52, und teilweise auch Brandes/Zierenberg 2017, S. 5 f., 8 u. 20. 
nicht nur zu reflektieren, sondern diese Überlegungen auch explizit in ihren Artikel einfliessen zu lassen. So tritt uns ein Fokus auf Praktiken in einem Beitrag denn auch als rein heuristische Kategorie entgegen, während in einem anderen aus den theoretischen Prämissen gar methodische Konsequenzen für den eigentlichen Forschungsprozess abgeleitet werden. Praxeologie wurde von den einzelnen Autorinnen und Autoren demnach wahlweise als Erkenntnisperspektive, als Fokus, aber auch als spezifische historiografische Methode mit ganz konkreten dos und don'ts verstanden. Im Zusammenhang mit dieser Vielfalt von Praxeologieverständnissen erscheint eine Zusammenschau der an die einzelnen Beiträge gekoppelten praxeologischen Zugangsweisen und Reflexionen gewinnbringend. $\mathrm{Ob}$ die Praxeologie als eine unter vielen weiteren Zugangsweisen in der (Historischen) Bildungsforschung andere, vergessene oder neue Erkenntnisse generieren konnte, kann natürlich nicht im luftleeren Raum, sondern letztlich nur mit Blick auf die in der scientific community bereits diskutierten Themen und Fragen beantwortet werden. Mit diesem Ziel werden nachfolgend Vorläufer von aktuell als praxeologisch gefassten Ansätzen für die (Historische) Bildungsforschung diskutiert (Abschnitt 2), um anschliessend zentrale Kristallisationspunkte der Debatten um Praxeologie in der (Historischen) Bildungsforschung darzustellen (Abschnitt 3). Im vierten und letzten Abschnitt dieser Einleitung wird schliesslich eine Übersicht über die in diesem Band versammelten Beiträge geboten.

\section{Praxeologie in der Historischen Bildungsforschung: konzeptionell-methodische Vorläufer und Importe}

\section{Altags-, Mikro- und Kulturgeschichte}

Nicht erst dezidiert praxeologische Konzepte, sondern etwa auch Ansätze in der Frühneuzeithistorie haben seit gut 40 Jahren das Verhältnis von Norm und Praxis problematisiert. Es war erst recht ein zentraler Kristallisationspunkt von Debatten innerhalb eines Forschungsfeldes, welches insbesondere in den 1990er-Jahren Konjunktur hatte und auf die frühneuzeitliche »gute Policey« fokussiert war. Frühere Ansätze der Alltagsgeschichte sahen die - staatliche bzw. kirchliche - Norm und die - lokale, widerständige - Praxis häufig als Gegensatzpaar. ${ }^{17}$ Diese stark binäre Sichtweise verstand alltägliche Praktiken nicht nur als einen vernachlässigten, sondern als einen versteckten, unterhalb der seinerzeit von mächtigen Eliten und Herrschenden geprägten sichtbaren Normen und kulturell gültigen Gewohnheiten liegenden Bereich, der teilweise durch subversive Eigenständigkeit von Teilen der Bevölkerung geprägt gewesen sei. Diese Sichtweise ist nahe

17 Van Dülmen 1984, S. 8 u. 10; Schindler 1984, S. 14f.; vgl. van Dülmen 1995, S. 421. 
an den theoretischen Erwägungen Michel de Certeaus. Er sieht Gesellschaft nicht nur durch normative, institutionalisierte Praktiken konstituiert, sondern auch aus »zahllosen anderen Praktiken [...], die `klein`, >minoritär geblieben sind, die (auch wenn sie keinen Diskurs organisieren) da sind und die ersten Sprösslinge oder Reste von differenten (institutionellen oder wissenschaftlichen) Hypothesen für diese oder für andere Gesellschaften enthalten. ${ }^{18}$ Ein solcher Ansatz, wonach »es autonome Eigentümlichkeiten des Alltags gebe, die von denen anderer Bezirke des gesellschaftlichen Lebens ganz verschieden sind und sogar im Gegensatz zu ihnen stehen«, wurde von Soziologen wie Norbert Elias, die in Prozesshaftigkeiten und Mentalitätsstrukturen (Studien über die Deutschen) denken, scharf zurückgewiesen, da es sonst einen sozial kaum zu bestimmenden Nichtalltag gebe. ${ }^{19}$ Elias' Argumentation passt zu Warnungen vor der durch quellennahes Nacherzählen geförderten Romantisierung, Idealisierung und neuer Absolutsetzung armer, stigmatisierter, mit dem Status der Aussenseiter/-innen behafteten Subjekte vor allem aus dem dörflich-ländlichen Raum. ${ }^{20}$ Der sich scheinbar ganz versiert inmitten von Machtstrukturen, sozioökonomischen Bedingungsfaktoren und materiellen Mangelerfahrungen mit taktischer $" L i s t ~ «{ }^{21}$ eigene Interessen und (Über-)Lebensstrategien verfolgende >kleine Mann`sei kein autonomes Subjekt gewesen.

Verflechtungen von Makro- und Mikroperspektive und somit eben von Norm und Praxis aufzuzeigen, war hingegen das dezidierte Ziel des Forschungsansatzes, der sich im weiteren Sinne als Historische Anthropologie konstituierte und dem auch das erwähnte Forschungsfeld zur >guten Policey` nahesteht. Statt einer binären Gegenüberstellung von gesellschaftlicher Norm und individueller Praxis sollten Abstrakta, wie etwa der Staat oder die Herrschaft, und die Entstehung bzw. Rezeption von Normen vor Ort durch einen dezidierten Fokus auf (Aus-) Handlung und Aneignung als soziale Praxis dargestellt werden. ${ }^{22}$ Achim Landwehr und Jürgen Schlumbohm haben stark dafür plädiert, den Blick von den nicht durchgesetzten Normen, die geradezu als »Strukturmerkmal des frühneuzeitlichen Staates« galten und diesen stets als defizitär erscheinen liessen, ab- und den (vor Ort) gelebten Praktiken zuzuwenden. ${ }^{23}$ Dieses Postulat ist im grösseren Kontext eines cultural turns zu verstehen, unter den auch der in etwa zeitgleiche

18 De Certeau 1988, S. 109 f.

19 Elias 1978, S. 24 (Zitat) u. 25.

20 Sarasin 2003, S. 20 u. 29; Müller 2018, S. 339.

21 De Certeau 1988, S. 13f., 16 u. 27 (Zitat).

22 Landwehr 2000a; Holenstein 2003; Eibach 1994; Sabean 1990, S. 26; Ulbricht 1994, S. 353; Lüdtke 1991 u. 1997; Müller 2018, S. 335; ein Überblick über das Forschungsfeld der »Guten Policey« findet sich bei Iseli 2009. 
Aufschwung der Kulturgeschichte oder der damals sogenannten neuen Politikgeschichte gefasst wurde. Die als »Geschichte ohne Menschen« kritisierten strukturund sozialgeschichtlichen Studien sollten nun ergänzt werden durch eine Hinwendung zu den »Gesichter[n] in der Menge«, zum Spezifischen, zu regionalen Kulturen und Wissen..$^{24}$ Durch diesen Fokus auf das Subjektive, auf eine Diversität von Erfahrungen, Wahrnehmungen und Deutungen, wurden Forderungen nach Mehrperspektivität in der Geschichtswissenschaft virulent. ${ }^{25}$

Nach Alf Lüdtke zeige sich in vielseitigen Aneignungsprozessen ein Ineinander von Nachahmung, Akzeptanz erwarteten Verhaltens und Übernahme von Regelhaftigkeiten sowie eigensinniger Nutzung von raumzeitlichen Spielräumen und Materialitäten, Spannbreiten und Bedeutungsnuancen durch je unterschiedliche Akzente. Formen und Ausprägungen von Aneignungen hängen demnach stark von sozialen Kontexten ab, wie Lüdtke am Beispiel von Praktiken im Arbeitermilieu zusammenfasst: »Aneignen ist also das Sich-immer-wieder-Einlassen auf Lärm und Hitze der Werkstatt wie der heimischen Küche, auf den eigenen Leib wie die Leiber der Kollegen und Vorgesetzten, auf die Präsenz von Nachbarn oder Kindern, aber die Materialität von Werkstoffen. $\aleph^{26} \mathrm{Um}$ weder vermeintlich allmächtigen Makrostrukturen noch dem Individuum im Sinne des die meisten Lebenssituationen eigenmächtig meisternden, souveränen Subjekts Geschichtsmächtigkeit zuzusprechen, wurden Geschichte und historischer Wandel in spannungsreichen täglichen Aneignungs- und Aushandlungsverhältnissen von (staatlicher) Norm und (lokaler) Widerständigkeit oder (individuellem) Eigensinn der Akteure und Akteurinnen verortet. ${ }^{27}$ In subjektiven Deutungen von Welt wird häufig irrational und unbewusst - an verbreitete Vorstellungen, Wahrnehmungen, sedimentierte Wissensstrukturen und Objektivierungen angeschlossen, aber eben mitunter situativ angepasst, je nach (kommunikativen) Kontexten mit spezifischen, möglicherweise ebenfalls routinisierten, nicht unbedingt neuen, in der ungeplanten und willkürlichen Komposition allerdings potenziell neu sich zeigenden Nuancen, Facetten und Varianten. ${ }^{28}$ Die Betonung von subjektiver Eigentümlichkeit und Variierbarkeit gegenüber institutionalisierten Regelhaftigkeiten in Aneignungsprozessen fasste de Certeau mit den Begriffen der »List«, der »Kreativität«, der »Taktik«. ${ }^{29}$

Vor diesem Hintergrund erscheint die Praxeologie als eine Form der Weiterentwicklung älterer historischer Herangehensweisen, gerade wenn diese - in

\footnotetext{
24 Burke 2005, S. 67.

25 Dinges 1997, S. 183; Lüdtke 1991.

26 Lüdtke 2003, S. 280; vgl. ebd. S. 281.

27 Chartier 1992, S. $20 f$.

28 Davis et al. 2008, S. 18.

29 De Certeau 1988, S. 19f., 23 u. 27.
} 
einer Formulierung von Dagmar Freist - darauf fokussiert, »wie sich soziale Ordnungen und relationale Positionen durch je situativ spezifische Ausformungen sozialer Praxis konstituieren und ebenso [...], wie diese verworfen werden, sie sich neu formieren und so historisch entstandene Praktiken sich wiederum fortschreiben, stabilisieren oder verändern. «Es sei genau diese "Aufmerksamkeit für das Strukturiert-Strukturierende, für die chiastische Verschränkung von Handlungen und Strukturen«, welche die Praxeologie kennzeichne, meint etwa auch Achim Landwehr. ${ }^{30}$

Diese Bezüge praxeologischer Zugangsweisen zu älteren Forschungsperspektiven der Mikro- und Alltagsgeschichte, welche teilweise unter dem Dach der Historischen Anthropologie oder der Kulturgeschichte subsumiert werden, bleiben in der historisch orientierten praxeologischen Literatur beinahe unbestritten. Dennoch werden Fragen aufgeworfen, ob und wie die neue praxeologische Ausrichtung über die Ansinnen dieser älteren Ansätze hinausgehe. So betont Landwehr etwa den mit den älteren Forschungszugängen geteilten Wunsch, »Geschichten von Menschen in der Zeit zu erzählen«, fügt gleichzeitig aber auch mahnend hin$\mathrm{zu}$, dass die historisch-praxeologischen Geschichten dem Menschen zwar sehr nahekommen dürfen, jedoch beim Schreiben - und hierin liegt vielleicht eine Radikalisierung der Mikrogeschichte oder Historischen Anthropologie - stets die »Einsicht in die Dezentralisierung des Subjekts « dazugehöre. ${ }^{31}$

Mit den Möglichkeiten einer solchen Radikalisierung der Historischen Anthropologie setzte sich jüngst Caroline Arni auseinander, indem sie für die Wiederaufnahme des zur Gründungszeit der Historischen Anthropologie inhärenten kritischen Moments plädierte. Ihrer Ansicht nach habe der Kulturbegriff in der Geschichtswissenschaft sein kritisches Potenzial verloren, sodass erneut Impulse aus der Anthropologie aufzugreifen seien. Ein solcher Impuls könnte, so Arni, das von Jakob Tanner, Bruno Latour und sozialanthropologischen Debatten vorbereitete Symmetrisierungspostulat als Hebel gegen Anthropozentrismus und Eurozentrismus sein. ${ }^{32}$ Dabei solle im Zuge historischer Arbeiten der onto-

30 Die Äusserungen von Freist und Landwehr fanden im Rahmen eines Runden Tisches statt, der im Band von Haasis/Rieske 2015b, S. 199-236 (Zitate: S. 207 u. 214) abgedruckt ist; vgl. auch Haasis/Rieske 2015a, S. 13. Landwehrs Ausspruch erinnert an Bourdieus Ansicht, wonach es Aufgabe praxeologischer Erkenntnisweise sei, »die dialektischen Beziehungen zwischen den objektiven Strukturen und den strukturierten Dispositionen«zu erkunden (vgl. Bourdieu 2015, S. 147).

31 Haasis/Rieske 2015b, S. 230.

32 Arni 2018, S. 203. Das Postulat, den Eurozentrismus zu transzendieren, kann angesichts der drei in diesem Band zusammengeführten, allesamt auf den deutschsprachigen Raum gerichteten Forschungsprojekte nicht weiter diskutiert werden. In manchen Beiträgen klingen Diskussionen über Materialität und Dinge als Akteure und damit Anschlussmöglichkeiten zur Debatte um den Anthropozentrismus an. 
logische Status von Dingen in ihrer relationalen Positionierung herausgearbeitet werden, sodass gerade in der Historischen Anthropologie etablierte Analysekategorien wie Aneignung, Wissen oder Deutung heute verworfen werden müssten, weil sie weiterhin der Vorstellung von Repräsentation und Episteme verbunden blieben. Anders ausgedrückt gingen sie immer noch davon aus, dass verschiedene Sichtweisen auf eine Welt repräsentiert würden, während es im Zuge des ontological turns gerade darum gehe, über die Analyse relationaler Positionierungen zu Aussagen darüber zu gelangen, was die Welt für andere ist. Im Zentrum stehe deshalb die Frage, was als Reales existiere - dies eben nicht im epistemischen oder repräsentationalen, sondern in einem durch und durch ontologischen Sinne. ${ }^{33}$ Dies erinnert trotz anderer Begrifflichkeiten auch an wissenssoziologische Ansätze etwa von Berger/Luckmann, die "Wissen « als die von an einem gewissen sozialen Ort und zu einer gewissen Zeit geteilte Gewissheit fassten, »dass Phänomene wirklich sind und bestimmbare Eigenschaften haben «. »Wirklichkeit« wird somit schlicht als »Qualität von Phänomenen [definiert], die ungeachtet unseres Wollens vorhanden sind «. ${ }^{34}$ Auch Martin Dinges' Aufruf, historische Phänomene mit Konzepten und Kategorien aus der untersuchten Zeit selbst (und nicht mit Analysekategorien der Gegenwart) zu beschreiben, hatte vielleicht eine ähnliche Stossrichtung wie die von Arni vorgeschlagene rekursive Geschichtsschreibung, welche über ein "rekursive[s] Hin und Her" von Konzepten Aufschluss über die zu beschreibenden Dinge gebe und damit die Alterität von der Deutung auf das Ding verschiebe. ${ }^{35}$ Rekursiv ist eine solche Geschichtsschreibung insofern, als sie die historische Konzeption des Dings auf dieselbe Stufe wie das Konzept der Historikerinnen und Historiker hebt und deren Analysekategorien über die so gewonnene Symmetrie infrage stellt. ${ }^{36}$ Hier ergibt sich eine gewisse Nähe zu älteren Forderungen etwa bei Paul Veyne, sich den Dingen über Korrelate von Praktiken zu nähern, denn »es gibt ja gerade keine Dinge, es gibt nur Praktiken «. ${ }^{37}$ Die Gemeinsamkeiten der in diversen Aspekten ganz unterschiedlichen Ansätze sollen hier nicht überstrapaziert, sondern eher darauf hingewiesen werden, dass an unterschiedlichen theoretischen und disziplinären Orten die unter dem cultural turn in den letzten 30 Jahren etablierten Ansätze etwa vor dem Hintergrund des ontological turns wieder kritisch auf ihr Potenzial, aber auch auf ihre Grenzen hin

33 Arni 2018, S. 207, 212 u. 214.

34 Berger/Luckmann 2007, S. 1.

35 Darauf, dass mit der Frage, was die Welt oder das In-der-Welt-Sein sei, trotzdem immer ein epistemologisches Problem mit wiederum methodologischen Implikationen verbunden bleibt, verweist Tatjana Thelen (2019, S. 277f.) in ihrem Kommentar zum Text von Arni.

Arni 2018, S. 216, 218 u. 222. 
befragt werden - dies nicht nur in der Geschichtswissenschaft, sondern auch in der Erziehungswissenschaft.

\section{Kulturwissenschaftliche Prägungen der Erziehungswissenschaft}

Ähnlich, wie Ute Daniel die Geschichtswissenschaft verortet hat, ${ }^{38}$ kann auch die Erziehungswissenschaft im disziplinären Geflecht als Kulturwissenschaft verstanden werden. Sie auf der Basis kulturtheoretischer Konzeptionen voranzutreiben, bedeutet, wahrzunehmen, dass Erziehungswissenschaft von den cultural turns in den Referenz- und Nachbardisziplinen beeinflusst wird - ganz so, wie es etwa Iris Clemens beschreibt, um theoretische Potenziale für die Erziehungswissenschaft zu ermitteln. ${ }^{39}$ Kulturtheoretisch beobachten und beschreiben zu können, heisst, die in der pädagogischen Tradition starke konzeptionell exponierte Stellung des Subjekts zu hinterfragen und sich mit auf die Formel gebrachten Überlegungen »there is action, but no agent « produktiv auseinanderzusetzen, auch um das Subjekt-Struktur-Problem nicht im Sinne einer simplen Richtungsentscheidung aufgreifen zu müssen. ${ }^{40}$ Ähnliche Überlegungen aufgreifend, identifizieren Christiane Thompson, Kerstin Jergus und Georg Breidenstein in den "produktiven Überlagerungen « und den »daraus resultierenden Bewegungen im Zwischen der Disziplinen, der Gegenstände, der Zugänge, der Erkenntnisweisen [...] wechselseitige Anregungen und Dialogmöglichkeiten für verschiedene Zweige der Erziehungswissenschaft« in Perspektiven kulturwissenschaftlicher Bildungsforschung. ${ }^{41}$ Während Clemens mit kulturtheoretisch informierten Beschreibungen in erziehungswissenschaftlichen Forschungszusammenhängen das Subjekt-Struktur-Problem als Ordnungsentwurf nicht reaktivieren resp. überstrapazieren möchte, bewerten Thompson, Jergus und Breidenstein Forschungsbewegungen im Sinne von kulturwissenschaftlichen Einsätzen in der Erziehungswissenschaft als produktiv, wenn mit einer Sensibilität »für operative Logiken und Unterscheidungspraxen [...] [eine] Verflüssigung leitender Kategorien und Konzepte « erzielt werden. ${ }^{42}$ Solche Fragen an die disziplinäre Pädagogik und Erziehungswissenschaft sowie an die dort eingelagerten Kategorien sind im Wandel der wissenschaftlichen Disziplinen nicht neu. Das in der Erziehungswissenschaft breit und auch in der Geschichtswissenschaft rezipierte Werk Niklas Luhmanns, ${ }^{43}$ welches wegen seines Blicks auf semantische Praktiken in juristi-

\footnotetext{
38 Daniel 2001.

39 Clemens 2015, S. 7.

40 Ebd., S. 11.

41 Thompson/Jergus/Breidenstein 2014, S. 7.

42 Ebd., S. 10.

43 Lenzen 2004; Becker/Reinhardt-Becker 2001.
} 
schen, pädagogischen, theologischen etc. Reflexionen mehrfach in die Nähe der Praxistheorie Pierre Bourdieus gerückt wurde ${ }^{44}$ in der wiederum Praxis mit Habitusbeschreibungen erschlossen wird, hat traditionell gefestigte Vorstellungen über die Autonomie des Subjekts bereits vor Jahrzehnten infrage gestellt. ${ }^{45}$ So wird Luhmanns "Lob der Routine« in praxeologisch sensiblen bildungshistorischen Studien "wiederentdeckt«, um vor allem auf Verwaltungspraktiken hinzuweisen, denen zufolge die Durchsetzung eines allgemeinen Regelapparates an einem Ort viele Einzelfallentscheidungen erspart und somit Arnold Gehlens Verständnis von der Entlastung des Menschen durch verlässliche Institutionen und Gewohnheiten ähnelt, aber die Gefahren eines »taktlosen« und »ausdrucksschwachen« Routinehandelns in sich birgt. ${ }^{46}$

Mit dem Verweis auf eine Wiederentdeckung oder Relektüre von soziologischen oder geschichtswissenschaftlichen, aber auch pädagogischen und erziehungswissenschaftlichen Texten vergangener Jahrzehnte ist angedeutet, dass Dimensionen der Routine und des Alltags bereits Trends waren, die analog zur Durchsetzung der Alltags- und Kulturgeschichte zu verstehen sind. Thomas Welskopp gelangt zu der Bewertung, dass das Ausrufen einer praxeologischen Wende in der Geschichtswissenschaft dann auch ein Anachronismus wäre und tatsächlich die "post-poststrukturalistische Perspektive s sich mit ihrem "offenen Konzeptarsenal « und ohne »theoretische Allheilsversprechen « in vielerlei historischen Darstellungen niedergeschlagen habe ${ }^{47} \mathrm{Als}$ ein Beispiel für das Geflecht von offenen Konzeptionen, Disziplinen sowie Theorie- und Methodentransfer und damit als Ausdruck von Querbeziehungen in Forschungspraktiken kann gemäss Jürgen Finger auch das Projekt "Datenhandbuch zur deutschen Bildungsgeschichte « gezählt werden.$^{48}$ Dieses folgte unter dem Dach »der historisch arbeitenden Pädagogik« dem Forschungstrend und der »Rezeption sozialwissenschaftlicher empirischer Methoden", ganz so wie es auch die Geschichtswissenschaft getan habe, »die gleichzeitig die erfahrungs- und alltagsgeschichtliche Dimension von Schule und Bildung [...] stärker berücksichtig[e] ${ }^{49}$ In der Erziehungswissenschaft werden für vorgängige Umakzentuierungen, die in die Richtung eines praxeologischen Verständnisses weisen, etwa Michael Parmentier mit seinen empirischen und hermeneutischen, auf frühe Überlegungen Klaus Mollenhauers verweisenden Analysen von Dingen angeführt. ${ }^{50}$ Theoretische und methodologi-

\footnotetext{
44 Nassehi/Nollmann 2004.

45 Luhmann/Schorr 1988, S. 178-187; Finger 2016, S. 126; Bourdieu 2015, S. 186. 
sche Überlegungen zur Praxeologie in eine erziehungswissenschaftlich imprägnierte Forschungspragmatik zu >übersetzen`, kann als Perspektive mehr an den in alltägliche Praktiken verwickelten Akteuren und Dingen orientiert sein. Mensch, Material und den Austausch- sowie Lernprozess zugleich in den Blick nehmend, so mutet Arnd-Michael Nohls Analyseentwurf der Materialität der Pädagogik an, dient dazu, Dinge, die in Lern- und Bildungsprozesse eingewoben sind, sichtbar zu machen. Leitend ist u.a. die Frage, was passiert, wenn Erziehungsabsichten an Dinge delegiert werden, die Subjekten dann »bestimmte Handlungen sowie die ihnen unterliegenden Orientierungen zumuten und somit selbst erziehen ${ }^{51}{ }^{51}$ Um das »transaktionale "Zusammenspiel zwischen Menschen und Dingen erforschen zu können, plädiert Nohl für eine, durch ihn auch an Fallbeispielen bereits explorierte Forschungsperspektive, die kleinteilige Rekonstruktionen zulässt, um Momente des alltäglichen Austauschs zwischen Menschen und Dingen zu dokumentieren. Mit Bezugnahmen auf Michael Parmentiers "Dinghermeneutik«, die auf tradierte Sinnzusammenhänge der "material culture « und ihre Bedeutungsverschiebungen eingeht, ${ }^{52}$ schlägt Nohl vor, nach »Logiken des Gebrauchs, unabhängig von den Zufälligkeiten des jeweils handelnden Individuums zu fragen «. ${ }^{53}$ Die von ihm gewählten Fallstudien mehrheitlich in ausserschulischen Feldern beziehen sich dann u.a. auf das Erlernen des Umgangs mit der Kupplung beim Autofahren oder auf den spielenden Gebrauch von Playmobil bei Kindern. Die Betonung der Logiken des Gebrauchs im Zusammenhang mit Lernvorgängen weist auf die zur Praxeologie in anderen Disziplinen geteilte Auffassung einer Regelmässigkeit des Geschehens hin, die als ein »Zusammenspiel von expliziten Regeln und Vorschriften, [von] in die Artefakte eingelassenen Anweisungen, [von] impliziten Regeln und normativen Verhaltensanforderungen « gedacht wird. ${ }^{54}$ Wie schulische Wissensordnungen durch Dinge, »die im Unterricht [...] und in ,Wissenspraktiken « etabliert und aktualisiert werden «, jeweils situiert sind, wird durch die interpretative Schul- und Unterrichtsforschung aufgegriffen..$^{55}$ Eine diesbezügliche Forschungsprogrammatik mit vorliegenden Studien etwa zur Tafel, zu Schreibheften und zu Lernmedien wird ergänzt durch Explorationen zu "Schlüsseln, Türen, Tischen und Stühlen«, eben zu den - nach Martin Lawn und Ian Grosvenor - Materialities of Schooling, wobei ein Forschungsbedarf bestehe, der auf die unerlaubten Dinge ziele, wie auf Zigaretten und Handys. ${ }^{56}$

\footnotetext{
51 Nohl 2011, S. 9.

52 Rittelmeyer/Parmentier 2001, S. 104-124.

53 Nohl 2011, S. 206.

54 Schmid 2012, S. 10.

55 Gebhard et al. 2015, S. 4.

56 Ebd., S. 6.
} 
Michel Foucaults typologisierenden Entwürfe von Macht-Wissen-Praktiken wiederum bieten nach Norbert Ricken und Sabine Reh Ansatzpunkte, um der pädagogischen Praxis von Prüfungen bildungshistorisch näher zu kommen. ${ }^{57}$ Foucault versucht diesen für (Prüfungs-)Praktiken bedeutsamen Komplex mit Forschungsperspektiven zu versehen: Um der Entstehung bestimmter Wissensarten nachzugehen und zu ermitteln, wie sich Machtinstanzen das Wissen unterordnen oder diesem ideologische Grenzen aufzwingen, schlägt Foucault vor, die Prüfung matrixförmig zu verstehen und zu untersuchen: als »ein Mittel, um die Norm, die Regel, [...], die Qualifikation, die Ausschließung festzulegen oder wieder einzuführen ${ }^{58}{ }^{58}$ Seine Annahme lautet dabei, dass die Prüfung neben dem Mass und der Untersuchung in vielen wissenschaftlichen Praktiken gleichzeitig als Methode und Instrument eingesetzt wurde.

Obwohl die historische Praxeologie an Traditionslinien empirisch fundierter Studien der Bildungsgeschichtsschreibung mit einer mikrohistorischen Tiefenschärfe anknüpfen kann, vermag sie auch gegenüber sozialhistorischen Erkenntnisinteressen offen $\mathrm{zu}$ sein, aber ebenso gleichzeitig Prozesse sozialer Ordnungsbildung und Subjektivierungsprozesse näher heranrücken zu lassen. ${ }^{59}$ Die Verflechtung von sozial- und kulturgeschichtlichen Dimensionen wird jüngst im erziehungswissenschaftlichen Raum mit methodischen und theoretischen Reflexionen zu sozialen Praktiken anhand Didier Eribons Buch Rückkehr nach Reims ${ }^{60}$ thematisiert. Dabei wird den "Autosoziobiografien« als Textsorte die methodische Potenz zugeschrieben, die Verschiebung und teils "Auslöschung« von sozialen Praktiken am autobiografischen Beispiel des (schwulen) Bildungsaufsteigers, der sich in einem Bruch mit seinem proletarischen Herkunftsmilieu und seiner Herkunftsfamilie befindet, zur Sprache zu bringen. Praktiken der Geschmacksbildung, der Gestik und der Sprache als soziale Kräfte historisch zu identifizieren, die an der Ausformung des eigenen wissenschaftlichen Habitus beteiligt waren, entspreche dabei einem methodischen `Forschungsprogramm<, das bereits Bourdieu mit seinem "Soziologische[n] Selbstversuch« vorlegte ${ }^{61}$ Gerade dieser Habitusansatz basiert auf einem Praxeologieverständnis, das von einer mal mehr unbewussten und mal mehr bewussten Beherrschung der durch Lernen erworbenen Regeln spezifisch sozialer Felder ausgeht. Demnach korrespondiere der Habitus mit den »Generierungsschemata [...] von Strategien, die den objektiven Interessen

\footnotetext{
57 Ricken/Reh 2017, S. $249 f$.

58 Foucault 2017, S. 300.

59 Berdelmann et al. 2019, S. 4f.

60 Eribon 2016.

61 Rieger-Ladich/Grabau 2018, S. 791-797; Bourdieu 2002.
} 
ihrer Urheber entsprechen können, ohne ausdrücklich auf diesen Zweck ausgerichtet zu sein«. ${ }^{62}$

\section{Zentrale Kristallisationspunkte der Debatten um Praxeologie in der (Historischen) Bildungsforschung}

Trotz der durch die beschriebene Offenheit des Rahmens gegebenen, auch erfrischenden Vielfalt an praxeologischen Spielarten soll der vorliegende Band über die Erkenntnisse der Einzelbeiträge hinausweisende Denkanstösse zu einer praxeologisch ausgerichteten Historischen Bildungsforschung bieten. So klingen gewisse Themen in vielen Beiträgen immer wieder an. Es sind dies etwa Fragen zum Verhältnis von Wissen, Diskursen und Praktiken, aber auch Fragen nach der Verortung von Praktiken bezüglich ihrer Kontextualität und Reziprozität, nach Narrativen, Meister-, Fortschritts- und Modernisierungserzählungen in der Geschichte und nach allfälligen methodischen Implikationen der Praxeologie.

\section{Wissen, Diskurse und Praktiken}

Wissen in seiner impliziten, gewussten - also institutionalisierten - Form ist ein Zentralbegriff in der praxeologischen Konzeption, gilt es doch als eine Art gesellschaftlich geteiltes, akzeptiertes und damit zunächst einmal eher stabiles Element, das gleichsam Praktiken konturiert und zugleich auch durch Praktiken immer wieder aktualisiert wird - allerdings auch verändert werden kann. ${ }^{63}$ Ein so gefasster Wissensbegriff verweist auf wissenssoziologische Ansätze ${ }^{64}$ und bezeichnet letztlich das breit abgestützte Verständnis einer Gesellschaft über das von ihr selbst sanktionierte Verhalten in bestimmten Kontexten und Situationen, über das also, was 'man< im Hinblick auf allgemeine Erwartungen tut oder eben nicht tut. In diesem Sinn werden etwa auch Wissensordnungen - häufig fast synonym mit dem Begriff der Norm verwendet - als wesentliche Faktoren für die Etablierung von Praktiken benannt, wobei eine Modifikation der Praktiken ebenfalls in einer Neukonfigurierung der Wissensordnung resultieren kann.

Insbesondere das schwierige Verhältnis von Habitus und bewussten Handlungsstrategien gibt Anlass, auch im methodologischen Sinne über die Vielschichtigkeit des impliziten Wissens mit Rekurs auf die Schriften von Pierre Bourdieu, Michael Polanyi oder Martin Heidegger nachzudenken: Ralf Bohnsack

62 Bourdieu 1993, S. 113.

63 Zum impliziten Wissen, das in der Wissensgeschichte auch als tacit knowledge bezeichnet wird, vgl. Freist 2015, S. 66; Vogel 2004, S. 642; Lipphardt/Patel 2008, S. 428 u. 431.

64 Berger/Luckmann 2007. 
verweist in diesem Zusammenhang darauf, dass sich die Übergänge vom Impliziten zum Expliziten von Fall zu Fall verschieben und immer wieder auch implizites Wissen von den Beteiligten selbst zur Explikation gebracht werden könne. Um den Komplex des impliziten Wissens weiter aufzufächern, schlägt er mit einer theoriegeschichtlichen und wissenssoziologischen Perspektivierung vor, einerseits zwischen habitualisiertem Wissen, das sich eher auf verbale Praktiken beziehe, und inkorporiertem Wissen zu unterscheiden, welches Praktiken betrifft, die eher mit körpergebundenen Ausdrucksformen, also Zeuggebrauch, etwa dem Fahrradfahren, zu tun haben. ${ }^{65}$ Andererseits unterscheidet Bohnsack imaginatives und imaginäres Wissen: Imaginatives Wissen könne sich sowohl beim Zeuggebrauch als auch in der kommunikativen Dimension finden lassen und sei nur zu einem Teil implizit. Das imaginäre Wissen sei eine weitere Ausprägung von Wissen im kommunikativen Bereich, das zu entdecken sei, wenn z.B. junge Menschen sich an virtuellen sozialen Identitäten aus der Werbung in ihren Alltagspraktiken orientieren. Anteile der virtuellen sozialen Identität werden in Selbstinszenierungen von Jugendlichen übernommen, teilweise aber auch als Pose erkannt und als solche kommuniziert. ${ }^{66}$ Mit diesen bewusst typologisierenden Differenzierungen des impliziten Wissens werden Anschlüsse vor allem an die im positiven Sinne eklektizistische Theorietradition und Kulturanalyse Pierre Bourdieus vorgenommen. Diese bleibt für die Praxeologie interessant, da sie in ihrer Orientierung den Gegensatz zwischen Subjektivismus und Objektivismus überwinden wollte und Anhaltspunkte für ein methodisch-methodologisch geleitetes erweitertes Verständnis bietet für die Entstehung und Vollzug sozialer Praktiken.

Mit Bohnsacks Hinweis auf die Explizierbarkeit und die Differenziertheit des impliziten Wissens deutet sich an, dass es keine geschlossene, unwandelbare Formation bildet.

Die Stabilität von Wissensordnungen schliesst nicht aus, dass Wissen auch delegitimiert und relegitimiert werden kann. Allerdings erfolgt diese neue Normalisierung gesellschaftlichen Wissens häufig in teilweise öffentlich ausgetragenen Wissenskämpfen ${ }^{67}$ - etwa wenn eine Lebensform (um an die von Jaeggi und Schlögel skizzierten und verwendeten Begriffe anzuknüpfen) von relevanten Teilen der Gesellschaft als nicht mehr zeit- und sinngemäss erachtet und in heftigen Konflikten durch eine andere Lebensform abgelöst wird. Ebenso schliesst die Wissensgeschichte an solche Grundsätze der gesellschaftlichen Konstruktion von Wissen, aber eben auch seiner Wandelbarkeit und seiner kontextuell bedingten Vielfalt an: "Inhalte, Formen und soziale Reichweite des Wissens sind nach diesem Verständnis immer Teil von komplexen Macht- und Aushandlungsprozessen,

65 Bohnsack 2017, S. 153.

66 Ebd., S. 167.

67 Foucault 2001, S. 213-217; vgl. Sabean 1990, S. 227. 
deren genaues Zusammenspiel stets im konkreten historischen Fall zu bestimmen ist. ${ }^{68}$

Während die praxeologische Vorstellung von etabliertem, vielfach geteiltem implizitem Wissen innerhalb der Gesellschaft fast Nähen zu dem später skizzierten Ansatz der öffentlichen Meinung als sozialer Kontrolle zu besitzen scheint, könnte der wissensgeschichtlichen Ansätzen zugrundeliegende Zirkulationsbegriff ergänzend und nicht ersetzend dazu eher das Performative und Situative von Praktiken betonen. ${ }^{69}$

Dabei steht gerade nicht nur schriftlich fixiertes, etwa wissenschaftliches Wissen, sondern oftmals auch praktisch im Alltag anwendbares, lokales, zugleich zirkulierendes Wissen im Analysezentrum. ${ }^{70}$ Bereits in alltags- und lokalgeschichtlichen Studien, etwa von David Sabean, wurde Wissen verstanden als »allgemein verbreitete Vorstellungen und Meinungen«, die er auch als »Sage«, »Gerücht«, »Stimme« benennt. ${ }^{71}$

Wissen in diesem Sinne ist soziales Wissen, entstanden in der beständigen Diskussion zwischen Nachbarn, Freunden und Familienangehörigen. Es ist auf gar keinen Fall eine bestimmte rationale >Wahrheit‘, eine kohärente Geschichte, die nur eine Fassung kennt, sondern vielmehr eine permanente Fortentwicklung eines bestimmten Themas, ein Abwägen der Wahrscheinlichkeiten, eine stetig sich verändernde Beurteilung. Seine besondere Beschaffenheit macht es zu einer Grundlage des praktischen Handelns. [...] Selbstverständlich gab es auch Raum für individuelle Interpretationen, geheime Eigeninteressen, Kenntnisse, Dummheit und Konservativismus. ${ }^{72}$

Im Duktus des wissensgeschichtlichen Leitbegriffs der Zirkulation von Wissen ${ }^{73}$ wird dieses als mäandernd, an Bestehendes, Tradiertes zurückgebunden, sich durch Zirkulation gleichwohl verändernd und sich in bestimmten Entstehungsund Verwendungskontexten, in medialen und kommunikativen Techniken und Materialitäten zwischen verschiedenen Orten, gesellschaftlichen Gruppen anpassend, wiederholend, abschleifend und so neue Wissen hervorbringend beschrie-

68 Vogel 2004, S. 650f.

69 Über die Wiederholungen, die kennzeichnend für Praktiken sind, läuft auch die performative Konstitution von Identitäten, z.B. derjenigen des Geschlechts, wie sie bei Judith Butler gefasst ist, wobei so hervorgebrachte geschlechtliche Markierungen durch widerständige Praktiken auch wieder gelöscht werden können (2019, S. 36 u. 50). Vogel 2004, S. 658; Lipphardt/Patel 2008, S. 429. Sabean 1990, S. 227.

72 Ebd., S. 226 (Hervorhebung im Original).

73 Sarasin 2011, S. 166. 
ben. Wissen wird teilweise gar selbst als eine Praktik untersucht, etwa im Bereich des ökonomischen oder wissenschaftlichen Wissens, welches durch Praktiken des Klassifizierens, Messens und Genealogisierens gekennzeichnet sei. ${ }^{74}$ Wissensgeschichtlich "umfasst der Begriff der Wissenspraktiken nicht nur akademische Formen der Wissensproduktion oder gesellschaftliche Anwendungskontexte, sondern auch Verschränkungs- und Translationsmechanismen zwischen unterschiedlichen Wissensmilieus «. ${ }^{75}$ Wissensgeschichtliche Überlegungen sind daher auch für historisch praxeologische Arbeiten in der Historischen Bildungsforschung relevant, da Schule und Lehrpersonenbildung stark auf Zirkulation von implizitem, wissenschaftlichem und lokalem bzw. praktischem Wissen beruhen können.

Dabei interessiert u.a., mit welchen »komplexen Aneignungsprozessen [...] die ursprünglich wissenschaftlichen Vorstellungen und Praktiken in das alltägliche gesellschaftliche Leben integriert wurden. ${ }^{76}$ Doch doing knowledge meint mehr: Ob und wie Wissen sozial als relevant und massgeblich für Handeln gilt sowie mit diversen Praktiken verwoben ist, hängt wesentlich von Formen der Zirkulation, der Sedimentierung, also von der Verflechtung unterschiedlicher Wissen ab, bzw. wie diese mit Akzeptanz und Macht verbunden sind. Selbst dann sei ein vermeintlich einheitliches Wissen kaum je für die ganze Bevölkerung oder soziale Gruppen unumstritten gültig. ${ }^{77}$

Mit soziologischem Blick »kulturwissenschaftliche Welten « durchmessend, setzte auch Andreas Reckwitz, in dezidiert praxeologischen Zusammenhängen, Praktiken und Diskurse sozialtheoretisch und methodologisch über den Wissensbegriff in Relation: Er plädierte dafür, den angeblichen Dualismus zwischen Praxis und Diskurs aufzuheben und mit einem »Modell von $>$ Praxis/Diskurs/Formationen $\mathrm{zu}$ arbeiten . $^{78}$ Praktiken und Diskurse seien demnach nicht in dualistischer Manier, sondern vielmehr als »zwei aneinander gekoppelte Ag-

74 Dommann et al. 2014; Lipphardt/Patel 2008, S. 433.

75 Lengwiler/Beck 2008, S. 492.

76 Vogel 2004, S. 649.

77 Den Komplex von Wissen und Praktiken hat David Sabean anhand württembergischer Dorfgesellschaften im 17. Jahrhundert untersucht. Hier blieben z.B. kursierende Gerüchte und das Geschwätz weitgehend unbeachtet, »und selbst diejenigen, die daran glauben, verhielten sich ganz verschieden und schenkten ihnen in unterschiedlichem Masse Clauben. Die Struktur des Wissens im Dorf bot die Grundlage für viele verschiedene Arten des Handelns «. Statt eines gültigen impliziten Wissens konnten verschiedene zirkulierende Wissen in unterschiedlichen Kontexten mit diversen Praktiken verbunden sein. So wurde das Geschwätz »nach den Regeln der öffentlichen Meinung« erst etwas »Ernsthaftes«, wenn es zum als ehrenrührig geltenden und gerichtsrelevanten »Ceschrey« erwuchs: Es beruhte anders als das Ceschwätz auf belastbarem Wissen und war mit anderen Praktiken konnotiert (1990, S. 174 U. 226). 
gregatzustände der materialen Existenz von kulturellen Wissensordnungen zu begreifen «. ${ }^{79}$ Somit definiert er Praktiken als »Wiederholung und permanente Verschiebung von Mustern der Bewegung und der Äusserung von aktiven Körpern und Dingen [...], welche zugleich durch Formen impliziten Wissens - Knowhow-Wissen, interpretatives Wissen routinisierter Sinnzuschreibungen, Komplexe kulturell modellierter Affekte und Motivationen - zusammengehalten und ermöglicht werden. ${ }^{80}$ Ein simpler Fokus auf Verkörperung oder Materialität von Praktiken ignoriere somit eine Seite der Doppelstruktur von Praktiken genauso, wie dies auch ein einseitiger Fokus auf die diskursive Ebene tun würde. $\mathrm{Zu}$ einer umfassenden Dechiffrierung von Praktiken müsse sich ein praxeologischer Forschungsansatz deshalb immer sowohl der Beschreibung der Praktiken selbst als auch den in den Praktiken enthaltenen kulturellen Codes und Ordnungen von implizitem und explizitem Wissen zuwenden. Dadurch wird auch die Entscheidung, ob Praktiken im engeren Sinn "verkörpert", also in den Körpern und Artefakten eingeschrieben oder als implizite und explizite Wissen eher mental verankert seien, obsolet. Die »Doppelstruktur « von Praktiken, die einerseits die materialen, über Sehen und Hören direkt wahrnehmbaren Körperbewegungen, andererseits aber auch die impliziten Sinnstrukturen umfassen, erteilt diesem Entweder-oder eine klare Absage und bezieht Position für das Sowohl-als-auch. ${ }^{81}$ Das Soziale bestehe somit aus Praktiken, womit eben auch die Normierungen oder die Diskurse als (wiederum eigene) Praktiken verstanden werden müssten und »damit nicht aus anderem Stoff gemacht seien. $^{82}$

Während Praxeologen materiell in Körpern und Artefakten verankerte soziale Praktiken als die kleinste Einheit des Sozialen und das damit zusammenhängende implizite Wissen aufspürten, scheine sich das Augenmerk des diskurstheoretischen Lagers auf den »intellektuelle[n] Überbau von Aussagen« zu konzentrieren, »die gewissermassen auf der Materialität des verkörperten und materiell verankerten Wissens raufsitzen ${ }^{8}{ }^{83}$ In methodologischer Sicht bedeuteten die unterschiedlichen Zugriffe für historische Studien ein voneinander abweichendes » $\mathrm{Zu}$ gänglichkeitsproblem«. Demnach lassen sich historisch vergangene Praktiken nicht miterlebend beobachten, denn das zeitgenössische Wissen sei abwesend. Allerdings gebe es mit zeitgenössischen Praxisbeschreibungen, Ego-Dokumenten und Artefakten historisches Material, mit dem nicht nur aus damaliger subjek-

79 Ebd., S. 202; ähnlich zur engen Verbindung von Diskursen und Praktiken Chartier 1989, S. 18. Nähen zum Diskursbegriff besitzt auch der Begriff der Lebensform von Jaeggi (2014, S. 106), wenn sie ihn als geteilte, d.h. verbreitete Interpretation von Praktiken versteht.

80 Reckwitz 2008, S. 202.

81 Ebd., S. 188 u. 196.

82 Ebd., S. 204.

83 Ebd., S. 190, 192 (Zitat). 
tiver Perspektive auf »die ‘äußere Sicht der Praktiken«, sondern streckenweise auch auf das implizite Wissen der Teilnehmenden, "das in diese Praktiken eingelassen ist, rückgeschlossen werden« könne. ${ }^{84}$ Demgegenüber sei die Methodologie der Diskurstheorie bereits auf historisches Material ausgerichtet. Mit dem Konzept der Wissensordnung werde nun das bezeichnet, was in Praktiken und Diskursen verhandelt wird und diesen ihre Form gibt. In einer kombinierten und verflochtenen Analyse lohne sich insbesondere die Suche nach Instabilitäten innerhalb der benannten Praxis/Diskurs-Formationen. ${ }^{85}$

Für ein solches, verbindendes Verständnis von Diskurs und Praxis plädiert in der seit einigen Jahren zu verzeichnenden Debatte über die historische Rekonstruktion von Erziehungspraktiken auch Hans-Rüdiger Müller. Mit dem Hinweis auf in Erziehungspraktiken eingelagertes diskursives Wissen soll angedeutet werden, dass konkrete soziale Praktiken nicht nur performativ vollzogen wurden, sondern stets auch ein reflexives Moment in sich trugen. Im alltäglichen Handeln könnten derartige Momente sich verselbstständigen, sodass einmal mehr implizites und einmal mehr explizites Praxiswissen für die Strukturierung z.B. des Erziehungs- und Schulalltags relevant gewesen ist. ${ }^{86}$

\section{Kontextualität und Reziprozität von Praktiken}

Praktiken werden situativ und kontextuell jeweils neu in Verbindung mit weiteren Praktiken bestimmt, die durch Kollektiv- oder Einzelakteure, durch Orte oder durch Materialitäten hervorgebracht werden oder sich bei ihnen niederschlagen bzw. zeigen. ${ }^{87}$ Sie basieren demnach, versteht man die Träger dieser Praktiken als Gegenüber, auf Reziprozität: So verursachen »unaufhörlich[e] [...] Kontrollen und Korrekturen [...] die Anpassung der Praktiken und Expressionen an die Erwartungen und Reaktionen der anderen Handlungssubjekte ${ }^{88}$ Zahlreiche Beiträge dieses Bandes greifen die kontextuelle Bedingtheit von Praktiken und ebenso reziproke Verhältnisse auf. Diese können in Form von Routinen und Ritualen bzw. Gewohnheiten - bei Jaeggi auch als Sitten und Gebräuche bezeichnet ${ }^{89}$ - eher stabil und festgelegt sein, sie können aber trotz Institutionalisierungen und implizitem Wissen situativ bedingte, gerade in schwer einzuschätzenden Konflikt- oder Krisenkontexten neue Aushandlungen bedeuten, welche Form oder Facetten von Praktiken situationsadäquat, sachangemessen und sinnstiftend sind.

\footnotetext{
84 Ebd., S. 198.

85 Ebd., S. 202.

86 Müller 2016, S. 269.

87 Jaeggi 2014, S. $103 f$.

88 Bourdieu 2015, S. 146.

89 Jaeggi 2014, S. 154.
} 
In der Geschichtswissenschaft hat u.a. Rudolf Schlögl die sozialen Beziehungen in sogenannten überschaubaren frühneuzeitlichen Dorfgemeinschaften als reziproke Kommunikation unter Anwesenden (Face-to-face-Kommunikation) bezeichnet. ${ }^{90}$ Sie sei durch den "Prozess des laufenden Aushandelns zwischen den politischen Akteuren ${ }^{91}$ gekennzeichnet gewesen. Herrschaft habe deshalb versucht, durch zeremonielle, inszenierte und arrangierte Darstellungen von öffentlichem Konsens öffentliche Kommunikation zu steuern.

Mit Schlögls Konzept der Kommunikation unter Anwesenden werden Momente der kontextuell bedingten, situativ angepassten Hervorbringung von Praktiken, der durch körperliche Präsenz und Präsentation gekennzeichneten Performanz und des Verlaufs von sozialen Interaktionen betont. ${ }^{92}$ Auch David Sabean vertrat nach seinen mikrohistorischen Erkenntnissen über die Lebenswelt in württembergischen Dörfern der Frühen Neuzeit die »Auffassung, daß sich die sozialen Beziehungen in den württembergischen Dörfern im betrachteten Zeitraum beständig veränderten. Tradierte Kulturelemente wechselten fortwährend ihre Gestalt, sobald sie in neue Kontexte gestellt wurden. ${ }^{{ }^{93}}$ In diesem Zusammenhang sei Herrschaft in der Frühen Neuzeit nicht ausschliesslich als politisch, ideologisch-kirchlich, materiell und symbolisch vorgegebene, unhinterfragte, statische und lineare Machtbeziehung zwischen König bzw. Fürst und Untertanen zu verstehen. Vielmehr seien reziproke, d.h. durch permanente Kommunikation befestigte oder auch variierte Elemente in diesem Verhältnis zu beachten. Aufgrund dieser Reziprozität »erfordern die ungleiche Machtverteilung und die alltäglichen Zwangspraktiken eine ständig erneuerte Legitimierung«. ${ }^{94}$

Als eine wesentliche Dimension für die Ausprägung wie auch Reproduktion sozialer Praktiken in reziproken Beziehungen zu gesellschaftlich geprägten Normen wird von Bourdieu mit Blick auf die kabylische Gesellschaft wie auch von Frühneuzeithistoriker/-innen die Ehre, die öffentliche Reputation genannt. ${ }^{95}$ Sie ist gleichsam implizit stets vorhanden, wenn sich Menschen entlang des Gewohnten, Regelhaften, öffentlich Erwarteten verhalten und dieses entsprechende Verhalten auch bei Anderen beobachten und einfordern. Und sie bringt erst recht Praktiken des Konfliktaustrags hervor, wenn Ehre, Ansehen und der gute

90 Schlögl 2000, S. 244.

91 Schlögl 2004, S. 40; vgl. Weber 2015, S. 564; Mergel 2002, S. 591 u. 597.

Performanz ist nicht auf autonome Subversion zu verengen, sondern ebenso durch eingeschriebene Normen und Regulationen bestimmt, vgl. Butler 2019, S. 190, 200 u. 205.

93 Sabean 1990, S. 14. Dieses fortwährende neue Hervorbringen bezeichnet Sabean als »historische Kräfte«bzw. soziale Kräfte.

94 Ebd., S. $35 f$.

Bourdieu 2015, S. 18, 22, 27f. u. 42. 
Ruf verletzt wurden. ${ }^{96}$ Bei den Kabylen geht es nach Ehrverletzungen nicht nur um die Wiederherstellung des gesellschaftlichen Ansehens, sondern auch um die soziale Balance als Ganzes.

Ehre und Ansehen einer Person wurden, so weist Sabean in seinen regionalhistorischen Studien zur Konfrontationen und Konfliktbewältigung in der Frühen Neuzeit nach, entscheidende Ressourcen »für die Konkurrenzposition seiner Bewohner u und "zur Herausbildung neuer vertikaler Beziehungen« abseits der Blutsverwandtschaft und insbesondere von Gemeinschaft, die nichts Unveränderliches und Institutionalisiertes sei, sondern etwas »beständig sich in Bewegung« Befindliches und zugleich »Geformtes $«{ }^{97}$ Das heisst: Prestige und Sozialstatus bedingen jeweils neu hervorgebrachte und zugleich festgeschriebene bzw. erwartete Umgangsweisen im Dorf mit, doch in einem reziproken Verhältnis unterliegen Ansehen und Ehre selbst Aushandlungen und der Legitimationsbedürftigkeit. ${ }^{98}$ So stützen oder modifizieren sie Formen und Konfigurationen von Kommunikation, sei es mit- oder übereinander, von Art und Weisen der Arbeit, des Feierns, der Nachbarschaft etc. und Optionen der gemeindlichen Selbstverwaltung bzw. des Umgangs mit Herrschaft.

Eng mit Ehre, Ansehen und Reputation ist bei Bourdieus Ethnologie der kabylischen Gesellschaft der Begriff der öffentlichen Meinung verbunden, die Bourdieu wahlweise als Wächter, Zeuge, Komplize, Tribunal und vollstreckende Instanz bezeichnet. ${ }^{99}$ Die öffentliche Meinung, verstanden nicht als öffentliches Räsonnement, sondern als soziale Kontrolle, ${ }^{100}$ beobachtet die Einhaltung ehrkonformen Verhaltens und rügt Ehrverletzungen. Sie erscheint fast als Synonym für das schon angesprochene, oft in praxeologischen Konzepten angeführte implizite Wissen und reproduziert, so stellt es Bourdieu dar, sozial sanktionierte Normen, Institutionalisierungen, Sitten und Gebräuche (Jaeggi) und ist indirekt an der Hervorbringung kontextuell angemessener und sinnhafter, d.h. gesellschaftlich goutierter Praktiken beteiligt. Derlei kommunikationstheoretische Überlegungen können gerade auch für Untersuchungen von Praktiken in insti-

96 Schlögl 2004, S. 42.

97 Sabean 1990, S. 23 U. 42 (Zitat); van Dülmen 1992.

98 Schlögl 2008, S. 176.

99 Bourdieu 2015, S. 24f., 33 U. 45. Nur vordergründig widerspricht Bourdieu (1993, S. 212) dieser Auffassung von der Bedeutung öffentlicher Meinung für Aushandlungen, Lebensregeln und auch Praktiken innerhalb von Cesellschaften, wenn er zwei Jahrzehnte später schreibt, dass es »die öffentliche Meinung «nicht gebe. Er meint hier aber die in sozialempirischen Befragungen addierte Form einer demoskopisch konstruierten öffentlichen Meinung.

100 Damit ist nicht öffentliche Meinung im Sinne von Habermas (1990) gemeint, sondern eher die Konzeption von Elisabeth Noelle-Neumann (2001); vgl. Neidhardt 1994, S. 27; Jaeggi (2014, S. 157) verwendet den Begriff der »Cebräuche«nahezu äquivalent zu der Bedeutung von öffentlicher Meinung als Kontrolle bzw. Konformität. 
tutionalisierten Bildungseinrichtungen hilfreich sein, werden doch organisatorische und curriculare Ausrichtungen von Schule ebenfalls auf öffentliche Erwartungen zurückgeführt. ${ }^{101}$

\section{Narrative: Meister-, Fortschritts- und Modernisierungserzählungen in der Geschichte}

Publikationen mit einer an Praktiken orientierten Neuausrichtung wissenschaftlicher Forschung vermögen zu völlig neuen Deutungen zu führen, stellen sie doch generelle Überlegungen zu Erkenntnistheorien an und Modernisierungs- und Fortschrittsperspektiven infrage. Gerade mit Blick auf Karl Schlögels Buch über die Sowjetunion dreht eine historisch-praxeologische Darstellungsweise die häufig geschichtspolitisch und -philosophisch geprägte Perspektive auf dieses Land um 180 Grad: Es steht nun nicht mehr im Fokus als politischer Gegner vergangener Blockkonfrontation oder als ideologischer Leuchtturm inmitten einer vom historischen Materialismus geprägten teleologischen Geschichtsauffassung. Vielmehr zeigen die gesellschaftlich-kulturellen Konfigurationen, Konstellationen, Lebensformen - eben Praktiken - Paradoxien, zyklische und zugleich komplex verschachtelte Entwicklungen, unerwartete Verflechtungen von Aufbrüchen und Tradierungen, dauerhaft etablierte Improvisationen, Freiheits- und Gestaltungsräume inmitten von ideologisch-polizeilicher Überwachung und Gewalt. Dies kann gerade auch für die Zeitgeschichte einen neuen Blick auf vermeintliche Gewissheiten und für die Geschichte des Nationalsozialismus etwa die »Parallelität von widerstreitenden Traditionslinien « und somit Komplexitätserhöhung in der Deutung bedeuten, die ohne eine eingängige, alle Kausalität auf sich vereinende Akteursbetonung auskommen kann. ${ }^{102}$ Historische Praxeologie bedeutet also häufig nicht nur eine methodisch-konzeptionelle (Neu-)Ausrichtung geschichtswissenschaftlicher Forschung, sondern damit verbunden ist oft auch eine Neubewertung des Geschehenen, zentraler Begriffe, von Zeitlichkeit, eine Absage an Geradlinigkeit und Folgerichtigkeit von Geschichte. ${ }^{103}$

Eine solche Sichtweise ist für die Historische Bildungsforschung in dem Sinne eine Herausforderung, als dass sie lange Zeit dem sozialgeschichtlich imprägnierten Modernisierungsparadigma folgte und zudem eine starke ideengeschichtli-

101 Tyack/Tobin 1994.

102 Kundrus/Steinbacher 2013, S. 20; vgl. Reichardt 2015.

103 Van Dülmen 1995, S. 423:»[...] doch die Untersuchung der historischen Praxis zeigt, daß es keine unilineare Entwicklung auf ein Ziel - die bürgerlich-demokratische Cesellschaft etwa - gibt, daß das menschliche Verhalten sich keinem einheitlichen Auslegungsmuster fügt, sondern Widersprüche und Ambivalenzen enthält, die für das Leben nicht minder aufschlußreich sind." 
che Vorliebe für Klassiker hegt. ${ }^{104}$ Der Bildungsbegriff unterliegt mitunter einer Normativität, die Ausdehnung und Expansion von Schule und Bildung wurde und wird oftmals unter dem Signum der verzögerten Umsetzung vorgängiger Reformentwürfe untersucht. Zwar haben lokal-, alltags-, kultur- und jüngst auch wissensgeschichtliche Zugänge in der Historischen Bildungsforschung bereits seit Jahrzehnten eine gewisse Konjunktur. ${ }^{105}$ Doch inwiefern die Zirkulation von implizitem, wissenschaftlichem und lokalem bzw. praktischem Wissen Konflikte, Kontinuität, Unterricht und Alltag von Schule und Lehrpersonenbildung prägen, ist in dieser Komplexität immer noch forschungsbedürftig.

So sind dezidiert praxeologische Ansätze für bildungsgeschichtliche Themen überschaubar, ${ }^{106}$ wenngleich sie in der erziehungswissenschaftlichen Disziplin unter ethnologisch/ethnografischen Vorzeichen etabliert sind. Mitunter erwartet man von "praxeologische[n] Zugänge[n] einen produktiven Beitrag gerade dort, wo es um eine genauere Erfassung von Transformationen, sei es in gegenwärtigen Reformen oder in den historischen Wandlungsprozessen von Schule, Unterricht und Erziehung, geht « ${ }^{107}$ Über Dynamiken, Entwicklungen und Prozesshaftigkeiten hinaus liegt das Potenzial historischer Praxeologie jedoch auch darin, dass institutionalisierte Bildung und Erziehung im "spannungsvolle[n] Zusammenspiel von Einpassung und Veränderung, von sozialer Reproduktion [...], von Unterordnung und Widerstand im praktischen Vollzug« wahrgenommen, erfahrbar und beschreibbar wird. ${ }^{108}$ Demnach können sicher gerade Krisenzeiten, in denen institutionalisiertes, implizites Wissen delegitimiert wird, als Ausgangspunkte genommen werden, um Formungen des gesellschaftlichen, schulischen oder bildungspolitischen Wandels praxeologisch erkennbar zu machen und zu untersuchen. Doch zugleich verweisen Krisen nicht nur auf Wandel und Neues, sondern gerade auf das - teilweise modifizierte - Fortbestehen von tradierten Gewohnheiten und Routinen. So könnte der Erklärungsansatz der "grammar of schoo-

104 Lundgreen 1980 u. 1981; Dollinger 2012; Raithel/Dollinger/Hörmann 2009, S. 36; Casale 2011.

105 Zum Beispiel Neugebauer 1985; Albrecht/Hinrichs 1995; Reh et al. 2017; als Verbindung lokal-, wissensgeschichtlicher und praxeologischer Perspektiven De Vincenti 2015; Mattes 2018.

106 Vgl. allerdings Reh/Wilde 2016; Ricken/Reh 2017; Hoffmann-Ocon 2017 und jüngst Berdelmann et al. 2019.

107 Ebd., S. 2. Allerdings sei die »Frage nach der Transformation weniger als Umbruch und weitgreifende Veränderung interessant, sondern als permanente, differenzerzeugende Wiederholung, die von Instabilitäten, Abweichungen und somit Verschiebungen durchzogen ist« (S. 3).

108 Freist 2015, S. 67. 
ling «, ${ }^{109}$ also der Schwerfälligkeit, in Schulen Wandel und Reformen dauerhaft umzusetzen, durchaus auch mit praxeologischen Ansätzen kombinierbar sein.

Die bislang etwa in der Geschichte der Lehrpersonenbildung häufig dominierende Fortschrittsperspektive ${ }^{110} \mathrm{zu}$ überdenken, ist auch ein Ziel des eingangs erwähnten bildungshistorischen Projekts zu Orten und Praktiken der Zürcher Primarlehrer/-innenbildung in der ersten Hälfte des 20 . Jahrhunderts «. Es folgt nicht vorgeblich fortschreitenden Wegen der Lehrpersonenbildung hin zum Seminar und zur Tertiarisierung. Vielmehr hinterfragt es das Narrativ vom vermeintlich unwissenschaftlichen Seminar und prüft, welche (Ausbildungs-)Praktiken an allen oder auch an einzelnen Ausbildungsorten - dem kantonalen Lehrerseminar in Küsnacht, dem Evangelischen Seminar Unterstrass, dem Seminar an der Höheren Töchterschule und dem Oberseminar - anhand von diversen Quellen beschreib- und untersuchbar sind.

\section{Neue Blicke auf bekannte Quellen in Archiven? Historische Methodenfragen und Praxeologie}

Historisch-praxeologische Studien sehen sich immer mit der Frage konfrontiert, auf welcher Quellenbasis und mit welchen Methoden denn Regelhaftigkeiten, Gewohnheiten, Routinen, Aneignungen sowie Fragen der Materialität und vermeintliche Inkorporierungen von Praktiken analysierbar sind. Während Themen der historischen Praxeologie immer unkonventioneller wurden, blieben die Quellen zumeist im erwarteten Rahmen: Briefwechsel, Gerichtsakten und vor allem EgoDokumente und viel Bildmaterial. ${ }^{111}$ Bei ethnomethodologischen Forschungsansätzen, die auf Protokollen eigener Beobachtung fussen, stellt sich die Frage nach der Qualität von Quellen in bildungshistorischen Arbeitszusammenhängen mittelbarer. Als bewährte Überlieferungen werden »direkte Produkte vergangenen alltäglichen Tuns oder Sprechens" genannt, die über den Einzelfall hinausweisen und die den Vollzug von Praktiken dokumentieren, so z.B. auch serielle Quellen aus dem Bereich der Pädagogik, der Schule und des Unterrichts. ${ }^{12}$ Die in diesen Zusammenhängen favorisierten Quellen sind meist nicht neu. So sind etwa Visitationsprotokolle schon lange und zuletzt gerade von lokal- und kultur-

109 Tyack/Tobin 1994, S. 465: »Habituated to the traditional organizational practices and either taking them for granted or seeing them as institutionally and socially functional, educators, school boards, and parents resisted fundamental change.«

111 Böth 2018; Settele 2017. 
geschichtlichen Arbeiten zur Historischen Bildungsforschung genutzt worden. ${ }^{113}$ Man könnte deshalb vielmehr von einer Wiederentdeckung bestimmter Quellen sprechen, die mit manchen der soeben genannten älteren Forschungsarbeiten eine sehr optimistische Sicht teilt, dass diese Quellen gleichsam aus sich heraus, durch neue »Lesbarkeit vergangener Praktiken« oder durch Betrachtung materieller Artefakte zu praxeologischen Erkenntnisgewinnen verhelfen können. ${ }^{114}$ So drohen die Quellen fast als Abbilder genommen zu werden, die gleichsam von selbst durch nahe Beschreibung Wirklichkeit, Praktiken, Interaktionen zeigen könnten, sodass Entstehungs- und Verwendungskontexte der Quellen etwas stark verblassen. ${ }^{115}$

Jüngst wurde dafür plädiert, auch für historisch-praxeologische Studien offizielle Dokumente, wie Jahresberichte von Verwaltungsorganisationen, zu verwenden und sie nicht nur mit hoher Sensibilität gegen den Strich, sondern geradezu mit dem Strich der Quellenproduzenten zu lesen. So können insbesondere bei seriellen Quellen zumindest Darstellungen von Wissensordnungen, Deutungs- und Argumentationsmustern, damit von Regelhaftigkeiten und Darstellungsroutinen ermittelt werden. ${ }^{116}$ Auch Sabean plädierte für die Nutzung von Quellen offizieller Provenienz, um Sichtweisen und alltägliche Praktiken der einfachen Bevölkerung, die selbst kaum schriftlich überliefert sind, zu untersuchen. Mit einer Mischung aus Forschungspragmatik und -konzeption betonte er, dass kleine Leute und Alltag eben reziprok mit Herrschaft und Macht verwoben und so auch quellenmässig analysierbar seien:

Es entbehrt nicht der Ironie, daß unser Material gerade deshalb, weil wir nur über den Herrn an den Bauern gelangen können, häufig ein guter Ausgangspunkt für die Betrachtung der Beziehungen ist, die wir erforschen wollen. Die Beschaffenheit bäuerlicher Vorstellungen kann nicht losgelöst von der Dynamik der Machtverhältnisse und hierarchischen Beziehungen untersucht werden [...]. ${ }^{117}$

113 Neugebauer 1985, S. 130, 162 u. 584; Albrecht/Hinrichs 1995; Grube 1999; Schlögl 2000; Hoffmann 2001.

114 Haasis/Rieske 2015a, S. 29.

115 Dies deutet sich bei Veronika Setteles anregenden Schilderungen der kapitalistischen Praktiken im westdeutschen Kuhstall an: Sie beruhen teilweise auf Filmsequenzen des von der Bundesregierung finanzierten und herausgegebenen »Deutschlandspiegel« (Settele 2017, S. 56 u. 58) - eine filmische Selbstdarstellung Westdeutschlands für das westliche Ausland (vgl. Grube 2005, S. 294), die eine bestimmte Sichtweise von moderner und zugleich volkstümlicher Landwirtschaft kolportieren wollte. Dieser politische (Macht-)Kontext bleibt jedoch aussen vor.

116 Müller 2018, S. 342; vgl. für die Auswertung von Jahresberichten von Lehrerseminaren De Vincenti/Grube/Hoffmann-Ocon 2018a, S. $121 f$.

117 Sabean 1990, S. 13. 
Dass die Perspektive der einfachen Bevölkerung in den überlieferten Quellen häufig unterrepräsentiert ist, kann als Mangel bzw. als Konstruktionsfehler archivalischer Überlieferung gesehen werden, die eher Zeugnisse der Mächtigen aufbewahrten, in denen sie sich über die Untertanen äusserten. So werden gegenwärtig in verschiedenen Studien Beispiele für historische Arbeitsweisen geliefert, wie das Wissen in den Archiven durch Archivpraktiken gesammelt, gebündelt sowie annotiert und so auch institutionalisiert wurde. Letztlich geht es um eine Perspektivverschiebung, die darauf aufmerksam machen will, dass die forschungspragmatisch sensiblen Momente "vorverlegt« gedacht werden müssten. Wie Archivpraktiken Wissenschaften mit Bürokratien, Märkten und Medientechnologien entlang und streckenweise entgegen wissenschaftlichen Trends verbanden, wie Filterstrategien hinsichtlich der Materialfülle entwickelt wurden und wie sich Findmittel als Instrumente etablierten, ${ }^{118}$ sind Fragen, die das Verhältnis von praxeologisch informierter Forschung und historischen Quellen zentral betreffen. Wie und durch wen Archive und Sammlungen angelegt wurden, etwa unter Anleitung von wissenschaftlichen, bürokratischen oder auch laienhaften Akteuren, und wie der Zutritt zu diesen Archiven geregelt wurde und wird, ${ }^{119}$ sind Aspekte, die für praxeologische Deutungszusammenhänge innerhalb der historischen Bildungsforschung bedeutsam sind.

Aufgrund der Quellenproblematik haben sich jüngst Vorstellungen manifestiert, die gerade historisch-praxeologisch Forschende als Detektiv/-innen, als Spurensuchende und Archäolog/-innen konzipieren. So wird das detektivische Paradigma von Achim Saupe als ein variables Muster historischer Sinnbildung etwa zwischen Historik, Kriminalistik und Historiografie verstanden, welches mit verschiedenen Wissenschaftsbegriffen kompatibel sei: Nicht nur kann »die historiographische Ermittlungsgeschichte von der fortschreitenden Erkenntnis des Historikers im Umgang mit seinen Quellen« und damit »von der Forschungspraxis der modernen Geschichtsschreibung« berichten, sondern auch von dem historisch Forschenden, »der sich als akribischer Spurensucher in Szene setzt und der sich auf einen kritischen Leser einstellt «. ${ }^{120}$ Saupes Befund ist, dass sich juristische Diskurse in historiografische eingeschrieben haben, sodass mit »der Metapher des Untersuchungsrichters und des Detektivs [...] die forschende Praxis und die Arbeit des Historikers gegenüber einer rein urteilenden Historie betont« werden. ${ }^{121}$ Damit rücken auch die narrativen Formen von mikrogeschichtlichen Arbeiten ins Zentrum. Wenn historisch Forschende in ihren Quellen »Spuren statt Anwesenheiten, Perspektive statt panoramatischer Rundblick« verfolgen,

118 Daston 2017, S. 9.

119 Strasser 2017, S. 188f.

120 Saupe 2009, S. 47.

121 Ebd., S. 472. 
dann werden in den Studien, so wie Ute Daniel es in Auseinandersetzung mit dem Werk von Carlo Ginzburg beschreibt, »rückblickend die Erkenntniswege und ihre Umsetzungen « bedeutsam für die Praxis der Geschichtsschreibung. ${ }^{122}$ So gerät »das Machen von Wissenschaft« und historischer (Bildungs-)Forschung mit vielfältigen Praktiken in den Blick, die, wie es die Rekurse auf das Detektivische und Kriminalistische zeigen, extrem verzahnt mit sozialen Praktiken weiterer gesellschaftlicher Felder sind. ${ }^{123}$ Hinter solchen Bildern und Überlegungen stecken zumeist Aufforderungen, vielfältige Quellen gleichsam auf indirektem Wege losgelöst von Intentionen ihrer Produzenten im Hinblick auf dargestellte, erinnerte bzw. gedeutete Praktiken zu erschliessen. Diese Vorstellung kann möglicherweise mit Reckwitz' Plädoyer für die Methode der Rückschlüsse »vom Expliziten aufs Implizite « in Verbindung gebracht werden: ${ }^{124}$ vom Interview, von den Beobachtungen und - so liesse sich ergänzen - von historischen Quellen auf Praktiken. Gleichwohl bleibe wegen der Differenz zwischen Quelle und tatsächlichem Tun Unbehagen. Doch gerade sogenannte Ego-Dokumente vermögen »nicht nur aus subjektiver Sicht die äussere Seite der Praktiken [zu beschreiben]; in ihnen kann möglicherweise auch auf das implizite Wissen der Teilnehmer, das in diese Praktiken eingelassen ist, rückgeschlossen werden.« ${ }^{125}$

\section{4 Übersicht über die im Band versammelten Beiträge}

Die in drei Hauptteile gruppierten Beiträge in diesem Band greifen die geschilderten Facetten, Merkmale, Ansätze und Leitbegriffe der (historischen) Praxeologie vielfältig auf. Das erste bildungshistorische Hauptkapitel fokussiert Lehrerinnen- und Lehrerseminare in Zürich in der ersten Hälfte des 20. Jahrhunderts: Sie bieten einen wichtigen Bezugspunkt für die Praktiken jener Akteur/-innen, die häufig mit Bildungsorten in Zusammenhang gebracht werden: angehende Unterrichtende, Seminar-Lehrpersonen und Direktoren. Durch Adrian Juens Beitrag wird das Tun einer bisher wenig beachteten Personengruppe zum Gegenstand einer praxeologischen Untersuchung. Die Hauswarte bildeten - teilweise als >doppelte Einheit mit ihren Ehefrauen - eine Akteurskonstellation, die durch ihre spezifischen Praktiken das Seminar und eine Seminarkultur überhaupt erst im Sinne der >Vorgängigkeit< ermöglichten. Werden Quellen untersucht, die sich mittel- oder unmittelbar mit Hauswartstätigkeiten um 1900 befassen, entsteht ein komplexeres Bild von Zusammenspiel und >Aushandlung` durch Praktiken

\footnotetext{
122 Daniel 2001, S. 289-291.

123 Rheinberger 2018, S. $107 f$.

124 Reckwitz 2008, S. 196.

125 Ebd., S. 198.
} 
verschiedener Akteure am Seminar. Technik und technische Neuerungen, etwa Zentralheizungen und elektrische Anlagen, gaben am Lehrerseminar Küsnacht des Kantons Zürich gewisse Raumordnungen und Spielregeln für alltägliche Hauswartsroutinen sowie auch für den Hauswartskörper vor. Juen entfaltet, wie Verschränkungen zwischen Technik, Routinen und Reglementen, die immer wieder einem Wandel und Anpassungen unterlagen, das Berufsbild prägten und den in diesen Rahmungen agierenden Akteuren Handlungsmuster und Wissen bereitstellten. Die Frage nach dem eigensinnigen und intentionalen resp. nichtintentionalen Charakter von Praktiken stellt sich, wenn etwa der Hauswart an der Höheren Töchterschule und dem Lehrerinnenseminar der Stadt Zürich sich darum bemüht, vom Arbeitgeber einen Wachhund bezahlt zu bekommen. Diesbezügliche Korrespondenzen scheinen als Kommunikationsort auf, an dem die Grenzen der Zusammenarbeitsroutinen zwischen Hauswart, Direktion und Anstellungsbehörden durch Verweise auf Gefahrenabwehr und Polizeidienst ausgehandelt wurden. Hauswartspraktiken erwiesen sich nicht nur als ein technikaffines Handlungsfeld, sondern konnten sich auch mit dem Unterricht oder mit der Produktion von Ratgeberliteratur verquicken. Zugleich kann der Beitrag als historische, praxistheoretische und methodologische Anreicherung der erziehungswissenschaftlich geprägten Diskussion zu Schulkulturen gelesen werden.

Eine weitere Komponente einer solchen Schulkultur könnte die von Jennifer Burri in ihrem Beitrag untersuchte Hervorbringung und Stabilisierung familialer Vergemeinschaftung anlässlich von Todesfällen an Seminaren in der ersten Hälfte des 20. Jahrhunderts sein. Burri ruft mit den explizierten Fällen an dem Evangelischen Lehrerseminar Unterstrass und an dem Lehrerinnenseminar der Höheren Töchterschule der Stadt Zürich Orte auf, die z.T. in Juens Artikel bereits beleuchtet wurden. Als wesentliche Quelle zieht die praxeologische Untersuchung Nekrologe heran; eine eigentümliche Textsorte, die häufig von Seminardirektoren verfasst wurde und durch Burri auf verschiedene Akzentuierungen von Erinnerungspraktiken und -kulturen hin untersucht wird. In dieser Perspektive wird der Ritualcharakter bei Inszenierungen von Gemeinschaft allgemein und die Performanz des Nekrologs speziell hervorgehoben. Damit wird ein Blickwinkel eingenommen, der etwa anhand von Grabreden neue Einblicke in textuelle Muster der Gedenkarbeit am Seminar Unterstrass liefert, aber auch auf eine Vielzahl weiterer Anschlussfragen verweist: Wie wurden vergangene Handlungsroutinen verstorbener Akteure von den Hinterbliebenen der Gemeinschaft gedeutet: als innere Bindung zum oder als Dienen für das Seminar? Die starke Ausprägung der Gedenkarbeit am Evangelischen Seminar bietet eine Optik auf die theologisch orientierte Fundierung des Seminars und diesbezügliche Führungspraktiken der Seminarleitung. Am Fall der Höheren Töchterschule wird deutlich, dass kollektive Erinnerungen mit Praktiken verknüpft sein können, die dem individuellen Charakter der verstorbenen Person eine Gestalt geben. Die Figur des gelungenen 
Lehrerlebens wurde häufig und ebenfalls von den Nachrufenden im Seminar Unterstrass als Deutungsfolie genutzt, auch um Kritik am Verstorbenen verhalten äussern zu können. Um den Praktiken der Vergemeinschaftung näherzukommen, bringt Burri die Tradition der Wohnstubenpädagogik und die im Zuge der Psychiatriereform zu verortende Anstaltsfamilie in den Zusammenhang mit Erinnerungsroutinen. Ob es sich denken liesse, dass Gemeinschaft weniger als Fluchtpunkt vergangener Praktiken an Seminaren anhand von Quellenmaterial erschlossen werden könne, sondern eher durch die Quelle selbst an Kontur gewinne, schwingt mindestens unterschwellig als Frage in der Analyse mit.

Als die Seminargemeinschaft gefährdend wurde die im Beitrag von Andrea De Vincenti fokussierte »Fidelitas«, eine abstinente Vereinigung von Zöglingen am Kantonalen Lehrerseminar Küsnacht, angesehen, während andere Zöglingsvereinigungen am Seminar nicht nur gebilligt, sondern gar breite Unterstützung durch Lehrerkonvent und Direktor erfuhren. Ausgehend von der Feststellung, dass Praktiken des Trinkens von Alkohol im Turnverein gebilligt, in der »Fidelitas« aber umgehend sanktioniert wurden und letztlich zu ihrer Auflösung führten, fragt die Autorin nach den jeweiligen Trinkpraktiken und den Gründen für die zwei so unterschiedlichen Umgangsweisen der Seminarleitung mit diesen Praktiken, respektive mit den sie praktizierenden Vereinen. Mit einer durch unterschiedliche Quellengattungen gegebenen mehrperspektivischen Auswertung der Praktiken des Trinkens im sanktionierten Verein sowie des Umgangs mit dem Verein und der Vereinszugehörigkeit einzelner Zöglinge des Seminars arbeitet De Vincenti die spezifischen Sinn- und Bedeutungsstrukturen der auf den ersten Blick mit dem anderen Verein überlappenden Trinkpraktiken heraus. Obwohl in beiden Vereinen das Trinken als gesellige Praxis etabliert und fest verankert war, können die jeweils unterschiedlichen sinnhaften Codierungen Aufschlüsse darüber geben, weshalb das Trinken einmal als legitim, einmal aber als Grund für harsche Sanktionen erschien. Anhand von theoretischen Überlegungen zu Praktiken, die eng auf das Fallbeispiel bezogen werden, plausibilisiert der Beitrag schliesslich die These, dass es keine Praktik des Trinkens per se geben könne, sondern jede Praktik stets nur in ihrem spezifischen Kontext, das heisst unter Berücksichtigung der stets orts- und zeitspezifischen Sinn- und Bedeutungsstrukturen, zu verstehen sei - auch wenn sie vordergründig, also auf der wahrnehmbaren körperlich-materialen Ebene, vielleicht identisch mit anderen erscheint. Vor dem Hintergrund dieser Überlegungen sieht die Autorin in einer praxeologischen Perspektive die Möglichkeit einer radikalen Historisierung: Praktiken seien erst durch eine möglichst vielperspektivische Kontextualisierung in ihrer »Doppelstruktur« (Reckwitz) von einerseits direkt wahrnehmbaren Bewegungen und Äusserungen und andererseits darin codierten Wissens- und Bedeutungsstrukturen zu erfassen, sodass Letztere immer auf den konkreten historischen Fall verwiesen. 
Dem Spannungsverhältnis von Kontrollregimen und Eigensinn der Zöglinge an Zürcher Lehrerseminaren und Erziehungsanstalten im späten 19. und frühen 20. Jahrhundert widmet sich der Beitrag von Norbert Grube. Inwieweit Eigensinn als individuelle Widerständigkeit und auch als gleichzeitig widersprüchliches und vieldeutiges Verhalten entlang institutionalisierter Praktiken von Unterricht und ordnenden Kontroll- und Alltagsroutinen im Seminar erinnert, dargestellt und ein Stück weit auch erfahren worden ist, wird anhand von Ego-Dokumenten analysiert. Mit Ausnahme der handschriftlichen Erinnerungen des Zürcher Lehrers Alfred Traber werden dabei autobiografisch geprägte Romane genutzt, deren Autoren - Jakob Christoph Heer, Jakob Schaffner, aber auch Hermann Hesse und Erich Kästner - ihren Besuch in unterschiedlichen Seminaren und damit verbundenen Erziehungsanstalten literarisch thematisiert haben. Quellenkritisch und im Hinblick auf praxeologische Zugangsweisen zu prüfen ist, inwieweit fiktive Literatur Autorenerfahrungen aufgreift und zugleich diskursive Muster hinsichtlich seminaristischer Lehrerbildung, etwa marktgängige Bilder von der Unterwerfung der Heranwachsenden in einer Kontroll- und Strafinstitution, verarbeitet. Diese methodisch-konzeptionelle Reflexion wird vertieft, indem ergänzend herangezogene Protokolle der Aufsichtskommission und des Lehrerkonvents aus dem Archivbestand des Seminars Küsnacht auf die aus den Ego-Dokumenten gewonnenen Analysebefunde quellenkritisch bezogen werden. Was sagen die unterschiedlichen Quellenarten über Wahrnehmung und Erinnerung von Eigensinn und Praktiken am Seminar aus? Indem die Zöglinge mehrschichtigen Ebenen von sozialer Kontrolle ausgesetzt sind, sowohl der Beobachtung und Bewertung der Lehrer sowie ihrer Freunde als auch zirkulierender Wissen im Seminar und in dessen städtischem Umfeld, wird abschliessend mit wissensgeschichtlicher Perspektive untersucht, inwieweit unterschiedliche institutionelle bzw. (teil-)öffentliche Erwartungen und Wissensordnungen Eigensinn und verschiedene, auch miteinander konfligierende Praktiken bedingen. Oder verweist vermeintlicher Eigensinn des Subjekts letztlich weniger auf individuelle Aneignung, als auf Kollisionen verschiedener, jeweils auf unterschiedlichen (Wissens-)Kontexten beruhender Praktiken?

Um eine Balance von Kontrolle und Eigensinn ging es auch bei der im Beitrag von Andreas Hoffmann-Ocon im Zentrum stehenden Eignungsabklärung, die unter einer doppelten Zielsetzung untersucht wird: Einerseits richtet sich der Fokus auf die Erschliessung von Praktiken der Eignungsabklärung angehender Zürcher Primarlehrpersonen um die Mitte des 20. Jahrhunderts anhand von Fallbeispielen, andererseits wird gegenstandsbezogen die Frage aufgegriffen, welche neuen Einblicke spezifische Quellen - etwa Kommissionsprotokolle, Ego-Dokumente und Praxisberichte angehender Unterrichtender und Jahresberichte - auf sich erneuernde und wandelnde Alltagsroutinen im Handlungsfeld der Eignungsabklärung bieten. Anders als im kantonalen Seminar Küsnacht, im Evangelischen Seminar 
Unterstrass oder im Lehrerinnenseminar der Höheren Töchterschule war das zu Beginn der 1940er-Jahre eingerichtete Oberseminar des Kantons Zürich ein Ort nachmaturitärer Ausbildung. Um die lokalen Praktiken und ihre vielfältigen Variationen seitens der Kandidierenden von der Dimension des zirkulierenden pädagogischen Wissens über Schülerbeobachtung, Taktgefühl und Selbstoptimierung, auf das in der Prüfungsphase rekurriert wurde, beschreiben und vermessen zu können, werden zeitgenössisch geläufige Diskurse und leitende Metaphern in die Analyse miteinbezogen. Die praxeologische Perspektive wird genutzt, um dasjenige an der eignungsrelevanten studentischen Praxisberichterstattung präziser zu bestimmen, was die situative Aushandlung des Prüfungsgrenzverlaufs in einer Phase akuten Lehrpersonenmangels bildete. Wie sehr das Soziale - z.B. in Form von Herkunft der Kandidierenden, von Arbeitsbedingungen in Krisen- und Kriegszeiten und Stadt-Land-Differenzen, in das die Eignungsabklärungspraktiken eingebettet war - in der Interaktion zwischen angehenden Lehrpersonen und Direktion eine erstaunliche Vielgestaltigkeit der Berichtspraxis hervorbrachte, zeigt Hoffmann-Ocons Beitrag. Die Differenz zwischen den Berichtstypen, vom Studentenaufsatz, der anstelle von Praxiseinblicken Versatzstücke aus der Pädagogikvorlesung reproduziert, bis zum lyrischen Spiel mit der eigenen Eignung, eröffnet den Blick auf das gesamte Praxisarrangement der Abklärung, das auch für eigensinnige Inszenierungen durch angehende Lehrpersonen zugänglich gewesen ist.

Im zweiten Hauptkapitel dominieren bildungshistorische und ethnologischethnografische Betrachtungen über Verhältnisse von Norm und Praxis des Lernens und Studierens. Leitende Perspektiven hierbei sind etwa Inkorporierungsund Einschreibeprozesse von Normen, die mit teils eigenständigen Aufschreibe-, Straf- und Spielpraktiken kontrastiert werden. Sabine Reh und Kerrin Klinger plädieren in ihrem Beitrag für ein ganz bestimmtes, vor allem an der Soziologie orientiertes Konzept von Praktiken und Praxis. Ausgehend von der strukturalistisch anmutenden Annahme, dass sich Spuren von Praktiken im Material einschreiben, sehen sie insbesondere in der Erforschung von Materialität eine Spezifik des Ansatzes, die sich auch auf die Auswahl der Quellenart, respektive auf die Fokussierung auf deren materielle Komponente auswirke. Unter diesen Prämissen gehen die Autorinnen mit ihrer Präferenz für serielle Quellen gegenüber der Mikrogeschichte, die sie als eine Form der histoire totale verwerfen, der Praxis des Studierens an der Universität Berlin nach, um darüber Prozesse der universitären Institutionalisierung sowie die damit verbundenen Konventionalisierungen von Formen der Wissensvermittlung zu erhellen. Diese seien wiederum für Professionalisierungsprozesse, Subjektivierungsformen sowie auch die Periodisierung bedeutsam. Mit den seit dem frühen 19. Jahrhundert aufgekommenen sogenannten hodegetischen Schriften, Anweisungen, wie Studierende $\mathrm{zu}$ studieren und Wissen zu erwerben hätten, liegt der Fokus des Beitrages denn zunächst auch 
auf einem - auf den ersten Blick eher präskriptiven - Quellentyp, um diesen aber dann in der Hauptsache mit vier Kollegheften des Studenten Friedrich Blanck aus den 1880er-Jahren zu kontrastieren. Blancks Mitschriften von Vorlesungen des an der Universität Berlin lehrenden Philosophie- und Pädagogikprofessors Friedrich Paulsen stellen eine punktuell leicht ergänzte fallorientierte Auswahl aus der digitalisierten seriellen Quelle von 400 Kollegheften dar, welche Reh und Klinger als Dokumentationen von Rezeptions- und Aufzeichnungspraktiken heranziehen. Sie fragen vor dem Hintergrund zeitgenössischer Kritik am angeblich wenig inspirierenden Format der Vorlesung u.a., inwiefern die universitäre Veranstaltung der Vorlesung die an sie gestellten Erwartungen erfüllte und wie das dort verbreitete Wissen aufgeschrieben, aufbereitet und kommentiert wurde. Der Beitrag diskutiert schliesslich, inwiefern der Fokus auf die Materialität der Kolleghefte, i.e. Unterstreichungen, Ergänzungen, Kommentare oder Zeichnungen, produktive Aspekte der Vorlesungen betonte und ob Studierende eher Empfänger wissenschaftlichen Wissens waren oder aber bei ihnen eine aktive, selbstständige, eigene Erfahrungshorizonte beinhaltende Wissensrezeption herausgearbeitet werden kann. Dabei wird unter anderem von der Materialität der Schrift am digitalisierten Quellenmaterial auf gleichsam intentionale Wissensaneignungen und -verwendungen geschlossen, während das Potenzial der seriellen Quelle der Vorlesungsmitschriften für Rezeptionspraktiken und fachliche Praktiken weiteren Forschungen vorbehalten bleibt.

Auch Rebekka Horlacher fokussiert Anleitungsschriften, die sich allerdings nicht auf das universitäre Studium, sondern auf den Unterricht an der Volksschule beziehen. Anhand von Leitfäden zum Lehrerhandeln aus der zweiten Hälfte des 18. Jahrhunderts sowie von thematisch einschlägigen Passagen von Lehrerantworten auf eine staatliche Schulumfrage aus dem Jahr 1799 in der Schweiz beschäftigt sich ihr Beitrag mit Praktiken des Fehlers sowie der Strafe in schulischen Kontexten um 1800. Praktiken versteht sie dabei als kontextualisierte Verhaltens- und Handlungsweisen und betont das wechselseitige Austauschverhältnis zwischen Normen und Praxis. Die in den Leitfäden enthaltenen Beschreibungen von Strafpraxis weisen, so die in diesem Beitrag entfaltete These, aufgrund ihrer Autorenschaft, die einer Bildungselite zuzurechnen sei, stets auch einen normierenden Gehalt auf. Vergleichbar dazu seien die Antworten der Schulumfrage ebenfalls eher von überaus engagierten Lehrpersonen gegeben worden, die sich freiwillig zu Praktiken des Fehlers oder der Strafe geäussert hätten. Der Beitrag greift Fragen zum Verhältnis der ausgewerteten angeblich auf eigenen Erfahrungen der Autoren fussenden Quellen zu einer an Schulen etablierten Strafpraxis auf. Gibt es eine inhaltlich zur schulischen Strafpraxis differente Praxis der schulischen Strafnormierung, etwa wenn die Leitfäden und Umfrageantworten von der an Schulen zwar etablierten Prügelstrafe berichten, diese jedoch durchgängig ablehnen? Diese und weitere Fragen werden in einer vergleichenden Perspektive 
anhand von Gemeinsamkeiten und Unterschieden zwischen den einzelnen Leitfäden, aber auch zwischen den darin postulierten normierenden und schulisch etablierten Praktiken für die Zeit des späten 18. Jahrhunderts diskutiert, etwa bezüglich der körperlichen Züchtigung, der Angemessenheit oder dem erzieherischen Gehalt von Strafen. Der Beitrag schliesst mit grundsätzlicheren Überlegungen zur möglicherweise anhaltenden Bedeutung von Ratgeberliteratur und einem historiografischen »Mehrwert« der praxeologischen Perspektive in Bezug auf dieses Thema.

Um Anleitung durch die Kindergärtnerin und die Inkorporierung von Normen geht es im Beitrag von Anja Sieber Egger und Gisela Unterweger, der mit schulethnologischen/-ethnografischen Perspektiven die alltägliche »Vollzugswirklichkeit ${ }^{126}$ von Praktiken des geleiteten Spiels im Kindergarten in den Blick nimmt. Er untersucht die Relevanz der Materialität für das Sprechen und die Positionierung von Körpern anhand des spielerischen Umgangs mit einer Sandwanne und diskutiert die Bedeutung von Artefakten für das raumzeitliche Verhalten von Subjekten, in diesem Fall von Kindern zwischen vier und sechs Jahren. Die Autorinnen betrachten Wechselbeziehungen von Interaktionen, Körperlichkeit und Artefakten (Materialität) mit Blick auf die Sinnhaftigkeit von Praktiken. Dabei wird einerseits mit Bezug zu Bourdieu von einer als habituell gebundenen Inkorporierung von implizitem Wissen und den auf diese Weise konstituierten Praktiken ausgegangen. Andererseits zeigt die Verwendung der die Analyse leitenden Begriffe der Aneignung, Aushandlung, Positionierung und Adressierung eine gewisse performative und situative Offenheit des hier zugrundeliegenden Praktikenbegriffs an, durch welche das jeweilige Verhalten der Akteurinnen und Akteure mitbestimmt ist. Entsprechend der übergeordneten Frage nach »Kinder[n], die auffallen« fokussiert der Beitrag von Sieber Egger und Unterweger stark das Verhalten eines ১Jimmy< genannten Jungen, der den Normen und Erwartungen der Kindergärtnerinnen im Hinblick der auf Konzentration, Sauberkeit, Behutsamkeit und Ordentlichkeit ausgerichteten Spielpraktiken mit der Sandwanne nicht immer gerecht werden kann. Jimmys Verstösse beim Sandwannenspiel gelten insofern als interessant, als dass sie eine Krise markieren und Facetten einer - teils nicht vollzogenen - Inkorporierung von Praktiken sichtbar werden lassen. Wie in dieser Situation Jimmy pädagogisch adressiert, Subjektivierung ermöglicht oder verschlossen und Differenz markiert wird, steht im Zentrum der Fallstudie, die auch Positionierungen, Profilierungen und Adressierungen der Kinder untereinander - und damit ihr Wissen um situativ adäquate Praktiken - berücksichtigt. Damit können mindestens zwei Anerkennungs- und Adressierungsmomente und -akteure kollidieren: das von der Kindergärtnerin beaufsichtigte Spiel und zugleich die Erwartung, Freunden Nähe und Aufmerksamkeit zu bezeugen. 
Der letzte Hauptteil bietet wissenssoziologische und die einzelnen Darstellungen zusammenfassend aufgreifende Reflexionen. Christoph Mäder entfaltet aus wissenssoziologischer Perspektive wissenschaftliche Rezeptions- und Verwendungspfade praxeologischer Konzepte. In seinem eher essayistischen Beitrag plädiert er dafür, bei der Rekonstruktion sozialer >Wirklichkeit`mittels Handlungen und Praktiken nie allein auf formale Strukturen von praktischen Handlungen $\mathrm{zu}$ fokussieren, sondern immer auch den Prozeduren, die den situativen Sinn erzeugen, Rechnung zu tragen. Dazu stellt er sich hochkomplex und detailverliebt gebenden, das Subjekt verflüssigenden Praxistheorien eine ethnomethodologischen Sicht auf Praktiken gegenüber, wonach Praktiken nicht die Auflösung des Subjekts in einer situativen Mimesis von Körpern und Dingen bedeuteten, sondern in Ergänzung zum Subjekt konzipiert seien. Praktische Handlungen weisen in dieser Perspektive jeweils vier formale Ebenen auf, welche stets allesamt in die Rekonstruktionen gelebter und sozialer >Wirklichkeit einzubeziehen wären. Die vier Bereiche der Indexikalität, der Sequenzialität, der Reflexivität und der Reziprozität verweisen letztlich in unterschiedlichen Dimensionen auf eine auch in einigen praxeologischen Ansätzen betonte Kontextualität praktischer Handlungen. Dies sowie auch Fragen nach der Konzeption des Subjekts oder eben der Akteurinnen und Akteure sowie auch nach Handlungssinn und seinem Verhältnis $\mathrm{zu}$ implizitem und explizitem Wissen bieten wiederum Anknüpfungspunkte zu vielen Beiträgen dieses Bandes.

Tomas Bascio wiederum wirft abschliessende und kommentierende Blicke auf die einzelnen in den jeweiligen Beiträgen untersuchten Fallstudien. Er greift in einer synoptischen Sicht die Bedeutungsvarianz zentraler Begrifflichkeiten, insbesondere die Bedeutungen von Norm und Normativität in den praxeologischen Beiträgen auf und streicht im Sinne des Sammelbandes Möglichkeiten und Grenzen der jeweils gewählten praxeologischen Analysezugänge und Quellen noch einmal im Überblick heraus. Indem Bascio den Zusammenhang von Praktiken und normierenden Ordnungen fokussiert, thematisieren seine Schlussreflexionen entlang dieser Perspektive die Diskussionslinien, Gemeinsamkeiten und Unterschiede im jeweiligen methodisch-konzeptionellen Ansatz sowie bei den Schlussfolgerungen. So sollen mögliche, aus den unterschiedlichen Perspektiven gewonnene Erträge und weiterführende Gedanken vorläufig festgehalten werden. Mit dieser vergleichenden Einschätzung der in diesem Band versammelten historisch-praxeologischen Studien ist weniger eine abschliessende Beurteilung beabsichtigt, sondern die Anregung, historische Praxeologie als ein produktives Forschungsmilieu mit vielfältigen interdisziplinären Berührungspunkten zu begreifen.

An der Entstehung dieses Buches haben - gerade mit Blick auf den gesamten Arbeits- und Gesprächszusammenhang, der mit den Planungen zum bereits angesprochenen Workshop von 2018 an der Pädagogischen Hochschule Zürich zu 
verorten ist - zahlreiche Wissenschaftler/-innen aus unterschiedlichen geistes-, kultur- und sozialwissenschaftlichen Disziplinen beigetragen. Nicht alle, denen wir ausserhalb des Projektteams danken möchten, sind in diesem Band mit einem Artikel vertreten: Tomas Bascio, Kathrin Berdelmann, Lucien Criblez, Kerrin Klinger, Christoph Maeder, Sabine Reh, Joachim Scholz, Anja Sieber Egger, Gisela Unterweger, Josefine Wähler, Max Wendland - und Rebekka Horlacher, die uns neben der Arbeit am eigenen Beitrag auch half, das Manuskript zu erstellen. Dank gebührt nicht zuletzt auch Johanna Tönsing und Anke Poppen vom transcript Verlag, der das vorliegende Buch in sein Programm aufgenommen hat, und dem Schweizerischen Nationalfonds für die grosszügigen Zuschüsse aus den Mitteln der Förderung der Open-access-Buchpublikation.

\section{Literatur}

Albrecht, Peter/Hinrichs, Ernst (Hg.) (1995): Das niedere Schulwesen im Übergang vom 18. und 19. Jahrhundert. Tübingen.

Arni, Caroline (2018): Nach der Kultur. Anthropologische Potentiale für eine rekursive Geschichtsschreibung. In: Historische Anthropologie 26, H. 2, S. 200223.

Becker, Frank/Reinhardt-Becker, Elke (2001): Systemtheorie. Eine Einführung für die Geschichts- und Kulturwissenschaften. Frankfurt a.M.

Berdelmann, Kathrin/Fritzsche, Bettina/Rabenstein, Kerstin/Scholz, Joachim (2019): Ein Umriss historischer und gegenwartsbezogener Forschungsperspektiven. In: Diess. (Hg.): Transformationen von Schule, Unterricht und Profession. Erträge praxistheoretischer Forschung [Sabine Reh zum 60. Geburtstag]. Wiesbaden, S. 1-29.

Berger, Peter L./Luckmann, Thomas (2007): Die gesellschaftliche Konstruktion der Wirklichkeit. 21. Aufl. Frankfurt a.M.

Bölling, Rainer (1983): Sozialgeschichte der deutschen Lehrer. Ein Überblick von 1800 bis zur Gegenwart. Göttingen.

Böth, Mareike (2018): »Ich handele, also bin ich«. Selbstzeugnisse praxeologisch lesen. In: Geschichte in Wissenschaft und Unterricht 69, H. 5/6, S. 253-270.

Bohnsack, Ralf (2017): Praxeologische Wissenssoziologie. Opladen, Toronto.

Bourdieu, Pierre (1993): Soziologische Fragen. Frankfurt a.M.

Bourdieu, Pierre (2002): Ein soziologischer Selbstversuch. Frankfurt a.M.

Bourdieu, Pierre (2015): Entwurf einer Theorie der Praxis auf der ethnologischen Grundlage der kabylischen Gesellschaft. 4. Aufl. Frankfurt a.M.

Brandes, Sören/Zierenberg, Malte (2017): Doing capitalism. Praxeologische Perspektiven. In: Mittelweg 36. Zeitschrift des Hamburger Instituts für Sozialforschung 26, H. 1, S. 3-24. 
Breidenstein, Georg (2008): Allgemeine Didaktik und praxeologische Unterrichtsforschung. In: Zeitschrift für Erziehungswissenschaft 10, Sonderheft 9, S. 201-215.

Breidenstein, Georg/Hirschauer, Stefan/Kalthoff, Herbert/Nieswand, Boris (2013): Ethnografie. Die Praxis der Feldforschung. Konstanz, München.

Brendecke, Arndt (Hg.) (2015): Praktiken der frühen Neuzeit. Akteure - Handlungen - Artefakte. Köln, Weimar, Wien.

Burke, Peter (2005): Was ist Kulturgeschichte? Frankfurt a.M. [engl. Orig.: What Is Cultural History? Cambridge 2004].

Butler, Judith (2019): Das Unbehagen der Geschlechter. 20. Aufl. Frankfurt a.M.

Casale, Rita (2011): Über die Aktualität der Bildungsphilosophie. In: Vierteljahresschrift für wissenschaftliche Pädagogik 87, H. 2, S. 322-332.

Chartier, Roger (1992): Einleitung: Kulturgeschichte zwischen Repräsentationen und Praktiken. In: Ders. (Hg.): Die unvollendete Vergangenheit. Geschichte und die Macht der Weltauslegung. Frankfurt a.M., S. 7-23.

Clemens, Iris (2015): Erziehungswissenschaft als Kulturwissenschaft. Die Potenziale der Netzwerktheorie für eine kulturwissenschaftliche und kulturtheoretische Ausrichtung der Erziehungswissenschaft. Weinheim, Basel.

Daniel, Ute (2001): Kompendium Kulturgeschichte. Theorien, Praxis, Schlüsselwörter. Frankfurt a.M.

Daston, Lorraine (2017): Introduction: Third Nature. In: Dies. (Hg.): Science in the Archive. Pasts, Presents, Futures. Chicago, London, S. 1-16.

Davis, Belinda/Lindenberger, Thomas/Wildt, Michael (2008): Einleitung. In: Diess. (Hg.): Alltag, Erfahrung, Eigensinn. Historisch-anthropologische Erkundungen. Frankfurt a.M., S. 11-28.

De Certeau, Michel (1988): Kunst des Handelns. Berlin.

De Vincenti, Andrea (2015): Schule der Gesellschaft. Wissensordnungen von Zürcher Unterrichtspraktiken zwischen 1771 und 1834. Zürich.

De Vincenti, Andrea/Grube, Norbert/Hoffmann-Ocon, Andreas (2018a): Wissenschaftsaffines Seminar und kontinuierliche Erziehungsmuster in der akademischen Pädagogik. Debatten und Dynamisierungen in der Ausbildungsreform Deutschschweizer Lehrpersonen im frühen 20. Jahrhundert. In: Wilfried Göttlicher/Jörg W. Link/Eva Matthes (Hg.): Bildungsreform als Thema der Bildungsgeschichte. Bad Heilbrunn, S. 117-130.

De Vincenti, Andrea/Grube, Norbert/Hoffmann-Ocon, Andreas (2018b): Pädagogisierung von Räumen: Reale, imaginierte und fiktive Bildungsorte in der Deutschschweiz im 19. und 20. Jahrhundert. Einleitung in den Themenschwerpunkt. In: Historia Scholastica 4, H. 1, S. 1-4.

Dinges, Martin (1997): »Historische Anthropologie« und »Gesellschaftsgeschichte«. Mit dem Lebensstilkonzept zu einer »Alltagskulturgeschichte« der frühen Neuzeit. In: Zeitschrift für Historische Forschung 24, H. 2, S. 179-214. 
Dollinger, Bernd (2012): Klassiker der Pädagogik. Die Bildung der modernen Gesellschaft. 3. Aufl. Wiesbaden.

Dommann, Monika/Speich Chassé, Daniel/Suter, Mischa (2014): Einleitung: Wissensgeschichte ökonomischer Praktiken. In: Beiträge zur Wissenschaftsgeschichte 37, S. 107-111.

Eibach, Joachim (1994): Der Staat vor Ort. Amtmänner und Bürger im 19. Jahrhundert am Beispiel Badens. Frankfurt a.M.

Elias, Norbert (1978): Zum Begriff des Alltags. In: Kurt Hammerich/Michael Klein (Hg.): Materialien zur Soziologie des Alltags. Opladen (Kölner Zeitschrift für Soziologie und Sozialpsychologie, Sonderheft 20), S. 22-29.

Enzelberger, Sabina (2001): Sozialgeschichte des Lehrerberufs. Gesellschaftliche Stellung und Professionalisierung von Lehrerinnen und Lehrern von den Anfängen bis zur Gegenwart. Weinheim, München.

Eribon, Didier (2016): Rückkehr nach Reims. Berlin.

Finger, Jürgen (2016): Eigensinn im Einheitsstaat. NS-Schulpolitik in Württemberg, Baden und im Elsass 1933-1945. Baden-Baden.

Foucault, Michel (2001): In Verteidigung der Gesellschaft. Vorlesungen am Collège de France 1975-1976. Frankfurt a.M.

Foucault, Michel (2017): Theorien und Institutionen der Strafe. Vorlesungen am Collège de France 1971-1972. Berlin.

Freist, Dagmar (2015): Historische Praxeologie als Mikro-Historie. In: Arndt Brendecke (Hg.): Praktiken der Frühen Neuzeit. Akteure, Handlungen, Artefakte. Köln, Weimar, Wien, S. 62-77.

Füssel, Marian (2015): Die Praxis der Theorie. Soziologie und Geschichtswissenschaft im Dialog. In: Arndt Brendecke (Hg.): Praktiken der Frühen Neuzeit. Akteure, Handlungen, Artefakte. Köln, Weimar, Wien, S. 21-33.

Gebhard, Ulrich/Hummrich, Merle/Rabenstein, Kerstin/Reh, Sabine (2015): Räume, Dinge und schulisches Wissen. Eine Einführung. In: Zeitschrift für interpretative Schul- und Unterrichtsforschung (ZISU) 4, S. 13-14.

Gehlen, Arnold (2004): Die Seele im technischen Zeitalter. Sozialpsychologische Probleme in der industriellen Gesellschaft [1957]. In: Karl-Siegbert Rehberg (Hg.): Arnold Gehlen. Die Seele im technischen Zeitalter und andere sozialpsychologische, soziologische und kulturanalytische Schriften. Frankfurt a.M., S. 1-137.

Grube, Norbert (1999): Das niedere und mittlere Schulwesen in den Propsteien Stormarn, Segeberg und Plön 1733 bis 1830. Realisierung von Sozialdisziplin? Frankfurt a.M. u.a.

Grube, Norbert (2005): Die Darstellung Deutschlands durch die semi-staatliche Auslandsnachrichtenagentur »Deutsche Korrespondenz« 1951-1967. In: Johannes Paulmann (Hg.): Auswärtige Repräsentationen. Deutsche Kulturdiplomatie nach 1945. Köln, S. 289-311. 
Haasis, Lucas/Rieske, Constantin (2015a): Historische Praxeologie. Eine Einführung. In: Diess. (Hg.): Historische Praxeologie. Dimensionen vergangenen Handelns. Paderborn, S. 7-54.

Haasis, Lucas/Rieske, Constantin (Hg.) (2015b): Historische Praxeologie. Dimensionen vergangenen Handelns. Paderborn.

Habermas, Jürgen (1990): Strukturwandel der Öffentlichkeit. Untersuchungen zu einer Kategorie der bürgerlichen Gesellschaft. Frankfurt a.M.

Hillebrandt, Frank (2015): Vergangene Praktiken. Wege zu ihrer Identifikation. In: Arndt Brendecke (Hg.): Praktiken der Frühen Neuzeit. Akteure, Handlungen, Artefakte. Köln, Weimar, Wien, S. 34-45.

Hoffmann, Andreas (2001): Schule und Akkulturation. Geschlechtsdifferente Erziehung von Knaben und Mädchen der Hamburger jüdisch-liberalen Oberschicht 1848-1942. Münster.

Hoffmann-Ocon, Andreas (Hg.) (2015): Orte der Lehrerinnen- und Lehrerbildung im Kanton Zürich. Bern.

Hoffmann-Ocon, Andreas (2017): Persönlichkeit oder Wissenschaftsbasierung? Einfluss von Ausbildungspraktiken auf Prüfungen Zürcher Volksschullehrpersonen um 1900. In: Zeitschrift für Pädagogik 63, H. 3, S. 299-316.

Holenstein, André (2003): »Gute Policey« und lokale Gesellschaft im Staat des Ancien Régime. Das Fallbeispiel der Markgrafschaft Baden(-Durlach). Tübingen.

Iseli, Andrea (2009): Gute Policey. Öffentliche Ordnung in der Frühen Neuzeit. Stuttgart.

Jaeggi, Rahel (2014): Kritik von Lebensformen. 2. Aufl. Berlin.

Kundrus, Birthe/Steinbacher, Sybille (2013): Einleitung. In: Diess. (Hg.): Kontinuitäten und Diskontinuitäten in der Geschichte des 20. Jahrhunderts. Göttingen, S. 9-29.

Landwehr, Achim (2000a): Policey im Alltag. Die Implementation frühneuzeitlicher Policeyordnungen in Leonberg. Frankfurt a.M.

Landwehr, Achim (2000b): »Normdurchsetzung« in der Frühen Neuzeit? Kritik eines Begriffs. In: Zeitschrift für Geschichtswissenschaft 48, S. 146-162.

Landwehr, Achim (2013): Kulturgeschichte, Version: 1.0. In: Docupedia-Zeitgeschichte vom 14. Mai 2013, online unter http://dx.doi.org/10.14765/zzf. dok.2.248.v1 (Zugriff: 15.04.2020).

Lengwiler, Martin/Beck, Stefan (2008): Historizität, Materialität und Hybridität von Wissenspraxen. Die Entwicklung europäischer Präventionsregime im 20. Jahrhundert. In: Geschichte und Gesellschaft 34, H. 4, S. 489-523.

Lenzen, Dieter (2004): Irritationen des Erziehungssystems. Pädagogische Resonanzen auf Niklas Luhmann. Frankfurt a.M.

Lipphardt, Veronika/Patel, Kiran Klaus (2008): Neuverzauberung im Gestus der Wissenschaftlichkeit. Wissenspraktiken im 20. Jahrhundert am Beispiel menschlicher Diversität. In: Geschichte und Gesellschaft 34, H. 4, S. 425-454. 
Lüdtke, Alf (1991): Einleitung: Herrschaft als soziale Praxis. In: Ders. (Hg.): Herrschaft als soziale Praxis. Historische und sozial-anthropologische Studien. Göttingen, S. 9-63.

Lüdtke, Alf (1997): Alltagsgeschichte: Aneignung und Akteure. Oder - es hat noch kaum begonnen! In: WerkstattGeschichte (Hamburg) 17, S. 83-92.

Lüdtke, Alf (2003): Alltagsgeschichte - ein Bericht von unterwegs. In: Historische Anthropologie 11, H. 2, S. 278-295.

Luhmann, Niklas (2018): Lob der Routine [1964]. In: Ders.: Die Wirklichkeit der Organisation. Hg. von Ernst Lukas und Veronika Tacke. Wiesbaden, S. 293332.

Luhmann, Niklas/Schorr, Karl Eberhard (1988): Reflexionsprobleme im Erziehungssystem. Frankfurt a.M.

Lundgreen, Peter (1980): Sozialgeschichte der deutschen Schule im Überblick. Teil I: 1770-1918. Göttingen.

Lundgreen, Peter (1981): Sozialgeschichte der deutschen Schule im Überblick. Teil II: 1918-1980. Göttingen.

Mattes, Monika (2018): Gesamtschule im Flächenversuch. Erfahrungen mit einem bildungspolitischen Experiment im hessischen Wetzlar 1965-1990. In: Jahrbuch für Historische Bildungsforschung 23, S. 29-58.

Mergel, Thomas (2002): Überlegungen zu einer Kulturgeschichte der Politik. In: Geschichte und Gesellschaft 28, H. 4, S. 574-606.

Mollenhauer, Klaus (1987): Die Dinge und die Bildung. In: Karl-Heinz Braun/Dieter Wunder (Hg.): Neue Bildung - Neue Schule. Weinheim, Basel, S. 32-46.

Müller, Hans-Rüdiger (2016): Zur historischen Rekonstruktion von Erziehungspraktiken in Elternbiographien. In: BIOS. Zeitschrift für Biographieforschung, Oral History und Lebensverlaufsanalysen 29, H. 2, S. 266-274.

Müller, Philipp (2018): Historische Anthropologie. Fragen und Konzepte zur Einführung. In: Geschichte in Wissenschaft und Unterricht 69, H. 5/6, S. 334-345.

Nassehi, Armin/Nollmann, Gerd (Hg.) (2004): Bourdieu und Luhmann. Ein Theorievergleich. Frankfurt a.M.

Neidhardt, Friedhelm (1994): Öffentlichkeit, öffentliche Meinung, soziale Bewegung. In: Ders. (Hg.): Öffentlichkeit, öffentliche Meinung, soziale Bewegung. Köln (Kölner Zeitschrift für Soziologie und Sozialpsychologie, Sonderheft 34), S. 7-41.

Neugebauer, Wolfgang (1985): Absolutistischer Staat und Schulwirklichkeit in Brandenburg-Preussen. Berlin.

Noelle-Neumann, Elisabeth (2001): Die Schweigespirale. Öffentliche Meinung, unsere soziale Haut. 6. Aufl. München.

Nohl, Arnd-Michael (2011): Pädagogik der Dinge. Bad Heilbrunn.

Parmentier, Michael (2001): Der Bildungswert der Dinge oder: Die Chancen des Museums. In: Zeitschrift für Erziehungswissenschaft 4, H. 1, S. 39-50. 
Raithel, Jürgen/Dollinger, Bernd/Hörmann, Georg (2009): Einführung Pädagogik. Begriffe, Strömungen, Klassiker, Fachrichtungen. 3. Aufl. Wiesbaden.

Reckwitz, Andreas (2003): Grundelemente einer Theorie sozialer Praktiken. Eine sozialtheoretische Perspektive. In: Zeitschrift für Soziologie 32, H. 4, S. 282301.

Reckwitz, Andreas (2008): Praktiken und Diskurse. Eine sozialtheoretische und methodologische Relation. In: Herbert Kalthoff/Stefan Hirschauer/Gesa Lindemann (Hg.): Theoretische Empirie: zur Relevanz qualitativer Forschung. Frankfurt a.M., S. 188-209.

Reh, Sabine/Wilde, Denise (2016): Die historische Erforschung der Praktiken des Lesen- und Schreibenlernens. Eine Einleitung. In: Diess. (Hg.): Die Materialität des Schreiben- und Lesenlernens. Zur Geschichte schulischer Unterweisungspraktiken seit der Mitte des 18. Jahrhunderts. Bad Heilbrunn, S. 7-21.

Reh, Sabine/Glaser, Edith/Behm, Britta/Drope, Tilman (Hg.) (2017): Wissen machen. Beiträge zu einer Geschichte erziehungswissenschaftlichen Wissens in Deutschland zwischen 1945 und 1990. Basel, Weinheim (Zeitschrift für Pädagogik, Beiheft 63).

Reichardt, Sven (2015): Zeithistorisches zur praxeologischen Geschichtswissenschaft. In: Arndt Brendecke (Hg.): Praktiken der Frühen Neuzeit. Akteure, Handlungen, Artefakte. Köln, Weimar, Wien, S. 46-61.

Rheinberger, Hans-Jörg (2018): Experimentalität. Im Gespräch über Labor, Atelier und Archiv. Berlin.

Ricken, Norbert/Reh, Sabine (2017): Prüfungen. Systematische Perspektiven der Geschichte einer pädagogischen Praxis. Einführung in den Thementeil. In: Zeitschrift für Pädagogik 63, H. 3, S. 247-258.

Rieger-Ladich, Markus/Grabau, Christian (2018): Didier Eribon: Porträt eines Bildungsaufsteigers. In: Zeitschrift für Pädagogik 64, H. 6, S. 788-803.

Rittelmeyer, Christian/Parmentier, Michael (2001): Einführung in die pädagogische Hermeneutik. Darmstadt.

Sabean, David W. (1990): Das zweischneidige Schwert. Herrschaft und Widerspruch im Württemberg der frühen Neuzeit. Frankfurt a.M.

Sarasin, Philipp (2003): Geschichtswissenschaft und Diskursanalyse. In: Ders.: Geschichtswissenschaft und Diskursanalyse. Frankfurt a.M., S. 10-60.

Sarasin, Philipp (2011): Was ist Wissensgeschichte? In: Internationales Archiv für Sozialgeschichte der deutschen Literatur 36, H. 1, S. 159-172.

Saupe, Achim (2009): Der Historiker als Detektiv - der Detektiv als Historiker. Historik, Kriminalistik und der Nationalsozialismus als Kriminalroman. Bielefeld.

Schindler, Norbert (1984): Spuren in der Geschichte der anderen Zivilisation. Probleme und Perspektiven einer historischen Volkskulturforschung. In: Richard 
van Dülmen/Norbert Schindler (Hg.): Volkskultur. Zur Wiederentdeckung eines vergessenen Alltags (16.-20. Jahrhundert). Frankfurt a.M., S. 13-77.

Schlögel, Karl (2017): Das sowjetische Jahrhundert. Archäologie einer untergegangenen Welt. München.

Schlögl, Rudolf (2000): Bedingungen dörflicher Kommunikation: Gemeindliche Öffentlichkeit und Visitation im 16. Jahrhundert. In: Werner Rösener (Hg.): Kommunikation in der ländlichen Gesellschaft vom Mittelalter bis zur Moderne. Göttingen, S. 241-262.

Schlögl, Rudolf (2004): Vergesellschaftung unter Anwesenden. Zur kommunikativen Form des Politischen in der vormodernen Stadt. In: Ders. (Hg.): Interaktion und Herrschaft. Die Politik der frühneuzeitlichen Stadt. Konstanz, S. 9-60.

Schlögl, Rudolf (2008): Kommunikation und Vergesellschaftung unter Anwesenden. Formen des Sozialen und ihre Transformation in der Frühen Neuzeit. In: Geschichte und Gesellschaft 34, H. 2, S. 155-224.

Schlumbohm, Jürgen (1997): Gesetze, die nicht durchgesetzt werden - ein Strukturmerkmal des frühneuzeitlichen Staates? In: Geschichte und Gesellschaft 23, H. 4, S. 647-663.

Schmid, Robert (2012): Soziologie der Praktiken. Konzeptionelle Studien und empirische Analysen. Berlin.

Settele, Veronika (2017): Mensch, Kuh, Maschine. Kapitalismus im westdeutschen Kuhstall, 1950-1980. In: Mittelweg 36. Zeitschrift des Hamburger Instituts für Sozialforschung 26, H. 1, S. 44-65.

Strasser, Bruno J. (2017): The »Data Deluge«: Turning Private Data into Public Archives. In: Lorraine Daston (Hg.): Science in the Archive. Pasts, Presents, Futures. Chicago, London, S. 185-202.

Tanner, Jakob (2012): Historische Anthropologie. Version 1.0. In: Docupedia-Zeitgeschichte vom 3. Januar 2012, online unter http://dx.doi.org/10.14765/zzf. dok.2.278.v1 (Zugriff 15.04.2020).

Thelen, Tatjana (2019): Kultur/en oder Ontologie/n als Kritik? Ein Kommentar zu Caroline Arni. In: Historische Anthropologie 27, H. 2, S. 275-280.

Thompson, Christiane/Jergus, Kerstin/Breidenstein, Georg (2014): Perspektiven kulturwissenschaftlicher Bildungsforschung. In: Diess. (Hg.): Interferenzen. Perspektiven kulturwissenschaftlicher Bildungsforschung. Weilerswist, S. 7-29.

Tyack, David/Tobin, William (1994): The "Grammar of Schooling: Why Has it Been so Hard to Change? In: American Educational Research Journal 31, H. 3, S. 453-479.

Ulbricht, Otto (1994): Mikrogeschichte: Versuch einer Vorstellung. In: Geschichte in Wissenschaft und Unterricht 45, H. 6, S. 347-365. 
Van Dülmen, Richard (1984): Vorbemerkung. In: Richard van Dülmen/Norbert Schindler (Hg.): Volkskultur. Zur Wiederentdeckung eines vergessenen Alltags (16.-20. Jahrhundert). Frankfurt a.M., S. 7-11.

Van Dülmen, Richard (1992): Kultur und Alltag in der Frühen Neuzeit. Bd. 2: Dorf und Stadt. München.

Van Dülmen, Richard (1995): Historische Kulturforschung zur Frühen Neuzeit. Entwicklung - Probleme - Aufgaben. In: Geschichte und Gesellschaft 21, H. 3, S. 403-429.

Vogel, Jakob (2004): Von der Wissenschafts- zur Wissensgeschichte. Für eine Historisierung der »Wissensgesellschaft«. In: Geschichte und Gesellschaft 30, H. 4, S. 639-660.

Weber, Nadir (2015): Praktiken des Verhandelns - Praktiken des Aushandelns. Zur Differenz und Komplementarität zweier politischer Interaktionsmodi am Beispiel der preußischen Monarchie im 18. Jahrhundert. In: Arndt Brendecke (Hg.): Praktiken der Frühen Neuzeit. Akteure, Handlungen, Artefakte. Köln, Weimar, Wien, S. 560-570.

Welskopp, Thomas (2017): Zukunft bewirtschaften. Überlegungen zu einer praxistheoretisch informierten Historisierung des Kapitalismus. In: Mittelweg 36. Zeitschrift des Hamburger Instituts für Sozialforschung 26, H. 1, S. 81-97. 
I Orte - Akteure - Praktiken. Historische Fallanalysen zum Alltag und zu Krisenmomenten an Zürcher Lehrpersonenseminaren im 19. und 20. Jahrhundert 



\section{Von Heizung und Hund Hauswarte an Zürcher Lehrerinnen- und Lehrerseminaren um 1900'}

Adrian Juen

In diesem Beitrag sollen ausgesuchte Quellen zu Lehrerinnen- und Lehrerseminaren im Kanton Zürich aus dem Zeitraum von 1888 bis 1917 in praxeologischer Perspektive untersucht werden. Dabei bilden Hauswarte und ergo Hauswartspraktiken den Forschungsgegenstand. ${ }^{2}$ Es ist vorab anzumerken, dass die Erforschung von Hauswarten für die Historische Bildungsforschung ein Desiderat darstellt, da sowohl in der erziehungswissenschaftlichen wie in der geschichtswissenschaftlichen Literatur kaum Hinweise auf das Tun von Schulhauswarten auffindbar sind. ${ }^{3}$ Quellen gibt es hingegen überraschend viele, zumindest für grössere Schulen, deren geschichtliche Dokumentation einem öffentlichen Archiv zufiel. Bei den nachfolgend berücksichtigten Schulen handelt es sich um das kantonale Seminar Küsnacht und das Lehrerinnenseminar der städtischen Höheren Töchterschule Zürich. Die beiden Seminare waren Mittelschulen der Lehrerinnenund Lehrerbildung, unterschieden sich aber bezüglich Trägerschaft, standortbedingtem Milieu sowie Schülerinnen- und Schülerpublikum. ${ }^{4}$ Im kurzen ersten Teil des Aufsatzes sei auf kulturhistorisch fruchtbare Theoriebezüge verwiesen, die praxeologische Ideen beinhalten und/oder voraussetzen. Anschliessend sollen zwei Aspekte der Schulhauswartung anhand ausgewählter Quellen unter dem Eindruck der genannten praxeologischen Überlegungen analysiert werden.

1 Dieser Beitrag entstand im Rahmen des SNF-Projekts 166008 »Wissenschaft - Erziehung und Alltag. Orte und Praktiken der Zürcher Primarlehrer/-innenbildung in der ersten Hälfte des 20. Jahrhunderts«.

2 〉Hauswart « ist neben `Abwart` der übliche Quellenbegriff für Hausmeister.

3 Schulhauswarte tauchen lediglich in populärwissenschaftlichen Reportagen (vgl. Miller 2016; Miller/Weber 2016) oder als Teil sozialanthropologischer Studien (vgl. Keßler 2017, S. 143-152) auf. Darüber hinaus wurden geschichtswissenschaftliche Untersuchungen zu verwandten Themen veröffentlicht (vgl. Schwartz 2011 zu den Dienstbotinnen am St Hugh's College; Wagener 1996 zu den Pedellen an der Universität Göttingen).

4 Vgl. Grube/Hoffmann-Ocon 2015. 


\section{Praktiken als Stoff der Kulturgeschichte}

Kulturgeschichtliche Arbeiten verweisen oft auf den 1973 mit der Publikation The Interpretation of Culture bekannt gemachten Kulturbegriff des US-amerikanischen Kulturanthropologen Clifford Geertz. ${ }^{5}$ Eine Kultur bezeichnet demnach das Beziehungsnetz bzw. die Bedeutungsstruktur von Praktiken, Wissen, Gedanken und Gefühlen in einer Gesellschaft, ${ }^{6}$ wobei Praktiken - und dies im Gegensatz $\mathrm{zu}$ Wissen, Gedanken und Gefühlen - beobachtbare Zeichen einer Kultur sind. Die (Neue) Kulturgeschichte legt also ein Augenmerk auf gesellschaftliche Praktiken in deren Beziehungen und Bedeutungen. Lucas Haasis und Constantin Rieske zitieren in ihrer Überblicksdarstellung zur historischen Praxeologie treffend den einflussreichen britischen Kulturhistoriker Peter Burke: »Praxis ist eines der Schlagwörter der Neuen Kulturgeschichte «. Tatsächlich konzentrierten sich (kultur-)historische Studien noch vor der gängigen Adaption anthropologischer Konzepte auf die Interpretation kollektiven (bzw. kollektiv verstandenen) Handelns. Bereits der Annales-Historiker Philippe Ariès bezog sich für sein wegweisendes Werk L'enfant et la vie familiale sous l'ancien régime von 1960 explizit auf erzieherische, schulische und familiale Praktiken, da Schule und Familie von ihm nicht als fixe Institutionen, sondern wandelbar als Summe von Praktiken gedacht wurden. ${ }^{8}$ Erst recht in der kulturgeschichtlichen (Bildungs-)Forschung des 21. Jahrhunderts sind eigentliche und ausdrückliche praxeologische Herangehensweisen nicht mehr wegzudenken. Man kann generell konstatieren, dass kulturhistorische und insbesondere als historisch anthropologisch explizierte Forschungskonzepte das Handeln der Menschen und damit (soziale) Praxis ins Zentrum stellen. ${ }^{9}$

Ich befürworte eine kulturhistorische bzw. historisch anthropologische Auffassung von Praxeologie, insbesondere bei meinem Forschungsgegenstand. Zumal in vorliegendem Beitrag zwei Orte, die beiden erwähnten Seminare, bearbeitet werden, sei im Folgenden auf das landscape-Konzept des britischen Anthropologen Tim Ingold verwiesen, das Orte räumlich und sozial zugleich fasst. ${ }^{10}$ Ingolds landscape bezeichnet das Leben und den Lebensraum von Wildbeuterinnen- und Wildbeuterkulturen, kann aber in meiner Lesart auch - so wie hier auf das Seminar angewandt - als Komplex von Gebäuden und den dort anwesenden Menschen verstanden werden. Diese landscape besteht aus ihren Baulichkeiten,

\footnotetext{
5 Daniel 1993, S. 82; vgl. Geertz 1987.

6 Ebd., S. 11, 15f. u. 21f.

7 Burke 2005, 86; Haasis/Rieske 2015, S. 18.

8 Vgl. Ariès 2014; so untersuchte er (S. 494-497) bspw. das Tisch- und Abendgebet als familiale Praktik.

9 Müller 2018, S. 338.

10 Vgl. Ingold 2000a.
} 
Gegenständen, Menschen, Tieren, Pflanzen, Geräuschen, Gerüchen, ihrer spürbaren Geschichte und Spuren der Vergangenheit. ${ }^{11}$ Denkt man das Seminar als landscape, rahmt es in seiner materiellen und körperlichen Beschaffenheit das Beziehungsnetz der Menschen und ihrer Praktiken vor Ort. Die landscape legt als analytisches Gerüst die physisch wahrnehmbaren Grenzen und Bedingungen der örtlichen Kultur fest. Mit Ingold sind Menschen und Praktiken am Seminar von der körperlich erfahrbaren Materie und Kultur vor Ort geprägt und prägen diese zugleich. Der Anthropologe führt das Wechselverhältnis von Ort, Menschen und Praktiken aus, indem er das Ensemble der Arbeitspraktiken (»tasks«) innerhalb einer landscape als taskscape zu fassen versucht: "[...] every task exists as part of what I have called a taskscape, understood as the totality of tasks making up the pattern of activity of a community [...]. «12 Tasks sind gewohnheits- wie geschäftsmässig, orts- wie personengebunden und geben den Menschen am Seminar eine »identity «. ${ }^{13}$ Folglich erscheinen Hauswarte am Seminar in ihren Praktiken (und in den Praktiken im Umgang mit Hauswarten). ${ }^{14}$

Die eben geschilderten von mir als praxeologisch bezeichneten Implikationen angelsächsischer Anthropologie sind aber keinesfalls einzigartig. Was Ingold kulturtheoretisch konzipierte, findet sich vielfach in anderen methodischen und disziplinären Wissenschaftskontexten wieder. So könnte Ingolds taskscape etwa der Praxisformation (einem örtlichen Arrangement von Praktikverkettungen) Frank Hillebrandts entsprechen. ${ }^{15}$ Überhaupt ist anzumerken, dass das Verständnis von Praktiken als gleichzeitig kulturell strukturiert und die Kultur strukturierend (bzw. als sozial strukturiert und das Soziale strukturierend) kein Vorrecht der Anthropologie ist, sondern auch in der soziologischen Praxistheorie, die oft auf Pierre Bourdieu rekurriert, ein wesentliches Element ist. ${ }^{16}$ Es darf als Allgemeingut gelten, dass Praktiken nicht nur Zeichen oder Symbole einer (vor-)bestimmenden Kultur sind, sondern die Kultur gleichzeitig hervorbringen, wie sie von ihr hervorgebracht werden. Deshalb ist in der kulturhistorischen Forschung nicht von einer ganzheitlichen, allumfassenden, geordneten oder zwingend sinnvollen bzw. zweckmässigen Kultur auszugehen. Unter diesen Vorzeichen ist auch meine

11 Ebd., S. $192 f$.

12 Ingold 2000b, S. 325.

13 Ingold 2000a, S. 195, und 200ob, S. 325 u. 332.

14 Wie Paul Veyne (1992, S. 35) dies prägnant formulierte: »Die Dinge [...] sind nur die Korrelate der Praktiken.«

Hillebrandt 2015, S. 38f.

16

Dinges 2006, S. 187. 
Bezugnahme auf den Geertz'schen Kulturbegriff zu verstehen, wenngleich Geertz der als >symbolisch < denominierten Anthropologie zugeordnet werden kann. ${ }^{17}$

Wie dem auch sei, keine theoretische Ausgangslage nimmt die Forschenden aus der Pflicht, verwendete Begriffe in der Konstellation des jeweiligen Forschungsvorhabens anzupassen. Ich definiere eine Praktik als eine Handlung, die von den Forschenden wiederholt gleich beobachtet, also gleich kontextuell interpretiert werden kann. ${ }^{18}$ Das heisst, dass Praktiken durchaus Arbeitspraktiken, stechnische Praktiken oder Aufgaben (Ingolds tasks), aber auch sogenannte ssoziale Praktiken`, also Rituale, regelmässige Interaktionen wie Umgangsformen, oder sogar Mimik, Gestik, Sprech-, Schreib- und Kleidungsstile sein können. Ingold spricht zwar ausdrücklich von tasks als »technical practices«, rät aber dennoch davon ab, eine starre Linie zwischen >technischen zu ziehen:

One of the great mistakes of recent anthropology [...] has been to insist upon a separation between the domains of technical and social activity, a separation that has blinded us to the fact that one of the outstanding features of human technical practices lies in their embeddedness in the current of sociality. ${ }^{19}$

Praktiken müssen soziokulturell kontextualisiert werden, wodurch sie in höchst diversen Charakteristika und teils fragmentarisch erscheinen können. Somit sind Hauswarte mehr als eine Verkörperung der Hausordnung, sie existieren nicht nur in ihren Aufgaben, sondern auch in deren sozialen Ausdifferenzierung: im Umgang, in Beziehungsgeflechten und in Wissenszusammenhängen. Abschliessend ist anzumerken, dass Praktiken für Zeitgenossinnen und Zeitgenossen gar nicht, aber auch unterschiedlich oder gleich wie für die geschichtlich Forschenden existieren konnten. Sie vermochten überdies bewusst und/oder intentional zu passieren, oder unbewusst und/oder ohne Intention.

Dieser Umriss des Praktikenbegriffs zeigt, dass der Praxeologie als Perspektive viele Möglichkeiten und eine grosse Offenheit innewohnen. Anthropologisch inspiriert, werden Praktiken in diesem Beitrag in einer Art historischer Beobachtung oder historischer Ethnografie rekonstruiert. ${ }^{20}$ Bei der Rekonstruktion

17 Daniel 1993, S. 82; Karl Hörning und Julia Reuter synthetisieren anthropologische Kulturund soziologische Praxistheorien unter dem Titel »Doing Culture«, indem sie Praktiken als Kultur in Aktion bzw. Kultur als soziale Praxis formulieren (2004, S. 9f.). Dabei wird Kultur als soziokulturelle Ordnung des Wissens, das einer Praktik innewohnt, ausdifferenziert (S. 15).

18 Grundlegend ist hierbei Ceertz' Ethnografie, die im Kern Interpretation und nicht blosse Beobachtung ist, da sie das Kulturelle oder Soziale explizit berücksichtigt (1987, S. 14). Ingold 2000a, S. 195.

20 Eine historische Beobachtung erfolgt im Gegensatz zur anthropologischen Beobachtung allerdings indirekt, da die Aufzeichnungen, die Beobachtungen zulassen, nicht nur die der 
historischer Praktiken müssen Vernetzung und Bedeutung der Praktiken berücksichtigt werden, was mit Geertz' Kulturverständnis im Begriff der Dichten Beschreibung zum Ausdruck kommt. ${ }^{21}$ "Die Aufgabe von Historikerinnen und Historikern ist es schliesslich«, wie es Philipp Müller in Bezug auf die Historische Anthropologie formuliert, "dieses Handeln in seinen sozialen Beziehungen, in seinen Oppositionen und Verwandtschaften $\mathrm{zu}$ anderen Handlungen, in seiner symbolischen Dimension zu analysieren und seine Begrenzung und Reichweite, seine Dynamik zu ermitteln. Erst im Zuge dieser Analyse wird aus einer Handlung auch eine soziale Praxis. ${ }^{22}$ Hauswartspraktiken sind also immer auf ihre Bedeutung am Seminar hin zu befragen. Mit anderen Worten: Welches >Wie? des Seminars ermöglichten Hauswarte ${ }^{23}$ Es versteht sich von selbst, dass Hauswarte dabei keine unbedingte aktive oder autonome Ermöglichungs- oder Formungsmacht ausübten. Sie waren am Seminar stets eingebunden in landscape und taskscape. Diese hätten ohne Hauswarte allerdings entschieden anders ausgesehen.

Bei der Quellenanalyse, die möglichst verschiedene Quellengattungen berücksichtigen sollte, ist darauf zu achten, was Hauswarte taten und wie sie dies taten. Etwas, das Hauswarte in den Augen der Forschenden wiederholt taten, soll als Praktik bezeichnet und eingehend beschrieben werden (wobei die Praktik in weitere nuancierte Praktiken, in Handlungsmuster, zerfallen kann und gerade dabei Praktiken als Umgang, Interaktion, zwischenmenschliche Beziehungen und Verflechtungen zur Geltung kommen). Weiterführend soll gefragt werden, was die beschriebene Praktik selbst am Seminar tat oder, wie oben ausgedrückt, welche Bedeutung dieser Praktik im kulturellen Raum Seminar zukam. Ich beabsichtige also nach Hauswartspraktiken, deren Vollzug und Bedeutung zu fragen. Dabei handelt es sich aber nur bedingt um drei aufeinander folgende Schritte. Ebenso wie eine Beobachtung ohne Interpretation weder erstrebenswert noch eigentlich möglich ist, überlappen sich die Teilfragen mehrheitlich.

Im folgenden Teil dieses Aufsatzes werden Quellen besprochen, die spezifische Hauswartspraktiken beobachtbar machen. Es ist mir ein Anliegen, darauf

Forschenden, sondern auch historische »Weltsichten und [...] Absichten portieren« (Patzold 2010, S. 147). Es gilt die Bedeutung der Quellen(-inhalte) für die Zeitgenossinnen und -genossen besonders zu berücksichtigen, so Steffen Patzold, der im Zuge seiner Überlegungen zum methodologischen Repertoire der Mediävistik auf die Anthropologie und damit auf die Forschung Gerd Althoffs zu »symbolische[r] Kommunikation und Ketten ritualisierter Handlungen « verweist (S. 146). Dagmar Freist (2015) legt pauschal nahe, dass die an den Beobachtungscharakter anschliessende historisch-praxeologische Perspektive eng mit der Mikrogeschichte verbunden ist.

21 Geertz 1987, S. 21; auch bei Ingold hängen alle Komponenten der »landscape« (2000a, S. 191) und die Praktiken untereinander (2000b, S. 325) zwingend zusammen.

Müller 2018, S. $338 f$.

Veyne 1992, S. 14f. u. 49. 
hinzuweisen, dass es sich dabei um Beispiele handelt, die schliesslich nur zwei Aspekte (von denen sich - wenn man so wollte - zwei Hauptpraktiken ableiten liessen) ausführlich begutachten und damit ein arg unvollkommenes Bild der Hauswarte und ihrer Praktiken abgeben. Exemplarisch wird aber auch dieses Bild seinen Zweck erfüllen und im Rahmen des vorliegenden Artikels auf eine denkbare Umsetzung praxeologischer Ideen in einer bildungshistorischen Studie hinweisen. Die beiden Fallbeispiele werden zuerst die Beheizung und Beleuchtung, danach die Aufsicht am Seminar ins Zentrum rücken. Darin erschöpfte sich der Tätigkeitskreis von Hauswarten allerdings keineswegs: Zu ihren Aufgaben gehörten neben Betrieb, Reinigung und Reparatur unter anderem auch die Betreuung und Sanktion der Schülerinnen und Schüler, Botengänge, Laborarbeiten oder das Begleiten von Exkursionen. Zudem wohnten Hauswartsehepaare sowohl in Küsnacht wie an der Töchterschule im Schulgebäude und gehörten damit fast ständig zu landscape.

\section{Wärme und Licht als technischer Aspekt des Seminars}

Das älteste im Archiv des Seminars Küsnacht auffindbare Reglement zur Hauswartung an besagter Schule datiert vom 9. Mai 1888. Der Anlass für den Druck des Reglements lässt sich aus den Quellen nicht nachvollziehen. In dieser »Dienstordnung für den Abwart am kantonalen Lehrerseminar in Küsnacht« ist zu Heizung und Licht im Schulgebäude das Folgende zu entnehmen. ${ }^{24}$

$\S 8$ 8. Alle Räumlichkeiten, welche für den Unterricht gebraucht werden, sind so zu heizen, dass mit Beginn der Stunden die Temperatur auf mindestens $12^{\circ} \mathrm{C}$. steht und allmälig auf $15-17^{\circ} \mathrm{C}$. steigt. Nötigenfalls ist auch am Mittag und Sonntag zu heizen, am Sonntag namentlich auch der Gesangsaal der Klavierübungen wegen. $\S 9$. Petroleum darf zum Anzünden unter keinen Umständen verwendet werden. $\S 10$. Vor Beginn des Unterrichts ist aus den Zimmern alles nicht gebrauchte Brennmaterial u. dgl. zu entfernen.

$\S 11$. Je am Abend nach Beendigung des Unterrichts sind die Öfen und das Brennmaterial für den folgenden Tag in Ordnung zu bringen.

$\S 12$. Das Cewächshaus ist so zu heizen und zu lüften, dass die Temperatur in demselben nie unter $5^{\circ} \mathrm{C}$. sinkt.

$\S 13$. Je am Morgen vor 8 Uhr oder in der Mittagspause sind alle Lampen, auch diejenigen, welche voraussichtlich im Laufe des Tages nicht gebraucht werden, nachzusehen, gründlich zu reinigen und nötigenfalls frisch zu füllen. Namentlich ist

24 StAZH Z 388.251 Dienstordnung für den Abwart am kantonalen Lehrerseminar in Küsnacht, 9. Mai 1888 , S. $2 f$. 
darauf zu achten, dass heruntergefallene Dochtresten sorgfältig aus den Brennern entfernt und die Abtropfschalen regelmässig entleert und gereinigt werden. In keinem Fall dürfen diese Arbeiten bei künstlicher Beleuchtung vorgenommen werden.

$\S 14$. Die Lampen sind rechtzeitig anzuzünden und unmittelbar nach Schluss der Stunden zu löschen, sofern nicht die Direktion eine andere Anordnung trifft.

$\S 15$. Es ist dafür zu sorgen, dass das Ausstreichen der Öfen, die Ausbesserung von schadhaft gewordenen, das Russen $u$. dgl. rechtzeitig vorgenommen werden.

1888 hatte der Hauswart die Seminarräumlichkeiten täglich mittels Zimmeröfen und Brennstofflampen zu heizen bzw. zu beleuchten. Dies änderte sich aber bald darauf. Ein Regierungsratsprotokoll von 1890 zeugt vom Beschluss der Kantonsregierung, am Seminar elektrische Anlagen zur Beleuchtung zu installieren. ${ }^{25} \mathrm{Da}-$ mit dürfte sich der Arbeitsalltag des Hauswarts bedeutend gewandelt haben. Die Lampen mussten nicht mehr täglich einzeln angezündet und unterhalten werden. Weitere sieben Jahre später wurde der Seminarkomplex um ein neues Schulgebäude, das mit einer Zentralheizung versehen war, erweitert. ${ }^{26}$ Wahrscheinlich im selben Jahr, auf jeden Fall bis 1896, wurde im alten Seminargebäude ebenfalls eine Zentralheizung eingerichtet, welche die auf die einzelnen Räume verteilten Öfen obsolet machte. Eine entsprechende Verfügung des Kantonsbaumeisters vom 12. Juni 1896 weist darauf hin, dass zu dem Zeitpunkt die Zentralheizung auch für die älteren Seminarräumlichkeiten bereits baulich umgesetzt war. ${ }^{27}$

In Folge Erstellung einer Centralheizung im Seminargebäude Küsnacht werden eine größere Anzahl teils noch neuer, teils alter Oefen entbehrlicht, nämlich:

Musiksaal: 2 Kachelofen in Eisengestell Sockel 55/45/1.70m. mit je 2 m. Rohr Stück 2 [Kachelofen] viereckig mit Sockel 40/40/1.50m [Stück] 1

[Kachelofen] [viereckig] [mit] [Sockel] 50/40/1.40[m] [Stück] 1

[Kachelofen] rund (Immerbrenner) 1,80m

Blechcylinderofen mit Tambour, $35 \mathrm{~cm}$ Durchmesser 1,30 m hoch [Stück] 1

Coaksofen 30-40 cm Durchmesser 1.30 m hoch mit Blechmantel [Stück] 2

[Coaksofen] in der Turnhalle, $50 \mathrm{~cm}$ Durchmesser $2 \mathrm{~m}$ hoch [Stück] 2

Blechcylinderofen 60-90 cm Durchmesser [Stück] 13

[insgesamt] Stück 23

Ein Ofen könnte Verwendung finden im Pfarrhaus Zollikon, die übrigen sind zu veräußern.

25 StAZH V II 17.3.6 Regierungsratsprotokoll, 2. August 1890.

26 Vgl. StAZH U 77.2.9 (Teil 1) Abwart und Abwartsgehilfe (1887-1925).

27 StAZH V II 17.3.5 Verfügung des Kantonsbaumeisters, 12. Juni 1896. 
Wirbeantragen Es wird verfügt:

1) Die Oefen im Seminargebäude Küsnacht sind zum Verkaufe auszuschreiben.

Dieser Quelle ist zu entnehmen, dass der Hauswart am Seminar vor der Installation der Zentralheizung während der kälteren Monate jeden Tag um die 23 Öfen anzufeuern und zu warten hatte. Der räumliche Arbeitsschwerpunkt des Hauswarts verlagerte sich von den Schulzimmern in den Keller und so trat dieser für die Schülerinnen und Schüler weniger in Erscheinung. In den Zimmern kehrte eine neue Ordnung, Sauberkeit und Wärme ein und die Geruchskulisse veränderte sich. Wie sich der Alltag des Hauswarts bezüglich Heizungsinfrastruktur wandelte, soll im Weiteren anhand der Geschichte Jakob Bünzlis vertieft werden. Bünzli war von 1900 bis 1907 als Hauswart in Küsnacht angestellt. Seine Episode am Seminar beginnt mit dem Hinschied seines Vorgängers: Im Herbst 1900 starb der bis dahin berufstätige Seminarhauswart Karl Hottinger. Sogleich wurde in mindestens einer Zeitung wie folgt für die vakante Stelle inseriert. ${ }^{28}$

Infolge Hinschieds des bisherigen Inhabers ist die Stelle eines Abwarts am kantonalen Lehrerseminar in Küsnacht sofort neu zu besetzen.

Die Bewerber müssen mit der Bedienung von elektrischen und Dampf-Anlagen vertraut sein. - Schriftliche Anmeldungen unter Beilegung von Zeugnissen sind bis spätestens 8. Oktober 1900 an Herrn Seminardirektor Heinrich Utzinger in Küsnacht zu richten, welcher auch über die nähern Anstellungsverhältnisse und Dienstobliegenheiten Auskunft erteilt.

Die Seminardirektion forderte von den Kandidaten Versiertheit im Umgang mit elektrischen und Heizanlagen. Dass entsprechende Kenntnisse Priorität hatten, zeigt auch ein Schreiben der Direktion der öffentlichen Bauten an den Erziehungsdirektor vom 2. Oktober 1900. "[D]as Laden der Batterie \& die Bedienung des Lokomobils« wurden während der Vakanz an die »Accumulatorenfabrik Oerlikon« delegiert. ${ }^{29}$ Der Direktor betonte ausserdem, dass »der neue Hauswart mit der Bedienung von elektrischen \& Dampfanlagen vertraut « sein müsse. ${ }^{30} \mathrm{Da}$ das elektrische Licht wohl rasch unentbehrlich geworden ist und der Winter nahte, musste schnellstmöglich Ersatz für den verstorbenen Hauswart gefunden werden. Unter den 23 Bewerbern befand sich auch Jakob Bünzli aus Zürich. Leider fehlt in der archivierten Dokumentation des Anstellungsprozesses das Bewerbungsschreiben Bünzlis, da sich noch ein zweiter Jakob Bünzli (wohnhaft in Küsnacht) auf die Stelle bewarb und `fälschlicherweise ‘ das Bewerbungsschreiben des

28 StAZH U 77.2.9 (Teil 1) Zeitungsinserat Hauswartstelle, 29. September 1900.

29 StAZH V II 17.3.6 Direktion der öffentlichen Bauten an Erziehungsdirektor, 2. Oktober 1900.

30 Ebd. 
Namensvetters im Archiv aufgehoben wurde. Die nicht mehr vorhandene Bewerbung Bünzlis muss bei der Seminardirektion aber Anklang gefunden haben und schaffte es in die engere Auswahl. Die detaillierten diesbezüglichen Aufzeichnungen der Seminardirektion (»Anmeldungen für die Abwarts-Stelle«) verraten das spezifische Interesse am Berufsmann Bünzli. ${ }^{31}$

3. Jakob Bünzli-Kempf v. Volketswil, geb 1866, Obmannamtsgasse 3. Z I erlernte den Eisendreherberuf in der Maschinenfabrik Oerlikon, seit 1890 Heizer \& Reparateur. $2^{1 / 2}$ ]ahre in der städt. Materialverwaltung als Maschinist der Dampfstrassenwalze. Seit 1893 Heizer \& Reparateur in der Buchdruckerei Zürcher \& Furrer, jetzt noch. Hat Dampfkessel, Zentralheizung, Gasmotor \& Beleuchtung zu besorgen. Besorgte 1898 während 3 Monaten nach 7 Uhr die Maschinenanlage der Buchdruckerei im Berichthaus. Frau war 14 Jahre Dienstmagd, 21/2 Jahre bei Bankdirektor Frei, hatte Reinhaltung der Lokale zu besorgen. - Sei bei der Abwartswahl des Bankvereins (Paradeplatz) von 119 Bewerbungen in 2. Linie gestellt worden. Frau persönl. Vorstellg. Guter Eindruck. - Gute Zeugnisse. Mann sei sehr solid, nach Aussage der Frau.

An dieser Passage kann - im Kontrast zum Hauswartsreglement von 1888 - ein Wandel des Berufsbildes und des Tätigkeitsfelds des Küsnachter Hauswarts festgemacht werden. Der Hauswart wurde nun als Fachkraft, nicht als Hilfsarbeiter oder Knecht, wie dies vor der Einrichtung der grossen technischen Anlagen der Fall gewesen sein könnte, wahrgenommen. Damit geht ein Wandel des Seminars in seiner materiellen und körperlichen Substanz als landscape einher.

Es darf im Zusammenhang mit den Bewerbungsunterlagen nicht ausgelassen werden, dass nicht nur die spezifische Profession des Hauswarts als Mechaniker ${ }^{32}$ zur Anstellung befähigte, sondern dass auch seine Person im Sinne von Persönlichkeit von grosser Wichtigkeit war. Die erwähnten Zeugnisse gaben Auskunft über den Charakter des Kandidaten, weniger über seine Anstellungsbiografie. Besonders regelmässig tritt dabei die positive Attribuierung mit Treue bzw. Treusein auf. In weiteren Personalunterlagen der Hauswarte verschärft sich dieser Eindruck: War die Seminardirektion oder Lehrerschaft mit dem Hauswart zufrieden, wurde dessen Treue gelobt. ${ }^{33}$ Wie Jennifer Burri in vorliegendem Sammelband ausführt, ist Treue am ebenfalls zürcherischen Seminar Unterstrass auch für Lehrpersonen sowie Schülerinnen und Schüler in der offiziellen Rezeption die

31 StAZH U 77.2.9 (Teil 1) Anmeldungen für die Abwarts-Stelle.

32 Später galt insbesondere auch eine Ausbildung als Elektromonteur als qualifizierend, wie bspw. den Bewerbungsunterlagen aus dem Personaldossier des Küsnachter Hauswarts Emil Kamm (1927-1952) zu entnehmen ist (vgl. StAZH Z 388.255 Kamm Emil, Hauswart). 
meistgenannte und -betonte Eigenschaft. In der hier zitierten Zusammenfassung von Bünzlis Bewerbung tritt auch die potenzielle Hauswartfrau mit einer interessanten Rollenzuschreibung in Erscheinung. Hauswarte fanden nur als Ehepaar Anstellung, ${ }^{34}$ die Frau des Hauswarts war selbstverständlich verpflichtet, täglich im Seminar mitzuarbeiten, wurde jedoch nicht dafür entlöhnt. Wie Briefe des Hauswarts an die Seminardirektion und des Direktors an das Hochbauamt aus dem Jahre 1930 zeigen, erhielt der spätere Küsnachter Hauswart Emil Kamm eine »Frauenzulage«, die am 2. Mai 1930 per Regierungsratsbeschluss auf 700 Franken pro Jahr erhöht wurde. ${ }^{35}$

Zur Jahrhundertwende, als Bünzli seine Anstellung erhielt, wurde elektrisches Licht am Seminar Küsnacht mit einer kohlebetriebenen Dampfmaschine erzeugt, die Zentralheizung hingegen wurde mit Koks betrieben. Dies geht aus einem Schreiben von Seminardirektor Utzinger an den Erziehungsdirektor vom 12. November 1900 hervor. ${ }^{36}$ In diesem Brief, welcher im Kern die Entlöhnung des Hauswarts thematisiert, wird der soeben angestellte Hauswart Bünzli als »intelligent und gewissenhaft«, als erfahrener, ausgebildeter und qualifizierter Mann dargestellt. Der Direktor zeigt sich seinem Hauswart verpflichtet. Bünzli anzustellen war gemeinsame Sache der Seminardirektion, der Aufsichtskommission und der Erziehungsdirektion, doch hinterlässt die Korrespondenz den Eindruck, als fühlte sich Seminardirektor Utzinger gegenüber dem Erziehungsdirektor für den Hauswart und damit auch für den Einstellungsentscheid verantwortlich. Man kann dem Direktor sogar eine gewisse Abhängigkeit vom Hauswart attestieren. Da es zum Zeitpunkt des erwähnten Schreibens bereits November war, musste die Heizung angefeuert und der Hauswart bei Laune gehalten werden. In keiner Weise war der Hauswart ein auswechselbarer Angestellter der Direktion - im Gegenteil, der Hauswart war relevanter Teil der Abläufe, die den Unterricht ermöglichten. Als Herr über Dampfmaschine und Heizung erlangte er ausserdem eine neue Autonomie, da nur er um die Besorgung der Anlage wusste. Dies alles hatte einen Einfluss auf das Beziehungsgefüge, die Umgangsformen oder Praktiken des Miteinanderlebens am Seminar.

Im Jahr darauf, 1901, wandte sich Hauswart Bünzli mit einem Anliegen an die Seminardirektion und damit schliesslich an die Erziehungsdirektion bzw. an den Regierungsrat. Bünzli ersuchte um Anstellung eines Hilfshauswarts. In seiner an Direktor Utzinger und die Aufsichtskommission gerichteten Anfrage vom 20. Juni 1901 schrieb Bünzli unter anderem das Folgende. ${ }^{37}$

34 Vgl. StAZH Z 388.255 Kamm Emil, Hauswart (1927-1952).

35 Ebd. Regierungsratsprotokoll, 2. Mai 1930.

36 StAZH U 77.2.9 (Teil 1) Seminardirektor an Erziehungsdirektor, 12. November 1900.

37 StAZHU 77.2.9 (Teil 1) Hauswart an Seminardirektor und Aufsichtskommission, 20. Juni 1901. 
Die beiden Central Heizungen brauchten vom 27. Oktbr. 1900 bis Ostern 1901 rund 1400 Ctr Coaks die Dampfmaschine 250 Ctr Steinkohlen und insgesamt den Transport 2000 Centnern veranlaßte wenn die Schlaken u Asche zu 350 Centner angenomen werden was bestimt als eher zu wenig angenommen ist als zu viel.

Daß in diesen Zahlen eine bedeutende Summe von höchst ungesunder Arbeit liegt wird jedermann begreifen können denn es muß die Arbeit neben dem andern eben nur von einem Mann bewältigt werden.

Daß die Bedienung der beiden Centralheizungen eine höchst ungesunde Arbeit ist komt eben daher daß dieselben weit von einander entfernt sind u wenn dann der Abwart in einer Hitze von $35^{\circ} \mathrm{K}$ [sic!] arbeiten muß um nacher den Weg zur andern bei einer Kälte von nur $12-14^{\circ}$ wie es ja vergangenen Winter längere Zeit war so ist der Beweis erbracht, daß diese Arbeit eben 2 Männer erfordert.

Bünzli argumentierte mit dem Arbeitsaufwand und der hergebrachten Arbeitsweise, die den Einsatz zweier Personen erforderte. Die Arbeitsbedingungen beschrieb der Hauswart in eindrücklicher Weise quantitativ. Generell ist in Quellen, die von Hauswarten selbst verfasst wurden, ein Hang zur Erwähnung von Zahlen bzw. Kosten- und Massangaben festzustellen. Der Duktus hat oft etwas diffus Technisches, was die (Selbst-)Wahrnehmung des Hauswarts als Technikfachmann unterstreicht. Der Hauswart betonte hier, dass er etwas von der Sache verstand und seine Einschätzung deshalb auch zu gewichten war. Zudem führte er die Gesundheit als Argument an, was zusätzlich einen emotionalen Eindruck hinterlässt. Man gewinnt eine ungefähre Vorstellung des hauswartlichen Arbeitsalltags nach Errichtung der Zentralheizung. In einem das Ersuchen Bünzlis ergänzenden Schreiben vom 5. Juli 1901 wandte sich Direktor Utzinger an den Regierungsrat. $^{38}$

Das Gesuch des Abwarts hat seine nächste Veranlassung darin, dass er im Laufe des letzten Winters an einem Magenleiden erkrankte, das sich durch auffallende und rasche Abmagerung Kund gab. Nach der Aussage des Arztes rührte das Übel hauptsächlich davon her, dass der Abwart bei der Reinigung der Kessel in den beiden Zentralheizungen, d.h. beim Herausziehen der Schlacken heisses Kohlegas und Kohlenstaub einschluckte, wodurch ausser der Lunge namentlich der Magen in leidenden Zustand versetzt wurde [...].

Diese [die Heizung] wird dadurch erschwert, dass 2 Zentralheizungen durch einen Mann zu bedienen sind. Im Heizraum des Neubaus besteht die unbequeme Einrichtung, dass die Kohlen auf dem Rücken vom Behälter eine Treppe hinauf in den Kohlenkessel getragen werden müssen. Die Asche und Schlacken müssen aus bei-

38 StAZH U 77.2.9 (Teil 1) Seminardirektor an Regierungsrat, 5. Juli 1901. 
den Heizräumen auf weitem Wege auf einen Platz hinter der Übungsschule getragen werden.

Die Hauptschwierigkeit besteht darin, dass die Coaks, welche nach Vorschrift zum Heizen verwendet werden müssen, sehr viel Schlacken ansetzen, weshalb die Reinigung, welche täglich, bei kaltem Wetter 2 mal im Tage, vorzunehmen ist, längere Zeit in Anspruch nimmt. Dabei entströmt dem Ofen heisses giftiges Gas, dem der Heizer während der ganzen Arbeit ausgesetzt ist. Unmittelbar nachher muss der Kessel mit Kohlen nachgefüllt werden, was den Mann zwingt, noch länger in der ungesunden Luft zu verweilen. Und doch muss diese Arbeit regelmässig und gewissenhaft ausgeführt werden, indem sonst die Heizvorrichtung beschädigt und der Heizeffekt vermindert, also der Kohleverbrauch vermehrt würde. Überdies setzt die Notwendigkeit, dass der Heizer wiederholt von einem Heizraum in den entfernten anderen gehen und inzwischen die kalte Luft einatmen muss, ihn der Cefahr der Erkältung aus.

3. In der Beleuchtung. Hierbei wirkt der Umstand erschwerend, dass der Akkumulatoren- und der Schaltraum sich im Hauptgebäude befinden, während die Dampf- und die Dynamomaschine in einem entfernten Anbau untergebracht sind; anderswo sind diese Räume neben einander, so dass der Elektriker ohne Zeitverlust und Cefährdung sich von einem in den anderen Raum begeben kann. Überdies erfordert die Bedienung der elektrischen Anlage sehr viel Detailkenntnisse, Genauigkeit und Aufmerksamkeit, ohne diese Eigenschaften kann, wie die Erfahrung mehrfach lehrt, ein Schaden von Hunderten oder Tausenden von Franken verursacht werden.

Im Winter muss die Batterie jede Woche mindestens 2 Tage lang geladen werden; gleichzeitig sind aber auch die beiden Heizungen zu bedienen, und wenn nun noch am Morgen die Wegräumung des Schnees dazu kommt, so ergibt sich eine Häufung von Arbeit, die gleichzeitig von einem Mann beim besten Willen nicht ordentlich zu bewältigen ist.

4. In der Heizung des Cewächshauses, die an kalten Wintertagen 1 bis 2 mal täglich vorzunehmen ist. [...]

Abwart Hottinger ist im 50. Lebensjahre, also im besten Mannesalters gestorben. Die Sektion ergab die beginnende Entartung mehrerer Organe. ${ }^{39}$

In dieser Quelle sammeln sich alle bereits angesprochenen Facetten bezüglich Hauswart, Heizung und elektrischer Anlage. Ausserdem zeigt sich explizit, dass die Hauswartstätigkeit als Schwerarbeit verstanden werden muss und dass das damit verbundene gesundheitliche Risiko nicht zu unterschätzen war. Der verstorbene Hauswart Hottinger wurde vom Direktor treu bis zum Tod, für das Seminar ein Opfer bringend, gezeichnet. Das scheint auch die Kantonsregierung 
überzeugt zu haben. Am 11. Juli 1901 wurde der Regierungsratsbeschluss gefasst, dass ab 1. Oktober für den kommenden Winter befristet ein Hauswartgehilfe angestellt werden sollte. ${ }^{40}$ Hauswart Bünzli ist es demnach gelungen, den Seminardirektor für seine Zwecke einzuspannen und politische Fürsprache zu erwirken.

Während der Folgejahre wurde über die Wintermonate stets eine Hilfskraft für die Heizung angestellt. Im Protokoll der Aufsichtskommission vom 30. September 1905 ist sodann auszumachen, dass Hauswart Bünzli einen permanent angestellten Assistenten wünschte. ${ }^{41}$ Dem Ansinnen des Hauswarts wurde aber nicht stattgegeben. Wie im Beschluss der Aufsichtskommission nachzulesen ist, war Bünzli bei Direktion und Lehrkörper in Ungnade gefallen, da er schlecht über das Seminar gesprochen, die Arbeitszeiten nicht eingehalten und die Schulzimmer sowie Toiletten nicht rein gehalten haben soll. ${ }^{42}$ Der Hauswart verlor den Rückhalt, da er seine Position nicht wie von der Direktion gewünscht wahrnehmen konnte oder wollte, dem Seminar also durch Lebenswandel und Arbeitsweise untreu wurde. Es wurde - wie dies bis anhin üblich war - im Herbst 1905 erneut temporär ein Gehilfe eingestellt, soweit das Protokoll des Erziehungsrates vom 20. Oktober 1905 . $^{43}$

I. Von der Mitteilung der Seminardirektion, daß sie als Hauswartsgehilfe am Seminar mit Amtsantritt auf1. November 1905 und mit einem Monatslohn von Fr. 120 angestellt habe: Albert Casser von Hohenems (Vorarlberg), Heizer der kantonalen Dampfwalze in Zürich, wird unter Cenehmigung der Wahl und der Besoldung Notiz am Protokoll genommen.

Wie dieser bezüglich Anstellungen von Hilfshauswarten leider einzigartig erhaltene Quellenauszug zeigt, war der berücksichtigte Kandidat Heizer von Beruf. Es wäre eine Interpretation, dass zu jener Zeit eine Professionalisierung des schulischen Hauspersonals stattfand oder dass zumindest eine gewisse Arbeitsteilung in den öffentlichen Schulen Einzug hielt. Gerade bezüglich Heizung und Beleuchtung entwickelte sich die Technik um die Jahrhundertwende stark: Ausgehend von einem Brief der Direktion der öffentlichen Bauten an den Erziehungsdirektor vom 27. April 1903 kann gefolgert werden, dass die Akkubatterie des Seminars ab 1903 oder 1904 durch das Stromnetz der Gemeinde Küsnacht gespeist wurde und die kohle- und holzgetriebene Dampfmaschine damit wahrscheinlich nicht länger als knappe 15 Jahre in Betrieb war. ${ }^{44}$ Um die Vorstellung der Alltagstätigkeiten

40 StAZH U 77.2.9 (Teil 1) Regierungsratsprotokoll, 11. Juli 1901.

41 StAZH Z 388.127 Aufsichtskommissionsprotokoll, 30. September 1905.

42 Ebd.

43 StAZH Z 388.127 Erziehungsratsprotokoll, 20. Oktober 1905.

44 StAZH V II 17.3.6 Direktion der öffentlichen Bauten an Erziehungsdirektor, 27. April 1903. 
des Hauswarts zu verdichten, seien die in derselben Quelle genannten 247 Glühlampen im Seminar des Jahres 1903 erwähnt, die die Brennstofflampen von 1889 und davor abgelöst hatten. ${ }^{45}$

Doch zurück zu Hauswart Bünzli, der 1907 von seiner Stelle am Seminar Küsnacht zurücktrat, aber auch nach seiner Demission für die Seminardirektion ein Thema blieb. Im Archiv befindet sich ein Schreiben, mit dem sich die Seminardirektion am 9. Dezember 1908 an das kantonale Hochbauamt wandte. ${ }^{46}$

Mit Gegenwärtigem möchte ich sie dringend ersuchen, meinem schon mehrfach geäusserten Wunsch entsprechend, im Gewächshaus des Seminars die Heizung wieder einzurichten.

Dem Drängen des früheren Abwartes Bünzli nachgebend, hat Herr Vizedirektor Scherrer im Frühjahr 1906, kurz vor Antritt des Unterzeichneten [sic!] die Heizeinrichtung entfernen lassen, was ein Fehlgriff war. Jetzt erweist sie sich notwendiger als je. Durch die Wahl von drei neuen Zeichenlehrern ist dieser Unterricht auf eine ganz andere Basis gestellt worden. Er bedarf eines reichen Pflanzenmaterials und zwar im Winter wie im Sommer. Zur Aufzucht der verschiedenen Pflanzen, sowie zur Ueberwinterung eines Teils derselben ist es absolut notwendig, dass das Cewächshaus beheizbar ist. Da es nicht als Warmhaus zu funktionieren hat, wird der Kohlenverbrauch gering sein.

Der jetzige Rebmann, der den verstorbenen Schneebeli [Hilfshauswart/Heizer bis 1906] ersetzt, ist zugleich Gärtner. Das Gewächshaus erhält also an ihm einen fachkundigen Ueberwacher. Durch Heizbarmachung wird es möglich, dass die für den Seminargarten notwendigen Gewächse selbst aufgezogen werden können, was bei den teuern [sic!] Verkaufspreisen der Gärtner eine Ersparnis bedeuten würde.

Während Hauswart Bünzli für Direktor Utzinger 1901 noch unentbehrlich schien, war er 1908, nun nicht mehr angestellt, für den neuen Direktor Edwin Zollinger ein willkommener Sündenbock. Das Entscheidende an diesem Quellenausschnitt ist denn auch, dass sich direkt zwischenmenschliche Praktiken, die an persönliche Beziehungen oder Verflechtungszusammenhänge gekoppelt sind, ebenfalls wandelten. Alternativ kann der Hauswart hier in einer aktiven Rolle gesehen werden: Er musste sich einmal mehr zu helfen wissen und veranlasste die Demontage des Heizkessels im Gewächshaus, was seinen Arbeitsaufwand reduzierte. Es ist aber nicht zwingend davon auszugehen, dass Bünzli überhaupt irgendetwas mit dem vorliegenden Fall zu tun hatte. Ausserdem kann am letzten Quellenauszug ganz banal vergegenwärtigt werden, wie die Hauswartstätigkeit das Pädagogische am Seminar ermöglichte. Vernachlässigte der Hauswart seine Pflich-

45 Ebd.

46 StAZH V II 17.3.5 Seminardirektion an Hochbauamt, 9. Dezember 1908. 
ten, hatten die Zeichenlehrer kein Anschauungs- oder Abzeichnungsmaterial für ihren Unterricht. Hierbei zeigt sich erneut die Verknüpfung des Hauswarts mit dem Unterricht. Er gehörte zum pädagogischen Gefüge. Des Weiteren belegt der erwähnte Rebmann/Hilfshauswart/Heizer/Gärtner, dass zwar eine Arbeitsteilung stattfand, nicht jedoch, dass von einer zwingenden Professionalisierung des Hauspersonals gesprochen werden kann.

Der Hauswart befeuerte, kontrollierte, wartete und putzte die Zentralheizung und die Dampfmaschine für die elektrischen Anlagen. Er bestellte, lagerte, schleppte und schaufelte das Brennmaterial. Kann man hierbei von Praktiken sprechen? Oder ist etwa das Heizen an sich die untersuchte Praktik? Es zeigen sich bei der Betrachtung dieser Praktik verschiedene Praktiken, die über das Heizen hinausgehen, gerade Interaktionen oder Praktiken des Umgangs. Es muss deshalb genügen, dass Praktiken manchmal als solche benannt werden und manchmal nicht, und es muss akzeptiert werden, dass Praktiken manchmal bei angebrachter Spitzfindigkeit in weitere Praktiken zerfallen. Das liegt vor allem auch daran, dass sich das unmittelbar Zwischenmenschliche und das >Technische oder >Arbeitspraktiken nicht trennen lassen und dass Hauswartpraktiken nicht fix dem Hauswartberuf (für den es ja auch keine Definition gegeben hätte), sondern eher einzelnen Hauswarten eigen gewesen zu sein scheinen.

Was bedeutet es nun, dass der Hauswart das Seminar auf die beschriebene Art beheizte und beleuchtete? Der Unterhalt der Heizung und der elektrischen Anlagen war eine körperlich schwere Arbeit. Der Hauswart musste kräftig und gesund sein, damit er dem Anspruch seines Berufs gerecht wurde. Allerdings litt er unter den Bedingungen und seine Gesundheit wurde in Mitleidenschaft gezogen. Hauswart Bünzli versuchte, sich der Situation anzupassen und sich wo nötig durchzusetzen. Er machte sich seine Position als Herr über Wärme und Licht zunutze und erreichte eine bessere Entlöhnung sowie die Anstellung eines Gehilfen. Dabei spielte Bünzli in die Hände, dass das Seminar und damit die Seminardirektion - insbesondere im Winter - von ihm abhängig waren. So wurde ihm vonseiten der Direktion einstweilen geschmeichelt, während er ein andermal zum Sündenbock taugte. Ebenso, wie sich die Zuschreibungen änderten, so änderten sich auch die Hauswarte mit ihren Praktiken und dem Seminar, das im Wandel war. Der Hauswartberuf wurde mit der neuen Technik industrieaffiner und vielleicht spezialisierter. Auf jeden Fall konnte sich der Hauswart durch die neue Technik als Fachmann positionieren. Er war der einzige Schwerarbeiter in einer Institution, in der alle anderen Anwesenden nichtkörperlich arbeiteten (mit Ausnahme der Schülerinnen und Schüler im Turnunterricht). Der Hauswart war dadurch als Handwerker von den Schülerinnen und Schülern sowie vom Lehrpersonal abgegrenzt und speziell attribuiert, etwa mit Pflichtbewusstsein und Loyalität. Genauso grenzten sich die Lehrer in Küsnacht dem Hauswart und der körperlichen 
Arbeit gegenüber $a b$, indem sie den Hauswart als Mann für das Materielle und Körperliche einsetzten, so etwa für die Umsetzung von Strafmassnahmen. ${ }^{47}$

\section{Aufsicht als Aspekt der Kontrolle am Seminar}

Im folgenden Abschnitt sei ein zweites Beispiel zu einer Hauswartpraktik oder mehreren entsprechenden Praktiken angeführt. Nach Jakob Bünzli sollen Hauswart Gotthold Laupper vom Lehrerinnenseminar der Höheren Töchterschule Zürich und dessen Hund unter die Lupe genommen werden. Laupper war von 1909 bis 1933 als Hauswart an der Töchterschule beschäftigt und zeichnete sich durch vielfältige Tätigkeiten aus. Gerade als Chemielaborant (ursprünglich als Laborgehilfe des Chemielehrers) betrieb er eigene Studien und publizierte insgesamt 13 Beiträge überwiegend zum Phänomen der spontanen Selbstentzündung von $\mathrm{Heu}$, aber auch Ratgeberliteratur für die Hauswartung an Schulhäusern. ${ }^{48}$ In seiner Schrift Obliegenheiten des Hauswartes im Schulhaus »Hohe Promenade « fasste er 1933 alle möglichen Aspekte seines Hauswartlebens, die Tücken und Vorzüge seiner Arbeit als überausführliches Pflichtenheft für seinen Nachfolger zusammen. ${ }^{49} \mathrm{Im}$ Rahmen des vorliegenden Beitrags möchte ich den nachfolgend von Laupper ausformulierten Be- und Überwachungsaspekt der hauswartlichen Arbeit genauer anschauen. Ein Blick voraus, in die Erinnerung bzw. Selbstdarstellung Lauppers, in die erwähnten »Obliegenheiten« gibt Aufschluss über den Charakter dieser Tätigkeit. ${ }^{50}$ Bezeichnenderweise beginnt der Text mit einer legitimationsstiftenden Verordnung, an welche die folgende Inszenierung des Hauswarts als Polizist anschliessen kann. Laupper schrieb 1933:. ${ }^{1}$

2. Nach Art. 33 der Verordnung vom 20. Dezember 1928 soll der Ein- und Ausgang der Schülerinnen überwacht werden; da aber auch ein sehr gewandter und flinker Hauswart nicht an mehreren Orten zugleich sein kann, können nur Patrouillengänge gemacht werden; diese aber so oft als möglich. Ueberhaupt muss der Hauswart die Fähigkeit haben, zu allen Zeiten des Tages ungerufen dort aufzutauchen, wo er nötig ist; er muss es spüren, wo er gebraucht wird. Bei der isolierten Lage des Hauses ist besonders auf lichtscheues Cesindel zu achten; die Erfahrung hat

47 Vgl. StAZH Z 388.6272 Lärmereien im Schulgebäude (1931-1932).

48 Exemplarisch: Laupper 1937 zu den Heustockbränden; Laupper 1927 zur Reinigung von Schulhäusern.

49 Laupper 1933.

50 Zum Umgang mit Selbstzeugnissen als Quellen siehe den Beitrag von Norbert Crube in diesem Band. 
gezeigt, dass sich Leute jeden Alters einzuschleichen versuchen. Die Gefahr für unsere Schülerinnen ist bei der Unübersichtlichkeit und Dunkelheit der meisten Nebenräume grösser als man denkt. Der Hauswart hat die Aufsicht im Haus zu üben und muss also auch nach Möglichkeit kontrollieren, wer an Besuchern einund ausgeht. Leute, die einem verdächtig vorkommen, müssen nach dem Grund ihres Kommens gefragt werden. Diese Kontrolle muss mit Umsicht und mit Takt ausgeführt werden und so, dass sie niemandem auffällt. Da auch Verhaftungen hin und wieder nötig werden, ist eine feste Hand erforderlich. Natürlich muss der Hauswart so viel Menschenkenntnis besitzen, um unterscheiden zu können, wer nur aus Neugier und wer mit bösen Absichten kommt. Dieser eigentliche Polizeidienst ist sehr ermüdend, insgesamt undankbar, weil er schon gar nicht nach Arbeit aussieht; es ist auch nicht angängig viel Wesens daraus zu machen und mit jedem einzelnen Fall das Rektorat zu belästigen. Leider ist es nicht mehr gestattet, einen Hund zu halten; diese Art Hilfspolizei hat stets die richtige Nase, findet immer die verdächtige Fährte, und ist ausserdem der beste persönliche Schutz für den Hauswart, besonders bei den nächtlichen Kontrollgängen.

Diese hauswartliche Praktik oder eben hauswartlichen Praktiken des Patrouillierens und der Kontrolle ist bzw. sind direkt an das Schulhaus und an seinen Standort geknüpft. 1913 bezog die Töchterschule das hier umschriebene, damals neugebaute Schulhaus an der Hohen Promenade oberhalb des Bahnhofs Stadelhofen. Dem Protokoll der Aufsichtskommissionssitzung vom 10. Oktober 1913, also kurz nach dem Umzug, ist untenstehende Passage zum Thema zu entnehmen. ${ }^{52}$

Mit Zuschrift vom 26. August 1913 an den Schulvorstand beantragt der Rektor, es möchte dem Wunsche des Abwartes Laupper um Anschaffung eines Hundes entsprochen werden; zur Begründung wird angeführt, daß in Anbetracht der Unsicherheit auf der Hohen Promenade es für den Abwart eine Beruhigung wäre, wenn er nachts bei der Ausübung der Aufsicht in und außer dem Hause zu seinem Schutz einen Hund besäße.

Bereits im Sommer hatte Hauswart Laupper um die Anschaffung eines schulischen Wachhundes gebeten. Seinem Wunsch wurde aber nicht entsprochen und er musste sich den Hund auf eigene Rechnung anschaffen. Lauppers Sorge um die Sicherheit und Sittlichkeit der Gegend rund um das neue Schulhaus scheint aber nicht ungeteilt gewesen zu sein. Am 12. Januar 1915 wandte sich der Rektor des Lehrerinnenseminars der Höheren Töchterschule Wilhelm von Wyss mit folgenden Worten an den städtischen Schulvorstand. ${ }^{53}$

52 SAZ V.H.a.53: 11. Aufsichtskommissionsprotokoll, 10. Oktober 1913.

53 SAZ V.H.c.98: 1.2.6. Rektor an Schulvorstand, 12. Januar 1915. 
Der Hund, den Herr Laupper hat, hat ihm schon recht gute Dienste geleistet. Wie zu erwarten war, hat die Nachbarschaft der Hohen Promenade die unangenehme Wirkung, dass sich besonders nachts viel Gesindel um das Haus herumtreibt, und der Umstand, dass mehrere Türen des Hauses beständig geöffnet sein müssen, verstärkt im weitern das Gefühl der Unsicherheit. Tatsächlich ist einmal abends 10 Uhr von Herrn Laupper im Keller ein Mann aufgegriffen worden, der sich eingeschlichen hatte. Ein anderes Mal hat ein Bettler von der Hohen Promenade her Einlass verlangt und, als ihm das Mädchen die Türe öffnete, den Fuss zwischen die Türflügel gesetzt, sodass das Schliessen der Türe nicht mehr möglich war. Keine Woche vergeht, ohne dass in der einen oder anderen Nacht in der Nähe des Hauses Lärm hörbar ist. Neulich wurden [sic!] von Leuten, die die Verbotstafeln auf dem Platze ausgerissen hatten, diese erst fallen gelassen, als der Hund anschlug. Es ist selbstverständlich, dass, wenn die Leute nicht wüssten, dass ein Hund im Hause ist, solche Belästigungen noch viel zahlreicher würden. Es ist auch durchaus begreiflich, dass Herr Laupper, wenn er abends seine Kontrollgänge im Hause und ausserhalb macht, froh ist, den Hund bei sich zu haben.

Ich beantrage daher neuerdings, dass Herr Laupper die Kosten für den Unterhalt und die Amortisation des Hundes in angemessenem Betrage vergütet werden.

Rektor Wyss bestätigte dem zuständigen Mitglied der Stadtregierung, Stadtrat Bosshardt, Lauppers Befürchtungen und dass dessen Anliegen, offiziell einen Wachhund zu halten, noch immer aktuell und gerechtfertigt sei. Schulvorstand Bosshardt brachte daraufhin in Erfahrung, was ein Polizeihund koste, und forderte Wyss und Laupper auf, sich erneut an einer Eingabe zu versuchen. Aus dem Archivmaterial geht nicht hervor, ob Laupper darauf reagierte. Jedoch ist es wieder Rektor Wyss, der sich nochmals 1915 (ohne Angabe des Datums) brieflich an Schulvorstand Bosshardt wandte. ${ }^{54}$

Es wird Sie interessieren zu hören, dass heute Vormittag in unserem Schulhaus ein Mann festgenommen wurde, der durch sein verdächtiges Benehmen Herrn Laupper aufgefallen war. Herr Laupper holte den Detektiven Scheidegger. Der Mann wollte darauf Herrn Scheidegger vom Hauseingang wegdrängen, um die Flucht zu ergreifen, wurde aber vom Hunde des Herrn Laupper gepackt, wobei es gelang den Mann festzunehmen. Bei der Untersuchung wurde festgestellt, dass er im Fahndungsblatt gesucht war. Ohne den Hund hätte die Festnahme wahrscheinlich grosse Schwierigkeiten bereitet. Jedenfalls hat sich neuerdings gezeigt, wie sehr das Halten des Hundes für Herrn Laupper und die Schule zur Beruhigung beiträgt und einen Schutz bildet.

54 Ebd. Rektor an Schulvorstand, 1915. 
Wiederum pochte Wyss, der sich wiederholt die Zeit nahm, sich schriftlich mit Bosshardt auseinanderzusetzen, auf das Anliegen seines Hauswarts. Davon zeugt eine weitere briefliche Notiz seitens Wyss an Bosshardt aus dem Jahre 1916 (ebenfalls ohne Datumsangabe). ${ }^{55}$

Vor einigen Tagen wurden wieder Schülerinnen von uns von Individuen belästigt, die unsittliche Handlungen vor ihnen vornahmen, und zwar waren es gleichzeitig zwei Männer, von denen der eine an der Promenadengasse, der andere am Abhang der Hohen Promenade gegen die Rämistrasse sich aufgestellt hatte. Selbstverständlich machte ich sofort der Polizei Mitteilung. Ich möchte aber anregen, dass der Eingang zu unserm Schulhause von der Promenadengasse her zwischen den Kirchen hindurch auf unserm Terrain selber beleuchtet und dass zu diesem Zwecke südlich der Englischen Kirche eine Laterne aufgestellt wurde.

Ich will nicht unterlassen beizufügen, dass Herr Laupper, der sich stets die grösste Mühe gibt, auf solche Männer, die unsere Schülerinnen belästigen und bedrohen, zu achten und sie womöglich der Polizei zu übergeben, gerade auch für diesen Zweck den Hund nötig hat.

Das letzte im Archiv auffindbare Schreiben Wyss' an Bosshardt in der Causa Hund stammt vom 6. März 1916. Nun reichte Laupper (erneut?) seine Eingabe bei Bosshardt ein. Wyss kommentierte dies in gewohnter Manier. ${ }^{56}$

Dass ein Hund für den Hauswart unserer Schule von der Polizei als notwendig anerkannt wird, geht schon daraus hervor, dass er nur zur halben Taxe versteuertt [sic!] werden muss. So viel ich weiss, haben Sie von der Polizei schon direkt Aeusserungen in diesem Sinne erhalten.

Tatsächlich hat uns der Hund schon recht gute Dienst geleistet. Er schlägt des nachts häufig an und scheucht damit allerlei Gesindel, das sich um das Haus herumstreicht, davon. Einmal hat er, als er Herrn Laupper auf seinem Rundgange begleitet, im Untergeschoss einen Mann aufgespürt, der sich dort verborgen hielt, ein anderes Mal ein Individium [sic!], das sich zu unsittlichen Zwecken ins Haus geschlichen hatte und das im Begriff war, sich den Händen des Detektivs zu entwinden, fest zu halten vermochte.

Es kann nun kein Zweifel darüber bestehen, dass nicht nur Herr Laupper, sondern jeder Hauswart, den wir bekommen würden, sich mit Recht weigern würde, bei der Lage, die unser Schulhaus hat, seinen Pflichten bei Tag und Nacht ohne Hund nachzukommen. 
Den jetzigen Hund kann Herr Laupper nicht länger behalten, weil er etwas gross ist, und zu den Zeiten, da Schülerinnen aus- und eingehen, kann er ihn nicht frei herumlaufen lassen. So hat er tatsächlich zu wenig Bewegung und Herr Laupper wird ihn verkaufen und einen andern kleinern anschaffen müssen, was natürlich wiederum eine gewisse Ausgabe bringt, denn den ursprünglichen Preis für den Hund wird er jedenfalls nicht erhalten.

Wyss unterstützte Laupper, indem er auf die Massgaben der Polizei verwies, die bisherigen Erfolge sowie die Notwendigkeit hervorstrich und die Angelegenheit zur offiziellen, von Laupper entkoppelten Schulsache erklärte. Mit der rhetorisch erzeugten Nähe zur Stadtpolizei und der Positionierung Lauppers als Hilfspolizist wurde der Hund offizialisiert und legitimiert. Damit gelangten Wyss und Laupper ans Ziel. Am 15. Januar 1917 erliess der Schulvorstand eine Verfügung, in der festgehalten wurde, dass Laupper das Futter für den Wachhund in Zukunft und rückwirkend bis 1914 bezahlt erhalten sollte. Zur Begründung gereichte der Bericht des Rektors, wonach der Hund bei der "Bewachung« des Schulhauses $\mathrm{zu}$ verhindern half, dass die Schülerinnen von »unsauberen Burschen« belästigt wurden. ${ }^{57}$

Was an der ganzen Geschichte auffällt, ist zunächst einmal, dass Rektor und Hauswart zusammenhielten. Wie beim ersten Beispiel Bünzli gesehen, setzte sich der Direktor durchaus vehement für den Hauswart ein. Das zeigen weitere Quellen von der Töchterschule: Als Laupper 1914 einen Vacuum Cleaner oder Entstaubungsapparat für doch 700 Franken anschaffen wollte, wurde das Anliegen des Hauswarts von Wyss unterstützt und vor den Behörden portiert. ${ }^{58}$ Auch während des Ersten Weltkriegs, als Laupper zum Militärdienst aufgeboten wurde, intervenierte Rektor Wyss erfolgreich bei Schulvorstand Bosshardt. ${ }^{59}$ Dass sich der Hauswart, oder das Hauswartehepaar, wie im Falle der Hundegeschichte immer wieder durchsetzen konnte, dürfte verschiedene Gründe gehabt haben. Wohl war Wyss Laupper auch freundschaftlich verbunden, allerdings war der Rektor schlicht auf den Hauswart angewiesen. Nicht umsonst bezeichnete er Laupper im Zusammenhang mit der Militärdienstbefreiung als für die Schule unverzichtbar: »[... es dürfte] unmöglich sein, eine Persönlichkeit zu finden, die für Herrn Lauper eintreten könnte«, so der Schlusssatz eines Briefes des Rektors an den städtischen Schulvorstand vom 23. September $1915 .^{60}$ Laupper hat sich an der Töchterschule in eine Position hineingearbeitet, die ihn unentbehrlich machte. Es scheint, als ob Rektor Wyss nachgerade von ihm abhängig war. Die Interessen von Rektor und

57 SAZ V.H.c.98: 1.2.8. Verfügung des Schulvorstands, 15. Januar 1917.

58 SAZ V.H.c.98: 1.2.5. Rektor an Schulvorstand, 14. Februar 1914.

59 SAZ V.H.c.98: 1.2.6. Rektor an Schulvorstand, 23. September 1915.

60 Ebd. 
Hauswart waren eng miteinander verwoben, da sich beide um die Administration und den Betrieb des Schulhauses kümmerten. Die beiden Figuren (und das Haus) standen manchmal in einer harmonisch-geregelten und mutualistischen, manchmal in einer widersprüchlichen umkämpften Beziehung zueinander. ${ }^{61}$ Es ist vorstellbar, dass sich Laupper mit seinen Kenntnissen des neuen Schulhauses innert kürzester Zeit ein exklusives Wissen angeeignet hat, dass ihn für den Alltag der Töchterschule so integral machte.

Der Hund diente vordergründig der Sicherheit des Hauswarts und der Schülerinnen. Die Geschichten, wie sie dem Stadtrat dargelegt wurden, vermitteln den Eindruck, als reagierten Hauswart und Rektor mit dem Hund auf die Sicherheitslage des Stadtteils. Die Schule verhielt sich mit dem Hund aber nicht nur zu effektiven Bedrohungspotenzialen, sondern zur Wahrnehmung des gesamten sozialen Kontextes des Viertels, in dem sich der Neubau der Töchterschule befand. Sowohl gegen aussen wie gegen innen: Sicherheit ist mit Kontrolle verbunden und die Kontrolle an der Töchterschule erstreckte sich auch über die Schülerinnen. Mit seinen Umgängen und Patrouillen trat der Hauswart als Hüter des Schulgeländes auf. Er wachte über den Hof, das Haus und seine Bewohnerinnen. So inszenierte sich der Hauswart in den hier besprochenen Praktiken sichtbar als verlängerter Arm der Polizei und als Beschützer der Schülerinnen, womit eine Disziplinierung verbunden ist, die gerade unter einer auf gender geschliffenen Brille interessant ist. Die Kultur an der Töchterschule dürfte von Praktiken der Isolation von der städtischen Umgebung mitgeprägt gewesen sein. Die Seminare boten jedoch auch Freiräume, Kooperations- und Fluchtmöglichkeit. Die Schülerinnen und Schüler waren nicht einer permanenten sozialen Kontrolle und einem absoluten Raumregime unterworfen. ${ }^{62}$ Die Schule war trotzdem darauf bedacht, dass die Schülerinnen nicht städtisch `kontaminiert`wurden. Dafür gibt es Quellennachweise, die über die Hauswartpraktiken hinausgehen. So wurde 1917 ein Ladenbesitzer, der scheinbar anstössige Bilder in seinen Schaufenstern ausgestellt hatte, vom Rektor gebeten, die Bilder zu entfernen, da die Schülerinnen auf dem Schulweg an besagtem Geschäft vorbeigehen mussten. ${ }^{63}$ Die Töchterschule sollte ein sicherer Ort sein, frei und rein von gesellschaftlichen und schulischen Schieflagen und Randständigkeiten - gerade zu Kriegszeiten. Türkontrollen und Patrouillen können so nicht nur als Sicherheitspraktiken, sondern auch als Praktiken von Be-

61 An einem anderen Zürcher Seminar, am kantonalen Oberseminar, das 1943 eröffnet wurde, verzichtete Direktor Walter Guyer beim Amtsantritt auf einen Schlüssel zum Schulgebäude, da er den mit dem Schlüsselbesitz verbundenen Auflagen der Erziehungsdirektion nicht zustimmen mochte. In der entsprechenden Verfügung dringt durch, dass der Hauswart der eigentliche Hüter der häuslichen Ordnung war und sich Guyer diesem in der Frage zu unterstellen hatte (StAZH Z 10.61. Direktor an Erziehungsdirektion, 29. September 1943). 
vormundung und Abschottung der Schülerinnen in einem als schwierig wahrgenommenen städtischen Umfeld verstanden werden. ${ }^{64}$ Diese Abschottung war ein Bestandteil der Charakterbildung bzw. des pädagogischen Settings an der Töchterschule. ${ }^{65}$ Ironischer- aber passenderweise war der Hund, als die Stadt endlich bereit war, für ihn aufzukommen, zu gross geworden und es muss angenommen werden, dass sich die Schülerinnen vor ihm fürchteten - was in einem begrenzten Ausmass durchaus so intendiert gewesen sein könnte. Wie sich die Hundegeschichte weiterentwickelte, ist den zur Verfügung stehenden Quellen nicht zu entnehmen. Wie gehabt, hielt Laupper in seinem Ratgeber von 1933 allerdings fest, dass es ihm irgendwann untersagt wurde, einen Hund zu halten.

Resümierend ist zu erwähnen, dass Hauswart Laupper und sein Hund genauso wie Hauswart Bünzli und seine Heizung am Seminar Küsnacht ins Gefüge der Schule bzw. in ihre Kultur eingriffen und diese beeinflussten, ebenso wie sie selbst von diesen, ihren Menschen und Erwartungen beeinflusst wurden. Des Weiteren erreichte auch Hauswart Laupper die Berücksichtigung persönlicher Anliegen auf politischer Ebene. Dabei spielten persönliche Beziehungen zum Rektor und Abhängigkeiten innerhalb der Töchterschule die entscheidende Rolle.

\section{Schluss}

Praxeologisch betrachtet werden nicht Funktion oder Zweck der Hauswarte innerhalb des sozialen Gefüges Seminar ausgelotet, sondern was sie dort taten und wie sie dies taten. Praktiken antworten nicht auf funktionale Forderungen, ${ }^{66}$ sondern zeigen die Schule als kulturellen Raum. Bei dieser Herangehensweise liegt für die Historische Bildungsforschung ein Bezug zur erziehungswissenschaftlichen Schulkulturtheorie nahe. ${ }^{67}$ Schul- oder eben Seminarkulturen werden dabei in der Regel als von Schulort zu Schulort divers verstanden (schliesslich unterscheiden sich die Schulen auch als landscape). Hauswartpraktiken sind als Teil einer solchen jeweils schulspezifischen Kultur zu begreifen, wobei verschiedene Schulkulturen bzw. die je untersuchten Praktiken verglichen werden können. Die hier gezeigten Praktiken zu Heizung, Beleuchtung, Aufsicht und Kontrolle sind nur erste Elemente einer Forschungsarbeit, die möglichst breit (ohne dabei

64 Die zeitgenössische Wahrnehmung der (Gross-)Stadt sah in dieser gerade für junge Frauen einen Gefahrenraum (vgl. Jenzer 2014 und Sabelus 2009).

65 Dass Aufsicht, Überwachung und das Fernhalten von der unmittelbaren Umwelt direkt an eine Erziehung zu Ordnung und Sauberkeit gekoppelt sein können, zeigt etwa die neuere Forschung zu Erziehungsheimen (vgl. Ralser et al. 2017, S. 735-742).

66 Veyne 1992, S. 57.

67 Vgl. Bendix/Kraul 2015; Helsper 2008; Keßler 2017; Kluchert 2009 (für die historische Forschung). 
allumfassend oder erschöpfend sein zu wollen oder können) von vielen Seiten und die Praktiken zu einander in Verbindung bringend betrachtet, wie mehrere Hauswarte mehrere Seminare mitgestalteten und im Gegenzug von diesen geprägt wurden. Augenfällig wird diese gegenseitige Beeinflussung von Mensch und landscape beim Heizen durch den Küsnachter Hauswart, der körperlich unter der Bewirtschaftung der Heizung litt, sich aber zumindest kurzfristig zu helfen wusste. Doch die hauswartliche Praxis erschöpft sich bei Bünzli nicht im Kohleschaufeln und bei Laupper nicht im Patrouillengang. Beide Hauswarte teilten einen Aufgabenkatalog und vergleichbare Praktiken innerhalb ihrer jeweiligen landscape. ${ }^{68}$ Seminare als landscapes auf das Lokale zu begrenzen, öffnet den Sichtwinkel für die Partizipation verschiedener Akteurinnen und Akteure wie Dinge und Tiere. Wenngleich hier mit Heizung und Hund zwei quellengesicherte Spezialfälle untersucht wurden, so bestimmten in einer herausgezoomten Optik Kontinuitäten den Alltag mit.

So wurde in diesem Aufsatz der Versuch unternommen, Ausschnitte des Alltags in der soziokulturellen (Wahrnehmungs-)Realität der Zeitgenossinnen und Zeitgenossen zu beobachten. Eine Auffassung der vorgestellten Quellen als primär materiell interpretierbares, blosses Zeugnis schulischer Verwaltungspraktiken, Beziehungspflege und Positionskämpfe, eine Reduktion der Analyse auf Funktion oder Wirkung und die sprachlich-schriftliche Darstellung des Quellentexts würde viel Forschungspotenzial ausschlagen. Praktiken erlauben Rückschlüsse über persönliche Beziehungen zwischen Personen, die in den Schulalltag involviert waren. So ist insbesondere auf das spezielle Verhältnis von Rektor und Hauswart zu verweisen. Die Art, wie Hauswarte und Direktoren miteinander umgingen, hat Gründe, die in den Quellen zumeist verborgen bleiben. Mit dem Fokus auf Praktiken (des Miteinanders und Gegeneinanders) kann jedoch dem Charakter einer Beziehung nachgespürt werden.

Wie gehabt werden in diesem Beitrag nur zwei Beispiele oder Geschichten von Hauswarten angeführt, welche für weitere Einsichten unbedingt zu erweitern wären. Eine umfangreiche Untersuchung von Hauswartpraktiken im veranschlagten Rahmen wird neue Facetten der Zürcher Schulgeschichte eröffnen. Darüber hinaus können mit der praxeologischen Perspektive die untererforschten Hauswarte als Teil einer gesamtheitlich pädagogisch wirkenden Schule profiliert werden. Mit Blick auf Hauswarte zeigt sich die häusliche Ordnung als wesentliche Dimension schulischer Pädagogik. Gerade an den Lehrerinnnen- und Lehrerseminaren um 1900 bestimmten nicht nur Lehrpersonen und Unterricht die Schulbildung mit, sondern auch durch Seminarstrukturen und -praxis mitschwingende Aspekte von Charakterbildung und Disziplinierung, die sich im Schulalltag

68 Im Vergleich resultiert letztlich eine Art schul(-kulturen-)übergreifende `Crammar of Housekeeping « oder `Crammar of Housekeepers« (vgl. Tyack/Tobin 1994). 
äusserten.$^{69}$ Dieser Alltag, der sich in den Klassenzimmern, in Bibliothek, Garten, Flur und Hof abspielte, war durchzogen von erzieherischen Konnotationen, von welchen Hauswarte nicht ausgeschlossen waren, sondern mit ihrem Tun Anteil hatten, etwa wenn sie die Schülerinnen und Schüler beaufsichtigten oder sanktionierten. In den rekonstruierten Hauswartpraktiken sind überdies pädagogische Implikationen des Seminaralltags erkennbar. Verlässlichkeit, Pünktlichkeit, Gründlichkeit, Sauberkeit, Treue, Sittlichkeit und Ordentlichkeit waren sowohl Erwartungen an Hauswarte als auch pädagogische Kriterien. In der Verkörperung durch Hauswarte treten Werte und Wissensordnungen in Erscheinung, die (in eventuell unterschiedlicher Akzentuierung) der pädagogischen Programmatik eines Seminars entsprachen. Die häusliche Ordnung, die mit Vorstellungen pädagogischer Ordnung verschmolz, steht im Kontrast zu einer kulturell zu deutenden Unordnung, die vermieden, ja bekämpft werden sollte. Und dies nicht nur hinsichtlich Sittlichkeit: Heizung und Beleuchtung bilden den technisch umgesetzten Gegenpol zu einer als bedrohlich und obskur wahrgenommenen, der Unordnung anverwandten Kälte und Dunkelheit. Hauswarte hielten mit Licht und Wärme im Haus sowie der Beaufsichtigung von sowohl Gelände als auch Schülerinnen und Schüler die Wache über Sicherheit und Ordnung des Seminars. Ganz grundlegend ist hierzu abschliessend anzumerken, dass Hauswarte durch Heizung, Unterhalt und Reinigung den Schulalltag bzw. Schulbetrieb konfigurierten, womit Unterricht überhaupt erst möglich wurde.

In der gleichzeitigen Betrachtung der Seminare resp. Hauswarte zeigen sich vergleichbare Aspekte und Praktiken. Wie dies anhand der Professionalisierungsidee (Mechanisierung, Arbeitsteilung) vorsichtig angetönt wurde, darf aufgrund der mikrohistorisch erarbeiteten lokalen Praktiken, die per definitionem schon eine gewisse Regelhaftigkeit aufweisen, auf grosse Linien oder Prozesse gesellschaftlicher Entwicklung verwiesen werden. Ohne, dass dies ein Ziel meines praxeologischen Ansatzes wäre, können gleichwohl derartige Überlegungen angestellt werden. Wie Jakob Tanner mit einem Beispiel Marcel Mauss' ausführt, bedingen sich Entwicklungen individueller und kollektiver Körper: Lernt jeder einzelne Matrose schwimmen, lernt die Marine schwimmen (und umgekehrt). ${ }^{70}$ Ein Wandel der allgemeinen Hauswarts(-selbst-)wahrnehmung ist vielleicht effektiv mit einer >Industrialisierung، (Zentralheizung, Elektrik) der Schulen auszumachen. Davon ausgehend auf das Individuum zu schliessen, wäre aber heikel. Das Beispiel Laupper von der Töchterschule lässt sich mit dieser einförmigen Professionalisierungsthese hin $\mathrm{zu}$ technischem Fachwissen nur bedingt in Einklang bringen. Gotthold Laupper nahm sich selbst als Hauswart mit Sicherheit

$69 \mathrm{Vgl}$. Grube/De Vincenti 2016 und Hoffmann-Ocon/De Vincenti/Grube 2016.

70 Tanner 2004, S. 192; Tanner schlägt ein changierendes Denken zwischen Mikro- und Makroebene im Stile von Jacques Revels »jeux d'échelles« vor (S. 114). 
anders wahr als Jakob Bünzli. Laupper war ausgebildeter Krankenwärter ${ }^{71}$ und hatte - wie bereits ausgeführt - einen starken Bezug zur (Natur-)Wissenschaft. ${ }^{72}$ Eine Kontrastierung der Praktiken Bünzlis mit Lauppers hinsichtlich Professionalisierung versagt jedoch auch, da sich Laupper in seinen Schriften zur Hauswartung wiederholt dafür aussprach, Putzabläufe zu standardisieren und städtisches Schulputzpersonal anzustellen, ${ }^{73}$ was für eine zwar andere, aber gleichwohl für eine Professionalisierungsbestrebung spricht. Gerade in diesem Zusammenhang lassen sich bei Laupper überdies (und mit allen angezeigten Vorbehalten) >typische Merkmale der zeitgenössischen Hygienebewegung feststellen. ${ }^{74} \mathrm{Ob}$ die unterschiedlichen Schwerpunkte in der Hauswartung an der Quellenlage, an den Schulen oder den Hauswarten liegen, bleibt vorerst offen.

\section{Quellen und Literatur}

\section{Ungedruckte Quellen}

\section{Stadtarchiv Zürich (SAZ)}

V.H.a.53:11. Protokoll der Aufsichtskommission 1913-1914.

V.H.c.98:1.2.5. Protokolle, Verfügungen, Beschlüsse und Akten 1914.

V.H.c.98:1.2.6. Protokolle, Verfügungen, Beschlüsse und Akten 1915.

V.H.c.98:1.2.7. Protokolle, Verfügungen, Beschlüsse und Akten 1916.

V.H.c.98:1.2.8. Protokolle, Verfügungen, Beschlüsse und Akten 1917.

\section{Staatsarchiv Zürich (StAZH)}

U 77.2.9 (Teil 1) Abwart und Abwartsgehilfe (1887-1925).

V II 17.3.1 Bauten, Reparaturen, Einrichtungen, Lokales etc. im Allgemeinen, Kollektivakten (1887-1920).

V II 17.3.5 Heizungen, Öfen (1894-1914).

V II 17.3.6 Elektrische Beleuchtung und andere elektrische Anlagen und Installationen (1889-1917).

Z 70.61 Lehrerbildung, Lehramtsschule, Unter- und Oberseminar, 1925-1980.

Z 388.127 Kommissionsakten, 1905.

71 ZB Nekr L 99: Nachruf Laupper, S. 3.

72 Laupper war seit 1922 Mitglied der Naturforschenden Cesellschaft in Zürich (Verzeichnis der Mitglieder der Naturforschenden Cesellschaft in Zürich 1923 [Seite L]).

73 Laupper 1927, S. 51f.

74 Laupper entwickelte im Laufe seines Berufslebens sehr genaue Vorstellungen von Reinigung und Reinhaltung des Schulhauses und berief sich dabei auf das »Wissen, das wir Hygiene und Bakteriologie verdanken« (1927, S. 40). 
Z 388.251 Dienstordnungen und Pflichtenhefte des Hauswarts am Seminar (18881927 (ca.).

Z 388.255 Kamm Emil, Hauswart (1927-1952).

Z 388.6272 Lärmereien im Schulgebäude (1931-1932).

\section{Naturforschende Gesellschaft in Zürich}

Verzeichnis der Mitglieder der Naturforschenden Gesellschaft in Zürich, abgeschlossen am 31. Dezember 1923. Online-Archiv der Naturforschenden Gesellschaft in Zürich: www.ngzh.ch/archiv/1923_68/68_3-4/68_28.pdf [23.10.2018].

\section{Zentralbibliothek Zürich (ZB)}

Nekr L 99 Worte, gesprochen von a. Prof. Dr. Leo Wehrli bei der Kremation des Herrn Gotthold Laupper-Oschwald. $† 22$. XII. 1944 im Krematorium zu Zürich am 26. XII. 1944.

\section{Gedruckte Ouellen}

Laupper, Gotthold (1937): Brandausbrüche durch Selbstentzündung. Ihre Ursachen, Erforschung und Verhütung. Zürich.

Laupper, Gotthold (1933): Obliegenheiten des Hauswartes im Schulhaus »Hohe Promenade«. In: Schweizerische Zeitschrift für Hygiene 13, H. 10, Separatabzug.

Laupper, Gotthold (1927): Die Reinigung des Schulhauses mit Arbeitsprogramm für den Hauswart. In: Schweizerische Zeitschrift für Gesundheitspflege 7, H. 1, S. 39-52.

\section{Literatur}

Ariès, Philippe (2004): Geschichte der Kindheit. 18. Aufl. München.

Bendix, Regina/Kraul, Margret (2015): Die Konstituierung von Schulkulturen in Räumen und räumlichen Inszenierungen. In: Zeitschrift für Pädagogik 61, H. 1, S. 82-100.

Brendecke, Arndt (Hg.) (2015): Praktiken der Frühen Neuzeit. Akteure, Handlungen, Artefakte. Köln, Weimar, Wien.

Burke, Peter (2005): Was ist Kulturgeschichte? Frankfurt a.M.

Daniel, Ute (1993): »Kultur« und »Gesellschaft«. Überlegungen zum Gegenstandsbereich der Sozialgeschichte. In: Geschichte und Gesellschaft 19, H. 1, S. 69-99.

De Vincenti, Andrea (2018): Kontrollierte Räume? Erziehende und gemeinschaftsbildende Settings neben den Unterrichtsräumen am Zürcher Seminar Küs- 
nacht im 19. und beginnenden 20. Jahrhundert. In: Historia Scholastica 4, H. 1, S. 5-16.

Dinges, Martin (2006): Neue Kulturgeschichte. In: Joachim Eibach/Günther Lottes (Hg.): Kompass der Geschichtswissenschaft. 2. Aufl. Göttingen, S. 179-192. Eibach, Joachim/Lottes, Günther (Hg.) (2006): Kompass der Geschichtswissenschaft. 2. Aufl. Göttingen.

Freist, Dagmar (2015): Historische Praxeologie als Mikro-Historie. In: Arndt Brendecke (Hg.): Praktiken der Frühen Neuzeit. Akteure, Handlungen, Artefakte. Köln, Weimar, Wien, S. 62-77.

Geertz, Clifford (1987): Dichte Beschreibung. Beiträge zum Verstehen kultureller Systeme. Frankfurt a.M.

Grube, Norbert (2018): Verortungsversuche von fluiden Bildungsräumen im Evangelischen Lehrerseminar Zürich Unterstrass 1870 bis 1950. Das familiale Leitbild als raumkonstituierender Ordnungsfaktor. In: Historia Scholastica 4, H. 1, S. 17-28.

Grube, Norbert/De Vincenti, Andrea (2016): Pädagogisches Wissen in seinen fachlichen und alltagspraktischen Ausprägungen. Die Seminare Küsnacht und Unterstrass zwischen 1830 und 1930. In: Andreas Hoffmann-Ocon/Rebekka Horlacher (Hg.): Pädagogik und pädagogisches Wissen. Ambitionen in der und Erwartungen an die Ausbildung von Lehrpersonen. Bad Heilbrunn, S. 93115.

Grube, Norbert/Hoffmann-Ocon, Andreas (2015): Orte der Lehrerinnen- und Lehrerbildung im Kanton Zürich. Überblick auf Dynamiken, Kontroversen und eine spannungsgeladene Vielfalt. In: Andreas Hoffmann-Ocon (Hg.): Orte der Lehrerinnen- und Lehrerbildung im Kanton Zürich. Bern, S. 25-95.

Haasis, Lucas/Rieske, Constantin (2015): Historische Praxeologie. Eine Einführung. In: Diess. (Hg.): Historische Praxeologie. Dimensionen vergangenen Handelns. Paderborn, S. 7-54.

Haasis, Lucas/Rieske, Constantin (Hg.) (2015): Historische Praxeologie. Dimensionen vergangenen Handelns. Paderborn.

Helsper, Werner (2008): Schulkulturen. Die Schule als symbolische Sinnordnung. In: Zeitschrift für Pädagogik 54, H. 1, S. 63-80.

Hillebrandt, Frank (2015): Vergangene Praktiken. Wege zur Identifikation. In: Arndt Brendecke (Hg.): Praktiken der Frühen Neuzeit. Akteure, Handlungen, Artefakte. Köln, Weimar, Wien, S. 34-45.

Hoffmann-Ocon, Andreas/De Vincenti, Andrea/Grube, Norbert (2016): Vom Pädagogischen zur Pädagogik? Die Ausbildung von Zürcher Lehrpersonen zwischen Seminar und Universität im 19. und 20. Jahrhundert. In: Sigrid Blömeke/Marcelo Caruso/Sabine Reh/Ulrich Salaschek/Jurik Stiller (Hg.): Tradition und Zukünfte. Beiträge zum 24. Kongress der Deutschen Gesellschaft für Erziehungswissenschaft. Opladen, Berlin, Toronto, S. 101-110. 
Hörning, Karl/Reuter, Julia (2004): Doing Culture. Kultur als Praxis. In: Diess. (Hg.): Doing Culture. Neue Positionen zum Verhältnis von Kultur und Praxis. Bielefeld, S. 9-15.

Ingold, Tim (2000a): The temporality of the landscape. In: Ders. (Hg.): The Perception of the Environment. Essays on livelihood, dwelling and skill. London, New York, S. 189-208.

Ingold, Tim (2000b): Work, time and industry. In: Ders. (Hg.): The Perception of the Environment. Essays on livelihood, dwelling and skill. London, New York, S. 323-338.

Jenzer, Sabine (2014): Die »Dirne«, der Bürger und der Staat. Private Erziehungsheime für junge Frauen und die Anfänge des Sozialstaates in der Deutschschweiz, 1870er bis 1930er Jahre. Köln.

Keßler, Catharina (2017): Doing School. Ein ethnographischer Beitrag zur Schulkulturforschung. Wiesbaden.

Kluchert, Gerhard (2009): Schulkultur(en) in historischer Perspektive. Einführung in das Thema. In: Zeitschrift für Pädagogik 55, H. 3, S. 326-333.

Miller, Damian (2016): Hausvater und Hausdrachen. In: Schulblatt des Kantons Thurgau 58, H. 4, S. $10 f$.

Miller, Damian/Weber, Hans (2016): Abwart - Hauswart - Facility-Manager. In: Schulblatt des Kantons Thurgau 58, H. 4, S. $45 f$.

Müller, Philipp (2018): Historische Anthropologie. Fragen und Konzepte zur Einführung. In: Geschichte in Wissenschaft und Unterricht 69, H. 5/6, S. 334-345.

Patzold, Steffen (2010): Konflikte im Stauferreich nördlich der Alpen. Methodische Überlegungen zur Messbarkeit eines Wandels der Konfliktführung im 12. Jahrhundert. In: Bernd Schneidmüller/Stefan Weinfurter/Alfried Wieczorek (Hg.): Verwandlungen des Stauferreichs. Drei Innovationsregionen im mittelalterlichen Europa. Darmstadt, S. 144-178.

Ralser, Michaela/Bischoff, Nora/Guerrini, Flavia/Jost, Christine/Leitner, Ulrich/ Reiterer, Martina (2017): Geschichte der Jugendfürsorge und Heimerziehung in Tirol und Vorarlberg. Innsbruck.

Sabelus, Esther (2009): Die weiße Sklavin. Mediale Inszenierungen von Sexualität und Großstadt um 1900. Berlin.

Schwartz, Laura (2011): A Serious Endeavour. Gender, Education and Community at St Hugh's 1886-2011. London.

Tanner, Jakob (2004): Historische Anthropologie. Zur Einführung. Hamburg.

Tyack, David/Tobin William (1994): The »Grammar« of Schooling. Why Has it Been so Hard to Change? In: American Educational Research Journal 33, H. 3, S. 453479.

Veyne, Paul (1992): Foucault. Die Revolutionierung der Geschichte. Frankfurt a.M. Wagener, Silke (1996): Pedelle, Mägde und Lakaien. Das Dienstpersonal an der Georg-August-Universität Göttingen 1737-1866. Göttingen. 


\section{Die "Seminarfamilie» Nekrologe als Medium von Vergemeinschaftung'}

Jennifer Burri

Im Jahresbericht 1932/33 der Stadtzürcher Töchterschule lesen wir, inmitten verschiedenster Personalnachrichten, folgende Mitteilung: »Wiederum ist der Hinschied einer Schülerin zu beklagen. Am 10. Dezember starb Grete Häcker, Schülerin der dritten Klasse der Frauenbildungsschule. $\aleph^{2}$ Aus dieser nüchternen Notiz wird erst einmal nicht ersichtlich, ob die Institution Töchterschule dem Tod einer Schülerin überhaupt eine Bedeutung zumisst und welche tragische Geschichte sich dahinter verbirgt. Fast wirkt der Tod einer Schülerin hier - eingereiht in Personalnachrichten und eingeleitet durch die Formulierung "wiederum « - als alltägliches Geschehnis. Im Bericht der Schulärztin, der sich etwas weiter vorne im selben Jahresbericht findet, werden für das Schuljahr zwei Todesfälle erwähnt: ein Fall von Tuberkulose und ein Suizid. Im Archiv der Töchterschule schliesslich findet sich eine Sammlung verschiedenster Traueransprachen und Nekrologe, die Rektor Fritz Enderlin während seiner Amtszeit (1930-1949) verfasst, gehalten oder bekommen und gesammelt hat. Hier erhält nun auch die einleitend zitierte Mitteilung ein Gesicht, findet sich hier doch der Durchschlag einer Rede mit dem Titel: »Kremation Gret Häcker «. ${ }^{3}$

Über die genauen Hintergründe ihres Todes lässt sich auch hier wenig in Erfahrung bringen, doch immerhin wird nun klar, dass sie sich selbst das Leben genommen haben muss. Der Rektor ringt in seiner Grabrede nach Worten. Die vielen durchgestrichenen Passagen mögen auf einen auch sonst bedachtsamen

1 Dieser Artikel basiert auf zwei Vorträgen, die im Rahmen meiner Arbeit im SNF-Forschungsprojekt »Wissenschaft - Erziehung und Alltag. Orte und Praktiken der Zürcher Primarlehrer/ -innenbildung in der ersten Hälfte des 20. Jahrhunderts« (SNF-Projekt 166008) entstanden sind: »Nachrufe als familienkonstituierende Praxis am Seminar?«, Vortrag im Rahmen des Workshops »Möglichkeiten und Grenzen der Praxeologie in der (Historischen) Bildungsforschung«, 1.-2. März 2018, Zürich; zus. mit Adrian Juen: »'School Family< as Nature-Given Form of Teacher Education? Practices of Community in Zurich's Normal Schools, 1875-1950«, Vortrag an der ISCHE, 29. August-1. September 2018, Berlin.

2 Jahresbericht der Töchterschule der Stadt Zürich, Schuljahr 1932/33, Abteilung I, S. 22.

3 SAZ V.H.c.98: 10.2. Traueransprachen, Nekrologe 1932-1963 (I). 
Verfasser hinweisen. Dennoch fällt auf, wie oft er beim Schreiben neu ansetzt und wie sehr sein Schreiben um eine Erklärung des Unbegreiflichen ringt. Grete Häcker sei mit einer Leichtigkeit durch Leben und Schule gegangen, die alle getäuscht habe: Dahinter hätten sich Ansprüche an sich selbst verborgen, an denen sie gescheitert sei. Und dieses Scheitern an sich selbst birgt ein Scheitern der Gemeinschaft und ihrer Gewissheiten:

Wenn das Ungeheure hereinbricht in die geordneten Bezirke unseres täglichen Wandels, versagen die Maßstäbe, mit denen wir Dinge und Menschen zu beurteilen pflegen. Wir erkennen mit Scham und mit Zittern, dass wir zu unrecht uns auf die Sicherheit dieser Ordnung verlassen haben, und das unser Anspruch auf den normalen Verlaufalteł der Dinge zerschellen muss an derabgründigen Wirklichkeit. ${ }^{4}$

Schliesslich muss auch die Ansprache selbst in ihrem Erklärungsanspruch scheitern. Nur fragend kommt sie voran: »Wer dürfte da noch richten wollen, wo jeden Richter die eigene Brust verklagt? Wer dürfte urteilen wollen, wo das Urteil am Unfassbaren zerbricht? Ich kann euch, liebe Schülerinnen, als Schulleiter keine Antwort geben auf die bange Frage eurer bangen Herzen [...]. $\aleph^{5}$

Das Ringen um Worte, Erklärungen, ja das explizite Konstatieren der Unerklärbarkeit dieses Todes und die noch grössere Unmöglichkeit, hierzu passende Worte zu finden: Hier ereignet sich exemplarisch das, was Eva Horn für Trauertexte seit dem 18. Jahrhundert als charakteristisch beschreibt: „Weil er sprechen muss, wo er nicht sprechen darf, wird der Text doppelbödig und selbstreflexiv. « ${ }^{6}$ Die Individualisierung des Todes (Ariès) - gemeint ist: der Tod eines (spezifischen) Anderen und die individuelle Trauer darüber als »tief[e] Verletzung des Überlebenden ${ }^{7}$ - macht den Tod unaussprechlich, undarstellbar, was sich auch in den Texten über die Toten spiegelt. ${ }^{8}$ Im Falle eines Suizids scheint dies noch verstärkt zu werden, da nicht nur der Tod, sondern auch die Tote und ihre Handlungen in den Bereich des Unerklärlichen fallen.

Trauerreden kommt die Funktion zu, Orientierung für die Hinterbliebenen $\mathrm{zu}$ bieten. ${ }^{9}$ So handelt es sich bei der vorliegenden Grabrede nicht nur um eine individuelle Aushandlung und Darstellung individueller Trauer, sondern sie hat auch repräsentative Funktion. Mit dieser Repräsentativität sind hier Elemente

4 Ebd., Kursivsetzung: handschriftlicher Einschub.

5 Ebd.

6 Horn 1998, S. 67.

7 Ebd., S. 65.

8 Thomas Macho ergänzt: »Das Wort `Todく ist selbst eine sabsolute Metapher für unsagbare Erfahrungen.« (1987, S. 188, Hervorhebung im Original). 
vorhanden, die Eva Horn den Trauertexten des barocken Totenkults zuschreibt. ${ }^{10}$ In der fordistischen Welt des 20 . Jahrhunderts wendet sich die Repräsentativität aber nicht nur gegen aussen, sondern auch gegen innen. ${ }^{11}$ Wenn Institutionen wie Schulen ihre Toten betrauern, dann stehen genau diese Funktionen im Zentrum: Trost spenden und - so möchte ich hier argumentieren - Gemeinschaft (wieder-) herstellen. Der Rektor, der anlässlich der Kremation einer verstorbenen Schülerin spricht, muss nicht nur erklären und einordnen, sondern auch versuchen, die Gemeinschaft an der Schule, die durch den Tod einer Schülerin empfindlich getroffen wurde, zu restituieren. Damit lassen sich Nekrologe auch als Medien von Vergemeinschaftung verstehen. Ich betrachte also das Verfassen, Vortragen, mitunter auch das Publizieren und Lesen von Nachrufen als eine unter anderen Praktiken der Herstellung von Gemeinschaft an Seminaren. ${ }^{12}$ Indem ich auf den Nekrolog als Praxis und die ihn umgebenden Praktiken abziele, möchte ich zeigen, welche sozialen Verhältnisse sich darin an den betreffenden Institutionen verfestigen.

Nekrologe sind ein überaus interessantes, aber nicht unbedingt sehr bekanntes Quellenmaterial. Deshalb wird der folgende Abschnitt die behandelten Quellen in ihrem lokalen und breiteren historischen Zusammenhängen situieren. Der nächste Abschnitt klärt im Hinblick auf das praxeologisch angeleitete Erkenntnisinteresse dieses Artikels nochmals zentrale Fragen und Begriffe. Danach stellen drei weitere Abschnitte dar, wie an den Zürcher Seminaren Unterstrass und der Höheren Töchterschule Verstorbene erinnert werden und inwiefern in diesem Prozess Gemeinschaft hergestellt wird. Ganz zum Schluss wird ein Aspekt vertieft werden, der sich in Nachrufen, aber auch in anderen Quellen zu Unterstrass auf besondere Weise herausschält: die Praxis der Gemeinschaft als Seminarfamilie oder Anstaltsfamilie.

\section{Praktiken der Nekrologie: Quellen und Kontexte}

Im Folgenden werden verschiedene Formen von Nachrufen an zwei Zürcher Institutionen zur Ausbildung von Lehrerinnen und Lehrern im Zentrum stehen: des Seminars an der Töchterschule und des Evangelischen Seminars in Unterstrass. Die städtische Töchterschule führte ab 1878 Seminarklassen für angehende Volksschullehrerinnen, ${ }^{13}$ später kamen Gymnasial-, Fortbildungs- und Handelsschulklassen hinzu. In Unterstrass wurde 1869 von pietistischer Seite das private Evangelische Seminar gegründet. Die Gründung erfolgte in der Tradition der

\footnotetext{
10 Horn 1998, S. $59 \mathrm{ff}$.

11 Vgl. Tersch 2007, S. 204

12 Zum Begriff der Cemeinschaft im Kontext der (Sozial-)Pädagogik vgl. Henseler/Reyer 2000.

13 Crotti 2015.
} 
christlichen Erziehungsanstalt Beuggen in Süddeutschland, dessen Leiter der Vater des späteren Seminardirektors Konrad Zeller war. ${ }^{14}$ Erst 1937 nahm das Seminar die erste Schülerin auf. ${ }^{15}$ Was an diesen zwei Institutionen über den Tod einer Schülerin, eines Lehrers, eines Vorstandsmitglieds oder eines Rektors geschrieben wurde, ist in seiner Form höchst unterschiedlich: Die Quellen, die ich gefunden habe (und in der Folge als Nachrufe bezeichnen werde), reichen von einer kurzen Notiz in einem Jahresbericht über einen längeren Nachruf am Ende des Jahresberichts bis zur Abschrift einer Rede des Rektors an der Kremation einer verstorbenen Schülerin. Den Nachruf verfassen in den meisten Fällen der Rektor bzw. Direktor der Institution, der sowohl die Texte der Jahresberichte zeichnet als auch die Rede am Sarg einer verstorbenen Schülerin hält. Als weitere Verfasser/-innen treten auch Vorstandsmitglieder, Lehrer oder Schülerinnen auf. Eine besonders reiche Quelle für Nachrufe ist das Unterstrasser Seminarblatt. Es wurde zwei- bis viermal im Jahr an alle Vereinsmitglieder und Ehemaligen verschickt und enthielt die Nachrufe auf alle verstorbenen ehemaligen Schüler sowie auf Lehrer und auf die besonders verdienten Vorstands- und Vereinsmitglieder. Verfasst wurden sie gewöhnlich eigens für das Seminarblatt und meist von Kolleginnen und Kollegen, ehemaligen Klassenkameraden oder dem Direktor. Einige wurden auch Organen wie der Schweizerischen Lehrerzeitung entnommen und abgedruckt.

Im Archivbestand der Töchterschule, der im Stadtarchiv Zürich verwahrt ist, und im hauseigenen Archiv Unterstrass sind überdies in einzelnen Fällen eigens gedruckte und wohl nach der Beerdigung des oder der Verstorbenen versandte oder verteilte Erinnerungsschriften überliefert. Diese mehrseitigen Broschüren enthalten ein Bild des oder der Verstorbenen, Begräbnisreden des Pfarrers sowie ggf. weiterer Personen und in Zeitungen oder anderen Organen publizierte Nachrufe. ${ }^{16}$ Ihr selektiver Bestand lässt darauf schliessen, dass diese Erinnerungsschriften wie auch die in Zeitungen publizierten Nachrufe einzelnen (bekannteren) Personen und/oder einer Schicht mit entsprechenden finanziellen Mitteln vorbehalten waren. Für Zürich ist in diesem Zusammenhang der Gedenkschriften-Verlag W. Frei bekannt, der ab den 1930er-Jahren Leichenpredigten und weitere Reden an Begräbnissen stenografisch (später mit Tonbandgerät) mitschrieb. Aufgrund von Todesanzeigen in Zeitungen fragte er die Angehörigen um ihr Interesse an der Mitschrift, einer Vervielfältigung oder einem Druck an. Die Praxis schien sich allmählich zu etablieren. So lässt sich aus dem in der Zentralbibliothek Zürich gelagerten Archiv herauslesen, dass der Verlag in den Kirchgemeinden Neumünster und Unterstrass besonders viele Abdankungen mitschrieb

14 Grube/Hoffmann-Ocon 2015, S. 36.

15 Hüppi 2007.

16 Siehe bspw. zum Tod von Dr. Ernst Theodor Pestalozzi SAZ V.H.c.98: 10.2. Traueransprachen, Nekrologe 1932-1963 (II). 
und bei den Pfarrern und sicherlich auch beim Publikum allmählich bekannt gewesen sein dürfte. ${ }^{17}$ Das Publikum war ein klar bürgerlich-mittelständisches, die protokollierten Abdankungen in der Mehrheit, aber nicht ausschliesslich, reformiert. ${ }^{18}$ Dies lässt sich auch aus den Erinnerungsschriften für Unterstrass und die Töchterschule eruieren. Der Verlag ist nicht immer genannt, es lässt sich aber vermuten, dass für den Platz Zürich weitere Verlage und Druckereien diesen Service anboten. ${ }^{19}$

Ähnliche Publikationspraktiken gab es schon früher: Für das 17. Jahrhundert ist überliefert, dass bei Todesfällen aus der gesellschaftlichen Elite die Grabreden gedruckt und verkauft wurden. ${ }^{20}$ Bekannt sind auch die katholischen "Totenzettel«, welche aber meist nur aus einem Blatt bestehen und neben einem Bild eine Kurzbiografie der verstorbenen Personen sowie Fürbitten enthielten. Sie wurden bei Beerdigungen verteilt und hatten ursprünglich die Funktion, an das Gebet für die Verstorbenen zu erinnern. Breit durchgesetzt haben sie sich, ebenso wie die umfangreicheren Erinnerungsschriften, erst anfangs des 20 . Jahrhunderts. ${ }^{21}$ Wichtige Basis dieser Erinnerungsschriften ist die evangelisch-reformiert geprägte Leichenpredigt, die der Erzählung der Biografie und dem Charakter der verstorbenen Person mehr Platz einräumt. Sie wurde bald auch gedruckt und ist laut Fischer ein Ausdruck zunehmender Individualisierung und Verweltlichung in Bezug auf das Totengedenken. ${ }^{22}$

Ich möchte jedoch vorsichtig sein, in Bezug auf den Nachruf als Erinnerungspraxis vorschnell historische Genealogien herauszuarbeiten. Tod, Trauer und Erinnerungskultur wurden aus kulturhistorischer Sicht ausreichend und gewinnbringend aufgearbeitet. ${ }^{23}$ Aus historisch-praxeologischer Sicht besteht noch Nachholbedarf. So könnten die Nachrufe zu einer Gruppe von Monumenten und Objekten zur Erinnerung der Toten gezählt werden, wie sie z.B. die im Mittelalter gestifteten Statuen und Epitaphien in der Kirche darstellen. ${ }^{24}$ Als schriftliches Dokument könnten sie auch in der Tradition der spirituellen Biografie stehen. Die Praxis, adligen Toten ein »Wappenzertifikat« auszustellen, spiegelt sich in den

17 Bodmer 1986.

18 Ebd. Bodmer vermutet zudem, dass Gedenkschriften eher für Personen, deren Tod als vorzeitig wahrgenommen wurde, verfasst wurden (FN 14).

19 Zum Beispiel die Buchdruckerei Berichthaus, die die o.g. Erinnerungsschrift von Theodor Pestalozzi gedruckt hat, wie übrigens auch die Jahresberichte des Seminars Unterstrass.

20 Fowler 2007, S. 53.

21 Aka 1993, S. 28; vgl. auch Halling 2009, S. 238f.

22 Fischer 2001a, S. 21.

23 Vgl. bspw. Oexle 1995 und Fischer 2001b. Prägend war in jedem Fall die (französische) Forschung mit und nach Philipp Ariès, vgl. bei Fowler 2007, S. 41ff. und Hugger 2002, S. 32ff. Von kulturwissenschaftlicher Seite vgl. auch Macho 1987; Bronfen 1992. 
bürgerlichen Nachrufen in ihrem Fokus auf Herkunft und Stammbaum des Verstorbenen..$^{25}$ Nachrufe sind jedoch, im Gegensatz zu Todesanzeigen oder Friedhöfen und Bestattungskultur im Allgemeinen, noch nicht oft zum Gegenstand historischer Forschung gemacht worden. ${ }^{26}$ Einzig ihr liturgischer \Zwilling Leichenpredigt oder die Leichenrede, hat einige Aufmerksamkeit erfahren. ${ }^{27} \mathrm{Ge}-$ sichert erscheint mir, dass die Nachrufe erst im 18. oder 19. Jahrhundert aufkommen und mit dem Entstehen einer bürgerlichen Öffentlichkeit und einem neuen, spezifisch modernen Umgang mit Tod und Trauer verbunden sind: "The obituary is thus a commemorative form which possesses its precursors and parallels in other cultural emblems, especially religious forms. Nevertheless, it only appears alongside modernity and it signals a death which is itself conceived vastly differently in modernity. $^{28}$ Oder anders formuliert: Die Memoria ändert sich, weil sich der gesellschaftliche Status der Toten ändert. ${ }^{29}$ In der Moderne wird dem Tod von der kultur- und mentalitätsgeschichtlichen Forschung ein individualisierter und privatisierter Charakter gegeben - und damit vom Tod in der Öffentlichkeit bzw. Gemeinschaft in der Vormoderne abgegrenzt. In der bürgerlichen Trauerkultur beginnen sich christliche Traditionen, private Emotionalität und symbolisch-gesellschaftliche Repräsentation zu vermischen. Im Tod wird nun der individuellen Lebensleistung der verstorbenen Person gedacht - mittels neuer Praktiken, wie z.B. der Rede am offenen Grab. Auch neue Techniken und Orte bilden sich heraus, wie etwa die Feuerbestattung und damit das Krematorium, wo auch Abdankungsfeiern abgehalten werden können. ${ }^{30}$ Diese Entwicklung zeigt sich auch in meinen Quellen. ${ }^{31}$ Auf der anderen Seite kennt die Moderne auch die öffentliche Trauer um den Tod bekannter Personen als nationales Grossereignis ${ }^{32}$ und das Schreiben von Nachrufen auf bekannte Persönlichkeiten in den Medien, das

25 Ebd. (Übersetzung der Verfasserin).

26 Dies zeigt bspw. der von Philippe Ariès ausgehende Überblick über die Forschungsliteratur bei Zihlmann-Märki 2010, S. 25ff. Besonders charakteristisch erscheint mir die Zweiteilung und gleichzeitig Konzentration der Forschung in `Orte< und `Medien`der Erinnerung, vgl. bspw. bei Halling 2009.

Dies gilt jedoch auch nur für die Frühe Neuzeit, vgl. Tersch 2007, S. 178. Vgl. auch die Publikationen des Marburger Personalschriftensymposions, Forschungsschwerpunkt Leichenpredigten, beginnend mit Lenz 1975 (bis heute sind drei weitere Bände veröffentlicht worden). Fowler 2007, S. 44.

29 Vgl. Oexle 1995.

30 Vgl. dazu und allg. zur modernen Trauerkultur Fischer 2001b. Das Krematorium in Zürich eröffnete 1889 auf dem Friedhof Sihlfeld, bereits 1915 musste ein grösseres gebaut werden. 1925 wurden erstmals mehr Menschen in Zürich kremiert statt begraben, siehe Stadt Zürich 2018.

31 Für die Töchterschule sind im Krematorium gehaltene Reden überliefert, vgl. bspw. [Anonym] 1933. 
erst gegen Ende des 19. Jahrhunderts Fahrt aufnimmt. ${ }^{33}$ Für meine Analyse greift das Begriffspaar öffentlich-privat jedoch zu kurz, weil es hier darum geht, wie die Verstorbenen im Kontext einer institutionellen Gemeinschaft erinnert werden.

\section{Nekrologe als Praxis: Erinnerung, Gemeinschaft, Ritual}

Dass es bei der (individuellen) Erinnerung bzw. bei dem Gedenken eines Individuums auch immer um Kollektivität geht, ist spätestens seit Maurice Halbwachs' Überlegungen zum kollektiven Gedächtnis ein Gemeinplatz. Das Begräbnis ist der Moment, in dem diese Erinnerung aufgerufen, (nach-)erzählt und damit auch erschaffen, kollektiviert und vereinheitlichet wird: "Memoria schafft Identität. « ${ }^{34}$ Nachrufe sind nicht nur Zeugnisse dieses Moments, sie sind auch ein Produkt davon, ein Teil der Praxis des Erinnerns und damit selber eine Erinnerungspraktik, die als ritualisierte, aber historisch und kulturell spezifische Handlung innerhalb des grösseren Handlungszusammenhangs des Totengedenkens fungiert. Ich lehne mich hier an den Praxisbegriff Frank Hillebrandts an, wonach Praktiken nur in Reihen und Relationen existieren. ${ }^{35}$ Nachrufe als Erinnerungspraktik sind damit wiederum selbst an der Herstellung von Erinnerung und Gemeinschaft grundlegend beteiligt. ${ }^{36}$

Das Totengedenken schafft in der kollektiven Rückbindung an den Toten auf paradigmatische Weise Gemeinschafts- oder Gruppenidentität(en), denn im Moment, da die Gruppe ein Mitglied verliert, vergegenwärtigt sie im sozialen (diskursiven) Austausch darüber Aspekte gemeinsamer, d.h. gruppenspezifischer Vergangenheit. ${ }^{37}$

In der »Krise des Todesfalls« hilft der Nachruf, die entstandene Lücke »zwischen Vergangenheit, Gegenwart und Zukunft« zu überbrücken, und wirkt auf die (Re-) Konstituierung der Gruppe hin. ${ }^{38}$

33 Fowler 2007, S. 6. Zum Gestaltwandel der Todesanzeigen Ende des 19. Jahrhunderts vgl. Halling 2009 , S. 240.

34 Oexle 1995, S. 10.

35 Hillebrandt 2014, S. 58. Ich übernehme aber nicht seine begriffliche Aufschlüsselung in Praktiken, Praxisformen und Praxisformationen.

36 Dies umso mehr, wenn mit Latour und dann mit Hillebrandt gesprochen, sich nicht nur Menschen, sondern auch Dinge als Aktanten zu Praxisformationen versammeln (vgl. ebd., S. 59).

37 Goetz 2008, S. 41.

38 Ebd. Vgl. auch Zihlmann-Märki 2010, S. 31ff. (mit Bezug auf Gennep). Spezifisch in Bezug zum vorzeitigen Tod Halling/Fehlemann/Vögele 2009. 
Unbestreitbar haben Erinnerungspraxen Ritualcharakter. Rituale rund um Tod und Bestattung markieren - wie Rituale allgemein - gleichzeitig Bruch und Kontinuität. ${ }^{39}$ Sie haben ganz spezifisch einen Gemeinschaft stiftenden Charakter:

Im Bestattungsritual vergewissert sich die Cemeinschaft - sei es die Familie, die Gemeinde, die Religionsgemeinschaft, der Herrschaftsverband usw. - ihrer eigenen Ordnung, die durch den einzelnen Tod eine Veränderung erfährt. Wie bei allen Übergangsritualen wird das einzelne Ereignis, hier der einzelne Todesfall, eingebettet in eine Struktur, die dieses Ereignis überdauert. ${ }^{40}$

Mit dem Hinweis auf die Ritualhaftigkeit des Totengedenkens kann nochmal genauer gefasst werden, wie ich mit meinen Quellen praxeologisch arbeiten möchte. Barbara Stollberg-Rilinger fasst Rituale als Abfolge von Handlungen, die charakterisiert sind durch eine standardisierte Form, ihre Wiederholung, durch Inszenierung, ihre symbolische Aufladung wie auch Performativität - d.h., etwas wird hergestellt. Dies ist für Historiker/-innen deshalb interessant, weil der performative Charakter daran erinnert, dass auch eine Textquelle immer in einem Aufführungszusammenhang gesehen werden muss, d.h. beispielsweise über ein Ritual eine besondere Wirkungsmacht erhält. ${ }^{41}$ Daran anknüpfend möchte ich hier Nekrologe als Quellen behandeln, die einerseits, indem sie in (rituelle) Handlungszusammenhänge eingebunden sind, auf andere Begräbnis- und Erinnerungspraktiken (Begräbnis, Kremation, Totengedenken im Rahmen von Veranstaltungen im Schulbetrieb oder im Jahresbericht) verweisen können. Andererseits stellen sie auch etwas her. Die Praxeologie als Perspektive lenkt den historiografischen Blick konsequent auf solche Herstellungsprozesse ${ }^{42}$ Geschärft wird diese Perspektive von einem Ritualbegriff, der ihre »sozial strukturbildende Wirkung« betont - sie sind ein »Scharnier zwischen Individuum und Gemeinschaft«. ${ }^{43}$ In ihrer Zeitlichkeit knüpfen Rituale die Gegenwart an Vergangenheit und Zukunft und garantieren damit gleichzeitig Beständigkeit und Wandel. Diese übergreifende Zeitlichkeit macht sie zu einer wesentlichen Stütze von Institutionen:

Dass sie ihre soziale Wirkung gerade durch den äußerlichen Vollzug erzielen, gerade darauf beruht ihre spezifische Leistungskraft: Denn innere Einstellungen

\footnotetext{
39 Stollberg-Rilinger 2013, S. 66

40 Ebd., S. $66 f$.

41 Ebd., S. 39.

42 Vgl. dazu auch Freist 2015, S. 67.

43 Stollberg-Rilinger 2013, S. 9 U. 13.
} 
schwanken bekanntlich, auf sie lassen sich keine dauerhaften Institutionen gründen; dazu bedarf es vielmehr gleichbleibender, äußerlich sichtbarer Formen ${ }^{44}$

Nachrufe oder Todesanzeigen als rituelle Erinnerungspraktiken im Kontext von Institutionen sind in diesem doppelten Rahmen zu interpretieren: Es gilt, nicht nur den Ruf des Verstorbenen, sondern auch den Ruf der Angehörigen, in diesem Fall der Anstalt, zu erhalten. ${ }^{45}$

Im Anschluss an die postulierte sozial strukturbildende Prägekraft ritualisierter Praktiken muss die Analyse von Nekrologen in einem weiteren Schritt auf die darin vermittelten Ideale abzielen, die in der Erinnerungspraxis verstetigt werden. Was schreiben, lesen, hören die Hinterbliebenen von ihren verstorbenen Rektoren, Lehrerinnen, Kameraden in Jahresberichten, Zeitschriften oder an Begräbnissen? Begräbnisse sind zwar von einer gewissen Gewohnheit geprägt, gleichzeitig in hohem Masse nicht alltäglich und risikobehaftet. Deshalb ist es interessant zu fragen, welche Ideale in diesem Moment angerufen werden. Für Luc Boltanski sind Beerdigungen »Prüfungen«, wie er es nennt, da sie als soziale Situation vom Scheitern viel stärker bedroht sind als andere. Beerdigungen gehören, mit anderen »offiziellen Zeremonien « wie Hochzeiten oder Staatsakten, zu den sogenannten "Wahrheitsprüfungen", die auf Bestätigung des Bestehenden ausgelegt sind sowie die Funktion haben, eine Norm aufzuzeigen. ${ }^{46}$ Damit sind sie gerade nicht durch Alltäglichkeit, aber umso mehr durch Verpflichtung gekennzeichnet. Nachrufe können also - mit Boltanski gelesen - als Zeugnisse von Momenten höchster Unalltäglichkeit und gleichzeitig als Dokumente zur Sicherung der gesellschaftlichen Kontinuität gelesen werden. Zudem erstaunt es nicht, dass sich schon Pierre Bourdieu explizit für Nachrufe im Kontext von Schule und Ausbildung interessiert hat - liegt der Bourdieu'schen Soziologie doch an der Analyse des Zustandekommens, vor allem aber der Perpetuierung sozialer Differenz, in der Gesellschaft wie auch in einzelnen Institutionen. ${ }^{47}$ Bourdieu hat also den empirischen Wert von Nachrufen erkannt und geschätzt. Daran kann die (Historische) Bildungsforschung anschliessen, wenn sie nach der Entstehung und Perpetuierung von Idealen und bestimmten Kulturen an der Institution Schule fragen will. Darauf werde ich im Kapitel 5 zurückkommen.

\footnotetext{
44 Ebd., S. 13.

45 Vgl. bez. Todesanzeige bei Halling 2009, S. 239.

46 Bogusz 2010, S. $141 \mathrm{f}$.

47 Vgl. Fowler 2007, S. 59ff.
} 


\section{Von Brüdern und treuen Dienern: beziehungsorientierte Gedenkarbeit in Unterstrass}

Inwiefern und wie wird nun in meinen Quellen Gemeinschaft (wieder-)hergestellt? In Unterstrass wird die Bindung des Verstorbenen ans Seminar wiederholt positiv hervorgehoben. Wenn familiäre Verbindungen bestehen, etwa der Vater schon am Seminar war, werden diese genannt. Auch für die Beschreibung nichtverwandtschaftlicher Beziehungen werden Familienmetaphern herangezogen. Über Jakob Muggli, Seminarist der 6. Promotion und später auch im Vorstand des Seminarvereins, der Trägerschaft des Seminars Unterstrass, tätig, heisst es in seinem Nachruf: »Unserer Mutteranstalt ist er bis zu seinem letzten Atemzug in großer Liebe und Dankbarkeit zugetan gewesen und es war ihm kein Opfer an Zeit, Mühe und Geld zu groß, um den Beweis davon zu erbringen.. $\aleph^{48}$ Paul Eppler, Seminardirektor von 1910 bis 1922, schreibt über ein altgedientes Vorstandsmitglied, er werde ihn als "väterliche[n] Berater in Erinnerung behalten. ${ }^{49}$ Familienbeziehungen strukturieren damit einerseits die Verbindungen zwischen Mitgliedern des Seminars, respektive über die Erinnerung zwischen Verstorbenen und Lebenden. Andererseits können sie die Verbindung des Einzelnen zur Institution beschreiben. An der Beerdigung von Johannes Friedrich Raillard, langjähriger Deutschlehrer am Seminar, hält sein Bruder, ein Pfarrer, die Grabrede. Wiederholt spricht er von unserem Bruder, also sowohl seiner als auch derjenige der Seminargemeinde und wohl letztlich der gesamten Glaubensgemeinde. Er fährt fort: "Die Tätigkeit am Seminar wurde ihm große, das ganze Leben ausfüllende Aufgabe, der er sich mit voller Anteilnahme hingeben konnte und aus der ihm reiche Befriedigung zufloss. $\aleph^{50}$

Der persönliche Bezug zum Seminar, innere Bindung und besonders aktive Teilnahme werden in den Nachrufen immer positiv erwähnt und geschätzt: »Infolgedessen kannte er jeden einzelnen Schüler persönlich und stand während der ganzen Zeit in engster Berührung mit dem Seminar. ${ }^{51}$ Eine wiederholt gezeichnete Idealfigur ist der treue Diener des Seminars, der sowohl ein langjähriger Lehrer als auch ein Vorstandsmitglied sein kann. Edwin Schneider, Seminarist der 29. Promotion und später von 1881 bis 1941 im Seminarvorstand, wird als »einer der allertreusten $\aleph^{52}$ Freunde des Seminars bezeichnet, weil seine Bindung von gleichmässiger Stabilität geprägt gewesen sei. Immer sei auf ihn Verlass gewesen, regelmässig habe er Geld- und Naturalgaben dem Seminar zukommen lassen. Da-

48 Seminarblatt aus dem Weißen Kreuz, Nr. 42, Februar 1929, S. 10.

49 Evangelisches Lehrerseminar Zürich, 39. Bericht, 1913/14, S. 14.

50 Seminarblatt aus dem Weißen Kreuz, Nr. 43, Dezember 1929, S. 9.

51 Evangelisches Lehrerseminar Zürich, 47. Bericht, 1922/23, S. 12.

52 Seminarblatt aus dem Evangelischen Seminar Zürich-Unterstrass, Nr. 45, Mai 1948, S. 1. 
rüber hinaus sei seine Verbindung an das Seminar auch eine innerliche gewesen, welche er als aktives Mitglied des Seminarvorstandes gelebt habe. Gerne wird in diesem Zusammenhang auf die "Gesinnungstreue « oder das Engagement für das Seminar als "Sache des Herzens « verwiesen. ${ }^{53}$ Im Idealfall ist die äussere - monetäre - Verbindung auch eine innere - aus Überzeugung. Natürlich ist das nicht in allen Nachrufen so extrem. Prinzipiell wird alles, jede Verbindung, geschätzt. Idealerweise jedoch ist die Verbindung körperlich und geistig zugleich: »Der Verstorbene war mit Leib und Seele ein \Untersträssler.. [...] Seine Beziehungen zum Seminar sind nie unterbrochen, ja kaum gelockert worden. ${ }^{54}$ Dass damit nicht nur Floskeln gemeint waren, zeigen Stellen, die exemplarisch diese Bindung und Nähe als gelebte Praxis illustrieren: Der ehemalige Seminarist und Seminarlehrer Heinrich Süsli, der fast 40 Jahre an der Übungsschule und 30 Jahre Methodik unterrichtet hatte, kümmerte sich nach seiner Pensionierung um Reparatur- und Gartenarbeiten am Seminar. Direktor Konrad Zeller erinnert diesen »Liebesdienst am Seminar im Jahresbericht folgendermaßen: »Jedes Frühjahr sah man, oft noch bei kühler Witterung und unfreundlichem Wind, den ehrwürdigen alten Mann, manchmal hoch auf der Leiter, dieser selbstgewählten Arbeit obliegen. « $^{55}$ Und schliesst: "Sein Leben war ein Leben mit dem Seminar und für das Seminar. $\aleph^{56}$

Die Nachrufe aus dem Seminar Unterstrass geben nicht nur Auskunft darüber, wie Gemeinschaft am Seminar gedacht und gelebt wurde. Sie enthalten auch Hinweise darauf, welche (Gedenk-)Praktiken sich an den Moment des Todes eines Mitglieds knüpfen - und wie darüber ganz konkret Beziehungen reaktiviert werden und die Seminargemeinschaft bekräftigt wird. Nach dem Tod von Dr. Raillard 1929 melden sich zwei ehemalige Schüler mit einem Kondolenzschreiben bei dem damaligen Direktor Zeller und teilen ihre Erinnerungen an den verstorbenen Seminarlehrer. ${ }^{57}$ In einem anderen Fall treffen sich Ehemalige am Grab eines verstorbenen Klassenkameraden. Verstirbt ein Lehrer im Amt oder ein Mitschüler, nehmen auch Seminaristen an der Abdankungsfeier teil. So singt der Schüler-

53 Evangelisches Lehrerseminar Zürich, 64. Bericht, 1939/40, S. 13.

54 Evangelisches Lehrerseminar Zürich, Jahresbericht 1947-48, S. 16. Zeller schreibt dazu: „Wir rechnen auch unsere Ehemaligen zu den Menschen, die unser Werk verkörpern.« (59. Bericht, $1934 / 35$, S. 15). Allgemein sind Körper- und Organismusmetaphern in diesem Jahresbericht sehr präsent und kehren auch in den Berichten der Folgejahre wieder.

55 Evangelisches Lehrerseminar Zürich, 62. Bericht, 1937/38, S. 16.

56 Ebd., S. 17.

57 Archiv Unterstrass, Abt II.B., 1. Seminarverein, 1.05.01 Nekrologe. Vgl. auch zum Tod eines Seminaristen Seminarblatt aus dem Weißen Kreuz, Nr. 17, November 1910, S. 15: »Am 31. März wurde er in seiner Heimatsgemeinde beigesetzt, seine Klassengenossen und alle Glarner aus dem Seminar geleiteten ihn auf dem letzten Gang.» 
chor 1926 an der Trauerfeier für Jakob Schenkel, Mathematiklehrer am Seminar. ${ }^{58}$ Auch in verschiedenen Gremien wird in Unterstrass den Toten gedacht: in den Vorstandssitzungen des Seminarvereins oder an der Quartalsversammlung des Evangelischen Schulvereins. ${ }^{59}$ Eben dort verliest Raillard einen eigens dafür verfassten Nachruf auf seinen Kollegen Schenkel, der anschliessend in dieser Form auch im Seminarblatt abgedruckt wird. Er wolle nun doch, obwohl er schon in der Kirche, im Schulblatt sowie in der Neuen Zürcher Zeitung gewürdigt worden sei, auch in diesem Rahmen »öffentlich de[n] Dank« aussprechen, »den ihm alle schulden $«{ }^{60}$ Diese ausführliche >Gedenkarbeit an ihren Verstorbenen - gegen innen wie aussen - ist meines Erachtens charakteristisch für das Evangelische Seminar Unterstrass und hier besonders ausgeprägt. Einige intensiv mit dem Seminar in Verbindung Stehende werden mit längeren Nachrufen im Jahresbericht und im Seminarblatt, wie auch öffentlich in Zeitungen und Zeitschriften, als >Untersträssler erinnert. Im Seminarblatt, dem internen Publikationsorgan im Gegensatz zum öffentlichen Jahresbericht, werden alle ehemaligen Seminaristen (erst ab 1938 auch Seminaristinnen) systematisch erinnert, ab ca. 1935 in gestalterisch vereinheitlichter Form und typografisch abgesetzt durch eine kleinere Schrift. Dies war wohl eine Reaktion auf die stets steigende Anzahl der zu verfassenden Nekrologe, wollte man dem Anspruch gerecht werden, alle Verstorbenen zu würdigen. ${ }^{61}$ Die ausgeprägte Gedenkarbeit und die Beziehungspflege $\mathrm{zu}$ den Ehemaligen als Gemeinschaft stiftende Praktiken müssen nicht zuletzt auch in Zusammenhang mit der christlichen Fundierung und der Situation eines privaten Seminars gesehen werden, das auf Spenden zugetaner und überzeugter Gönner/-innen angewiesen war. ${ }^{62}$

58 Zeitungsausschnitt im Archiv Unterstrass, Abt II.B., 1. Seminarverein, 1.05.01 Nekrologe.

59 Der Evangelische Schulverein wurde 1881 gegründet und bildete eine Art Interessensvertretung für die christlichen Schulen und die christliche Schulbildung in der Schweiz, vgl. Schlienger-Schoch 1931. Mit der oben erwähnten Quartalsversammlung ist wahrscheinlich jene der Sektion Zürich gemeint.

60 Seminarblatt aus dem Weißen Kreuz, Nr. 38, März 1926, S. 2.

61 Seminarblatt aus dem Weißen Kreuz, Nr. 21, Dezember 1912, S. 10: »Bitte. Bei Todesfällen aus dem Kreise der `Ehemaligen o oder der Mitglieder der Sektion Zürich des evangel. Schulvereins bitten wir die Angehörigen oder nächste Kollegen um sofortige (womöglich telegraphische) Mitteilung an die Seminardirektion, die vom Schulverein als Zentralstelle für derlei Anzeigen bezeichnet worden ist."

62 Das Seminar finanzierte sich zu zwei Dritteln aus Spenden von Vereinen und Privatpersonen (u.a. waren auch Legate eine nicht unwesentliche Einnahmequelle). Die Pflege eines Netzwerks war also zentral, vgl. Hardegger 2008. 


\section{Partielle Erinnerung an der Töchterschule}

In den Nachrufen und generell in den Jahresberichten der Töchterschule fehlen Familienmetaphern weitestgehend. In den Jahresberichten wird von den Aktivitäten während des Schuljahres, bspw. Exkursionen, Skitage etc., berichtet und ihre gemeinschaftsbildende Wirkung explizit herausgestrichen, jedoch ohne den Appell an eine Familie oder den familienähnlichen Charakter dieser Gemeinschaft. In den Nachrufen, die an der Töchterschule im Rahmen des Jahresberichtes publiziert werden, fällt die Charakterauszeichnung der »väterliche[n] Güte« im ausgewerteten Zeitraum nur ein einziges Mal, und zwar im Nachruf auf Prof. Dr. Hans Wissler, Deutschlehrer und Bibliothekar. ${ }^{63}$ Doch auch hier wird Gemeinschaft bekräftigt. In einigen Nachrufen wird die Bindung und Treue zur Institution, etwa durch langjährige Lehrtätigkeit oder gar über diese hinaus, positiv hervorgehoben. ${ }^{64}$ So hat auch H. Wissler »der Schule mit großer Hingabe gedient «. ${ }^{65}$ In seinen Abschiedsworten im Krematorium lobt Rektor Enderlin zudem Wisslers »rege Teilnahme« im Schulbetrieb und die Führung der Bibliothek als »Herzenssache ${ }^{66}$

Ein zweites Beispiel kann weitere Unterschiede, aber auch Gemeinsamkeiten aufzeigen. Obschon weniger ausgeprägt als in Unterstrass, wird auch an der Töchterschule im Gedenken an Verstorbene Gemeinschaft hergestellt, indem auf eine gemeinsame, institutionelle Identität verwiesen wird. Als im Schuljahr 1929/30 Rektor Wilhelm von Wyss überraschend stirbt, zeichnet der Jahresbericht folgendes Bild dieses Moments: »[...] es war, als sei alles Leben auf der Promenade [Schulhaus] erstorben. ${ }^{67}$ Und im ausführlichen Nachruf auf den Rektor heisst es in derselben Ausgabe: "Die Saat, die er gestreut, hat sich entfaltet und hat jenen guten Geist der Gemeinschaft gezeitigt, der für Lehrende und Lernende die Arbeit auf der Hohen Promenade so schön macht. ${ }^{68}{ }^{8}$ Die Identität scheint hier eher an einen Ort bzw. das Schulgebäude (>HoPros) gebunden zu sein (im Gegensatz zum »Untersträssler« als Person). Der Tod des langjährigen Rektors hinterlässt markante Spuren, wohl nicht zuletzt, weil er mitten ins Schuljahr fällt. Entsprechend spontan werden Andachten organisiert. Nur einige Tage später findet in der Turnhalle eine »Trauerkundgebung «statt, an der eine Schülerin, eine Ehemalige sowie der Prorektor sprechen. ${ }^{69}$ Die Ehemaligen hätten, aufgrund des

63 Jahresbericht der Töchterschule der Stadt Zürich, Schuljahr 1932/33, Abteilung I, S. 41.

64 Vgl. [Anonym] 1933; [Anonym] 1936.

65 Jahresbericht der Töchterschule der Stadt Zürich, Schuljahr 1932/33, Abteilung I, S. 21.

66 Abgedruckt in ebd., hier S. 41.

67 Jahresbericht der Töchterschule der Stadt Zürich, Schuljahr 1929/30, S. 20.

68 Ebd., S. 45.

69 Ebd., S. $20 f$. 
Platzmangels, eine eigene »Erinnerungsfeier« abgehalten. Auch sei, so der Jahresbericht weiter, eine Erinnerungsschrift gedruckt worden: »Die an den Trauerfeiern gehaltenen Ansprachen sind in einer Erinnerungsschrift gesammelt worden, welche durch hochherziges Geschenk von Frau Prof. v. Wyss allen gegenwärtigen und ehemaligen Schülerinnen, die in ihren Besitz kommen wollten, ausgehändigt wurde. $\ll^{70}$

Die Unterschiede zwischen den beiden Institutionen, was die Erinnerung von Ehemaligen betrifft, sind auffällig. Zwar hat das Seminar der Töchterschule als städtische Schule eine andere Ausgangsposition als das privat finanzierte Evangelische Seminar Unterstrass. So besitzt die Töchterschule neben dem offiziellen Jahresbericht kein weiteres Publikationsorgan, das sich, wie das Seminarblatt in Unterstrass, an Ehemalige und Zugewandte, Gönner und Gönnerinnen richten würde. Im Vergleich wird an der Töchterschule den ehemaligen Lehrern und Lehrerinnen weniger gedacht. Nur einzelne werden erinnert: So widmet der Jahresbericht 1930/31 Professor Gertrud Knecht, »eine markante Persönlichkeit der Grossmünsterschule«, die zwei Jahre nach ihrer Pensionierung verstarb, einen umfassenden Nachruf. ${ }^{71}$ Andere hingegen scheinen vergessen worden $\mathrm{zu}$ sein. Nachrufe auf einige von ihnen können jedoch beispielsweise in der Schweizerischen Lehrerinnenzeitung gefunden werden, wie etwa auf Emma Coradi-Stahl, Haushaltungslehrerin und schweizweit bekannte Förderin des hauswirtschaftlichen Unterrichts ${ }^{72}$ oder Dr. med. Anna Heer, Hygienelehrerin. ${ }^{73} 1931$ stirbt Sophie Heim, die von 1875 an 25 Jahre lang Italienisch an der Zürcher Töchterschule unterrichtet hatte. Auch sie wird im Jahresbericht nicht erinnert, ein Nachruf findet sich jedoch in der Schweizerischen Lehrerinnenzeitung. ${ }^{74}$ Unterstrass dagegen erwähnt den Tod der langjährigen Arbeitsschullehrerin der Übungsschule, Berta Heller, zumindest kurz im Jahresbericht und ausführlich im Seminarblatt. ${ }^{75}$ Der Tod vieler weiterer, nach ihrem Rücktritt verstorbener ehemaliger Mitglieder des Unterstrasser Lehrkörpers wird entweder im Jahresbericht oder sicher im Seminarblatt erinnert.

70 Ebd., S. 21.

71 Jahresbericht der Töchterschule der Stadt Zürich, Schuljahr 1930/31, S. 61f., hier S. 61.

72 Eberhard 1911/12.

73 Benz 1918/19. Emilie Benz war 34 Jahre lang Übungsschullehrerin an der Töchterschule und wurde im Jahresbericht 1928/29 in einem Kurznachruf folgendermassen erinnert: »Sie war eine selbständige und originelle Persönlichkeit, die auch ausserhalb der Schule durch ihr Eintreten für die Sache der Lehrerinnen und der Frauen überhaupt wertvolle Arbeit leistete.« Jahresbericht der Töchterschule der Stadt Zürich, Schuljahr 1928/29, S. 17.

74 [Anonym] 1931/32.

75 Vgl. Evangelisches Lehrerseminar Zürich, 59. Bericht, 1934/35, S. 14; Seminarblatt aus dem Weißen Kreuz, Nr. 51, Dezember 1934, S. 11. 
An der Töchterschule scheint das institutionelle Gedächtnis` weniger gross bzw. lang gewesen zu sein. Immerhin: Der Nachruf auf Sophie Heim erwähnt die Rede ihrer Nachfolgerin an der Trauerfeier. Das weist darauf hin, dass Lehrerinnen und Lehrer untereinander das Gedenken bewahrten. Auch der Rektor spricht, wie die archivierten Reden zeigen, regelmässig an Trauerfeiern verstorbener Lehrer, Lehrerinnen und Schülerinnen.

Dies wirft die Frage auf, ob und inwiefern Frauen anders erinnert werden als Männer und ob die Memoria im 20. Jahrhundert ein hauptsächlich männliches Privileg ist. Bridget Fowler stellt eine ähnliche Frage und bezieht sich dabei auf Judith Butler, die in Bezug auf das Amerika nach 9/11 gezeigt hat, dass bestimmte Leben (hier: westliche, nicht-muslimische) eher >betrauerbar sind als andere. ${ }^{76}$ Der Fakt, dass weibliche Lehrpersonen die Erinnerungen an ihre verstorbenen Kolleginnen in eigenen, geschlechtsspezifischen Strukturen - nationale Vereine, Publikationen - abhielten, ist ein starker Hinweis darauf, dass die vorherrschenden, oft patriarchalen Strukturen diese Erinnerung vergassen. Ich möchte hier jedoch vor allem argumentieren, dass die institutionelle Kultur, das Verständnis von Gemeinschaft und damit die Erinnerungskultur an den beiden Institutionen Töchterschule und Unterstrass sehr unterschiedlich waren. Und dies ist nicht nur auf das Geschlecht ihrer Schüler und Schülerinnen zurückzuführen. ${ }^{77}$ Es spielt für das >Klima an den Institutionen und meine Frage der Gemeinschaft viel eher eine Rolle, dass die Töchterschule in einer Tradition des humanistischen Gymnasiums steht, Unterstrass in jener eine christlichen Freien (Privat-)Schule. Und zusätzlich existieren Strukturen, die zu einer völlig unterschiedlichen Alltags- resp. Schulerfahrung führen: Die Schülerinnen der Töchterschule gehen jeden Tag von der Schule in der Stadt nach Hause, während die Seminaristen in Unterstrass in ihrer Mehrheit im zugehörigen Konvikt essen, schlafen und ihre Freizeit verbringen. Die Seminargemeinschaft ist damit ein viel wesentlicherer Teil des Lebens in Unterstrass als an der Töchterschule.

Nicht zuletzt unterscheiden sich die beiden Institutionen auch bezüglich Form und Struktur ihrer Publikationen. Die offiziellen Jahresberichte, in denen

76 Vgl. Fowler 2010, S. 3f. Gleichzeitig notiert Fowler, dass die Reichweite der Erinnerbarkeit in Nachrufen, was Geschlecht, Klasse oder Ethnizität betrifft, sich in den letzten 100 Jahren extrem vergrössert hat.

77 Zur Frage von Geschlecht und Bildung ist wesentlich, dass im 19. und beginnenden 20. Jahrhundert nur die Mädchenbildung geschlechtsspezifisch fundiert und legitimiert werden musste. Die Knabenbildung musste dies aufgrund der universalistischen Cleichsetzung des Mannes mit dem allgemein Menschlichen nicht. Die höhere Mädchenbildung bezog sich im politischen Kampf um Legitimität relativ erfolgreich auf das Ideal der »geistigen Mütterlichkeit«, wie Juliane Jacobi (1990) für Deutschland gezeigt hat. Damit ist die doppelte Ausrichtung der Mädchenbildung auf Beruf und Mutterrolle gemeint. Beatrix Mesmer (1988) spricht in diesem Zusammenhang »Vom >doppelten Cebrauchswert der Frau«. 
üblicherweise die Nachrufe an der Töchterschule veröffentlicht werden, haben im Vergleich zu jenen aus Unterstrass eine viel strengere Form. Mit der Zeit wird an der Töchterschule die kurze Erwähnung in den Personalia zugunsten von einzelnen längeren Nachrufen, die dem Jahresbericht nachgestellt werden, aufgegeben. Hieraus lässt sich die These aufstellen, dass die Praxis, umfassende Nachrufe zu publizieren, ganz generell erst in den ersten Jahrzehnten des 20 . Jahrhunderts allmählich Fahrt aufnahm. Diese These deckt sich mit dem oben angesprochenen Befund der Soziologin Bridget Fowler, die das Entstehen der Kategorie des Nachrufs in grossen Englischen Tageszeitungen wie The Times auf das Ende des 19. Jahrhunderts ansetzt. ${ }^{78}$ In Unterstrass wiederum scheint sich die Praxis des Nachrufens etwas früher etabliert zu haben - wohl, weil sie aufgrund ihrer stärkeren evangelisch-theologischen Fundierung mit der Praxis der Leichenrede vertrauter waren. ${ }^{79}$

\section{Von der Erinnerung des Individuums zur Reproduktion der Seminargemeinschaft}

Nachrufe als (bildungs-)historisches Quellenmaterial $\mathrm{zu}$ verwenden, ist m.W. nicht sehr verbreitet. Jedoch hat bspw. die Soziologie auf Nachrufe als empirisches Material zurückgegriffen. Bourdieu, der selbst gerne hin und wieder Nachrufe verfasste, fundierte seine Studie La noblesse d'état mit der Analyse von Nachrufen aus dem Kontext französischer Bildungsinstitutionen, genauer des ENS. ${ }^{80}$ Sein Interesse galt der Frage, wie Schulen zur Reproduktion sozialer Unterschiede beitragen..$^{81}$ In Anlehnung daran stehen im Folgenden die Biografien im Vordergrund, die die Nachrufe von den verstorbenen Lehrerinnen und Lehrern zeichnen. Vor allem aber spiegelt das Quellenmaterial auch die mit dem Lehrberuf verbundenen Werte und Idealvorstellungen. "The obituaries, [Bourdieu] suggests, reveal with great clarity the occupational ethics of the academic and teaching profession. ${ }^{82}$ Gerade wenn wir Nekrologe als Erinnerungspraxis und als Teil eines Gefüges von Erinnerungspraktiken in dem spezifischen Kontext der Institution begreifen, ist es wichtig, auf die darin transportierten Werte und Ideale zu schauen. Denn die Inhalte der Nekrologe werden von den Hinterbliebenen wahrgenommen - indem sie individuell zu Hause im Seminarblatt gelesen werden und noch mehr, wenn Ansprachen bei Abdankungsfeiern in Kirche oder Krematorium gehalten werden.

78 Fowler 2007, S. 6.

79 Einige der Seminardirektoren, z.B. Jakob Gut (1897-1910), waren Pfarrer.

80 Fowler 2007, S. 63.

81 Vgl. Papilloud 2003, S. 75.

82 Fowler 2007, S. 63. 
Dazu eignet sich das umfangreiche Material aus Unterstrass. Die relativ grosse Zahl der gefundenen Nachrufe, insbesondere jene aus dem Seminarblatt, macht sie in hohem Masse vergleichbar. Auf diese Nachrufe auf ehemalige »Untersträssler« möchte ich mich im Folgenden hauptsächlich konzentrieren. ${ }^{83}$

Dabei sind Nachrufe eine schwierige Quelle, da sie stark von Floskeln geprägt sind. Von Dr. Hans Steiner, dem 1939 plötzlich verstorbenen Naturwissenschaftslehrer, heisst es: „Er hat aber seine Eigenart nicht selbstgefällig gepflegt, sondern als Mensch und Christ in den Dienst unserer Schule gestellt, der seine ganze Arbeitskraft - fast ohne Nebenbeschäftigung - gehört hat. ${ }^{84}$ Der Lehrer, dem Schule und Beruf alles sind, ist im Übrigen ein in Nachrufen besonders gerne gesehener Charakter - und deswegen wohl als Topos zu betrachten. Daneben kommen aber auch durchaus überraschende Elemente in den Nachrufen zum Tragen, wie die folgende Analyse zeigen wird.

Welche zentralen Charakteristiken und Ideale rufen die Nachrufe aus Unterstrass auf? Es gibt eine Reihe von (positiven) Werten, die wohl in fast jedem Nachruf erwähnt werden: Treue, Gewissenhaftigkeit, Pflichtbewusstsein, Arbeitsamkeit, Bescheidenheit. Diese entsprechen erstaunlich genau den in der Unterstrasser Hausordnung aufgelisteten pädagogischen Tugenden. ${ }^{85}$ Nun gehört es natürlich in besonderer Weise zur Textgattung des Nachrufs, positive Eigenschaften der Verstorbenen herauszustreichen - de mortuis nihil nisi bene. Ebenso denkbar ist dies bei der oben erwähnten »Eigenart « des Charakters, der insbesondere männliche Lehrer des Öfteren eher auszuzeichnen statt $\mathrm{zu}$ disqualifizieren scheint. Solche Eigenarten werden in Nachrufen teilweise liebevoll nachgezeichnet. Mitunter dienen dazu Schilderungen von spezifischen Situationen im Klassenzimmer, die den verstorbenen Lehrer besonders lebendig wirken lassen. Zum (erwartbaren) 'geborenen Lehrer kommt also in der Nachrufpraxis der sindividuelle Lehrer noch der >verkannte Lehrer<, der, eher streng, vielleicht schroff und manchmal etwas trocken, einen geradlinigen Unterricht führte und den seine Schüler erst später zu schätzen lernten. Diesen Charakter finden wir deshalb besonders oft bei den Seminarlehrern, werden doch seine Schüler später selber Lehrer.

83 Das meist drei- bis viermal im Jahr erscheinende Seminarblatt umfasste 1905-1950 229 als Nachruf zu klassifizierende Einträge. Davon wurden in die Analyse einbezogen: 1. Einträge zu all jenen Personen, die auch im Jahresbericht oder in weiterem Archivmaterial erinnert werden, also eine relativ kleine Gruppe sprägender Figuren; 2. Die restlichen Einträge wurden nach Jahrzehnten durch Abzählen ausgewählt, was einer möglichst regelmässigen Verteilung sowie ihrer mit den Jahrzehnten zunehmenden Häufung Rechnung tragen soll (1905-1920 je 2, 1921-1930 je 3 und 1931-1950 je 4).

84 Evangelisches Lehrerseminar Zürich, 63. Bericht, 1938/39, S. $22 f$.

85 Vgl. Grube/De Vincenti 2016, S. 105. Dies sind jedoch typische Tugenden, die auch in vielen anderen Seminar- und Schulordnungen enthalten sein können. 
Weniger zu erwarten ist die vereinzelt geäusserte Kritik an Verstorbenen. Dr. Christian Beyel, ein ehemaliger Hochschuldozent und Mitglied des Seminarvorstands in Unterstrass, sei zwar ein Theoretiker gewesen, er wird aber für sein vielseitiges, immer verlässliches Engagement in christlich-konservativen Kreisen gelobt. Von Seminarlehrer Raillard werden »Fehler und Eigenarten « erwähnt. ${ }^{86}$ Anderswo heisst es, er sei ein »geschätzter Lehrer« gewesen, und zwar, obwohl er "Schwung und Begeisterung« völlig habe vermissen lassen. "Seine Schüler aber merkten, dass er etwas besaß, das mehr ist als hinreißende Kraft. Es war jene Vereinigung von Strenge und Liebe, die auch ihm nichts Selbstverständliches war, sondern vielmehr die Frucht seines Glaubens. ${ }^{87}$ So versöhnt immer der Glaube die Lehrer und Lehrerinnen in Unterstrass mit der (christlichen) Gemeinschaft.

Auch negative Charaktereigenschaften werden in Nachrufen erinnert. Von einem 1945 verstorbenen ehemaligen Seminaristen schreibt der langjährige Rektor Zeller in einem sehr persönlich anmutenden Nachruf, er sei ein »eigenartiger Mensch" gewesen; zwar intellektuell begabt, aber unbeholfen und verkrampft, habe er nie den Zugang zu seinen Schülern finden können. Zeller beschreibt ein schwieriges, schlussendlich nicht eigentlich gelungenes Leben. Fast erscheint der Nachruf als eine Mahnung an die Hinterbliebenen. Aber trotzdem: Auch diesen >Untersträssler< erlöst Gottes Güte am Ende.

Zentral erscheint mir hier, dass Zeller erwähnt, der Verstorbene habe sehr viele verschiedene Stellen innegehabt. Er wird als Lehrer beschrieben, der seine ,Wirkungsstätte<, wo er seine Begabungen ausleben konnte, nie fand. ${ }^{88}$ Ein wichtiger Bestandteil eines gelungenen Lehrerlebens scheint es nämlich gewesen $\mathrm{zu}$ sein, jene Stelle zu finden, an der man länger bleibt und/oder sich seinen Neigungen entsprechend entfalten kann. Dies entspricht dem sindividuellen Lehrertypus, der gleichzeitig der am häufigsten gezeichnete Charaktertypus in den analysierten Nachrufen ist. So scheint es, trotz unvermeidlicher Topoi, gerade die Aufgabe des modernen Nachrufs gewesen zu sein, den individuellen Charakter der Verstorbenen möglichst adäquat zu beschreiben, Stärken wie auch Schwächen zu erwähnen, um die hinterbliebene Gemeinschaft mit ihm zu versöhnen.

Eine Figur, die in den Nachrufen aus Unterstrass immer wieder auftaucht, ist die des ersten Seminardirektors Heinrich Bachofner. Er leitete die Anstalt seit ihrer Gründung 1869 bis zu seinem Tod 1897. Bis weit über seinen Tod hinaus bezeugen die Nachrufe auf seine ehemaligen Schüler die absolute Verehrung des >Gründungsvaters` am Seminar Unterstrass. Zu Seminarlehrer Süsli heisst es: »Die christlich ausgeprägte Persönlichkeit und der Unterricht des geliebten

86 Seminarblatt aus dem Weißen Kreuz, Nr. 43, Dezember 1929, S. 9.

87 Evangelisches Lehrerseminar Zürich, 53. Bericht, 1928/29, S. 17.

88 Seminarblatt aus dem Evangelischen Seminar Zürich-Unterstrass, Nr. 33, Mai 1945, S. $75 f$. 
Direktors Heinrich Bachofner blieben ihm zeitlebens ein leuchtendes Vorbild. «" ${ }^{89}$ Mit der Erinnerung der Ehemaligen wird also gleichzeitig immer Bachofner-Erinnerung betrieben. Auch seine Ideale gehen nicht vergessen: Rudolf Oberholzer, Bachofner-Schüler und Primarlehrer, sei dem »Bachofnerschen Ideal« des Dorflehrers besonders nahegekommen, der "von der Liebe und Achtung seiner Dörfler getragen, seines Amtes waltet, an Freud und Leid seiner Dorfgenossen Anteil nimmt, allmählich fürs ganze Dorf ein Segen wird und dabei von Herzen gern auf Glanz und Schimmer verzichtet. ${ }^{90}$ Diese Verehrung und fortlaufende Erinnerung Bachofners gleicht einer Mythenbildung. Ein Kennzeichen der Mythenproduktion ist die zyklische, wiederholte Erinnerung, etwa an Jahrestagen. ${ }^{91}$ Auch Bachofner wird - neben der ständig aufscheinenden Erinnerung in Nachrufen seiner Schüler - zum zehnten Todestag erneut gewürdigt. ${ }^{92}$ Die Praxis des Nachrufens gerinnt so auch zur Mythologisierung der eigenen Institution.

Nicht nur Mythen, sondern auch die Identität einer Institution wird über Nachrufe sgemacht und damit Gemeinschaft hergestellt. Wesentlicher Teil dieser Praxis ist, wie wir gesehen haben, die Zeichnung von Lehreridealen. Dazu gehört auch die Beschreibung einer (erfolgreichen) Lehrerbiografie. ${ }^{93}$ Nekrologe geben nicht nur der Historikerin wichtige Einblicke in verschiedene Biografien auch die zahlreichen Leserinnen und Leser des Seminarblatts lesen so über das Gelingen (und manchmal auch das Scheitern) des Lebens aus dem ihnen nahestehenden Kreis der christlichen Lehrerbildung. Wir lesen von Biografien klassischer bürgerlicher Männlichkeit aus dem christlich-konservativen Milieu, ${ }^{94}$ aber auch von sAufsteigern v vom einfachen Bauernsohn zum Lehrer. Obschon die Nekrologe teilweise sehr verschiedene Lebensläufe zeichnen, vermitteln sie doch ein eher einseitiges Bild. Sie sind Trägerinnen vorherrschender Ideale bezüglich Geschlecht und Klasse und perpetuieren damit die Identitätskonstruktionen der Institutionen und Gemeinschaften, aus denen sie hervorgehen. Gleichzeitig transzendieren sie diese Ideale durch die Erzählung individueller, bisweilen ab-

89 Seminarblatt aus dem Evangelischen Seminar Zürich-Unterstrass, Nr. 7, November 1938, S. 11. Diverse ähnliche Formulierungen sind zu finden.

Seminarblatt aus dem Weißen Kreuz, Nr. 21, Dezember 1912, S. 5.

Vgl. Stollberg-Rilinger 2013, S. 76.

Seminarblatt aus dem Weißen Kreuz, Nr. 7, Juli 1907, S. 15-18. Sogar Bachofners Grabstein wird, als der Friedhof aufgehoben wird, durch die Verantwortlichen in Unterstrass gerettet und im Seminargarten aufgestellt. Siehe dazu Seminarblatt aus dem Weißen Kreuz, Nr. 37, November 1925, S. 4 f.

93 Tersch (2007, S. 204) weist darauf hin, dass die Schilderung der Berufsbiografie heute selbstverständlich zur Totenrede gehört, während sie im 19. Jahrhundert oft explizit weggelassen wurde.

94 Exemplarisch: Die Nachrufe auf Jakob Muggli und J.F. Raillard im Seminarblatt Nr. 42, Februar 1929, u. Nr. 43, Dezember 1929. 
weichender Lebensläufe. Es ist ein Spannungsfeld, das Nachrufe überbrücken müssen: Erinnerung vs. gelebtes Leben, Ideal vs. Individualität. Charakteristisch für alle Nachrufe ist ihr Fokus auf das Individuum bzw. das individuelle Leben, das aber gleichzeitig immer unter dem Gesichtspunkt eines Lebens in und für die Institution erzählt wird. Das Individuum wird also im Verlaufe des Textes zuerst skizziert und anschliessend quasi >verallgemeinert $<$ und gleichsam (rückwirkend) der Anstalt seinverleibt،. An der Töchterschule ist die Zeichnung des individuellen Charakters des oder der Verstorbenen stärker ausgeprägt. Diesem Charakter wird zum Schluss des Nachrufs in Bezug auf das Lehrerkollegium oder die Schule als Ganzes ein Platz zugewiesen. In Unterstrass geschieht dies in ähnlicher Weise, aber weniger ausgeprägt: Hier ist es letztlich der Mensch als Christ, der die Verbindung zum Seminar und zur Seminargemeinde schafft.

Diese Aussöhnung von Widersprüchlichem unterscheidet die Nachrufe von anderen Quellen. Briefe zwischen dem Direktor und ehemaligen Seminaristen aus dem Seminararchiv Unterstrass vermitteln ein konfliktäres Bild: vielfältige, gebrochene Biografien wie auch Menschen. Dieses Bild ist wiederum nur fragmentarisch, da die ehemaligen Schüler vor allem dann dem Seminardirektor schreiben, wenn sie Probleme haben. Doch zeigen gerade diese Briefe von und an Direktor Zeller noch einmal deutlich, wie wichtig das persönliche Netzwerk am Seminar Unterstrass war. Dass es damit auch eine Familienfunktion erfüllte, soll im nächsten Abschnitt thematisiert werden.

\section{Seminarfamilie als sSpezialfall der Vergemeinschaftung in Unterstrass}

Gemeinschaft leben heisst am Evangelischen Seminar Unterstrass im 19. und zu Beginn des 20. Jahrhunderts auch, Familie sein, oder genauer: wie eine Familie sein. Wie oben gezeigt, bemühen Nachrufe Familienmetaphern, streichen verwandtschaftliche Verbindungen heraus und loben besondere Nähe zum Seminar. Das Seminar nimmt in dieser Hinsicht eine gesonderte Stellung ein. Hier beginnt sogar der Rechnungsteil des Jahresberichts mit einem Familiengleichnis: Gleich dem »mit Kindern gesegneten Familienvater«, der wegen Geldsorgen schlaflose Nächte hat, um seinen »begabten Söhnen« ein Studium zu ermöglichen, sei es dem Vorstand des Seminars oft zumute, wenn er die Rechnung präsentieren müsse, schreibt der Präsident des Seminarvereins 1925. ${ }^{95}$ Überhaupt wird in den Jahresberichten aus Unterstrass des Öfteren mit einer strengen Form gebrochen: Im selben Jahr lässt Direktor Konrad Zeller das Jahr in der Form von Briefen an einen imaginären Freund Revue passieren. Dies, um »Einblick [zu] gewähren in

95 Evangelisches Lehrerseminar Zürich, 49. Bericht, 1924/25, S. 27. 
das Seminarleben«, und zwar "möglichst wahrheitsgetreu«. ${ }^{96}$ Hier schildert er folgende Szene:

Vorgestern war die Hälfte der dritten Klasse nach dem Nachtessen bei uns in der Wohnstube. Ich veranstalte mit Frau Rychner zusammen, wenn irgend möglich jede Woche, einen solchen Abend für je etwa zehn Schüler der beiden oberen Klassen. Frau Rychner sorgt mit Tee und etwas Cebäck für das körperliche Wohl, und ich muss für die geistige Nahrung aufkommen. ${ }^{97}$

Er müsse ihnen einerseits Autorität sein, andererseits wolle er »als Hausvater mitten unter ihnen sein ${ }^{98}{ }^{98}$ Er fährt fort:

Zugleich hoffe ich den Seminaristen damit ein Stück Familie geben zu können. Frau Rychner ist ja auch dabei, wenn wir beisammen sitzen, und das ist sehr wichtig, denn die Mutter macht doch vor allem die Familie, und deshalb darf die Hausmutter nicht fehlen, wenn die Schüler aus dem Anstaltsbetrieb für einige Zeit in einen Familienkreis treten sollen; und umgekehrt! Weil sie dabei ist, so sind diese gemütlichen Abende mehr als unterhaltliche Zusammenkünfte, sie sind eben, wie ich hoffe, ein Stück Familie.99

Die Anstalt könne und dürfe die Familie jedoch nicht ganz ersetzen, solle jedoch

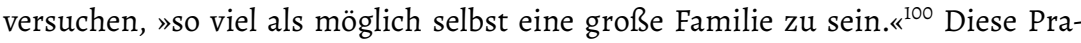
xis ist angelehnt an Pestalozzis Wohnstubenpädagogik, die in Unterstrass eine spezifische Tradition hat. In den ersten Jahren des Seminars hat Direktor Bachofner die Schüler in seinem Wohnzimmer unterrichtet. ${ }^{101}$ Der "Hausvater « und die »Hausmutter" haben sich, wie das Beispiel oben zeigt, bis ins 20. Jahrhundert tradiert. Da Zeller zu diesem Zeitpunkt noch unverheiratet war, übernimmt hier eine Angestellte, Mina Rychner, die Arbeit der Hausmutter, die andernfalls immer der Ehefrau des Direktors zufiel. Als Zeller heiratet, will seine Frau diese Rolle nicht übernehmen, und man ist froh, bleibt dafür Frau Rychner »als Hausmutter ${ }^{102}$ im Haus.

Hier entsteht $>$ Familie als ebenso vorgestellte wie gelebte Praxis einer Anstaltsgemeinschaft. Diese Praxis gleicht dem patriarchalischen Modell der vor-

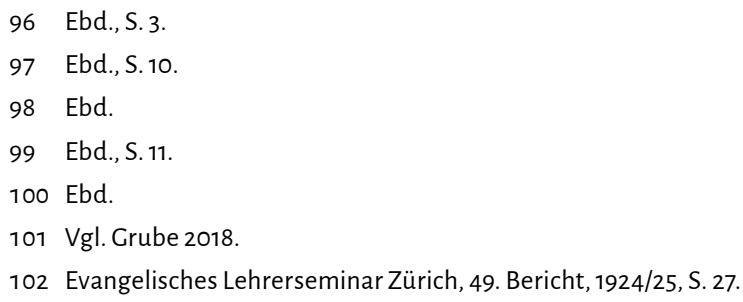


modernen Familie als Arbeitsgemeinschaft, charakterisiert durch »Hausvater« und »Hausmutter«, die dem Familienverband vorstehen. Durch Praktiken des gemeinsamen Essens und Beisammensitzens wird das familiale Gefüge hergestellt bzw. erhalten. Gleichzeitig scheint es notwendig gewesen zu sein, dieses Arrangement gegen aussen von der >richtigen Familie abzugrenzen. Direktor Zeller erhofft sich eine verbindende und schliesslich pädagogische Wirkung der oben beschriebenen Zusammenkünfte. Dies erinnert an Pestalozzis Roman Lienhard und Gertrud, wo der Unterricht mit der Unterweisung der Mutter im Wohnzimmer beginnt, die der Lehrer in der Schule kopieren und fortführen solle. ${ }^{103}$

Seltsam unbelichtet bleibt, was im obigen Zitat Zellers mit `Familieく, insbesondere der Herkunftsfamilie, gemeint ist. Wir befinden uns mit den ersten Jahrzehnten des 20. Jahrhunderts in einer Zeit, die gemeinhin als die Zeit der Blüte und der Durchsetzung des Ideals der bürgerlichen Kleinfamilie gefasst wird. ${ }^{104}$ Gleichzeitig wird die Familie immer wieder als bedroht wahrgenommen durch verschiedenste >Krisen` der Moderne: Wahlweise werden dafür Individualisierungstendenzen, Verarmung, Alkoholismus, Geschlechtskrankheiten oder allgemeiner ein »Sittenzerfall« verantwortlich gemacht. In den 1920er- und 1930er-Jahren werden in der Schweiz verschiedenste familienpolitische Modelle diskutiert, wie der Staat Unterstützungsleistungen für Familien ausrichten könne. ${ }^{105}$ Unter anderem erhält hier die Vorstellung einer bäuerlich-vorindustriellen Grossfamilie als Idealtypus einer vormals funktionierenden, sozialintegrativen Gemeinschaft wieder Auftrieb.

Dies sind nur einige Schlaglichter; sie sollen jedoch zeigen, wie sehr in den Nachrufen und seminaristischen Selbstdarstellungen (Jahresberichten) Familie einer Chimäre gleicht, die sowohl >moderneく Lebensweisen wie auch verklärte, scheinbar vormoderne familiale Lebensweisen enthält. ${ }^{106}$ Schaut man jedoch auf die oben dargestellte Praxis einer Seminar- bzw. Anstaltsfamilie, sind die Parallelen zur vormodernen Arbeitsgemeinschaft, die durch das gemeinsame Wohnen und Arbeiten verschiedener, auch familienfremder Mitglieder charakterisiert ist, unverkennbar. Unterstrass betreibt zu dieser Zeit immer noch ein Konvikt, das die Hausmutter leitet. Der Direktor und allenfalls seine Ehefrau oder eine separate Hausmutter (wie im Falle der Frau Rychner) oder ein Hausverwalter wohnen im Seminargebäude. Unterstrass ist in dieser Hinsicht kein sSpezialfalk: Die Familie als Organisationsform ist im Anstaltswesen des 19. und beginnenden 20. Jahrhunderts sehr verbreitet. Im Erziehungs- und Armenwesen und vor allem in der

103 Vgl. dazu und zu Pestalozzis Familienbild Horlacher 2015.

104 Vgl. bspw. Gugerli 1991.

105 Vgl. u.a. Studer 1997; Wecker/Studer/Sutter 2001.

106 Zum Mythos Großfamilie als Projektion restaurativer Sozialutopien vgl. Mesmer 1991, S. 35f.; zur historisch-demographischen Entmystifizierung der Großfamilie Mitterauer 1984. 
Krankenpflege ${ }^{107}$ und der Psychiatrie ist die »Anstaltsfamilie« als Organisationsform bekannt. In Deutschland hatte erstmals der Psychiater Christian Friedrich Wilhelm Roller 1842 im badischen Illenau eine Anstalt in dieser Form geführt. Ihm folgte im letzten Drittel des Jahrhunderts u.a. Heinrich Cramer, der die Irrenheilanstalt Marburg nach dem Modell der Anstaltsfamilie organisierte: Er selbst lebte mit seiner Familie auf dem Anstaltsgelände, das Pflegepersonal lebte rund um die Uhr mit den Insass/-innen zusammen und bestritt mit ihnen zusammen den Alltag. Die über das Gelände der Anstalt verteilten verschiedenen Einzelgebäude wurden »Familienhäuser « genannt. ${ }^{108}$ Insgesamt ging es darum, die Anstalt und die psychiatrische Pflege zu reformieren. ${ }^{109}$ Nach Karen Nolte hängt dieses Familienmodell in Anstalten gerade mit dem Aufkommen der bürgerlichen Kernfamilie zusammen, in deren Kompetenzen die Anstaltspsychiatrie eben empfindlich eingriff:

Die in der Irrenheilanstalt inszenierte Familie ist [...] eine Reaktion auf ein Crunddilemma, mit dem die aus dem gehobenen Bürgertum stammenden >Irrenärzteく konfrontiert waren. Die bürgerliche Kleinfamilie wurde im Sinne eines Allgemeingültigkeit beanspruchenden Konzepts als der private Schutzraum schlechthin konstruiert, in dessen intimer Atmosphäre die Familienmitglieder insbesondere in emotionaler Hinsicht reproduziert werden sollten. Andererseits griffen Zwangseinweisungen von psychisch Kranken in die modernen Irrenanstalten empfindlich in diesen intimen Schutzraum ein. ${ }^{110}$

Indem die Anstalt der Familie eine entsprechende Kompetenz abspricht, muss sie eine überzeugende Alternative bieten: »Kern der Anstaltsbehandlung wurde eben wegen der eigentlichen Familienfeindlichkeit der Anstaltspsychiatrie [...] die Inszenierung der Anstaltsgemeinschaft aus Patient/-innen, Wärter/-innen und den Ärzten als >Anstaltsfamilie`. «"11 $̈$ Ähnlich kann auch über das Verhältnis von Schule und Familie nachgedacht werden, denn wenn auch die Schule wohl weniger stark

107 Zum Familienbild in der religiös geprägten Krankenpflege Büttner 2009. Sie beschreibt dies in Zusammenhang mit der Herausforderung, die der Tod einer Mitschwester innerhalb der Schwesternschaft bedeutete, »ersetzte doch das nach dem patriarchalischen Eltern-TöchterPrinzip organisierte Mutterhaus die eigene Familie« (ebd., S. 146).

108 Nolte 2003, S. 43ff., hier S. 45.

109 Ähnliche Ansätze sind aber bereits aus dem 18. und beginnenden 19. Jahrhundert aus England (Tuke, das Quäker-Umfeld in York mit ihrem Konzept des »Retreats«, Conollys »No-Restraint«System) und Frankreich (Pinel, Esquirol) bekannt, auf die sich auch die deutschen Psychiater bezogen. Vgl. Nolte 2003, S. 29ff. und auch Dörner 1999, S. $82 \mathrm{ff}$.

110 Nolte 2003, S. 43.

111 Ebd., S. 44. 
in Familien eingriff, stand sie gleichwohl in der Erziehung mit der (bürgerlichen) Familie tendenziell in Konkurrenz. ${ }^{112}$

Unterstrass ist mit der Anrufung der »Seminarfamilie« in den Jahresberichten und der Betonung der "Nähe« der Verstorbenen zum Seminar in den Nachrufen bezüglich der Stärke und der allgegenwärtigen Verbreitung dieses Modells sicher ein Spezialfall. Als alltägliche Praxis aber hat das gemeinsame Leben in der Anstalt nicht zuletzt ein pädagogisches Ziel. Bittner/Kessl sprechen von einer »Familiarisierung des Pädagogischen«, wenn sich pädagogische Institutionen die Herkunftsfamilie als Modell und Ideal aneignen und deren Praktiken in den pädagogischen Alltag überführen. ${ }^{113}$ Grube/De Vincenti haben gezeigt, dass in Unterstrass pädagogisches Wissen vor allem über das Prinzip der Tradierung innerhalb der »Seminarfamilie«, von erfahrenen Seminarlehrern auf die angehenden Primarlehrer, sowie durch die allägliche Integration in diese Seminarfamilie weitergegeben wurde. ${ }^{114}$ Auch für das kantonale Seminar Küsnacht, das nur bis 1875 ein Konvikt betrieb, ${ }^{115}$ sind familienähnliche Gemeinschaftspraktiken ausgewiesen. ${ }^{116}$ Dort sowie an der Töchterschule lebten ebenfalls die Hauswartehepaare auf dem Schulgelände. ${ }^{117}$ In ihrer Rhetorik orientiert sich die Töchterschule aber nicht an der Anstaltsfamilie, sondern an der abstrakteren "Gemeinschaft« oder einem Gemeinschaftsgefühl, das es an der Schule zu erhalten und zu pflegen gelte. ${ }^{118}$ Damit zeigt sich noch einmal abschliessend, was in der Analyse wiederholt deutlich geworden ist: dass die Töchterschule als städtisches Gymnasium auf andere institu-

112 Grube/De Vincenti (2016, S. 100) sprechen vom Konflikt zwischen der shäuslichen Erziehung (basierend auf Instinkt, Tradition) und der öffentlichen Erziehung (basierend auf Theorie, Pädagogik). Zum Verhältnis von Schule und Familie im historischen Überblick, und wie Familiarisierung sich dabei zu einer Art Qualitätsmerkmal für Schule entwickelt hat, vgl. Reh 2009; Scholz/Reh 2009. Zum Familienbegriff in pädagogischer Praxis und Theorie notiert Herrmann (2009, S. 156f.): »Im Zuge seiner Karriere als Präfixoid (Familienalumnat, Familienprinzip etc.) wurde der Familienbegriff zugleich auf wenige formale Merkmale (begrenzte Schülerzahl, Inspektor, Hausdame) reduziert und im Zuge seiner Inflationierung anschlussfähig an den reformpädagogisch besetzten Begriff der >Gemeinschaft<-bis hin zur Austauschbarkeit.«

113 Bittner/Kessl 2019, S. 291.

114 Grube/De Vincenti 2016.

115 Grob 1982, S. 42.

116 Vgl. Grube/De Vincenti 2016, S. 96.

117 Zum Hauswartehepaar sowie Hauswartpraktiken vgl. den Artikel von Adrian Juen in diesem Band.

118 So schreibt Enderlin als Rektor der Töchterschule vom »Problem der Erhaltung der Gemeinschaft in einer Schule, deren Crösse das übliche Mass überschritten hat, war naturgemäss das Leitmotiv fast aller Bestrebungen im inneren Schulleben. [...] Maibummel, Schulreise, Wettspiele, Uetlibergbummel taten ihre altbewährten gemeinschaftsfördernden Dienste. Dazu kam die Wiederbelebung der Einrichtungen von Skikolonien und ferner eine neue Veranstaltung: der Skitag.« (Jahresbericht der Töchterschule der Stadt Zürich, Schuljahr 1930/31, S. 24f.). 
tionelle Voraussetzungen als das Evangelische Seminar Unterstrass gründet, was sich auch in unterschiedlichen Gedenk- und Vergemeinschaftspraktiken zeigt.

\section{Schluss}

Die praxeologische Lesart meiner Quellen hat zum einen Darstellungs- und Schreibpraktiken im institutionellen Totengedenken aufgeschlüsselt. Zum anderen standen im Zentrum der Analyse Trauer- und Erinnerungspraktiken, die sich mit dem Nachruf verknüpfen, die er hervorbringt und zu denen er selbst gezählt werden muss. Dabei ging es mir weniger um eine detaillierte Beschreibung von singulären Praktiken als um den Versuch einer Lektüre des historischen Geschehens durch eine praxeologische $>$ Brille $\prec .{ }^{119}$ Die Praxeologie als Perspektive lenkt den Blick konsequent auf die Frage, was in den Quellen hergestellt, "gemacht" wird. In meinem Beispiel wäre dies die Herstellung von Gemeinschaft über Erinnerungs- und Trauerpraktiken innerhalb des Seminars, aber auch über den Jahresbericht allgemein, der gleichsam als Praxis zur Herstellung von Gemeinschaft, aber auch Exklusivität betrachtet werden kann.

Ein konsequenterer Blick auf Praktiken würde auch für eine allgemeinere Geschichte des Todes gewinnbringend sein: Statt die Kulturgeschichte des Todes/ der Trauer würde dieser evtl. andere Phänomene und Genealogien aufschlüsseln. So gälte es noch zu klären, ob die Funktion, Gemeinschaft zu bekräftigen, eine genuin moderne Erinnerungspraxis ausmacht oder sie mit einer vormodernen verbindet. Wie unterschiedlich diese Gemeinschaft zudem ausfallen kann, hat die komparativ angelegte Analyse dieses Artikels gezeigt. Zudem verfehlt es eine Kulturgeschichte des Todes, die eine Individualisierung und Privatisierung der Trauerkultur in der Moderne diagnostiziert, darzustellen, was im Angesicht des Todes auch noch geschieht: nämlich eine Anrufung und Bestärkung der Gemeinschaft im Trauern und Erinnern, und zwar nicht nur im Kontext der Nation, wie im Falle von Staatsbegräbnissen oder Prominenten, sondern auch im Bezug auf Institutionen.

Damit ist eine praxeologisch gewendete Geschichte des Todes, der Erinnerung und der Gemeinschaft am Seminar auch ein Beitrag zu einer radikalen Historisierung von historischen Gegenständen und knüpft damit an einen Anspruch an, den die Historische Anthropologie seit den 1990er-Jahren verfolgt. ${ }^{120}$ In Bezug auf meinen Beitrag heisst radikale Historisierung einerseits die Historisierung von scheinbar Ahistorischem (Tod, Gemeinschaft, Familie). Andererseits kann mit-

119 Vgl. zu diesem »Forschungsblick auf die Vergangenheit durch eine spezifische Optik« Haasis/ Rieske 2015, S. 24.

120 Arni 2018. 
tels einer praxeologischen Perspektive nicht nur gefragt werden, welche Praktiken Dokumente hervorbringen, sondern auch, inwiefern diese Dokumente selbst Elemente im Geschehen sind. Anders formuliert: Es gäbe kein Handeln, wären die Nachrufe nicht da, d.h. würden vorgetragen, gedruckt, verteilt, gelesen, aufbewahrt usw. Sie werden damit zu wesentlichen Elementen im Handlungsgefüge, im historischen Geschehen - zu Medien der Vergemeinschaftung. Sie werden zu Akteuren in diesem Prozess wie auch in dessen historiografischer Aufschlüsselung.

Die Nachrufe aus Unterstrass betonen die Nähe und Familiarität der verstorbenen Personen und lassen damit ein eng geknüpftes Netz der Gemeinschaft des Seminars Unterstrass vor den Augen der Hinterbliebenen wieder aufleben und tragen dieses Netz als Wunsch in die Zukunft der Institution. Wiederholt hat sich eine ausgeprägte Erinnerungspraxis in Unterstrass herausgeschält. Neben der fast akribischen Erinnerung aller verstorbenen Ehemaligen und Zugewandten (es wurde sogar Buch geführt!) stehen weitere Praktiken der Herstellung von Gemeinschaft: das gemeinsame Essen, das Leben als »Seminarfamilie« oder die Briefe zwischen dem Direktor und Seminaristen und Seminaristinnen. Im Vergleich dazu hat die städtische Töchterschule ein weniger grosses - oder langes - institutionelles Gedächtnis. Hier werden nur einzelne Verstorbene in den schuleigenen Publikationen erinnert. Überlieferte Grabreden des Rektors zeigen jedoch, wie auch hier der Tod im Kontext der Schulgemeinschaft präsent war und der Rektor durch seine Präsenz an Begräbnissen die institutionelle Gemeinschaft aufrechterhalten hat.

Ein Beispiel dafür lieferte die eingangs zitierte Passage aus der Rede bei der Kremation der Schülerin Gret Häcker. Ein wesentlicher Teil von Grabreden bzw. Nachrufen auf Schülerinnen, Lehrer oder Vorstandsmitglieder - die Biografie und Charakterskizze - fehlt hier. Dies hat einerseits mit der Kürze ihres Lebens $\mathrm{zu}$ tun. Andererseits scheint die sonst übliche abschliessende Skizzierung des Charakters aufgrund ihres Selbstmords zu scheitern. Die anschliessende Verallgemeinerung in die Gemeinschaft der Schule gelingt hier nicht. Doch auch - und vielleicht gerade - in diesem Fall schafft der Nachruf Gemeinschaft unter den Lebenden. Nicht zufällig schliesst der Rektor mit den Worten: »Wir sind eine Gemeinschaft Schuldiger und Leidender geworden. Mögen wir uns finden zu einer Gemeinschaft bussfertiger und hilfsbereiter Herzen. ${ }^{121}$

121 Handschriftliche Ergänzung auf dem Durchschlag (SAZ V.H.c.98: 10.2. Traueransprachen, Nekrologe 1932-1963 [I]). 


\section{Quellen und Literatur}

\section{Ungedruckte Quellen}

\section{Stadtarchiv Zürich (SAZ)}

V.H.c.98. 10.2. Ansprachen und Reden 1932-1963, Traueransprachen, Nekrologe 1932-1963 (I-III).

\section{Archiv Unterstrass}

Nachlass von Konrad Zeller. A: Schachtel 4-5: Briefe von ehemaligen Schülern bis 1978.

Seminarverein, Nekrologe. Abt II.B., 1.05.01.

\section{Gedruckte Quellen}

\section{Evangelisches Lehrerseminar Zürich}

Bericht über das Evangelische Seminar Unterstrass. Zürich, 1900-1911.

Bericht. Zürich, 1912-1941.

Jahresbericht. Zürich, 1942-1950.

Seminarblatt aus dem Weißen Kreuz. Zürich, 1905-1937.

Das neue Seminarblatt. Zürich, 1937-1937.

Seminarblatt aus dem Evangelischen Seminar Zürich-Unterstrass. Zürich, 19371950.

\section{Töchterschule der Stadt Zürich}

[Anonym] (1931): † Frl. Sophie Heim. In: Schweizerische Lehrerinnenzeitung 36, H. 2, S. 18-20.

[Anonym] (1933): Nachruf auf Hans Wissler. In: Jahresbericht der Töchterschule der Stadt Zürich, Schuljahr 1932/33, Abteilung I, S. 21 und 41.

[Anonym] (1936): Nachruf auf Leonie Bindschedler. In: Jahresbericht der Töchterschule der Stadt Zürich, Schuljahr 1935/36, S. 30-32.

Benz, Emilie (1919): $\uparrow$ Dr. med. Anna Heer. In: Schweizerische Lehrerinnenzeitung 23, H. 6, S. 118-124.

Eberhard, L. (1912): Frau Emma Coradi-Stahl. In: Schweizerische Lehrerinnenzeitung 16, H. 9, S. 189-193.

Grob, C. (1982): Das Lehrerseminar des Kantons Zürich in Küsnacht. Zur Feier des 50-jährigen Jubiläums der Anstalt. Zürich.

Jahresberichte der Töchterschule der Stadt Zürich. Zürich, 1928-1933.

Schlienger-Schoch, Friedrich (1931): Aus der Geschichte des Evangelischen Schulvereins der Schweiz, 1881-1931. Basel. 


\section{Literatur}

Aka, Christine (1993): Tot und vergessen? Sterbebilder als Zeugnis katholischen Totengedenkens. Detmold.

Arni, Caroline (2018): Nach der Kultur. Anthropologische Potentiale für eine rekursive Geschichtsschreibung. In: Historische Anthropologie 26, H. 2, S. 200223.

Bittner, Martin/Kessl, Fabian (2019): Zur Institutionalisierung des Pädagogischen am Beispiel familiarisierter Vergemeinschaftung. In: Kathrin Berdelmann/ Bettina Fritzsche/Kerstin Rabenstein/Joachim Scholz (Hg.): Transformationen von Schule, Unterricht und Profession. Erträge praxistheoretischer Forschung. Wiesbaden, S. 289-305.

Bodmer, Jean-Pierre (1986): Das Archiv des »Gedenkschriften-Verlages W. Frei«. Separatdruck aus dem Zürcher Taschenbuch auf das Jahr 1987. Zürich, S. 233244.

Bogusz, Tanja (2010): Zur Aktualität von Luc Boltanski. Einleitung in sein Werk. Wiesbaden.

Bronfen, Elisabeth (1992): Over Her Dead Body. Death, Femininity and the Aesthetic. Manchester.

Büttner, Annett (2009): »Herr ist meines Lebens Kraft, vor wem sollte ich mich fürchten?« Die religiöse Deutung des vorzeitigen Todes durch evangelische Diakonissen im 19. Jahrhundert. In: Historical Social Research/Historische Sozialforschung 34, H. 4 (130), S. 133-153.

Crotti, Claudia (2015): Höhere Töchterschule und Lehrerinnenseminar Zürich. Das Seminar als Sprungbrett an die Alma Mater (1878-1905). In: Andreas Hoffmann-Ocon (Hg.): Orte der Lehrerinnen- und Lehrerbildung im Kanton Zürich. Bern, S. 131-143.

Dörner, Klaus (1999): Bürger und Irre. Zur Sozialgeschichte und Wissenschaftssoziologie der Psychiatrie [1969]. 2. Aufl. Hamburg.

Fischer, Norbert (2001a): Geschichte des Todes in der Neuzeit. Erfurt.

Fischer, Norbert (2001b): Zur Geschichte der Trauerkultur in der Neuzeit. Kulturhistorische Skizzen zur Individualisierung, Säkularisierung und Technisierung des Totengedenkens. In: Markwart Herzog (Hg.): Totengedenken und Trauerkultur. Geschichte und Zukunft des Umgangs mit Verstorbenen. Stuttgart, S. 41-57.

Fowler, Bridget (2007): The Obituary as Collective Memory. New York, London.

Freist, Dagmar (2015): Historische Praxeologie als Mikro-Historie. In: Arndt Brendecke (Hg.): Praktiken der Frühen Neuzeit. Akteure, Handlungen, Artefakte. Köln, Weimar, Wien, S. 62-77.

Goetz, Thomas (2008): Poetik des Nachrufs. Zur Kultur der Nekrologie und zur Nachrufszene auf dem Theater. Wien. 
Grube, Norbert (2018): Verortungsversuche von fluiden Bildungsräumen im Evangelischen Lehrerseminar Zürich Unterstrass 1870 bis 1950. Das familiale Leitbild als raumkonstituierender Ordnungsfaktor. In: Historia Scholastica 4, H. 1, S. 17-28.

Grube, Norbert/De Vincenti, Andrea (2016): Pädagogisches Wissen in seinen fachlichen und alltäglichen Ausprägungen. Die Seminare Küsnacht und Unterstrass zwischen 1830 und 1930. In: Andreas Hoffmann-Ocon/Rebekka Horlacher (Hg.): Pädagogik und pädagogisches Wissen. Ambitionen in und Erwartungen an die Ausbildung von Lehrpersonen. Bad Heilbrunn, S. 93-115.

Grube, Norbert/Hoffmann-Ocon, Andreas (2015): Orte der Lehrerinnen- und Lehrerbildung im Kanton Zürich. Überblick auf Dynamiken, Kontroversen und eine spannungsgeladene Vielfalt. In: Andreas Hoffmann-Ocon (Hg.): Orte der Lehrerinnen- und Lehrerbildung im Kanton Zürich. Bern, S. 25-95.

Gugerli, David (1991): Das bürgerliche Familienbild im sozialen Wandel. In: Thomas Fleiner-Gerster/Pierre Gilliand/Kurt Lüscher (Hg.): Familien in der Schweiz. Familles en Suisse. Fribourg, S. 59-74.

Haasis, Lucas/Rieske, Constantin (2015): Historische Praxeologie. Zur Einführung. In: Diess. (Hg.): Historische Praxeologie. Dimensionen vergangenen Handelns. Paderborn, S. 7-54.

Halling, Thorsten (2009): »Plötzlich und für uns alle unfassbar ...«. Der vorzeitige Tod zwischen privater und öffentlicher Erinnerung seit dem Zeitalter der Aufklärung. In: Historical Social Research/Historische Sozialforschung 34, H. 4, S. 231-246.

Halling, Thorsten/Fehlemann, Silke/Vögele, Jörg (2009): Der vorzeitige Tod als Identitäts- und Sinnstiftungsmuster in historischer Perspektive. Einige einführende Überlegungen. In: Historical Social Research/Historische Sozialforschung 34, H. 4, S. 9-19.

Hardegger, Urs (2008): »Bis dass sie wissen, dass sie nichts wissen«. Gründung und Persistenz des Evangelischen Lehrerseminars Zürich. In: Michael Göhlich/Caroline Hopf/Daniel Tröhler (Hg.): Persistenz und Verschwinden. Pädagogische Organisationen im historischen Kontext. Wiesbaden, S. 119-129.

Henseler, Joachim/Reyer, Jürgen (Hg.) (2000): Sozialpädagogik und Gemeinschaft. Historische Beiträge zur Rekonstruktion eines konstitutiven Verhältnisses. Baltmannsweiler.

Herrmann, Ulrich G. (2009): Elternhaus und Schule - Kooperation und Opposition. Zum Wechselverhältnis beider Sozialisationsinstanzen im 19. Jahrhundert. In: Jutta Ecarius/Carola Groppe/Hans Malmede (Hg.): Familie und öffentliche Erziehung. Theoretische Konzeptionen, historische und aktuelle Analysen. Wiesbaden, S. 139-158.

Hillebrandt, Frank (2014): Soziologische Praxistheorien. Eine Einführung. Wiesbaden. 
Horlacher, Rebekka (2015): Die Familie als Keimzelle der Gesellschaft bei Johann Heinrich Pestalozzi. In: Michèle Hofmann/Lukas Boser/Anna Bütikofer/Evelyne Wannack (Hg.): Lehrbuch Pädagogik. Eine Einführung in grundlegende Themenfelder. Bern, S. 113-130.

Horn, Eva (1998): Trauer schreiben. Die Toten im Text der Goethezeit. München.

Hugger, Paul (2002): Meister Tod. Zur Kulturgeschichte des Sterbens in der Schweiz und in Liechtenstein. Zürich.

Hüppi, Hans-Martin (2007): Die Geschichte von »unterstrass.edu« als »Seminar Unterstrass« bzw. »Evangelisches Lehrerseminar/Kindergärtnerinnenseminar Zürich«, online unter www.unterstrass.edu/assets/files/ueber-uns/Ge schichte_von_Unterstrass-170925.pdf (Zugriff: 15.04.2020).

Jacobi, Juliane (1990): »Geistige Mütterlichkeit«. Bildungstheorie oder strategischer Kampfbegriff gegen Männerdominanz im Mädchenschulwesen? In: Die Deutsche Schule. Zeitschrift für Erziehungswissenschaft, Bildungspolitik und pädagogische Praxis, Beiheft, S. 209-224, online unter https://publis hup.uni-potsdam.de/files/3754/1990_Geistige_Muetterlichkeit.pdf (Zugriff: 15.04.2020).

Lenz, Rudolf (Hg.) (1975): Leichenpredigten als Quelle historischer Wissenschaften. (Erstes Marburger Personalschriftensymposium, Forschungsschwerpunkt Leichenpredigten.) Köln, Wien.

Macho, Thomas H. (1987): Todesmetaphern. Zur Logik der Grenzerfahrung. Frankfurt a.M.

Mesmer, Beatrix (1991): Familienformen und gesellschaftliche Strukturen. In: Thomas Fleiner-Gerster/Pierre Gilliand/Kurt Lüscher (Hg.): Familien in der Schweiz/Familles en Suisse. Fribourg, S. 31-57.

Mesmer, Beatrix (1988): Vom »doppelten Gebrauchswert« der Frau - eine Einführung. In: Marie-Louise Barben/Elisabeth Ryter (Hg.): verflixt und zugenäht! Frauenberufsbildung - Frauenerwerbsarbeit 1888-1988: Beiträge zur gleichnamigen Ausstellung im Rahmen des hundertjährigen Jubiläums der Berufs-, Fach- und Fortbildungsschule Bern, Oktober 1988. Zürich, S. 15-21.

Mitterauer, Michael (1984): Der Mythos von der vorindustriellen Großfamilie. In: Ders./Sieder, Reinhard: Vom Patriarchat zur Partnerschaft. Zum Strukturwandel der Familie. 3. Aufl. München, S. 13-37.

Nolte, Karen (2003): Gelebte Hysterie. Erfahrung, Eigensinn und psychiatrische Diskurse im Anstaltsalltag um 1900. Frankfurt a.M.

Oexle, Otto Gerhard (1995): Memoria als Kultur. In: Ders. (Hg.): Memoria als Kultur. Göttingen, S. 9-78.

Papilloud, Christian (2003): Bourdieu lesen. Einführung in eine Soziologie des Unterschieds. Mit einem Nachwort von Loïc Wacquant. Bielefeld.

Reh, Sabine (2009): "Der aufmerksame Beobachter des modernen großstädtischen Lebens wird zugeben, dass die Familie heute leider nicht mehr den 
erziehlichen Wert früherer Tage besitzt.« Defizitdiagnosen zur Familie als wiederkehrendes Motiv in deutschen reformpädagogischen Schulentwürfen und Schulreformdiskursen im ersten Drittel des 20. Jahrhunderts. In: Jutta Ecarius/Carola Groppe/Hans Malmede (Hg.): Familie und öffentliche Erziehung. Theoretische Konzeptionen, historische und aktuelle Analysen. Wiesbaden, S. 159-182.

Scholz, Joachim/Reh, Sabine (2009): Verwahrloste Familien - Familiarisierte Schulen. Zum Verhältnis von Schule und Familie in den Diskursen der deutschen Schulgeschichte seit 1800 . In: Fritz-Ulrich Kolbe/Sabine Reh/Till-Sebastian Idel/Bettina Fritzsche/Kerstin Rabenstein (Hg.): Ganztagsschule als symbolische Konstruktion. Wiesbaden (Schule und Gesellschaft 38), S. 159-177.

Stadt Zürich, Präsidialdepartement (2018): Kremationsgeschichte, online unter www.stadt-zuerich.ch/prd/de/index/bevoelkerungsamt/tod/krematorium/ kremationsgeschichte.html (Zugriff: 15.04.2020).

Stollberg-Rilinger, Barbara (2013): Rituale. Frankfurt a.M. (Historische Einführungen 16).

Studer, Brigitte (1997): Familienzulagen statt Mutterschaftsversicherung? Die $\mathrm{Zu-}$ schreibung der Geschlechterkompetenzen im sich formierenden Schweizer Sozialstaat 1920-1945. In: Schweizerische Zeitschrift für Geschichte 4, H. 2, S. 151-170.

Tersch, Harald (2007): Leere Worte? Die Totenrede und ihre Entwicklung. In: Wolfgang Hameter/Meta Niederkorn-Bruck/Martin Scheutz (Hg.): Freund Hein? Tod und Ritual. Innsbruck, Wien, Bozen, S. 177-205.

Wecker, Regina/Studer, Brigitte/Sutter, Gaby (2001): Die »schutzbedürftige Frau«. Zur Konstruktion von Geschlecht durch Mutterschaftsversicherung, Nachtarbeitsverbot und Sonderschutzgesetzgebung. Zürich.

Zihlmann-Märki, Patricia (2010): Gott gebe das wir das Liebe Engelein mit Freüden wieder sehen Mögen«. Eine kulturgeschichtliche Untersuchung des Todes in Basel 1750-1850. Zürich. 



\section{Praktiken des Trinkens in Schülervereinen der Küsnachter Seminaristen zu Beginn des 20. Jahrhunderts Überlegungen zum Fokus auf Praktiken als Möglichkeit einer radikalen Historisierung'}

Andrea De Vincenti

An einem Mittwochnachmittag, dem 10. November 1904, um 13.30 Uhr versammelte sich eine Hand voll Zöglinge des Seminars Küsnacht im Klassenzimmer der IIIb. Sie waren gekommen, um ihre Strafe entgegenzunehmen. Der Aufruf zu diesem Treffen war von der Seminardirektion am Schwarzen Brett ausgehängt worden und richtete sich an »sämtliche Zöglinge, welche der Verbindung Fidelitas angehört hatten, bis diese aufgelöst wurde«. Zu Beginn der Versammlung wurde die Mitgliederliste verlesen und jeder Zögling musste mit einem »hier« seine Anwesenheit bekunden. ${ }^{2}$

Zuvor hatte die Seminardirektion eine gute Woche lang Nachforschungen angestellt, »Einvernahmen « geführt, Dokumente gesammelt. Nachdem sie die Vereinsstatuten gesichtet hatte, entschloss sie sich zum harten Durchgreifen. ${ }^{3}$

Die »Fidelitas« war eine Vereinigung von Zöglingen des Seminars Küsnacht, welche gemäss Statuten den Zweck verfolgte, »unter ihren Mitgliedern die Freundschaft und die Brüderschaft wo möglich zu fördern“, über das »commentmässige Betragen der Brüder zu wachen, und von Zeit zu Zeit einen Ausflug, oder

1 Dieser Beitrag entstand im Rahmen des SNF-Projekts 166008 »Wissenschaft - Erziehung und Alltag. Orte und Praktiken der Zürcher Primarlehrer/-innenbildung in der ersten Hälfte des 20. Jahrhunderts«.

2 Schreiben der Seminardirektion an die Erziehungsdirektion des Kantons Zürich vom 16. November 1904. U 73.3.11, S. [2].

3 Offenbar wurden der Seminardirektion nach dem Entdecken der Fidelitas zunächst falsche Statuten vorgelegt, welche den wahren Vereinszweck hätten verschleiern sollen. Dies würde darauf hinweisen, dass die Zöglinge die negative Reaktion der Seminarleitung auf ihren Verein möglicherweise antizipiert hatten. Siehe dazu die Bemerkung im Protokoll der Aufsichtskommission vom 25. November 1904, Eintrag 524. 
eine Reise zu machen. $\aleph^{4}$ Dazu trafen sich die Mitglieder jeweils am Samstagnachmittag in einem Lokal der Stadt Zürich, zuletzt am 30. Oktober im Hotel Merkur, wo es ein gutes Münchner Bier gegeben habe, zu einer Kneipe. An einer Kneipe stand jeweils das gemeinsame Trinken von alkoholischen Getränken im Mittelpunkt. Der gesamte Ablauf war streng reglementiert und wurde durch die Vereinshierarchie überwacht. Missachtungen des Reglements ebenso wie etwa unentschuldigtes Fernbleiben von den Versammlungen wurden mit in den Statuten festgelegten Bussen geahndet.

Formal ganz ähnlich war auch der Seminarturnverein organisiert. Eine strenge Hierarchie und ein Reglement mit einem Bussensystem sollten auch dort für Ordnung und Disziplin sorgen. Eine weitere, allerdings im Falle des Turnvereins in den Statuten nicht formell festgehaltene Gemeinsamkeit mit der Fidelitas ist die Praktik des Trinkens. Auch die Seminarturner tranken gemeinsam - etwa an den als Voraussetzung zur Teilnahme an eidgenössischen Turnfesten obligatorisch zu absolvierenden Turnfahrten oder an den Turnfesten. Man scheute sich auch nicht, diese Praktiken in den offiziellen und bei Direktion und Aufsichtskommission des Seminars einzureichenden Jahresberichten des Vereines ausführlich darzustellen. So heisst es dort etwa, dass der Seminarturnverein Küsnacht (S.T.V.K.) am 20. Mai 1909 am frühen Morgen unter kräftigem Trommelwirbel zur Seeverbands-Turnfahrt auf den Pfannenstiel aufbrach, wo der "schneidige Gastwirt zum /Sternen« « die Seminarturner bereits um 10.30 bei gedeckten Tischen erwartet habe. »Ein kräftiges Mittagessen, verbunden mit der sHinunterbringung، von einigen Flaschen Bier oder Bilz« habe die Turner dort anderthalb Stunden versäumt. ${ }^{5}$ Nach einem zweistündigen Marsch mit 700 Turnern sei der eigentliche Festakt begangen worden, an den sich ein üppiges Mahl angeschlossen habe. ${ }^{6}$ Auch als die erfolgreichen Seminarturner vom Eidgenössischen Turnfest in Lausanne bekränzt nach Küsnacht zurückkamen, seien sie dort wie üblich von der Gemeinde Küsnacht am Bahnhof empfangen und mit einem alkoholischen Trunk begrüsst worden: »Die Schönen von Küsnacht kredenzten die Becher voll süssen Weines.« Es folgte der Zug durch den Ort, der wiederum im Gasthof »Ochsen« geendet habe. ${ }^{7}$ Auch im darauf folgenden Jahr, etwa am Seeverbandsturnfest in Männedorf, waren Turnfahrten und Festteilnahmen jeweils Anlass zu geselligem Essen und Trinken und Ursache für »brummende[...] Schädel« und »wacklige[...] Beine ${ }^{8}{ }^{8}$

\footnotetext{
4 Fidelitas Statuten, S. [1].

5 Jahresbericht Seminar-Turnverein 1909, S. 4.

6 Jahresbericht Seminar-Turnverein 1909, S. 4.

7 Ebd., S. 6.

8 Jahresbericht Seminar-Turnverein 1910, S. 4 U. 6 (Zitate).
} 
Trinken von Alkohol war demnach als gesellige Praktik im Seminarturnverein $\mathrm{zu}$ Beginn des 20. Jahrhunderts etabliert und auch breit akzeptiert. Das gemeinsame Essen und Trinken wurde in den Jahresberichten dieser Zeit jeweils ausführlich und prominent geschildert. Dennoch galt der Turnverein als Repräsentant des Seminars, dessen Erfolge man gerne auch in der Teilöffentlichkeit des Wirtshauses feierte. So begrüsste der Seminardirektor die heimkehrenden Turner etwa im »Ochsen «, drückte ihnen dort seine Wertschätzung für die erturnten Kränze und Becher aus und ermunterte zu weiterer Arbeit an Körper und Geist. ${ }^{9}$ Weitere Unterstützung wurde dem Turnverein sowohl vonseiten des Kantons Zürich sowie auch des schweizerischen Bundesstaates zuteil, indem jährliche Geldbeiträge an ihn ausgeschüttet wurden. ${ }^{10}$ Warum also, so die nachfolgend im Zentrum stehende Frage, erschien die Praktik des Trinkens im Fall des Seminarturnvereins legitim, während sie im Fall der Fidelitas mit harten Strafen geahndet wurde?

Zur Diskussion dieser Frage werden im vorliegenden Beitrag unterschiedliche Quellengattungen in Ergänzung zu einander ausgewertet, um so eine die Einzeldeutungen kontextualisierende Vielperspektivität auf die Praktiken des Trinkens und die ihnen zugeschriebenen Bedeutungen zu gewährleisten. ${ }^{11}$ Konkret basieren die nachfolgenden Überlegungen auf Akten der Fidelitas, auf diversen Korrespondenzen zwischen Eltern und der Seminardirektion, zwischen Letzterer und der Erziehungsdirektion sowie auch zwischen Lehrerkonvent und Erziehungsdirektion, zudem auf Jahresberichten der Seminarleitung und Protokollen des Lehrerkonvents. Vorbereitend auf die Diskussion des Fallbeispiels der Fidelitas, wird der meinen Überlegungen zugrunde liegende Praktikenbegriff in einem ersten Kapitel umrissen und die These präsentiert, der Fokus auf Praktiken könne als Möglichkeit einer radikalen Historisierung gesehen werden (2). In einem zweiten, ausführlichen Kapitel wird der Fall der Fidelitas und seine Bearbeitung am Seminar Küsnacht ausgebreitet (2), in einem dritten Kapitel schliesslich wird die These zu den Praktiken als Möglichkeit einer radikalen Historisierung anhand des Falles nochmals reflektiert und plausibilisiert (3).

9 Jahresbericht Seminar-Turnverein 1909, S. 6; Jahresbericht Seminar-Turnverein 1912, S. 7.

10 Davon zeugen die entsprechenden Gesuche des Vereins an die Erziehungsdirektion. Dem Gesuch mussten jeweils Jahresbericht und Rechnung beigelegt werden. Siehe etwa Schreiben Seminar-Turnverein, 23. Dezember 1910.

11 Siehe dazu das Konzept der zweifachen Konstruktion in der Geschichtsschreibung, welches zwar »die vielfältigen Perspektiven und Denkwelten der historischen Individuen selbst in Betracht zieht, sie aber gleichzeitig in einen übergreifenden Sinnzusammenhang einbettet, dessen sich die historischen Akteure nicht unbedingt bewusst waren« (Kolář 2012, S. 5). 


\section{Der Fokus auf Praktiken als Möglichkeit einer radikalen Historisierung}

Praktiken und Praxis sind Begriffe, welche sowohl in neueren, als "praxeologisch « oder "praxistheoretisch" markierten Ansätzen als auch in älteren historiografischen Zugängen, etwa unter der Bezeichnung Historische Anthropologie, Alltags- oder Mikrogeschichte, vorkommen. Unscharf bestimmt bleibt indes das Verhältnis von älteren und neueren Ansätzen. So wird in neueren Publikationen zuweilen in Abgrenzung, zuweilen auch in Anlehnung, auf ältere Vorarbeiten verwiesen. Laut Dagmar Freist habe ein angeblich der Geschichtswissenschaft eigener »freizügiger Umgang« mit Begriffen etwa dazu geführt, dass praxeologische Untersuchungsperspektiven bisher nur ansatzweise und weitgehend ohne die vor allem in der Soziologie breit geführte praxistheoretische Debatte zu rezipieren, zur Anwendung gelangt seien. ${ }^{12}$ Eine »begriffliche Unschärfe« bezüglich Praktiken ortet auch Marian Füssel und verweist auf eine praxeologisch ausgerichtete Geschichtswissenschaft bereits seit den 1980er-Jahren und sogar auf eine praxeologische Wende der Disziplin Ende der 1990er-Jahre. Die Unschärfe sei insbesondere einer »verstärkte[n] empirische[n] Vereinnahmung« des Praktikenbegriffs geschuldet. ${ }^{13}$ Auch Lukas Haasis und Constantin Rieske konzedieren, ältere Ansätze der Historiografie, namentlich die Mikrogeschichte, wiesen Parallelen zu praxeologischen Ansätzen auf, doch hätten diese nicht konkrete Praktiken fokussiert und als Ausgangspunkt der Untersuchung genommen. ${ }^{14}$

Die Einschätzung der Relevanz älterer, sich mit Praxis oder Praktiken befassender Arbeiten für die heutigen Debatten fällt demnach ambivalent und sehr unterschiedlich akzentuiert aus. Ebenso heterogen sind die Einschätzungen bezüglich des Ausmasses bereits erfolgter sowie bezüglich noch zu leistender Theorierezeption aus benachbarten Disziplinen, zumal auch das dortige Theorieangebot durchaus heterogen und somit begrifflich ebenso unscharf wird, sobald man sich bei der Rezeption nicht auf einen einzigen Autor oder eine einzige Autorin beschränkt. ${ }^{15}$

Angesichts dieser Gemengelage und der allseitig beklagten Unschärfen und Eklektizismen lohnt es sich möglicherweise, nicht gleich Begriffsdefinitionen und -implikationen zu verhandeln, sondern die Überlegungen zunächst beim Problem

12 Freist 2015, S. 64.

13 Füssel 2015, S. 21-23, Zitate S. 23.

14 Haasis/Rieske 2015, S. 20.

15 Diese Feststellung ebenfalls bei Freist (2015, S. 63f.), welche die sich im Zuge des »practice turn« etablierenden heterogenen Denkfiguren nicht als »kohärente praxeologische Theorie«, sondern als »sich ergänzende analytische Blickwinkel auf das Soziale« versteht, die allerdings in gewissen Postulaten übereinstimmen. 
beginnen zu lassen, welches ein auf Praxis und/oder Praktiken fokussierter Ansatz in der Geschichtswissenschaft bearbeiten könnte. Konkret hiesse dies, sich zunächst der Frage zuzuwenden, welchen Zugewinn eine praxeologische Ausrichtung der Historiografie bringen und was der Ansatz neu sichtbar machen könnte. Dies selbstverständlich immer im Wissen darum, dass jede neue Perspektive wiederum neue blinde Flecken und Problemlagen generiert.

Haasis/Rieske erwähnen in ihrer Einführung in die historische Praxeologie eine Gemeinsamkeit älterer und neuerer praxeologischer Arbeiten, die möglicherweise auf einen solchen Problemkomplex verweist: Es gehe, so Haasis/Rieske mit Bezug auf Hans Medick, sowohl in aktuellen historisch-praxeologischen Zugängen wie auch der älteren Mikrogeschichte letztlich um die Frage, wie »die komplexe und wechselseitige Beziehung zwischen Lebens-, Produktions- und Herrschaftsverhältnissen und den Erfahrungen und Verhaltensweisen der Betroffenen erfasst und dargestellt werden ${ }^{16}{ }^{16}$ In der Tat wurde in den 1990er-Jahren in der Geschichtswissenschaft, insbesondere unter Frühneuzeithistorikerinnen und -historikern, eine Debatte über einen sogenannten »Praxis-Ansatz $\aleph^{17}$ geführt. Dieser wurde damals etwa auf Bourdieu oder Giddens zurückgeführt und als Erweiterung einer stark strukturgeschichtlich und somit einseitig auf die Makroperspektive ausgerichteten Gesellschaftsgeschichte zur Rezeption vorgeschlagen. So hat Ute Daniel in ihrem 1993 erschienenen, programmatischen Aufsatz «Kultur« und "Gesellschaft« eine »bedeutungsorientierte Erweiterung der Sozial- bzw. Gesellschaftsgeschichte unter dem Oberbegriff ,Kultur« im Sinne kollektiver Sinnkonstruktionen gefordert. Ziel sei eine »historische Kulturwissenschaft, die die sinnstiftende menschliche Praxis, verstanden als »komplexe Einheit von Gedanken und Handeln «, in den Mittelpunkt stellt und damit nicht nur zum Zentrum der Analyse, sondern auch der wissenschaftlichen Konstruktion der Wirklichkeit macht. ${ }^{18}$ Damit betont sie die Relevanz von "Welt- und Gesellschaftsdeutungen" für soziales Handeln und Verhalten, indem Bedeutung durch Handeln erst hergestellt wird, Handeln jedoch gleichzeitig auch auf Bedeutung fusst. Historikerinnen und Historiker müssten sich demnach im Forschungsprozess das aneignen, »was die Akteure schon wissen und wissen müssen, um sich in den täglichen Aktivitäten des gesellschaftlichen Lebens >zurechtfinden zu können «.$^{19}$ Der kulturgeschichtlichen Erforschung von »Bedeutung, die Menschen ihrer Welt und ihren eigenen Handlungen in ihr verleihen", wird deshalb eine zentrale Rolle zugewiesen, weil sie mit der Erforschung eines dynamischen Wechselverhältnisses von Gesellschaft oder Kultur und Individuum zusammenfällt und somit konstitutiv

\footnotetext{
16 Haasis/Rieske 2015, S. 20.

17 Daniel 1993, S. 96, Fussnote 111.

18 Daniel 1993, S. 72 u. 99, Zitat: S. 84.

19 Ebd., S. 84 u. 93.
} 
für die soziale Konstruktion von Wirklichkeit ist. Die von Daniel vorgeschlagene Fokussierung auf Handeln/Praxis sollte also auch den Dualismus zwischen objektiver Gesellschaft und subjektivem Individuum zugunsten eines Fokus auf die Wechselwirkungen zwischen beiden überwinden. ${ }^{20}$

In der angesprochenen historiografischen Debatte ging es also zentral um das Verhältnis von »Struktur« und »Subjekt«/»Akteur« oder um die Frage, inwiefern Strukturen »hinter dem Rücken der Subjekte« ihre Wirkungen entfalten können und inwiefern Sinn und Bedeutung der von Menschen erlebten Welt Teil der Historiografie sein sollten. Daniel betonte, die Wichtigkeit der »Welt- und Gesellschaftsdeutungen in ihrer Relevanz für soziales Handeln und Verhalten, für gesellschaftliche Kontinuitäten und Diskontinuitäten«, diese seien »ebenso ernst zu nehmen wie sozioökonomische oder andere Strukturen $«{ }^{21}$ Die Aufwertung des Sinnes, »den die historischen Akteure ihren Handlungen geben«, steht auch für Martin Dinges im Zentrum seiner mindestens in der Intention zwischen Gesellschaftsgeschichte und Historischer Anthropologie vermittelnden Überlegungen. Er hält es für ebenso inakzeptabel, die »historischen Subjekte« als »Deppen der Geschichte« darzustellen, welche die herrschenden Strukturen verkennen, wie auch ihnen vorwiegend bewusste, rationale oder auch rein habituell begründete Wahlentscheidungen zu unterstellen. ${ }^{22}$ Er schlägt deshalb in einem Aufsatz in der Zeitschrift für historische Forschung 1997 vor, mit einem auf Lebensstile fokussierten Konzept eine »Alltagskulturgeschichte« $\mathrm{zu}$ lancieren, welche »die Errungenschaften von Gesellschaftsgeschichte und Historischer Anthropologie« vereine und in der die "zeitgenössische Sicht der Dinge maßgeblich das Raster der historischen Analyse vorstrukturiert «. ${ }^{23}$ Obwohl er als Vertreter der bei Dinges mit der Gesellschaftsgeschichte zu versöhnenden Historischen Anthropologie gilt, schlug Alf Lüdtke mit Blick auf eine von ihm propagierte Alltagsgeschichte in ganz ähnlichem Duktus vor, die Zweipoligkeit zwischen »Struktur« und »Subjekt« mit dem Begriff der »Aneignung«, welche »Wahrnehmungs-, Deutungs- und Verhaltensweisen « bezeichne, zu vermeiden, sodass Individuen und Gruppen in »Konfigurationen sozialer Kräftefelder gezeigt werden können«. Ein »genaues Erkunden der Praxen der Aneignung« müsse demnach der Gegenstand einer so verstandenen Alltagsgeschichte sein. ${ }^{24}$ Damit sehen Daniel, Dinges und Lüdt-

20 Ebd., S. 84 u. 96.

21 Ebd., S. 93.

22

3 Ebd., zur Skizze des Konzepts siehe S. 198-202; für die Zitate S. 180 u. 213.

Lüdtke 1997, S. 84, 86f. u. 89. Martin Dinges grenzt sich mit seinem zwischen der Historischen Anthropologie und der Gesellschaftsgeschichte vermittelnden Konzept der »Alltagskulturgeschichte« mit ihrer »doppelten Bezugnahme auf globale Strukturen und sindividuelle Handlungsentwürfe« sowohl vom Strukturalismus als auch vom symbolischen Interaktionismus ab. Dinges 1997, S. 185. 
ke in einem soziokulturell kontextualisierten Fokus auf Handlungen und somit auf Praxis oder Praktiken einen Weg aus der Auseinandersetzung zwischen einer makroperspektivischen Gesellschaftsgeschichte und einer (allzu) mikroperspektivisch orientierten Alltagsgeschichte oder Historischen Anthropologie. Francisca Loetz liest Daniels oben referiertes Plädoyer für eine Hinwendung der Geschichtswissenschaft zu Handlung und Bedeutung fast zehn Jahre später als Aufforderung, »Praktiken als für die Handelnden sinnvolle und sinnstiftende Verhaltensmuster auf dem Hintergrund bestehender Lebensbedingungen zu erkennen«, und weist damit in eine ähnliche Denkrichtung. ${ }^{25}$ Praktiken ergeben sich in diesen Verständnissen also aus überlieferten Verhaltensentscheiden, welche Menschen im Spannungsfeld von subjektiven Wahlmöglichkeiten und struktureller Determiniertheit getroffen haben. Menschliches Handeln beruht demnach auf "polyvalenten Handlungsoptionen, welche in ihrer Kontingenz Kultur hervorbringen. Kultur wird nicht als System verstanden, sondern als »Vielfalt von Formen, in denen Individuen, Gruppen oder ganze Gesellschaften ihre Bedürfnisse ausdrücken ${ }^{26}$

Menschliche Vorstellungsweisen und Deutungsvorgänge seien also bei der Verwandlung von »Gesellschaft in eine soziale Tatsache« ernst zu nehmen. ${ }^{27}$ Diese gesellschaftliche Dimension von Handlungen betont beinahe 20 Jahre später auch Dagmar Freist, wenn sie Praktiken als Handlungen versteht, die »Teil übersubjektiver, kollektiver Handlungsmuster und Alltagsroutinen [sind], in deren praktischen Vollzügen kollektive Wissens- und Deutungsschemata fortlaufend aufgerufen, bestätigt, irritiert und verändert werden «. ${ }^{28}$ Der hier zusätzlich eingeführte Wissensbegriff verweist stärker noch als derjenige der Deutung auf das Überindividuelle, auf praktisches Wissen im Sinne eines knowing hows oder des »Sag- und Machbare[n]«, welches einerseits angeeignet und verinnerlicht, dabei aber auch stets "transzendiert, umgedeutet und $>$ überschrieben « wird. ${ }^{29}$ Noch stärker die Zirkulation der stets fluiden Wissen in der Gesellschaft betont seit den 2000er-Jahren die Wissensgeschichte, welche ebenso auf die mit dem Zirkulieren fast zwangsläufig einhergehenden ständigen Modifikationen, heterogenen Rezeptionen und Produktionen dieser Wissen verweist und damit den

25 Loetz 2002 (diskutiert hier Daniel und Gadamer), S. 65.

26 Ebd., S. 69.

27 Daniel 1993, S. 72 u. 92f., Loetz 2002, S. 65; Damit zeigen sich natürlich auch Nähen zu Arbeiten der Wissenssoziologie etwa von Berger und Luckmann. Geschichtsschreibung, die sich in einem kulturgeschichtlichen Kontext mit Praktiken beschäftigt, bearbeitet stets auch die von ihnen formulierte Frage, »wie es vor sich geht, dass gesellschaftlich entwickeltes, vermitteltes und bewahrtes Wissen für den Mann auf der Strasse zu ausser Frage stehender ,Wirklichkeit`gerinnt« (2007, S. 3). 
Fokus potenziell von den sich Wissen aneignenden Akteuren hin zu den Wissen selbst verschiebt. ${ }^{30}$ Ausgehend von einer aus "materiale[n] Körperbewegungen « und »implizite[r] Sinnstruktur« sich ergebenden »Doppelstruktur« von Praktiken verweist auch Andreas Reckwitz auf die (impliziten) Wissen, welche nur über die direkt wahrnehmbaren Komponenten von Praktiken, also die sich wiederholenden und verschiebenden »Muster[ ] der Bewegung und der Äußerung von aktiven Körpern und Dingen« erschlossen werden können. In Praktiken und Clustern von Praktiken sind demnach stets Ordnungen des Wissens und kulturelle Codes enthalten. ${ }^{31}$ Während explizite, also geäusserte Wissen mit anderen historiografischen Ansätzen gut erforschbar sind, bietet die praxeologische Perspektive eine Möglichkeit, sich auch impliziten Wissen, die handelnd aktualisiert, aber auch modifiziert werden, zuzuwenden. Dies weil sowohl implizites als auch explizites Wissen in den Praktiken in einem beobacht- und deshalb auch überliefer- und erforschbaren Aggregatszustand manifest wird. In den Praktiken koexistieren die impliziten und expliziten Wissen der Vielen, die in Wissenskämpfen Positionen als etablierte oder unterworfene Wissen zugewiesen bekommen und auch wieder verlieren können, weshalb diese immer nur für eine gewisse Zeit etablierten Wissensordnungen auch Machtstrukturen abbilden. ${ }^{32}$

Wahrheit und Wirklichkeit sind unter diesen Prämissen stets vielfältig, an Perspektiven und Wahrnehmungen von zeitgenössischen Akteuren (und natürlich auch des Historikers oder der Historikerin) gebunden und werden erst im »Vollzug von Praktiken« hervorgebracht. ${ }^{33}$ Aus einem Fokus auf Praktiken resultiert deshalb keine Wirklichkeit im Singular, die historisch rekonstruiert werden könnte, da die praxeologisch inspirierte Perspektive Forschende nicht näher an die vergangene Wirklichkeit heranbringt, als dies etwa der klassischen Politik-, Ideen- oder Gesellschaftsgeschichte gelungen ist. Praxis ist deshalb nicht das Gegenüber einer (nicht durchgesetzten) Norm - deren Setzung übrigens selbst wieder als Praxis begriffen und untersucht werden könnte. ${ }^{34}$ Die von den Zeitgenossen als solche erlebten »Wirklichkeiten« können daher treffender und mit einem Begriff von Paul Veyne als »Objektivierungen« verstanden werden, die heterogenen Praktiken entsprechen und kontingent, also in der Gesamtheit von

30 Zur Wissensgeschichte siehe Sarasin 2011, S. 164 u.166; Foucault 2014, S. 21f.; Lipphardt/Patel 2008.

31 Reckwitz 2008, S. 196 u. $202 f$.

32 Veyne 1992, S. 43; Foucault 2014, S. 21; De Vincenti 2015, S. $17 f$.

33 Freist 2015, S. 67.

34 So setzte z.B. Wolfgang Neugebauer (1985) den nicht durchgesetzten staatlichen Normen die »Schulwirklichkeit« entgegen; zur Debatte zu Beginn der 1990er-Jahre siehe etwa Daniel 1993, Dinges 1997, Lüdtke 1991, Schlumbohm 1997, Landwehr 2000 und Loetz 2002; eine neuere Auseinandersetzung mit dem Thema bei Crube 2016. 
niemandem so intendiert sind. ${ }^{35}$ Folgt man diesen Überlegungen, existiert also auch das Trinken nicht als Praktik(en) per se. Dieses kann lediglich als »Korrelat« datierter und verorteter Praktiken, also »in einer Praktik und durch eine Praktik« gefasst werden. ${ }^{36}$ Praktiken nehmen ihre Konturen, das heisst die ihnen von den Zeitgenossen zugewiesenen Bedeutungen, generell erst in ihren Beziehungen zu weiteren Praktiken an, durch ihre Situierung in einem Geflecht oder eben Korrelat von Praktiken, genau wie ein Stein erst in einem grösseren Ensemble von Steinen zu einem Binder- oder Schlussstein wird: durch seine relative Position in einem grösseren Gefüge. ${ }^{37}$ Deshalb ist die Vergangenheit eben keine »Verkettung von Praktiken", welche eine lineare Einheit unterstellt, sondern die Praktiken koexistieren als »Vielheit« - wie »eine goldene Uhr, eine Zitronenschale und ein Waschbär«, die nicht darunter leidet, eben eine solche Vielheit zu sein. ${ }^{38} \mathrm{Ge}-$ schichte ist in diesem Verständnis eine Geschichte von Praktiken, in denen Menschen Wahrheiten gesehen haben, und eine Geschichte von ihren Kämpfen um diese Wahrheiten, von den impliziten und expliziten Wissen der Vielen in ihrem Kampf um Etablierung, wie sie sich in den Praktiken zeigten. ${ }^{39}$ Praktiken sind also nicht a priori, sondern erst aus dem Material heraus als solche zu bestimmen. Dennoch konturieren die vergangenen Praktiken nicht die Geschichtsschreibung, dies leisten vielmehr Fragestellung und eingenommene Perspektive der Forschenden sowie auch das Quellenmaterial.

Wenn nun Praktiken also durch nichts konstituiert werden ausser durch sich selbst respektive durch benachbarte Praktiken und unsere Forschungsbewegungen auch auf diese zielen, werden nicht nur Begriffe, sondern auch sogenannte Grossthesen nicht einfach vorausgesetzt, sondern über die Rekonstruktion der Korrelate von Praktiken auf ihre facettenreichen Ausprägungen und Plausibilitäten hin befragt. An die Stelle von Masternarratives, welche den Anspruch hatten, die ganze Wirklichkeit abzubilden, tritt laut Dinges im von ihm propagierten, strukturelle und prozessuale Aspekte verknüpfenden Ansatz eine Vielfalt von unterschiedlichen und auch widersprüchlichen Deutungen der Akteure, welche die Historikerin oder der Historiker in ihren unterschiedlichen und auch wandelbaren Machtverhältnissen rekonstruiert. ${ }^{40}$ Auch Daniel verweist auf die »sehr wünschenswerte Nebenfolge« einer Hinwendung der Historiografie zu Handeln/ Praxis und Struktur, indem das »mehr oder weniger explizite[] Modernisierungs-

Veyne 1992, S. 36 u. 4 of.

Ebd., S. 61 u. 49. 
theorem « unter Druck käme. ${ }^{41}$ Neueren Datums ist der Hinweis von Freist, das der Mikrogeschichte eigene »kritische Potential« in praxeologischen Studien fruchtbar zu machen. ${ }^{42}$ Der unter dieser Perspektive gebotene vorsichtige Umgang mit scheinbar klaren Begriffen und der Fokus auf ihre Aktualisierung durch datierte und verortete Praktiken favorisieren eine Historisierung eben dieser Begrifflichkeiten in radikaler Weise. Unter Historisierung kann nach Pavel Kolář zunächst mal ein »Akt der Transformation von stoten«, vergangenen Überlieferungen und Artefakten in sinnvolle, zeitlich geordnete Erzählungen und Geschichten« verstanden werden. ${ }^{43}$ Damit ist der Blick geschärft für die Unterscheidung von Vergangenheit und Geschichte sowie auch für das stets der Gegenwart entspringende Erkenntnisinteresse. Eine so verstandene Historisierung verweist auch auf eine bestimmte Auffassung von Geschichtswissenschaft, welche sich von zwei »unkritischen« oder nichtkritischen Formen der Historiografie abgrenzt. Es ist dies nach Landwehr zum einen eine identitäts- und kontinuitätsstiftende, Nähe anstatt Distanz herstellende Vorgeschichte der Gegenwart, zum andern aber auch eine die Vergangenheit bewertende oder gar verurteilende Geschichtsschreibung, welche Vergangenes vor den Richtstuhl der Gegenwart zieht, um sie besserwisserisch zu verurteilen, zumal es zur Verurteilung von Kolonialismus, Massenmord, Diktaturen und Ausbeutung keiner historischen Belege bedürfe. Mit der Möglichkeit einer Historisierung wird in Abgrenzung dazu auf eine »kritische Geschichtswissenschaft « verwiesen, welche nicht bereits die richtigen Antworten kennt und damit zwangsläufig normativ und dogmatisch wird, sondern der Gegenwart andere Wirklichkeiten oder Selbstverständlichkeiten gegenüberstellt, um über die Auseinandersetzung mit der Andersheit dieser Geschichten die Gegenwart einer »Entselbstverständlichung « zu unterziehen. ${ }^{44}$

Nachfolgend werde ich nun versuchen, anhand des bereits angerissenen Fallbeispiels des Trinkens am Seminar Küsnacht dieses Verständnis einer Geschichtsschreibung in praxeologischer Perspektive sowie auch meine These der dieser Perspektive inhärenten Möglichkeit einer radikalen Historisierung zu plausibilisieren.

41 Daniel 1993, S. $96 f$.

42 Freist 2015, S. 75.

43 Kolář 2012, S. 2.

44 Landwehr 2012, S. 8 u. 10. 


\section{Praktiken des Trinkens im Seminarverein "Fidelitas" und ihre heterogenen Deutungen}

In den bereits erwähnten Statuten der Fidelitas wird der Vereinszweck folgendermassen ausformuliert: »1. Die >Fidelitas $<$ hat den Zweck, unter ihren Mitgliedern die Freundschaft und die Brüderschaft wo möglich zu fördern; sie soll über das commentmässige Betragen der Brüder wachen, und von Zeit zu Zeit einen Ausflug, oder eine Reise machen. ${ }^{45}$ Der Verein ist, wie auch der Turnverein, hierarchisch organisiert und kennt ein Bussensystem. Ihm stehen ein Präsis sowie ein Vicepräsis, der gleichzeitig Kontor und Stellvertreter des Präsidiums ist, vor. Der Präsis selbst untersteht nur dem Comment, also dem Regelwerk der Vereinigung, ansonsten ist er "selbständig«, er hat das Recht, Bussen zu verhängen, und die Aufgabe, ein Protokoll und ein Kassabuch zu führen. Die Mitglieder der Fidelitas sind dem Präsis während der Kneipe $\mathrm{zu}$ »unbedingtem Gehorsam« verpflichtet und unterstehen somit wenigstens für die kurze Zeit der Treffen der Fidelitas einer anderen Hierarchie als derjenigen des Seminars. ${ }^{46}$ Damit formierten die Mitglieder der Fidelitas eine zu derjenigen des Seminars alternative Gemeinschaft, die auch als Gegengemeinschaft verstanden werden konnte.

An der Kneipe, also einem Wirtshausbesuch von drei Stunden jeweils am Samstag von drei bis sechs Uhr, wurden »commentmässige Stoffe, Wein oder Bier verabfolgt«, das Vereinslokal wurde von den Mitgliedern nach ihrem Gutdünken ausgewählt. ${ }^{47}$ Begonnen scheint die Fidelitas im Restaurant Weiher an der Holbeinstraße zu haben, anschliessend haben sie sich in der Bierhalle Schlauch getroffen und schliesslich im Hotel Merkur. Zumindest sind diese Lokale in der Reihenfolge auf den Statuten vermerkt und die ersten beiden durchgestrichen. Der erste Lokalname ist zudem noch mit derselben Tinte und auch in derselben Kalligrafie wie die Statuten selbst geschrieben. Gründungsmitglieder waren wohl sechs oder sieben Zöglinge, ihre Namen und Verbindungsübernamen stehen jedenfalls als letzter Paragraf in den Statuten, mit Bleistift wurden dann auf einer anderen Seite sukzessive die Namen der neu eingetretenen Zöglinge aufnotiert. ${ }^{48}$ Teilweise mehrfach veränderte und überschriebene Partien in den Statuten deuten darauf hin, dass diese ernst genommen wurden und Differenzen zwischen den Trinkpraktiken an den samstäglichen Treffen und dem Statutentext vermieden werden sollten.

Redaktionelle Arbeiten an den Statuten beziehen sich etwa auf den Trinkzwang, der unter den Mitgliedern umstritten war. So stand zwar der berühm-

\footnotetext{
45 Fidelitas Statuten, S. [1].

46 Ebd., S. [2].

47 Ebd., S. [1].

48 Ebd., S. [8].
} 
te, auch in anderen Biercomments jeweils den Trinkzwang festschreibende und die persönlichen »Grenzen des Trinkenkönnens und Trinkenwollens [...] ausser Kraft « setzende Paragraf 11 (»Es wird fortgesoffen«) auch in den Statuten der Fidelitas. ${ }^{49}$ Es findet sich jedoch auch der Paragraf 13, der festhält: »Es soll Trinkfreiheit herrschen. ${ }^{50}$ Gestrichen wurde mit Bleistift der Paragraf 12, der gebot, niemand dürfe am Biertisch beim leeren Glase sitzen. In Kraft blieb indes der Paragraf 14, der demjenigen eine Sanktion androht, der »von einem vollen Topf wegläuft, oder denselben nicht austrinkt innerhalb von 5 B[ier] M[inuten]«, wobei eine Bierminute einer halben herkömmlichen Minute entsprach. ${ }^{51}$ Die strenge Reglementierung des Trinkens sah vor, dass sich jemand erst von seinem Topf entfernen durfte, nachdem er vorgängig beim Präsis »Tempus« eine Auszeit verlangt hatte. Kehrte er nicht innert fünf Bierminuten zurück, musste er eine Busse von 15 Rappen bezahlen oder er wurde »in den ersten Bierverschiss « eingeschrieben. Dies entsprach der Höchststrafe, weil der Eintrag mit dem vorläufigen Ehrverlust im »Bierstaat", also der Vereinigung, verbunden war. ${ }^{52}$ Auch hier waren zunächst sowohl der Eintrag - und damit verbunden die Ächtung - als auch die Busse als Sanktionen vorgesehen, später wurden die Statuten überarbeitet und die beiden Sanktionen als Alternativen dargestellt.

Obwohl es in der Fidelitas wie in vielen studentischen Verbindungen offensichtlich um die kollektive Überschreitung körperlicher Grenzen ging, zeigen diese kleinen redaktionellen Arbeiten an den Statuten, dass um die Härte der Trinkreglementierung in der Vereinigung gerungen wurde und somit Praktiken aus studentischen Kreisen nicht einfach übernommen, sondern durchaus auch adaptiert wurden. Dabei war das Ausmass der Adaption offenbar umstritten. ${ }^{53}$ Eine weitere Analogie zwischen der Fidelitas und studentischen Verbindungen war die obligatorische Anschaffung eines Kommersbuches, also eines studentischen Liederbuches, - wahlweise mit oder ohne die abgedruckten Musiknoten - für jedes Mitglied der Fidelitas. Doch sollte nicht nur in studentischer Manier gesungen, sondern auch so geredet werden, indem »studentische Redensarten besonders berücksichtigt werden ${ }^{54}$ Mit dem commentmässigen Trinken, Sprechen und

49 Ebd., S. [3]; Blattmann 1996, S. 124; Blattmann 1995, S. 151.

50 Fidelitas Statuten, S. [3].

51 Ebd., S. [4].

52 Fidelitas Statuten, S. [4]; Blattmann 1996, S. 124.

53 Auf den Zusammenhang von Gemeinschaft und kollektiver Überschreitung körperlicher Grenzen verweist auch Sonja Levsen (2007, S. 175 u. 177-179). Sie zeigt auf, inwiefern Männlichkeit in der deutschen Studentenschaft einerseits über Mensur und andererseits durch hoch formalisierte Trinkgelage hergestellt wurde. Beide Praktiken zielten aber nicht nur auf die Herstellung von Männlichket, sondern auch von Gemeinschaft, unter die sich der Student bei der Mensur unterordnen und mit der er beim Trinken verschmelzen sollte. 
Singen orientierte sich die Fidelitas also in hohem Masse an etablierten Praktiken studentischer Verbindungen, rang jedoch offenbar um die konkreten Ausdeutungen und spezifischen Aktualisierungen dieser Bezugsnorm.

Neben den Statuten wurde die Fidelitas vor allem im Zusammenhang mit der Aushandlung des Strafmasses aktenkundig, mit dem die Mitgliedschaft in dieser nicht von der Seminardirektion genehmigten Verbindung geahndet werden sollte. ${ }^{55}$ Es wurden Höchststrafen verhängt und beschlossen, sämtliche Mitglieder für das laufende Semester von allen Vereinen auszuschliessen, den Stipendianten ihr Stipendium bis zum Frühling 1905 zurückzubehalten und die Auszahlung an ihr Betragen zu knüpfen, allen Beteiligten einen Eintrag in das kommende Zeugnis zu setzen sowie die Eltern zu informieren. ${ }^{56}$ Einzig die direkte Wegweisung vom Seminar hätte als Steigerungsmöglichkeit des Strafmasses noch zur Verfügung gestanden: Einigen bereits zuvor wegen ihres Verhaltens aufgefallenen Zöglingen wurde diese neben einem Eintrag im Zeugnis sowie der Sistierung der Stipendien auch tatsächlich angedroht. ${ }^{57}$

Als der Lehrerkonvent am 6. November 1904 der Aufsichtskommission des Seminars den Fall der Fidelitas meldete, sprach er von einer Vereinsgründung mit dem »ausgesprochenen Zwecke, die Geselligkeit zu pflegen dh. [sic!] zu kneipen«. Verwiesen wurde zudem auf Praktiken, welche als »Anlehnung an den Kneipkomment studentischer Verbindungen« bewertet wurden: etwa die Vorstandswahl, das Aufstellen von Statuten oder die wöchentlichen Treffen jeweils samstags von drei bis sechs Uhr in einem Bierlokal in Zürich. ${ }^{58}$ Der Lehrerkonvent habe eine Woche zuvor zufällig vom Bestehen des Vereins Kenntnis erhalten und diesen sofort aufgelöst. Seine Orientierung an Praktiken des studentischen Kneipens und das damit wohl einhergehende Selbstverständnis einer eigenständigen Gemeinschaft ausserhalb oder gar in Opposition zur Seminargemeinschaft, die sich in eigenen Statuten auch formal niederschlug, war offenbar der Punkt, der am meisten Anstoss erregte. An der vorgängigen Sitzung des Lehrerkonvents vom 4. November wurde die Fidelitas zunächst als Verein beschrieben, der sich stark an den »Kneipkomment studentischer Verbindungen« angelehnt habe. Erst an zweiter Stelle wurden auch im Protokoll die Versäumnisse, für die Fidelitas die Genehmigung der Seminarleitung einzuholen und die Mitgliederlisten einzureichen, sowie der Verstoss des Vereinszwecks gegen die Seminarordnung genannt. ${ }^{59}$ Es

55 Die Fidelitas hatte gut anderthalb Jahre bestand.

56 Schreiben Lehrerkonvent an die Aufsichtskommission, 6. November 1904, S. [2].

57 Ebd., S. [2f.]

58 Ebd., S. [1].

59 Sitzung vom 4. November 1904, Protokoll des Lehrerkonventes, S. 177f.; ähnlich wird der Fall auch im Jahresbericht skizziert: 21 Zöglinge hätten, ohne die Erlaubnis des Konvents einzuholen und ohne die Statuten einzureichen, einen Verein zum Zwecke der Geselligkeit 
wird später noch ausführlicher zu zeigen sein, dass die Seminarleitung die Zöglinge dezidiert nicht als Studenten, sondern als angehende Berufsleute und Volkserzieher sah, welchen studentische Freiheiten und die Möglichkeit zur Bildung von eigenen, vom Seminar unabhängigen Gemeinschaften gerade nicht gewährt werden sollte. ${ }^{60}$ Eine Diskussion des Falles ist für die erwähnte Konventsitzung nicht protokolliert. Dies im Gegensatz zu anderen Debatten über Vereinstätigkeiten, an denen sich oftmals Fürsprecher des Vereinswesens am Seminar und diesbezüglich eher skeptisch eingestellte Lehrer gegenüberstanden. Nach einer kurzen Schilderung der Fidelitas und ihren Aktivitäten wird direkt der einstimmige Beschluss zum Strafmass festgehalten. ${ }^{61}$

Tatsächlich war es den Zöglingen am Seminar Küsnacht laut $\$ 24$ der Seminarordnung erlaubt, »zum Zwecke ihrer wissenschaftlichen oder praktischen Ausbildung« ihre eigenen Vereine zu gründen und zu unterhalten. Diese mussten aber vom Konvent genehmigt werden und periodisch Bericht über die Tätigkeiten erstatten. Die »Übungen der Vereine« seien ausserdem in den Lokalitäten des Seminargebäudes abzuhalten. ${ }^{62}$ Alle Zöglinge, so der nächste Paragraf der Seminarordnung, unterstehen sowohl in als ausser der Schule der Disziplin der Anstalt, welche folgende Vergehen ahndet:

Vernachlässigung der Studien; Verletzung des Anstandes; Ungehorsam gegen Schulbehörden und Lehrer, sowie Widersetzlichkeit gegen die Schulordnung; mutwillige Beschädigung des Eigentums der Anstalt; dauernde Ausübung eines nachteiligen Einflusses auf die Klasse; öfterer Wirtshausbesuch und damit im Zusammenhang stehender Unfug; Verletzung der Sittlichkeit.

Zur Handhabung der Ordnung und Disziplin sind zunächst Zurechtweisungen und Strafen der einzelnen Lehrer oder des Direktors vorgesehen, je nach der »Natur des Falles « folgen dann der Verweis durch den Seminardirektor vor der Klasse, ein Vereinsverbot für den Fehlbaren, der Verweis durch den Präsidenten der Aufsichtskommission, der Entzug des Stipendiums, die Androhung der Wegweisung und schliesslich die Wegweisung aus der Anstalt. ${ }^{63}$

gegründet. Jahresbericht 1904, S. 7. Im Jahresbericht von 1905 wird der Fall dann gar nicht mehr erwähnt, obwohl sich insbesondere die Debatten um den Vollzug der Bestrafung der involvierten Zöglinge noch bis in das Frühjahr 1905 hinzogen.

60 Zu den studentischen Freiheiten im Zusammenhang mit der academic citizenship an deutschen Universitäten vgl. Mazon 2003, insbes. S. 19-49.

61 Sitzung vom 4. November 1904, Protokoll des Lehrerkonventes, S. 178.

62 Seminarordnung für das Lehrerseminar des Kantons Zürich, S. 6. Zu den Raum-Zeit-Regimen am Seminar vgl. Crube 2018.

63 Seminarordnung für das Lehrerseminar des Kantons Zürich, S. 7. 
Obwohl also mit den Vereinsaktivitäten formal klar gegen die Seminarordnung verstossen wurde, dürfte dies nicht allein ausschlaggebend oder sogar zweitrangig für das harte Durchgreifen der Seminarleitung gewesen sein. Dafür spricht auch der Umgang der Direktion mit einem anderen nicht angemeldeten Zusammenschluss, diesmal von Seminaristinnen. Den Töchtern war die Teilnahme am Vereinsleben am Seminar aufgrund ihres Geschlechts generell untersagt. Dennoch traf sich eine kleine Gruppe von Küsnachter Seminaristinnen regelmässig, um der Sache der Abstinenz Vorschub zu leisten. Sie pflegten auch Verbindungen zum Abstinentenverein am Seminar, der Fraternitas. ${ }^{64}$ Als die Zusammenkünfte der Seminaristinnen und ihre Verbindung zur Fraternitas ruchbar wurden, griff die Seminarleitung jedoch nicht wie bei der Fidelitas hart durch, sondern erteilte dem Kränzchen offiziell die Erlaubnis, sich auch künftig am Seminar zu treffen. ${ }^{65}$ Die formalen Verstösse gegen die Seminarordnung dürften also, wie bereits das Schreiben an die Aufsichtskommission suggerierte, nicht der eigentliche Stein des Anstosses gewesen sein. Vielmehr spielte bei der Beurteilung der Sache durch den Lehrerkonvent der jeweilige Vereinszweck eine zentrale Rolle. Im einen Fall stand die Förderung der Abstinenz, im andern aber das studentische Kneipen im Vordergrund. An Letzterem störte sich der Konvent sichtlich. Er formulierte es in seinem Schreiben an die Aufsichtskommission des Seminars folgendermassen: »Der Konvent findet ferner, es sei die Nachahmung studentischer Sitten von Seite der Seminaristen vom Übel [sic!], umso mehr als die Schuldigen zu zwei Dritteln Stipendiaten sind. " $^{66}$

In der schliesslich von der Aufsichtskommission des Seminars erlassenen Verfügung wird die vom Lehrerkonvent vertretene Lesart des Falles Fidelitas genauso übernommen wie auch das vorgeschlagene Strafmass.$^{67}$ Die Seminardirektion wird ausserdem dazu eingeladen, der Erziehungsdirektion die Namen der schuldigen Stipendianten zu nennen. Auf der Verfügung zur Sistierung der entspre-

64 Dieses Kränzchen abstinenter Seminaristinnen hatte bereits um die Jahrhundertwende herum bestanden und wurde dann 1906 nochmal neu gegründet. 1908 wurden dem Konvent von einem anderen Seminaristenverein die Kontakte dieses Kränzchens mit dem Abstinentenverein Fraternitas enthüllt. Protokoll des Lehrerkonventes, Sitzung v. 16. Januar 1908, S. 275; De Vincenti 2020.

65 Zum Kränzchen abstinenter Seminaristinnen: Schmid 1982, S. 31; De Vincenti 2020.

66 Noch härter sollten drei Zöglinge der Klasse Illb bestraft werden, da deren Betragen bereits während des Sommersemesters mehrmals Anlass zu Klagen gegeben habe und sie die Betragensnote »nicht befriedigend« erhalten haben. Ihnen sollte zusätzlich zu den oben genannten Massnahmen die Wegweisung vom Seminar angedroht werden. Dieser Beschluss wurde nicht einstimmig gefällt, sondern mit dem Stimmenverhältnis 6:3-die Minderheit sprach sich für die sofortige Ausweisung zweier Zöglinge aus. Schreiben Lehrerkonvent an die Aufsichtskommission, 6. November 1904, S. [1ff.].

67 Abschrift Präsidialverfügung Aufsichtskommission, 7. November 1904. 
chenden Stipendien ist schliesslich auch handschriftlich die Bemerkung notiert, welche allen Fehlbaren im Wortlaut in ihr Zeugnis des Winterhalbjahres geschrieben werden sollte. Unter »Vorbehalt guten Verhaltens « sollte sie folgendermassen lauten: »Der Zögling hat am Anfange des Semesters einer vom Lehrerkonvente nicht genehmigten Verbindung angehört; seither aber gab sein Verhalten zu keinerlei Klagen Anlass. ${ }^{68}$ Die Sistierung der Stipendien wurde nicht in allen Fällen gleich gehandhabt. Für einige der Zöglinge wurde die Ausschüttung des Stipendiums beschlossen, für zwei bereits früher auffällig gewordene Schüler hingegen nicht. ${ }^{69}$

Unmittelbar nach Erhalt des Elternbriefes wandten sich mehrere Väter schriftlich an die Seminar- und die Erziehungsdirektion. Als erster schrieb Emil Knecht, der Vater von Arthur Knecht, an die Seminardirektion, um eine »Erklärung« der Sache abzugeben. ${ }^{70}$ In seinem Schreiben zeichnete er seinen Sohn als rechtschaffen und ehrenhaft. Am Abend sei er stets zu Hause und widme sich fleissig seinen Aufgaben. Er besuche nie (gross und unterstrichen) alleine eine Wirtschaft, sondern allenfalls in Begleitung des Vaters oder des älteren Bruders, am Sonntag widme er sich zu Hause der Musik. In der Familie werde überhaupt kein Alkohol genossen. Sein Freund, der nicht Seminarist, sondern Handelsschüler sei und mit dem er am meisten freundschaftlichen Verkehr pflege, sei Abstinent. Im Sommer hätten sie eine strenge Tour in den Alpen unternommen, ganz ohne Alkohol zu geniessen. Nicht nur der Lernfleiss, sondern auch die Abstinenz wird in dieser Beschreibung also mit Tugendhaftigkeit gleichgesetzt und die Anstrengung in der freien Natur als ehrenhafte und seriöse Freizeitgestaltung dargestellt - genauso wie auch die Musik im häuslichen Umfeld. Das Wirtshaus wird hingegen als übel beleumdeter Ort skizziert, ${ }^{71}$ den der Sohn nie alleine aufsuche, sondern

68 Präsidialverfügung, 9. November 1904, S. [2].

69 Protokoll Aufsichtskommission, 14. April 1905, Eintrag 562.

70 Schreiben Emil Knecht an die Seminardirektion, 10. November 1904.

71 Bereits in der Frühen Neuzeit war das Wirtshaus ein schillernder Ort. Einerseits neben Ratshaus und Kirche ein »drittes soziales Zentrum in Städten und Dörfern«, »Absteige-, Informations- und Geschäftsort für Kaufleute und mobile Gewerbetreibende«, andererseits natürlich auch »Zentrum nachbarschaftlicher Soziabilität«, wird das Wirtshaus auch in einer Gegenüberstellung von ehrlicher Arbeit und einem nicht ehrbaren (übermässigen) Genuss von Ess- und Trinkwaren als zwielichtiger Ort dargestellt, an dem es auch zur Begegnung der Geschlechter mitunter zu sexuellen Kontakten bis hin zur Prostitution kommen konnte. Auf der »öffentlichen Bühne« des Wirtshauses stand stets die persönliche Ehre auf dem Spiel (Kümin 2005, S. 88-90, 92 u. 94). Dies scheint auch der zentrale Punkt gewesen zu sein, weshalb ein ehrbarer Seminarist sich nicht unbegleitet im Wirtshaus aufzuhalten hatte. Für die zentrale Bedeutung der Ehre spricht auch ein Vorfall, der schliesslich doch noch zur Wegweisung des Fidelitasmitglieds Heinrich Burkhardt vom Seminar geführt hat, nachdem man wegen schwerer Krankheit seines Vaters zunächst davon abgesehen hatte. So hatte Burkhardt an einem sogenannten Bockabend teilgenommen und in einem Wirtshaus 
vielmehr dazu verführt worden sei: Erst wenige Wochen vor dem Bekanntwerden der Fidelitas sei er von seinen Klassengenossen in die Fidelitas hineingezogen worden. Eine Vereinigung, die sich angeblich nicht dem Trinken, sondern der "Geselligkeit, der Musik und dem Vortrage« widmete. Deshalb hätten auch die Eltern nichts dagegen einzuwenden gehabt, dass er sich am Samstagabend für zwei Stunden in Gesellschaft seiner Mitseminaristen aufhalte. Der Vater zeigte sich einverstanden mit einer Bestrafung, da sein Sohn gegen die Seminarordnung verstossen habe, eine Bemerkung im Zeugnis wies er allerdings als zu weitgehende Massregelung zurück: Dieser Makel wäre unauslöschlich in seinem Zeugnis, der einzigen Beurteilungsgrundlage eines jungen Lehrers, festgehalten: »[D]enken Sie doch daran, hochgeehrter Herr Direktor, dass das ein Makel wäre für ihn, Zeit seines Lebens«, zumal der junge Lehrer allein nach dem Zeugnis beurteilt werde. Die Fehlbaren verlören durch eine solche Bemerkung daher eher den Mut zur fleissigen Arbeit. ${ }^{72}$ Ähnlich argumentierte der Vater des Zöglings Max Herter gegenüber der Erziehungsdirektion: Der Eintrag hätte nicht beabsichtigte, schwere Folgen auf die Ausübung des Berufes der Betreffenden, indem er die »Missetat« für die "ganze weitere Lebenszeit« festnagle und sie dadurch »viel grösser erscheinen [lässt], als sie wirklich ist. Sie denunzierte den Inhaber des Zeugnisses als einen, dem nicht so recht zu trauen ist. Sie kann ihm - es braucht dies nicht mehr ausgeführt zu werden - in seiner spätern Laufbahn schweren Schaden zufügen. " Diese Wirkung könne von der Seminardirektion nicht beabsichtigt sein, wäre sie doch unverhältnismässig, da das Vergehen als »jugendliche Torheit zu taxieren « sei. ${ }^{73}$ Wie auch weitere Väter versuchen sie, die Ehre ihrer Familien und Kinder und damit auch deren Aussichten auf eine Anstellung als Lehrpersonen $\mathrm{zu}$ retten, und deuten die Fidelitas entsprechend als eine Jugendsünde, die zwar ohne Zweifel verurteilt und durch harschen Tadel bestraft werden sollte, die Zerstörung einer Berufslaufbahn jedoch nicht rechtfertige.

Die Seminardirektion hingegen, wies in einem Schreiben an die Erziehungsdirektion des Kantons Zürich vom 14. November 1904 die Deutungen in den elterlichen Briefen sowie die darin enthaltenen Bitten zurück, auf den Zeugniseintrag $\mathrm{zu}$ verzichten. ${ }^{74}$ Die Strafe würde ohne den Zeugniseintrag erheblich abgeschwächt, was angesichts des Vergehens nicht angezeigt sei. Wieder wurde

Musik gemacht. Im Protokoll der Aufsichtskommission heisst es entsprechend: »Die Seminardirektion wird beauftragt, die Zöglinge des Seminars nachdrücklich darauf aufmerksam zu mach [sic!], dass es für einen angehenden Volkserzieher im höchsten Grade unschicklich ist, in Wirtschaften öffentlich Musik aufzuspielen, und ihnen die Teilnahme an öffentlichen Produktionen in Wirtschaften mit dem Zwecke, Geld zu verdienen, unter Androhung der Wegweisung zu verbieten.«Protokoll Aufsichtskommission, 10. März 1905, Eintrag 545.

72 Schreiben Emil Knecht an die Seminardirektion, 10. November 1904, S. [2].

73 Schreiben ]. Herter an die Erziehungsdirektion, 12. XI. 1904, S. [2].

74 Schreiben Seminardirektion an die Erziehungsdirektion, 14. November 1904. 
auf die Imitation studentischer Trinkpraktiken verwiesen und in dem Zusammenhang dazu aufgerufen, die Betragensnote im Zeugnis auch ernst zu nehmen:

Die Schuldigen haben heimlicherweise einer unerlaubten Vereinigung angehört und jeden Samstag-Nachmittag unter Nachäffung studentischer Formen ein Trinkgelage veranstaltet. Wenn man sich vergegenwärtigt, dass am Seminar mit seinen rund 200 männlichen Zöglingen nicht weniger als vier Vereine bestehen und dass man hier in Vereinsangelegenheiten von einer Liberalität ist, die kaum ihresgleichen anderswo haben dürfte, so kann das Betragen der Bestraften gewiss nicht 'gut genannt werden. Und wenn das Betragen nicht gut ist, so muss das im Semesterzeugnis zum Ausdruck kommen, oder dann höre man lieber auf, Betragensnoten auszustellen. ${ }^{75}$

Mit den Betragensnoten sei man in der letzten Zeit ohnehin sehr milde umgegangen, damit habe man »ein anmassendes, oft geradezu flegelhaftes Benehmen einzelner Seminaristen « erreicht. Diese Seminaristen schickten sich nun an, die Anstalt zu verlassen, »um als Erzieher unserer Jugend ins Volk hinauszutreten." Das Schreiben argumentiert weiter, dass bei einem Verzicht die Nichtstipendianten, darunter auch der Präsident des Vereins, »dank ihrer besseren ökonomischen Situation « straflos ausgingen, »was entschieden nicht zu billigen wäre«. Zudem sässen neun der Schuldigen in der »berüchtigten Klasse 3b, die zu schonen man gar keine Ursache hat«. Es gehe aber auch nicht an, die Schüler aus der vierten Klasse, die das Seminar zum Semesterende verlassen würden, milder zu behandeln als die anderen. ${ }^{76}$ Noch deutlicher und mit einem Verweis auf den künftigen Beruf der Zöglinge formulierte das Protokoll der Aufsichtskommission: Die Massnahmen seien "nach jeder Richtung dem Vergehen der in Frage stehenden Zöglinge entsprechend, und das ganz besonders, weil es sich hier um künftige Bildner der Jugend handelt, von denen in erhöhtem Grade erwartet werden muss, dass ihr Verhalten den Anforderungen von Zucht und Ordnung entspreche. $\aleph^{77} \mathrm{Se}$ minardirektion und Aufsichtskommission wiesen also den Vorwurf zurück, der Zeugniseintrag liesse die »Missetat" grösser erscheinen, als sie war. In der Formulierung des Zeugniseintrages sei durchaus ersichtlich, dass es sich nicht um ein »Staatsverbrechen" gehandelt habe. Das Interesse des Staates müsse aber neben demjenigen des Zeugnisinhabers auch in Betracht gezogen werden. Der Kanton Zürich unterhalte sein Seminar, »um daran die Lehrer seiner Jugend erziehen und ausbilden zu lassen ${ }^{78}$ Die Schulvorsteherschaften, die einen Lehrer

75 Ebd., S. [2]

76 Ebd., S. [2f.].

77 Protokoll der Aufsichtskommission vom 25. November 1904, Eintrag 524.

78 Schreiben Seminardirektion an die Erziehungsdirektion, 14. November 1904, S. [4]. 
anstellten, hätten daher das Recht, sich nach seinem Charakter zu erkundigen, und die staatliche Lehrerbildungsanstalt habe die Pflicht, den Schulbehörden diesbezüglich die Wahrheit zu sagen. Rhetorisch und offensichtlich um die Ehre des eigenen Personals besorgt, fragte das Schreiben der Seminardirektion dann:

Wenn man die beiliegenden Statuten der Fidelitas durchliest, wenn der Präsident selbst erklärt, die Versammlungen seien in Zürich im Merkur abgehalten worden, weil man ein gutes Münchnerbier haben wollte, so darf man sich denn doch die Frage erlauben: Ist das das Holz, aus dem man tüchtige Volksschullehrer macht? Und wenn am Ende doch einer dieser Jünglinge später als Lehrer entgleist und man erfährt, was am Seminar passiert ist, wie wird man dann über die Männer urteilen, die jenen die Betragensnote sgut serteilt haben?

Ausserdem, so ein letzter Punkt in der Argumentation, brächte die Zurücknahme eines Punktes der Verfügung den Lehrerkonvent und die gegenwärtige Leitung der Anstalt »in eine recht fatale Lage gegenüber Eltern und Schülern«. Aus all diesen Gründen sei am Zeugniseintrag festzuhalten. ${ }^{79}$

\section{Trinkpraktiken und benachbarte Praktiken - Historisierung durch Dezentrierung}

Zunächst kann also festgehalten werden, dass die Trinkpraktiken der Fidelitas von allen Beteiligten als eine Nachahmung studentischer Trinkpraktiken verstanden wurden. Mag dies für die Mitglieder des Vereins einen Hauch des Subversiven, einen Hauch von akademischer Freiheit oder auch eines Sich-dem-seminaristischen-Erziehungsregime-Entziehens bedeutet haben, deuteten ihre Eltern diese Trinkpraktiken sicherlich auch strategisch aber innerhalb der Grenze des Sagbaren zwar als strafbare Handlung, immer aber auch als eine verzeihliche Jugendsünde, die es keinesfalls rechtfertige, eine künftige Anstellung der FidelitasMitglieder zu gefährden. Der Lehrerkonvent und die Seminardirektion lasen dieselben Praktiken hingegen als bedeutenden Verstoss gegen die Seminarordnung und vor allem als eine Nachäffung studentischer Verhaltensweisen, die strengstens zu ahnden sei. Dies, so kann aufgrund des im zweiten Kapitel dargelegten korrelativen Verständnisses von Praktiken gefolgert werden, weil sie durch die Trinkpraktiken der Fidelitas weitere Praktiken, die sie als zentral, ja konstitutiv für das Seminar verstanden, gefährdet sahen.

Mit dem Fall Fidelitas wird nämlich auch das Seminar als Institution infrage gestellt und das Verständnis davon in den geführten Debatten aktualisiert. 
Offensichtlich standen Befürchtungen im Raum, das Ansehen des kantonalen Lehrerseminars und seiner Lehrer könnte beschädigt werden. Dies wird an den kontroversen Diskussionen von Praktiken, etwa des Strafens oder Ahndens von Vergehen, der Herstellung von Ordnung und Disziplin, aber auch der Verhaltensbeurteilung der Zöglinge (Betragensnote), die streng und gerecht sein sollten, jedoch offenbar weder das eine noch das andere waren, deutlich. Ebenso zeigt sich dies im Zusammenhang mit der besonderen Empörung über die Stipendianten in der Fidelitas oder in der Klage über zu wohlwollende Betragensnoten. Die Kontroversen um die Fidelitas verweisen auf Praktiken der Selbstdarstellung und -profilierung des Seminars in der Öffentlichkeit: indem man sich sorgte, wie dereinst über die Beurteilenden selbst geurteilt würde, wenn einer dieser aus Nachlässigkeit mit guten Betragensnoten ausgestatteten Zöglinge erneut fehlbar würde. Die Ausweisung aus dem Seminar aufgrund schlechten Betragens zeugt von einem in der Seminardirektion sowie auch im Lehrerkonvent etablierten Verständnis der Ausbildung zum Lehrer, welches nicht nur die Formung des Charakters der angehenden Volkserzieher zum Ziel hatte, ${ }^{80}$ sondern ebenso eine charakterliche Selektion beinhaltete - so wurden Ausweisungen aus dem Seminar auch mit charakterlicher Unzulänglichkeit begründet, die nicht unbedingt mit schlechten Leistungen einhergehen musste. ${ }^{81}$ Im Zusammenhang mit solchen Praktiken zur Bewahrung der Anstaltsreputation, wird auf eine Verpflichtung gegenüber dem Staat verwiesen: das Seminar sei eine Anstalt der Berufsbildung und weder ein akademisches Studium noch eine auf ein Studium vorbereitende Mittelschule. Aus dem Seminar müssten »tüchtige Volksschullehrer" hervorgehen, die später nicht nur Kinder unterrichten, sondern ebenso Verantwortung für ein vielfältiges Vereinswesen in den Gemeinden tragen sollten. Insbesondere für Seminarzöglinge, die - im Unterschied zu anderen Mittelschülern - nach Ab-

80 Schreiben Seminardirektion an die Erziehungsdirektion, 14. November 1904, S. [4]; vonseiten der Aufsichtskommission sowie auch des Lehrerkonvents wurde gar gewünscht, »den ins Leben hinaus tretenden Lehrern am Schlusse ihrer Studienzeit in einem feierlichen Akte ihre Pflichten als Bürger u. als Volksschullehrer noch besonders vorzuführen «. Sitzung vom 3. März 1905, Protokoll des Lehrerkonvents, S. 187.

81 So wurde etwa für den Zögling Walter Leemann ein Ausweisungsgesuch aus dem Seminar gestellt. Leemann war, wie seine Kostfamilie gemeldet hatte, bereits in seinem ersten Studienjahr wegen späten Heimkehrens an seinen Kostort verwarnt worden. Dann, als er in der dritten Klasse war, tauchte er betrunken an einer Versammlung des Turnvereins auf, die im Saal eines örtlichen Wirtshauses stattfand. Als der Vorwurf im Raum stand, Leemann bereite den anwesenden Seminaristen »Unehre«, bedrohte er den Lehrer, der diesen Vorwurf geäussert hatte, mit einem Revolver, verliess dann aber den Saal, nachdem ihn ein Wurfgeschoss beinahe getroffen hatte. Der Vorfall zeige, so der Befund des Lehrerkonvents, dass Leemann ein »Entgleiste[r]«, ein »roher Mensch «sei und ein »für einen Lehrer durchaus ungeeignetes Wesen« habe. Schreiben Lehrerkonvent Lehrerseminar Küsnacht an die Aufsichtskommission, 4. November 1915, S. [1f]; siehe auch De Vincenti 2018, S. $16 f$. 
schluss ihrer Ausbildung direkt in das Berufsleben einstiegen, sei es wichtig, so etwa Direktor Edwin Zollinger in Übereinstimmung mit der Konventsmehrheit, Erfahrungen mit Vereinen zu sammeln, zumal es oft die Lehrer seien, welche in den Dörfern Vereine präsidierten. ${ }^{82}$ Die bewilligten Schülervereine und ebenso das zunächst nicht bewilligte Kränzchen der Seminaristinnen wurden von der Seminardirektion und auch vom Konvent schliesslich mit dem Argument unterstützt, sie förderten Selbsttätigkeit und Selbstorganisation der Seminarist/-innen und dienten somit einem Ausbildungsziel des Seminars zu: der Hervorbringung eines tüchtigen, charakterlich integren Lehrers und Staatsbürgers.

Gerade diese charakterbildende Eigenschaft wurde insbesondere den Turnern stark zugeschrieben, obwohl auch sie Alkohol tranken. Dies geschah aber in Kontexten wie etwa den Turnfesten, die an etablierte und als legitim erachtete Praktiken des Trinkens ausserhalb des Seminars anschlossen. An Turn-, Schützen- oder Sängerfesten galt der oftmals exzessive Alkoholkonsum gar als Voraussetzung für das Erleben und die Hervorbringung des »erstrebten Gemeinschaftsgefühl[s]«, der konfessionelle, regionale oder soziale Gräben überwindenden "nationale[n] Einheit « sowie des charakterlich integren und an der Gemeinschaft orientierten Staatsbürgers. ${ }^{83}$ Dieser Stellenwert des Alkoholkonsums blieb in der eidgenössischen Festkultur lange unumstritten. Als 1922 im Zuge eines virulenter werdenden Gesundheits- und Leistungsdiskurses ${ }^{84}$ das sogenannte Gedeck (»couvert«) am Eidgenössischen Turnfest in St. Gallen erstmals ohne die traditionelle Flasche Wein pro Person abgegeben werden sollte, opponierten die Organisatoren mit der Begründung, diese »Neuerung dürfte auch der Pflege des Gemeinsinns und der Solidarität, der Ein- und Unterordnung in ein grosses Ganzes nicht förderlich sein, wohl aber den egoistischen und philisterhaften Sonderbestrebungen $\ll .{ }^{85}$

Vor solchen Interpretationsfolien wurde das Trinken im Turnverein anders bewertet als das Trinken in der Fidelitas: Ersteres diente in der Wahrnehmung der Akteure der Herausbildung einer durchaus erwünschten charakterlichen Stärke und einer patriotischen Gesinnung der angehenden Volkserzieher. Letzteres wurde hingegen als Nachäffung studentischer Gepflogenheiten ohne bildenden Gehalt betrachtet und für die dezidiert nicht als Studenten wahrgenommenen Zöglinge des Seminars Küsnacht als nicht angemessen beurteilt. Dies obwohl in studentischen Kontexten gerade auch den teilweise hoch formalisierten Trinkexzessen ganz ähnliche Bedeutungen zugeschrieben wurden wie dem Trinken an

82 Antrag an die Seminaraufsichtskommission, 19. Januar 1909, S. 3.; siehe auch De Vincenti 2018, S. 14.

83 De Capitani 2010, S. 36 u. 34.

84 Hofmann 2016; im Zusammenhang mit dem Turnen Kern 2009, S. $55 f$.

85 De Capitani 2010, Zitat S. 39. 
Turnfesten: Durch die kollektiven und rituellen Überschreitungen körperlicher Grenzen sowie dem damit einhergehenden Kontrollverlust sollten Gemeinschaft, die Fähigkeit zur Unterordnung sowie auch Männlichkeit herangebildet werden. ${ }^{86}$ Solche studentischen Trinkpraktiken wurden jedoch von Eltern, Lehrern und der Seminarleitung in Küsnacht negativ bewertet und mit der Begründung zurückgewiesen, die Seminaristen seien keine Studenten, sondern angehende Volkserzieher in einer Berufsausbildung, welche auf ihre unmittelbar an das Studium anschliessende Berufstätigkeit vorbereitet werden müssten. Die Trinkpraktiken der Mitglieder der Fraternitas wurden daher nicht als Ausdruck einer erwünschten Gemeinschaftsfähigkeit, sondern als Hinweis auf einen gefährdeten Charakter sowie auf eine das Seminar gefährdende Gegengemeinschaft gedeutet.

Erst durch einen Blick auf jeweils benachbarte Praktiken konnten die vordergründig ähnlichen Trinkpraktiken im Seminarturnverein und in der Fidelitas eingeordnet und die ihnen von den Zeitgenossen zugeschriebenen Deutungen freigelegt werden. Praktiken des Trinkens können in ihren Bezugnahmen auf andere Praktiken, in ihrer Komplementarität und auch in ihrer Widersprüchlichkeit $\mathrm{zu}$ diesen beschrieben werden. Der Fokus auf solche Korrelate von Praktiken ermöglicht es, ein Geflecht von Beziehungen zwischen unterschiedlichen Praktiken herauszuarbeiten, aus dem sich zeitgenössische Deutungen der jeweiligen Praktiken und somit die Praktiken selbst erst erschliessen lassen.

Der scheinbar überzeitliche Begriff des Trinkens wird mit dem Ansatz der Historischen Praxeologie zudem aus dem Material heraus zeitlich und räumlich verortet und kontextualisiert. Dadurch wurden auch die Facetten seiner Deutungen und Bewertungen herausgearbeitet. In der Forschungsliteratur etablierte Narrative etwa bezüglich des Trinkens von Studenten oder bezüglich Strenge und Disziplin am Seminar oder bezüglich des Seminars als Institution können so mit den herausgearbeiteten Ergebnissen konfrontiert und diskutiert werden und verlieren ihren A-priori-Charakter. ${ }^{87}$ Unter Berücksichtigung solcher Bedeutungszuschreibungen können schliesslich perspektivierte Bilder einer wiederum orts- und zeitspezifischen Seminarkultur gewonnen werden - dies ohne die Erzählungen bei gesetzten Normen und/oder Meistererzählungen ${ }^{88}$ über das Semi-

86 Levsen 2007, S. 178f.; Blattmann 1996, S. 126.

87 Pavel Kolář (2012, S. 9) spricht in dem Zusammenhang von der »Fragmentierung identitätsstiftender Großerzählungen«.

88 So gab es gemäss einschlägiger Fachliteratur am Seminar Küsnacht vier Schülervereine und eine Vereinigung der Seminaristinnen (z.B. Schmid 1982, S. 27-31; Bloch 1992). Dieser Forschungsstand wird implizit bis heute durch die Archivordnung gestützt, welche die vier in der Forschung benannten Vereine (Turnverein, Stenographieverein, Leseverein, Abstinentenvereine) unter einer entsprechenden Rubrik führt. Die Fidelitas war eine Vereinigung von Seminaristen, die sich Vereinsstatuten gegeben hatte, und könnte somit auch unter den Vereinigungen der Seminaristen abgelegt werden. Dass sie bis heute als Disziplinarfall be- 
nar beginnen zu lassen. Insofern kann der Fokus auf Praktiken als Möglichkeit einer radikalen Historisierung bezeichnet werden.

\section{Quellen und Literatur}

\section{Ungedruckte Quellen}

\section{Staatsarchiv des Kantons Zürich (StAZH)}

Abschrift der Präsidialverfügung der Aufsichtskommission des Seminars Küsnacht vom 7. November 1904 (U 73.3.11).

Antrag an die Seminaraufsichtskommission vom 19. Januar 1909 (U 73.4.12).

Fidelitas Zürich. Gegründet 10. Februar 1903. Statuten (U 73.3.11).

Jahresbericht über das Kantonale Lehrerseminar in Küsnacht für 1904 (Z 388.785). Jahresbericht über das Kantonale Lehrerseminar in Küsnacht für 1905 (Z 388.786). Präsidialverfügung vom 9. November 1904 (U 73.3.11).

Protokoll der Aufsichtskommission, Sitzung vom 25. November 1904 (UU 20.20).

Protokoll der Aufsichtskommission, Sitzung vom 10. März 1905 (UU 20.20).

Protokoll der Aufsichtskommission, Sitzung vom 14. April 1905 (UU 20.20).

Protokoll des Lehrerkonventes Seminar Küsnacht (1895 - 1908) (Z 388.1586).

Schreiben von J. Herter an die Erziehungsdirektion des Kantons Zürich. 12. XI. 1904 (U 73. 3.11).

Schreiben von Emil Knecht, Lini[e]rer, an die Seminardirektion Küsnacht vom 10. November 1904 (U 73.3.11).

Schreiben des Lehrerkonvents an die Aufsichtskommission des Seminars vom 6. November 1904 (U 73.3.11).

Schreiben des Lehrerkonvents des Zürcherischen Lehrerseminars Küsnacht an die Aufsichtskommission des Lehrerseminars Küsnacht, datiert auf den 4 . November 1915 (U 73.4.10).

Schreiben der Seminardirektion an die Erziehungsdirektion des Kantons Zürich vom 14. November 1904 (U 73.3.11).

Schreiben des Seminar-Turnvereins an die Erziehungsdirektion des Kantons Zürich vom 23. Dezember 1910 (U 73.4.15).

\section{Forschungsbibliothek Pestalozzianum PH Zürich}

Seminarordnung für das Lehrerseminar des Kantons Zürich in Küsnacht (vom 30. Dezember 1901). Forschungsbibliothek Pestalozzianum, (ZH HA II 5). 


\section{Gedruckte Ouellen}

Jahresbericht des Seminar-Turnvereins Küsnacht pro 1908-09. Küsnacht, 1909. Jahresbericht des Seminar-Turnvereins Küsnacht pro 1909-1910. Küsnacht, 1910.

\section{Literatur}

Berger, Peter L./Luckmann, Thomas (2007): Die gesellschaftliche Konstruktion der Wirklichkeit. 21. Aufl. Frankfurt a.M.

Blattmann, Lynn (1996): »Lasst uns den Eid des neuen Bundes schwören ...«. Schweizerische Studentenverbindungen als Männerbünde 1870-1914. In: Thomas Kühne (Hg.): Männergeschichte - Geschlechtergeschichte. Männlichkeit im Wandel der Moderne. Frankfurt a.M., New York, S. 119-135.

Blattmann, Lynn (1995): Entgrenzungs- und Verbindungsrituale in schweizerischen Studentenverbindungen, 1870-1914. In: Rudolf Jaun/Brigitte Studer (Hg.): weiblich-männlich. Geschlechterverhältnisse in der Schweiz: Rechtsprechung, Diskurs, Praktiken. Zürich, S. 145-157.

Bloch, Alexandra (1992): Lehrerbildung im 19. und 20. Jahrhundert. Der Beitrag des neuerschlossenen Seminararchivs Küsnacht zur Zürcher Schulgeschichte. In Zürcher Taschenbuch 1993 N. F. 113. Zürich, S. 99-130.

Daniel, Ute (1993): »Kultur« und »Gesellschaft«. Überlegungen zum Gegenstandsbereich der Sozialgeschichte. In: Geschichte und Gesellschaft 19, S. 69-99.

De Capitani (2010): Tafeln zu Ehren des Vaterlandes: Essen und Trinken an den schweizerischen Verbandsfesten im 19. Jahrhundert. In: Kunst + Architektur in der Schweiz 61, S. 34-39.

De Vincenti, Andrea (2020): Erziehen zur Abstinenz? Das »abstinente Kränzchen« am kantonalen Lehrerseminar Küsnacht (1906 - 1926). In: Andrea De Vincenti, Norbert Grube, Michèle Hofmann, Lukas Boser (Hg.): Pädagogisierung des "guten Lebens«. Bildungshistorische Perspektiven auf Ambitionen und Dynamiken im 20. Jahrhundert. Bern, S. 71-94.

De Vincenti, Andrea (2018): Kontrollierte Räume? Erziehende und gemeinschaftsbildende Settings neben den Unterrichtsräumen am Zürcher Seminar Küsnacht im 19. und beginnenden 20. Jahrhundert. In: Historia Scholastica 1 (2018), S. 5-16.

De Vincenti, Andrea (2015): Schule der Gesellschaft. Wissensordnungen von Zürcher Unterrichtspraktiken zwischen 1771 und 1834. Zürich.

Dinges, Martin (1997): »Historische Anthropologie« und »Gesellschaftsgeschichte«. Mit dem Lebensstilkonzept zu einer »Alltagskulturgeschichte« der frühen Neuzeit? In: Zeitschrift für Historische Forschung 24, H. 2, S. 179-214. 
Foucault, Michel (2014): In Verteidigung der Gesellschaft. Vorlesungen am Collège de France (1975-1976). 4. Aufl. Frankfurt a.M.

Freist, Dagmar (2015): Historische Praxeologie als Mikro-Historie. In: Arndt Brendecke (Hg.): Praktiken der Frühen Neuzeit. Akteure, Handlungen, Artefakte. Köln, Weimar, Wien, S. 62-77.

Füssel, Marian (2015): Die Praxis der Theorie. Soziologie und Geschichtswissenschaft im Dialog. In: Arndt Brendecke (Hg.): Praktiken der Frühen Neuzeit. Akteure, Handlungen, Artefakte. Köln, Weimar, Wien, S. 21-33.

Giddens, Anthony (1997): Die Konstitution der Gesellschaft. Grundzüge einer Theorie der Strukturierung. 3. Aufl. Frankfurt a.M., New York.

Grube, Norbert (2018). Verortungsversuche von fluiden Bildungsräumen im Evangelischen Lehrerseminar Zürich Unterstrass 1870 bis 1950. Das familiale Leitbild als raumkonstituierender Ordnungsfaktor. In: Historia Scholastica 4, H. 1, S. 17-28.

Grube, Norbert (2016): Schulwirklichkeit? Wissensproduktion über Volksschulen in Holstein und in der Helvetischen Republik um 1800. In: Daniel Tröhler (Hg.): Schule, Lehrerschaft und Bildungspolitik um 1800. Neue Studien im Umfeld der Helvetischen Stapfer-Enquête von 1799. Bad Heilbrunn, S. 181-198. Haasis, Lucas/Rieske, Constantin (2015): Historische Praxeologie. Zur Einführung. In: Diess. (Hg.): Historische Praxeologie. Dimensionen vergangenen Handelns. Paderborn, S. 7-24.

Hofmann, Michèle (2016): Gesundheitswissen in der Schule. Schulhygiene in der deutschsprachigen Schweiz im 19. und 20. Jahrhundert. Bielefeld.

Kern, Stefan (2009): Turnen für das Vaterland und die Gesundheit. Der Eidgenössische Turnverein und seine Ansichten vom Schulturnen, dem freiwilligen Vorunterricht und dem Vereinsturnen 1900-1930. München.

Kolář, Pavel (2012): Historisierung. Version: 2.0. In: Docupedia-Zeitgeschichte vom 22. Oktober 2012, online unter http://docupedia.de/zg/kolar_historisie rung_v2_de_2012 (Zugriff: 15.04.2020).

Kümin, Beat (2005): Das vormoderne Wirtshaus im Spannungsfeld zwischen Arbeit und Freizeit. In Schweizerische Gesellschaft für Wirtschafts- und Sozialgeschichte 20, S. 87-98.

Landwehr, Achim (2012): Die Kunst, sich nicht allzu sicher zu sein: Möglichkeiten kritischer Geschichtsschreibung. In: WerkstattGeschichte 61, S. 7-14.

Landwehr, Achim (2000): »Normdurchsetzung« in der Frühen Neuzeit? Kritik eines Begriffs, in: Zeitschrift für Geschichtswissenschaft 48, S. 146-162.

Levsen, Sonja (2007): Männliche Bierbäuche oder männliche Muskeln? Studenten, Männlichkeit und Gesundheit zwischen 1900 und 1930. In: Martin Dinges (Hg.): Männlichkeit und Gesundheit im historischen Wandel ca. 1800-2000. Stuttgart, S. 175-190. 
Lipphardt, Veronika/Patel, Kiran Klaus (2008): Neuverzauberung im Gestus der Wissenschaftlichkeit. Wissenspraktiken im 20. Jahrhundert am Beispiel menschlicher Diversität. In: Geschichte und Gesellschaft 34, H. 4, S. 425-454.

Loetz, Francisca (2002): Mit Gott handeln. Von den Zürcher Gotteslästerern der Frühen Neuzeit zu einer Kulturgeschichte des Religiösen. Göttingen.

Lüdtke, Alf (1997): Alltagsgeschichte: Aneignung und Akteure. Oder - es hat noch kaum begonnen! In: WerkstattGeschichte 17, S. 83-92.

Lüdtke, Alf (1991): Herrschaft als soziale Praxis. Historische und sozial-anthropologische Studien, Göttingen.

Mazon, Patricia M. (2003): Gender and the Modern Research University. The Admission of Women to German Higher Education, 1865-1914. Stanford.

Neugebauer, Wolfgang (1985): Absolutistischer Staat und Schulwirklichkeit in Brandenburg-Preussen. Berlin.

Reckwitz, Andreas (2008): Praktiken und Diskurse. Eine sozialtheoretische und methodologische Relation. In: Herbert Kalthoff/Stefan Hirschauer/Gesa Lindemann (Hg.): Theoretische Empirie: zur Relevanz qualitativer Forschung. Frankfurt a.M. 2008, S. 188-209.

Sarasin, Philipp (2011): Was ist Wissensgeschichte? In: Internationales Archiv für Sozialgeschichte der deutschen Literatur 36, H. 1, S. 159-172.

Schlumbohm, Jürgen (1997): Gesetze, die nicht durchgesetzt werden - ein Strukturmerkmal des frühneuzeitlichen Staates? In: Geschichte und Gesellschaft 23, S. 647-663.

Schmid, Christian (1982): Das Seminar Küsnacht. Seine Geschichte von 1832-1982. Zürich.

Veyne, Paul (1992): Foucault: Die Revolutionierung der Geschichte. Frankfurt a.M. 


\section{Kontrollregime und Eigensinn am Zürcher Lehrerseminar und an Erziehungsanstalten im späten 19. und frühen 20 . Jahrhundert Analysen von Selbstzeugnissen und Archivquellen'}

Norbert Grube

\section{1 Überlegungen zu Ansätzen und Begriffen der historischen Praxeologie}

Konzepte der historischen Praxeologie werden häufig idealtypisch oder dualistisch verkürzt auf Debatten zurückgeführt, wie sie etwa vor 30 Jahren über die Alltags- und Mikrogeschichte geführt wurden. ${ }^{2}$ Auf der einen Seite wird ein Begriff von Praktiken entfaltet, der in Anlehnung an Michael Polanyi auf sogenanntem implizitem Wissen fusst, ${ }^{3}$ mit wissenssoziologischen Ansätzen der Institutionalisierung ${ }^{4}$ kombiniert ist und stark die Bedeutung strukturhafter Muster, Normen, Gewohnheiten und Rituale im Kontext bestimmter Arenen und Interaktionen betont. Diese Annahme eröffnet Nähen zu sozial- und kommunikationstheoretischen Konzepten von kultureller Kohärenz und Konformität, etwa zu Arnold Gehlens Begriff der Institutionen, ${ }^{5}$ oder aber zu Theorien der öffentlichen Meinung als sozialer Kontrolle. Diese Ansätze sind weniger auf eine im rationalen, freien Kommunikationsaustausch konturierte Öffentlichkeit ausgerichtet, ${ }^{6}$ sondern auf institutionalisierte, ungeschriebene und allgemein gültige Regeln, die

1 Dieser Beitrag entstand im Rahmen des SNF-Projekts 166008 »Wissenschaft - Erziehung und Alltag. Orte und Praktiken der Zürcher Primarlehrer/-innenbildung in der ersten Hälfte des 20. Jahrhunderts«.

2 Vgl. dazu zusammenfassend Füssel 2015; Lüdtke 1997; Sarasin 2003.

3 Vgl. Reckwitz 2008, S. 188 u. 191; Jaeggi 2014, S. 124f.; Lipphardt/Patel 2008, S. 426.

4 Vgl. Berger/Luckmann 2001, S. 33-35 u. 58.

5 Gehlen 2004, S. 65 u. 81f.

6 Habermas 1990. 
öffentlich eher stillschweigend akzeptiert und sanktioniert werden. ${ }^{7}$ Schon Bourdieus Studien zur kabylischen Verhaltensregulierung, aber auch frühneuzeitliche lokalgeschichtliche Forschungen hoben die hohe Relevanz der öffentlichen Meinung bei der Zuweisung bzw. Aberkennung von Ehre und als eine Art soziale Richterinstanz für erwartungskonformes Verhalten hervor. ${ }^{8}$ Sie trage in diversen Kontexten massgeblich zur Legitimation und damit zur Geltung von Praktiken in bestimmten sozialen Kontexten bei. Derlei kommunikationstheoretische Ansätze vermögen auch für praxeologische Studien neue Einsichten zu bieten.

Auf der anderen Seite werden mit Alltagspraktiken spezifische individuelle Aneignungs- und Verhaltensoptionen verschiedener Akteure, wie sie "an der $\mathrm{Zu}$ richtung ihrer Natur teilnehmen «, ${ }^{9}$ in den Blick genommen. Demnach reproduzieren Akteure nicht nur die alltäglichen Abläufen zugrundeliegenden impliziten Normen und Erwartungen einer teils eher unsichtbaren öffentlichen Meinung, sondern modifizieren oder prägen sie gar durch je eigenwillige Facetten des Mitmachens und der Nachahmung und bringen sie wiederum leicht modifizierend mit hervor. Die sogenannte agency der Subjekte wurde u.a. mit dem vor etwa drei Jahrzehnten eingeführten Begriff der Aneignung und des Eigensinns alltagsgeschichtlich zu konzeptionalisieren versucht. Mit diesem Ansatz erfuhr der Blick auf Deutungs- und damit Machtkämpfe über kulturelle Sinnzuschreibungen und -produktion neue Relevanz..$^{10}$ Eigensinn ist in seinem Facettenreichtum und seiner Widersprüchlichkeit zu verstehen: Er impliziere ein Mitmachen gegenüber institutionalisierten Regeln und Normen ebenso wie ein gleichzeitiges Distanzieren oder emotionale, inkonsistente Abweisung. ${ }^{11}$ Der Begriff verweist nicht per se auf Einzigartigkeit und Resistenz oder Subversion, sondern mauf die Vieldeutigkeit, Unvermitteltheit, auch Unvereinbarkeit von Verhaltensweisen von einzelnen Akteuren - jenseits der Ein- oder Zuordnung in übergreifenden Strukturen $\ll .{ }^{12}$ Derartige Auffassungen von eigensinnigen Aneignungen tendieren zu dem kulturhistorischen Begriff der Aushandlung, ${ }^{13}$ sofern er nicht rein intentional gedacht wird.

Der hier bewusst zugespitzte Dualismus zwischen strukturell durch Wissensordnungen geprägten Praktiken und individuellen Modifikationsoptionen könnte - verkürzt gesagt - eine Parallele finden in Michel de Certeaus Gegenüberstellung von Strategie der Mächtigen und Taktiken der Schwachen: Strategie

7 Tönnies 1920; Noelle-Neumann 2001. Ähnlichkeiten zu Noelle-Neumanns Definition von öffentlicher Meinung besitzt Rahel Jaeggis (2014, S. 154) Begriff der Gebräuche.

8 Bourdieu 2015, S. 25, 45 u. 146; Sabean 1990, S. 174; vgl. Schlögl 2008, S. 176.

9 Conrad/Kessel 1998, S. 27.

10 Vgl. Lüdtke 2003, S. 281; vgl. auch Tanner 2012 und Reichardt 2015, S. $51 f$.

11 Vgl. Lüdtke 1997, S. 86f. u. 90; 2003.

12 Vgl. Davis et al. 2008, S. 18; Conrad/Kessel 1998, S. 18.

13 Vgl. Mergel 2000, S. 591 u. 597. 
beruhe demnach auf Plan und Ratio, während Taktiken durch situativ bedingte und zugleich scharfsinnige List bzw. intuitivem Spiel geleitetet seien und so Gewohn- und Regelhaftigkeiten nuancenhaft variieren können: »Viele Alltagspraktiken [...] haben einen taktischen Charakter. ${ }^{14}$

So sind in der Frage, ob Praktiken nun eher die »Reproduktion« soziokulturell etablierter Ordnungen forcierten oder in bestimmten Kontexten sich als »Widerständigkeit $\aleph^{15}$ der Subjekte, eine spezifische Option des Eigensinns, hervorbringen, auch jüngst synthesehafte Lösungsangebote vorgelegt worden. Haasis und Rieske sprechen von einem dialektischen Verhältnis von Struktur und Handeln und betonen zugleich, dass verschiedene Praktiken mehrschichtig miteinander verwoben bzw. verzwirnt seien. ${ }^{16}$ Diskurse und Praktiken seien, so Marian Füssel, komplementär aufeinander bezogen - und beide als Materialisierungen von kultureller Wissensordnung zu begreifen, die gleichsam »in Praktiken und Diskursen verhandelt wird « und diese damit auch präformiert. ${ }^{17}$ Von sozialphilosophischer Seite aus hat Rahel Jaeggi vor Kurzem mit dem Begriff der Lebensform die Beständigkeit und lediglich wenigen krisenhaften Änderungsmomente von »Orientierungen und Ordnungen sozialen Verhaltens«bzw. von »Werten und Routinen « betont. Lebensform beruhe auf einem Bündel mehrerer Praktiken - also "gewohnheitsmäßige, regelgeleitete, sozial bedeutsame Komplexe ineinandergreifender Handlungen, die ermöglichenden Charakter haben und mit denen Zwecke verfolgt werden ${ }^{18}{ }^{18}$ Sie überlebe lange, so Jaeggi in eigentümlicher marxistischdialektischer und fast an das Narrativ der Degeneration anschliessender Sicht, wenn sie funktional notwendig, sachangemessen, konventionell und ethisch für ein sogenanntes gutes Leben begründbar sei. ${ }^{19}$ Doch zugleich betont Jaeggi mit dem »stage-setting character« von Praktiken in bestimmten Kontexten fast intentional gedachte Handlungsoption (Ermöglichungscharakter). ${ }^{20}$ Lebensformen seien nicht erstarrt, sondern sie formieren sich durch ein »Ensemble lebendiger Praktiken « täglich neu, wie zuletzt etwa am Beispiel »doing capitalism « ${ }^{21}$ gezeigt wurde. Schon die Erforschung frühneuzeitlicher lokaler Lebenswelten hat am Beispiel der Bedeutung von Ehre betont, wie Ansehen sowie Konfrontationen im Dorf feste Sozialstrukturen transzendierend »zur Herausbildung neuer vertikaler

\footnotetext{
14 De Certeau 1988, S. 24; Conrad/Kessel 1998, S. 18.

15 Füssel 2015, S. 25.

16 Haasis/Rieske 2015, S. 13 u. 16.

17 Füssel 2015, S. 23; Reckwitz 2008, 190, 202 (Zitat).

18 Jaeggi 2014, S. 102f.; vgl. Schlögel 2017, S. 20, dem der Begriff der Lebensform als Analysekomposition zur Geschichte der sowjetischen Gesellschaft diente.

19 Jaeggi 2014, S. $165 f$.

20 Ebd., S. $99 f$.

21 Brandes/Zierenberg 2017, S. $5 f$.
} 
Beziehungen« beitragen können, die »beständig [...] in Bewegung« und zugleich etwas »Geformtes « seien. ${ }^{22}$

So wurde gerade in jüngsten Darstellungen zur historischen Praxeologie eine ständige Reziprozität bzw. Zirkulation zwischen institutionalisierten Handlungsmustern, Gewohnheiten und Regelhaftigkeiten sowie individuellen Aneignungen und eigensinnigen Umformungen hervorgehoben. Diese Syntheseperspektive, die Anschlussmöglichkeiten an kommunikationstheoretisch geleitete Arbeiten zur Frühen Neuzeit und an wissensgeschichtliche Ansätze erlaubt, ${ }^{23}$ klingt plausibel. Doch kann sie phasenweise auch einen gleichsam holistisch-totalen, ausleuchtenden Blick auf komplexe Verläufe der kontextuell je spezifischen subjektiven Anknüpfungen und Modifikationsoptionen von zugleich stabilen sozialen Wissensordnungen, Routinen und Normen insinuieren. Die Ambition de Certeaus, mit seinem Forschungsansatz in die »Finsternis eindringen « $\mathrm{zu}$ wollen, forcierten jüngste praxeologische Beiträge, in denen die Spurensuche nach Praktiken mit der Aufdeckung von Alltags- oder »Vollzugswirklichkeit« verbunden wurde. ${ }^{24}$ Solchen zu weitgehenden Vorstellungen kann der praxeologische Ansatz Vorschub leisten, wenn mit seiner Ausrichtung auf Materialität und seiner Präferenz des »quellennahen Erzählen[s] « und der Arbeit »möglichst nah am Material« am Ende doch wieder eher das historische »So-Sein«, das Resultat, die vermeintliche Tatsache und weniger die Pfade, Wahrnehmungen, Erfahrungen des »So-Gemacht-Sein ${ }^{25}$ bzw. das So-Geworden-Sein dominieren. ${ }^{26}$ Das schon Mitte der 1980er-Jahre formulierte alltags- und bildungshistorische Ansinnen, >Wirklichkeit ermitteln zu können, wurde jedoch vor einiger Zeit unter konstruktivistischen Vorzeichen zurückgewiesen. ${ }^{27}$ Statt $\mathrm{zu}$ einer vermeintlichen $>$ wirklichen Totalschau und -deutung auf das gesamte Bündel von Praktiken zu gelangen, sollte sich eine historisch praxeologische Studie allein schon wegen einer methodisch aufwendigen, gegen mögliche Autorintentionen gegengebürsteten Quellenanalyse und der behutsamen »Sensibilität für das Tracing der Vergangenheit ${ }^{28}$

22 Sabean 1990, S. 23 U. 42 (Zitat).

23 Schlögl 2008 sieht mit vordringender Verschriftlichung und Verherrschaftlichung in der Frühen Neuzeit einen Wandel der dörflichen Interaktionspraxis; vgl. Sarasin 2011.

24 De Certeau 1988, S. 11 (dort das erste Zitat); Hillebrand 2015, S. 37f. (dort das zweite Zitat); vgl. Settele 2017, S. 46.

25 Landwehr 2003, S. 103.

26 Haasis/Rieske 2015, S. 51.

27 Neugebauer 1985, vgl. kritisch dazu De Vincenti 2016.

28 Tanner 2012, S. 11. Nietzsche kritisierte »eine Historie, welche die Vielfalt der Zeit in eine geschlossene Totalität einbringen und auf einen Nenner bringen will«, so Foucault 1974/1998, S. 56. 
darauf beschränken, nur ausschnittsweise Praktiken in bestimmten Kontexten zu untersuchen. Ein Ausgangspunkt dieser mit Bildern der Archäologie und Mosaikzusammensetzung illustrierten Spurensuche ${ }^{29}$ der strukturell auf Wissensordnungen beruhenden Praktiken und ihrer eigensinnigen, individuellen Adaptionen bzw. Modifikationen kann dabei sein, wie sich dieses problematisierte Wechselspiel »in der subjektiven Sicht der Zeitgenossen abgespielt« hat. ${ }^{30}$

\section{Selbstzeugnisse, Wissen und Praktiken: Fragestellung, Vorgehen und Quellen}

Die folgende Untersuchung fragt am Beispiel Deutschschweizer Erziehungsanstalten und speziell des 1832 gegründeten Lehrerseminars Küsnacht im Kanton Zürich im ausgehenden 19. und frühen 20. Jahrhundert nach öffentlich akzeptierten, also institutionalisierten Kontrollmustern und routinehaft, gewöhnlich gewordenen, implizit gewussten Abläufen im Seminaralltag als auch nach individuellen Wahrnehmungen, mimetisch-widerständigen Aneignungen und potenziellen Krisen bzw. Konflikten insbesondere zwischen Zöglingen und Lehrpersonen. Als Quellen dienen hierfür vor allem Selbstzeugnisse, insbesondere stark autobiografische Züge aufweisende Romane ehemaliger Seminaristen, aber auch ergänzende Archivdokumente. Damit werden gleichsam zwei Stossrichtungen verfolgt: Erstens soll mit dem nachfolgend noch kritisch reflektierten Quellenkorpus ein erster Analyseblick auf unterschiedliche bzw. verschieden wahrgenommene und womöglich durch Verflechtungen von konträren Kontextlogiken auch konfliktreiche Praktiken gerichtet werden; zweitens werden methodisch konzeptionell immer wieder auch das Potenzial und die Grenzen von autobiografisch geprägten Romanen in praxeologischen historischen Studien diskutiert. Gemäss dieser Erkenntnisinteressen gliedert sich der Beitrag in fünf weitere Kapitel: Nach den methodischen Reflexionen stehen in den Kapiteln drei und vier zunächst zeitliche und räumliche Regelhaftigkeiten des Seminaralltags im Zentrum: Welche Eingliederungen in die dort erlebte(n) Wissensordnung(en) zeichnen die ehemaligen Seminaristen literarisch auf, welche - vielfältigen - Hierarchien erleben sie dabei und welche Konfliktszenarien bzw. Strafpraktiken auf das kapitale Vergehen des Ausbruchs werden in den Quellen jeweils geltend gemacht? Kapitel fünf befasst sich mit individuell markierten Anpassungen an institutionalisierte Ordnungen im Seminar sowie dem paradoxen Wechselverhältnis von reklamiertem Eigensinn und moralischer Selbstüberhöhung. In Kapitel 6 hingegen wird dafür plädiert, das Lehrerseminar weder als massregelnde Kaserne noch als

29 Schlögel 2017, S. $20 f$.

30 Goetz 1979, S. 260; vgl. Conrad/Kessel 1998, S. 11 . 
Tummelplatz individuellen Opponierens, sondern durch Berücksichtigung wissensgeschichtlicher Perspektiven als Ort von Wissenskämpfen und -zirkulation um 1900 zu skizzieren, an dem Praktiken der Wissensnormalisierung mit Aneignungen städtischen, politischen und intellektuellen Wissens bzw. den ihm zugrundeliegenden Praktiken kollidieren. ${ }^{31}$ Ein Fazit bietet Reflexionen zu Erkenntnispotenzialen und Problematiken des Untersuchungsansatzes und zur Vielfalt von Praktiken inmitten kollidierender (Teil-)Gemeinschaften und Loyalitäten.

Ego-Dokumente, denen man zunächst zuschrieb, »möglichst direkten Zugriff« auf die »Selbstwahrnehmung«, Sinn- bzw. Weltdeutung von Individuen zu verschaffen, ${ }^{32}$ sind einer zunehmenden Quellenkritik unterzogen worden: Erstens verleiten sie zur quellennahen Nachzeichnung der somit zu intentional und autonom auftretenden Akteure und leisten so einem naiven, auf oberflächlich einleuchtende Sinnstiftungen rekurrierenden Quellenverständnis Vorschub. ${ }^{33}$ Zweitens bestehe eine Differenz zwischen erlebter, erinnerter und verschriftlichter Zeit. Selektives Erzählen sowie Schreib- und Kompositionsarrangements insinuieren oft im moralisierenden Duktus eine kohärente Weltsicht des Autors/der Autorin. ${ }^{34}$ Da die Bezeichnung »Ego-Dokumente« zu sehr auf eine Gesamtheit des Subjekts verweise, wird seit Kurzem »self-narratives « präferiert: So seien lediglich wenige Aspekte des Selbst angesprochen. ${ }^{35}$ Drittens seien Selbstzeugnisse nicht sorglos als »Faktensteinbruch « für die vermeintliche Wirklichkeit auszuwerten, weil sonst »stillschweigend Text und soziale Praktiken in eins gesetzt « werden. ${ }^{36}$

Eingedenk dieser Quellenkritik sollen in diesem Beitrag nicht der autobiografische Einzelfall und Analysen von Subjektkonstitutionen durch Praktiken des Aufschreibens bzw. Publizierens dominieren. ${ }^{37}$ Vielmehr werden mehrere autobiografisch grundierte Romane und Erinnerungstexte herangezogen, um Darstellungsmuster über Alltagsabläufe und Ordnungsroutinen, aber auch über Normverstösse sowie konfliktreiche Lehrer-Schüler-Verhältnisse in Lehrerse-

31 Foucault 2001, S. 217; zu Nähen zwischen »practical turn« und wissensgeschichtlichen Ansätzen Lipphardt/Patel 2008.

32 Schulze 1996, S. 13, 14 u. 28.

33 Sarasin 2003, S. 20 u. 29; Tanner 2012, S. 5; Heinze 2010, S. 96.

34 Heinze 2010, S. 102, 105, 110 u. 114f.; in Autobiografien gehe es nicht nur um die Rekonstruktion des Vergangenen, sondern um die Positionierung in der Gegenwart: ähnlich Günther 2001, S. 53. Zu Schreibpraktiken: Haasis/Rieske 2015, S. 31.

35 Greyerz 2010, S. 281.

36 Günther 2001, S. 45. Geht man so vor, »werden stillschweigend Text und soziale Praktiken in eins gesetzt« (ebd., S. 38); vgl. Rieger-Ladich 2014, S. 71.

37 Günther 2001, S. 35, 46, 51 u. 54f. Nach Dagmar Günther könne man Selbstzeugnisse nur als »kommunikativen Akt«(S. 49) bezeichnen. 
minaren herauszuarbeiten..$^{38}$ Die so ermittelten Muster können als Hinweise auf verbreitete Vorstellungen und Elemente des sogenannten diskursiven Archivs ${ }^{39}$ hinsichtlich >des Seminars gelten. Ob autobiografisch grundierte Romane wegen ihres fiktiven Charakters zu den Selbstzeugnissen zu zählen sind, ist umstritten. Da auch nichtliterarische Selbstzeugnisse zwischen dokumentierter und selektiv erzählter Erinnerung oszillierten und somit fiktionale Elemente enthalten können, mehrten sich zuletzt Plädoyers, dass mit und in autobiografisch angelegten Romanen Wechselbeziehungen zwischen Literatur, verschriftlichtem Erlebtem und Erfahrenem sowie diskursiven Formationen analysierbar werden. ${ }^{40}$ Dies gilt zumal für die hier genutzten, ein breites Publikum erreichenden Bestseller, die gerade auch durch ihre Kritik an Einrichtungen und Abläufen der Lehrerbildung zur modifizierenden Befestigung der gesellschaftlichen Institutionalisierung des »Seminars«als Lebensform (Jaeggi) beitragen.

Herangezogen werden zwei autobiografisch ausgerichtete Romane der Deutschschweizer Schriftsteller Jakob Schaffner (1875-1944) und Jakob Christoph Heer (1859-1925) sowie die unveröffentlichten handschriftlichen Erinnerungen des sozialistischen Zürcher Lehrers Alfred Traber (1884-1970). ${ }^{41}$ Ergänzend dazu wurden auch Hermann Hesses Erzählung Unterm Rad (1906) und Erich Kästners Fabian (1931) genutzt. Jakob Schaffner behandelt in Johannes, dem 1922 veröffentlichten »Roman einer Jugend«, den Aufenthalt des Titelhelden in der pietistischen Erziehungs- und Lehrerbildungsanstalt "Demutt«, wobei nach Ansicht der Forschung die reale Anstalt in Beuggen und Schaffners dort zugebrachte Zeit von 1885 bis 1891 Vorbild für die romanhafte Verarbeitung gewesen seien. Der wegen seiner späteren Parteinahme für den Nationalsozialismus als zerrissen geltende Schriftsteller befestigte mit diesem Buch sein literarisches Ansehen auch in Deutschland, etwa bei seinem Korrespondenzpartner Hermann Hesse. ${ }^{42} 20$ Jahre vor Schaffners Johannes und zwei Jahre vor Hesses Unterm Rad schildert Jakob

38 Böth 2018, S. 258: »Historische Selbstzeugnisforschung richtet ihren Blick also auf die ge- und beschriebenen Praktiken [...]«. So lassen sich »Beschreibungen einer Vielzahl [...] alltäglicher Praktiken [...] aus der Lektüre dieser Quellen rekonstruieren«. Sarasin 2003, S. 35

40 Heinze (2010, S. 112), Rieger-Ladich (2014) und Klika (2016) betonen die Wechselbeziehung zwischen autobiografischer Literatur und Diskurs. Das gelte nach Whittaker (2013, S. 16) auch für schulliterarische Texte, vgl. Dekker 2002, S. 13.

41 Trabers autobiografischer Roman Unser Weg (1925) thematisiert die Seminarzeit nicht und wird daher nicht berücksichtigt.

42 Zur Biografie Schaffners vgl. Siegrist 1995. Hesse teilte Schaffner am 21. März 1923 mit, er habe Johannes »mit Freude und voll Spannung « gelesen: »ch fand manches von meiner eigenen Kindertheologie wieder«. Schaffner wiederum stufte Unterm Rad gegenüber Hesses früheren Romanen als »leidender, in der Stoffwahl sentimentaler«, also gelungener ein, vgl. Schaffner an Hesse, 22. November 1910 (Wamister 2009, S. 56 u. 63). 
Christoph Heer 1902 mit Joggeli. Die Geschichte einer Jugend u.a. die Ausbildung des jungen Helden am Seminar »Kuosen«, das allein lautlich an das von Heer selbst zwischen 1875 und 1879 besuchte Zürcher kantonale Lehrerseminar Küsnacht erinnert. Autobiografische Bezüge werden u.a. in der Einbettung des real in Küsnacht unterrichtenden Deutschlehrers Adolf Calmberg in den Romankontext sichtbar. Vom Landschullehrer avancierte Heer 1892 zum Feuilletonredakteur der Neuen Zürcher Zeitung und Bestsellerautor der Heimatromane An heiligen Wassern (1898) und Der König der Bernina (1900). ${ }^{43}$ Johannes und Joggeli zählen zur um 1900 aufgekommenen Internatsliteratur, in der aus Schülersicht die erlebte Zeit in geschlossenen Erziehungsanstalten oder Lehrerseminaren zumeist als Unterdrückung dargestellt wird. ${ }^{44}$ Als Prototyp gilt etwa die Erzählung Unterm Rad, die Bezüge zu Hermann Hesses Zeit am württembergischen Priesterseminar Maulbronn aufweist. Elemente eines Internatsromans enthält auch Erich Kästners Fabian. Die Geschichte eines Moralisten von 1931. Kästner, der ab 1913 das Freiherrlich von Fletchersche Lehrerseminar in Dresden besuchte, ${ }^{45}$ erzählt darin das private und berufliche Scheitern des ehemaligen Seminaristen und promovierten Philosophen Jakob Fabian als Werbetexter im Berlin der Weimarer Republik.

Von diesen Bestsellerautoren weichen die sechsbändigen handschriftlichen, posthum teilveröffentlichten Erinnerungen des von 1899 bis 1903 im Seminar Küsnacht ausgebildeten Lehrers Alfred Traber ab. ${ }^{46}$ Traber, als sozialdemokratischer Stadt-, Kantonsrat und Gewerkschaftsführer der Strassenbahner ein politischer Multifunktionär in Zürich, begann seinen an seine Töchter adressierten Rückblick 1944 unter der selbst gestellten Losung »Erkenne dich selbst «, $^{47}$ setzte sie im Spätherbst 1957 fort und attestierte sich gleich zu Beginn eigensinnige, dem öffentlichen Meinungsduktus trotzende Geradlinigkeit in seinen politischen Überzeugungen: »Ich wagte es, mich zum Überbrachten in Gegensatz zu stellen, ich mied die Landstraße der Gedankenlosen und der Streber, ich hatte Freude am eigenen Weg. ${ }^{48}$ Diese Selbststilisierung weist auf fiktionale Elemente im gesamten, nicht nur literarischen Spektrum des autobiografischen Schreibens hin.

Um die Spurensuche nach vermeintlichem Eigensinn der - ehemaligen - Zöglinge gegen Seminarlehrer und -strukturen zu vertiefen, wird neben den autobiografischen Texten noch weiteres Quellenmaterial herangezogen: Ordnungen des

43 Heers zweiter autobiografischer Roman Tobias Heider (1922) wird nicht berücksichtigt, da er fast nur seine Lehrerzeit thematisiert.

44 Johann 2003, S. 7, 28 u. 30; Whittaker 2013, S. 16.

45 Vgl. Hanuschek 1999, S. 50 u. 56.

46 Traber 2011.

47 Traber 1960, S. 1f. Sein Lebensrückblick befindet sich im Stadtarchiv Zürich (SAZ) VII.148: 1.2.1. (NL Traber).

48 Ebd., S. 3. 
Seminars Küsnacht, Disziplinar- und Klassenakten, Protokolle des Lehrerkonvents und der Aufsichtskommission aus der Zeit von 1875 bis 1879 und 1899 bis 1903 sowie Deutschaufsatzhefte und Schülerzeitungen aus dem Nachlass Alfred Trabers. Die zusätzlichen Quellen sollen nicht bloss den `Wahrheitswert der von den ehemaligen Seminaristen geschriebenen Selbstzeugnisse für eine praxeologische Analyse kontrollieren, sondern mit Einschätzungen der Aufsichtskommission und Bewertungen von Lehrern ergänzende Einsichten in Kontexte seminaristischer Praktiken und die öffentliche Reputation des Seminars ermöglichen. So soll auch das Verhältnis von erinnerten, literarisch geschilderten Alltagsabläufen in Lehrerbildungs- und Erziehungsanstalten sowie dem reklamierten Eigensinn und den Aneignungen von Regelhaftigkeiten, ${ }^{49}$ die gerade auch in wissensgeschichtlicher Sicht als »[U]mfrisieren $\aleph^{50}$ von Normen verstanden werden können, analysiert werden.

\section{Einfügung und Verfügbarkeit der Zöglinge: ordnende Alltagsroutinen und -hierarchien}

Alltag und Abläufe in seminaristischen Einrichtungen sind in den autobiografisch gefärbten Romanen massgeblich durch strikte Zeit- und Raumordnungen strukturiert. ${ }^{51}$ Die dortigen Schilderungen des gedrängten Seminaralltags lassen sich bildungshistorisch etwa an westfälischen Lehrerbildungsanstalten bestätigen, wo er bis zu 83 Wochenstunden umfassen konnte, und finden sich ähnlich auch in Kästners Fabian: Hier wird der Seminartag als eine unaufhörliche, früh vom Hausmeister eingeläutete »Jagd« zwischen Schlaf-, Wasch- und Speisesaal, Schrank-, Wohn- und Klassenzimmer beschrieben - mit Hausdiensten, Unterricht und Schularbeiten. ${ }^{52}$ Das Zeitregime enthielt immer Vorgaben, in welchem Gebäuderaum sich die Zöglinge aufzuhalten und wie zu verhalten hatten. Auch Schaffner liess seinen die Hausglocke erfahrenden und Arbeitseffizienz erlernenden Romanhelden Johannes Schattenhold aufseufzen, dass er in der Erziehungsanstalt Demutt lernte, was Zeit sei. ${ }^{53}$ Diese materialisierte sich im Wecker, der »Zeitzerkleinerungsmaschine in billigem Blech mit zwei Glocken und einem atemlosen Sekundenzeiger «. ${ }^{54}$ Der »Kultus mit der Uhr« sei dominanter Teil einer Herrschaftspraxis, um die »erkrankte, entartete Zeit« zu kontrollieren und die

\footnotetext{
49 Tanner 2012, S. 5 U. 11.

50 De Certeau 1988, S. 15.

51 Crube 2018, S. 23.

52 Kästner 1931/1983, S. 180; für Westfalen vgl. Stratmann 2006, S. 129-132.

53 Schaffner 2005, S. 111.

54 Ebd., S. 173.
} 
Zöglinge mit Zeiteffizienz »zu plagen und zu ängstigen «. ${ }^{55}$ Schaffners Darstellungen, wie Johannes unter der durch Uhr und auch Waage vermessenen handwerklichen Arbeits- und Leistungserbringung in Demutt litt, ${ }^{56}$ lassen Bezüge erkennen zu der um 1900 weit verbreiteten Klage von der zeitlichen Gedrängtheit und Arbeitsüberlastung der Seminaristen. Viele Seminarordnungen, Lehrpläne und Jahresberichte belegen die ganztägige Verfügbarkeit über die Zöglinge von morgens bis abends. So begann 1925 der lange vielfältige Lern- und Pflichtenalltag im Evangelischen Lehrerseminar in Zürich Unterstrass schon um fünf Uhr und dauerte bis etwa 21 Uhr. $^{57}$

Mit dem Zeitregime wird häufig die Darstellung der Gebäude und Räumlichkeiten von Seminaren und Erziehungsanstalten als bedrohlich, beengend, ja als klausurhaftes, Kloster- bzw. Kasernendisziplin imitierendes Disziplinierungsinstrument parallelisiert. In den hier untersuchten autobiografisch geprägten Schriften schildern jedoch nur Schaffner und Kästner das Seminar und die Erziehungsanstalt Demutt, an der ebenfalls Lehrer ausgebildet wurden, als einen solchen düsteren Kontrollort. ${ }^{58}$ Während Traber keine sonderlichen Orts- und Raumbeschreibungen bietet und ebenso wenig wie Heer Praktiken des Zeitregimes aufzeigt, erfolgen in Hesses Unterm Rad und in Heers Joggeli fast identische idyllisierende Darstellungen des jeweiligen Seminargebäudes. Demnach verschmelzen das ehemalige Zisterzienserkloster in Maulbronn und die ehemalige Johanniterkomturei in Kuosen (Küsnacht) mit der umgebenden Natur, also mit Bergen, wellenblauen Flüssen, Bächen und Seen. Diese harmonische Symbiose findet in beiden Fällen mit dem sprudelnden Brunnen am Eingang ein dingliches Symbol. ${ }^{59}$

55 Ebd., S. $174 f$.

56 Ebd., S. 110ff. u. 172-174: In Demutt hatten junge Zöglinge zunächst Borsten aus der Schweinehaut in einer bestimmten Zeit zu zupfen. Die Menge wurde durch Cewichtsmessung ermittelt, die Arbeit im Hinblick auf Akkuratesse bewertet.

57 Zeller 1925, S. 7f. Einen ähnlich gedrängten, allerdings erst um 6.30 Uhr startenden Alltag im Priesterseminar Maulbronn berichtete Hesse seinen Eltern im September 1891 (Michels 2008, S. 136-139). Vergleichbare Zeitabläufe prägten den Alltag im als reformpädagogisch geltenden Landerziehungsheim Haubinda, vgl. Keim/Schwerdt 2013, S. 678.

58 Kästner 1985, S. 179f.; Schaffner 2005, S. 88-90. Kästner selbst verglich seine Seminarzeit mit dem Bild der Kaserne, vgl. Hanuschek 1999, S. 56. Kaserne, Internate und-abgeschwächt wohl auch das Lehrerseminar - zählen nach Erving Coffmann zu den totalen Institutionen, deren Kennzeichen der gemeinschaftliche, rational geplante und zeitlich effiziente Alltagsablauf unter einer Autorität sei und nach Johann (2003, S. 50f. u. 271) häufig im Internatsroman dargestellt sind, z.B. in Robert Musils Die Verwirrungen des Zöglings Törleß.

59 Heer 1902, S. 269; Hesse 2017, S. 53f. Hesse beschreibt seinen Eltern den Seminarort und dessen landschaftliche Umgebung als ästhetisch reizvoll und träumerisch entspannend und widmete noch 1914 dem »Brunnen im Maulbronner Kreuzgang« eine kurze literarische Reminiszenz, vgl. Michels 2008, S. 72-78 u. $141 f$. 
Doch trotz aller heimeliger Geborgenheit in den verwinkelten und neue Freiräume ermöglichenden Seminargebäuden erfahren Hesses und Heers Romanhelden Hans Giebenrath und Jakob Sturm ähnlich wie Schaffners Johannes Entfremdungen von der während ihrer kindlichen Sozialisation als ursprünglich erlebten Naturidylle. Die Ungebundenheit der Natur, womit die Freiheit des Kindes insinuiert wird, findet in Kuosen ihre Begrenzung durch den als kalt und nüchtern skizzierten naturwissenschaftlich ausgerichteten Seminardirektor Walter Wetzmann, dem lautlich nur wenig veränderten literarischen Alter Ego des Seminardirektors Heinrich Wettstein in Küsnacht. ${ }^{60}$ Bei Hesse verfinstern nicht nur »stürmische, dunkle Novembertage« rasch das Maulbronner Seminaridyll, sondern die zeitliche Überbürdung des Protagonisten Hans Giebenrath, sowohl schulisches Lernen als auch Pflege seminaristischer Freundschaften, etwa zu Hermann Heilner, zu vereinbaren. Dieser Loyalitätskonflikt gegenüber Lehrern und Seminarleitung einerseits sowie den "peers « andererseits resultierte aus unterschiedlichen, ja gegensätzlichen Erwartungen, Gehorsamserfordernissen und Freundschaftsverpflichtungen in einander potenziell gegenüberstehenden (teil-)öffentlichen Gruppen und Hierarchieebenen am Seminar. Sie erforderten von den Protagonisten einen versierten Umgang mit divergierenden Praktiken und führte letztlich zur Erschöpfung, Entfremdung und Vereinsamung. ${ }^{61}$

Die von der Forschung herausgearbeitete bedeutende Rolle der peers für den Seminaralltag ${ }^{62}$ nimmt in den untersuchten autobiografisch grundierten Texten beträchtlichen Raum ein, und zwar bereits für die Einfügung junger Seminaristen in alltägliche Ordnungsstrukturen. Nach Trabers Erinnerungen praktizierten in Küsnacht ältere Seminaristen als Aufnahmeritual das Strecken der neuen Zöglinge, indem sie diese so bezeichneten »Ferkel« an Händen und Füssen packten und langzogen. Dies empfanden, so Traber, viele als Blossstellung, zumal es weitgehend von den Lehrern gedeckt worden sei. Besonders heftig traf es wohl Trabers Sitznachbar Alfred Seidel, sodass sein Vater, der bekannte Zürcher Sozialdemokrat und Arbeitsschulpädagoge Robert Seidel, bei der Seminarleitung interveniert habe. ${ }^{63}$ Schaffner wiederum lässt seinen Johannes in Demutt ältere

60 Heer 1902, S. $278 f$.

61 Hesse 2017, S. 77, 79, 96, 98 u. 101.

62 Stratmann 2006, S. 187-224.

63 Traber 1960, S. 17f. Ausweislich der Protokolle des Lehrerkonvents litt Alfred Seidel unter Bleichsucht, galt als schwächlich und schien nach wenigen Monaten dem Seminar »in reglementswidriger Weise« entfliehen zu wollen, kehrte aber zurück, vgl. StAZH Z 388.1586, Protokollbuch Lehrerkonvent, Sitzungen vom 13. September 1899, 27. Januar und 13. März 1900 sowie 15. Mai 1903, S. 59f., 73, 77 u. 146. Stratmann (2006, S. 196-198) nennt für westfälische Seminare als Aufnahmerituale das sogenannte Einräuchern der neuen Seminaristen durch Pfeife rauchende Oberklässler, welche die sjungen Füchse nach dem `Verhör mit dem Fusstritt in den Hintern aus dem Raum trieben. 
Zöglinge zunächst vor allem in ihrer Funktion als Aufsichtspersonal im Arbeits-, Speise- und Schlafsaal erfahren. ${ }^{64}$ Der Roman erzählt, wie sie Neuankömmlingen beibrachten, "sich in einem hierarchischen System, in dem es klar definierte Befehlsketten gab, $\mathrm{zu}$ bewegen ${ }^{65}{ }^{65}$

Die Einfügung in solche vor allem von Hilfslehrern, Aufsichtspersonen, Erziehern, Lehrern und Direktoren geprägten Ordnungsstrukturen erfolgte jedoch nicht nur durch bzw. gegen die peers, sondern durch die jeweiligen seminaristischen Hierarchieebenen, in welche die autobiografisch angelegten Romanhelden u.a. durch die Übernahme von Hausdiensten involviert waren. ${ }^{66}$ Genannt werden das Aufräumen von Turngeräten, die Assistenz beim Orgelspiel oder Sekretariats-, also Schreib- bzw. Vorlesetätigkeiten ${ }^{67}$ für die Anstaltsdirektoren. So konnte - fast musterhaft für zahlreiche schulliterarische Romane - ein persönliches Verhältnis zwischen Zögling sowie Direktor und Lehrer dramaturgisch-literarisch entfaltet werden, und zwar als eine konfliktreiche Abfolge von Vertrauen bzw. Integration und dann - wie noch gezeigt wird - von Enttäuschung, Strenge und Strafe. Die Romane legen nahe, dass nicht nur die Hausdienste, sondern die vertraulichen Gespräche zwischen Seminaristen und Lehrern, die gemeinsamen Ausflüge, sommerlichen Abendandachten im Freien und Memorierstunden von Bibelsprüchen mit dem Direktor eine Seminargemeinschaft reproduzieren helfen, die als familiär konnotiert ist. ${ }^{68}$ Diese familiäre Ordnungsstruktur verbalisiert sich bei Schaffner in der Anrede des Anstaltsdirektors mit "Herr Vater« und seiner Frau mit »Frau Mutter«. Romanheld Johannes sollte trotz diverser Vergehen in Demutt sogar vom Anstaltsvater adoptiert werden. ${ }^{69}$ Auch Hesse schildert den Vorsteher des Maulbronner Priesterseminars als väterlichen Freund, der zugleich wie der Vater in Demutt auf seine Autorität poche. ${ }^{70}$ Ähnlich charakterisiert Heer im Joggeli Mathematiklehrer Truninger als "Schrecken der Zöglinge«, der für den Romanhelden jedoch »ein eigenartiges väterliches Wohlwollen an den Tag legte«, während Deutschlehrer Calmberg als peinlich strenger Grammatiker ebenso wie als feinsinniger Lyriker gekennzeichnet wird, der Joggelis literarische Ambitionen fördert und ihn mit dem Theater bekannt macht. ${ }^{71}$ Indem Lehrer und Direktoren zugleich als strenge Führer und väterliche Freunde der Zöglinge skiz-

64 Schaffner 2005, S. 94 f. u. 100.

65 So für westfälische Seminare um 1900 Stratmann 2006, S. 145.

66 Heer 1902, S. 272; Schaffner 2005, S. $99 f ., 134,158$ u. 300 ff.

67 Johannes hatte als Zeitungsvorleser dem Anstaltsleiter aus den Basler Nachrichten vorzulesen und als Sekretär zu dienen, vgl. Schaffner 2005, S. 158 u. 238.

68 Grube 2018, S. 22-vgl. den Beitrag von Jennifer Burri.

69 Schaffner 2005, S. 304.

70 Hesse 2017, S. 91.

71 Heer 1902, S. 273, 282, 291f., 298 u. 317. 
ziert werden, sind Muster der verbreiteten sogenannten pädagogischen Polaritätsmethode sichtbar, die etwa im Evangelischen Lehrerseminar Zürich Unterstrass bereits um 1915 praktiziert und um 1930 in der geisteswissenschaftlichen Pädagogik von Herman Nohl expliziert wurde. ${ }^{72}$

Die Selbstzeugnisse greifen mit der Schilderung der seminaristischen Zeitund Raumregime, der Seminarhierarchie der Aufsichtspersonen und peers sowie der familiären Gemeinschaft Ordnungsstrukturen, die in Seminarordnungen kodifiziert waren, aber auch schulkritische Diskurse der Überbürdung auf. ${ }^{73}$ Sie führen ein Ensemble von etablierten und etwa in Jahresberichten wiederholt genannten Aufsichts- und Kontrollpraktiken an, die das Seminar als eine bestimmte Lebensform festigen. Die autobiografischen Romane arrangieren mit diesen Bezügen einen seminaristischen Aufsichts- und Kontrollrahmen, um darauf aufbauend und mit Blick auf verschiedene Hierarchie- und Gemeinschaftsebenen von Seminarleitung und Peers Verstösse von einzelnen Zöglingen als krisenhafte Konflikte zuzuspitzen.

\section{Ausbruch aus dem Seminar: Eigensinnige Normverstösse und Strafpraktiken in verschiedenen Ouellenperspektiven}

Verstösse gegen das vorgängig skizzierte Seminarregime werden in den hier untersuchten autobiografischen Romanen vor allem als unerlaubtes Entweichen oder gar als Flucht aus der jeweiligen Seminaranstalt literarisch dramatisiert. In Heers Joggeli entzieht sich der Held dem Unterricht und sonntäglichen Gottesdiensten durch mehrfache »Waldspaziergänge[] und tolle[] Wasserfahrten« auf dem Zürichsee und unerlaubte Ausflüge in die nahe Stadt. Hermann Hesses Ausbruch aus dem Priesterseminar Maulbronn lässt der Autor in der Erzählung Unterm Rad Hans Giebenraths Freund Hermann Heilner vollziehen, während in Schaffners Johannes Kleiber, ebenfalls der Freund des Romanhelden, aus der Anstalt Demutt ausreisst. ${ }^{74}$ Eigensinnige Taktiken der Seminaristen äussern sich hier in eigenständiger Verwendung von Raum und Zeit abseits der offiziellen Seminarordnung und -kontrolle. Sie zeigen damit jedoch kein einzigartiges Verhalten auf, sondern ein autobiografisches, dramaturgisches Muster, das übliche

72 De Vincenti/Grube/Hoffmann-Ocon 2018, S. 123 f.

73 Whittaker (2013, S. 16) betont die Durchdringung von »schulliterarischen Texte[n] und [...] außerliterarischen Diskussionen «. 
Praktiken des unerlaubten Entfernens aus dem Seminar, wie sie etwa für Westfalen nachzuweisen sind, aufgreift. ${ }^{75}$

Die Bestrafung für die missglückte Flucht bzw. die verbotene Seminarabsenz mündet in den autobiografischen Texten in ein eskalierendes und langwieriges persönliches Duell zwischen dem jeweiligen Zögling und den Direktoren. So rügte Seminardirektor Wetzmann Romanheld Joggeli als »Rebell«, »seltsamer Mensch « und »Lump«, der das Seminar - und das war der schlimmste Vorwurf in ein "schiefes Licht" bringe, also dessen öffentliche Reputation beschädige. ${ }^{76}$ Der Konflikt mit Wetzmann steigerte sich rasch in eine durch einen »feindseligen Klang« geprägte persönliche Abneigung, in deren Folge Joggeli beim Erziehungsdirektor denunziert wurde und nur schlecht dotierte Landstellen erhielt. ${ }^{77}$ Die naturromantischen Neigungen Joggelis wurden im Roman so delegitimiert und als charakterliche Schwäche geradezu pathologisiert.

Auch Johannes Schattenholds Vergehen führten zu Stigmatisierungen seines Charakters: Er sei verstockt, hochfahrend, hochmütig und vor allem ein Anarchist. ${ }^{78}$ Sein aus Demutt geflohener Freund Kleiber wird im autobiografischen Roman in einem öffentlichen Verhör, das einem beschämenden Schauprozess vor der lüsternd beobachtenden Seminarversammlung gleichkommt, von dem >Vater als Abweichler gebrandmarkt, der dennoch durch Geständnis und Reue wieder in die Seminargemeinschaft aufgenommen werden könne. ${ }^{79}$ Durch eine Kombination von Kollektivstrafen des Essens- und Freiheitsentzugs, von öffentlich exerzierten Prügelstrafen und einem psychologisch, mehrfach gebrochenen Machtspiel, in dem der >Vater $<$ in Demutt den Delinquenten abwechselnd als züchtigender, dann wiederum als selbst zweifelnder bzw. leidender und väterlich-vertrauter Inquisitor mit einem ganzen Arsenal von Fragen verhört, wird das taktische Verteidigungsmittel des angeklagten Zöglings, das Schweigen, gebrochen und das Vergehen wie in einer Beichte gestanden. Die Selbstbezichtigungen und Akzeptanz der Strafe durch den Delinquenten sind romanhaft als eine Befreiung der angeblich teuflischen Seele dargestellt. ${ }^{80}$ Die Höchststrafe der Entlassung aus dem Seminar wurde in den untersuchten Romanen nur bei Hermann

75 Stratmann 2006, S. 233-236. Mit Vorliebe suchten Seminaristen verbotenerweise städtische Wirtshäuser auf, vgl. den Beitrag von Andrea De Vincenti.

76 Heer 1902, S. 273, 277 u. 296.

77 Ebd., S. 277 u. 317-319.

78 Schaffner 2005, S. 234 U. 350.

79 Heer 1902, S. 274 U. 277; Schaffner 2005, S. 155; Hesse 2017, S. $92 f$. Hans Giebenrath wird vom Ephorus verhört wegen seiner Freundschaft mit Heilner.

80 Schaffner 2005, S. 130-132 u. 150; s. auch S. 313f. u. S. 316: »Das war ja das Furchtbare, daß er bei allem, was er uns auferlegte, niemals unbeteiligt blieb, ja, daß er im Leiden stets der vorderste war!« Zum Schweigen als Taktik der Unterlegenen im Frageverhör vgl. Canetti 2003, S. 337-343. 
Heilner in Hesses Unterm Rad ausgesprochen, obwohl etwa die reale Ordnung für das Seminar Küsnacht unerlaubtes Entfernen vom Seminar strikt untersagte und etwa verbotene Dampfschifffahrten mancher Seminaristen auf dem Zürichsee laut den dortigen Lehrerkonventsprotokollen zum Ausschluss führten. ${ }^{81}$ Zwar erhielt Jakob Sturm im Joggeli für seine Ausfahrten auf dem Zürichsee mehrere Verweise. ${ }^{82}$ Doch gemäss des literarisch-autobiografischen Spannungsbogens folgen hier wie auch in den übrigen Romanen statt des Ausschlusses zunächst patriarchalische Versuche der Resozialisierung in die Seminargemeinschaft, bevor sich die unversöhnliche Vergeltung des Seminarleiters zuspitzt: Sie reicht von der Gleichgültigkeit über die Verachtung bis hin zu wiederholten Diskreditierungen der schuldigen Zöglinge. ${ }^{83}$ So werden komplexe Konflikte im Seminar zur persönlichen Auseinandersetzung zwischen dem Direktor als personifizierter, stilisierter Inbegriff des »gottgleichen Lehrertyrannen « ${ }^{84}$ und dem schuldhaften Zögling literarisch-autobiografisch dramatisiert und zugleich reduziert.

Der im Seminar Küsnacht für »die geistige und sittliche Entwicklung der gesamten Zöglinge« zuständige Lehrerkonvent und die nächst höhere Aufsichtsinstanz, die Aufsichtskommission, die den Ausschluss beschliessen konnte, tauchen dagegen in Heers Joggeli nicht auf. ${ }^{85}$ Umgekehrt findet das autobiografisch geschilderte Fehlverhalten Joggelis, seine zahlreichen Unterrichtsversäumnisse aufgrund von Bootsfahrten und Wanderungen, in den Protokollen der Aufsichtskommission und des Lehrerkonvents oder in den Klassenakten keinen Niederschlag für den Romanautor Heer. Zugespitzt gesagt: Der literarisch kreierte Held "Joggeli« erscheint eigensinniger und renitenter als sein Schöpfer Heer in den Archivakten des Seminars, auf die nun der Blick gewendet wird. Heers 22 bzw. 33 Fehlstunden in den Wintersemestern 1877/78 und 1878/79 werden als entschuldigt in den Klassenakten notiert. ${ }^{86}$ In den Sommersemestern stehen nur wenige Fehlstunden zu Buche. In den Protokollen des Lehrerkonvents wird Heer zwar dreimal erwähnt, was sich jedoch im Vergleich zu anderen Zöglingen relativ belang-

81 Hesse 2017, S. 106. Seminarordnung für das Lehrerseminar des Kantons Zürich in Küsnacht, 30. Dezember 1901, S. 3 (im Folgenden zitiert als Seminarordnung Küsnacht 1901). StAZH Z 388.1584, Protokollbuch Lehrerkonvent, Circularbeschluss vom 18. November 1875.

82 Heer 1902, S. 278.

83 Hesse 2017, S. 107; Heer 1902, S. 297f. u. 317; Schaffner 2005, S. $319 f$.

84 Johann 2003, S. 145.

85 Forschungsbibliothek Pestalozzianum ZH HA II, 5: Reglement für das Zürcherische Lehrerseminar 1861, § 64, S. 15 (Zitat); Seminarordnung Küsnacht 1901, § 26, S. 7. Hesse (2017, S. 106) bezeichnet den Lehrerkonvent als »Femegericht«, der den Ausbrecher Heilner »in Schanden entlassen« habe. Die Protokolle zeigen den Küsnachter Lehrerkonvent jedoch auch als eine Art Mitbestimmungsgremium für die Lehrer bei Lehrplanreformen.

StAZH, Seminar Küsnacht, Z 388.6943 (Klassenakten Wintersemester 1877/78), Z 388.6950 (Wintersemester 1878/79). 
los ausnimmt. Im März 1876 wird er demnach ohne Angaben von Gründen nur vorläufig "promovirt«, doch schon im Juni definitiv versetzt, und er erhält sogar ein Stipendium. ${ }^{87}$ Mündliche Verwarnungen wegen häufiger Absenzen erhalten dagegen andere Seminaristen. Im März 1878, als bei der sogenannten »Erlenbacher Katastrophe« zwei Zöglinge und ein Auditor bei einer Bootspartie auf dem See ertranken, wurde auch Heer neben anderen Zöglingen vom Lehrerkonvent $\mathrm{zu}$ »gleichmäßigerem Fleiße« ermahnt. Dies scheint jedoch nicht gefruchtet $\mathrm{zu}$ haben, denn im Abgangszeugnis erhielt er als einer von nur drei Seminaristen die sehr mittelmässige Note Drei in Fleiss, jedoch eine Fünf in Betragen. ${ }^{88}$ Die Involvierung Heers in das Bootsunglück und damit in eine grössere Ordnungskrise am Seminar scheint demnach eher marginal gewesen zu sein. Da jedoch der Direktor befürchtete, dass durch den dreifachen Ertrinkungstod die Seminarreputation erheblich leide, sollte laut den Protokollen von Lehrerkonvent und Aufsichtskommission Direktor Wettstein einzelne Zöglinge vernehmen, was es mit den »Gerüchten, die nach dem Unglücksfall in der Presse herumgeboten wurden, von ungeziemenden Betragen der Seminarzöglinge« auf sich habe, da sie »geeignet sein könnten, den Ruf der Anstalt zu gefährden «. ${ }^{89}$ Allerdings wurde diese Untersuchung rasch eingestellt, nachdem alle Zöglinge »durch ihre ganze Haltung und offene Darlegung « versichert hätten, dass die Gerüchte haltlos seien. ${ }^{90}$

Im Hinblick auf die Fragestellung nach Eigensinn, Widerständigkeit und Kontrollregimen im Seminar und auf quellenkritische Überlegungen zum Wert von autobiografisch grundierten Romanen für historisch-praxeologische Untersuchungen lassen sich drei vorläufige Schlussfolgerungen ziehen: Erstens scheint Heer die mittels ergänzender Archivquellen verifizierbare häufige Praxis der von mehreren Seminaristen unternommenen unerlaubten Bootspartien in seinem autobiografischen Roman vorrangig auf seinen Helden Joggeli übertragen zu haben. Er positioniert ihn damit als eigensinniger und widerständiger, als dies die Protokolle des Lehrerkonvents und der Aufsichtskommission für Heer selbst ausweisen. Anders als etwa der Seminarist Hardmeyer, der nur kurz nach der Erlenbacher Affäre seinen Ertrinkungstod aus Frust über seine Nichtnominierung zum Vorturner vortäuschte und mit einer nur vorläufigen Duldung am Seminar erheblich bestraft wurde, ${ }^{91}$ wurde Heer von den Aufsichtsgremien in Küsnacht

87 StAZH Z 388.1584 Protokollbuch Lehrerkonvent, Protokoll vom 27. März und 21. Juni 1876.

88 StAZH, UU 20.17, Protokollbuch der Aufsichtskommission 1874-1880, Actum 3. April 1879, S. 167. In der Schweiz ist eine Sechs die beste, eine Eins die schlechteste Note.

89 StAZH UU 20.17 Protokollbuch Aufsichtskommission 1874-1880, S. 126: Präsidialverfügung vom 5. März 1878; Actum 16. März 1878. StAZH Z 388.1584 Protokollbuch Lehrerkonvent, Sitzungen vom 25. und 27. März 1878. StAZH Z 388.1584 Protokollbuch Lehrerkonvent, Sitzung vom 16. Mai 1878. 
kaum als straffällig markiert. Zweitens bieten die Protokolle von Lehrerkonvent und Aufsichtskommission lediglich Hinweise auf Konflikte, jedoch weniger auf einzelne Konfliktverläufe am Seminar. Dies wiederum ermöglichen eher autobiografisch gefärbte Romane, wenn man diese Ego-Dokumente - wie einleitend skizziert - als Quellen von wahrgenommenen, erinnerten und teils literarisch aufbereiteten patriarchalischen Aufsichtsstrukturen und von idealtypisch zugespitzter Widerständigkeit liest, jedoch nicht als Beleg für eine Wirklichkeit am Seminar. Denn sie betonen so eher ausserordentliche Krisenmomente gegenüber dem Regelhaften des Alltags. Drittens wird aus allen hier untersuchten Quellen die grosse Bedeutung der öffentlichen Reputation für die Existenz des Seminars deutlich. Diese Orientierung an der öffentlichen und medial dargebrachten Meinung ist am Umgang der Aufsichtskommission mit gravierenden Ordnungsverstössen am Seminar Küsnacht erkennbar sowie auch am Beispiel Wetzmanns im Joggeli, der das Seminar von seinen Zöglingen im rechten Licht gesetzt sehen wollte. Ähnlich sorgt sich der Ephorus in Hesses Unterm Rad nach mehreren Vergehen um den Ansehensverlust des Seminars Maulbronn bei der Schulbehörde. ${ }^{92}$ Das Seminar als Lebensform, um die Formulierung Rahel Jaeggis aufzugreifen, existiert demnach nicht nur als Ensemble bestimmter Erziehungs- und Ordnungspraktiken, sondern vor allem auch, wenn die Institution selbst und damit die ihnen zugeschriebenen Praktiken weiterhin gesellschaftliche Akzeptanz behalten und öffentlich nicht, etwa durch skandalöse Ausbrüche oder Todesfälle, diskreditiert werden.

Gerade die autobiografischen Romane deuten jedoch an, dass nicht nur eine, etwa medial oder gesellschaftlich sgemachte »öffentliche Meinung« Praktiken des Seminars normierend mitstrukturierte. Vielmehr waren Seminaristen mehreren, zumeist in sich wiederum differenzierten sozialen Kontrollkontexten und damit Wissens- und Loyalitätskämpfen ausgesetzt, z.B. der offiziellen, wenn auch nicht total kontrollierenden Seminarnorm, die auf öffentlichen Bildungsund Erziehungserwartungen beruhte, und dem Wertesystem der peers, also der zum Teil in Geheimbünden zusammengefassten Freunde, die zu verraten als sunmännlich und unehrenhaft galt. ${ }^{93}$ Flucht und verbotene Abwesenheit aus dem Seminar sind häufig eng mit unerwünschten Lieb- oder Freundschaften von Zöglingen, etwa innerhalb eines Geheimbundes, verbunden. ${ }^{94}$ In diesem literarischen Szenario stehen die Romanhelden im Loyalitätskonflikt zwischen Regelhaftigkeiten seminaristischer Normen und der sozialen Kontrolle, Ehrzuweisung bzw. -entzug durch Freundeskreise, die ebenfalls mit Verpflichtungen verbunden sind.

92 Hesse 2017, S. 110.

93 Schaffner 2005, S. 305; Hesse 2017, S. 78f. u. 88-90; vgl. Bourdieu 2015, S. 33 u. 45.

94 Schaffner 2005, S. 199-205; Hesse 2017, S. 66-68 u. 74-76: naturidyllisches, vertrauliches Beisammensein von Hans Giebenrath und Hermann Heilner. 
So können eigensinnig-taktisch anmutende Umgangsweisen der Zöglinge mit Ordnungsregimen im Seminar eher zu Praktiken des Freundschaftskontextes tendieren - mit eigener Sprache, Verschwiegenheit, Treue, gemeinsamen Unternehmungen und Lektüren, die wiederum mit Erziehungs- und Ausbildungspraktiken kollidieren konnten.

\section{Eigensinn und moralische Selbstüberhöhungen: paradoxe Verflechtungen}

$\mathrm{Zu}$ den Paradoxien der hier untersuchten autobiografisch geprägten Romane und Erinnerungstexte gehört, dass die den Romanhelden attestierte Widerständigkeit im Seminar im literarischen Kontext sowohl von ihren Freunden bestätigt wurde, als auch von dem jeweils feindlich gesonnenen Direktor. Wetzmanns Verunglimpfung Joggelis als »Sonderling« gilt nicht nur als Demütigung, sondern zugleich als Beleg für die Besonderheit des eigensinnig sich gebenden Seminaristen und mitsamt seiner "starren Eigenwilligkeit «. ${ }^{95}$ Somit werden die literarisch phasenweise als Tyrannen dämonisierten Seminarherrscher ausgerechnet zu Kronzeugen des Eigensinns, den die Verfasser der Selbstzeugnisse und ehemaligen Seminaristen über die romanhafte Hauptfigur auch sich selbst zuweisen. Durch die Urteile des als Feind markierten Anderen erfolgt in der Autobiografie die Selbstpositionierung, erfährt das vermeintliche Fehlverhalten die moralische Überhöhung des Widerständigen. ${ }^{96}$

Wie sehr Selbstzeugnisse selbststilisierenden und moralisch selbstüberhöhenden Charakter haben, somit subjektiv wahrgenommene und erinnerte Praktiken und Konflikte am Seminar zwar analysierbar machen, jedoch nicht per se Handlungswirklichkeiten aufzeigen, wird anhand der Memoiren Alfred Trabers deutlich. Sie sind das einzige in diesem Beitrag behandelte Selbstzeugnis, das nicht zur Veröffentlichung vorgesehen war. Der 1916 in der Zürcher Presse als "sozialdemokratischer Schulmeister mit düsteren Fanatikeraugen« bezeichnete Traber attestierte sich selbst Prinzipien- und Charakterfestigkeit und habe daher als einer der wenigen das Ideal seminaristischer Persönlichkeitsbildung erfüllt. ${ }^{97}$

Ähnlich wie Jakob Sturm im Joggeli, der ein besserer Lehrer zu werden hoffte als sein verhasster Gymnasiallehrer und im Seminar Ausgangsmöglichkeiten für einen späteren Universitätsbesuch oder seine literarische Ambitionen erblickte, ${ }^{98}$ richtete Traber laut seines Rückblicks hohe Erwartungen an seinen Seminar-

95 Heer 1902, S. 278f.

96 Vgl.zur Benötigung des Anderen für die Selbstpositionierung Tanner 2012, S. 9.

97 Traber 2011, S. 39.

98 Heer 1902, S. 265 u. 269. 
besuch. »Mein Streben nach Tadellosigkeit [...] verstärkte sich noch, als [...] mein Eintritt ins Lehrerseminar Küsnacht bevorstand. Jetzt schwebte mir die Pflicht zur Selbsterziehung in vermehrtem Masse vor, da ich die charakterliche Erzogenheit als erste Voraussetzung eines Lehrers betrachtete. ${ }^{99}$ In dieser nachträglichen Bekundung zur Selbsterziehung sind Bezüge zu seinerzeit insbesondere von Friedrich Wilhelm Foerster gerade auch in Zürich verbreiteten Konzepten der selbstständigen Charakter- und Persönlichkeitsbildung erkennbar. ${ }^{100}$ Zwar habe ihm, so Traber in der Rückschau, der seminaristische Abstinenzverein »Fraternitas« Gelegenheit geboten, seine Lebensentscheidung des Alkoholverzichts umzusetzen und so ein besserer, dann auch sozialistisch integrer Mensch zu werden. ${ }^{101}$ Doch habe er nicht wegen, sondern trotz des Seminars Charakter- und Willensfestigkeit erworben. Traber skizziert Küsnacht als mediokre, ja verkommene Bildungsstätte. Demnach verstiessen zahlreiche Lehrer, wie Zeichenlehrer Ruedi Ringger und sein »Saufkumpan« Musiklehrer Walter Zuppinger, mit ihrem Alkoholkonsum gegen manche in der Seminarordnung fixierten Trinkverbote für Zöglinge. ${ }^{102}$ Ringger habe Traber zudem ungerechtfertigt mit Ohrfeigen gezüchtigt, Zuppinger unbeherrscht durch die Klasse geschrien. ${ }^{103}$ Diese Darstellung lässt sich in Protokollen des Lehrerkonvents und der Aufsichtskommission nicht belegen, allerdings wurde dort der Alkoholismus des Turnlehrers Eduard Brunner aktenkundig: Er wurde nach Verwarnungen und »Ausschreitungen" entlassen, da »bei dessen moralischen Qualifikationen von einem gedeihlichen Wirken desselben am Lehrerseminar keine Rede mehr sein könne«. ${ }^{104}$

Laut Trabers Vorwürfen verhielten sich die Seminarlehrer den Schülern gegenüber zynisch, humorlos, verächtlich und verachtend. Diskreditierend sei etwa die Verballhornung der Nachnamen der Schüler gewesen. Französischlehrer Jakob Bosshard habe Traber "galopin" genannt und seinen Freund Karl Göhri mit »Göhri, qu'est-ce que je ghöri? « aufgerufen. ${ }^{105}$ Manche Lehrer hätten »öfters unvorbereitet« unterrichtet, z.B. Dr. Fritz Oppliger, der in seiner Naturkundestunde »die Zeit damit totschlug, daß er beim Referierenlassen nach einem wenig sattel-

99 Traber 1960, S. 16.

100 Foerster 1902, S. 123-125 u. 138; Heer 1902, S. 278; Traber 1960, S. 9. Traber und Heer beschreiben sich bzw. ihren Romanhelden als eher schwächliche, autodidaktische Aussenseiter in ihrer Jugendzeit, die in ihren Bildungsaspirationen stark von der Mutter, kaum vom zum Teil früh verstorbenen Vater gefördert wurden.

101 Traber 1960, S. 24 u. 28.

102 Seminarordnung Küsnacht 1901, § 25, S. 7.

103 Traber 1960, S. 19 (dort das Zitat), 20. Prügel durch Aufseher Ladurch schildert auch Schaffner 2005, S. 172.

104 StAZH, UU 20.20, Protokollbuch der Aufsichtskommission, Sitzungen vom 13. Juli 1900 sowie vom 7. Juni, 3. Juli, 13. Juli und 31. August 1901.

105 Traber 1960, S. 19. 
festen Schüler fahndete, um dann dessen Gestammel mit der Aufforderung: - Sehen Sie, das ist alles nix. Fangen Sie nochmals vorn an! wiederholen zu lassen. «106

Aufgrund der so erinnerten und zugeschriebenen charakterlichen Defizite sprachen Traber und teilweise auch Heer den Lehrern die Fähigkeit zur Leistungsbewertung ab. Am augenfälligsten wird dies bei beiden im Konflikt mit Musiklehrer Zuppinger. Musik war als Unterrichtsfach häufig konfliktreich, vermutlich weil die Seminaristen beim exponierten Spielen der Geige oder beim Gesang ehrverletzendem, hämischem Spott des Lehrers oder der Mitschüler stärker als in anderen Fächern ausgesetzt waren. Dies führte sowohl im Joggeli wie nach Trabers Rückblick jeweils zum heftigen, fast sogar körperlich ausgetragenen Konflikt mit Lehrer Zuppinger, sodass beide Zöglinge - wie im Übrigen zahlreiche Seminaristen - vom Musikunterricht dispensiert wurden. ${ }^{107}$

Letztlich skizziert Traber ähnlich wie Schaffner eine seminaristische Kultur der Heuchelei, Pseudomoral, Missachtung, Verdächtigung und der Degeneration - einem seinerzeit gerade in Abstinenzkreisen gängigen Narrativ, indem die Bildungsanstalt als krank, faulig und verkommen beschrieben wird. So habe Traber das Seminar entgegen seiner hohen Anfangserwartungen »voller innerer Auflehnung « verlassen. ${ }^{108}$ Hehre Seminarziele der Charaktererziehung und Persönlichkeitsbildung erscheinen nunmehr als Scharlatanerie. Eine ähnliche, eher sarkastische Abrechnung nahm auch Kästners Fabian vor, der als promovierter Germanist und arbeitsloser Werbetexter den Ermahnungen seines ehemaligen "wohlgenährten, selbstgefälligen« Seminardirektors nach mehr Charakter- und Persönlichkeitsbildung entgegnete: »Sie mit Ihrer abgerundeten Persönlichkeit!« und so das sinnlose Gespräch beendete. ${ }^{109}$

Entgegen der so dargestellten Unmoral der Lehrer skizziert sich Traber als beherrschter und bildungshungriger Gegenentwurf, der für sich Widerständigkeit reklamierte. So verunglimpfte er als Autor des in der Seminarabschlusszeitung Die Eiterbeule publizierten Spottgedichts Moderner Zirkus Musiklehrer Zuppinger als das Publikum verschreckender, fauchender, brüllender, wild sich gebärdender Indianer, als »Delawar« - mit der Folge, dass laut Traber der Erziehungsrat den Entzug des gerade erteilten Lehrerpatents prüfte. Trabers Lyrik ist - wie einleitend bemerkt - keineswegs originell und singulär, sondern eine in Kreisen von Abiturienten und Studentenverbindungen gängige und von Pädagogen als sehr problematisch erachtete Praxis, um in sogenannten Bierzeitungen Lehrer zu kri-

106 Ebd., S. 21.

107 Ebd., S. 22f.; Heer 1902, S. 273.

108 Traber 1960, S. 47; vgl. Schaffner 2005, S. 250 u. 272. Zum Narrativ der Degenration vgl. Pross 2013.

109 Kästner 1985, S. 183. 
tisieren. ${ }^{110}$ So verfasste Schaffners Johannes wiederholt Schmähgedichte, etwa gegen den prügelnden Erzieher Ladurch: »Ladurch mit dem Besenstiel/Haut die Buben allzuviel./Allzuviel ist ungesund./Ladurch ist ein Lumpenhund. «111 Die Zöglinge zeigten bei diesen Schmähschriften eigensinnige, listige Fantasie und knüpften teilweise an literarische Vorbilder und etablierte Darstellungsformen der Schülerkritik an. Dabei nutzen sie ähnlich verächtliche, diskreditierende Wortspiele, die sie selbst den Lehrern vorwarfen. Somit verblieb der Eigensinn innerhalb der Rahmung des Seminars - nur wurden Diskreditierungspraktiken sumfrisiert (de Certeau) und umgeleitet.

Trabers sich selbst zugewiesene Renitenz und Andersheit wird allerdings wie schon bei Heer - in den entsprechenden seminaristischen Klassenakten und Zeugnissen kaum sichtbar. Sein Betragen wird hier stets mit "gut« bewertet, der besten Note für dieses Beurteilungskriterium. ${ }^{112}$ Ausser in Musik und Französisch, teilweise auch im Freihandzeichnen und Turnen hat Traber jeweils Zeugnisnoten von Vier bis Fünf erhalten. Dabei wird die Benotung der Fächer doppelt geführt: für (Lern-)»Fortschritt« und für »Fleiß«. Eine Dreieinhalb wird als »genügend« gewertet. Insgesamt erzielte Traber 100 1/2 Punkte im Abschlusszeugnis und lag damit im oberen Drittel. ${ }^{113}$ Zeugnisse und Bewertungsdokumente >machen $<$ den guten Lehrer und verschweigen mitunter - nicht immer, wie der Beitrag von Andrea De Vincenti zeigt - Konflikte innerhalb des Seminars. Denn die Anzahl der vergebenen Lehrerpatente war für die soziokulturelle Reputation und damit für die diskursive Aufrechterhaltung des Seminars als spezifische Lebensform existenziell wichtig.

Auch die Protokolle von Lehrerkonvent und Aufsichtskommission in Küsnacht weisen Traber nicht als opponierenden Aussenseiter aus: Anders als Heer wird er nicht einmal marginal erwähnt, denn nur vermeintlich erhebliche Normabweichungen, wie Homosexualität, wurden in den Aufsichtsgremien aktenkundig. ${ }^{114}$ Eigensinnige Scharmützel, so sehr sie in Selbstzeugnissen stilisiert sein mögen, verblieben häufig im Halbdunkeln und Informellen, sodass autobiografische Darstellungen über krisenhafte Verhältnisse am Seminar trotz Übertreibungen ergänzenden Quellenwert besitzen. Mitunter deuten sich allerdings auch im Lehrerkonvent Wissenskämpfe ${ }^{115}$ zwischen Lehrern und Schülern an, die sich etwa

110 Dudek 2002, S. $92 f$.

111 Schaffner 2005, S. 183 u. 250. Hesse (2007, S. 98) erwähnt das von Seminaristen herausgegebene»Witzblatt«Stachelschwein.

112 Seminarordnung Küsnacht 1901, S. 6f.; SAZ VII.148: 1.3.3. Schulzeugnisse vom Seminar Küsnacht (NL Traber).

113 SAZ VII.148: 1.3.3. Prüfungszeugnis für Primarlehrer, 15. April 1903 (NL Traber).

114 Hoffmann-Ocon 2017, S. 309.

115 Foucault 2001, S. 213. 
im Juli 1900 bei der Seminardirektion »über zu viel Hausaufgaben in Mathematik, techn. Zeichnen + Französisch beklagen «. ${ }^{116}$ Den hiermit für andere Aktivitäten in konkurrierenden Wissensräumen geforderten Freiraum werteten die Lehrer als Indiz der Faulheit der Schüler und drohten ihnen kollektiv mit der schlechten Note Zwei in Betragen.

\section{Das Seminar - ein Ort inmitten von Wissenskämpfen und -zirkulation}

Das Seminar war laut Selbstzeugnissen keineswegs nur ein Furcht einflössender Ort mit einer Zeit und Raum überwachenden Seminardirektion und einer sich selbst kontrollierenden Gemeinschaft zur »Normalisierung und Hierarchisierung des Wissens «. ${ }^{117}$ Vielmehr stand Küsnacht ausweislich dieser Dokumente inmitten einer Zirkulation verschiedener Wissen, ja, das Seminar ermöglichte gleichermassen diese Wissenszirkulation und war ebenso wie die universitäre Wissenschaft auch Ort von Wissenskämpfen. ${ }^{118}$

Traber beschreibt, wie er und seine Freunde Georg Forster und Jakob Böschenstein durch die Zugehörigkeit zum offiziellen seminaristischen Stenografenverein »Cuosa« und Abstinenzverein »Fraternitas«, einer Sektion der abstinenten Mittelschulverbindung "Helvetia«, ${ }_{119}^{19}$ auch Teil informeller Lesegruppen werden konnten. Diese hatten allerdings nicht den Charakter des von Schaffner geschilderten geheimen Johannesbundes der Zöglinge in der Erziehungsanstalt Demutt. ${ }^{120}$ Die von Traber skizzierte Lesegruppe in Küsnacht wilderte ${ }^{121}$ vielmehr ganz offen in den Büchern: Gemeinsame Lektüren von Immanuel Kant, Arthur Schopenhauer, Friedrich Nietzsche, Peter Kropotkin und den Anarchisten, auch von Gottfried Keller, Conrad Ferdinand Meyer und Carl Spitteler sorgten bei Seminaristen für eigensinnige Aneignung intellektuellen Wissens. In studentisch anmutenden Dachkammern des ehemaligen Gymnasiasten Adolf Attenhofer, so erinnert sich Traber fast romantisierend, wurden in kontroversen Diskussionen Wissensüberlegenheit zelebriert, aber auch Wissensdefizite eingestanden. ${ }^{122}$

Inmitten und im lokalen Umfeld des Seminars Küsnacht und in Demutt/ Beuggen zirkulierten laut den Selbstzeugnissen mannigfaltige Bücher und Lek-

\footnotetext{
116 StAZH, Protokollbuch Lehrerkonvent, S. 91 u. 101: Sitzungen am 12. Juli und 5. Oktober 1900.

117 Foucault 2001, S. 214 u. 217.

118 Sarasin 2011; zur Verflechtung von Wissen und praktischem Handeln vgl. Sabean 1990, S. $226 f$.

119 Traber 1960, S. 24, 26 u. 28.

120 Schaffner 2005, S. 202.

121 Zum Begriff des Wilderns als eigensinnige Buchlektüre De Certeau 1988, S. $297 \mathrm{ff}$. u. 308.

122 Traber 1960, S. 29, 33 u. 37.
} 
türeerlebnisse, sei es durch Besuche der Pestalozzibibliothek in Zürich oder durch Buchtausch mit Mitzöglingen, wodurch etwa Johannes Schattenhold Zugang zu James Fenimore Coopers Lederstrumpf, Jonathan Swifts Gullivers Reisen und Mark Twains Onkel Toms Hütte erhielt. ${ }^{123}$ Gemeinsame Wege von Zürich zum Seminar Küsnacht schufen Zeit und Raum für Gespräche über neues, erlesenes Wissen. ${ }^{124}$ Über die »Fraternitas« war Traber Teil von weiterem gesellschaftlich zirkulierendem Wissen: Er wurde mit sozialistischen Ideen vertraut, u.a. durch das vom Linksaktivisten Max Tobler redaktionell betreute Vereins-Mitteilungsblatt, das wiederum auf die Zeitschrift Junge Schweiz des sozialdemokratischen Arbeiterarztes Fritz Brupbacher in Aussersihl hinwies. ${ }^{125}$ Der Besuch von alkoholfreien Wirtschaften und der mit Abstinenz sympathisierenden Familie des Psychiaters Eugen Bleuler im »Gugger « in Zollikon führte Traber zur auch in der Arbeiterbewegung rezipierten wissenschaftlichen Eugenik. ${ }^{126}$ Den Sozialisten näherte sich Traber bereits im Seminar an, bevor er 1917/18 als Freund des Lenin-Vertrauten Fritz Platten an zentralen Streikaktionen und Demonstrationen in Zürich beteiligt war.

Heer wiederum schreibt Joggelis literarische Förderung seinem Küsnachter Deutschlehrer Adolf Calmberg zu, der als einzige Romanfigur mit dem Realnamen benannt ist und ein anerkannter Schriftsteller war. ${ }^{127}$ Dank Calmberg erlebte Joggeli - und wohl auch Heer - Besuche des Theaters in Zürich, das im Roman als wahre Bildungsanstalt stilisiert ist. ${ }^{128}$ Manche Lehrer gingen somit über den Wissenskanon des Seminars hinaus und sprengten die in Kapitel drei beschriebenen Zeit- und Raumordnungen sowie die Seminarhierarchie.

Die mit diesen hier nur angerissenen Arenen und Orten verbundenen Leseerfahrungen und Wissenszirkulationen gingen deutlich über den traditionellen seminaristischen Lektürekanon von Goethe und Schiller hinaus. In neuen Vergemeinschaftungen am Seminar formierten sich vielmehr weitergehende Praktiken des Lesens und des kulturell-intellektuellen Austauschs. Besonders anhand der Lektüre Nietzsches begründete z.B. Traber das Recht und die Notwendigkeit der Entfaltung einer starken, über das Mittelmass hinausgehenden Persönlichkeit. Gerade nach dessen Tod 1900 gerann Nietzsche nicht nur in Küsnacht,

123 Ebd., S. 35; Schaffner 2005, S. 324 U. 347.

124 Traber 1960, S. 27.

125 Ebd., S. 31 u. $35 f$. Zu Brupbacher jüngst Hardegger 2017, S. $267 f$.

126 Traber 1960, S. 33. Zur Familie Bleuler und zu eugenischen Zweigen der Abstinenzbewegung vgl. Grube/De Vincenti 2013, S. 216 u. 219.

127 Calmberg leitete das Laientheater am Seminar und versuchte vergeblich, den Deutschaufsatz zu reformieren, vgl. StAZH UU 20.17, Protokollbuch der Aufsichtskommission, Actum 25. Mai 1878, S. 138, und Actum 3. April 1879, S. 169.

128 Heer 1902, S. 287 U. 291. 
sondern auch in der deutschen Lehrerbildung zum gemeinschaftsstiftenden Autor der Seminaristen: »für uns Oppositionelle«, so Traber, gegen die Seminarlehrer, die in der Rolle als »Wissenspolizei ${ }^{129}$ Nietzsche als Scharlatan abtaten. Nietzsche diente als verbreitetes Medium reformpädagogisch orientierter Wissens- und Meinungsmobilisierung gegen eine als verkrustet aufgefasste Schule und Lehrerschaft. Gerade über die zum »Meinungsbildungszwang « $^{130}$ anregende Figur Nietzsche wurde ein Kampf Alt gegen Jung sowie gegen eine oberflächliche, stumpfsinnige und intellektuelle Versenkung verhindernde Bildungsauffassung geführt. ${ }^{131}$ Die sich an Nietzsche entzündende Wissenskrise an Zürcher Seminaren wurde Jahrzehnte später etwa im Evangelischen Seminar Zürich Unterstrass so zu lösen versucht, dass die als umstritten geltenden Werke Nietzsches Eingang in der Seminarbibliothek fanden, einem Ort der Leseermöglichung und -kontrolle. ${ }^{132}$

Subtile Praktiken der intellektuellen Erprobung und des Wissenskampfes zeigten sich auch im etablierten Prüfungsformat des Deutschaufsatzes, in den die sschreibenden< Seminaristen ihr serlesenes،, angeeignetes und als elitär empfundenes Wissen hineinmanövrieren und die Lehrer damit konfrontieren konnten. In einem Aufsatz mit Thema Was verdanken wir der Erfindung des Glases? fügte der Jungabstinenzler Traber spöttische Invektiven gegen Trunksucht ein, etwa als er die Funktion der ygläsernen Strassenlaternen darin qualifizierte, dass sie "Angetrunkenen für einige Augenblicke Stand« bieten. Diese Demonstration des in Abstinenzkreisen gewonnenen Wissens rügte der Lehrer in roter Schrift am Seitenrand: »missratener Witz!«, »unverständlich!«, »Mehr Inhalt, aber weniger verfehlte Spässe «. ${ }^{133}$ In der Abschlussklasse zeigte Traber in seinem Aufsatz Das Urteil der Menge beträchtliche Kenntnisse von Massentheorie wie zugleich auch Massenskepsis. Fast auf Nietzsche oder aber auch auf Ansätze der Lebensreformbewegung zurückführen könnte man Trabers Auffassung, wonach das Urteil der Menge beim einzelnen Menschen gewaltsamen Konformitätsdruck ausübe: „Die freie Handlungsweise ist ihm gänzlich genommen.« Der Lehrer riet zur Mässigung und mahnte: »Nur nicht übertreiben!«, »Etwas mehr Ruhe und Sachlichkeit! $\ll^{134}$ Der Seminarist Traber versagte mit seiner Darstellungsweise eine zentrale Lehrererwartung hinsichtlich des Deutschaufsatzes: dass der Schüler mit

129 Foucault 2001, S. 218.

130 Gehlen 2004, S. 57.

131 Niemeyer 1999, S. 211-213; Whittaker 2013, S. 18-21.

132 Traber 1960, S. 36f. (dort das Zitat zu Nietzsche). Zur Rezeption Nietzsches im Evangelischen Seminar Unterstrass vgl. [Anonym] 1943, S. 10. Zur Bibliotheksordnung vgl. Seminarordnung Küsnacht 1901, S. 4.

133 SAZ VII.148: 1.3.4. Schulhefte Traber: Aufsätze II, Klasse Ilb (NL Traber).

134 Ebd.: Aufsätze I Traber Klasse IVb (NL Traber). 
seinem Text »eine angenehme Rezeptionserfahrung « biete, ${ }^{135}$ also dem Wissen des Lehrers entspreche. Traber hingegen bot phasenweise zu viel Eigenständiges, was - etwa nach 1950 - immer wieder gefordert wurde, ${ }^{136}$ jedoch in diesem Fall als in Inhalt und Schreibpraktik übertrieben gewertet wurde. Seine durchgehend gute bzw. "ziemlich« gute Benotung im Fach Deutsch zeigt aber auch, dass sein eigensinniges Schreibverhalten, das auf Lesepraktiken und intellektuellen Erprobungen beruhte, trotz aller Wissenskonflikte nicht völlig gegen die Erwartungsund Bewertungsmuster des Seminars verstiess. Zugleich ahmte er verbreitete Lese- und Schreibpraktiken seiner Zeit nach, und die Lehrer in Küsnacht schienen in ihrem Ordnungsrahmen einen Umgang damit gefunden zu haben und erteilten Traber weitgehend ohne offiziellen Widerspruch ein gutes Prüfungszeugnis für Primarlehrer. ${ }^{137}$

\section{Vielfältige, eigensinnige Praktiken in unterschiedlichen Ordnungskontexten am Seminar: ein Fazit}

Die hier untersuchten Selbstzeugnisse weisen zahlreiche Strukturelemente auf, wie ein Seminar in Tageseinteilungen, Ordnungsmustern, Erziehungs- und Strafpraktiken regelmässig und nach der zwiespältigen Wahrnehmung und erinnerten Erfahrung der Autoren abzulaufen schien. Die ehemaligen Zöglinge schildern das Seminar um 1900 in fiktionalen Texten mit hohen autobiografischen Anteilen häufig als quasitotalen Begrenzungs- und Kontrollort, dem Seminaristen teils schikanös ausgeliefert seien. Mit dieser Negativdarstellung griffen sie diskursive Muster der Schulkritik auf. Thesenhaft könnte man behaupten, dass die veröffentlichten Romane trotz ihrer Kritik an der Stabilisierung bzw. Hervorbringung von Vorstellungen über Seminarpraktiken beitrugen. Denn Praktiken, so die Annahme und in Teilen auch das Ergebnis, bedürfen der breiten Akzeptanz, des impliziten Wissens, geteilter Vorstellungen und korrespondieren wechselseitig mit einer öffentlich etablierten Meinung. Deswegen scheint die phasenweise in dem Beitrag aufleuchtende Sorge der Seminardirektion vor Reputationsverlust des Seminars insofern berechtigt, als ein nachhaltiger Ansehensverfall Konsequenzen für etablierte Routinen, Abläufe, eben Praktiken des raumzeitlichen und familial konnotierten Kontrollregimes hätten.

Die Selbstzeugnisse zeigen jedoch auch auf, dass die Zöglinge nicht nur dauerhaften Bewertungen durch Lehrpersonen und Erzieher, sondern auch

135 Reh et al. 2017, S. 292.

136 Ebd., S. 291.

137 SAZ VII.148: 1.3.3. Schulzeugnisse vom Seminar Küsnacht, Primarlehrerpatent und Wählbarkeitszeugnis. 
durch Mitseminaristen ausgesetzt waren. In den Selbstzeugnissen werden mit Freund- und Feindschaften, Geheimbünden, Lesegruppen und Vereinen (Stenografie, Abstinenz) vielfältige, konkurrierende Gemeinschaften, Hierarchien und damit Loyalitätskonflikte in unterschiedlichen Sozial- und Handlungskontexten aufgerufen. So brachte etwa Trabers Mitgliedschaft in der Fraternitas nicht nur neue Freundschaften und Wissenszugänge, sondern auch Verachtung von Mitseminaristen ein. ${ }^{138}$ Der von den Autoren reklamierte Eigensinn zeigte sich eben nicht nur gegenüber Lehrern und Direktoren, sondern auch gegenüber den Peers, denn zwischen und innerhalb der Teilgemeinschaften am Seminar herrschten verschiedene Binnenfriktionen vor.

In den autobiografischen Romanen dominiert literarisch-dramaturgisch zugespitzt das personalisierte, emotionalisierte, zwischen patriarchalischer Freundschaft und Strenge wechselnde Duell zwischen Direktor und Zögling. Aufsichtsinstanzen des Seminars bleiben hierbei weitgehend aussen vor. Die aus diesem persönlichen Beziehungskonflikt hervorgehenden Strafpraktiken bilden sich nicht in den Archivquellen des Lehrerkonvents und der Aufsichtskommission als seminaristische Aufsichtsinstanzen ab, die Vergehen von Zöglingen zumeist nüchtern mit vorläufigen Versetzungen, Stipendienentzug, Verweisen und Entlassungen ahnden. Selbstzeugnisse betonen vor allem die Krisenmomente an Lehrerbildungs- und Erziehungsanstalten, aber eben auch - wenngleich literarisch inszeniert - anderweitig selten dokumentierte Krisenverläufe, die jedoch im Hinblick auf ihr Deutungspotenzial durch Vergleiche mit anderen Quellen relativiert werden müssen.

Die Autoren stellen Romanhelden in Ego-Dokumenten auf den ersten Blick als eigensinnige und - mit de Certeau gesprochen - listige Abweichler von etablierten Gewohnheiten, Ritualen und Abläufen im Seminar dar, dessen Lehrer und Unterricht sie als sich selbst so begreifende Aussenseiter teilweise verachten. Doch was als individueller Eigensinn erscheint, kommt bei vertiefter und vergleichender Quellenanalyse auch als Loyalitätskonflikt zwischen verschiedenen sozialen Anspruchsgruppen und -kontexten daher. Praktiken der freundschaftlichen Solidarität, der literarischen Erprobung und Verschwiegenheit können im Ordnungskontext des Seminars, in dem Ehrbezeugung und Gehorsamsgebote gelten, als eigensinnige Verstösse wahrgenommen werden, im Kommunikationskontext der peers jedoch als erwartetes Verhalten. Beim Changieren zwischen verschiedenen sozialen Kontexten im Seminar eignen sich Seminaristen ausweislich der Selbstzeugnisse den Umgang mit widerstreitenden Praktiken, unterschiedlichen Meinungsbildungen und Anerkennungserwartungen teilweise subtil eigensinnig an. Dabei sind sie Teil von Wissenszirkulation in unterschiedlichen Seminarkontexten, etwa indem sie eigensinnig und wildernd offiziell nur wenig goutierte Bücher

138 Traber 1960, S. 24. 
(Nietzsche) lesen. ${ }^{139}$ So erproben sie sich intellektuell, selbst wenn ihre Lektüre nur Teil verbreiteter intellektueller Mode ist. Im listigen, spielfähigen Umgang mit unterschiedlichen Handlungskontexten und Wissenskämpfen am Seminar handeln sie mit aus, welches (kulturell verwertbares) Wissen gelten soll. Wissenskämpfe konnten in den Unterricht, etwa im Deutschaufsatz, einfliessen - hier bieten vielfältige, über Selbstzeugnisse hinausgehende Quellen ergänzende Analysemöglichkeiten für das einleitend erwähnte »Tracing« historischer Praktiken.

Der Seminaralltag kann so zu einer die vermeintliche Lebensform des Seminars krisenhaft attackierenden oder aber durch Reetablierung von Konventionen befestigenden Arena der Auseinandersetzung verschiedener Wissen werden. ${ }^{140}$ In öffentlich im Seminar ausgetragenen (Wissens-)Konflikten, die letztlich Folgen für Veränderungen von Praktiken haben konnten, ging es oft um Beschämung und Ansehen (Ehre) von Seminaristen, aber auch von Lehrern. Die von Traber geschilderte Empörung über den neuen Französischlehrer Dr. Theodor Flury, der Seminaristen bei falschen Antworten als »imbécile « bezeichnete, ${ }^{141}$ veranlasste die Klasse zu folgendem Aushang am Schwarzen Brett: »Muß sich ein zukünftiger Lehrer mit imbécile benennen lassen?« Indem dieser Konflikt öffentlich gemacht wurde, scheute der Lehrer - ausweislich Traber - die Auseinandersetzung und unterliess entsprechende Diskreditierungen. Selbstzeugnisse können somit auch Wahrnehmungen, Einschätzungen und Hinweise auf leicht modifizierte, angepasste Verhalten und Beziehungen zwischen Lehrern und Schülern enthalten.

Verschiedene Praktiken, eigensinniges Verhalten und Kontrollregime im Seminar stehen häufig diversen Kommunikationszusammenhängen gegenüber, sodass für weitere historisch-praxeologische Arbeiten kombinierte Bezüge zu Kommunikationstheorien und wissensgeschichtlichen Ansätzen vielversprechend sein können. ${ }^{142}$

\title{
Quellen und Literatur
}

\section{Ungedruckte Quellen}

\section{Forschungsbibliothek Pestalozzianum PH Zürich}

Reglement für das Zürcherische Lehrerseminar 1861 (ZH HA II, 5).

Seminarordnung für das Lehrerseminar des Kantons Zürich in Küsnacht vom 30.

Dezember 1901 (ZH HA II, 5).

\author{
139 De Certeau 1988, S. 293. \\ 140 Vgl. Boltanski/Thevenot 2011, S. 45. \\ 141 Traber 1960, S. 20. \\ 142 Hinweise dazu Haasis/Rieske S. 38ff.; Landwehr 2003; Reckwitz 2008; Stratmann 2006.
}




\section{Staatsarchiv Zürich (StAZH)}

Z 388.1584: Protokollbuch Lehrerkonvent (1875-1887).

Z 388.1586: Protokollbuch Lehrerkonvent (1895-1908).

Z 388.6932, 388.6937, 388.6943, 388.6950: Klassenakten I. Klasse 1875/6; II. Klasse 1876/7; III. Klasse 1877/8; IV. Klasse 1878/9.

UU 20.17: Protokollbuch Aufsichtskommission (1874-1880).

UU 20.20: Protokollbuch Aufsichtskommission (1900-1906).

\section{Stadtarchiv Zürich, Nachlass Alfred Traber (SAZ, NL Traber)}

VII.148.1.2.1: Traber, Alfred (1960): Rückblick auf mein Leben. Bd. 1 (hdschr. MS).

VII.148.1.3.3: Schulzeugnisse vom Seminar Küsnacht, Primarlehrerpatent und Wählbarkeitszeugnis.

VII.148.1.3.4: Schulhefte »Aufsätze« 1899-1903.

\section{Gedruckte Quellen}

[Anonym] (1943): Ein Jahr weitgreifender Entschlüsse. In: Evangelisches Lehrerseminar Zürich. Jahresbericht 1942-43, Zürich, S. 4-15.

Canetti, Elias (2003): Masse und Macht. 29. Aufl. Frankfurt a.M.

Foerster, Friedrich Wilhelm (1902): Bedeutung und Methoden des Moralunterrichts in der Schule. In: Bericht über die Verhandlungen der Zürcherischen Schulsynode von 1902. Zürich, S. 121-160.

Heer, Jakob Christoph (1902): Joggeli. Die Geschichte einer Jugend. Stuttgart, Berlin.

Hesse, Hermann (2017): Unterm Rad. Erzählung [1906]. Frankfurt a.M.

Kästner, Erich (1983): Fabian. Die Geschichte eines Moralisten [1931]. In: Kästner für Erwachsene. Ausgewählte Schriften. Bd. 3. Zürich, S. 11-195.

Michels, Volker (Hg.) (2008): Herman Hesse »Unterm Rad«. Entstehungsgeschichte in Selbstzeugnissen des Autors. Frankfurt a.M.

Schaffner, Jakob (2005): Johannes. Roman einer Jugend [1922]. Mit einem Nachwort von Peter Hamm. München, Wien.

Traber, Alfred (2011): Ich war der »Trämlergeneral«. Rückblick auf mein Leben. Hg. v. Mario Florin. Zürich.

Wamister, Christof (Hg.) (2009): »Es ging am Anfang nicht leicht mit uns«. Hermann Hesse und Jakob Schaffner im Briefwechsel 1905-1933. Zürich.

Zeller, Konrad (1925): [Ohne Titel]. In: Evangelisches Lehrerseminar Unterstrass. 49. Bericht 1924/25. Zürich, S. 3-27. 


\section{Literatur}

Berger, Peter L./Luckmann, Thomas (2001): Die gesellschaftliche Konstruktion der Wirklichkeit. Eine Theorie der Wissenssoziologie. 18. Aufl. Frankfurt a.M. Böth, Mareike (2018): »Ich handele, also bin ich«. Selbstzeugnisse praxeologisch lesen. In: Geschichte in Wissenschaft und Unterricht 69, H. 5/6, S. 253-270.

Boltanski, Luc/Thévenot, Laurent (2011): Die Soziologie der kritischen Kompetenzen. In: Rainer Diaz-Bohne (Hg.): Soziologie der Konventionen. Grundlagen einer pragmatischen Anthropologie. Frankfurt a.M., New York, S. 43-68.

Bourdieu, Pierre (2015): Entwurf einer Theorie der Praxis auf der ethnologischen Grundlage der kabylischen Gesellschaft. 4. Aufl. Frankfurt a.M.

Brandes, Sören/Zierenberg, Malte (2017): Doing capitalism. Praxeologische Perspektiven. In: Mittelweg 36. Zeitschrift des Hamburger Instituts für Sozialforschung 26, H. 1, S. 3-24.

Conrad, Christoph/Kessel, Martina (1998): Blickwechsel: Moderne, Kultur, Geschichte. In: Diess. (Hg.): Kultur \& Geschichte. Neue Einblicke in eine alte Beziehung. Stuttgart, S. 9-40.

Davis, Belinda/Lindenberger, Thomas/Wildt, Michael (2008): Einleitung. In: Diess. (Hg.): Alltag, Erfahrung, Eigensinn. Historisch-anthropologische Erkundungen. Frankfurt a.M., S. 11-28.

De Certeau, Michel (1988): Kunst des Handelns. Berlin.

De Vincenti, Andrea (2015): Schule der Gesellschaft. Wissensordnungen von Zürcher Unterrichtspraktiken zwischen 1771 und 1834. Zürich.

De Vincenti, Andrea/Grube, Norbert/Hoffmann-Ocon, Andreas (2018): Wissenschaftsaffines Seminar und kontinuierliche Erziehungsmuster in der akademischen Pädagogik. Debatten und Dynamisierungen in der Ausbildungsreform Deutschschweizer Lehrpersonen im frühen 20. Jahrhundert. In: Wilfried Göttlicher/Jörg W. Link/Eva Matthes (Hg.): Bildungsreform als Thema der Bildungsgeschichte. Bad Heilbrunn, S. 117-130.

Dekker, Rudolf (2002): Introduction. In: Ders. (Hg.): Egodocuments and History. Autobiographical Writing in Its Social Context since the Middle Age. Hilversum, S. 7-20.

Dudek, Peter (2002): Fetisch Jugend. Walter Benjamin und Siegfried Bernfeld: Jugendprotest am Vorabend des Ersten Weltkrieges. Bad Heilbrunn.

Foucault, Michel (1998): Nietzsche, die Genealogie, die Historie [1974]. In: Christoph Conrad/Martina Kessel (Hg.): Kultur \& Geschichte. Neue Einblicke in eine alte Beziehung. Stuttgart, S. 43-71.

Foucault, Michel (2001): In Verteidigung der Gesellschaft. Vorlesungen am Collège de France (1975-76). Frankfurt a.M. 
Füssel, Marian (2015): Die Praxis der Theorie. Soziologie und Geschichtswissenschaft im Dialog. In: Arndt Brendecke (Hg.): Praktiken der Frühen Neuzeit. Akteure, Handlungen, Artefakte. Köln, Weimar, Wien, S. 21-33.

Gehlen, Arnold (2004): Die Seele im technischen Zeitalter. Sozialpsychologische Probleme in der industriellen Gesellschaft [1957]. In: Karl-Siegbert Rehberg (Hg.): Arnold Gehlen. Die Seele im technischen Zeitalter und andere sozialpsychologische, soziologische und kulturanalytische Schriften. Frankfurt a.M., S. 1-137.

Goetz, Hans-Werner (1979): »Vorstellungsgeschichte«. Menschliche Vorstellungen und Meinungen als Dimension der Vergangenheit. In: Archiv für Kulturgeschichte 61, S. 253-271.

Greyerz, Kaspar von (2010): Ego-Documents: The Last Word? In: German History 28, H. 3, S. 273-282.

Grube, Norbert (2018): Verortungsversuche von fluiden Bildungsräumen im Evangelischen Lehrerseminar Zürich Unterstrass 1870 bis 1950. Das familiale Leitbild als raumkonstituierender Ordnungsfaktor. In: Historia Scholastica 4, H. 1, S. 17-28.

Grube, Norbert/De Vincenti, Andrea (2013): Die Abstinenzbewegung gegen das alkoholisierte Volk. Zirkulation wissenschaftlichen Wissens in Schule und Öffentlichkeit in der Schweiz um 1900. In: International Journal for the Historiography of Education 3, H. 2, S. 209-225.

Günther, Dagmar (2001): »And now for something completely different«. Prolegomena zur Autobiographie als Quelle der Geschichtswissenschaft. In: Historische Zeitschrift 278, H. 1, S. 25-61.

Haasis, Lucas/Rieske, Constantin (2015): Historische Praxeologie. Zur Einführung. In: Diess. (Hg.): Historische Praxeologie. Dimensionen vergangenen Handelns. Paderborn, S. 7-54.

Habermas, Jürgen (1990): Strukturwandel der Öffentlichkeit. Untersuchungen zu einer Kategorie der bürgerlichen Gesellschaft. Neuauflage der Ausgabe von 1962. Frankfurt a.M.

Hanuschek, Sven (1999): Keiner blickt Dir hinter das Gesicht. Das Leben des Erich Kästner. München.

Hardegger, Urs (2017): Revolution der Bildung oder Bildung zur Revolution? Jugenderziehung am Beispiel der Sozialistischen Jugendbewegung. In: Norbert Grube/Andreas Hoffmann-Ocon/Andrea De Vincenti (Hg.): Erster Weltkrieg, Schule und Volksbildung in der Deutschschweiz. Pädagogisierungsambitionen und -dynamiken zwischen Mobilisierung und gesellschaftlicher Balance. Münster, Zürich, S. 259-291.

Heinze, Carsten (2010): Autobiographie und zeitgeschichtliche Erfahrung. Über autobiographisches Schreiben und Erinnern in sozialkommunikativen Kontexten. In: Geschichte und Gesellschaft 36, H. 1, S. 93-128. 
Hillebrandt, Frank (2015): Vergangene Praktiken. Wege zu ihrer Identifikation. In: Arndt Brendecke (Hg.): Praktiken der Frühen Neuzeit. Akteure, Handlungen, Artefakte. Köln, Weimar, Wien, S. 34-45.

Hoffmann-Ocon, Andreas (2017): Persönlichkeit oder Wissenschaftsbasierung? Einfluss von Ausbildungspraktiken auf Prüfungen Zürcher Volksschullehrpersonen um 1900. In: Zeitschrift für Pädagogik 63, H. 3, S. 299-316.

Jaeggi, Rahel (2014): Kritik von Lebensformen. 2. Aufl. Frankfurt a.M.

Johann, Klaus (2003): Grenze und Halt: Der Einzelne im »Haus der Regeln«. Zur deutschsprachigen Internatsliteratur. Heidelberg.

Keim, Wolfgang/Schwerdt, Ulrich (2013): Schule. In: Diess. (Hg.): Handbuch der Reformpädagogik in Deutschland (1890-1933). Teil 2: Praxisfelder und pädagogische Handlungssituationen. Frankfurt a.M., S. 657-775.

Klika, Dorle (2016): Autobiographien als Kinder ihrer Zeit. In: BIOS. Zeitschrift für Biographieforschung, Oral History und Lebensverlaufsanalysen 29, H. 2, S. 275-287.

Landwehr, Achim (2003): Diskurs - Macht - Wissen. Perspektiven einer Kulturgeschichte des Politischen. In: Archiv für Kulturgeschichte 85, S. 71-117.

Lipphardt, Veronika/Patel, Kiran Klaus (2008): Neuverzauberung im Gestus der Wissenschaftlichkeit. Wissenspraktiken im 20. Jahrhundert am Beispiel menschlicher Diversität. In: Geschichte und Gesellschaft 34, H. 4, S. 425-454.

Lüdtke, Alf (1997): Geschichte und Eigensinn. In: Berliner Geschichtswerkstatt (Hg.): Alltagskultur, Subjektivität und Geschichte. Zur Theorie und Praxis von Alltagsgeschichte. Münster, S. 139-154.

Lüdtke, Alf (2003): Alltagsgeschichte - ein Bericht von unterwegs. In: Historische Anthropologie 11, H. 2, S. 278-295.

Mergel, Thomas (2002): Überlegungen zu einer Kulturgeschichte der Politik. In: Geschichte und Gesellschaft 28, H. 4, S. 574-606.

Neugebauer, Wolfgang (1985): Absolutistischer Staat und Schulwirklichkeit in Brandenburg-Preussen. Berlin.

Niemeyer, Christian (1999): »Plündernde Soldaten«. Die pädagogische NietzscheRezeption im Ersten Weltkrieg. In: Zeitschrift für Pädagogik 45, H. 2, S. 209229.

Noelle-Neumann, Elisabeth (2001): Die Schweigespirale. Öffentliche Meinung unsere soziale Haut. 6. Aufl. München.

Pross, Caroline (2013): Dekadenz. Studien zu einer großen Erzählung der frühen Moderne. Göttingen.

Reckwitz, Andreas (2008): Praktiken und Diskurse. Eine sozialtheoretische und methodologische Relation. In: Herbert Kalthoff/Stefan Hirschauer/Gesa Lindemann (Hg.): Theoretische Empirie. Zur Relevanz qualitativer Forschung. Frankfurt a.M., S. 188-209. 
Reh, Sabine/Kämper-van den Boogaart, Michael/Scholz, Joachim (2017): Eine lange Geschichte: Der deutsche Abituraufsatz als »Gesammtbildung der Examinanden«. In: Zeitschrift für Pädagogik 63, H. 3, S. 280-298.

Reichardt, Sven (2015): Zeithistorisches zur praxeologischen Geschichtswissenschaft. In: Arndt Brendecke (Hg.): Praktiken der Frühen Neuzeit. Akteure, Handlungen, Artefakte. Köln, Weimar, Wien, S. 46-61.

Rieger-Ladich, Markus (2014): Historische Romane als Elemente diskursiver Formationen. In: Patrick Bühler/Thomas Bühler/Marianne Helfenberger/Fritz Osterwalder (Hg.): Erziehung in der europäischen Literatur des 19. Jahrhunderts. Bern (Prisma - Beiträge zur Erziehungswissenschaft aus historischer, psychologischer und soziologischer Perspektive 21), S. 55-74.

Sabean, David W. (1990): Das zweischneidige Schwert. Herrschaft und Widerspruch im Württemberg der frühen Neuzeit. Frankfurt a.M.

Sarasin, Philipp (2003): Geschichtswissenschaft und Diskursanalyse. In: Ders.: Geschichtswissenschaft und Diskursanalyse. Frankfurt a.M., S. 10-60.

Sarasin, Philipp (2011): Was ist Wissensgeschichte? In: Internationales Archiv für Sozialgeschichte der deutschen Literatur 36, H. 1, S. 159-172.

Schlögel, Karl (2017): Das sowjetische Jahrhundert. Archäologie einer untergegangenen Welt. München.

Schlögl, Rudolf (2008): Kommunikation und Vergesellschaftung unter Anwesenden. Formen des Sozialen und ihre Transformation in der Frühen Neuzeit. In: Geschichte und Gesellschaft 34, H. 2, S. 155-224.

Schulze, Winfried (1996): Ego-Dokumente: Annäherung an den Menschen in der Geschichte. Vorüberlegungen für die Tagung »EGO-DOKUMENTE«. In: Ders. (Hg.): Ego-Dokumente. Annäherung an den Menschen in der Geschichte. Berlin, S. 11-30.

Settele, Veronika (2017): Mensch, Kuh, Maschine. Kapitalismus im westdeutschen Kuhstall, 1950-1980. In: Mittelweg 36. Zeitschrift des Hamburger Instituts für Sozialforschung 26, H. 1, S. 44-65.

Siegrist, Christoph (1995): Der zerrissene Jakob Schaffner: überzeugter Nationalsozialist und Schweizer Patriot. In: Aram Mattioli (Hg.): Intellektuelle von rechts. Ideologie und Politik in der Schweiz 1918-1939. Zürich, S. 55-71.

Stratmann, Hildegard (2006): Lehrer werden. Berufliche Sozialisation in der Volksschullehrer-Ausbildung in Westfalen (1870-1914). Münster.

Tanner, Jakob (2012): Historische Anthropologie. Version 1.o. In: Docupedia-Zeitgeschichte vom 3. Januar 2012, online unter DOI: http://dx.doi.org/10.14765/ zzf.dok.2.278.v1 (Zugriff: 15.04.2020).

Tönnies, Ferdinand (1920): Gemeinschaft und Gesellschaft. Grundbegriffe der reinen Soziologie [1887]. 3. Aufl. Berlin.

Whittaker, Gwendolyn (2013): Überbürdung - Subversion - Ermächtigung. Die Schule und die literarische Moderne 1880-1918. Göttingen. 


\section{Praktiken der Eignungsabklärung von angehenden Zürcher Primarlehrpersonen (1940-1960)'}

Andreas Hoffmann-Ocon

\section{Annäherung an Praktiken der Eignungsabklärung und Praktiken ihrer Erschliessung}

Die Frage nach der Eignung von angehenden Unterrichtenden gehört fast wie ein Schatten zu den sowohl akademischen und intellektuellen Debatten als auch Orten und Institutionen der Lehrpersonenbildung. Eine diesbezügliche Abklärung hat viele Facetten. Gegenwärtig werden im deutschsprachigen Raum angesichts verschiedener Bestimmungen beruflicher Anforderungen eine Vielfalt an Verfahren angewandt und teilweise auch gleichzeitig beforscht. Von biografieorientierten Verfahren über Simulationen ausgewählter beruflicher Aufgaben oder Fähigkeits-, Persönlichkeits- und Interessentests zur Diagnose des Potenzials einer Person ${ }^{2}$ und der Kombination verschiedener Instrumente, wie etwa ein Assessment Centre für angehende Studierende ohne Maturitätsabschluss, ${ }^{3}$ reicht die unübersichtliche Palette denkbarer Abklärungen. Unter dem Stichwort der negativen Selbstselektion befassen sich weitere Untersuchungen mit der Frage, ob angesichts des expliziten Konkurrenzverhältnisses zu anderen Ausbildungen und Studiengängen Faktoren bestimmt werden können, welche erklären, warum Maturand/-innen sich eher für oder gegen den Lehrberuf entscheiden. Einen (ehemaligen) »Aufstiegsberuf « anstrebend, ${ }^{4}$ zeichnen sich die Aspirant/-innen im Vergleich mit Studienkolleg/-innen anderer Fächer durch geringere sozioökonomische und kulturelle Ressourcen aus. Deutschschweizerische Studien weisen darauf hin, dass ein Teil der lehramtsinteressierten Maturand/-innen geringes Interesse an wissenschaftlichem Arbeiten haben, sodass die späteren Studierenden

1 Dieser Beitrag entstand im Rahmen des SNF-Projekts 166008 »Wissenschaft - Erziehung und Alltag. Orte und Praktiken der Zürcher Primarlehrer/-innenbildung in der ersten Hälfte des 20. Jahrhunderts«.

2 Zum Beispiel Pässler/Hell/Schuler 2011, S. 639-643

3 Zum Beispiel Bieri Buschor/Schuler Braunschweig 2011.

4 Enzelberger 2001, S. $74 \mathrm{f}$. 
mit ihren Orientierungen das auf wissenschaftliches Wissen basierende Konzept der Hochschulen eher unterlaufen. ${ }^{5}$

Was folgt aus einer Skizzierung heutiger Fragen zur Eignungsabklärung für die Betrachtung diesbezüglicher historischer Praktiken? Zunächst einmal geht es darum, eine historische Praxis der Eignungsabklärung von angehenden Zürcher Primarlehrpersonen nicht bloss von ihrem Ende her, der aktuellen Situierung, zu denken. Ebenfalls wäre es zu kurz gegriffen, Konfigurationen und Routinen der Eignungsabklärung, z.B. von 1943, lediglich als Vorgeschichte aktueller Verfahren zu begreifen. Die angehenden Unterrichtenden und Seminarlehrpersonen folgten damals durchaus anderen Deutungsmustern zur Eignung für ein Lehramt, sodass Gedankenoperationen, vom Späteren schlankerhand auf das Frühere zu schliessen und in einer theoretisch verengten Perspektive lediglich Kontinuitäten, Kausalketten oder verborgenen Wirkungszusammenhänge aufzuspüren, die an momentane Abklärungspraktiken anschliessen, skeptisch zu beurteilen sind. Allerdings sollte der folgend skizzierte Zugriff eine »Durchquerung des Aktuellen mittels der Geschichte« nicht ausschliessen. ${ }^{6}$ Womöglich bergen Regime der Eignungsabklärung von Lehrpersonen und der dazugehörenden Berichterstattung grundsätzliche Praktiken, welche die derzeitigen Verfahren mitkonstituieren. Denkbar wäre auch, dass sich als ganz wesentlich die Verbindung zwischen den kategorialen Vorgaben der Seminarlehrpersonen resp. Dozierenden und der Berichterstattung vonseiten der angehenden Unterrichtenden herausstellt. Welche Macht kann diese unterschiedlichen Elemente derart zusammenschweissen, dass geeignete Lehrpersonen daraus hervorgehen? Einen Schritt in die Richtung, sich verschiedenen Auswahldispositiven um 1900 und aktuell anzunähern, hat etwa Andreas Kaminski unternommen, indem er das Dispositiv von 1900 mit dem von 2000 vergleicht: Während das Dispositiv um 1900 von der idealen Überlegung einer harmonisierten Gesellschaft geprägt sei, in der sich jede Person an dem für sie besten Funktionsort befinde und so ihre Potenziale ausreizen könne, solle um 2000 das Individuum seine Kompetenzen in Auseinandersetzung mit sich selbst optimieren. ${ }^{7}$ In die Dispositive konnten Versatzstücke ganz verschiedener Ansätze einfliessen: Das konnten Amalgamierungen etwa von Überlegungen zur Begabungsvererbung mit Betrachtungen von Gruppen als neue psychologische Einheit sein. Eignung war und bleibt, ähnlich wie Leistung und Begabung, eine Frage der Perspektive und »Spielfelder $:^{8}$ So ist bei einer ersten Inaugenscheinnahme gar nicht klar, ob in Ausbildungskontexten für ein Lehramt der Grad einer Anstrengung oder aber das dadurch hervorgebrachte Ergebnis, die auf eine bestimmte

\footnotetext{
5 Vgl. Denzler/Fiechter/Wolter 2005, S. 584.

6 Vgl. Foucault 2003, S. 10.

7 Vgl. Kaminski 2018, S. 229.

8 Schmidt 2013, S. 38.
} 
Situation hin gezeigte Performance, belohnt wurde. ${ }^{9}$ So anregend solche Überlegungen auch sein mögen, vorerst sollen sie genügen, um den Kontext anzudeuten, in den Eignungsabklärungen von Lehrpersonen einzuordnen sind.

Hinweise darauf, was aus einer praxeologischen Perspektive zu einer Eignungsabklärungspraxis zu bedenken wäre, liessen sich - in abstrahierter Form bei Rahel Jaeggi finden: Ziel von Untersuchungen zu Ensembles sozialer Praktiken ist es, mit diesen verbundene Konflikte sichtbar zu machen und soziale Praktiken nicht als unhinterfragbar »Letztes" darzustellen, »sondern als von Menschen gestaltete und transformierbare Lebensbedingungen « $\mathrm{zu}$ begreifen, die unter normativen und funktionalen Aspekten eine »Problemlösungsstrategie verkörpern «. ${ }^{10}$ Gegen dieses Verständnis richten sich womöglich andere praxeologische Aussagen, die danach fragen, aus welchen `Letztelementen aller Praxis sich Praktiken und Praxisformationen zusammensetzten. ${ }^{11}$ Eignungsabklärungen, so eine Ausgangsthese, haben, ähnlich wie Prüfungen allgemein, kontextualisiert und normativ den Problemkomplex bearbeitet, welche Eigenschaften angehende Lehrpersonen aufweisen sollten, um als geeignet für das Unterrichten zu gelten. Sie bildeten "zeitgenössisch geltende, überindividuelle, dabei zugleich kollektiv geteilte wie individuell erfahrbare, praktische Ordnungszusammenhänge«, die sich historiografisch greifen lassen. ${ }^{12}$

Was für die Auseinandersetzung mit der Prüfung allgemein gilt, dass diese »bisher erstaunlich selten als eigenständige Praxis oder als Ensemble rekonstruiert worden [ist] und eine Leerstelle pädagogischer Reflexion [bleibt] «, ${ }^{13}$ lässt sich auf die Eignungsabklärung ebenfalls anwenden. Während Examens- und Wählbarkeits- resp. Fähigkeitsprüfungen am Abschluss des komplexen Lehramtsstudiengangs standen, der sich u.a. auf mehrere Referenzsysteme, Gütekriterien, wissenschaftliche Disziplinen und schulpraktische Übungen bezog, ${ }^{14}$ galt die Eignungsabklärung oftmals als Ausgangspunkt oder Entree der Ausbildung. Eignungsabklärungen von zukünftigen Lehrpersonen hatten auch in der Vergangenheit einerseits pädagogische Debatten angetrieben und verschiedene Abklärungsformate und -konstellationen hervorgebracht. Andererseits waren die Eignungsabklärungen mitverantwortlich dafür, dass der Zugang zu Ausbildungsgängen für Lehrpersonen selbst immer wieder thematisiert, kritisiert und reformiert worden ist.

9 Vgl. Verheyen 2018, S. 13.

10 Jaeggi 2014, S. $58 \mathrm{f}$.

11 Vgl. Hillebrandt 2015, S. 41.

12 Haasis/Rieske 2015, S. 14-18.

13 Ricken/Reh 2017, S. 247.

14 Vgl. Hoffmann-Ocon 2017, S. 302. 
Ein doppeltes Erkenntnisinteresse strukturiert das hier verfolgte Vorgehen: In diesem Beitrag soll der Versuch unternommen werden, anhand von Fallbeispielen nicht nur nach alltäglichen Modi der Konstitution und dem Wandel von Praktiken der Eignungsabklärung angehender Primarlehrpersonen zu fragen, sondern vor allem nach forschungspragmatischen Justierungen mit Quellen in praxeologischer Perspektive. Daher stehen neben der Erschliessung von Praktiken der Eignungsabklärung auch Fragen im Zentrum, die in Anlehnung an Ute Daniel und Pierre Bourdieu darauf zielen, »Zu wissen was man tut, wenn man Wissenschaft treibt «, ${ }^{15}$ in diesem Fall eine kulturwissenschaftlich und praxistheoretisch informierte Historische Bildungsforschung. Der Zirkularität wissenschaftlichen Tuns zufolge bedingen sich historische Erschliessungsmethode und Befund; praxeologisch formuliert soll die quellengeleitete Arbeit in diesem Beitrag ebenfalls immer wieder als ein Ensemble von Praktiken reflexiv aufgegriffen werden.

Um sich an die lokalen Konstruktionsakte der pädagogischen Eignung und den diesbezüglichen Verfahren vom Allgemeinen her zu nähern, sollen - erstens - zunächst schwerpunktmässig die das Feld der Lehrpersonenbildung beobachtenden Debatten, berufspraktischen und teilweise wissenschaftsaffinen Diskurse ins Sichtfeld rücken. In einem mehrschrittigen Vorgehen erst mit normativ geprägten Beobachterperspektiven zu beginnen, ist der Überlegung geschuldet, dass diese, teilweise wissenschaftlich orientierten, Aussagen und Interpretationen den in Eignungsabklärungspraktiken involvierten Personen Bezugnahmen ermöglichten und so Rahmenbedingungen des alltäglichen Handelns gewährleisteten. ${ }^{16}$ Die Überlegung einer solchen >Entlastung des Praxisfeldes durch normative Wissensordnungen geht davon aus, dass die Akteure, angehende Lehrpersonen und Seminarlehrpersonen, nicht nur Inhaber von unreflektierten Positionen in Routinen der Eignungsabklärung waren, sondern potenziell auch praktisch ins normative und wissenschaftliche Sprachspiel Involvierte sein konnten. ${ }^{17}$ So kann man, vorausgreifend auf erste Quellenhinweise, zeigen, dass nicht nur die Seminarlehrpersonen, sondern auch die Studierenden Muster kannten, die es für eine positive Abklärung zu beachten galt. Ohnehin sind die Diskurse und Praxisfelder nicht als hermetisch getrennt zu denken, sondern diskursive Elemente können den Praktiken innewohnen, so wie Diskurse Ergebnisse von Praktiken sein können und dementsprechend Diskurse sich auch als Praktiken untersuchen liessen. ${ }^{18}$ Konkrete soziale Praxis, etwa Ensembles von Praktiken zur Eignungsabklärung, wurde nicht nur performativ vollzogen, sondern trug stets ein reflexives Moment in sich. Dabei konnte für die Strukturierung des Seminaralltags (diskursives)

15 Daniel 2001, S. 13; Bourdieu 1993, S. 79. 
Wissen explizit oder implizit relevant werden: ${ }^{19}$ Eignungszuschreibungen gegenüber angehenden Lehrpersonen konnten auf Berufung von pädagogisch-psychologischer Literatur oder vor dem Hintergrund eigener Ausbildungserfahrungen erfolgen. Während z.B. von Direktoren und Seminarlehrpersonen verfasste Jahresberichte Aufschluss über Verfahren der Eignungsabklärung durch Praxisbeschreibungen liefern, finden sich in Ego-Dokumenten der Lehramtskandidierenden Hinweise auf das implizite Wissen der an der Eignungsabklärung Teilnehmenden. Gerade der Begriff des (für Eignungsabllärungen herangezogenen unterschiedlichen) Wissens ermöglicht es, die Frage nach jenen Praktiken zu stellen, durch die es konstituiert wurde. ${ }^{20}$ Praktiken zur Eignungsabklärung enthielten also Wissensordnungen, was aber nicht heisst, dass von vergangenen widerspruchsfreien, einheitlichen »Praxis-Diskurs-Formationen « auszugehen ist. ${ }^{21}$

In einem zweiten Schritt wird mit dem Quellentyp >Praxisbericht< Material herangezogen, das auf einer gewissen Ebene »die Wiederholung und die Gleichförmigkeit von immer wieder ähnlich Gesagtem oder Geschriebenem« erwarten lässt. ${ }^{22}$ Die These drängt sich auf: Je unübersichtlicher und heteronomer die Kontextbedingungen der damaligen Ausbildungsorte waren, desto vielfältiger die Berichtsproduktion, die mit ihren Ergebnissen einen Teil des Quellenausschnitts bildet. Mit der Arbeit am Material ist die Frage verbunden, welcher analytische Gewinn die Arbeit mit diesem speziellen Korpus für die Auffächerung von Praktiken der Eignungsabklärung vor dem Hintergrund der Lokalität der Situation bietet. Dabei ist es auch wichtig zu wissen, in welcher Ausbildungsphase für das Primarlehramt die Berichte entstanden sind. Im Resümee wird versucht, die doppelte Zielsetzung des Beitrags vor der Hintergrundannahme, dass Praktiken keine Wesenhaftigkeit beanspruchen können, sondern eher helfen sollen, verborgene Alltagsroutinen aufzudecken und zu identifizieren sowie auf eine abstraktere Ebene zu heben. Hier soll das Potenzial praxeologischer Ansätze für die Historische Bildungsforschung als Analyseoptik diskutiert werden. Am Ende wird keine abschliessende Bewertung auf Praktiken erfolgen, die »diejenige Wirklichkeit, auf die sie verweisen, erst hervorgebracht « haben, ${ }^{23}$ sondern auch Unklarheiten und nebulöse Verschiebungen benannt werden, die nun deutlicher zu sehen sind.

\footnotetext{
19 Vgl. Müller 2016, S. 271.

20 Nigro 2015, S. 80.

21 Reckwitz 2008, S. 206.

22 Landwehr 2008, S. 102.

23 Freist 2015, S. 67.
} 


\section{Diskursfeld Eignung von Lehrpersonen}

\section{Pädagogisches Taktgefühl}

In dem Diskursfeld `Eignung lassen sich verschiedene, miteinander streitende Artikulationsformen antreffen. An der Schwelle zum 20. Jahrhundert gewannen unter dem Eindruck experimenteller und empirischer pädagogisch-psychologischer Forschungen Redeweisen über Talente und Befähigungen weitere und vor allem konzeptartige Konturen. ${ }^{24}$

In der Literatur oft vertretene Positionen der plakativen Typen des "geborenen Lehrers « und des "Emporringers « banden je unterschiedliche Überlegungen der Überprüfung und Handlungsorientierung an sich. ${ }^{25}$ Zeitgenössische reflexive Zugriffsversuche auf das Thema >Eignung von Lehrpersonen • bezogen sich in der Deutschschweiz oftmals auf die Schrift Die seelische Veranlagung zum Erzieherund Lehrerberuf des deutschen Arbeitspädagogen Georg Kerschensteiner, welche im Jahrbuch der Schweizerischen Gesellschaft für Schulgesundheitspflege publiziert wurde: Kerschensteiner benennt in diesem Werk die analytischen Grenzen der deskriptiven Psychologie und schlägt für die Eignungsabklärung vor, anhand einem an Eduard Sprangers Schriften ${ }^{26}$ orientierten Set von sechs idealen Seelentypen den sozialen Menschen zu ermitteln, um diesen als angehende Lehrperson $\mathrm{zu}$ unterstützen und von den theoretischen, künstlerischen, religiösen, wirtschaftlichen und machterfüllten Menschen zu unterscheiden. ${ }^{27}$ Insbesondere die Ausführungen in Kerschensteiners Studie, die auf die Gabe der pädagogischen Einfühlung, auf die Fähigkeit des divinatorischen, intuitiven Erfassens einer Menschenseele aus den Bruchstücken der Worte, Handlungen und Gebärden sowie auf den pädagogischen Takt als das eigentliche Wesen pädagogischer Veranlagung abhoben, wurden z.B. in der Schweizerischen Lehrerzeitung ausführlich besprochen und stark betont. ${ }^{28}$

Die Eignung zum Lehramt, so ein 1923 publiziertes Werk des Zürcher Dozenten für Allgemeine Didaktik und Leiter des Pestalozzianums sowie der alle grossen Zürcher Institutionen der Lehrpersonenbildung zusammenfassenden Übungsschule, ${ }^{29}$ Hans Stettbacher, wollte »das Tun des Lehrers « in den »Rahmen« von »kulturellen Leistungen « stellen. ${ }^{30}$ Stettbacher zufolge lässt sich die Eignung zum

24 Vgl. Kössler 2018, S. 195.

25 Stettbacher 1923, S. 9.

26 Etwa Spranger 1921.

27 Vgl. Kerschensteiner 1919, S. 164.

28 Vgl. W.K. 1920, S. 104.

29 Vgl. Hofstetter/Schneuwly 2011, S. 535.

30 Stettbacher 1923, S. 3. 
Lehramt nicht auf eine Dimension wie etwa das Fachwissen zurückbinden. Vielmehr müssten - ausgehend vom Kandidaten - vier Beziehungen geprüft werden, eben diejenige zum Lehrstoff, zum Schüler, zum gesamten Kulturleben und zum eigenen Ich. So gerieten nicht nur Attribute angehender Lehrpersonen auf die Sichtachse, sondern auch der Bezugsrahmen des Seminars, in dem jeweils ausgebildet und orientiert wurde. Stettbacher wird in seiner Erörterung sehr konkret: Neben der Einstellung zum gesamten Kulturleben zählen die Einstellung zum Schüler und vor allem verschiedene Wissensformen, insbesondere aus den Bereichen der Psychologie und Pädagogik und das Vermögen, mit diesen verschiedenen Wissen eine feine Beobachtungs- und Deutungsfähigkeit für das zu entwickeln, "was sich im geistigen Leben des Zöglings abspielt und doch immer nur aus Äusserungen erschlossen werden muss, nie der direkten Beobachtung zugänglich ist «. ${ }^{31}$ Pädagogisches und psychologisches Wissen der angehenden Lehrpersonen könne aber nur eine Vorstufe sein: "Massgebend ist im entscheidenden Moment die geistige Beweglichkeit des Unterrichtenden und ein pädagogisches Taktgefühl, das dem einen fast ohne Mühe zuteilwird, während es ein anderer in jahrelanger Arbeit an sich selbst erwirbt «. ${ }^{32}$ Besonders interessant an Stettbachers Reflexionen ist, dass er neben Kerschensteiner ebenfalls die (durch Johann Friedrich Herbart) tradierte pädagogische Denkfigur des pädagogischen Taktes als bedeutsam einschätzte und sah, wie sich der Charakter wissenschaftlichen Wissens ändern kann, wenn dieses materiell in Körpern von Unterrichtenden zum pädagogischen Taktgefühl amalgamiert und nicht ohne Weiteres mehr verbalisiert werden konnte. In diesen Überlegungen klingen bereits praxeologische Sichtweisen von Verhaltensroutinen an, die von impliziten Wissen abhängen. ${ }^{33}$ Die wissenschaftlich geschulte Fähigkeit zur Zergliederung genüge für das Taktgefühl nicht, eine Lehrperson müsse gestalten können, z.B. das Bewusstsein der Schüler. Dazu bedürfe es neben der Einsicht in die psychische Eigenart des Kindes und einem Gestaltungswillen, der nicht von einem >l'art pour l'art «-Standpunkt aus sich entfalten sollte, einer Anteilnahme am Kinde oder an der neuen Generation: »Diese Einstellung [...] müsste bei der Frage nach der Eignung zum Lehramt besonders sorgfältig geprüft werden. Nicht etwa vor einer Prüfungskommission! Viel eher im stillen Kämmerlein «. ${ }^{34}$ Diese Sicherheit des Benehmens, der pädagogische Takt, ist eben nicht nur ein theoretisches, sondern zugleich auch ein praktisches Verhalten, das präzise auf die Situation der Unbestimmtheit eingeht, wie sie Erziehung kennzeichnet. ${ }^{35}$ Welche Spuren diese Überlegungen an

\footnotetext{
31 Ebd., S. 4.

32 Ebd., S. 5.

33 Reckwitz 2008, S. 192.

34 Stettbacher 1923, S. 6.

35 Tenorth 1986, S. 295.
} 
Debattenorten zur Lehrpersonen-Eignung, in reflektierenden Texten der angehenden Unterrichtenden und am Oberseminar selbst hinterlassen haben, soll nun aufgegriffen werden.

\section{"Krisen auslösen «? - Kommissionsprotokolle und Ego-Dokumente von angehenden Lehrpersonen als sich ergänzende Quellen}

Ein Quellentyp, der mit seinem Erschliessungspotenzial eigentümlich zwischen den Aufmerksamkeitsrichtungen von Diskurs und Praktik steht und eher changierend ist, bilden die Protokolle der Kommission zur Revision der Lehrerbildung, denen Streitgespräche zwischen den Seminardirektoren zu entnehmen sind, welche stellvertretend für ihre Institutionen und mit dem Geltungsanspruch ihres Amtes die jeweiligen Kulturen der Eignungsabklärung in Position brachten oder verteidigten. Die Quelle ermöglicht - so eine vorläufige Annahme - zu erforschen, wie Exponenten der Zürcher Lehrerbildung »ein Stück der Wirklichkeit, in der sie lebten, verstanden und zu verstehen gaben ${ }^{36}{ }^{36}$ Diejenigen, die sich eher am Bild des geborenen Lehrers orientierten, plädierten zur Eignungsabklärung für eine frühe Konfrontation des Kandidaten mit dem Schulbetrieb und für schulfeldorientierten Pädagogikunterricht auf Unterseminarstufe. Skeptiker dieses Modells erachteten das artifizielle frühe Auslösen einer Krise bei den Studierenden als unangemessen und führten positive Erfahrungen mit Kandidaten an, die noch mit Problemen in das Oberseminar gekommen seien und "nicht schon glaubten, fertig zu sein «. ${ }^{37}$ Diese Quelle wäre weiter danach zu befragen, was sie schwerpunktmässig repräsentiere: eher Auskünfte über normative Vorstellungen einer >Lehrerbildungs- und Seminarelite`, eher Einblicke in sozial geregelte und routinisierte Formen der Eignungsabklärung im Seminaralltag oder Elemente von beiden Formen zugleich? Den Kern von Argumentationen in den Protokollen bildete die Konfrontation der Kandidaten mit der Schule, welche als potenziell krisenauslösend wahrgenommen und als Anlass für studentische Berichterstattung begriffen wurde. Strittig zwischen den Seminaren und Seminardirektoren bleib der Zeitpunkt der >Initialzündungく, die Einbettung der Abklärung in ein curriculares Gefüge des jeweiligen Seminars (mit Bezugnahmen zu verschiedenen pädagogischen Wissen) und die Formate der Berichterstattung.

Neben der Frage, welche Lehrpersonen-Bilder sich im Zusammenhang mit der Eignungsabklärung von Protagonisten der Zürcher Lehrpersonenbildung anhand von Kommissionsprotokollen erschliessen lassen, ist es angesichts des zeitgenössischen Interesses an >Krisenauslösungく ebenfalls bedeutsam zu erkunden, wer sich für eine Ausbildung am Oberseminar bewarb. Die Kandidierenden nicht

36 Chartier 1989, S. 12.

37 Kanton Zürich 1953: StAZH Kommission Postulat 743, 30.10.1953, S. 19-23. 
ausschliesslich als Adressaten von Erziehungs- und Wissensvermittlungsprozessen zu sehen, sondern durch eine Perspektivverschiebung als eigensinnige Figuren mit eigenen Routinen, lenkt den Blick auf die Akteure selbst.

\section{`Soziale Herkünfte` am Seminar - verschriftlichte "Eindrücke» in Ego-Dokumenten}

»Eindrücke vom Oberseminar« nannte etwa 1944 der Kandidat Hans Seiler seinen Bericht, der sich sowohl auf die sozialen Seiten des Seminars, aber auch auf die Formen der Wissenssammlung, Wissensordnung und Wissenspräsentation neben der räumlichen Situierung bezog. Diese Eindrücke waren eingebettet in ein Chronikbuch der Kandidierenden, die eine Seminargemeinde bilden wollten. Die auf Seite 2 beschriebene selbstgesteckte Absicht zielte darauf, Festlichkeiten und Begebenheiten aus dem Seminarleben, Eindrücke und Gedanken von Lehrpersonen und Kandidierenden über Seminarbetrieb, Örtlichkeiten und wichtige Abmachungen der Seminargemeinde festzuhalten. Die 13 angehenden Lehrpersonen, darunter acht Frauen, welche den ersten Beitrag unterschrieben hatten, wollten mit der im Winter 1943/44 nachträglich begonnenen Chronik »der Erinnerung dienen und eine gewisse Tradition schaffen«, sodass diese zukünftig »à jour nachgeführt « werde. ${ }^{38}$ Mit diesem Konzept befand sich die Seminargemeinde-Gruppe ganz nah an der Idee des zirkulierenden »Korrespondenzbuches der 1881-1883 raus Schiers hervorgegangenen Lehrer«; wobei hier die mitwirkenden Absolventen das Anliegen verfolgten, »sich nicht völlig aus den Augen [zu] verlieren und in der anspruchsvollen Berufsarbeit gegenseitig [zu] ermutigen «. ${ }^{39}$ Die »Eindrücke«als Ego-Dokument geben Einblick in die Deutung der Seminarerfahrungen aus der Perspektive eines Kandidaten selbst; die Quellen dürfen jedoch nicht als Möglichkeit betrachtet werden, zur unverfälschten Sicht der angehenden Lehrpersonen im Seminar vorzudringen. Viel eher handelt es sich um eine nah an den historischen Akteur, der wiederum in Praktiken verwickelt war, heranreichende Quelle, von der nicht authentische Äusserungen eines vergangenen >Ichs< erwartet werden dürfen. Forschungspragmatisch angemessener erscheint es, von vielschichtigen Ich-Konstruktionen der damaligen Schreibenden auszugehen. ${ }^{40}$ Der Eintrag von Hans Seiler am Oberseminar lautete nun:

Mittwochnachmittag, 14:15, Zimmer 3 im Rechberg. [...] Wir sitzen an Konferenztischen und warten auf unsern Dozenten. Ich habe mir vorhin den Rechberg etwas besehen und sollte jetzt ein Loblied auf das Cebäude singen, wie es etwa im

38 Oberseminar ZH, Chronik Seminargemeinde, Winter 1943/1944, S. 2.

39 Lerch 2005, S. 5.

40 Vgl. Leitner 2016, S. 262. 
Baedeker steht. [...] Am meisten imponiert mir das schmiedeiserne Tor gegen die Künstlergasse, an dem mein Vater als Schlosserstift einmal den Rost abgebürstet hat [...]. An diesem Nachmittag hat sich nun auch Gelegenheit geboten, unsere Nicht-Küsnachter Kollegen näher kennen zu lernen. In unserer Heimatkundegruppe sind neben lauter Küsnachter Burschen noch 4 »höhere Töchter, die sich recht manierlich aufführen« [...]. Am Abend [...] sitzen wir in der E.T.H. bei Herrn Prof. Dr. Guggenbühl zu einer Plauderei am Kaminfeuer, sich drehend um Staats- und Verfassungskunde. Ich wundere mich, wie die höheren Töchter und die Winterthurer Landknaben und -mädchen fleissig aufschreiben und nehme mir vor, das Kapitel dann mal im Bürgerbuch nachzulesen. ${ }^{41}$

Aus der Sicht Seilers präsentierte sich das Oberseminar durch verschiedene Gruppierungen von Kandidaten. Der Autor selber zählte zu den sozialen Aufsteigern, welcher den eigenen Start in die quasiakademische Welt beschrieb, indem er mit freundlicher und vielleicht ein wenig spöttischer Distanz auf die angestrengte Studienhaltung der sogenannten Nicht-Küsnachter aus Winterthur oder der Kandidatinnen gegenüber dem ETH-Professor verwies. Das Seminar Küsnacht lieferte immer wieder für angehende Unterrichtende aus landwirtschaftlich orientierten Familien oder Arbeiterkreisen das Milieu für einen sozialen Aufstieg durch den Lehrberuf. ${ }^{42}$ Offenbar hegte der Historiker Gottfried Guggenbühl (1888-1959) eine gewisse Sympathie für die Anliegen der Kandidierenden, wenn er die Seminargruppe, u.a. bestehend aus Bildungsaufsteigern und höheren Töchtern, durch ein Kamingespräch in den Kreislauf bürgerlicher Kommunikation einführte, das Auserwähltsein und Zwanglosigkeit zugleich suggerieren sollte. Diese merkwürdige Einheit, die - Konzepten der Persönlichkeitsbildung zufolge - zwischen Studierenden und Lehrenden an den Hochschulen und nicht nur zwischen Seminarlehrpersonen und Kandidaten normativ vorherrschen sollte, aber womöglich nie so existierte, wurde durch Guggenbühl gestärkt. Konzepte einer akademischen »Erziehung zum Geiste«, der zufolge in Institutionen höherer Bildung einzelne Fächer gelehrt, aber nicht Fachpersonen herangezogen werden sollten, setzten auf einen intensiven Austausch zwischen Dozierenden und Studierenden, mussten aber gleichzeitig anerkennen, dass schulische »Betriebe der Massengesellschaft « zur »Mechanik« neigten. ${ }^{43}$ Im Kontext der Lehrpersonenbildung wurde oftmals noch darauf verwiesen, dass eine "Ausschliesslichkeit eines nur wissenschaftlichen Betriebes [zu] vermeiden« sei und »das Lehrziel [...] nicht wie auf der Universität ein Fach, sondern der Mensch, und die Methode nicht die der reinen,

41 Oberseminar ZH, Chronik Seminargemeinde, Seiler, 17. Februar 1944, S. $28 \mathrm{f}$. aktuell Lautenbach 2019. 
sondern der angewandten Erkenntnis«sei - so, wie es der in der deutschsprachigen Schweiz mit seinen Hochschulschriften stark rezipierte Carl Heinrich Becker formulierte. ${ }^{44}$

Guggenbühl, der zu Beginn des 20. Jahrhunderts selbst das Seminar Küsnacht besucht hatte, ${ }^{45}$ war vor seiner Berufung an die ETH Zürich mehrere Jahre an der Handels- und Oberrealschule in Zürich als Lehrer tätig. Welches Wissen in dem Seminarkontext als richtig erachtet wurde, wird vom Kandidat Seiler immer wieder in Verbindung mit einzelnen Dozenten genannt: Der Direktor zitiert in seinem Pädagogikkurs aus dem wissenschaftsphilosophischen Werk Discours sur la methode von René Descartes, der Vizedirektor Robert Honegger nutzte für die Beschreibung von Konzentration in Bezug auf die Mathematikdidaktik Hugo Gaudigs Didaktische Präludien. ${ }^{46}$ Innerhalb des Seminars, das ist der bedeutsame Quellenhinweis, gab es nach der Wahrnehmung und Darstellung Seilers eine Auffächerung von sozialen Gruppen. Waren die Praktiken der Eignungsabklärung darauf angelegt, die soziale Ordnung und die (Macht-)Verhältnisse zu reproduzieren oder sie zu wandeln? Die Frage nach der sozialen Gruppe, die im Seminar als erwünscht galt, bietet einen wichtigen Bezugspunkt für jene teilweise heftigen Auseinandersetzungen um die Eignung zum Lehramt.

\section{Woher kommen die "wertvollen Leute«? - Kommissionsprotokolle als Quelle}

Nach dem zehnjährigen Bestehen des Oberseminars beriet die Kommission »Revision Lehrerbildung« des Kantonsrats Fragen vor, die auch die Eignungsabklärung betrafen. Ernst Vaterlaus, Regierungsrat, Erziehungsdirektor und 1945 für wenige Monate Direktor des Unterseminars Küsnacht, stellte sehr selbstkritisch fest, »dass in den vergangenen Jahren die wertvollsten Leute von den Maturitätsschulen her kommen, und nicht vom Seminar Küsnacht «. ${ }^{47}$ Der Kaufmann und LdU-Abgeordnete (Landesring der Unabhängigen; eine von Gottlieb Duttwiler, dem Gründer und Chef der Migros, ins Leben gerufene Liste und Partei, die die Interessen von Arbeitern und Angestellten als Konsumenten vertreten wollte) Walter Bräm plädierte für weniger Allgemein- und mehr Berufsbildung in der Ausbildung von Lehrpersonen und für die Aufhebung der Trennung zwischen Unterseminar und Oberseminar sowie den damit zusammenhängenden Wissenssphären. Das Kommissionsmitglied Edwin Hardmeier widersprach: "Der Lehrer muss auch gegenüber den Eltern seiner Schüler bestehen können«, lautete sein Ein-

\footnotetext{
44 Becker 1926, S. 6of.; Neue Zürcher Zeitung vom 1. September 1931 (Abendausgabe), S. 5.

45 Vgl. Stadler 2007.

46 Oberseminar ZH, Chronik Seminargemeinde, Seiler, 1944, S. 30.

47 StAZH, M 14g. 48. 12, Kommission betr. Postulat 743, 26. August 1953, S. 2.
} 
wand und Argument für eine übergeordnete Bedeutung der Allgemeinbildung. ${ }^{48}$ Dass die Überlegung, Personen mit hoher Allgemeinbildung auszulesen, nicht nur verfängt, gab Karl Kleb zu bedenken: Unter den Mädchen [gibt es] viele, die wohl das Seminar besuchen, ohne aber den Lehrberuf zu ergreifen; dem Staat also keine Dienste leisten.$^{49}$ Der Befund, dass der Primarlehrberuf nicht für alle Ausbildungsinteressierte das endgültige Ziel, sondern in den individuellen berufsbiografischen Prospektionen in einem polyvalenten Verständnis eine Zwischenstufe sei, etwa als Fundament für ein anschliessendes Universitätsstudium, findet sich tatsächlich in vielen Studien. ${ }^{50}$ Walter Guyer warb für Gelassenheit gegenüber der Entwicklung, dass neben den Absolventen des Unterseminars auch viele Maturanden eine Ausbildung am Oberseminar ergreifen wollten. In diesem nicht lehramtsspezifischen Zuwachs sah er weniger einen Traditionsabbruch, sondern ein Mehr an kultureller Vielfalt am Rechberg. Dass diese Kandidatenpopulation noch keine Einführung in Pädagogik und Psychologie bekommen hatte, so wie die Unterseminaristen, empfand er auch nicht als Mangel, vielmehr hielt er eine Hochschulreife für die bessere Voraussetzung, sich diesem Stoffgebiet der Pädagogik und Psychologie zu nähern. Während Guyer seine Argumentation soweit trieb, dass Unterseminare als Überbleibsel einer maturitätsgebundenen Lehrpersonenbildung gänzlich verzichtbar wären, führte Walter Zulliger, Direktor des durch interne Konflikte krisengeschüttelten Unterseminars Küsnacht, an, dass Schüler, die vom Land ins Seminar kommen, "nicht einfach in die Stadt gesteckt werden [können und dürfen] «. ${ }^{51}$ So zu sprechen war nur möglich, weil Kreise der Lehrpersonenbildung dem Seminar auf dem Land Funktionen der sozialen Mobilität und Akkulturation an bürgerliche Bildung und Kultur zuschrieben. ${ }^{52}$ In vielen deutschsprachigen Regionen galt das ländliche Seminar eben als Rekrutierungsfeld »für bildungsferne Schichten«, das den Berufsstand des Volksschullehrers in seiner inferioren gesellschaftlichen Verortung stagnieren liess «. ${ }^{53}$

Der Konflikt über die angemessene Eignungsabklärung angesichts unterschiedlicher (sozialer) Gruppen von Kandidierenden entzündete sich nicht zuletzt an der Frage, ob die Unterseminaristen, die eine Mittelschulbildung mit ästhetisch-musischen und in Zürich auch mit pädagogischem Profil durchliefen, zu privilegieren seien. Die Spannungen brachen in dem Punkt auf, als vorberaten werden musste, ob die frühe Integration von Pädagogik und Psychologie im Curriculum der Unterseminaristen bedeuten könnte, dass die Eignung zum Lehramt

48 Ebd., S. 3.

49 Ebd., S. 11.

50 Frey 1969, S. 602; Crotti 2015, S. 136f.; Hoffmann-Ocon 2014.

51 StAZH, M 14g. 48. 12, Kommission betr. Postulat 743, 30. Oktober 1953, S. 24.

52 Hoffmann-Ocon 2018, S. 39.

53 Titze 1991, S. 360. 
bereits mehr gegeben sei als bei denjenigen Gruppen, die aus anderen Mittelschulen kamen: Das Reglement von 1943 schrieb vor, dass die Kandidierenden der Kantonsschule Winterthur, der kantonalen Oberrealschulen und Gymnasien Zürich und Winterthur sowie der Gymnasialabteilung der Töchterschule Zürich u.a. in Pädagogik, in Kunstfächern und im Turnen »auf den Stand der Ausbildung gebracht werden, der zum Eintritt in das Oberseminar auch für die Unterseminaren verbindlich ist.$^{54}$ Normativer Ausgangspunkt jeder Deutung zur Lehramtseignung in der Gründungszeit des Oberseminars war die Vorstellung, dass der Weg durch das Unterseminar die gesellschaftlichen Bedürfnisse an zukünftig Unterrichtende unverfälscht zum Ausdruck bringt.

Von der Überlegenheit eines eindeutig lehramtsspezifischen Ausbildungswegs war überzeugt, wer entlang von Johann Friedrich Herbarts »Allgemeiner Pädagogik« davon ausging, dass jeder Unterricht in einer bestimmte Weise erziehe und bestimmte institutionelle Bildungsprogramme sowie die soziale Organisation des Seminars die professionelle Erfüllung der Erziehungsaufgabe gewährleisten könnten ${ }^{55}$ »Erziehung durch Unterricht« als Überlegung und Konzept ging von einer Parallelführung aus: Um eine moralisch integre, pädagogisch, didaktisch und psychologisch gut aufgestellte Lehrerpersönlichkeit zu werden, sollte es nötig sein, dass man angehende Unterrichtende erfahren liess, welches "Muster" und welche »Ordnung « sie später mit ihrem schulischen Handeln zu verfolgen haben. ${ }^{56}$ Herbarts Anliegen war es, zumindest in vielen Deutungen seiner Adepten, dass in der durch Feingefühl und pädagogischen Takt gekennzeichneten kontinuierlichen Begegnung zwischen Lehrer und Schüler in einem pädagogischen Setting der geeignete Filter für die Selbstreflexion nach und nach entstehe, sodass die Frage nach der Eignungsprüfung eher eine Frage der Selbstbildung und pädagogischen Reflexivität sei. ${ }^{57}$

Mit seinen Äusserungen in der Kommission stellte Walter Guyer einigermassen deutlich fest, dass sich ein rein pädagogisch-lehramtsspezifischer Bildungsund Ausbildungspfad nicht fundieren liesse, da die Kandidaten, die von den Maturitätsschulen kämen, sich durchaus als geeignet erwiesen. Er sperrte sich gegen die Favorisierung eines Lehramtspfades durch das Unterseminar. ${ }^{58}$ So riet er der Kommission: »Der Entscheid für den Lehrberuf kann nicht spät genug erfolgen. Persönlich bin ich dafür, dass die >Initialzündung« erst spät ausgelöst wird «. ${ }^{59}$ Das Kommissionsmitglied Willy Wagner, Chefredaktor des von Gottlieb Duttweiler

\footnotetext{
54 Vgl. Kanton Zürich, Provisorisches Reglement für das Oberseminar, 20./29. April 1943, § 2, 1.

55 Baumert/Kunter 2006, S. 474.

56 Herbart 1806, S. 21-23.

57 Reitemeyer 2011, S. 191.

58 StAZH, M 14g. 48. 12, Kommission betr. Postulat 743, 30. Oktober 1953, S. 16.

59 Ebd., S. 24.
} 
gegründeten Wochenblatts des sozialen Kapitals Wir Brückenbauer, plädierte weiterhin für eine frühe Auslösung der Krise, damit diese sich nicht erst einstelle, wenn es bereits zu spät sei, einen anderen Beruf zu ergreifen: „Die Erfahrungen zeigen, dass wenn die Lehre erst später erfolgt und wenn dann der >Verleider kommt, alles daran gesetzt wird, dass die Lehre beendigt wird «. ${ }^{60}$ Wenn Wagner - abseits der eigenen Erfahrungswelt - konsequent von der »Lehre« gegenüber einer postmaturitären Ausbildung sprach, markierte er hier ziemlich sicher ideologische Vorbehalte einer kurzen, aber hochschulähnlichen Ausbildungspraxis. Mit der entschiedenen Zurückweisung von Guyers Überlegungen wollte er an dem Narrativ des geborenen Lehrers festhalten, der durch eine sehr frühe, im Unterseminar erfolgende, krisenhafte Konfrontation mit dem Schulbetrieb herausgefiltert werden könnte.

Die normative, aber zuweilen aus Sicht von Direktoren individual-empirisch unterfütterte Debatte in der Kommission zeigt, wie sich ein ganzes Feld möglichen Eignungsabklärungsdenkens und -handelns um mindestens drei soziale Gruppen herum mit ihren je spezifischen Wissensvoraussetzungen formierte und damit Anschlussdiskurse auslöste: Die Unterseminaristen (als soziale Aufsteiger) sowie die sogenannten höheren Töchter und Kantonsschüler gerieten in diesem Diskursdispositiv in den Blick. Die Hegemonialkämpfe auf dem Gebiet der Eignungsabklärung am Beispiel des Oberseminars verstärkten die Zweifel an einfachen Modellen der Eignungsabklärung. Die Erosion von Massstäben, wie etwa eine Absolvierung des Unterseminars, fand ihre Entsprechung in den Kantonsschülern, wo das traditionalistische Argument >ohne frühe Berührung mit pädagogischen Stoffen können die das Unterrichten nicht lernen « an Zugkraft verlor.

Mit Blick auf den Zusammenhang zwischen Quelle und methodischem $\mathrm{Zu}$ griff ist das Dokument des Kandidaten Hans Seiler als Selbstverortung eine aufschlussreiche Ergänzung zu den Kommissionsprotokollen. Wenn die in den Kommissionsprotokollen erschliessbaren Diskurse als Signifikation verstanden werden, ${ }^{61}$ die auf Schwierigkeiten einer gemeinsamen Perspektive der Akteure gegenüber Eignungsabklärungen verweisen, gibt der Kandidatenbericht Hinweise, die die Zerfahrenheit der Einstiegssituation durch unterschiedliche soziale Gruppen angehender Unterrichtender zeigt, ohne dass dieser mit der Absicht verfasst wurde, einen Beitrag zur Eignungsabklärung zu liefern. In dieser Interdependenz der Quellen angesichts der fokussierten Frage nach der Eignungsabklärung kann angedeutet werden, dass die Reflexions- und Dokumentationsweisen der angehenden Unterrichtenden über den Ausbildungseinstieg am Oberseminar sinnerweiternd in den Kontext der Eignungsabklärungsdebatten der Lehrerbildungskommission gestellt werden können, die eher einen diskursiven Charak-

60 Ebd., S. 23.

61 Vgl. Reckwitz 2008, S. 192. 
ter tragen. Diskurse und individuelle Reflexionspraktiken hängen in der Regel zusammen, da anzunehmen ist, dass die Seminarkultur von den individuellen Chronikberichten der angehenden Unterrichtenden nicht unbeeinflusst blieb, sodass diese Praktiken des Aufschreibens womöglich den Eignungsabklärungsdiskurs der Lehrerbildungs-Kommission mitveränderten. ${ }^{62}$

\section{Dokumente der 'Verwandlung«?}

Stellte die Praxis der Semestereröffnung, in religiös-spirituell wahrgenommener Atmosphäre Zusammenhänge durch einen gemeinsamen pädagogischen Auftrag $\mathrm{zu}$ stiften, Verkettungen zwischen verschiedenen sozialen Gruppen, verschiedenen Wissen und auch verschiedenen Orten der schulischen Herkunft her? Das Oberseminar als Lebensform in den Blick genommen, wäre diese Institution zunächst eher als eine (Pseudo-)Gemeinschaft zu betrachten, die immer auch ein Resultat von Auseinandersetzungen ist. ${ }^{63}$ Wollte man den Eintritt in das Oberseminar symbolisch und vom Ritual her zugespitzt erfassen, eignet sich dafür, die Perspektive eines Seminarkandidaten resp. einer Seminarkandidatin zu erschliessen. Die sich mit dem Kürzel EK bezeichnende angehende Lehrperson hielt ihre Wahrnehmungen der am 27. April 1943 erfolgten Eröffnungsfeier des Oberseminars in der Wasserkirche Zürich in der Erinnerung ein knappes Jahr später für die Seminarchronik fest, die zwischen den Mitgliedern der Seminargemeinde zirkulierte:

Erwartungsvoll standen wir vor der Türe der Wasserkirche. Von allen Seiten her kamen Burschen (die späteren Herren des Oberseminars) mit blauen, fast rechten Studentenkappen. Natürlich fehlten auch Lederhandschuhe, richtige >Clacéhändsche « nicht. [...] Die Feier wurde mit dem Lied der «Kandidaten (denn dazu waren wir avanciert!) eröffnet. [...] Wir vernahmen allerlei von der Geschichte des zürcherischen Schulwesens und es wurde uns erst jetzt bewusst, dass wir ja jetzt auch zur >weiteren Ceschichte des Schulwesens in der allerneuesten Zeit gehören sollten.く [...] Nach einer hübschen Mozarteinleitung folgte der wichtigste Punkt: >Ers!, der grosse Unbekannte, der `es`, das noch grössere Unbekannte leiten und uns jetzt von den Zielen beider berichten sollte. [...] Das aber war das Ziel der neuen Schule! Reifen - helfen! Das hatte ich aus der Rede herausgelesen. Mir schien als ob das Rot der Fenster noch feuriger, noch aktiver geworden sei. [...] [D]as Tiefblau daneben schien [...] unergründlich, geheimnisvoll. Diese beiden Farbklänge wurden mir

62 Vgl. Landwehr, S. 2008, S. 160.

63 Jaeggi 2014, S. 13. 
zur Darstellung der Worte aus der Rede. Rot - erziehen, Arbeit, Kraft; blau - reifen, verstehen. ${ }^{64}$

Die Beschreibung des erlebten Szenarios verweist auf Aneignungen, Verkörperungen und vielleicht Wandlung einer Maturandin oder eines Maturanden $\mathrm{zu}$ einer Kandidatin resp. zu einem Kandidaten. In welchem Verhältnis dieser Quellenauszug zu dem Erlebten von »EK« stand, ist schwer zu ermitteln. Die vorgegebenen synästhetischen Verknüpfungen der berichterstattenden Person schliessen eine erweiterte Perspektive auf höhere Bildungseinrichtungen und generell eine Empfänglichkeit für den Eigensinn pädagogischer Institutionen ein: In der Reflexion der berichterstattenden Person erscheint das Seminar weniger als formal geregelte Organisation, sondern mehr als sinnkonstituierende Institution, die durch das Handeln von Akteuren der Lehrpersonenbildung erzeugt wird, wobei die darin erzeugten kulturellen Regeln wiederum als Möglichkeits-, aber auch Begrenzungsraum pädagogischen Handelns betrachtet werden können. ${ }^{65}$ "EK« hat mit der Beschreibung der Verwandlung von einer sich am Oberseminar bewerbenden Person zum Kandidaten durch die performative Inszenierung der Eröffnungsfeier die vielschichtigen Umstände am Seminar angedeutet. Diese Andeutungen bieten Kontextelemente für ein Verständnis von Praktiken der Eignungsabklärung am Seminar.

\section{Der Praxisbericht als literarisches Werk - eine subversive Praktik?}

Die historische Spurensuche soll in einem weiteren Schritt mit der quellenkritischen Frage fortgesetzt werden, welchen Erkenntniswert die Dokumentensorte >Praxisbericht ‘ in Verbindung mit ergänzenden Quellen (z.B. Jahresberichten, Schülerzeitungen, Seminargemeinde-Chroniken) für eine kontextualisierende Beschreibung von Praktiken der Eignungsabklärung in sich birgt. Anlass zu dieser besonderen Schreibpraktik gaben am Oberseminar Zürich die ab 1943 dokumentierte >Stadt- und Landpraxis sowie die >Kandidaten-Vikariateく, welche den rapide angestiegenen Bedarf an Unterrichtenden durch die Teilmobilisierung regulärer Lehrer für die Grenzsicherung im Zweiten Weltkrieg decken sollten. Im Quartal zwischen Sommerferien und Wintersemester, also von Ende August bis Anfang Oktober absolvierten die Kandidierenden die Stadt- und Landpraxis. Das Stadtpraktikum konnte in Städten und grossen Gemeinden wie Zürich, Winterthur, Horgen, Stäfa und Uster absolviert werden, für ein Landpraktikum mussten

64 Oberseminar ZH, Chronik Seminargemeinde, Eröffnungsfeier 1943, 16. Februar 1944, S. 24.

65 Vgl. Helsper 2008, S. 116. 
die angehenden Lehrpersonen an mehrklassigen Dorfschulen des Kantons Zürich unterrichten. Die bereits angesprochenen >Kandidaten-Vikariate wurden, anders als die Praktika, mit einem reduzierten Salär abgegolten. ${ }^{66}$ Die Aufsicht über die Praktika und Vikariate teilten sich der Direktor und Vizedirektor, die einen Bericht über die Praxisbegegnung von den Kandidierenden einforderten. Die Gestaltungsvorgaben für den Bericht über die mehrwöchigen Unterrichtseinsätze orientierten sich an Kategorien einer Milieu-Anamnese und Selbstbeobachtung: »eder Kandidat hatte über die Stadt- und Landpraxis und über die Vikariate einen Bericht abzugeben, der die allgemeinen Schul- und Milieuverhältnisse, die Einrichtung des Schulhauses und Schulraumes, das Absenzenwesen, den Kontakt mit der Bevölkerung, die Klassen und einzelnen Schülertypen, den Stoffplan, die einzelnen Lektionen, das Methodische des Vorgehens in den einzelnen Fächern und je eine Besinnung über wichtige Punkte der gehaltenen Lektionen und Schultage zu schildern hatte «. ${ }^{67}$ Wie die Gestaltungsprinzipien sich nun konkret in den Texten der Vikar/-innen manifestierten und ob es Loslösungen von den Orientierungspunkten gab, soll folgend ins Zentrum gerückt werden. Welche Zeichen von Regeln und normativen Ansprüchen manifestieren sich in den - wahrscheinlich nicht mit Ziffern benoteten - Berichten? Wie und nach welchen Routinen wurden sie verfasst? Stabilisierten sie leitende Vorstellungen zur Eignung? Fokussiert werden Berichtsformen mit vielfältigen, eigensinnigen Aneignungen von alltäglichem, wissenschaftlichem, intellektuellem, didaktischem und literarischem Wissen.

\section{Der Bericht als Wiederholung vorgestanzter Formulierungen aus der Pädagogikvorlesung}

Dem Kandidat Werner Gysin wurde nach den Herbstferien 1945 das Vikariat in dem »Bauerndorf« Trüllikon mit dem Auftrag zugewiesen, die sog. Oberschule (4.-8. Klasse) zu übernehmen. Gysin vertrat eine Auffassung, nach der Novizen im Unterrichtsgeschäft keine pädagogisch-didaktischen Revolutionen anstreben sollten, aber die Seminarzeit womöglich den Keim zu einem spezifischen Berufsethos des Lehrers gelegt habe - solche Erwägungen gingen Hand in Hand mit damaligen Berufsauffassungen und Lehrerleitbildern: ${ }^{68}$

Ich gestaltete dort den Unterricht etwa in der herkömmlichen Art, sofern ich das ohne Erfahrung zu sagen vermag; denn ich war mir zuvor bewusst, dass wir nicht als grosse Erneuerer an eine Aufgabe herantreten können, über deren Lösung wir

\footnotetext{
66 Vgl. Kanton Zürich 1944, OS Jahresbericht Schuljahr 1943/44, S. 5.

67 Ebd., S. 5.

68 Vgl. Schohaus 1954, S. 15.
} 
eigentlich noch herzlich wenig wissen. Zuerst müssen wir erleben und erfahren. Wenn wir stürmisch mit einer alleinseligmachenden Methode daherbrausen, vermauern wir uns vielleicht gerade dadurch den Zugang zum Kinde. Methode ist nicht alles. Das gute Neue wird sich nur nach und nach mit sorgfältigen Massnahmen durchsetzen. Vorbedingung dazu ist aber eine Beziehung zum Kind. Überblicke ich die vier Wochen meines Vikariats, so sehe ich darin ein oft mühsames Ringen um Kontakt. Es wird sicher noch manchem so ergangen sein wie mir: einmal fühlt man sich bewusst überlegen, ein ander Mal ist man in tastende Zurückhaltung gedrängt. Wenn auch dieser Wechsel manchmal Unsicherheit zulässt, so ist diese vielleicht gerade nötig, damit wir uns selber als Lehrer kennen lernen. Dennund dies scheint mir die wichtigste Erfahrung zu sein, die ich gemacht habe -: Arbeit an andern Menschen und mit andern Menschen zusammen erfordert vor allem Arbeit an sich selbst. ${ }^{69}$

Bei dieser zentralen Passage, die den Bericht dominiert, handelt es sich im engeren Sinn nicht um einen Praxisbericht. Allein das Gestaltungsprinzip »Besinnung « wird hier vollends entfaltet. Was bietet dieser Text den Aufsicht führenden Direktoren als Zielscheibe der Eignungsüberprüfung an? Die Formulierungen »Methode ist nicht alles«, die »Beziehung zum Kind als Vorbedingung « und das "mühsame Ringen um Kontakt« finden sich in Guyers am Oberseminar verwendeten Studienbuch Grundlagen einer Erziehungs- und Bildungslehre (1949) in dem Kapitel »Methode und Lehrerpersönlichkeit«:

Niemand bestreitet wohl im Ernst die Berechtigung der These [die Methode sei zumindest höchst sekundär], dass bei allem erzieherischen, also auch beim Lehrer, das persönliche Moment das eigentliche und letzte Geheimnis des »Erfolges« ausmacht. [...] Wir wiesen im dritten Kapitel auf Kerschensteiners Analyse der »Seele des Erziehers « hin, die zum Ergebnis kommt, dass die eigentliche Lebensform des Lehrers die soziale sei. $^{70}$

Allerdings hütet Guyer in diesem Kapitel sich vor der Aussage, dass das Lehramt an eine angeborene Begabung gebunden sei. Vielmehr sei durch »Kraftquellen« Erziehung dort gewährleistet, »wo beim Erziehenden das Ringen mit sich selbst sichtbar wird. Die tieferen Quellen für diesen Kampf aber, Liebe und Glaube, sind Begnadung, nicht Begabung ${ }^{71}{ }^{71}$ Ringen mit sich selbst, Arbeit an sich selbst letztlich wiederholt der Kandidat in seinem Text die von Guyer vorgestanzten Begriffe und Formulierungen. Das Potenzial von Berichten und Gutachten liegt

69 Zürcher Oberseminar II, Praxisberichte, Cysin.

70 Guyer 1949, S. 266.

71 Ebd., S. 267. 
Michel Foucault zufolge darin, eine Verbindung von quasiwissenschaftlicher Erkenntnis mit einer eigentümlichen Geltungsmacht herzustellen, dank des Spiels, das mit dem Bericht zwischen diesen Instanzen betrieben wird..$^{72}$ In diesem Fall eignete sich der Kandidat die Begriffe Guyers an und reproduzierte sie in der Verknüpfung mit der suggerierten Dokumentation seiner Unterrichtspraxis. Ein solcher Schreibakt könnte als Teil einer Arrivierungsstrategie begriffen werden, sich mit pädagogischen Formulierungen und Formeln einer sozialen und wissenschaftlichen Anerkennung zu versichern. ${ }^{73}$ Die Passage aus dem Bericht verweist insgesamt darauf, dass die Berichte der angehenden Unterrichtenden einfachen aktuellen Klassifikationsversuchen gegenüber der Textsorte >Bericht entgleiten können, da diese auch die seinerzeit eingeforderten Gestaltungsprinzipien teilweise verletzten. Für die Frage nach dem Stellenwert von Quellen für das inhaltliche Elaborieren eines dichten Bildes zur Eignungsabklärung scheint nicht das Problem geklärt werden zu müssen, dass aus der Retrospektive die Berichterstattungs-Praxis gegenüber den seinerzeitigen Gestaltungsprinzipien >falsch «irkt, sondern unter welchen bestimmten historischen Umständen diese als rakzeptabek, wenn nicht gar als >richtig< erachtet wurden. ${ }^{74}$

\section{Der Bericht als Prosagedicht}

Die Kandidatin Lisbeth Peter interpretierte den Auftrag der Berichterstattung als literarische Herausforderung. Mit dieser Verschiebung erhob sich die Oberseminaristin zur Zentralfigur und gab dem nüchternen Beobachtungsauftrag eine Absage. Jedoch setzte sie sich mit dieser scheinbar überlegenen Position »unnötigerweise « der Gefahr des Scheiterns und Versagens aus. ${ }^{75}$ Allem Anschein nach wurden von der Seminarleitung Elemente der Dramaturgie und Lyrik nicht von vornherein unter Verdacht gestellt, durch unnötige Dekorationen die Abweichung vom Auftrag zu verschleiern. In der Perspektive »von unten« könnte die spezielle Bearbeitung der Kandidatin einige Hinweise dazu liefern, dass die in der Forschungsliteratur angenommene Inkubationszeit des Kreativitätsdispositivs zwischen 1900 bis in die $1960 e r-J a h r e$ auch das Feld der Lehrpersonenbildung mitprägte. ${ }^{76}$ Guyer vertrat in seinem an angehende Lehrpersonen adressierten Werk Grundlagen einer Erziehungs- und Bildungslehre die Auffassung, dass im ästhetischen Verhalten des Menschen eine individuelle Freiheit von Widerspruch, Anfechtung und Zwiespalt sowie »eine Erlöstheit und Beglückung ohne jedes Zweck-

\footnotetext{
72 Vgl. Foucault 2003, S. 46.

73 Vgl. Hess 2015, S. 89

74 Vgl. Nigro 2015, S. 79.

75 Vgl. Ullrich 2014, S. 24.

76 Vgl. ebd., S. 26.
} 
wollen« zu erreichen sei - allerdings nur als Ausnahmesituation, die wiederum zum Denken, Schaffen und Handeln herausfordere. ${ }^{77}$ Vor allem beruhe auf dem Ästhetischen als »das grosse Fenster mit dem schönen Ausblick« die Möglichkeit, »dass es den Menschen heraushebt aus der Verkrampfung, Programmhaftigkeit und Pedanterie in eine Atmosphäre freien Atmens $\ll^{78}$ Ob diese ästhetischen Betrachtungen Guyers als Ausdruck dafür gelten können, dass Berichtspraktiken von angehenden Unterrichteten in einer Seminaratmosphäre mit »künstlerischen und gegenkulturellen Nischen und mit »Emanzipationshoffnungen« vollzogen wurden, ist schwer zu ermitteln. Zumindest steht der folgende >Bericht $`$ für einen Umformungsversuch in der Perspektive des Ästhetischen:

\section{$2 \times 4$ Klasse}

Widikon./Ein strahlender Tag. Das Schulzimmer voller Sonne. Goldene Blätter tanzen. Durchs Fenster nichts als Wiesen, Bäume, Berge. Alles hell und klar.

Vor mir vierzig aufgeweckte, frische Knöpfe, die eifrig die ältesten Brunnen Zürichs studieren. Keine Musterkinder, doch eine lebendige, fröhliche, oft übermütige Schar, die sich mitreissen lässt./Wer dächte da gerne ans bald beginnende Semester?

Dietikon./Nasskaltes Vorwinterwetter. Regen fällt. Graue Wolken schleichen. Hohe, dunkle Häuser vor dem Fenster.

Im düsteren Schulzimmer eine verdrossene Klasse an der Arbeit. Alles, freche laute Kinder. Obschon sich alle über die Hefte beugen, weiss ich, dass sie nichts tun. Sie denken sich jetzt aus, wie sie in der Pause einander quälen können. Eine drückerische, durch nichts zu begeisternde Masse, die nur arbeitet, wenn sie unter der Peitsche steht.

Keine Kinder./Wenn nur das Semester morgen anfangen würde! ${ }^{79}$

Warum die Seminarleitung solche Texte als Berichterstattung annahm, ist zunächst schwer zu verstehen - gerade vor dem Hintergrund der vorgegebenen Gestaltungsprinzipien und Orientierungspunkte, die auch durch ein ästhetischmusisches Seminarklima nicht hintergangen werden dürften. Anstatt die Dis$\operatorname{tanz}$ des beschriebenen Geschehens zum Adressaten hin zu verkleinern, fördert die Textsorte des Prosagedichts die einer ästhetischen Verfremdung geschuldete (dingliche) Entkontextualisierung. Das Prosagedicht entzieht dem angedachten Berichtstext seinen Gebrauchswert, verleiht jedoch dem Geschilderten einen

77 Guyer 1949, S. $112 f$.

78 Ebd., S. 114.

79 Forschungsbibliothek PHZH: Schulgeschichte. Zürcher Oberseminar II: Praxisberichte der Abschlussklasse 1944/45. Lisbeth Peter. 
auratischen Zeugniswert. ${ }^{80}$ Würde man mit einer literarischen Wertung ansetzen, müsste man vielleicht diesen Text unter den Aspekten des pädagogischen Kitsches betrachten, der mit der Gegenüberstellung von typologisierten guten und bösen Kindern sowie der pauschalisierenden Darstellung von Schulklassen als wesenhaften Gesamtzusammenhang Elemente von Selbsttäuschung enthalten könnte. ${ }^{81}$ Der Text lässt sich auch so deuten, dass hier die Entlarvung einer Selbsttäuschung, etwa wie leicht es nach einem anfänglichen Flowerlebnis über eine gelungene Lektion generell sei zu unterrichten, von der Kandidatin ins Zentrum gerückt wird. Die Darstellung einer widerspruchs- und anfechtungsfreien Unterrichtspraxis sollte womöglich gerade demontiert werden. So wäre das Gedicht der Versuch, der erlebten Unterrichtspraxis mit den Diskrepanzen zwischen den eigenen Orientierungsmustern und den Formen alltäglichen Erfahrens in ihren schwierigen Vermittlungen nachzugehen. ${ }^{82}$ Derart verstanden, handelte es sich hier nicht um eine synthetisierende Darstellung der eigenen Unterrichtspraxis, einer Form heroisch-pädagogischer Inszenierung, welche auch in den Berichten zu finden ist. Diese merkwürdige Mischung aus Evidenz und Überraschung könnte der Seminardirektion als gelungene Präsentation einer Unabschliessbarkeit pädagogischer Situationen gegolten haben, die von der Mobilisierung möglichst vieler Lesarten lebte. Die wechselnde und schwer antizipierbare Eigenstruktur von Unterricht wäre eigenständig beschrieben worden. ${ }^{83}$

\section{Der Bericht als Provokation gegenüber pädagogischem Wissen}

Margrit Kuhn vikarisierte im Herbst 1944 in den Gemeinden Dübendorf und Aesch. Durchaus orientiert an den vorgegebenen Gestaltungsprinzipien und mit impliziter Bezugnahme auf methodische resp. didaktische Überlegungen, beschrieb sie zunächst die allgemeinen Schulverhältnisse. Kuhn verfasste diesen Text vor dem lokalen Hintergrund des Oberseminars Zürich, an dem nicht wenige Seminarlehrer eine Schreibpraxis von Studienbüchern, die sie im alltäglichen Unterricht nutzten, entfaltet hatten. Die Seminarlehrpersonen als Studienbuchautoren schufen so einen speziellen Wissensraum mit einer Zwitterstellung des Oberseminars zwischen einer postmaturitären, ansatzweisen hochschulähnlichen Einrichtung und einer pädagogisch-handwerklichen Ausbildungsstätte. Die Seminarlehrpersonen können als eine Art »hybride Experten ${ }^{84}$ betrachtet werden, die im Selbstverständnis belesene und schreibende Schulpraktiker waren. In

\footnotetext{
80 Vgl. Welzbacher 2017, S. 75.

81 Vgl. Reichenbach 2003, S. 777.

82 Vgl. Haasis/Rieske 2015, S. 19.

83 Vgl. Gruschka 2011, S. $30 \mathrm{f}$.

84 Klein 2016, S. 88.
} 
diesem Überschneidungsgebiet tätig, dehnten sie ihre pädagogisch-didaktischen und unterrichtsbezogenen Analysen teilweise über den unmittelbaren schulpraktischen Bedarf hinaus aus, sodass sie mit allgemeinen kulturkritischen Anmerkungen und Explorationen den angehenden Unterrichtenden, wohl aber auch sich selbst, in einem performativen Akt neue Wissenshorizonte eröffneten. Vor dem Hintergrund einer solchen Mischzone von nützlichem und gelehrtem, kulturkritischem Wissen verfassten die noch nicht diplomierten Lehrpersonen ihre Berichte:

Dübendorf 1. und 2. Klasse

Eine kurze Woche arbeitete ich hier in dem nicht sehr sanmächeligen ‘ alten Dorfschulhaus (Mäuse), mit überraschend lieben Kindern (geschickt, diszipliniert, freundlich), umschlossen von einem bewegten Luftraum (Me 109 [deutsches ]agdflugzeug; d. Verf.], C 35, C 36 [Flugzeuge der Schweizer Luftwaffe; d. Verf.]. Meine Anwesenheit scheint immerhin die Landung neuer Fliegender Festungen verhindert zu haben!)

Aesch/Maur

Allein im Schulhaus! 1., 2., 3., 4. und 6. Klasse, ein reiches Betätigungsfeld für eine bewegliche Seele! Leider absorbierte der Kampf mit der Organisation (hauptsächlich der stillen Beschäftigungen!) die Energie so sehr, dass für kühne Neuerungen wenig Raum blieb. [...]

Im allgemeinen machte mir die Arbeit mit der Aeschener Jugend viel Freude. Eine Frage für Spezialisten in der Schul-Kommission: Was tut man, wenn der Sohn eines Schulpflegers eines Nachmittags fehlen will mit der Begründung, er müsse dreschen helfen, und wenn sein Beispiel in der ganzen Schule Schule macht?

Eine Frage für Arbeitsprinzipler: Wie, wenn ein als Anschauungsmaterial ins Schulzimmer geschlepptes Stachelschwein sich während der Stunde plötzlich als schlecht erzogen, das heisst als nicht stubenrein, erweist? ${ }^{85}$

Worauf spielte Margrit Kuhn in ihrem Bericht genau an? Mit dem Format »Eine Frage für ...« stellte sie Bezüge zu pädagogischen und didaktischen Lehrinhalten her, die etwa eine Planbarkeit von Unterricht vorgaben oder Lehrtechnologien, Lehrkünste konzeptionell anboten, wie z.B. der Seminarlehrer Hans Leuthold mit seinem Werk Lebendiger Unterricht. ${ }^{86}$ Bei genauerer Lektüre dieser Studienbücher stösst man aber auch auf Passagen, die eine Planmässigkeit von Unterricht trotz der pädagogischen Absicht infrage stellen: »Die Unvollkommenheit der Schüler müht uns oft sehr; aber noch mehr schmerzt den wahren Lehrer die eigene Unvollkommenheit. Ach, wie wenig erreichen wir von dem, was wir wollen; wie viel

85 Forschungsbibliothek PHZH: Schulgeschichte. Zürcher Oberseminar II: Praxisberichte der Abschlussklasse 1944/45. Margrit Kuhn.

86 Leuthold 1944. 
lassen wir liegen; wie oft bleiben wir stecken! ${ }^{87}$ Tatsächlich finden sich in den Didaktiken am Oberseminar zu dieser Zeit »weit gespannte Vorstellungen über den normativen Sinnhorizont von Schule und Unterricht « - jedoch ebenfalls auch konkrete Fragelisten für Unterrichtsvorbereitung. ${ }^{88}$ Hingabe und gute Erzieherliebe müssen beim Kandidaten am Anfang des Strebens nach didaktischer Erneuerung stehen; ${ }^{89}$ neben solchen geisteswissenschaftlich inspirierten Aussagen finden sich Listen, um Unterrichtsfragen mit Denkanstössen zu ersetzen. ${ }^{90}$ In diesem im Seminarunterricht vorgeschlagenen Zusammenspiel von Lehrbegabung, -kunst und -technologie zielen die im Bericht angeführten Anfragen der Kandidatin Kuhn auf eine vorgegebene erlebte Praxis, die keinem Studienbuch gehorchte, »sondern das Ergebnis der chaotischen Wirklichkeit eines [...] Bereichs mit eigenen Regeln " war. ${ }^{91}$ Was geschah in den Unterrichtslektionen im Vikariat? Diese zunächst provokativ erscheinende Frage angesichts einer Störung oder Irritation von Handlungsroutinen im Unterricht forderte eine weitere Mobilisierung von Wissen ein.

Doch bei genauerer Betrachtung befanden sich die Anfragen innerhalb einer dem Oberseminar angemessenen Lebensform und den damit verbundenen denkbaren Verhaltensweisen. Falls die Kandidatin beabsichtigte, die Grenzen ihrer Vetomacht gegenüber der Seminardirektion abzustecken, so zeugen die mündlich protokollierten Kommissionsäusserungen oder Texte der Studienbücher Guyers von einer Seminarkultur und Binnenperspektive, die derartige Anfragen in ihre Kooperationserwartung miteinbauten. Die gespielte Ratlosigkeit gegenüber schulischen Unwägbarkeiten durch Schulabsentismus und Stachelschweine in der Schulstube zielte zum einen auf das Narrativ der Einzigartigkeit und Eigensinnigkeit pädagogischer Handlungssituationen. ${ }^{92}$ Begreift man die Studienbücher der Seminarlehrpersonen, etwa diejenigen von Guyer oder Leuthold, als Repräsentationen des an diesem Ort zirkulierenden Wissens, dann gehörte es zum pädagogischen Credo, Fach- und didaktisches Wissen in allgemeinen Formulierungen vorzulegen, die von den angehenden Lehrpersonen in ihren ersten Unterrichtsversuchen auf einzigartige Situationen und Menschen zu beziehen seien. Zum anderen gehörte auch die »Umstrittenheit pädagogischen Wissens« zum Common Sense in der Literatur des Oberseminars: ${ }^{93}$ Insgesamt repräsentieren Guyers »Grundlagen einer Erziehungs- und Bildungslehre« eine für angehende

\footnotetext{
87 Ebd., S. 15.

88 Terhart 2009, S. 158.

89 Vgl. Leuthold 1944, S. 9.

90 Vgl. ebd., S. 27-29.

91 Vgl. Settele 2017, S. 46.

92 Vgl. Koller 2004, S. 12.

93 Vgl. ebd., S. 11.
} 
Lehrpersonen aufbereitete Kompilation geisteswissenschaftlich-pädagogischer Aussagesysteme der ersten drei Jahrzehnte des 20. Jahrhunderts. Die Auseinandersetzung mit schulfeldnützlichen Wissensbestandteilen u.a. aus der Philologie, Theologie, Philosophie, Medizin und Psychologie, die Guyer als "Auslese« bezeichnete, ${ }^{94}$ war ein zusammenhängendes Orientierungsangebot an die Kandidierenden, freilich nicht ohne normative Implikationen. Dass es über die Aneignung von pädagogischem Wissen im Oberseminar hinaus noch einer Arbeit an sich selbst bedarf, um Erziehungssituationen kritisch beurteilen zu können, teilte Guyer den angehenden Lehrpersonen an der Semestereröffnung mit.

\section{Studentische Berichterstattung als `Teilpraktikı?}

Einem ersten Verständnis zufolge stellten viele im Bericht zu Papier gebrachte >Beobachtungen dramaturgische Inszenierungen des anfänglichen Scheiterns eigenen Unterrichtshandelns dar, welches durch widrige - und sehr vielgestaltig beschriebene - Milieubedingungen begründet wurde. Zu einem weiteren Muster angeblicher Dokumentationspraxis gehörte die Selbststilisierung als junge Lehrperson, die eine »Beziehung zum Kind« aufbauen kann. Zu dieser Textstrategie zählte auch, durch exakte Übernahmen von Formulierungen aus den im Seminar gebräuchlichen Pädagogik- und Didaktik-Lehr- und Studienbüchern sich einer sowohl pädagogisch normativen als auch wissenschaftsorientierten Anerkennung zu versichern.

Die studentische Berichterstattung als >Teilpraktik im grossen Komplex der Eignungsüberprüfung provoziert zum einen mit seiner Muster- und Strategiehaftigkeit und zum anderen mit je eigensinnigen und kreativen Verarbeitungen Rückfragen an praxeologische Überlegungen: Welche Anteile des Berichts lassen sich unbewussten, nichtintentionalen und Machtverhältnisse reproduzierenden Handlungen zuordnen, welche Anteile waren darauf angelegt, Ordnungen der Eignungsabklärungen (subversiv) zu wandeln? Lässt sich hier einer Praxis nachspüren, die »zugleich regelmässig und regelwidrig, [...] zugleich strategisch und illusorisch" war $?^{95}$ Versuchten der Seminardirektor und sein Stellvertreter die Grenzen der Vetomacht von berichtschreibenden Studierenden zu markieren - in einer historischen Phase des Lehrpersonenmangels? Gibt es in den Quellen sublime Hinweise einer eigenwilligen Verflechtung von Selektions- und Sorgepraktiken der Seminarleitung?

Mögen die Berichte ein Instrument zur Steuerung, Neubewertung und Perspektivierung erster Unterrichtsversuche angehender Lehrpersonen gewesen sein, als Selektionsinstrument zur Öffnung oder Schliessung des Lehrberufs

94 Cuyer 1949, S. 48.

95 Füssel 2015, S. 25. 
wurden sie kaum verwendet. Die Statistiken in den Jahresberichten zeugen von einer sehr schwach ausgeprägten selektiven Eignungsabklärungspraxis. So wurden die (Fähigkeits-)Prüfungen 1944 von allen 68 Kandidaten bestanden. Wer die Stadt- oder Landpraxis wegen Krankheit nicht absolvieren konnte oder wegen Dispensation sein Turnpensum nicht erfüllte, bekam lediglich die Auflage, das Verpasste zu wiederholen. ${ }^{96}$ Diese konstitutiven Voraussetzungen als Kontext der studentischen Berichtspraxis sprechen eher gegen den subversiven Charakter der Berichte. Vielmehr scheint es, dass die Studierenden mit den Berichten den "praktischen Sinn« verbanden, sich mit eigenen kulturellen Formen und Symbolen am Seminar Ausdruck zu verschaffen resp. sich die vorwaltenden `Lesarten der Seminarlehrpersonen anzueignen. ${ }^{97}$ Dazu konnte sich mit der 1943 durch die Erziehungsdirektion Zürich erfolgten günstigen Beurteilung der Berufsaussichten für Volkschullehrpersonen ${ }^{98}$ und dem weit verbreiteten Bild der Lehrperson als Künstler resp. als das Kind entdeckenden Künstler ${ }^{99}$ die Gewissheit gesellen, in einem bildungspolitischen Klima des wahrgenommenen Lehrermangels die Ausbildung zu absolvieren.

Die rasch ansteigende Zahl angehender Lehrpersonen wurde als Unübersichtlichkeit wahrgenommen. Zur Abschiedsrede, eine in den Jahresberichten gut dokumentierte Praxis, äusserte 1948 der Direktor Guyer, dass nicht nur die Kandidaten, sondern auch die Seminarlehrpersonen die grosse Zahl zukünftiger Lehrpersonen als Belastung gespürt haben. Sie hätte den angehenden Unterrichtenden als Entschuldigungsgrund gedient, dass man sich im Seminar nicht genügend kennenlernen könne. Es sei aber eher ein Entschuldigungsgrund zum Auskneifen gewesen: "Ein ausgesprochener Individualismus macht sich ja überall geltend - im Staat, in der Kirche, im gesellschaftlichen Leben, und besonders in einer durch den letzten Krieg desillusionierten Jugend $« .{ }^{100}$ Und eben auch in der Verfertigung von Berichten zur Stadt- und Landpraxis sowie zu den Vikariaten. 1949 bestanden alle 113 Absolvierende des Seminars die Fähigkeitsprüfung. Von den 166 Kandidaten 1953 fielen lediglich drei durch die Prüfung. ${ }^{101}$ Das durch einen Lehrpersonenmangel bedingte offenere Bildungsklima, welches einen Sogeffekt von Rekrutierungen aus verschiedenen gesellschaftlichen Schichten an das Oberseminar begünstigte, ${ }^{102}$ hier sei an die sozialen Aufsteiger, höheren Töchter und die Kantonsschüler erinnert, wurde von Guyer als Problem wahrgenommen.

\footnotetext{
96 Vgl. Oberseminar Kanton Zürich, Jahresbericht 1943/44, S. 10.

97 Hillebrandt 2015, S. 432.

98 Tuggener 1963 S. 30.

99 Ebd., S. 113.

100 Oberseminar Kanton Zürich, Jahresbericht 1948/49, S. 20.

101 Ebd. 1952/53, S. 12.

102 Vgl. Schmeitzner 2009, S. 59-63.
} 
Im Duktus der Abschiedsrede knüpfte er 1955 ziemlich deutlich an diesen Umstand an: »Unsere Bitte geht dahin, Sie alle möchten diese Situation nicht ausnützen, d.h. Sie möchten es von sich aus niemanden zu spüren geben, dass man sie so nötig hat, und Sie möchten deswegen nicht in [...] Ihrer ganzen Haltung unbescheiden werden ${ }^{103}$ Während die Abschiedsrede an bestimmte Höflichkeitsformeln - eben wie eine Bitte an Absolvierende - gebunden und nicht zur Publikumsbeschimpfung geeignet ist, wurde zur gleichen Zeit der Lehrpersonenmangel als spezifischer Kontext in der >Arena der Kommission »Revision Lehrerbildung« des Kantonsrats von Guyer mit anderen Worten angesprochen: „Wir zählen heute 237 Kandidaten, die durchgeschleust werden müssen. Als schlimm müssen wir bezeichnen, dass heute jeder Absolvent des Oberseminars sofort einen Posten erhält, während früher stets einige Jahre gewartet werden musste ${ }^{104}$

Die beiden Quellentypen Jahresbericht und Kommissionsprotokoll ergänzen in der praxeologischen Perspektivierung des Sozialen die studentischen Berichte durch unterschiedliche Betonungen. Was nach Auskunft des Jahresberichts gegenüber den Seminarabsolvierenden als Bitte vorgetragen wurde, wurde in dem Kommissionsprotokoll als Lamento über die wenig selektive Situation der in einer zur Masseninstitution verdammten Lehrerbildungsanstalt situierten Studierenden aufnotiert. Aus Sicht des Seminardirektors mögen sich die unterschiedlichen Vollzüge als jeweilige Einzelereignisse als adressatenorientiertes Sprechen operativ aufeinander bezogen und verkettet haben, sodass man von einer Praxisformation sprechen könnte. ${ }^{105}$ Die Seminarabsolvierenden konnten demgegenüber nicht in der gesamten Praxisformation des Direktors mitwirken. Praktiken, das zeigt das Zusammenspiel verschiedener Quellentypen, können abhängig von »Trägern« und »Teilnehmern« zum einen isoliert und zum anderen so beschrieben und erschlossen werden, dass sie verschiedene Orte und lokale Routinen als Netz miteinander verbinden. ${ }^{106}$ Schliesslich soll im Resümee übergeordnet zur Diskussion gestellt werden, ob der Versuch, sich in historisch-praxeologischer Perspektive mit einem begrenzten Set an Quellenmaterial der Eignungsabklärung von angehenden Primarlehrpersonen anzunähern, die gleichzeitige Strukturiertheit und Offenheit des in der Vergangenheit liegenden Geschehens herum fassbarer, lesbarer und tiefenschärfer macht.

103 Oberseminar Kanton Zürich, Jahresbericht 1954/55, S. 16.

104 StAZH, M14g. 48. 12, Kommission betr. Postulat 743, 30. Oktober 1953, S. 16.

105 Hillebrandt 2015, S. 439.

106 Schmidt 2012, S. 64. 


\section{Resümee}

Die uneinheitliche Quellenlage - es gibt sehr viele prüfungsstrategisch gebundene Selbstzeugnisse von den angehenden Unterrichtenden, die Beiträge der Seminardirektoren und -lehrpersonen schlugen sich vor allem in Kommissionsprotokollen, Jahresberichten und Studienbüchern nieder - lässt den historischpraxeologischen Zugriff anspruchsvoll werden. Während die Beiträge der Seminarlehrpersonen mit ihrem oftmals normierenden Ansprüchen eher als Texte zu manifesten Diskursen zu betrachten sind, entsprechen die Berichte der angehenden Lehrpersonen eher einer Textsorte, die rekonstruierbare Alltagsmuster manifestieren und in einer Mikrologik des Sozialen die wechselseitige Beziehung zwischen den schwach ausgeprägten Eignungsabklärungsstrukturen des Seminars und den Praktiken der Studierenden darstellen. ${ }^{107}$ Dem selbstgesteckten Auftrag, auch den verborgenen Teilen des `Eisberges der Eignungsabklärungく am Oberseminar nachzugehen, archäologisch das »Nichtgesagte « zu heben, ${ }^{108}$ mit aussergewöhnlich normalen Quellen den Beobachtungsfokus zu verschieben, gelingt womöglich mit den Quellen besser, die von den Seminarabsolvierenden produziert wurden. So stösst die Analyse von Praktiken der Eignungsabklärung an Erkenntnisgrenzen. Sie muss auf der Seite der seminarleitenden Akteure ohne Mikroskop auskommen und erfasst den Bereich gewöhnlich unsichtbarer Dinge nur noch bedingt. Die studentische Berichtspraxis, die sich in ihren Berichtsvollzügen gegen damalige normierende und verschriftlichte Gestaltungsprinzipien wenden konnte und trotzdem auf Akzeptanz stiess, gehorchte dennoch einer eigentümlichen Dramaturgie: Die Fähigkeit, sich selbst in einer Prüfungssituation Massstäbe zu setzen, ${ }^{109}$ manifestierte sich in einer Anrufung der pädagogischen Figur des mehr oder weniger unmittelbaren Bezugs zum Kind. Dass das »oberste Prinzip aller Lehrerbildung [...] nicht die Wissenschaftlichkeit noch die Trennung von allgemeiner und beruflicher Bildung, sondern die Prägung [...] in einer Erziehungsgemeinschaft« sei, ${ }^{110}$ kristallisiert sich in den verschiedenen Quellenlektüren als eine Art damalige interne Verständigung hinter dem Schirm des Oberseminars heraus.

In der erziehungswissenschaftlichen Literatur wird oftmals kritisiert, dass die sozialwissenschaftliche Prämisse einer Sinnkonstituiertheit der sozialen Welt durch praxeologische Ansätze infrage gestellt wird: »Sinnhaft handelnde Akteure gelten ebenso wie Dinge lediglich als >Partizipanden` von Praktiken«, sodass die Praxisanalyse weniger auf die hermeneutische Entschlüsselung von Sinn und

\footnotetext{
107 Haasis/Rieske 2015, S. 20.

108 Herbst 2004, S. 158.

109 Schäfer 1996, S. 183.

110 Tuggener 1962, S. 299.
} 
Bedeutung ziele, sondern sich mehr auf die Entdeckung von Praktiken konzentriere. ${ }^{111}$ Auch wenn diese Kritik praxeologischen Ansätzen eine Verengung des Blickwinkels zuschreibt, die vielleicht so in dieser Härte nicht gegeben ist, lohnt es sich, an dieser Stelle noch einmal innezuhalten. Die tatsächliche Fokussierung von Zugriffen der historischen Praxeologie auf Handlungsroutinen und kollektive Handlungsgefüge schliesst die Annahme eines "feeling for the game« historischer Individualakteure nicht aus, sodass ein Potenzial in der Deutungsverschiebung auf der Identifizierung der »Mitspielfähigkeit« von Subjekten liegen könnte. ${ }^{112}$ In dieser Perspektive lassen sich die studentischen Berichte kritisch erkunden, denen eine Sensibilität für die Grenzbearbeitung zwischen der Kreativität des Handelns und der eher blassen >roten Linieく innegewohnt zu haben schien, wo die Basisprozesse der Eignungsabklärung gestört worden wären. Der Vollzug dieser kreativen Grenzbearbeitungen brachte eigene, historisch bedingte lokale Bedeutungen hervor und beanspruchte damit eine souveräne Position von angehenden Lehrpersonen am Seminar. $\mathrm{Zu}$ praxeologischen Orientierungen und Fokussierungen gehört aber auch, die Krisenanfälligkeit von Alltagsroutinen in den Blick zu nehmen. In diesem Sinne könnte das »Streben nach Originalität, nach einer Unverwechselbarkeit des Ichs« und nach Eigensinn der scheinbar eigenwillig berichterstattenden angehenden Lehrpersonen auch umschlagen in einen Handlungsvollzug, der das Abweichende gegenüber dem Standard der Gestaltungsprinzipien zum hegemonialen Muster werden lässt. ${ }^{113}$

So bleibt im Vergleich zu historischen anderen Ansätzen in dem praxeologisch orientierten und quellenbasierten Problemaufriss der unverstellte Bezug zum »Mysterium des Realen in der Moderne ${ }^{114}$ selbstverständlich ebenfalls versagt, aber womöglich wird die Nicht-Feststellbarkeit des Realen durch den hier vorgestellten Zugriff mit dem Filter der parallel sich ereignenden Musterhaftigkeit und Eigensinnigkeit menschlicher Erfahrungen ein wenig greifbarer.

\section{Quellen und Literatur}

\section{Ungedruckte Quellen}

\section{Forschungsbibliothek Pestalozzianum PH Zürich:}

Schulgeschichte. Zürcher Oberseminar I: Chronik der Seminargemeinde, 19451951 [handschriftlich].

111 Rademacher/Wernet 2015, S. 106.

112 Freist 2015, S. 71f.

113 Reckwitz 2012, S. 12.

114 Koschorke 2015, S. 19. 
Schulgeschichte. Zürcher Oberseminar II: Praxisberichte der Abschlussklasse 1944/45 [handschriftlich].

Neue Zürcher Zeitung, Dienstag, 1. September 1931, Blatt 5: Lehrerbildungsreform im Kanton Zürich [ZH HF III 1].

Oberseminar des Kantons Zürich. Jahresbericht. Schuljahr 1954/55 [ZH HF II 2].

Oberseminar des Kantons Zürich. Jahresbericht. Schuljahr 1952/53 [ZH HF II 2].

Oberseminar des Kantons Zürich. Jahresbericht. Schuljahr 1948/49 [ZH HF II 2].

Oberseminar des Kantons Zürich. Jahresbericht. Schuljahr 1943/44 [ZH HF II 2].

\section{Staatsarchiv Zürich (StAZH)}

Kanton Zürich, Staatsarchiv, M 14g. 48. 12. Kommission betr. Postulat 743 (Revision Lehrerbildung). 2. Sitzung, 30. Oktober 1953.

\section{Gedruckte Quellen}

Becker, Carl Heinrich (1926): Die Pädagogische Akademie im Aufbau unseres nationalen Bildungswesens. Leipzig.

Frey, Karl (1969): Wer wird Lehrer? Die Neigung zum Lehrberuf. In: Schweizerische Lehrerzeitung 114, H. 20, S. 602-604.

Guyer, Walter (1949): Grundlagen einer Erziehungs- und Bildungslehre. Zürich.

Herbart, Johann Friedrich (1806): Allgemeine Pädagogik aus dem Zweck der Erziehung abgeleitet. Göttingen.

Horkheimer, Max (1985): Akademisches Studium [1952]. In: Ders.: Gesammelte Schriften. Band 8. Vorträge und Aufzeichnungen 1949-1973. Herausgegeben von Gunzelin Schmid Noerr. Frankfurt a.M., S. 381-390.

Kerschensteiner, Georg (1919): Die seelische Veranlagung zum Erzieher- und Lehrerberuf. In: Jahrbuch der Schweizerischen Gesellschaft für Schulgesundheitspflege 20, S. 161-193.

Leuthold, Hans (1944): Lebendiger Unterricht. Didaktische Briefe über den Gesamtunterricht, das Unterrichtsgespräch und den Gruppenunterricht. Zürich.

Schohaus, Willi (1954): Seele und Beruf des Lehrers. Dritte, revidierte und erweiterte Aufl. Frauenfeld.

Spranger, Eduard (1921): Lebensformen. Geisteswissenschaftliche Psychologie und Ethik der Persönlichkeit. Halle.

Stettbacher, Hans (1923): Die Eignung zum Lehramt. Zürich.

Tuggener, Heinrich (1962): Der Lehrer. Studien über Stand, Beruf und Bildung des Volksschullehrers. Zürich.

Tuggener, Heinrich (1963) Der Lehrermangel. Zürich.

W.K. (1920): Die seelische Veranlagung zum Erzieher und Lehrerberuf. In: Schweizerische Lehrerzeitung 65, H. 15, S. 103 f. 


\section{Literatur}

Baumert Jürgen/Kunter, Mareike (2006): Stichwort: Professionelle Kompetenz von Lehrkräften. In: Zeitschrift für Erziehungswissenschaft 10, H. 4, S. 469-520.

Bieri Buschor, Christine/Schuler Braunschweig, Patricia (2011): Check-point Assessment Centre für angehende Lehramtsstudierende. Empirische Befunde zur prognostischen Validität und zur Übereinstimmung von Selbst- und Fremdeinschätzung eignungsrelevanter Merkmale. In: Zeitschrift für Pädagogik 57, H. 5, S. 695-710.

Bloch Pfister, Alexandra (2007): Priester der Volksbildung. Der Professionalisierungsprozess der Zürcher Volksschullehrkräfte zwischen 1770 und 1914. Zürich.

Bourdieu, Pierre (1993): Soziologische Fragen. Frankfurt a.M.

Breidbach, Olaf (2011): Radikale Historisierung. Kulturelle Selbstversicherung im Postdarwinismus. Berlin.

Chartier, Roger (1989): Einleitung: Kulturgeschichte zwischen Repräsentation und Praktiken. In: Ders.: Die unvollendete Vergangenheit. Geschichte und die Macht der Weltauslegung. Frankfurt a.M., S. 7-23.

Crotti, Claudia (2015): Höhere Töchterschule und Lehrerinnenseminar Zürich. Das Seminar als Sprungbrett an die Alma Mater (1878-1905). In: Andreas Hoffmann-Ocon (Hg.): Orte der Lehrerinnen- und Lehrerbildung im Kanton Zürich. Bern, S. 131-144.

Daniel, Ute (2001): Kompendium Kulturgeschichte. Theorien, Praxis, Schlüsselwörter. Frankfurt a.M.

Denzler, Stefan/Fiechter, Ursula/Wolter, Stefan C. (2005): Die Lehrkräfte von morgen. Eine empirische Untersuchung der Bestimmungsfaktoren des Berufswunsches bei bernischen Gymnasiasten. In: Zeitschrift für Erziehungswissenschaft 8, H. 4, S. 576-594.

Enzelberger, Sabina (2001): Sozialgeschichte des Lehrerberufs. Gesellschaftliche Stellung und Professionalisierung von Lehrerinnen und Lehrern von den Anfängen bis zur Gegenwart. Weinheim, München.

Foucault, Michel (2003): Die Anormalen. Vorlesungen am Collège de France (19741975). [Vorwort von François Ewald und Allessandro Fontana, 7-12]. Frankfurt a.M.

Freist, Dagmar (2015): Historische Praxeologie als Mikro-Historie. In: Arndt Brendecke (Hg.): Praktiken der frühen Neuzeit. Akteure - Handlungen - Artefakte. Köln, S. 62-77.

Füssel, Marian (2015): Die Praxis der Theorie. Soziologie und Geschichtswissenschaft im Dialog. In: Arndt Brendecke (Hg.): Praktiken der frühen Neuzeit. Akteure - Handlungen - Artefakte. Köln, S. 21-33. 
Gruschka, Andreas (2011): Pädagogische Forschung als Erforschung der Pädagogik. Eine Grundlegung. Opladen.

Haasis, Lucas/Rieske, Constantin (2015): Historische Praxeologie. Zur Einführung. In: Diess. (Hg.): Historische Praxeologie. Dimensionen vergangenen Handelns. Paderborn, S. 7-54.

Helsper, Werner (2008): Schulkulturen als symbolische Sinnordnungen und ihre Bedeutung für die pädagogische Professionalität. In: Ders./Susann Busse/ Merle Hummrich/Rolf-Torsten Kramer (Hg.): Pädagogische Professionalität in Organisationen. Neue Verhältnisbestimmungen am Beispiel der Schule. Wiesbaden, S. 115-148.

Herbst, Ludolf (2004): Komplexität und Chaos. Grundzüge einer Theorie der Geschichte. München.

Hess, Volker (2015): Schreiben als Praktik. In: Arndt Brendecke (Hg.): Praktiken der frühen Neuzeit. Akteure - Handlungen - Artefakte. Köln, S. 82-99.

Hillebrandt, Frank (2015a): Vergangene Praktiken. Wege zu ihrer Identifikation. In: Arndt Brendecke (Hg.): Praktiken der frühen Neuzeit. Akteure - Handlungen - Artefakte. Köln, S. 21-33.

Hillebrandt, Frank (2015b): Praxistheorie und Schulkultur. Identifikation und Analyse schulischer Praktiken. In: Jeanette Böhme/Merle Hummrich/RolfThorsten Kramer (Hg.): Schulkultur. Theoriebildung im Diskurs. Wiesbaden, S. 429-448.

Hoffmann-Ocon, Andreas (2014): Akademisierung oder Verakademisierung? Lesarten zu Ausbildungsformen von Lehrpersonen am Beispiel des Kantons Zürich aus bildungshistorischer Perspektive. In: IJHE Bildungsgeschichte. International Journal for the Historiography of Education 4, H. 2, S. $204 f$.

Hoffmann-Ocon, Andreas (2017) Persönlichkeit oder Wissenschaftsbasierung? Einfluss von Ausbildungspraktiken auf Prüfungen Zürcher Volksschullehrpersonen um 1900. In: Zeitschrift für Pädagogik 63, H. 3, S. 299-316.

Hoffmann-Ocon, Andreas (2018): Stadt-Land-Differenzen als Prägefaktoren in der Ausbildung von Lehrpersonen? Annäherungen an die Beispiele Basel und Zürich in der ersten Hälfte des 20. Jahrhunderts. In: Historia Scholastica 4, H. 1, S. 29-45.

Hoffmann-Ocon, Andreas/Grube, Norbert (2016): »Lehrer auf Abwegen« - Bildungshistorische Annäherungen an "gebrochene« und »eigensinnige« Berufsbiografien in der ersten Hälfte des 20. Jahrhunderts. BIOS. Zeitschrift für Biographieforschung, Oral History und Lebensverlaufsanalysen 29, H. 2, S. 208-219.

Hofstetter, Rita/Schneuwly, Bernard 2011: Zur Geschichte der Erziehungswissenschaften in der Schweiz. Vom Ende des 19. Jahrhunderts bis zur Mitte des 20. Jahrhunderts. Bern.

Jaeggi, Rahel (2014): Kritik von Lebensformen. Berlin. 
Kaminski, Andreas (2018): Die harmonische Gesellschaft. Das evolutionäre Prüfungsdispositiv um 1900. In: Sabine Reh/Norbert Ricken (Hg.): Leistung als Paradigma. Zur Entstehung und Transformation eines pädagogischen Konzepts. Wiesbaden, S. 227-250.

Klein, Ursula (2016): Nützliches Wissen. Die Erfindung der Technikwissenschaften. Göttingen.

Koller, Hans-Christoph (2004): Grundbegriffe, Theorien und Methoden der Erziehungswissenschaft. Stuttgart.

Koschorke, Albrecht (2015): Das Mysterium des Realen in der Moderne. In: Helmut Lethen/Ludwig Jäger/Ders. (Hg.).: Auf die Wirklichkeit zeigen. Zum Evidenzproblem in den Kulturwissenschaften. Frankfurt a.M., New York, S. 13-38.

Kössler, Till (2018): Leistung, Begabung und Nation nach 1900. In: Sabine Reh/ Norbert Ricken (Hg.): Leistung als Paradigma. Zur Entstehung und Transformation eines pädagogischen Konzepts. Wiesbaden, S. 193-210.

Landwehr, Achim (2008): Historische Diskursanalyse. Frankfurt a.M., New York.

Lautenbach, Corinna (2019): Das Lehramt als Aufstiegsfach. Der Zusammenhang von sozialer Herkunft und der Wahl von Lehramtsstudiengängen aus werterwartungstheoretischer Perspektive In: Zeitschrift für Erziehungswissenschaft 22, S. 1461-1488.

Leitner, Ulrich (2016): Ego-Dokumente als Quellen historischer Bildungsforschung. In: BIOS. Zeitschrift für Biographieforschung, Oral History und Lebensverlaufsanalysen 29, H. 2, S. 253-265.

Lerch, Walter (2005): Mit kollegialischem Grusse. Das erste Korrespondenzbuch der 1881-1893 »aus Schiers hervorgegangenen Lehrer«. Chur.

Müller, Hans-Rüdiger (2016): Zur historischen Rekonstruktion von Erziehungspraktiken in Elternbiographien. In: BIOS. Zeitschrift für Biographieforschung, Oral History und Lebensverlaufsanalysen 29, H. 2, S. 266-274.

Nigro, Roberto (2015): Wahrheitsregime. Zürich, Berlin.

Pässler, Katja/Hell, Benedikt/Schuler, Heinz (2011): Grundlagen der Berufseignungsdiagnostik und ihre Anwendung auf den Lehrerberuf. In: Zeitschrift für Pädagogik 57, H. 5, S. 639-654.

Rademacher, Sandra/Wernet, Andreas (2015): Struktur, Funktion und Eigenlogik. Schultheoretische Anmerkungen zum Verhältnis von Schule und Gesellschaft. In: Jeanette Böhme/Merle Hummrich/Rolf-Thorsten Kramer (Hg.): Schulkultur. Theoriebildung im Diskurs. Wiesbaden, S. 95-116.

Reckwitz, Andreas (2008): Praktiken und Diskurse. Eine sozialtheoretische und methodologische Relation. In: Herbert Kalthoff/Stefan Hirschauer/Gesa Lindemann (Hg.): Theoretische Empirie. Zur Relevanz qualitativer Forschung. Frankfurt a.M., S. 188-209.

Reckwitz, Andreas (2012): Die Erfindung der Kreativität. Zum Prozess gesellschaftlicher Ästhetisierung. Berlin. 
Reichenbach, Roland (2003): Pädagogischer Kitsch. In: Zeitschrift für Pädagogik 49, H. 6, S. 775-789.

Reitemeyer, Ursula (2011): Johann Friedrich Herbart. Allgemeine Pädagogik aus dem Zweck der Erziehung abgeleitet. In: Winfried Böhm/Birgitta Fuchs/Sabine Seichter (Hg.): Hauptwerke der Pädagogik. Paderborn, S. 189-192.

Ricken, Norbert/Reh, Sabine (2017): Prüfungen - Systematische Perspektiven der Geschichte einer pädagogischen Praxis. In: Zeitschrift für Pädagogik 63, H. 3, S. 247-258.

Schäfer, Alfred (1993): Autonomie - zwischen Illusion und Zumutung. In: Vierteljahrsschrift für wissenschaftliche Pädagogik 72, H. 2, S. 175-189.

Schmeitzner, Anke (2009): Deutungsmustern von Lehrern. Eine inhaltsanalytische Untersuchung von Lehrerautobiografien aus dem 19. und 20. Jahrhundert. Lüneburg [Diss.; Typoskript].

Schmidt, Robert (2012): Soziologie der Praktiken. Konzeptionelle Studien und empirische Analysen. Berlin.

Settele, Veronika (2017): Mensch, Kuh, Maschine. Kapitalismus im westdeutschen Kuhstall, 1950-1980. In: Mittelweg 36. Zeitschrift des Hamburger Instituts für Sozialforschung 26, H. 1, S. 44-65.

Stadler, Peter (2007): Art. »Guggenbühl, Gottfried« [20.03.2007]. In: Historisches Lexikon der Schweiz online unter www.hls-dhs-dss.ch/textes/d/D27063.php (Zugriff: 15.04.2020).

Terhart, Ewald (2009): Didaktik. Eine Einführung. Stuttgart.

Tenorth, Heinz-Elmar (1986): »Lehrberuf s. Dilettantismus«. Wie die Lehrprofession ihr Geschäft verstand. In: Niklas Luhmann/Karl Eberhard Schorr (Hg.): Zwischen Intransparenz und Verstehen. Frankfurt a.M., S. 275-322.

Titze, Hartmut (1991): Lehrerbildung und Professionalisierung. In: Christa Berg (Hg.): Handbuch der deutschen Bildungsgeschichte. Band IV. 1870-1918. Von der Reichsgründung bis zum Ende des Ersten Weltkriegs. München, S. 345370.

Ullrich, Wolfgang (2014): Des Geistes Gegenwart. Eine Wissenschaftspoetik. Berlin.

Ullrich, Wolfgang (2016): Der kreative Mensch. Streit um eine Frage. Salzburg, Wien.

Verheyen, Nina (2018): Die Erfindung der Leistung. Berlin.

Welzbacher, Christian (2017): Das totale Museum. Berlin. 



\section{Anleitungszusammenhänge. Interdisziplinäre Blicke auf Norm und Praxis des Lernens und Studierens}





\section{Perspektiven einer bildungshistorischen Praxeologie Studieren als Praxis}

Sabine Reh/Kerrin Klinger

Wie die anderen Geisteswissenschaften unterliegt auch die Bildungshistoriografie thematischen und methodischen Konjunkturen. Sie ist selbst historischen Veränderungen unterworfen ${ }^{1}$ und reagiert nicht nur auf Entwicklungen der bildungsund wissenschaftspolitischen Gegebenheiten, ${ }^{2}$ sondern auch - manchmal mit zeitlichen Verzögerungen - auf epistemologische Verschiebungen oder »turns « in den Geistes- und Kulturwissenschaften, auf »Neuorientierungen der theoretischkonzeptuellen Aufmerksamkeit«. ${ }^{3}$

So wird die sozialhistorische Sichtweise auch in der Bildungshistoriografie gegenwärtig um eine kulturhistorische Perspektive auf Materialitäten und den Umgang damit, auf Räume, Dinge und Körper ergänzt. ${ }^{4}$ Im Sinne eines »spatial turn«, eines »material« oder eines »practical turn « wird nach der Geschichte materieller Kultur gefragt und versucht, in einem weiten Sinne, »kulturell kodierte

$1 \quad$ Bildungsgeschichte kann daher hinsichtlich ihrer undiskutierten Vorannahmen und Kategorien historisiert, vgl. Fendler 2013, S. 225-227, werden; zu nationalen Schwerpunktsetzungen vgl. etwa Heinemann 1979; in jüngerer Zeit z.B. die Beiträge in Larsen 2012; auch diejenigen in Popkewitz 2013, der die-aus seiner Sicht-besondere Situation und traditionelle Orientierung der amerikanischen historischen Bildungsforschung zum Ausgangspunkt einer Sammlung von internationalen Beiträgen macht, um unterschiedliche Stile des Denkens bzw. des historischen Arbeitens - man könnte sagen, einen »historistischen« und »historisierenden« - voneinander zu unterscheiden.

2 Vgl. etwa Groppe 2012; kritisch Tröhler 2011.

3 Bachmann-Medick 2013, S. 399f.; vgl. Casale/Tröhler/Oelkers 2006.

4 Vgl. für die bildungsgeschichtliche Rezeption dieser neuen Orientierungen und Aufmerksamkeiten international z.B. Lawn/Grosvenor 2005, für die deutschsprachige Historische Bildungsforschung zu einzelnen Aspekten, etwa Räumen, Jelich/Kemnitz 2003, zu Materialitäten Priem/König/Casale 2012.

5 Inwiefern etwa der»spatial turn«, der»material turn« und ein »practical turn«miteinander verbunden sind, worauf sich einzelne Autoren auch jeweils unterschiedlich theoretisch beziehen und wie sich die Forschungsprogramme unterscheiden, ob das konsistent ist oder nicht, kann hier aus Platzgründen nicht diskutiert werden. Vgl. zum »practical turn« Schatzki/Knorr-Cetina/von Savigny 2001. Materialität spielt eine besondere Rolle in der Anthropologie, vgl. Hicks 
Praktiken historischer Akteure und die sich diesen Praktiken verdankenden geistigen und materiellen Erzeugnisse $\aleph^{6}$ zu rekonstruieren. Ganz grob gesagt, liegt es im Interesse einer explizit praxeologischen Perspektive der Bildungsgeschichte, die Rekonstruktion und Analyse der Entstehung und Veränderung spädagogischer Praktiken, ihrer materiellen Rahmungen und Institutionalisierungen mit Transformationen des Wissens über das Aufwachsen, das Lehren und Lernen in der Gesellschaft, also mit einer Geschichte spädagogischer< Denkformen, zu verbinden und deren wechselseitige Einflüsse zu untersuchen. Die Frage jedoch danach, was genau eigentlich eine »praxeologisch « orientierte Historische Bildungsforschung tut, wie sie also verfährt, in welcher Weise sie mit Quellen arbeitet und ob sie auf neue Quellen angewiesen ist, wird inzwischen immer breiter diskutiert. ${ }^{7}$ Eine Frage schiebt sich dabei in den Vordergrund: Ist es möglich, mit dem Blick auf Praktiken Neues in der Bildungsgeschichte zu entdecken, lässt diese Perspektive neue Dinge erkennen oder Bekanntes in einem anderen Licht erscheinen? Erst die positive Beantwortung dieser Frage nämlich macht es sinnvoll, sich als Bildungshistoriker/-in auf eine praxeologische Perspektive einzulassen - und das nicht einfach deshalb zu tun, weil man einer Mode folgt.

Im Folgenden werden wir versuchen, aus unserer Sicht Antworten auf diese Frage zu geben. Dazu werden wir zunächst einige Ausführungen zur Rezeption der Praxeologie und ihrer theoretischen Ansätze in der deutschen Historiografie machen und die besondere Bedeutung skizzieren, die der Untersuchung von Materialitäten in einer historisch-praxeologischen Perspektive zukommt (I), um in den folgenden Schritten mithilfe eines Beispiels, der Praxis des Studierens als einer besonderen Praxis des Lernens oder Sich-Bildens, den Gewinn einer praxeologischen Perspektive in der Bildungshistoriografie aufzuzeigen. Dafür wird zunächst erläutert, was bisher über die Praxis des Studierens im 19. Jahrhundert bekannt ist (2),

2010, und in den Kulturwissenschaften, vgl. etwa König 2005, Miller 2005, Tietmeyer et al. 2010.

6 Tschopp 2009, S. 588. Vgl. für die deutsche Ceschichtswissenschaft insgesamt Daniel 2001, Raphael 2010, S. 228-246, und Hütig 2010; zu einer »neuen Kulturgeschichte« Vierhaus 1995; zu der Auseinandersetzung um »alte« und »neue Kulturgeschichte« Maurer 2005; zu deren gegenwärtigem Stand Tschopp 2009; Kusber u.a. 2010. International wurde eine solche Perspektive schon früher debattiert. Das dokumentieren in den USA etwa die Beiträge von Biernacki 1999, 2005, in denen der Autor sich damit auseinandersetzt, welche Folgen die Beschränkungen auf ein Verständnis von Kultur als System von Zeichen hat und in dem er plädiert für ein erweitertes, materielle und praxeologische Aspekte berücksichtigendes Verständnis von Kultur; vgl. insgesamt dazu auch die Beiträge in Spiegel 2005. In Frankreich lassen sich früh schon ähnlich interessierte Ansätze erkennen, theoretisch ambitioniert De Certeau 1988, aber z.B. auch die kulturhistorischen Forschungen zur Geschichte des Lesens und dessen Praktiken, vgl. Chartier 1990.

7 Vgl. Reh 2014, auf den wir hier teilweise zurückgreifen, vgl. jüngst auch Berdelmann u.a. 2018, ebenso in diesem Band Hoffmann-Ocon/De Vincenti/Crube. 
um anschliessend anhand der Praxis des Mitschreibens in Vorlesungen am Ende des 19. Jahrhunderts anzudeuten, welche Aussagen sich hier über das Studium an deutschen Universitäten und insbesondere über die vielgeschmähten Vorlesungen gewinnen lassen (3). Abschliessend werden wir zusammenfassen, worin der Gewinn einer bildungshistorischen Praxeologie liegen könnte (4).

\section{Praxeologische Ansätze in der deutschen Geschichtswissenschaft}

Marian Füssel hat sowohl in quellennahen Studien wie auch in theoretisch informierten und gleichzeitig kritisch-reflektierten Veröffentlichungen beleuchtet, was die Potenziale, aber auch die Grenzen einer praxeologischen Historiografie sind. ${ }^{8}$ Der Autor - selbst Frühneuzeitforscher ${ }^{9}$ - setzt am Hauptproblem der Übertragung dieses Forschungsansatzes aus den Sozial- bzw. Kulturwissenschaften in die Geschichtswissenschaft an. Während dort Praktiken zumeist ethnografisch erforscht, also von den Forscher/-innen selbst situativ - wie es heisst: teilnehmend - beobachtet werden, gibt es keine direkte Beobachtung einer vergangenen Praxis; diese scheint sich damit einer Rekonstruktion zu entziehen. Vor dem Hintergrund eines Booms praxeologischer Studien zur Frühen Neuzeit warnt Füssel daher vor zwei entgegengesetzten Gefahren. Denn obwohl der praxeologische Ansatz die Geschichtswissenschaft mittlerweile enorm bereichert und eine Vielzahl von innovativen Studien angeregt habe, berge er gleichwohl die Gefahr, einer »begrifflichen Nivellierung«, einer Veralltäglichung des Begriffs der Praktik einerseits und einer »Übertheoretisierung andererseits «. ${ }^{10}$ Teilweise steht der hohe theoretische Aufwand, der betrieben wird, um eine historische Praxistheorie $\mathrm{zu}$ entwickeln, eher enttäuschenden Ergebnissen entsprechender historischer Studien gegenüber.

Zunächst einmal ist - um der ersten Gefahr zu entgehen - das theoretische Konzept der Praktik tatsächlich ernst zu nehmen und starkzumachen, wie

8 Zum Beispiel Füssel 2006, 2011, 2015a u. 2015b.

9 Gerade Frühneuzeitforscher/-innen setzen im deutschen Sprachraum vergleichsweise stark auf den Begriff der Praktiken, und unter ihnen befinden sich einige der profiliertesten, wenn auch nicht die einzigen praxeologisch arbeitenden Historiker/-innen, vgl. neben Marian Füssel Dagmar Freist vor allem zu historischen Praktiken der Subjektivierung, z.B. 2013a, $2013 \mathrm{~b}$ u. 2015, auch Haasis/Rieske 2015.

10 Füssel 2015b, S. 269. Auch die angeführte theoretisch ambitionierte Einführung von Haasis/ Rieske 2015 entgeht dieser Gefahr - ebenso wie der frühe Aufsatz des Zeithistorikers Sven Reichardt 2007 - nicht ganz, kritisch dazu auch Graf 2008. 
es "Praxistheoretiker", vor allem Bourdieu, ${ }^{11}$ aber auch Giddens ${ }^{12}$ oder Schatz$\mathrm{ki}^{13}$ tun. Ausgegangen wird hier davon, dass Kulturen als zusammenhängende, mehrfach und auf unterschiedlichen Ebenen symbolisch vermittelte Bedeutungskonstruktionen und Selbstauslegungen in Praktiken produziert und reproduziert werden. Praktiken sind wiederholbare, quasi institutionalisierte Formen sinnhaften Tuns. Sie können als erste Formen einer Institutionalisierung, als kleinste Einheiten des Sozialen aufgefasst werden ${ }^{14}$ und erscheinen hier als "a set of doings and sayings «. ${ }^{15}$ Sie werden betrachtet als ein offenes, aber von Aufgaben und Projekten organisiertes und sich zeitlich entfaltendes Netz von Aktivitäten, die körperlich und direkt aufgeführt werden, also nicht nebenbei, nicht etwas anderes unternehmend, verfolgt werden. ${ }^{16}$ Schatzki fasst die Merkmale von Praktiken zusammen: »More specifically, the doings and sayings that compose a given practice are linked (1) through practical understandings, (2) rules, (3) a teleoaffective structure, and (4) general understandings «. ${ }^{17}$

In den Blick gerät auf diese Weise der menschliche Körper als Träger eines routinierten Wissens, eines tacit knowledge bzw. tacit knowing oder impliziten Wissens, wie Polanyi ${ }^{18}$ es versteht oder eines Habitus, wie Bourdieu ihn als strukturierte und gleichzeitig strukturierende Struktur entworfen hat. ${ }^{19}$ Das Tun bzw. Können des Körpers gilt nicht nur als eine mentale Strukturierung, sondern erscheint als wirklich körperliche Routine ${ }^{20}$ in einer alläglichen, also einer sich immer wieder ereignenden Praxis. In den Praktiken, in den Routinen, ist also so die hier vertretene praxistheoretische Position - eine Art praktisches Wissen eingelagert. In der Teilnahme an ihnen werden Individuen als Subjekte ssozialisiert $<,{ }^{21}$ werden die materialen und die mentalen Dimensionen von Kulturen je sozial vermittelt.

11 Bourdieu 1979, vgl. die Einschätzung und Hinweise zur besonderen Rolle Bourdieus in der Auseinandersetzung zwischen sozial- und kulturwissenschaftlichen Ansätzen Füssel 2015b.

Giddens 1995.

Schatzki 1996, 2002 u. 2010.

Vgl. Reckwitz 2003.

Schatzki 2002, S. 73.

Vgl. ebd., S. 71-73 u. 59-122.

Ebd., S. 77.

Polanyi 1985.

Vgl. Bourdieu 1979, S. 188.

Vgl. zur Nutzung des Konzepts der Routine in historiografischer Forschung Sarasin 2013.

Vgl. zur Konzeption von Sozialisation als Subjektivierung in Praktiken Alkemeyer 2013; Ricken 2013a u. 2013b. »Mind«, »goals and intentions« werden als eingelagert in Praktiken verstanden und müssen deshalb nicht als mentale Dispositionen ausschliesslich auf der Seite eines autonomen Subjekts verankert werden. Auch wenn das Subjekt auf diese Weise konzipiert wird als eines, das über sich selbst nicht vollständig im Bilde ist und dementsprechend auch nicht 
Ein solches praxeologisches Verständnis von Kulturen, darin von herstellenden Praktiken und von den über die Teilnahme an Praktiken ssubjektivierten< Individuen, grenzt sich damit ab von einem Verständnis von »Kultur als Text«, wie Geertz formulierte, ${ }^{22}$ von einem kulturwissenschaftlichen "Mentalismus «, wie Reckwitz diese Positionen zusammenfassend charakterisiert. ${ }^{23}$ Auch wenn in diesem kulturwissenschaftlichen Zusammenhang weder theoretisch noch empirisch abschliessend geklärt ist, wie das Verhältnis mentaler Wissensordnungen, körperlicher Verhaltensroutinen und von Artefakten zueinander genau zu bestimmen ist, ${ }^{24}$ wird mit einem solchen praxistheoretischen Verständnis dem cartesianischen Dualismus von Körper und Geist und der gerade von Bourdieu immer wieder kritisierten strikten Entgegensetzung von Subjekt und Objekt in sozialwissenschaftlicher Betrachtung ${ }^{25}$ entgegengewirkt.

Nimmt man also nun ein solches, theoretisch durchaus elaboriertes Verständnis von Praktiken ernst, greift also nicht einfach auf ein Alltagsverständnis von >Praxis`im Sinne eines tätig-handelnden Umganges mit der Welt im Gegensatz $\mathrm{zu}$ einem theoretischen Weltverhältnis zurück, müssten die Probleme, die sich praxeologisch perspektivierenden Historiker/-innen stellen, auf der Ebene der Quellen wie der Verfahren ihres Forschens präziser beschrieben werden können. Wenn etwa die Sozialhistoriker/-innen und heute vor allem die Zeithistoriker/innen quantifizierende Methoden nutzen bzw. auf entsprechende Daten zurückgreifen und die neueren Formen der Ideengeschichte auf unterschiedliche Spielarten der Hermeneutik oder auf rhetorische Analysen setzen ${ }^{26}$ - was tut dann die praxeologische Historiografie? Hat sie spezifische Quellen, spezifische Verfahren? So lautet die wiederum berechtigte Frage Füssels.

Praxeologisch orientierte Historiker/-innen können - wie Soziologen - davon ausgehen, dass »alle Praxis sich materiell ereignet ${ }^{27}$ und den Blick auf eine mate-

in jeder Hinsicht souverän und autonom handelt, muss es keinesfalls als vollständige Illusion verabschiedet werden. Vielmehr kann, wie Reddy (2001, S. 95) skizziert, das Individuum als ein Knotenpunkt erscheinen, als »disaggregated self«, dem sich in Praktiken bestimmte »translation tasks«stellen, die es je nach Aktivitäts- und Aufmerksamkeitszustand unterschiedlich bewältigt: Das Individuum ist »a site where messages arrive in many different languages or codes, and where some of the messages are succesfully translated into other codes, while others are not « (Reddy 2001, S. 80); vgl. zu einer entsprechenden praxeologischen Analyse des Schüler-Subjekts Reh 2013.

Vgl. Geertz 1983.

Vgl. Reckwitz 2000, S. 588ff., dazu auch Biernacki 2005.

Vgl. Reckwitz 2000, S. 590.

Das ist - wie Bourdieu immer wieder betont - eines der Hauptanliegen seiner Theorie einer Praxis, vgl. z.B. 1979, S. 148-151. 
riell sich vollziehende Praxis richten: $Z$ Zuerst werden die Dinge als notwendige Bestandteile von Praktiken erkennbar, weil sie diese affizieren und prägen. Sie werden in allen Praktiken gehandhabt. ${ }^{28}$ Wie nun können Historiker/-innen ihren Blick auf eine materiell sich vollziehende Praxis in der Vergangenheit richten? Statt unmittelbarer Beobachtungen einer Praxis stehen den Historiker/-innen zunächst einmal - aus unterschiedlichen Gründen und für verschiedene Zwecke angefertigte - Beschreibungen und Berichte von Zeitzeugen über eine eigene Praxis in verschiedenen Feldern zur Verfügung. Da Praktiken aber, sofern sie im oben aufgeführten Sinne und damit als Routinen verstanden werden, von einem impliziten Wissen getragen werden, nicht immer bewusst sind, berichten Akteure als Zeitzeugen oft gerade dann, wenn sie ihre alltägliche Praxis in den Blick nehmen, nicht immer explizit über einzelne Praktiken. Auf Praktiken muss der Historiker oder die Historikerin also auch mithilfe von smaterialen spuren in verschiedenen Arten von Quellen und Überresten schliessen - so wie es etwa Marc Bloch für die Arbeit des Historikers generell beschrieben hat. ${ }^{29}$ Stärker als Füssel, der herausstellt, dass die historische Praxeologie - als Charakterisierung einer bestimmten Perspektive, die auf die Vergangenheit gerichtet wird - sich eben keiner besonderen Quellen bedienen kann und sich im Hinblick auf Verfahren des Umgehens mit ihnen auch nur wenig unterscheidet von der üblichen historischen Arbeit, stellen andere Vertreter/-innen einer historischen Praxeologie, wie etwa Dagmar Freist, inzwischen stärker die Beachtung der Materialität heraus. In ihrer historischen Arbeit spielen Artefakte eine besondere Rolle. Sie sind wesentliche Bestandteile von Praktiken, und zwar nicht nur als Ergebnisse, sondern auch als Bedingungen und Ausgangspunkte. Praktiken hinterlassen ihre Spuren im Material. Die Betrachtung von Artefakten aber auch der materiellen Seite von Text- und Bildquellen stellt demnach eine wichtige Ergänzung zum Verständnis textlich- oder bildlich-symbolischer Überlieferung dar. Deren Bedeutungsgehalt muss vor dem Hintergrund eines kontextualisierenden Wissens, das aus verschiedenen Quellen entsteht, ermittelt werden. Im Sinne einer historischen Praxeologie kann nach den »Bedingungen der Möglichkeiten von Handlungsweisen ${ }^{30}$ gefragt werden, »um unter der wissenschaftlichen Beobachterperspektive eines mikroskopischen Blicks die Komplexität sozialer Praktiken, Kontingenzen in den Vollzügen sozialer Praktiken, die Gleichzeitigkeit verschiedener Möglichkeitsräume und damit

28 Ebd. Die Konzepte in den Sozialwissenschaften reichen von »Object lessons« bis hin zu Mensch-Ding-Assoziationen in der ethnografischen Unterrichtsforschung, wobei dann die Dinge - möglicherweise in Analogie zu den Wissens- oder epistemischen Dingen der Wissenschaftsforschung - geradezu zu spädagogischen Dingen` werden, vgl. Lehmann 2016; Asbrand/Martens/Petersen 2013. 
auch die Gestaltbarkeiten des Sozialen in je spezifischen >Praxisgegenwarten sichtbar zu machen ${ }^{31}$

Während also - so liesse sich die dargelegte Position zu den Ausgangsfragen zusammenfassen - Arten und Formen des Suchens, Erschliessens und rekonstruktiven Aufarbeitens von Quellen seitens des historisch-praxeologisch Forschenden »nicht von der hermeneutischen Standardarbeit des Historikers « im Umgang mit dem »historischen Material « abweichen, ${ }^{32}$ spielt - und darin unterscheidet sich die hier vertretene Position von der Füssels - im Kontext einer historischen Praxeologie doch eine besondere Art von Quellen bzw. ein besonderer Aspekt dieser, nämlich ihre Materialität, oft eine wichtige Rolle. Hinsichtlich des zweiten Teils unserer Ausgangsfragen, also im Hinblick auf die Frage nach dem Gewinn, den man mit der historischen Praxeologie erzielen könnte, kommt Füssel zu einem dezidierten Ergebnis. Das führt er anhand eigener Forschungen zur Praktik des ständischen Rangstreites in der Vormoderne aus. ${ }^{33}$ Eine historische Praxeologie so Füssel - strebt keine Fallstudien an, sucht nicht die »histoire totale« im Kleinen zu schreiben, sondern muss zeigen, dass Praktiken immer wieder ähnlich auftauchen. Ein Historiker, der praxeologisch arbeitet, rekonstruiert nicht Einzelereignisse - deren Status als Ereignisse er unter Umständen sogar infrage stellt, wie Füssel das bei dem Ereignis »Schlacht« tut. ${ }^{34}$ Das bedeutet: Er ist erstens an Wiederholungen und kleinen Abweichungen, an der >Serie und an einem Panorama der Praktiken interessiert, muss entsprechend seine Suchstrategien anlegen und nimmt zweitens Kontextualisierungen nicht von Einzelereignissen vor, sondern versucht Praktiken material in Raum und Zeit zu verankern. Füssel kommt daher zu dem Ergebnis, dass es mit einem praxeologisch fokussierten Verfahren durchaus von gegenwärtig beobachtbaren Praktiken ausgehend und nach deren Genealogie fragend - in besonderer Weise möglich ist, den "gängigen Feinde[n] der Historisierung«, nämlich der »vielgescholtene[n] anthropologische[n] Konstante und dem »Anachronismus « zu entgehen ${ }^{35}$ Der Gewinn einer in diesem Sinne verstandenen historischen Praxeologie in der Bildungsgeschichte liegt in der Historisierung eingewöhnter und nicht infrage gestellter Selbstverständlich-

31 Ebd.

32 Füssel (2015b, S. 270f.) kritisiert den Begriff der »Quelle«, weil diese Metapher immer schon das Auratische des Ursprungs enthält, den man ebenso infrage stellen müsse wie die Vorstellung vom Archiv als dem Ort der Sammlung objektiver Daten, der also die eigentliche Ceschichte enthielte; vgl. Friedrich 2013, S. 266-270. Das vertritt Füssel vor dem Hintergrund der von Lorraine Daston herausgestellten eigentlichen Arbeit von Historiker/-innen, die Unterscheidung von Quelle und Literatur, der Kult des Archivs und das Handwerk der Fussnote, vgl. Daston 2000, S. $19 f$.

Vgl. dazu vor allem Füssel 2006. 
keiten der Betrachtungen von Prozessen und Phänomenen der Sozialisation, von Bildung und Erziehung - so etwa, wenn Praktiken der Beobachtung und des Prüfens, der Gruppierung und der Bildung von Rangordnung in Klassenräumen als Momente der Herausbildung eines Dispositivs der Leistung, das nicht immer so schon bestanden hat, ausgemacht werden. ${ }^{36}$ Was das nun heissen und welches Erkenntnispotenzial sich daraus ergeben kann, soll im Folgenden an einem Beispiel gezeigt werden.

\section{Bildungshistorische Forschung zur Praxis des Studierens}

Die Schul- und Unterrichtsgeschichte hat sich wie ähnlich auch die Universitätsgeschichte lange Zeit - unter anderem aufgrund der Quellenlage - nur am Rande damit beschäftigt, wie eigentlich an den Schulen unterrichtet ${ }^{37}$ und wie an den Universitäten gearbeitet, wie gelehrt wurde und vor allem, wie Studenten gelernt und hier gelebt haben. ${ }^{38}$ Bis die Öffnung gegenüber kulturwissenschaftlichen Ansätzen und die Frage nach sich wandelnden Wissen(-schaft-)skulturen zu einer Erweiterung des Blickfeldes führte, ${ }^{39}$ wurden vor allem die institutionellen Strukturen, ihre sozialhistorische Einbettung und das Curriculum anhand des Lehrprogramms bzw. dessen, was in Verzeichnissen als zu Vermittelndes aufgelistet wurde,${ }^{40}$ untersucht. Nicht selten wurde dabei vor allem in der Universitätsgeschichte unterstellt, dass die Ankündigung auch umgesetzt und das Gelehrte auch gelernt wurde. ${ }^{41}$ Obwohl schon früh Ratgeberliteratur für Studenten, die hodegetischen Schriften, ${ }^{42}$ Anlass, hier skeptisch zu sein, und auch zeitgenössi-

36 Vgl. Reh/Ricken 2018.

37 Vgl. zusammenfassend Caruso/Reh 2020 (i.Dr.).

38 Vgl. zusammenfassend Bruch 2001; Dowe 2007; Tenorth 2012; zu Studenten und aus deren Perspektive Jarausch 1984; allerdings sind in jüngerer Zeit zunehmend Studien zum Lesen als einer akademischen Praxis in der Frühen Neuzeit erschienen, vgl. unten Fussnote 82.

39 Zum Beispiel für Universitäten im deutschen Sprachraum Steckel 2011; Kintzinger/Steckel 2015; für Schulen um 1800 Klinger 2014.

40 So für die Schulgeschichte etwa in den Schulprogrammen des 19. Jahrhunderts, vgl. z.B. Kipf 1999.

41 Vgl. z.B. Bach/Maatsch/Rasche 2008; kritisch Tenorth 2012, S. 239.

42 Es handelt sich hierbei um Schriften, die sich als Wegweisung, als Anleitung zum Universitätsstudium verstehen und hauptsächlich im Zeitraum zwischen etwa 1730 und 1900 entstanden, vor allem in der Zeit zwischen etwa 1790 und 1840. Sie enthalten Verzeichnisse von Büchern zu einzelnen Wissensgebieten, enzyklopädisch, reichern diese an mit Hinweisen und Ratschlägen zum Verhalten der jungen Akademiker, zu deren Lebensweise und Arbeiten an der Universität. In einer Bibliographie der deutschen Universitäten. Systematisch geordnetes Verzeichnis der bis Ende 1899 gedruckten Bücher und Aufsätze über das deutsche Universitätswesen in drei Bänden 
sche Universitätsbeobachter gegen Ende des 19. Jahrhunderts auf diesbezügliche Probleme hinwiesen, ${ }^{43}$ hielten sich in der Bildungshistoriografie Mythen über die Lehrleistungen der Universität. Lange Zeit wurde die Tatsache geleugnet, dass in der deutschen Universität der Qualität der Lehre weniger institutionelles Gewicht beigemessen wurde; deren Geschichte ist auch deshalb nicht umfänglich erforscht. Mit einem praxeologisch ausgerichteten Blick können daher möglicherweise, ausgehend von einer Praxis des Studierens, neue Erkenntnisse über die Konventionalisierung von Formen der Wissensvermittlung und auf die damit einhergehenden Professionalisierungsprozesse und Subjektivierungsformen ${ }^{44}$ gewonnen werden, die gleichzeitig ein neues Licht auf Periodisierungsfragen in der Universitätsgeschichte werfen.

\section{Die deutsche Universität im 19. Jahrhundert}

Die Krise der frühneuzeitlichen Universität und ihres veraltenden Gelehrsamkeitsideals, mit der aufklärerischen Kritik daran und der Aufwertung neuer Wissenschaften seit der zweiten Hälfte des 18. Jahrhunderts, fand ihren Ausdruck in einem starken Spannungsverhältnis zwischen neuen, auch staatlich formulierten (Qualifikations-)Erwartungen und dem, was die Universitäten bis dahin an Ausbildung boten. ${ }^{45}$ Nach und nach setzten sich mit den staatlichen Schulreformen und einem entsprechenden Prüfungssystem eine zunehmende Spezialisierung in der universitären Wissensgenerierung und -vermittlung, verschärfte Leistungsanforderungen und schliesslich auch ein entsprechendes Ethos aufseiten der Studenten durch. Veränderte Vorstellungen über die Lehre und das Lernen der Studenten an den Universitäten schienen dem zu entsprechen. ${ }^{46}$ Die neugegründeten deutschen Universitäten, vor allem die Berliner - oft und durchaus problematisch als Vorbild einer modernen forschungsorientierten Universität angesehen ${ }^{47}$ - kamen dem anscheinend entgegen. ${ }^{48}$ Die Universität, wie sie Humboldt vorgeschwebt hatte, sollte sich durch eine enge Verbindung von Forschung und Lehre auszeichnen, in der im »Selbstaktus« der Mensch an der Universität zur »Einsicht in die reine Wissenschaft « gelange. ${ }^{49}$ Der liberalen Idee der Wissenschaftsfreiheit

gehen Wilhelm Ermann und Ewald Horn von ca. 1000 hodegetischen Schriften aus; vgl. Jackstel 1986, S. 41.

Vgl. Paulsen 1902

Vgl. Reh 2017.

Vgl. Hardtwig 1985.

6 Vgl. ebd., S. 156.

47 Vgl. insgesamt Ash 1999; Bruch 1999.

48 Vgl. Hardtwig 1985, S. 175

49 Humboldt 2002, S. 191. 
entsprach die »neuhumanistische Überzeugung vollendeter Selbstbildung durch Wissenschaft «, ${ }^{50}$ die - so wird interpretiert - zu einem Verzicht auf strukturierende Vorgaben für das Studium führte. ${ }^{51}$

Die neuen Universitäten in Deutschland entwickelten tatsächlich erst in der zweiten Hälfte des 19. Jahrhunderts Studienpläne und das Studium an den philosophischen Fakultäten war, wenn überhaupt, dann von den staatlichen Prüfungen her strukturiert..$^{52}$ Nicht nur die materielle Situation an der Berliner Universität war prekär. So mussten etwa die Dozenten noch in den 1820er-Jahren für die Beleuchtung der Hörsäle selber sorgen oder die Veranstaltungen fanden in den Privaträumen der Professoren statt. Auch die Arbeitsbedingungen für Studierende, etwa Möglichkeiten, Bücher zu erhalten, waren miserabel. Hauptveranstaltungsform an der Universität des 19. Jahrhunderts war die Vorlesung, deren äussere Form und Charakter sich im Laufe der Zeit änderten bzw. die ohnehin unterschiedlich je nach Disziplin, der Tatsache, ob und in welcher Weise Lehrbücher vorhanden waren, und je nach Lehrendem verschieden ausgeführt und gestaltet zu sein schienen. Bei dieser Hauptveranstaltung der Universität wurden keinerlei Unterschiede in Bezug auf die Adressaten gemacht. ${ }^{53}$ Ergänzt wurde sie schon früh durch die Einrichtung von Seminaren, in denen Übungen in wissenschaftlicher Arbeit stattfanden. ${ }^{54}$ Hier konnte - folgt man den Beschreibungen, wie sie die Seminarordnungen bieten - das philologische Forschen, das Erklären von Texten und das lehrreiche Sprechen darüber eingeübt werden. ${ }^{55}$ Die "prinzipielle Gleichwertigkeit und damit Gleichrangigkeit der Lernenden und Lehrenden« als solche, die im Sinne des Humboldt'schen Verständnisses für die Wissenschaft da seien, ${ }^{56}$ fand hier ihren Widerhall. Das Lehrformat des Seminars sollte, so Schleiermacher in seinen Bemühungen um die Organisation der Berliner Universität, einen intensiveren Austausch ermöglichen. ${ }^{57}$ An den Universitäten des Kaiserreiches beanspruchten die Vorlesungen nun weniger Zeit im Studienplan, die Zahl der Überblicksvorlesungen nahm ab und die der Spezialvorlesungen zu,

50 Bruch 2001, S. 96.

51 Vgl. Brandt 2001, S. 143. Siehe zum Universitätsmodell auch grundsätzlich Schubring 1991.

52 Tenorth 2012, S. 235-239; für einen etwas engeren Zusammenhang argumentiert Dowe 2007, S. 61; für die Problematik, dass die Fakultäten sich wenig um die staatlich abzunehmenden Prüfungen, etwa für das Lehramt, kümmerten und Fachgebiete der Professoren sich nicht mit Prüfungsfächern deckten, z.B. in der Germanistik vgl. Meves 2011. Vgl. Tenorth 2012, S. 234 u. 243.

54 Vgl. für die Berliner Universität die Beschreibung des neben dem theologischen schon sehr früh von Boeckh gegründeten philologischen Seminars, Seifert 2016. Siehe zur weiteren Entwicklung Brocke 2001.

55 Vgl. Reh/Scholz 2019.

56 Bruch 2001, S. 65.

57 Ebd., S. 72. 
und die Lehrveranstaltungen wurden immer seltener in den Privatwohnungen der Dozenten abgehalten. ${ }^{58}$ Als institutionalisierte Einrichtungen gewannen die Seminare mehr und mehr Bedeutung; sie besassen einen Raum, oftmals einen Bücherbestand, Bibliotheken zur Nutzung für die Mitglieder des Seminars und ein Budget z.B. für die Vergabe von Stipendien. ${ }^{59}$

\section{Die Praxis der Lehrveranstaltungen}

Aufschluss über die Herausforderungen, vor die ein Studium mit den dargestellten Angeboten die Studenten in der ersten Hälfte des 19. Jahrhunderts stellen konnte, geben - wie oben schon erwähnt - die sogenannten hodegetischen Schriften. ${ }^{60}$ In ihnen sind detaillierte Anweisungen gegeben, wie man studieren und lernen solle. Techniken werden aufgeführt, die helfen, schnell, zeitsparend die Menge an Lesestoff zu bewältigen und das Aufgenommene, das Gelesene, zu behalten.

Ein Problem, das sich offensichtlich den Studenten stellte, war es, eine Auswahl von Vorlesungen aus dem Fächerangebot und eine Auswahl aus dem Angebot von zu lesenden Büchern zu treffen. Das lässt sich nicht nur den Ratgebern als Führern durch das Studium entnehmen, sondern auch der Praxis, studierenden Mitgliedern des höheren Adels auch im ersten Drittel des 19. Jahrhunderts noch private Lehrer zur Seite zu stellen, die die jungen Adligen an die Universität begleiteten und für sie Auswahl und Reihenfolge der Vorlesungen bzw. der zu hörenden Professoren bestimmten. Kontrolliert wurde von den privaten Lehrern teilweise auch, dass aus den Notizen, die sich die Zuhörer in den Vorlesungen gemacht hatten, nach Diktaten von Vorlesungen oder aus Abschriften von Büchern der Professoren Aufsätze zu den Themen der Vorlesungen in einer »Präparationsund Repetitionszeit " geschrieben wurden. ${ }^{61}$

Bekannte »Führer« durch das Studium sind etwa die Schriften von Johann Gottfried Kiesewetter (1766-1819), ${ }^{62}$ Friedrich Eduard Beneke (1798-1854), ${ }^{63}$ Karl

58 Vgl. Dowe 2007.

59 Vgl. Erben 1913; Clark 1989; Spoerhase/Dehrmann 2011; Spoerhase 2015.

60 Die erziehungswissenschaftliche und insbesondere die seit dem Ende des 19. Jahrhunderts sich entwickelnde hochschulpädagogische Rezeption unterschied Phasen des hodegetischen Schrifttums. Einem »methodischen Moralismus« (vgl. Rosenbrock 1979; Leitner 1984; Stary 1994) in der Zeit vor und teilweise noch um 1800 bzw. einer »lebenspraktischen akademischen Tatmoral« (Olbertz 1986) folgte eine sneuhumanistisch geprägte Phase, in der Studieren in den Hodegetiken als »schöpferische Tätigkeit« verstanden bzw. ein allgemeinbildendes Studium statt eines Brotstudiums propagiert wurde, bis schliesslich die späten Hodegetiken zu einer Anleitung wurden, das Studium als Ausbildung zu verstehen.

61 Vgl. Bosbach 2010.

62 Kiesewetter 1811.

63 Beneke 1826. 
Hermann Scheidler (1795-1866), ${ }^{64}$ Maximilian Leopold Löwe (1795-1865) ${ }^{65}$ und von Johann Eduard Erdmann (1805-1892). ${ }^{66}$ Kiesewetter beantwortet etwa die Fragen, in welcher Reihenfolge was zu studieren sei, was der Zuhörer vor, während und nach der Vorlesung tun solle, wie man schliesslich aus den Vorlesungen den grösstmöglichen Nutzen ziehen könne und was und wie man selbst lesen solle. Ziel ist die »selbsttätige« Aufnahme, die verarbeitende Aufnahme dessen, was gehört und gelesen wurde, es gehe nicht darum, »blindlings Autoritäten« nachzubeten: ${ }^{67} »$ Das Geschäft des Studierens ist vorzüglich dreifach: Er soll dem mündlichen Lehrvortrag beiwohnen, er soll wissenschaftliche Werke lesen und er soll sich bemühen durch eigenes Denken und Forschen seine gelehrten Erkenntnisse $\mathrm{zu}$ vermehren und zu vervollkommnen. $\aleph^{68}$ Und Kiesewetter betont ferner:

Der Zweck des akademischen Vortrages beschränkt sich nicht etwa blos darauf den Kopf des Zuhörers mit neuen Erkenntnissen zu bereichern, sondern er geht auch vorzüglich dahin die intellektuellen Kräfte desselben zu wecken, damit er selbstthätig zum Fortschritt in der Wissenschaft, und zum Fortschritt der Wissenschaft selbst mitwirke und der wissenschaftliche Geist ihn sowohl fürs Erkennen als für das Leben durchbringe. ${ }^{69}$

Was folgt, liest sich wie Hinweise zu einem >neuhumanistischen Studienplan<, den es in dieser Form seitens der Universitäten nicht gab:

7. Man hüte sich zu viel auf einmal zu studiren, weil man sonst keine Zeit und Kraft behält, das von andern Empfangene gehörig selbstthätig zu verarbeiten; man falle aber auch nicht in den entgegengesetzten Fehler, weil man sonst den Vortrag mancher wesentlichen Disziplinen vielleicht würde entbehren müssen.

8. Die Erfahrung lehrt, daß Wechsel in den Geistesarbeiten die Kräfte des Cemüths stärkt und minder erschöpfend und ermüdend ist, daher ist es zweckmäßig, daß der Studierende so viel es sich thun läßt, mannigfaltige Vorlesungen hören; er wird also Sprachen und Wissenschaften, und von den letzteren wiederum historische, philosophische und mathematische neben einander studiren können. Nur muß er verhüten, daß die Mannigfaltigkeit ihn nicht verwirre. [...] $]^{70}$

\footnotetext{
64 Scheidler 1835.

65 Löwe 1839.

66 Erdmann 1858.

67 Kiesewetter 1811, S. 159.

68 Ebd., S. $33 f$.

69 Ebd., S. 149.

70 Ebd., S. 147-149.
} 
Gewarnt wird vor dem Abschreiben von Büchern; aber auch die Hochschullehrer werden Adressaten von Ermahnungen, man solle möglichst Abstand davon nehmen, die Vorlesungen zu diktieren. Verstand Kiesewetter den professoralen Vortrag noch als eine Ergänzung zur Lehrbuchlektüre, so unterscheidet Erdmann die Vorlesung von einem autoritativen Lehrbuch: Der Professor trete dort als Ratgebender auf. ${ }^{71}$ Dass Studierende sich langweilen und sich angewöhnen, nicht das ganze Buch zu lesen oder nicht der gesamten Vorlesung zu folgen, ${ }^{72}$ ist Erdmann ebenso vertraut wie die "Impertinenz « mancher Dozenten, eine Vorlesung in die Feder zu diktieren - das bevormunde die Studierenden. ${ }^{73}$

Bis zum Ende des Jahrhunderts wurde die Kritik an der Vorlesung immer lauter. Diese fördere Passivität, Stumpfsinn und führe schliesslich zu Schwänzerei. ${ }^{74}$ Unter Juristen wird vor allem stark kritisiert, dass das, was geprüft werde, nicht in den Vorlesungen gelernt werde; das eine habe mit dem anderen nichts zu tun; die Studenten der juristischen Fakultäten organisierten sich daher selbst in studentischen Vereinigungen, in denen Vorlesungsmitschriften und Prüfungsberichte weitergereicht werden. ${ }^{75}$

Friedrich Paulsen fasst die Kritik an der Vorlesung in seinem Überblickswerk Die deutschen Universitäten und das Universitätsstudium zusammen, um sie dann aber doch gegen das Buch als persönliche, im besten Falle anschauliche, lebendige und charismatische Veranstaltung zu verteidigen. Er hatte mit seiner 1902 erschienenen Schrift zwar noch eine Art Führer im Sinne der alten Hodegetiken verfasst, schickte sich dabei jedoch an, die universitären Veranstaltungen im Einzelnen zu kritisieren. ${ }^{76}$ Die Kritik bezog sich vor allem auf den Vortragsstil und die Praxis des »in die Feder-Diktierens «, ${ }^{77}$ was zu Langeweile führe, aber gleichzeitig von den Studierenden nachgefragt sei, wollten diese sich doch ein vollständiges Nachschlagewerk mithilfe ihrer Mitschriften anlegen. ${ }^{78}$ Paulsen konzentriert sich in seinen Betrachtungen stärker auf die Seite des Vortragenden und gibt Empfehlungen zur angemessenen Gestaltung der Vorlesung, die jedem Buch vorzuziehen sei:

Die Vorlesung ist auch hier freier; sie mag, dem Interesse des Lehrers oder der Hörer nachgebend, bei einem Kapitel eingehender verweilen, um dafür über ein anderes, das systematisch nicht minder wichtig ist, schneller hinwegzugehen; sie will

\footnotetext{
71 Erdmann 1858, S. $187 \mathrm{ff}$.

72 Ebd., S. 253.

73 Ebd., S. 263.

74 Vgl. Tenorth 1999.

75 Vgl. Lönnecker 2015, S. 179.

76 VgI. Paulsen 1902, S. IX-XII.

77 Ebd., S. 237.

78 Vgl. ebd., S. $237 f f$.
} 
ja nicht Nachschlagewerke liefern, von dem mit Recht Vollständigkeit und Cleichmässigkeit verlangt wird, sondern zur Auffassung der Dinge anleiten [...]. ${ }^{79}$

Paulsen spricht sich grundsätzlich gegen das Diktieren aus: »Das Diktieren schliesst, wie lebendige Mitteilung, so auch lebendige Auffassung aus; es wird dabei regelmässig auf eine blos mechanische Tätigkeit, ohne innere Spannung auf beiden Seiten hinauslaufen $« .{ }^{80}$

Paulsen reagiert schreibend auf die Krise der deutschen Universität, wie sie sich bereits bei Erdmann angedeutet hat, indem er vorschlägt, das strenge Gefüge der Vorlesung als Verlesen eines Lehrbuches aufzulösen, zeitlich zu konzentrieren und explizit Fragen aus dem Auditorium für zulässig zu erklären. Neben den Lehrvortrag stellt er - der zeitgenössischen Kritik begegnend - die Übungen, die in das wissenschaftliche Arbeiten, also die fachspezifische Wissensgenese, einführen sollen. ${ }^{81}$

Hodegetische Schriften liefern Hinweise auf etwas, was als eine spezifische Problemlage seitens der Universitäten und der Professoren gesehen wurde: Studenten würden an der Universität in eine Situation versetzt, die auf unterschiedlichen Ebenen Anforderungen an »Selbstthätigkeit« stellte; sie mussten sich einerseits auf eine studentisch-akademische Lebensweise einstellen und andererseits ohne Studienplan angesichts eines umfangreicher werdenden Angebotes einen eigenen Weg durch die Universität finden. Vor diesem Hintergrund boten hodegetische Schriften damals Anweisung zur »Aneignung« von Wissen und damit für Bildungshistoriker/-innen heute eine Grundlage zur Rekonstruktion langlebiger, sich aber dennoch in ihrem Nutzen und Gebrauch, ihrer Kontextuierung voneinander unterscheidender professoraler Lehr- und studentischer Lernpraktiken. Sie offenbaren Vorstellungen über Selbsttätigkeit, Verstehen und Lernen, mit denen gleichzeitig alles verdächtig wird, was mechanisch erscheint.

79 Ebd., S. 245.

80 Ebd., S. 257. Auf diese Praxis des Diktierens verweisen gedruckte Vorlesungsdiktate, Hefte, die unter Autorenschaft der Dozenten als »graue« Literatur publiziert und daher nur selten in den Katalogen der Bibliotheken geführt wurden. Daher sind sie bisher von der Forschung meist übersehen worden. In den Vorlesungsverzeichnissen finden sich darüber hinaus Vermerke, dass die Hochschullehrer auch aus gedruckten eigenen oder fremden Lehrbüchern lasen.

81 Vgl. ebd., S. 266ff. u. 368ff. 


\section{Materialität und Praktiken des Studierens am Ende des 19. Jahrhunderts}

Eine stärker von der Materialität der Praxis ausgehende Rekonstruktion der Lehrund Lernpraktiken an Universitäten erlaubt es, über die Hodegetiken hinausgehend einen Blick darauf zu werfen, was möglicherweise in den verschiedenen Veranstaltungsformen geschah und ob und in welcher Weise die Probleme, die vor allem der Vorlesung zugeschrieben wurden, ihren Niederschlag fanden.

In jüngerer Zeit wurden Praktiken des akademischen Lesens, einer Wissensaneignung durch Lesen also, untersucht. ${ }^{82}$ Das geschah, um historische Prozesse der Wissensproduktion in ihrem Wandel seit dem Mittelalter beschreiben zu können. ${ }^{83}$ Das "gelehrte Lesen " konnte - so die damit verbundenen Annahmen - der Verankerung von gelehrtem Wissen im Gedächtnis dienen. ${ }^{84}$ Schreiben wurde insbesondere im Zusammenhang mit dem Lesen als Exzerpieren ${ }^{85}$ oder aber im $\mathrm{Zu}$ sammenhang mit Prozessen des Lesenlernens thematisiert. ${ }^{86}$ Die gelehrten Exzerpiertechniken zielten auf eine enzyklopädische Wissensverbuchung. Die Exzerpte wurden, selbst wenn sie zunächst auf einzelnen Zetteln angefertigt worden waren, in Buchform gebracht und damit fest im Buch- und Gedächtnisraum verankert. ${ }^{87}$

Studierende lasen und exzerpierten tatsächlich nicht nur, sie schrieben auch >mit - und dies genauso selbstverständlich, wie die Lehrenden Vorlesungen hielten. Eine bekannte, aber bislang nicht praxeologisch ausgewertete Quelle bilden Kolleghefte (oder auch Kollegienhefte genannt), die sich in Universitätsbibliotheken oder -archiven finden ${ }^{88}$ und - im weitesten Sinne - seit der Frühen Neuzeit Mitschriften, d.h. Verschriftlichungen der von den Schreibenden gehörten Lehrveranstaltung an der Universität darstellen. Sie sind daher sowohl Speichermedium wissenschaftlicher Inhalte, wie ihr Verfassen aber auch als eine Art von universitärer Wissenspraktik ${ }^{89}$ und das Artefakt des Kollegheftes damit als Dokument universitären Lehrens und Lernens gelten kann. Das konnte dem Einzelnen dann nützlich werden und später als Fundgrube dem `Zitatepicken dienen $^{90}$ jedenfalls handelt es sich bei den Kollegheften um selbstverständliche Elemente

\footnotetext{
82 Mulsow 2007; Stickler 2010.

83 Vgl. Füssel 2015a; Schneider 2005 u. 2008; Steckel 2015; Zedelmaier 2001.

84 Ebd., S. 27.

85 Vgl. Décultot 2017.

86 Vgl. die Beiträge in Reh/Wilde 2016.

87 Vgl. Zedelmaier 2002; siehe dazu auch Gierl 2001.

88 Vgl.z.B. Koolman 1989.

89 Vgl. die Beschreibung und Aufzählung von Wissenspraktiken bei Burke 2014.

90 Wie Zitate aus Kollegheften genutzt wurden, beschreibt Katarzyna Jaśtal am Rande ihrer Ausführungen zu Heines Prosa (2009, Anm. 5, S. 158f.).
} 
des akademischen >Umweltlichen<, wie sie Heidegger im Kontext des "Kathetererlebnisses « in seinen frühen Vorlesungen aufzählt: »Katheder, Buch, Tafel, Kollegheft, Füllfeder, Pedell, Korpsstudent, Straßenbahn, Automobil usf. usf. «11

\section{Kolleghefte als Quellen}

Wenn bisher in historischen Studien Kolleghefte als eine Quelle herangezogen wurden, dann um Aussagen zu einem absolvierten Studienprogramm zu machen. ${ }^{92}$ $\mathrm{Zu}$ wertvollen Quellen werden sie vor allem dann, wenn es Texte bedeutsamer Gelehrter aus solchen Mitschriften zu rekonstruieren gilt. ${ }^{93}$ Hinsichtlich der in ihnen hinterlassenen Schreibspuren und dessen, was man daraus über das Zuhören, das Lernen und Verstehen der Studenten erfahren kann, sind sie bisher trotz ihres seriellen Vorkommens nicht in den Blick genommen worden..$^{94}$ Dies ist vermutlich ihrem vermeintlich nachgeordneten Status geschuldet, wonach Kolleghefte lediglich die durch den akademischen Rahmen autorisierte Lehrmeinung eines Dozenten wiedergeben. Nicht selten werden Ungenauigkeiten und Fehler beklagt, wenn versucht wird, mithilfe von Kollegheften Vorlesungstexte zu rekonstruieren. Dabei wird weder in Betracht gezogen, dass sich der Lehrende schlecht ausgedrückt haben könnte, noch interessiert, wie die Mitschreibenden etwas verstanden haben.

Statt nun Kolleghefte als unzuverlässige Mitschriften zu bewerten, können an diese Quelle, viele Kolleghefte vergleichend und sie in ihrer Materialität betrachtend, auch andere Fragen gestellt werden: Wie hat man sich dieses Niederschreiben vorzustellen und wie sind die beobachteten unterschiedlichen Formen solcher Mitschriften zu erklären? Hodegetiken bieten erste Anhaltspunkte. ${ }^{95}$ Erdmann betont den Zusammenhang zwischen der Form der Mitschriften und dem Vortragsstil des Dozierenden und beschreibt unter anderem nach Erfahrungen mit dem Berliner Lehrbetrieb drei Vorlesungstypen, einen diktierenden und auf Kontrolle bedachten Dozenten, einen schnell sprechenden oder lesenden Dozenten (als einen solchen betrachtet er Schleiermacher) und schliesslich einen nach Worten ringenden Dozenten mit unsortierten Notizen (hier verweist er auf Hegel). Diesen Typen habe er sein Niederschreiben in den Vorlesungen angepasst. Während er beim ersten natürlich mitgeschrieben und sich gelangweilt habe, konnte er beim zweiten versuchen, mit zu stenografieren, und schliesslich war dem dritten nicht

91 Heidegger 1919, S. $72 f$.

92 Vgl. Bosbach 2010; Bresslau 2007; vgl. auch Beispiele wie Semper/Bunand 1860.

93 Etwa Schulze 2008.

94 Siehe zu Textkulturen grundlegend Meier 2015; zu den bislang von der Universitätsgeschichte rezipierten Quellen besonders Rasche 2011. 
leicht $\mathrm{zu}$ folgen, und die Notizen mussten das Gehörte eher paraphrasieren. Letztere Praxis habe den nachhaltigsten Lernerfolg erbracht, schätzt Erdmann ein. ${ }^{96}$

\section{Kolleghefte der Humboldt-Universität zu Berlin - Mitschriften zu Paulsen}

Exemplarisch kann ein Quellenbestand sein, der durch die Handschriftenabteilung der Bibliothek der Humboldt-Universität zu Berlin als digitale Ressource zur Verfügung gestellt wird. Es handelt sich um über 400 online-recherchierbare Kolleghefte überwiegend aus dem 19. Jahrhundert. Die Kolleghefte stammen zum grössten Teil aus Nachlässen ehemaliger Studierender oder aus gezielten Ankäufen der Bibliothek. Bei einer kursorischen Durchsicht der digitalisierten Kolleghefte fallen verschiedene Verschriftlichungsformen auf, darunter sind ausgearbeitete Texte, die man vielleicht als Essays beschreiben könnte, stichpunktartige Mitschriften, mit kurzen Absätzen oder auch nochmals durchgearbeitete Texte mit farbigen Unterstreichungen und Ergänzungen. Auch stenografische Mitschriften und sogar gedruckte Kolleghefte - Lithografien, die die handschriftliche Anmutung drucktechnisch reproduzieren - finden sich im Bestand. ${ }^{97}$

Im Folgenden sollen die Mitschriften zu Vorlesungen von Friedrich Paulsen etwas eingehender betrachtet werden. Paulsen lehrte von 1882 bis 1908 an der Berliner Friedrich-Wilhelms-Universität Philosophie und Pädagogik und gilt als Wegbereiter der historischen Bildungsforschung in Deutschland. ${ }^{98} \mathrm{Zu}$ Paulsen sind in der Autografensammlung der Universitätsbibliothek der Humboldt-Universität zu Berlin fünf Kolleghefte zugänglich, die zwei Studenten mit Bezug auf dessen Lehrangebot abfassten. Von Friedrich Blanck, dessen Studienschwerpunkt die Nationalökonomie war, stammen vier der Mitschriften zu Paulsens Vorlesungen. ${ }^{99}$ Blanck bewahrte seine Studienunterlagen in recht grossem Um-

96 Ebd., S. 263-266.

97 Es gibt Hinweise darauf, dass es eine Art >Markt‘ für diese Schriften gab: So rät schon Kiesewetter 1811: »Viel Zeit wird gewonnen, wenn der Studierende sich vor dem unnützen Schreiben hütet (wohin vorzüglich das Abschreiben von andern nachgeschriebene Collegienhefte gehört)«(S. 259). Wobei für ihn das Mitschreiben in Vorlesungen - er spricht von Nachschreiben« (S. 152) - zwar selbstverständlich ist, aber doch in gewisser Weise erlernt bzw. optimiert werden muss. Der Student müsse sich auf die Vorlesung vorbereiten, um zu wissen, was wichtig ist, und dann Abkürzungen gebrauchen, um dem Vortrag folgen zu können. Für Kiesewetter ist es überdies ganz normal, dass der Dozent stellenweise diktieren müsse.

Siehe zu Stellung und Wirken Paulsens an der Berliner Universität Horn 2002; Steensen 2010; Tenorth 2010; 2004; Drewek 2002; Kellmann 2010.

Wie sich den Studentenverzeichnissen der Universität entnehmen lässt; 1910 publizierte ein Friedrich Blanck das Buch Der deutsche Nachrichtenmarkt und reichte es als Dissertationsschrift an der Universität Heidelberg ein. Auf der Katalogkarte der Bayerischen Staatsbibliothek München zu diesem Buch finden sich ausserdem folgende Angaben zum Autor: »Ceb. 26. April 55 Pleetz; Wohnort: Heidelberg; Staatsangeh. Mecklenburg-Strehlitz; Vorbildung: Gymn. 
fang auf und liess sie teilweise binden, wodurch er sie auch in das Gefüge einer häuslichen Bibliothek eingliedern konnte. ${ }^{100}$

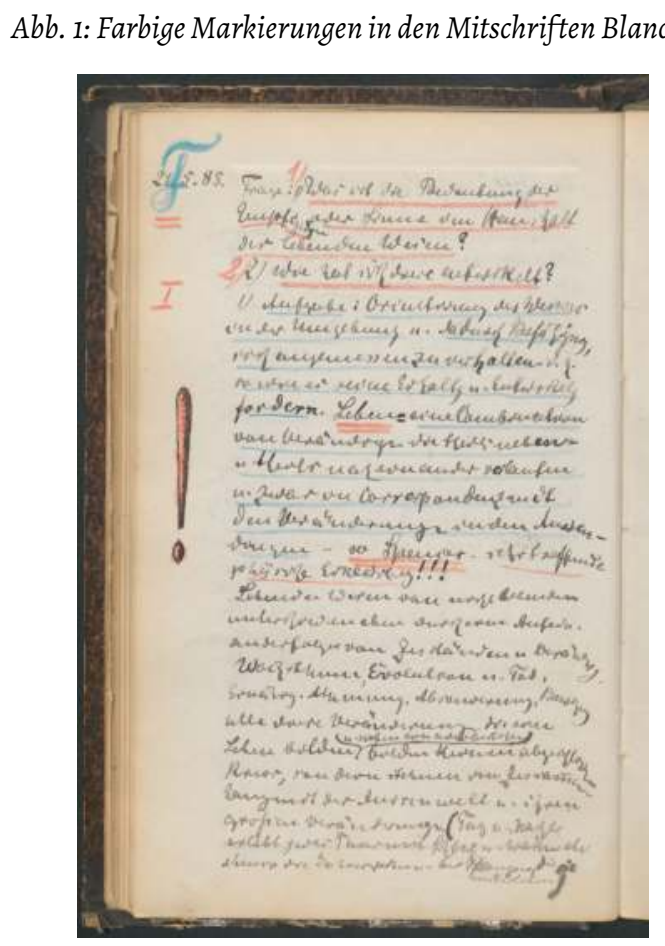

Neubrandenburg Reife M. 76; Studium: Berlin 12S., Rig. 28. Febr. 08." Da auch im Verzeichnis der Berliner Universität »Mecklenburg-Strelitz« angegeben ist und auch das Berliner Studium verzeichnet ist, kann davon ausgegangen werden, dass es sich um denselben Friedrich Blanck handelt. Blanck war später in Heidelberg als Journalist tätig und engagierte sich ab 1911 in der Internationalen Vereinigung für vergleichende Rechtswissenschaft und Volkswirtschaftslehre in Berlin. Blanck korrespondierte mit Max Weber, weil er in eine Auseinandersetzung zwischen dessen Frau, Marianne Weber, und Arnold Ruge involviert war, vgl. Briefe 13., 14. u. 17. Dez. 1910, Heidelberg; siehe Weber 1994. Insgesamt digitalisierte die Universitätsbibliothek bislang 39 Hefte von Blanck.

Die Akzessionsnummer D. 1939. 629, die von Bibliotheksmitarbeiter/-innen in sämtlichen Kollegheften Blancks mit Bleistift eingetragen wurde, verweist darauf, dass der Bestand 1939 der Bibliothek geschenkt wurde ( $\mathrm{D}=$ Dona). Im Akzessionsjournal der Universitätsbibliothek für 1939 findet sich im Band Dona/Tausch auf Seite 36: [32] der entsprechende Eintrag: »Kolleghefte von Dr. Fr. Blanck über Vorlesungen der Professoren Paulsen, Pernice, Zeller, Schmoller [u.a.] aus den 8oziger Jahren. $13 \mathrm{H}$. geb., $27 \mathrm{H}$. ungeb.« Als Lieferant ist in die Tabelle des Journals »Frau A. Blanck Heidelberg« eingetragen. 
Blanck schrieb zu folgenden Vorlesungen Paulsens Kolleghefte: 1. „Geschichte der modernen Philosophie«, 2. »Einleitung in die Philosophie«, 3. »Ethik mit Einschluss der Grundlinien der Staats- und Gesellschaftslehre [Wintersemester 1884/85] «, 4. »Prof. Friedrich Paulsen's Vorlesungen über Psychologie \& Anthropologie ${ }^{102}$ (Abb. 1). Während die ersten drei Mitschriften durch ein flüchtig wirkendes Schriftbild mit relativ starker Schräglage der Schrift und unregelmässigem Tintenfluss ein schnelles Mitschreiben erahnen lassen, wirkt das vierte Heft sorgfältiger und unter entspannten Umständen geschrieben. In allen Heften verweisen Datumsangaben auf einzelne Vorlesungseinheiten. Die Unterstreichungen markieren entweder in gleicher Tinte Hervorhebungen, die offensichtlich zeitgleich während der Aufzeichnung von Relevanz waren oder, wenn sie mit farbigen Stiften - Blanck präferierte Rot und Blau - vorgenommen wurden, sind sie vermutlich Spuren eines nachträglichen Durcharbeitens und könnten Element einer Memoriertechnik sein. Blanck kommentiert das Aufgezeichnete durch Ausrufe- oder Fragezeichen, die er an den Textrand setzte, oder er notiert Stichworte, die beispielsweise auf andere Autoren verweisen, ${ }^{103}$ aber auch seinen Zweifeln tat er auf diese Weise in Grossbuchstaben kund. Er nimmt also zum professoral legitimierten Wissen eine eigene Position ein. Offensichtlich trug Blanck auch Textpassagen mithilfe der Kolleghefte seiner Kommilitonen nach, was einerseits auf Fehlzeiten und andererseits auf den Austausch der Hefte unter Kommilitonen schliessen lässt. ${ }^{104}$ In seltsamem Verhältnis zum Geschriebenen stehen kleine Feder- oder Bleistiftskizzen wie die von einem Soldaten neben der Niederschrift zu Paulsens Ausführungen über die Mnemotechnik. ${ }^{105}$ In diesen Zeichnungen schimmern andere Kontexte auf, seine Assoziationen oder auch der Blick aus dem Vorlesungssaal.

Im Gegensatz zu den Aufzeichnungen Blancks ist das Kollegheft, das Carl Rengel zu Paulsens »Paedagogik« 1883 schrieb, in akribischer Reinschrift verfasst. ${ }^{106}$ In regelmässiger Handschrift und mit nur seltenen Korrekturen erinnert das Heft an die in Kanzleien verfassten Schriftstücke, in denen die Entwürfe -

102 Diese Mitschriften Blancks wurden durch die Bibliothek der Humboldt-Universität zu Berlin digitalisiert. Die Digitalisate sind über die Homepage der Bibliothek zugänglich. Die Signaturen der einzelnen Hefte sind im Literaturverzeichnis unter ungedruckte Quellen aufgeführt.

103 Vgl. Blanck, Psychologie und Anthropologie, S. 37.

104 Er vermerkt dann unter dem Datum »nachtragen«, Blanck, Psychologie und Anthropologie, S. 53, oder »Nachgetragen nach den Heften von ...", ebd., S. 127.

105 Blanck, Psychologie und Anthropologie, S. 123.

106 Das Digitalisat ist über die Homepage der Bibliothek der Humboldt-Universität zu Berlin zugänglich, der Nachweis findet sich hier unter ungedruckte Quellen. 
hier etwa die Notizen aus der Vorlesung - nochmals sprachlich überarbeitet und dann in Geltung beanspruchender Form schriftlich fixiert wurden. ${ }^{107}$

\section{Zum Verhältnis von Vorlesung und Mitschrift}

Den genannten Vorlesungstiteln lassen sich folgende Werke Paulsens zuordnen: »System der Ethik. Mit einem Umriss der Staats- und Gesellschaftslehre «, ${ }^{108}$ »Einleitung in die Philosophie $\ll^{109}$ und ${ }^{P a ̈ d a g o g i k} «^{110}$ - darüber hinaus finden sich Aspekte der Vorlesung "Psychologie und Anthropologie« in Kapiteln des Pädagogik-Bandes. Die postum erschienene »Pädagogik« ist deshalb bemerkenswert, weil der Herausgeber Willy Kabitz im Auftrag von Paulsens Witwe den Text aus nachgelassenen Notizen Paulsens und im Abgleich mit Kollegheften zweier ehemaliger Studenten rekonstruierte - und im Vorwort beklagte, es fänden sich Ungenauigkeiten in den Mitschriften.

Abb. 2: Mappe aus dem Nachlass Paulsen mit seinen Arbeitsnotizen ${ }^{111}$

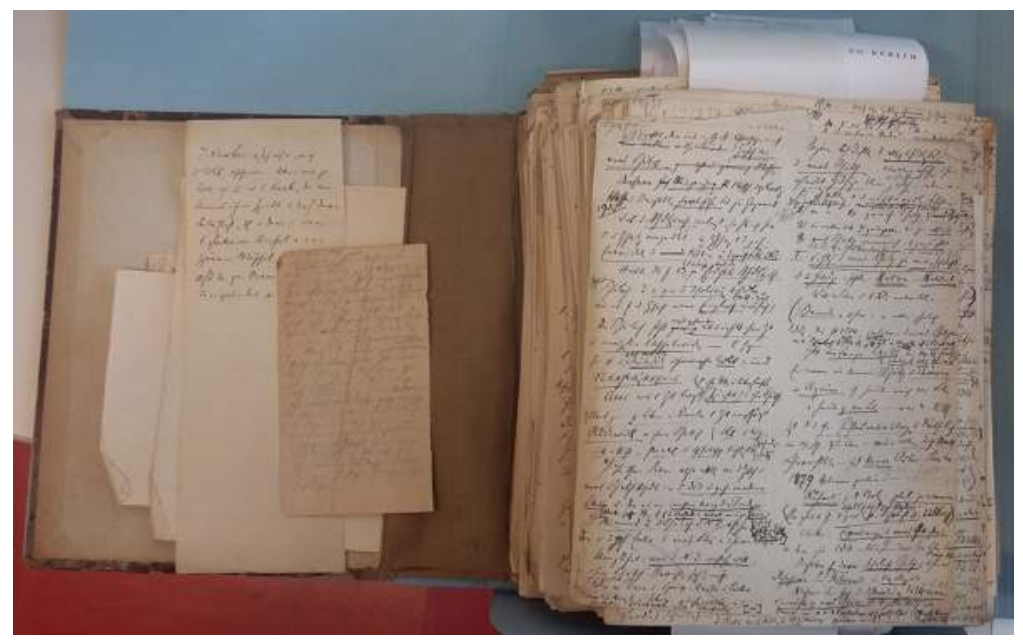

107 Von Carl Rengel sind ausserdem eine physikalische und vier mathematische Mitschriften erhalten. Sein weiterer Lebensweg sollte ihn als Mathematiklehrer in den höheren Berliner Schuldienst führen, vgl. Bieler 2007, S. 89, Anm. 74. Von einem Oberlehrer aus Potsdam namens Karl Rengel wurde im März 1896 an der Berliner Universität die Dissertation mit dem Titel Der Einfluss der auswärtigen Politik aufdie Kriegführung Friedrichs des Grossen im siebenjährigen Kriege, vornehmlich in den Jahren 1758-1763 eingereicht.

108 Paulsen 1889.

109 Ebd. 1892.

110 Ebd. 1911.

111 Universitätsarchiv der Humboldt-Universität zu Berlin, Karton: NL Paulsen, Mskr. 2b. 
Die im Nachlass Paulsen überlieferten Konzepte und Notizen, die mehrfach beund überarbeitet wurden, zeugen davon, wie Paulsen seine Rede im Sprechen hervorbrachte und sich dabei auf vorher gemachte Notizen bezog, die er ergänzte und teilweise strich und die im Nachhinein kaum als fortlaufender Text $\mathrm{zu}$ entschlüsseln sind schrieb (Abb. 2). ${ }^{112}$ Eine Vorlesung wird gehalten - dabei sind selbstverständlich Änderungen der zuvor getroffenen sprachlichen und inhaltlichen Entscheidungen möglich, ja sogar notwendig, der Vortragende muss modifizieren, ausformulieren, kürzen, erklären. Paulsen wusste, dass sich diese Anpassungen des Skripts im Redeakt in Wechselwirkung mit dem Auditorium vollziehen und schrieb $\mathrm{zu}$ dieser gemeinsamen und aufeinander abgestimmten Produktivität: »Was dem Lehrer und Hörer die Freude an der Sache giebt, das ist, dass sie die Wissenschaft im Lauf der Vorlesung gleichsam mit einander aufbauen. ${ }^{113}$

Vortrag ist Performanz und Interaktion mit dem Auditorium und gerade dann, wenn Paulsen seine Vorlesungen mitunter in kleinem oder gar privatem Kreis hielt, konnte er auf seine Zuhörer und Gäste eingehen und zugleich seine Gedanken >laufen lassen<. So konnte es genügen, sich vorab nur Umrisse zu skizzieren, die im Redefluss gefüllt wurden. Ist nun das Vortragen eine einen Text im Sprechen konstruierende Praktik, so das Mitschreiben der Studierenden eine weitere Konstruktion zwischen dem Hören eines vorgetragenen Textes und dem Schreiben. Das Schreiben kann ein Mitschreiben sein oder ein Nachschreiben, was auf den ersten Blick schon durch das sorgsame und flüchtige Schriftbild (unsauber, keine geraden Zeilen, unterschiedliche Schriftneigung) unterscheidbar ist. Ob es sich um Mitschriften oder Nachschriften handelt, ist oft auch anhand der Datumsangaben erkennbar. Mitschreiben ist, wie Erdmann schon ausführte, auch unterschiedlich im jeweiligen Anspruch, das Gehörte zu erfassen. Aufgrund der unterschiedlichen Zeitspannen, die Sprechen und das Aufschreiben des Gesagten mit der Feder beanspruchen, zeichnen sich Mitschriften, die sich unmittelbar in der Situation des Zuhörens vollziehen, in der Regel durch Verkürzungen aus - Wortabkürzungen (teilweise wird stenografiert), Stichworte, Paraphrasen. Anders war es, wenn der Dozierende ins Heft diktierte: Dann wurden ganze Merksätze festgehalten. Nachschriften sind >Verarbeitungen Ebene - hier wird im Nachhinein das Verstandene und Verarbeitete festgehalten. Sie sind deshalb häufig als sorgfältig ausgearbeitete Essays überliefert, die sich auf Teilaspekte der Vorlesung konzentrieren. Der Inhalt eines Kollegheftes wird demnach von mehreren Akteuren gestaltet, in diesem Sinne ist das nun schriftlich Fixierte etwas anderes als das vormals als Vorlesungsmanuskript Entworfene.

112 Vgl. das Vorwort des Herausgebers Willy Kabitz, S. IV, zu Paulsen 1911.

113 Paulsen 1902, S. 258. 
Abb. 3: An dieser Stelle bezweifelt der Student die Aussage seines Professors ${ }^{114}$

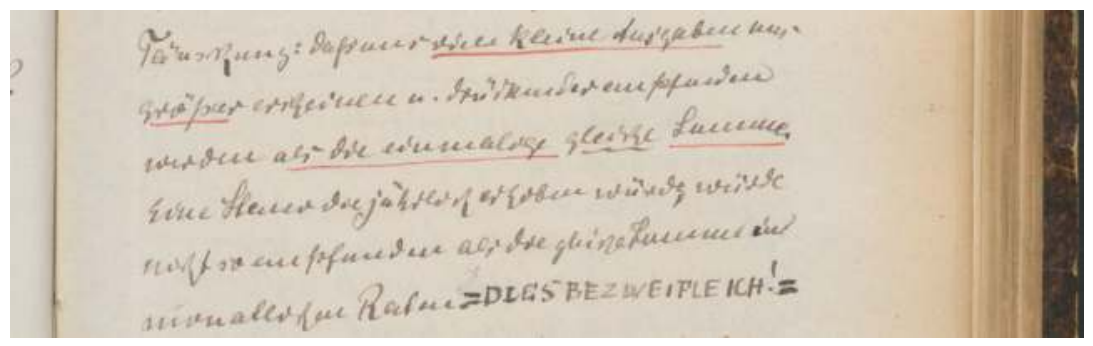

Die Kolleghefte sind - je nachdem, ob sie Mit- oder Nachschriften enthalten - in unterschiedlichem Grad mit mündlich Doziertem verbunden. Differenzen in den Nachschriften - wie sie auch Kabitz für die Vorlesungen Paulsens rekonstruiert und als defizitär interpretiert hat - können auf mangelndem Verständnis oder unterlassener Mitteilung beruhen, man könnte sie jedoch auch als Spuren des von Paulsen angesprochenen >lebendigen Auffassen[s]< begreifen. Mehr oder weniger prägnant sind nachträgliche Bearbeitungen wie eigenhändige Korrekturen (bei Verwendung von Bleistift, unterschiedlicher Status im Vergleich zur Mitschrift in Tinte). Persönliche Kommentare werden zumeist eher subtil, aber mitunter auch sehr explizit eingefügt wie hier bei Blanck (siehe Abb. 3). Die Mitschreibenden markierten die Differenz zwischen dem unmittelbar Notierten und dem dazu Selbstgedachten durch den Gebrauch unterschiedlicher Stifte, verschiedener Schriftstile oder schlicht durch die Platzierung der Anmerkungen etwa am äusseren Rand der Seite. Blanck notierte an einer Stelle in Druckbuchstaben »DIES BEZWEIFLE ICH! «115 (siehe Abb. 3) und distanziert sich damit von der gerade erst festgehaltenen Lehrmeinung. Dass Blanck seine Mitschriften durcharbeitete, lässt darauf schliessen, dass er sie im Rahmen von Memorierpraktiken nutzte, er das Wissen also beispielsweise in einer Prüfung wiedergeben zu müssen meinte. Das Binden der Hefte als präsentable Teile seiner Bibliothek (mit auf dem Buchrücken geprägten Titel) verhalf dem verzeichneten Wissensbestand ausserdem zumindest in seinem privaten Rahmen - zu einer gewissen Dauer.

\section{$4 \quad$ Fazit und Ausblick}

Was hat der Blick auf die Kolleghefte und ihre Materialität an Erkenntnissen über deutsche Universitäten am Ende des 19. Jahrhunderts und die damalige Praxis der Lehre zeigen können? Welche weiteren Fragen können, ausgehend von den an

114 (c) UB der HU zu Berlin, Historische Sammlungen: Hdschr. Koll.290, S. 177.

115 Blanck, Ethik, S. 177. 
diesen Fällen nur beispielhaft gewonnenen Befunden, gestellt werden und welche Schlüsse für eine Universitäts- als Bildungsgeschichte lassen sich daraus möglicherweise ziehen?

Mit der Untersuchung der Kolleghefte als Artefakte einer universitären Praxis und vor allem der studentischen Praxis des Mitschreibens ist der produktive Aspekt von Vorlesungen in das Blickfeld geraten. Das erweist Studierende als Akteure des Wissenschaftsbetriebes. Einen Gewinn an Komplexität bedeutet die Wahrnehmung der Kolleghefte in ihrer Materialität. In den erhaltenen Heften Blancks zeigen sich Spuren seiner Auseinandersetzung mit dem Gehörten in mehreren Hinsichten: Er unterstreicht und ergänzt, seine Textarbeit vollzieht sich also in mehreren Etappen (a). Er notiert Literaturverweise und stellt paratextuelle und intertextuelle Bezüge her (b). Er fügt Zeichnungen ein und verweist so auf andere, eigene Erfahrungshorizonte, mit denen das dargebotene Wissen rangereichert wird (c, vgl. Abb. 4). Er bezweifelt und kommentiert, was er gehört hat, und positioniert sich damit zu einem Wissen, das vermittelt wurde (d). Gerade der Fall Blanck zeigt auf, dass Studierende sich nicht immer und nicht alle schlicht als blosse Empfänger wissenschaftlichen Wissens verstanden, sondern dieses zu relationieren wussten. Die Mitschriften sind individuelle Verarbeitungen eines Gehörten; sie stellen eine bestimmte Form der Aneignung von Wissensbeständen dar. Schreiben wird als heuristische Praxis fassbar, mit der das relevante Wissen eines Faches aufgenommen wird. Indem Studierende mitschrieben, legten sie sich eigene Wissensspeicher an.

In diesem Sinne bestätigen die nachträglichen Beobachtungen der Arbeitsspuren, die die zuhörenden Studenten am Ende des 19. Jahrhunderts in Ausübung der Praktik des Mitschreibens hinterlassen haben, Paulsens Rettung der Vorlesung: Vorlesungen müssen keinesfalls nur einer Art mechanischer Mitschrift dienen; sie stellen nicht per se nur eine rezeptive, gar passiv aufnehmende und so als gering einzuschätzende Leistung dar. Sie erweisen damit zwar keinesfalls die Kritik an der Vorlesung, wie sie gegen Ende des 19. Jahrhunderts geäussert wurde, als falsch, aber sie relativieren doch deren allgemeine Gültigkeit. Zudem könnten sie auch als Ausdruck eines wirksam werdenden kulturellen Musters gelten, einer Universitätskritik, die sich selbst gegen Ende des 19. Jahrhunderts nun als pädagogisch zu verstehen gibt und dabei alles mit dem Verdacht der Unwirksamkeit belegt, was nicht in einem engen Sinne als selbsttätiges und an Forschung ausgerichtetes Lernen aufgefasst werden, was nicht einem tieferen Verstehen dienen konnte.

Betrachtet man die Mitschriften zu Paulsens Vorlesungen im Kontext des grösseren Bestandes an Kollegheften in der Bibliothek der Humboldt-Universität zu Berlin und vergleicht diese miteinander, erweisen sie sich aber nicht nur als Zeugnisse individueller Wissensaneignung. Die systematische Auswertung von 
Abb. 4: Hin und wieder fügt Blanck Zeichnungen in seine Mitschriften ein ${ }^{116}$

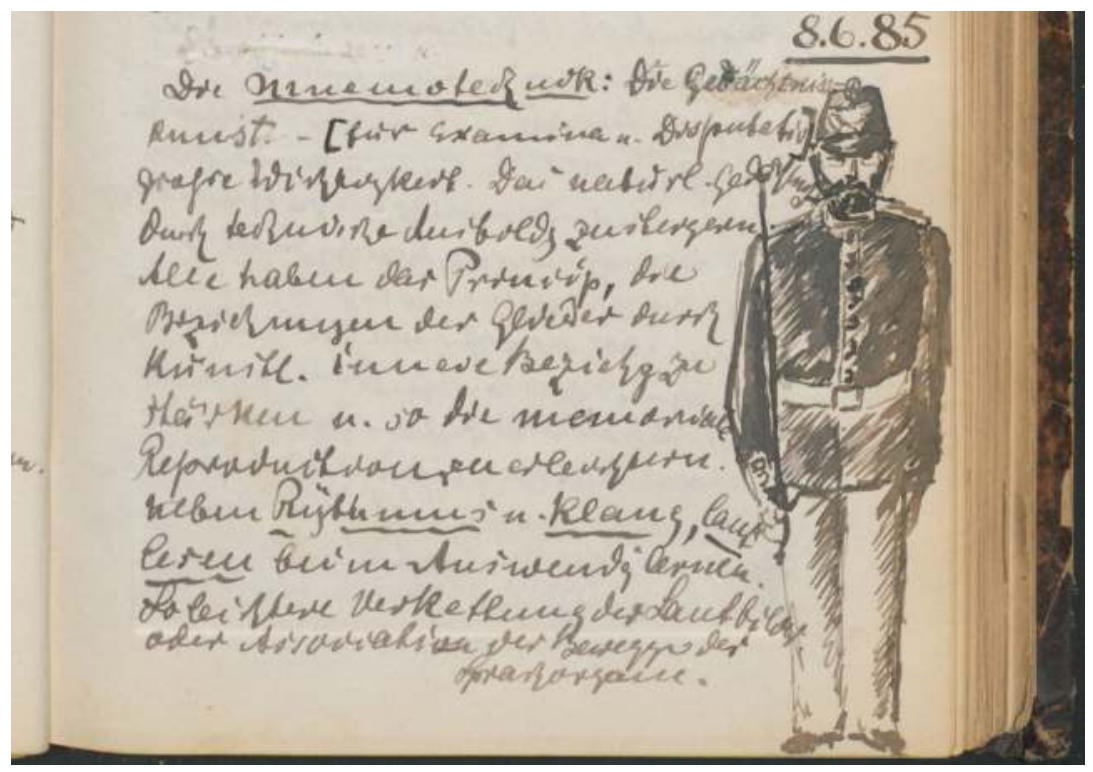

Kollegheften in diesem Sinne als eine Art serieller Quelle kann Hinweise auf übliche, typische oder aber auch variierende Rezeptionspraktiken geben. Hier wäre $\mathrm{zu}$ fragen, ob die Form der Niederschrift und die jeweilige Schreibsituation systematisch korrelieren, ob etwa ein schneller oder unsystematischer Vortragstil bei einer Mitschrift vorherrschte oder ob die häusliche Ruhe einer Nachschrift oder das Vorhandensein eines Lehrbuchs zur Orientierung die Handschrift und die Art der Niederschrift veränderten - und ob vielleicht für bestimmte Zeiten eher das eine oder andere zu beobachten ist. Auch die Möglichkeit zu Rückfragen veränderte möglicherweise die Form der Niederschrift. Die serielle Auswertung liesse nicht nur Aussagen zu üblichen Schreibgeräten, sondern auch zur Entwicklung spezifischer Markierungspraktiken zu, z.B. inwiefern Unterstreichungen (verschiedene Farben und Stifte, Markierungen am Rand wie Striche, Kreuzchen, aber auch Frage- und Ausrufezeichen) oder Schriftbilder (Schreibstile, Schreiben im vorgeprägten Satzspiegel, halbbrüchige Schreibweise) fachspezifisch oder individuell sind und welchen Wandlungsprozessen sie unterliegen. Darüber hinaus liessen sie sich möglicherweise als Hinweise auf Vorläufigkeit oder auf Hierarchieverhältnisse (z.B. ranghöherer Korrektor) interpretieren. Untersucht werden könnte, ob diese Markierungen und Textbearbeitungen im Rahmen von Memoriertechniken auch über Studienzeiten hinaus Geltung hatten. 
Im Sinne disziplingeschichtlicher Fragestellungen kann nach fachlichen Praktiken gefragt werden. Identitäten einzelner Fachdisziplinen konstituieren sich im Vollzug spezifischer Praktiken. ${ }^{117}$ Im Hinblick darauf kann analysiert werden, wie Literaturverweise in Mitschriften eingefügt wurden, was also überhaupt und in welcher Weise zitiert und wie mit Fachtermini und Abkürzungen umgegangen wurde. Auch Konventionen zum Wechsel von Hand- und Druckschrift - etwa in der Beschriftung von Herbarbelegen - können so historisch verortet werden. Von Interesse im Hinblick auf die Geschichte der Disziplinen und des disziplinären Wissens ist es auch, die Ordnung und die Untergliederung von Sinneinheiten zu Vermittlungsinhalten in den Mitschriften und deren nachträglichen Bearbeitungen zu identifizieren: Wurden etwa eine Datumsgliederung angewandt, Kapiteleinteilungen vorgenommen, ein Index oder ein Inhaltsverzeichnis (mit Seitenangaben für das Heft) angelegt oder Schlagworte in den Marginalien oder in der Kopfzeile (Kolumnentitel) angeführt?

Darüber hinaus kann von unterschiedlichen Rezeptionspraktiken des weitergegebenen Wissens - das Mitschreiben in Vorlesungen ist als eine Rezeptionspraktik zu verstehen - in verschiedenen Gruppen ausgegangen werden, die sich durch je spezifische Rezeptionskulturen auszeichneten und so eine Art von Rezeptionsidentität, die Identität einer Fachdisziplin, einer Fachcommunity, ausbildeten. ${ }^{118}$ So sahen die Ergänzungen oder Korrekturen in mathematischen Kollegheften anders aus als die in der Altertumskunde. Die in dieser Form ausgebildeten Gruppenidentitäten konnten sich dann wiederum ändern, indem sich die Gruppen in ihrer Zusammensetzung änderten und einzelne Mitglieder unterschiedlichen Gruppen zugleich und zu unterschiedlichen Zeiten angehörten.

Mit Blick auf den Bestand an der Bibliothek der Humboldt-Universität zu Berlin ist auszumachen, dass sich die Aufzeichnungspraktiken der Studierenden nicht nur je unterschiedlich für ein Fach ausbildeten, sie wandelten sich über bestimmte Zeiträume: Einerseits sind für das 20. Jahrhundert weniger Hefte überliefert - was mit der wechselvollen Zeitgeschichte in Zusammenhang stehen könnte, aber auch mit der geringeren Halbwertszeit des Wissens - und andererseits haben die vorhandenen eine individualisierte Anmutung. Sowohl die Beschreibstoffe (in Format, Liniatur etc.) als auch die Formen der Aufzeichnungen im Laufe des 20. Jahrhunderts wirken bei kursorischer Durchsicht heterogener. Man hat den Eindruck einer stärkeren Unmittelbarkeit, die Mitschriften wirken flüchtiger und weniger auf eine dauerhafte Speicherung ausgerichtet. Versteht man die >Reinschrift als eine wertvolle Lernpraktik, so könnte man aufgrund des Bestandes von Kollegheften in der Bibliothek der Humboldt-Universität annehmen, dass sie in der Universität jedenfalls an Bedeutung verliert.

117 Vgl. Daston 2000.

$118 \mathrm{Vgl}$. Bach/Breidtbach/Wiesenfeld 2005. 
Auch in der Bildungsgeschichte führt - so sei abschliessend festgehalten eine praxeologische Perspektivierung und eine Beobachtung materieller Spuren vergangenen Lehrens und des Lernens zu einer `Epistemologisierung und gleichzeitig zu einer >Historisierung` der Gegenstände und Konzeptionen des Beforschten. Ein reflektiertes Vorgehen, in dem kaum ein Begriff oder ein Phänomen der Frage nach ihrer jeweiligen Geschichte und kaum eine Beobachtung der Frage danach, was denn die problematischen erkenntnistheoretischen Grundlagen dieser sind, entgehen, entspricht einer praxeologischen Perspektive auf die Bildungsgeschichte - aber sicherlich nicht nur dieser.

\section{Quellen und Literatur}

\section{Ungedruckte Quellen}

\section{Archiv der Humboldt-Universität zu Berlin}

[Anonym:] Paulsen. Geschichte der neueren Philosophie. vermutl. nach $1887 \mathrm{wg}$. entsprechendem Literaturvermerk. Nachlass Paulsen.

[Anonym:] Psychologie und Anthropologie von Prof. Paulsen, vermutl. 1885. Nachlass Paulsen.

\section{Handschriften Abteilung der Bibliothek der Humboldt-Universität zu Berlin}

Blanck, Friedrich: [Paulsen] Einleitung in die Philosophie. Wintersemester 1883/84. (Hdschr. Koll. 250).

Blanck, Friedrich: [Paulsen] Ethik. Mit Einschluss der Grundlinien der Staatsund Gesellschaftslehre. Wintersemester 1884/85. (Hdschr. Koll. 291).

Blanck, Friedrich: [Paulsen] Geschichte der modernen Philosophie. Sommersemester 1883. (Hdschr. Koll. 249).

Blanck, Friedrich: Prof. Friedrich Paulsen's Vorlesungen über Psychologie und Anthropologie. Sommersemester 1885. (Hdschr. Koll. 290).

Rengel, Carl : [Paulsen] Paedagogik. Wintersemester 1882/83. (Hdschr. Koll. 257).

\section{ETH-Bibliothek}

Semper, Gottfried/Bunand, Eugène (1860): Styllehre. Kollegnachschrift. Hochschularchiv, Hs 64 [I A].

\section{Universitätsbibliothek der Humboldt-Universität zu Berlin}

Historische Sammlungen: Hdschr. Koll.290. 


\section{Gedruckte Ouellen}

Beneke, Friedrich Eduard (1826): Allgemeine Einleitung in das akademische Studium. Allen wahren Jüngern der Wissenschaft gewidmet. Göttingen.

Erdmann, Johann Eduard (1858): Vorlesungen über akademisches Leben und Studium. Hannover.

Humboldt, Wilhelm von (2002): Der Königsberger und der Litauische Schulplan [1809]. In: Andreas Flitner/Klaus Giel (Hg.): Wilhelm von Humboldt. Werke in fünf Bänden. Band IV. Schriften zur Politik und zum Bildungswesen. 6. Aufl. Darmstadt, S. 168-195.

Kiesewetter, Johann Gottfried Karl Christian (1811): Lehrbuch der Hodegetik oder Kurze Anweisung zum Studiren. Berlin.

Löwe, Maximilian Leopold (1839): Grundriß der allgemeinen Hodegetik. Als Leitfaden bei dem Beginn der akademischen Studien und bei allgemeinen hodegetisch-methodologisch-encyclopädischen Vorträgen. Dresden.

Paulsen, Friedrich (1889): System der Ethik. Mit einem Umriß der Staats- und Gesellschaftslehre. Berlin.

Paulsen, Friedrich (1892): Einleitung in die Philosophie. Berlin.

Paulsen, Friedrich (1902): Die deutschen Universitäten und das Universitätsstudium. Berlin.

Paulsen, Friedrich (1911): Pädagogik. Stuttgart.

Scheidler, Karl Hermann (1835): Deducirter Plan zu Vorträgen über die Hodegetik und zu einem damit zu verbindenden hodegetischen Leseverein. Jena.

\section{Literatur}

Alkemeyer, Thomas (2013): Subjektivierung in sozialen Praktiken. Umrisse einer praxeologischen Analytik. In: Thomas Alkemeyer/Gunilla Budde/Dagmar Freist (Hg.): Selbst-Bildungen. Soziale und kulturelle Praktiken der Subjektivierung. Bielefeld, S. 33-68.

Asbrand, Barbara/Martens, Matthias/Petersen, Dorthe (2013): Die Rolle der Dinge in schulischen Lehr-Lernprozessen. In: Zeitschrift für Erziehungswissenschaft 16, S. 171-188.

Ash, Mitchell G. (Hg.) (1999): Mythos Humboldt. Vergangenheit und Zukunft der deutschen Universitäten. Wien.

Bach, Thomas/Breidbach, Olaf/Wiesenfeldt, Gerhard (2005): Rezeptionsidentitäten und Rezeptionsschichtungen: Methodische Zugänge zur Wissenschaftskultur um 1800. In: Jahrbuch für europäische Wissenschaftskultur 1, S. 131f.

Bach, Thomas/Maatsch, Jonas/Rasche, Ulrich (2008): >Gelehrte<Wissenschaft. Das Vorlesungsprogramm der Universität Jena um 1800. Stuttgart. 
Bachmann-Medick, Doris (2013): Art. »Turn(s)«. In: Ute Frietsch/Jörg Rogge (Hg.): Über die Praxis des kulturwissenschaftlichen Arbeitens. Ein Handwörterbuch. Bielefeld, S. 399-404.

Berdelmann, Kathrin/Fritzsche, Bettina/Rabenstein, Kerstin/Scholz, Joachim (2018): Praxeologie in der Bildungsforschung. Ein Umriss historischer und gegenwartsbezogener Forschungsperspektiven. In: Diess. (Hg.): Transformationen von Schule, Unterricht und Profession. Erträge praxistheoretischer Forschung. Wiesbaden, S. 1-28.

Bieler, Katharina (2007): Im preußischen Schuldienst. Arbeitsverhältnisse und Berufsbiographien von Lehrerinnen und Lehrern in Berlin-Schöneberg 18711933. Köln.

Biernacki, Richard (1999): Method and metaphor after the new cultural history. In: Victoria E. Bonnell/Lynn Hunt (Hg.): Beyond the cultural turn. New directions in the study of society and culture. Berkeley, Los Angeles, S. 62-92.

Biernacki, Richard (2005): Language and the shift from signs to practices in cultural inquiry. In: Gabrielle M. Spiegel (Hg.): Practicing history. New directions in historical writing after the linguistic turn. Rewriting Histories. New York, London, S. 228-244.

Bloch, Marc (2002): Apologie der Geschichtswissenschaft oder der Beruf des Historikers. Stuttgart.

Bosbach, Franz (2010): Die Studien des Prinzen Albert an der Universität Bonn (1837-1838). Prinz-Albert-Forschungen. Berlin, New York.

Bourdieu, Pierre (1979): Entwurf einer Theorie der Praxis auf der ethnologischen Grundlage der kabylischen Gesellschaft. Frankfurt a.M.

Brandt, Harm-Hinrich (2001): Studierende im Humboldt'schen Modell des 19. Jahrhunderts. In: Rainer Christoph Schwinges (Hg.): Humboldt International. Der Export des deutschen Universitätsmodells im 19. und 20. Jahrhundert. Basel, S. 131-150.

Bresslau, Harry (2007): Berliner Kolleghefte 1866/67 - 1869. Nachschriften zu Vorlesungen von Mommsen, Jaffé, Köpke, Ranke, Droysen. Marburg.

Brocke, Bernhard vom (2001): Die Entstehung der deutschen Forschungsuniversität, ihre Blüte und Kriese um 1900. In: Rainer Christoph Schwinges (Hg.): Humboldt International. Der Export des deutschen Universitätsmodells im 19. und 20. Jahrhundert. Basel, S. 367-401.

Bruch, Rüdiger vom (1999): Langsamer Abschied von Humboldt? Etappen deutscher Universitätsgeschichte 1810-1945. In: Mitchell G. Ash (Hg.): Mythos Humboldt. Vergangenheit und Zukunft der deutschen Universitäten. Wien, S. 29-57.

Bruch, Rüdiger vom (2001): Die Gründung der Berliner Universität. In: Rainer Christoph Schwinges (Hg.): Humboldt International. Der Export des deutschen Universitätsmodells im 19. und 20. Jahrhundert. Basel, S. 53-73. 
Burke, Peter (2014): Die Explosion des Wissens. Von der Encyclopédie bis Wikipedia. Berlin.

Caruso, Marcelo/Reh, Sabine (2020): Unterricht. In: Marcelo Caruso/Carola Groppe/Klaus-Peter Horn/Gerhard Kluchert/Ulrike Mietzner (Hg.): Historische Bildungsforschung. Ein Handbuch (in Druck).

Casale, Rita/Tröhler, Daniel/Oelkers, Jürgen (Hg.) (2006): Methoden und Kontexte. Historiographische Probleme der Bildungsforschung. Göttingen.

Chartier, Roger (1990): Lesewelten. Buch und Lektüre in der frühen Neuzeit. Frankfurt a.M., New York, Paris.

Clark, William (1989): On the Dialectic Origins of the Research Seminar. In: History of Science 27, H. 2, S. 111-154.

Daniel, Ute (2001): Kompendium Kulturgeschichte. Theorien, Praxis, Schlüsselwörter. Frankfurt a.M.

Daston, Lorraine (2000): Die unerschütterliche Praxis. In: Kiesow, Rainer Maria/ Simon, Dieter (Hg.): Auf der Suche nach der verlorenen Wahrheit. Frankfurt a.M., S. 13-25.

De Certeau, Michel (1988): Die Kunst des Handelns. Berlin.

Décultot, Élisabeth (2017): Exzerpt, Plagiat, Archiv. Untersuchungen zur neuzeitlichen Schriftkultur. Halle (Saale).

Dowe, Christopher (2007): Ein Zeitalter der Lehre. Deutsche Universitäten im Kaiserreich. In: Jahrbuch für Historische Bildungsforschung 13, S. 57-88.

Drewek, Peter (2002): Friedrich Paulsen. Bildungstheorie und Bildungsgeschichte. In: Klaus-Peter Horn (Hg.): Pädagogik Unter den Linden. Von der Gründung der Berliner Universität im Jahre 1810 bis zum Ende des 20. Jahrhunderts. Stuttgart, S. 101-124.

Erben, Wilhelm (1913): Die Entstehung der Universitäts-Seminare. In: Internationale Monatsschrift für Wissenschaft, Kunst und Technik 7, Sp. 1247-1264 u. 1335-1348.

Ermann, Wilhelm/Horn, Ewald (1904/05): Bibliographie der deutschen Universitäten. Systematisch geordnetes Verzeichnis der bis Ende 1899 gedruckten Bücher und Aufsätze über das deutsche Universitätswesen. Leipzig [u.a.].

Fendler, Lynn (2013): There Are No Independent Variables in History. In: Thomas Popkewitz (Hg.): Rethinking the History of Education. Transnational Perspectives on its Questions, Methods, and Knowledge. New York, S. 223-244.

Freist, Dagmar (2013a): Dress to impress. Mode als materielle Praktik sozialer Distinktion in der ländlichen Oberschicht Nordwestdeutschlands. In: Dies./ Frank Schmekel (Hg.): Hinter dem Horizont. Projektion und Distinktion ländlicher Oberschichten im europäischen Vergleich. Münster, S. 91-103.

Freist, Dagmar (2013b): »Ich will Dir selbst ein Bild von mir entwerfen«. Praktiken der Selbst-Bildung im Spannungsfeld ständischer Normen und gesellschaftliche Dynamik. In: Thomas Alkemeyer/Gunilla Budde/Dies. (Hg.): Selbst- 
Bildungen. Soziale und kulturelle Praktiken der Subjektivierung. Bielefeld, S. 151-174.

Freist, Dagmar (2015): Diskurs - Körper - Artefakte. Historische Praxeologie in der Frühneuzeitforschung - eine Annäherung. In: Dies. (Hg.): Diskurs - Körper - Artefakte. Historische Praxeologie in der Frühneuzeitforschung. Bielefeld, S. 9-30.

Friedrich, Markus (2013): Die Geburt des Archivs. Eine Wissensgeschichte. München.

Füssel, Marian (2006): Gelehrtenkultur als symbolische Praxis. Rang, Ritual und Konflikt an der Universität der Frühen Neuzeit. Symbolische Kommunikation in der Vormoderne. Darmstadt.

Füssel, Marian (2011): Die feinen Unterschiede in der Ständegesellschaft. Der praxeologische Ansatz Pierre Bourdieus. In: Ders,/Thomas Weller (Hg.): Soziologische Theorie und Ständische Gesellschaft. Theorien und Debatten in der Frühneuzeitforschung. Frankfurt a.M., S. 24-46.

Füssel, Marian/Sikora, Michael (2014): Kulturgeschichte der Schlacht. Krieg in der Geschichte. Paderborn.

Füssel, Marian (2015a): Lehre ohne Forschung? Die Praxis des Wissens an der vormodernen Universität. In: Martin Kintzinger/Sita Steckel (Hg.): Akademische Wissenskulturen. Praktiken des Lehrens und Forschens vom Mittelalter bis zur Moderne. Basel.

Füssel, Marian (2015b): Praktiken historisieren. Geschichtswissenschaft und Praxistheorie im Dialog. In: Franke Schäfer/Anna Daniel/Frank Hillebrandt (Hg.): Methoden einer Soziologie der Praxis. Bielefeld, S. 267-287.

Geertz, Clifford (1983): Dichte Beschreibung. Frankfurt a.M.

Giddens, Anthony (1995): Die Konstitution der Gesellschaft. Grundzüge einer Theorie der Strukturierung. Frankfurt a.M.

Gierl, Martin (2001): Kompilation und die Produktion von Wissen im 18. Jahrhundert. In: Helmut Zedelmaier/Martin Mulsown (Hg.): Die Praktiken der Gelehrsamkeit in der Frühen Neuzeit. Tübingen, S. 63-94.

Graf, Rüdiger (2008): Was macht die Theorie in der Geschichte? »Praxeologie«als Anwendung des "gesunden Menschenverstandes«. In: Janes Hacke/Matthias Pohlig (Hg.): Theorie in der Geschichtswissenschaft. Frankfurt a.M., S. 111-129. Groppe, Carola (2012): History of Education in Germany. Historic development Results - Raison d'être. In: Jesper Eckhardt Larsen (Hg.): Knowledge, politics and the history of education. Berlin, S. 179-193.

Haasis, Lucas/Rieske, Constantin (Hg.) (2015): Historische Praxeologie. Dimensionen vergangenen Handelns. Paderborn.

Hardtwig, Wolfgang (1985): Krise der Universität, studentische Reformbewegung (1750 - 1819) und die Sozialisation der jugendlichen deutschen Bildungs- 
schicht. Aufriß eines Forschungsproblems. In: Geschichte und Gesellschaft 11, H. 2, S. 155-176.

Heidegger, Martin (1919/1987): Zur Bestimmung der Philosophie. Gesamtausgabe.

Abt. 2: Vorlesungen. Bd. 56/57. Hg. von Bernd Heimbüchel. Frankfurt a.M.

Heinemann, Manfred (Hg.) (1979): Die historische Pädagogik in Europa und den USA. Berichte über die historische Bildungsforschung. Stuttgart.

Hicks, Dan (2010): The Material-Cultural turn. Event and Effect. In: Ders./Mary

C. Beaudry (Hg.): The Oxford handbook of material culture studies. Oxford, S. 25-98.

Hillebrandt, Frank (2015): Was ist der Gegenstand einer Soziologie der Praxis? In:

Frank Schäfer/Anna Daniel/Ders. (Hg.): Methoden einer Soziologie der Praxis. Sozialtheorie. Berlin, S. 15-36.

Horn, Klaus-Peter (Hg.) (2002): Pädagogik Unter den Linden. Von der Gründung der Berliner Universität im Jahre 1810 bis zum Ende des 20. Jahrhunderts. Stuttgart.

Hütig, Andreas (2010): Dimensionen des Kulturbegriffs. In: Jan Kusber/Mechthild Dreyer/Jörg Rogge/Ders.s (Hg.): Historische Kulturwissenschaften. Positionen, Praktiken und Perspektiven. Bielefeld, S. 105-124.

Jackstel, Karl-Heinz (Hg.) (1986): Studien zur Geschichte der Hochschulpädagogik.

Halle (Wissenschaftliche Beiträge der Martin-Luther-Universität Halle-Wittenberg 3).

Jarausch, Konrad H. (1984): Deutsche Studenten. 1800-1970. Frankfurt a.M. Jaśtal, Katarzyna (2009): Körperkonstruktionen in der frühen Prosa Heinrich Heines. Krakau.

Jelich, Franz-Josef/Kemnitz, Heidemarie (Hg.) (2003): Die pädagogische Gestaltung des Raums. Geschichte und Modernität. Bad Heilbrunn.

Kellmann, Klaus (2010): Friedrich Paulsen und das Kaiserreich. Neumünster.

Kintzinger, Martin/Steckel, Sita (Hg.) (2015): Akademische Wissenskulturen.

Praktiken des Lehrens und Forschens vom Mittelalter bis zur Moderne. Basel.

Kipf, Stefan (1999): Herodot als Schulautor. Ein Beitrag zur Geschichte des Griechischunterrichts in Deutschland vom 15. bis zum 20. Jahrhundert. Köln.

Klinger, Kerrin (2014): Zwischen Gelehrtenwissen und handwerklicher Praxis. Zum mathematischen Unterricht in Weimar um 1800. Paderborn.

König, Gudrun M. (2005): Alltagsdinge. Erkundungen der materiellen Kultur. Tübingen.

Koolman, Egbert (1989): Die Kollegnachschriften der Landesbibliothek Oldenburg. Katalog. Oldenburg.

Kusber, Jan/Dreyer, Mechthild/Rogge, Jörg/Hütig, Andreas (Hg.) (2010): Historische Kulturwissenschaften. Positionen, Praktiken und Perspektiven. Bielefeld. 
Larsen, Jesper Eckhardt (Hg.) (2012): Knowledge, politics and the history of education. Berlin.

Lawn, Martin/Grosvenor, Ian (2005): Materialities of schooling. Design, technology, objects, routines. Comparative histories of education. Oxford.

Lehmann, Ann-Sophie (2016): Objektstunden. Vom Materialwissen zur Materialbildung. In: Herbert Kalthoff/Torsten Cress/Tobias Röhl (Hg.): Materialität. Herausforderungen für die Sozial- und Kulturwissenschaften. Paderborn, S. 171-193.

Leitner, Erich (1984): Hochschul-Pädagogik. Zur Genese und Funktion der Hochschul-Pädagogik im Rahmen der Entwicklung der deutschen Universität, 1800-1968. Frankfurt a.M.

Lönnecker, Harald (Hg.) (2015): »Deutschland immer gedient $\mathrm{zu}$ haben ist unser höchstes Lob!« Zweihundert Jahre Deutsche Burschenschaften: eine Festschrift zur 200. Wiederkehr des Gründungstages der Burschenschaft am 12. Juni 1815 in Jena. Heidelberg.

Maurer, Michael (2005): Alte Kulturgeschichte - Neue Kulturgeschichte. In: Historische Zeitschrift 280, H. 2, S. 281-304.

Meier, Thomas (2015): Materiale Textkulturen. Konzepte - Materialien - Praktiken. Berlin [u.a.].

Meves, Uwe (2011): Deutsche Philologie an den preußischen Universitäten im 19. Jahrhundert. Dokumente zum Institutionalisierungsprozess. Teilbd. 1 und 2. Berlin, New York.

Miller, Daniel (Hg.) (2005): Materiality. Durham.

Mulsow, Martin (2007): Die unanständige Gelehrtenrepublik. Wissen, Libertinage und Kommunikation in der Frühen Neuzeit. Stuttgart [u.a.].

Olbertz, Jan (1986): Hodegetik als akademische Morallehre. In: Karl-Heinz Jackstel (Hg.): Studien zur Geschichte der Hochschulpädagogik. Halle (Wissenschaftliche Beiträge der Martin-Luther-Universität Halle-Wittenberg 3), S. 47-58.

Polanyi, Michael (1985): Das implizite Wissen. Frankfurt a.M.

Popkewitz, Thomas S. (2013): Styles of reason: Historicism, historicizing, and their historical objects in the history of education. In: Popkewitz, Thomas (Hg.): Rethinking the History of Education. Transnational Perspectives on its Questions, Methods, and Knowledge. New York, S. 1-26.

Priem, Karin/König, Gudrun M./Casale, Rita (2012): Die Materialität der Erziehung. Kulturelle und soziale Aspekte pädagogischer Objekte. Einleitung zum Beiheft. In: Priem, Karin/König, Gudrun/Casale, Rita (Hg.): Die Materialität der Erziehung. Kulturelle und soziale Aspekte pädagogischer Objekte. Weinheim (Zeitschrift für Pädagogik 58 [Beih.]), S. 7-13.

Raphael, Lutz (2010): Geschichtswissenschaft im Zeitalter der Extreme. Theorien, Methoden, Tendenzen von 1900 bis zur Gegenwart. München. 
Rasche, Ulrich (2011): Die frühneuzeitliche Universitätsgeschichte und ihre Quellen. Idee und Konzeption dieses Bandes. In: Ders. (Hg.): Quellen zur frühneuzeitlichen Universitätsgeschichte. Typen, Bestände, Forschungsperspektiven. Wiesbaden, S. 13-28.

Reckwitz, Andreas (2000): Die Transformation der Kulturtheorien. Zur Entwicklung eines Theorieprogramms. Weilerswist.

Reckwitz, Andreas (2003): Grundelemente einer Theorie sozialer Praktiken. Eine sozialtheoretische Perspektive. In: Zeitschrift für Soziologie 32, H. 4, S. 282301.

Reddy, William M. (2001): The navigation of feeling. A framework for the history of emotions. Cambridge.

Reh, Sabine (2013): Die Produktion von (Un-)Selbständigkeit in individualisierten Lernformen. Zur Analyse von schulischen Subjektivierungspraktiken. In: Andreas Gelhard/Thomas Alkemeyer/Norbert Ricken (Hg.): Techniken der Subjektivierung. München, S. 189-200.

Reh, Sabine (2014): Can we discover something new by looking at practices? Practice theory and the history of education. In: Encounters in Theory and History of Education 15, S. 183-207.

Reh, Sabine (2017): Statt einer pädagogischen Theorie der Schule: eine Geschichte des modernen Fachunterrichts als Geschichte subjektivierender Wissenspraktiken. In: Roland Reichenbach/Patrick Bühler (Hg.): Fragmente zu einer pädagogischen Theorie der Schule. Erziehungswissenschaftliche Perspektiven auf eine Leerstelle. Weinheim, Basel, S. 152-173.

Reh, Sabine/Ricken, Norbert (Hg.) (2018): Leistung als Paradigma. Zur Entstehung und Transformation eines pädagogischen Konzepts. Wiesbaden.

Reh, Sabine/Scholz, Joachim (2019): Seminare um 1800. Zur (In)Kohärenz universitärer und schulisch- praktischer Lehrerausbildung. In: Maria Degeling/Nadine Franken/ Stefan Freund/Silvia Greiten/Daniela Neuhaus/Judith Schellenbach-Zell (Hg.): Herausforderung Kohärenz: Praxisphasen in der universitären Lehrerbildung. Bildungswissenschaftliche und fachdidaktische Perspektiven. Bad Heilbrunn, S. 65-80.

Reh, Sabine/Wilde, Denise (Hg.) (2016): Die Materialität des Schreiben- und Lesenlernens. Zur Geschichte schulischer Unterweisungspraktiken seit der Mitte des 18. Jahrhunderts. Heilbrunn.

Reichardt, Sven (2007): Praxeologische Geschichtswissenschaft. Eine Diskussionsanregung. In: Sozial. Geschichte. Zeitschrift für historische Analyse des 20. und 21. Jahrhunderts 22, H. 3, S. 43-65.

Ricken, Norbert (2013a): Anerkennung als Adressierung. Über die Bedeutung von Anerkennung für Subjektivationsprozesse. In: Thomas Alkemeyer/Gunilla Budde/Dagmar Freist (Hg.): Selbst-Bildungen. Soziale und kulturelle Praktiken der Subjektivierung, Bielefeld, S. 69-100. 
Ricken, Norbert (2013b): Zur Logik der Subjektivierung: Überlegungen an den Rändern eines Konzepts. In: Andreas Gelhard/Thomas Alkemeyer/Ders. (Hg.): Techniken der Subjektivierung. München, S. 29-47.

Rosenbrock, Gerd (1979): Bildung und Ausbildung. Ansätze zur pädagogischen Theorie der Universität im 19. Jahrhundert. In: Zeitschrift für Pädagogik 25, H. 6, S. 905-917.

Sarasin, Philipp (2013): Art. »Routine«. In: Ute Frietsch/Jörg Rogge (Hg.): Über die Praxis des kulturwissenschaftlichen Arbeitens. Ein Handwörterbuch. Bielefeld, S. 352-357.

Schatzki, Theodore R. (1996): Social practices. A Wittgensteinian approach to human activity and the social. Cambridge.

Schatzki, Theodore R. (2002): The site of the social. A philosophical account of the constitution of social life and change. Pennsylvania.

Schatzki, Theodore R. (2010): The timespace of human activity. On performance, society, and history as indeterminate teleological events. Lanham, New York, Toronto, Plymouth.

Schatzki, Theodore R./Knorr-Cetina, Karin/Savigny, Eike von (Hg.) (2001): The practice turn in contemporary theory. London, New York.

Schneider, Ulrich Johannes (2005): Kultur der Kommunikation. Die europäische Gelehrtenrepublik im Zeitalter von Leibniz und Lessing. Wiesbaden.

Schneider, Ulrich Johannes (2008): Kulturen des Wissens im 18. Jahrhundert. Berlin [u.a.].

Schubring, Gert (1991): Spezialschulmodell versus Universitätsmodell. Die Institutionalisierung von Forschung. In: Ders. (Hg.): »Einsamkeit und Freiheit« neu besichtigt. Universitätsreformen und Disziplinenbildung in Preußen als Modell für Wissenschaftspolitik im Europa des 19. Jahrhunderts. Stuttgart, S. 276-326.

Schulze, Gottlob Ernst (2008): Schopenhauers Kollegnachschriften der Metaphysik- und Psychologievorlesungen (Göttingen, 1810-11). Würzburg.

Seifert, Sabine (2016): Die Ursprünge der Berliner Forschungsuniversität. August Boeckhs philologisches Seminar in Konzeption und Praxis (1812-1826). Berlin (Dissertation, Manuskript).

Spiegel, Gabrielle M. (Hg.) (2005): Practicing history. New directions in historical writing after the linguistic turn. Rewriting Histories. New York.

Spoerhase, Carlos/Dehrmann, Mark-Georg (2011): Die Idee der Universität: Friedrich August Wolf und die Praxis des Seminars. In: Zeitschrift für Ideengeschichte 5, H. 1, S. 105-117.

Spoerhase, Carlos (2015): Das »Laboratorium« der Philologie? Das philologische Seminar als Raum der Vermittlung von Praxiswissen (circa 1850-1900). In: Andrea Albrecht/Lutz Danneberg/Olav Krämer/Carlos Spoerhase (Hg.): Theo- 
rien, Methoden und Praktiken des Interpretierens. Berlin, München, Boston, S. $53-80$.

Stary, Joachim (1994): Hodegetik oder »Ein Mittel gegen das Elend der Studierfähigkeit«. Eine historische Betrachtung zu einem Dauerproblem der Universität. In: Das Hochschulwesen 42, H. 4, S. 160-164.

Steckel, Sita (2011): Kulturen des Lehrens im Früh- und Hochmittelalter. Autorität, Wissenskonzepte und Netzwerke von Gelehrten. Köln, Weimar, Wien.

Steckel, Sita (2015): Wissensgeschichten. Zugänge, Probleme und Potentiale in der Erforschung mittelalterlicher Wissenskulturen. In: Martin Kintzinger/Dies. (Hg.): Akademische Wissenskulturen. Praktiken des Lehrens und Forschens vom Mittelalter bis zur Moderne. Basel, S. 9-58.

Steensen, Thomas (2010): Friedrich Paulsen. Weg, Werk und Wirkung eines Gelehrten aus Nordfriesland. Husum.

Stickler, Matthias (2010): Universität als Lebensform? Überlegungen zur Selbststeuerung studentischer Sozialisation im langen 19. Jahrhundert. In: Rüdiger vom Bruch (Hg.): Die Berliner Universität im Kontext der deutschen Universitätslandschaft nach 1800, um 1860 und um 1910. München, S. 149-186.

Tenorth, Heinz-Elmar (1999): „Über das Verderben auf den deutschen Universitäten« - Kritik der Hochschullehre im 19. Jahrhundert. In: Jahrbuch für Universitätsgeschichte 2, S. 11-22.

Tenorth, Heinz-Elmar (2004): Erziehungswissenschaft. In: Dietrich Benner/Jürgen Oelkers (Hg.): Historisches Wörterbuch der Pädagogik. Weinheim, Basel, S. 341-381.

Tenorth, Heinz-Elmar (2010): Paulsen als Historiker der Erziehung und seine Stellung an der Berliner Universität. In: Thomas Steensen (Hg.): Friedrich Paulsen. Weg, Werk und Wirkung eines Gelehrten aus Nordfriesland. Husum, S. 43-58.

Tenorth, Heinz-Elmar (2012): Studenten, Studium und Lehre. In: Heinz-Elmar Tenorth (Hg.): Geschichte der Universität Unter den Linden. Band 1: Gründung und Blütezeit der Universität zu Berlin 1810 - 1918. Berlin, S. 209-268.

Tietmeyer, Elisabeth/Hirschberger, Claudia/Noack, Karoline/Redlin, Jane (Hg.) (2010): Die Sprache der Dinge. Kulturwissenschaftliche Perspektiven auf die materielle Kultur. Münster.

Tröhler, Daniel (2011): Historiographische Herausforderungen der Bildungsgeschichte. In: Bildungsgeschichte. International Journal for the Historiography of Education 1, H. 1, S. 9-22.

Tschopp, Silvia Serena (2009): Die Neue Kulturgeschichte. Eine (Zwischen-)Bilanz. In: Historische Zeitschrift 289, H. 3, S. 573-605.

Vierhaus, Rudolf (Hg.) (1995): Wege zu einer neuen Kulturgeschichte. Göttingen.

Weber, Max (1994): Briefe 1909-1910. In: Mario Rainer Lepsius/Wolfgang J. Mommsen (Hg.): Max Weber. Gesamtausgabe. Tübingen. 
Zedelmaier, Helmut (2001): Lesetechniken. Die Praktiken der Lektüre in der Neuzeit. In: Ders./Martin Mulsow (Hg.): Die Praktiken der Gelehrsamkeit in der frühen Neuzeit. Tübingen, S. 11-30.

Zedelmaier, Helmut (2002): Buch, Exzerpt, Zettelschrank, Zettelkasten. In: Hedwig Pompe/Leander Scholz (Hg.): Archivprozesse. Die Kommunikation der Aufbewahrung. Köln, S. 38-53. 


\section{Fehler- und Strafpraktiken am Ende der Frühen Neuzeit am Beispiel von Schule und Unterricht in der Deutschschweiz}

Rebekka Horlacher

Der mahnende Zeigefinger von Wilhelm Buschs Lehrer Lämpel ist aus der Ikonografie des Schulmeisters nicht wegzudenken, dies zumindest im deutschsprachigen Raum. Die Körpersprache der auf dieser Zeichnung skizzierten Figur mahnt nicht nur eine unsichtbare Schülerschaft zur Aufmerksamkeit, sondern impliziert auch deren potenzielles Fehlverhalten sowie die entsprechende Bestrafung. Der Lehrer, so der Eindruck, der durch dieses Bild hervorgerufen wird, ist nicht nur ein Vermittler von Wissen, sondern auch für das richtige Verhalten zuständig, was - im Wissen um die Fortsetzung der Geschichte von >Max und Moritz‘, die in der Getreidemühle und als Entenfutter enden - nicht ohne eine bestimmte Form des Strafens möglich zu sein scheint. Solche oder ähnliche Überlegungen könnten Busch zu seiner Zeichnung motiviert haben und sie können auch als Hinweise auf ein bestimmtes Bild des Lehrers verstanden werden. Sie sind aber keine Aussagen darüber, wie sich die Lehrer um 1865, dem Jahr der Erstpublikation von >Max und Moritz , in ihrem Unterrichtsalltag verhalten haben, noch bietet die Zeichnung ein Abbild einer konkreten Unterrichtspraxis oder der damit verbundenen gesellschaftlichen Normvorstellungen. Es ist vielmehr die zeichnerische Darstellung einer Lehrerfigur, die historische Vorbilder haben kann, aber nicht haben muss und die eine bestimmte Praxis spiegeln möchte, diese in der Darstellung aber auch ironisieren oder verfremden kann.

Die Differenz von Bild - oder Text - zur historischen »Wirklichkeit« ist ein wiederkehrendes Thema der Historiografie, das viele verschiedene Antworten generiert hat, die aber alle keinen abschliessenden Wahrheitsgehalt für sich beanspruchen können. Das »Problem« von Fakten und deren Interpretation bleibt als epistemologisches Thema konstant. ${ }^{1}$ Die Frage, inwiefern Texte als Beschreibung oder Abbild von Praxis gelesen werden können, beschäftigt die Kulturgeschichte seit dem 19. Jahrhundert. Da in dieser Tradition nicht politische Handlungen, Gesetzgebungen, statistische Daten oder philosophische Konzepte im Fokus des 
Forschungsinteresses stehen, sondern Bräuche, Sitten oder Gewohnheiten, die sich in Tätigkeiten ausdrücken, erfuhren diese Fragen besondere Aufmerksamkeit, wobei sich diese Debatten spätestens seit den 1970er-Jahren und mit dem Aufkommen der Alltagsgeschichte, der Mikrogeschichte oder der Historischen Anthropologie deutlich intensiviert haben. ${ }^{2}$ Ohne hier näher auf die unterschiedlichen Traditionen von Kulturgeschichte einzugehen, die eng mit den verschiedenen Kulturbegriffen im deutsch-, französisch- oder englischsprachigen Kontext zusammenhängen, ${ }^{3}$ kann festgehalten werden, dass der mit diesen historiografischen Entwicklungen verbundene cultural turn in der Geschichtswissenschaft den Blick der Forschenden verstärkt auf die materielle Basis der Vergangenheit und auf verschiedene Formen von »Praxis« gelenkt hat, wobei jeweils sehr unterschiedlich ausfällt, welche Aspekte berücksichtigt werden.

Eine dieser Möglichkeiten ist die Beschäftigung mit Praktiken, die hier als »Verhaltens- und Handlungsweisen in ihren historisch-sozialen Zusammenhängen « verstanden werden. ${ }^{4}$ Praktiken bezeichnen Tätigkeiten, deren Beschreibungen, Begründungen und Legitimationen. Mit dem Einbezug der Begründungsund Legitimationsebene ist immer auch die Frage nach der Norm verbunden, wobei sich diese »auf verschiedenen Ebenen abspielen [kann], die viel mehr repräsentieren als allein obrigkeitliche Ordnungen und deren Befolgung oder Nichtbefolgung «. ${ }^{5}$ Die Norm ist keine Vorgabe, die Auswirkungen auf Praxis hat und der gefolgt oder die verletzt werden kann. Zum einen fliesst Praxis ebenso in die Norm mit ein und bestimmt diese mit, zum andern kann auch eine institutionalisierte Praxis, die breite gesellschaftliche Akzeptanz geniesst, normative Züge aufweisen, auch wenn sie gesetzlich nicht kodifiziert ist. Norm und Praxis sind somit keine statischen Konzepte, sondern entstehen im Austausch, und in Wechselwirkung. ${ }^{6}$ Bei der Diskussion um das Verhältnis von Norm und Praxis geht es denn auch nicht um die Frage von »Einfluss«, sondern um die Berücksichtigung der gegenseitigen Bedingtheiten vor dem Hintergrund der epistemologischen Frage, was »gemeint« ist, wenn etwas "gesagt« wird bzw. getan wurde. ${ }^{7}$

2 Wohl nicht zufällig waren es vor allem Frühneuzeitforscherinnen und -forscher, die in diesen Fragen besonders innovative Ideen in die Diskussion einbrachten, wird doch bei der Beschäftigung mit der Frühen Neuzeit die Differenz zur Gegenwart und die kulturelle »Andersheit« der untersuchten Zeit besonders offenkundig (Schmidt/Aspelmeier 2006, S. 8). Dies etwa im Unterschied zu Forschungen im 19. oder 20. Jahrhundert, die sich einfacherwenn auch nicht weniger unzutreffend - aus einer präsentistischen Perspektive und als "Vorgeschichte«der Gegenwart konzipieren lassen.

3 Vgl. Dinges 2002.

4 Mitterauer/Saurer 1993, S. 1.

5 Jaritz 1997, S. 18.

6 Alkemeyer/Buschmann/Michaeler 2015, S. $25 f$.

7 Vgl. Skinner 2002. 
Norm entsteht zudem nicht ausserhalb und unabhängig von Praxis, sie ist nicht göttlich oder natürlich, sondern sozial konstruiert und damit immer auch Teil der Praktik. "Eine von Normen unabhängige Praxis ist mithin ebenso wenig vorstellbar, wie sie überdies abseits einer - ausformulierten oder unreflektiert implizit unterstellten - >Theorie der Praxis beobachtet werden kann ${ }^{8}{ }^{8}$ Damit wird hier nicht ein Verständnis von Praxeologie in den Mittelpunkt gestellt, wie es vor allem in den 1970er- und 1980er-Jahren als Entwurf einer Allgemeinen Pädagogik diskutiert worden ist. Josef Derbolav beispielsweise formulierte eine Theorie der Pädagogik als Praxeologie, die sich als Handlungswissenschaft verstand und ethische Fragen ins Zentrum rückte. Ethik wurde dabei im Rückgriff auf einen aristotelischen Praxisbegriff als Verantwortungsethik konzipiert. ${ }^{9}$ Im Mittelpunkt steht vielmehr eine Praktik von Beschreibung und Reflexion konkreter Erfahrungen oder vorgestellter Handlungen, die auch als "normale Praxis $\aleph^{10}$ bezeichnet worden ist, wobei durch den Fokus auf Praktiken versucht wird, den "historischen Diskurs « der Praxis zu rekonstruieren. ${ }^{11}$

Am Beispiel von Überlegungen und konkreten Anweisungen zur Funktion und Prävention von und zum Umgang mit Fehlern und Strafen in verschiedenen »Leitfäden für Schulmeister « aus den letzten Dekaden des 18. Jahrhunderts sowie anhand von Bemerkungen zu Fehlern und Strafen in der Stapfer-Enquête wird hier danach gefragt, welche Praktiken des Fehlers und der Strafe sich im Lehreralltag am Ende des 18. Jahrhunderts zeigen. Die hier zum einen als Quellen dienenden »Leitfäden«, die in der zweiten Hälfte des 18. Jahrhunderts weit verbreitet waren, sind für diese Fragestellung besonders geeignet, weil sie als didaktisches Hilfsmittel und konkrete Unterstützung der Arbeit der Schulmeister gedacht waren. ${ }^{12}$ Ziel dieser Publikationen war es, den Lehrpersonen eine Anleitung und

9 Vgl. Derbolav 1975. An Derbolavs Überlegungen zur »Cesamtpraxis« schloss etwa Dietrich Benner in seiner Allgemeinen Pädagogik (1987) an (vgl. Müller 1995).

10 Dross 2006, S. 220.

11 Die deutschsprachige Bildungsgeschichte hat sich im Unterschied zur amerikanischen Forschung (vgl. z.B. Cuban 1984) lange Zeit eher schwer damit getan, anstelle von Ideen, Strukturen, Institutionen oder politischen Prozessen die Materialität und die Praxis von Erziehungsprozessen in den Blick zu nehmen (Depaepe 2000a, S. 10; vgl. Depaepe 2000b, S. 45f.). Erst in den letzten Jahren ist ein deutlicher Anstieg an entsprechender Forschung sichtbar geworden (vgl. z.B. Priem/König/Casale 2012).

12 Nicht berücksichtigt werden hier die verschiedenen »Landschulbibliotheken«, die zwar ein ähnliches Ziel verfolgten, bei denen es sich aber in der Regel um umfangreiche, mehrbändige Sammelwerke handelt, die nicht nur praktische Anleitungen zum Unterrichten boten, sondern sich auch auf theoretischer Ebene mit Schule, Unterricht und Erziehung befassten und die vor allem als regelmässig erscheinende Publikationen konzipiert waren. Damit boten sie eine fortlaufende Weiterbildungsmöglichkeit für aktive Lehrpersonen und beabsichtigten, das »neueste« pädagogische Wissen zu den Schulmeistern zu bringen (vgl. z.B. 
ein Hilfsmittel für ihre Berufstätigkeit zur Verfügung zu stellen, das nicht auf einer abstrakt-theoretischen Ebene Fragen von Erziehung, Bildung, Schule und Unterricht diskutierte. Vielmehr beanspruchten diese Publikationen - durchaus in einem (volks-)aufklärerischen Selbstverständnis - eine "nützliche« Unterstützung bei der organisatorischen und methodisch-didaktischen Bewältigung des Schulmeister-Alltags zu bieten. Damit war auch die Absicht verbunden, die Qualität der bestehenden Schule und des Unterrichts zu verbessern, ohne diese Qualitätsverbesserungen von Schulreformen oder anderen institutionellen Veränderungen abhängig machen zu müssen.

Als zweite Quelle dient die sogenannte Stapfer-Enquête, eine breit angelegte Schulumfrage, die der damalige helvetische Bildungsminister Philipp Albert Stapfer (1766-1840) 1799 veranlasst hatte, um auf einer empirisch soliden Basis die Schule reformieren und den neuen (politischen) Anforderungen anpassen zu können. ${ }^{13}$ Da sich der Fragebogen vor allem auf die organisatorischen Belange von Schule und Unterricht konzentriert, ist die Rubrik »Bemerkungen« für die hier verfolgte Fragestellung von besonderem Interesse. Die Lehrpersonen hatten dort die Möglichkeit, ihre persönlichen Fragen, Anregungen oder Überlegungen zu Schule und Unterricht zu notieren, und konnten so der helvetischen Regierung Vorschläge machen, wo und wie aus ihrer Sicht Schule und Unterricht zu reformieren waren.

Mit dieser Quellengrundlage wird nicht eine konkrete Strafpraxis als Reaktion auf fehlerhaftes Verhalten in den Blick genommen, ${ }^{14}$ sondern vielmehr das Reden bzw. Schreiben von einzelnen, teilweise auch als Schulmeister praktisch tätigen Personen auf das Themenfeld von Fehlern und Strafen. Da sich vor allem die Verfasser der Leitfäden nicht als beliebige Einzelpersonen verstanden, die ihr Nachdenken über schulisches, methodisches und pädagogisches Handeln zufälligerweise aufgeschrieben hatten, sondern ihre diesbezüglichen Publikationen als für die praktische Tätigkeit hilfreich und handlungsanleitend einschätzten, zeigt sich hier die Praktik des Strafens in dem Sinn, als dass die Beschreibung der Strafpraxis immer auch mit Begründungen versehen sind. ${ }^{15}$ Damit kommt diesen Quellen auch eine normierende Funktion zu, da sie auch zeigen, »wie Eliten - übrigens ganz verschiedener Art [...] - ein Stück der Wirklichkeit, in der sie lebten, verstanden und $\mathrm{zu}$ verstehen gaben«, wobei »diese Abbildungen des Sozialen [...] keine neutralen Reden« sind. "Sie erzeugen [vielmehr] Strategien und [...] Prak-

Johann Friedrich Prenningers Landschulbibliothek. Oder Handbuch für Schullehrer auf dem Lande. 4 Bde. [1780-1790] oder Johann Rudolf Steinmüllers Helvetische Schulmeister-Bibliothek 2 Bde. [1801]).

13 Vgl. Holenstein 2014.

14 Vgl.z.B. Herman u.a. 2003.

15 Dinges 1997, S. 41; Schmidt/Aspelmeier 2006, S. 8. 
tiken, die Autorität beanspruchen - und zwar auf Kosten anderer, denen sie abgesprochen « werden. ${ }^{16}$ Dabei ist interessant zu vergleichen - und dazu dienen die Bemerkungen in der Stapfer-Enquête -, inwiefern sich die in diesen "Leitfäden" geäusserten Überlegungen zu Fehlern und Strafen von den Aussagen der Schulmeister unterscheiden, die - aus welchen Gründen auch immer - dieses Themenfeld in ihren Antworten auf die Stapfer-Umfrage angesprochen haben. Allerdings ist auch hier festzuhalten, dass sich diese Schulmeister durch das Anfügen von Bemerkungen ebenfalls von der Mehrheit der "schweigenden« Schulmeister abhoben und damit in dem Sinne als »elitär« zu verstehen sind, als dass sie das Thema als diskussionswürdig erachteten.

In den ersten drei der insgesamt fünf Abschnitte dieses Beitrags werden fünf "Leitfäden « vorgestellt und auf ihre Aussagen zu den Themenfeldern von Fehlern und Strafen hin untersucht, wobei Publikationen ausgewählt wurden, die in der Schweiz im Umlauf waren, was ein Vergleich zu den Aussagen in der Stapfer-Enquête möglich macht, da sich die verschiedenen Quellen auf den gleichen Kontext beziehen bzw. von den Zeitgenossen als für den gleichen Kontext als passend angesehen wurden. Zunächst werden die beiden Anleitungen von Gottfried Christian Brünings (1727-1793) und Emanuel Merian (1732-1818) diskutiert, die beide an Basler Schulen verwendet wurden. Anschliessend werden die beiden »katholischen« Methodenbücher vorgestellt, das »Original « von Johann Ignaz von Felbiger (1724-1788) und die Schweizer Adaptation von Nivard Crauer (1747-1799), die in der Schweiz vor allem im Kanton Solothurn verbreitet waren. ${ }^{17}$ Der dritte Abschnitt beschäftigt sich mit den Bemerkungen von Johannes Büel (1761-1830), die hauptsächlich in der Region Zürich in Gebrauch waren und die mit ihren nummerierten »Merksätzen« eine von den anderen Handreichungen etwas unterschiedliche Form aufweisen. Der vierte Abschnitt beleuchtet das Thema Fehler und Strafe aus dem Blickwinkel der Schulmeister, die sich in der Stapfer-Enquête zu dieser Frage geäussert haben. Dabei zeigen sich grosse Übereinstimmungen zu den in den »Leitfäden« diskutierten Überlegungen, auch wenn sich nur sehr wenige Schulmeister zu diesem Themenkomplex geäussert haben. Im abschliessenden Abschnitt werden die Resultate zusammengefasst und die Frage diskutiert, ob und wenn ja welche Praktiken des Fehlers und des Strafens sich aus den Leitfäden und Bemerkungen in der Stapfer-Enquête rekonstruieren lassen, womit auch die Frage nach dem historiografischen »Mehrwert« einer solchen Perspektive diskutiert wird.

16 Chartier 1989, S. 12.

17 Vgl. Horlacher 2018. 


\section{Brünings' und Merians Anleitungen für Schulmeister}

1778 veröffentlichte der zu dieser Zeit in Heidelberg tätige und im kurpfälzischen Kreuznach geborene Pfarrer Brünings in Mannheim eine sAnleitung zu fruchtbarer Lehrart in den niedern Schulen<, die auf Veranlassung der Basler Aufmunterungsgesellschaft ${ }^{18}$ den Schulmeistern in Basel verteilt wurde. Brünings stellte im Vorwort der Anleitung seine Überlegungen als Resultat seiner bisherigen Arbeit als Beauftragter für die Vorbereitung der »Schul-Expektanten meines Vaterlandes « dar ${ }^{19}$ und wies darauf hin, dass sie »Resultat des ernstlichen Nachdenkens« seien, »durch welches ich den besten Weg, den niedern Schulen eine nutzbare und empfehlende Einrichtung zu geben, zu erforschen getrachtet habe ${ }^{20}$ Zudem betonte er, dass es sich bei diesen Überlegungen nicht um eine "Sammlung aus andern Erziehungsschriften ${ }^{21}$ handle, sondern um Überlegungen, die aus eigener Erfahrung stammten; ${ }^{22}$ ein in allen Anleitungen wiederkehrendes Argument, das jeweils die Qualität und die Nützlichkeit der eigenen Publikation betonen sollte.

Brünings Schrift stiess in Basel auf Kritik, da sie nicht das richtige Zielpublikum vor Augen habe. Bei den Basler Lehrern handle es sich in der Regel um "unstudierte Landleute«, weshalb er, der »würdige Vorsteher der baselischen Kirchen « Emanuel Merian, beschlossen habe, selber »eine solche [Anleitung] zu verfertigen, die den Bedürfnissen und den Fähigkeiten derer besonders angemessen wäre, welche die Gesellschaft diese Wohlthat zugedacht hatte.«In Merians Augen war die Brünings'sche Anleitung zu schwierig, zu komplex und zu umfangreich, um den Landschullehrern die gewünschte Hilfestellung zu leisten. In Merians Anleitung für die Landschulmeister (1778) dagegen würden die Schulmeister - so ist zumindest in einer Besprechung in Isaak Iselins Ephemeriden der Menschheit zu lesen -, »in dem wahren Tone eines Vaters und eines Hirten [...] von der Absicht ihres wichtigen Berufes « belehrt und mit denjenigen Mitteln ausgestattet, die sie für eine erfolgreiche Berufstätigkeit benötigten. ${ }^{23}$

Trotz dieser unterschiedlichen zeitgenössischen Wahrnehmung, was die Qualität und die Zielgruppenangemessenheit der beiden Anleitungen betrifft, unterscheiden sie sich nicht wesentlich in ihren Absichten, sie differieren allerdings in der Länge (Brünings: 128 Seiten, Merian: 63 Seiten) und in der inhaltlichen Breite.

18 Die Basler Aufmunterungsgesellschaft widmete sich der Förderung der Ausbildung der Bevölkerung und der Bekämpfung der Armut und war eine Vorläufergesellschaft der heutigen Gesellschaft für das Gute und Gemeinnützige (GCG). 
Während Brünings die »klassischen Unterrichtsfächer« Lesen, Rechnen, Schreiben, Singen, Katechismus jeweils in Bezug auf ihre methodische Umsetzung diskutierte und diesen Abschnitten einige grundsätzliche Kapitel zur Schule und zur Aufgabe des Schulmeisters voranstellte, widmete Merian den grössten Teil seiner Abhandlung nicht den Unterrichtsfächern, sondern der Schule und den Aufgaben des Schulmeisters. Methodische Anleitungen für den Unterricht scheinen in Merians Augen offenbar kein Bedürfnis der Basler Schulmeister darzustellen, Ratschläge und Leitlinien für das richtige Verständnis von Schule und dem dazugehörigen beruflichen Selbstverständnis allerdings schon. Einer dieser Abschnitte war - dies sowohl bei Brünings als auch bei Merian - der »Schulzucht« gewidmet und damit der Frage nach dem pädagogischen Auftrag von Unterricht und Schule, was in diesen Handreichungen immer im Kontext der Überlegungen zu Fehlern und Strafen diskutiert wurde.

In Brünings Überlegungen, die mit »Rathgebungen wegen der Schulzucht» überschrieben sind, wird verschiedentlich deutlich, dass - dies durchaus in Übereinstimmung mit den zeitgenössischen Schulordnungen ${ }^{24}$ - das Strafen nicht der Normalfall, sondern die Ausnahme sein soll. ${ }^{25}$ Strafen waren in seinen Augen keine »normale« erzieherische Tätigkeit, sondern nur sehr gezielt, in bestimmten Fällen und mit einer spezifischen Absicht anzuwenden, wobei immer darauf zu achten sei, dass diese Tätigkeit die »Erlernung und Ausübung guter Sitten« befördere. ${ }^{26}$ Strafen waren zudem nicht zur Beschämung der Kinder einzusetzen ${ }^{27}$ oder um »knechtisches « Verhalten hervorzurufen, ${ }^{28}$ sondern zielten darauf $a b$, sich »überflüssig« zu machen, »die Kinder lenksam und gesittet« und »die Schulen zu einem eben so angenehmen als nützlichen Aufenthalt für die Kinder« werden zu lassen. ${ }^{29}$

Strafen sanktionierten bei Brünings allerdings nicht ausschliesslich moralisches Fehlverhalten, sondern dienten auch dazu, das Einüben der »klassischen« Sekundärtugenden wie Pünktlichkeit, Anstand und ein gepflegtes Erscheinen $\mathrm{zu}$ fördern, wobei Letzteres vor allem in einer Art »Sauberkeitserziehung « bestand und die Durchsetzung von hygienischen Standards unterstützte. ${ }^{30}$ Sowohl Pünktlichkeit als auch Anstand und gepflegtes Erscheinen waren aber nicht nur »äußere« Merkmale und Erziehungsziele, sondern bestimmten in Brünings' Vorstellung ganz entscheidend die moralische Erziehung mit. Strafen beförderten

\footnotetext{
24 Vgl. Schulordnung Basel 1766, S. $103 f$.

25 Brünings 1778, S. 111f. u. 115.

26 Ebd., S. 110.

27 Ebd., S. 114.

28 Ebd., S. 115.

29 Ebd., S. 116.

30 Ebd., S. 108.
} 
damit die Umsetzung von als »richtig« oder "gut« eingeschätzten Normvorstellungen, wobei in den Anleitungen nicht eine »theoretische« Norm formuliert wurde, der dann die eigene Strafpraxis zu folgen hatte. Es wurde im Gegenteil auf die eigene Erfahrung und damit die Praxis des Verfassers verwiesen und diese als Norm gesetzt, wobei auch die Gefahren einer fehlerhaften Anwendung diskutiert wurden.

Für Brünings mussten Strafen den gefehlt habenden Kindern einsichtig und nachvollziehbar gemacht werden, weshalb sie nicht leichtfertig anzudrohen und durchzuführen waren, ganz im Gegenteil: »Die angedrohete Strafen müssen auf eine feyerliche Art vollzogen werden $« .{ }^{31}$ Dem Strafen kam damit, ähnlich wie einer Belohnung, ein ritueller Aspekt zu, wobei es auch darum ging, die Kinder bzw. die Schülerinnen und Schüler in einen »strafempfänglichen« Zustand zu bringen. Die Herstellung dieses Zustandes betraf allerdings nicht nur die zu Bestrafenden, sondern auch den Schulmeister als strafende Person, der Strafen nicht im Affekt aussprechen oder gar ausführen sollte. Vielmehr war er angehalten, immer wieder von Neuem darauf hinzuweisen, »dass er in der Nothwendigkeit sey zu strafen, so ungern er es auch thut «, ${ }^{32}$ womit der Anschein vermieden werden konnte, »als ob er aus persönlicher Feindschaft, ungerecht, im Zorne, oder doch übereilt strafe $;^{33}$ alles Handlungen, die als unpassend bzw. als nicht den Normvorstellungen entsprechend abqualifiziert wurden.

Während bei Brünings die Überlegungen zur Strafe innerhalb des Kapitels "Rathgebungen wegen der Schulzucht» diskutiert wurden, stellte Merian seine Anmerkungen unter den Titel »Von den Züchtigungen, was dabei zu beobachten ist «. ${ }^{34}$ Im Unterschied zu Brünings konstatierte Merian gleich zu Beginn, dass die Ausübung der »Strafzucht « in der Schule »unumgänglich nothwendig« sei. ${ }^{35}$ Denn: »Die Bosheit, die sich bey der Jugend zeiget, und ohne Ahndung und Züchtigung zu ihrem grösten Verderben bey derselben überhand nehmen würde, macht die Strafe unentbehrlich «. ${ }^{36}$ Es war für Merian nicht die Frage, ob und wenn ja wie Strafe allenfalls notwendig sei. Die Notwendigkeit der Strafe wurde als natürlich bzw. göttlich gegeben angesehen, was mit einem Zitat Salomons aus den Sprüchen unterstützt wurde: "Laß nicht $a b$, den Knaben zu züchtigen; denn wenn $d u$ ihn mit der Ruthe hauest, so darfman ihn nicht tödten, sagt Salomo, Sprüchw. 23,13 «. ${ }^{37}$ Hingegen wurde auch bei Merian die »pädagogische Anwendung« der Strafe be-

31 Ebd., S. 111.

32 Ebd.

33 Ebd.

34 Merian 1779, S. 4.

35 Ebd., S. 46.

36 Ebd., S. $46 f$.

37 Ebd., S. 47. 
tont, da Strafen nur dann sinnvoll seien, wenn sie sowohl den Bestraften als auch die »Zuschauenden« davon abhalten würden, die bestrafte Tat ebenfalls oder erneut zu begehen. Das Strafen war damit für Merian nicht nur das Ausüben einer bestimmten Handlung bzw. das »reine« Sanktionieren einer nicht erwünschten Tat oder Äusserung, sondern stellt auch in dem Sinne eine Praktik dar, als damit eine normative Aussage verbunden war, die nicht nur die zu bestrafende Person betraf, sondern im konkreten Fall eine ganze Schulklasse.

Merian unterschied zudem zwischen verschiedenen »Fehlern«, die nicht alle zu bestrafen waren. Grundsätzlich durften nur »Fehler«, die nicht als »Naturfehler « zu klassieren waren, das heisst Fehlverhalten, das nicht auf eine körperliche Schwäche oder ein Defizit zurückzuführen sei, bestraft werden. Wenn etwa Schulaufgaben wegen mangelnder Gedächtnisleistung nicht zur Zufriedenheit des Schulmeisters ausgeführt wurden oder die Schüler auf Fragen nicht die richtige Antwort gaben, dann war unter bestimmten Umständen von einer Bestrafung abzusehen. Konkret war dies etwa dann der Fall, wenn der Schüler oder die Schülerin die Aufgaben nicht aus Faulheit, sondern aus intellektuellem Unvermögen oder einer anderen nicht selbst verschuldeten Ursache nicht oder falsch erledigt hatte. Gründete das Nichtwissen allerdings auf Faulheit, dann lag ein moralisches Fehlverhalten vor, das zu bestrafen war. ${ }^{38}$

Merian unterschied nicht nur verschiedene Fehler, Unterschiede gab es auch bei der konkreten Strafpraxis, wobei diese nicht primär und auch nicht ausschliesslich aus Körperstrafen bestand. Grundsätzlich sollte zuerst mit Worten bestraft werden, wobei auch hier darauf zu achten war, dass strafende Worte nicht im Affekt ausgesprochen wurden. ${ }^{39}$ Ausführlich wurde zudem darauf verwiesen, dass und vor allem auch wie die Einsicht in die "pädagogische Notwendigkeit« der Strafe beim zu bestrafenden Kind hervorzurufen sei. "Stellet ihm vor, wie ihr es ungerne thut; es euch aber zwinge, weil es so gütigen Ermahnungen und Warnungen nicht gefolget habe; wie ihr es vor Gott zu verantworten hättet, wenn ihr das Böse dulden, und nicht strafen würdet; und wie es sein gröstes Unglück wäre, wenn ihr es ungestraft lassen würdet.$^{40}$ Strafen wurde als (religiöse) Pflicht charakterisiert, die schlimmeres Fehlverhalten verhindere, wobei deutlich zwischen einer Zeit für den Unterricht und einer Zeit für die Bestrafung getrennt wurde. Bestrafungen hatten immer erst nach dem Unterricht zu erfolgen, wobei auch darauf zu achten war, diese »unpartheyisch $\aleph^{41}$ auszuführen. Gegen eine reale oder diskursiv als real konstruierte Strafpraxis, die von Merian als ungerecht

\footnotetext{
38 Ebd.

39 Ebd., S. 48.

40 Ebd.

41 Ebd., S. 49.
} 
etikettiert wurde, zeigte der Leitfaden alternative Handlungsmöglichkeiten auf, wobei eine solche Beschreibung auch als normsetzende Praktik zu verstehen ist.

Trotz der zahlreichen Gemeinsamkeiten in den beiden Leitfäden von Brünings und Merian werden in diesen Publikationen auch unterschiedliche Strafverständnisse sichtbar. Die beiden Anleitungen teilten zweifellos die Überzeugung, dass zwischen »moralischen « und "andern« Fehlern zu unterscheiden sei, wobei nur die »moralischen« Fehler zu bestrafen waren. Welches Verhalten allerdings als "moralisches« Fehlverhalten $\mathrm{zu}$ bewerten war sowie die Frage, ob eine grundsätzliche Notwendigkeit für Strafen bestehe, wurde unterschiedlich eingeschätzt. Übereinstimmung wiederum herrschte in der Betonung der Trennung von Unterricht und Bestrafung sowie in den verschiedenen Hinweisen zur Körperstrafe bzw. den damit verbundenen Ermahnungen, nicht im Affekt und nicht auf empfindliche Körperteile wie den Kopf zu schlagen. Das lässt darauf schliessen, dass diese Strafen nicht nur existierten, sondern dass sie vor allem auch als unpassend und als zu vermeidend beurteilt wurden. Strafen werden somit in diesen beiden Anleitungen als durchaus alltägliche historische Praxis des Schulmeisters dargestellt, die ohne grosses Nachdenken und als `kulturelle Selbstverständlichkeit a ausgeübt wurde. Entgegen diesen Gewohnheiten versuchten die Handreichungen die mit dieser Praxis verbundenen Normvorstellungen durch die Beschreibung von alternativen Handlungsmöglichkeiten zu verändern, wobei diese Alternativen nicht theoretisch oder normativ, sondern mit Verweis auf die eigene, erfolgreiche Praxis begründet wurden. Damit lässt sich die in den Handreichungen beschriebene Strafpraxis auch als normgebende Praktik verstehen mit dem Ziel, eine konkrete Praxis zu modifizieren.

\section{Felbigers und Crauers Methodenbuch}

Das Thema "Schulzucht « wurde auch in Felbigers und in Crauers Methodenbuch diskutiert, den beiden wesentlichen Handreichungen für Schulmeister in katholischen Regionen Mitteleuropas bzw. der Schweiz. Vergleichbar zur Brünings und Merian betonte Felbiger in seiner 1775 erstmals erschienenen Publikation die Stufenförmigkeit von Strafen, wobei er ein sehr differenziertes Stufensystem vorschlug. Dieses reichte von mündlicher Ermahnung bis zur körperlichen Bestrafung mit der Rute und schloss auch den Schulausschluss mit ein, eine Strafe, die dann anzuwenden war, wenn körperliche Züchtigung nicht zum gewünschten Erfolg führe. ${ }^{42}$ Am ausführlichsten diskutierte Felbiger die Sanktion von Fehlver-

42 Felbiger 1775, S. 450. Die einzelnen Strafen wurden bei Felbiger detailliert beschrieben, womit das Methodenbuch seinen Anspruch, eine ausführliche und auf die Praxis hin orientierte Handreichung für Lehrer und Schulbehörden zu sein, wohl am »praxistauglichsten« von al- 
halten durch »Strafen «, da hier in den Schulen »meistens [...] übertrieben « werde, ${ }^{43}$ womit auch Felbiger wie schon Brünings und Merian auf die Alltäglichkeit des Strafens hinweist. Auch Felbiger ging davon aus, dass körperliche oder geistige Fehler, die auf Unvermögen beruhten, nicht zu bestrafen seien. »Temperamentsfehler« hatten bei Felbiger ebenfalls keine Bestrafung zur Folge, wobei zwischen denjenigen Fehlern unterschieden wurde, die aus »Uibereilung« und denjenigen, die aus »Unbesonnenheit« resultierten. ${ }^{44}$ Während die der Hektik geschuldeten Fehler straflos blieben, waren Fehler aus Unbesonnenheit, die bei Brünings als Fehler der »Sekundärtugenden« oder als »Verhaltensfehler« bezeichnet wurden »Flüchtigkeit, Unachtsamkeit, Schläfrigkeit, und Langsamkeit«- ${ }^{45}$ durchaus zu bestrafen.

Ebenfalls nicht zu bestrafen waren Fehler, die ausserhalb der Schule bzw. der Unterrichtszeit vorgefallen waren, oder Fehler, für welche nicht die Schüler, sondern deren Eltern, das Gesinde oder weitere Mitglieder des Haushalts verantwortlich waren. Während die Autoren der verschiedenen Anleitungen darin übereinstimmten - falls dieser Fall überhaupt thematisiert wurde -, dass die Schülerinnen und Schüler nicht für Fehler anderer verantwortlich gemacht werden durften, war der Umgang mit Fehlern, die ausserhalb der Schule oder der konkreten Unterrichtszeit begangen wurden, durchaus unterschiedlich. Bei Merian etwa - und mit ihm bei allen der hier diskutierten, aus protestantischer Feder stammenden Anleitungen - wurden die Schulmeister daran erinnert, dass sich ihre Aufgabe nicht auf die Unterrichtszeit beschränke, im Gegenteil. Sie irrten, wenn sie davon ausgehen würden, dass sie ihrem »Berufe schon ein Genüge gethan« hätten, wenn sie auf die »Kinder in der Kirche und in der Schule sehet. Eure Aufsicht und Sorgfalt für dieselben gehet noch weiter «, ${ }^{46}$ ermahnte etwa Merian seine Leserschaft. Er sprach in diesem Kontext zwar nicht von Strafen, wies aber darauf hin, dass sich die Schulmeister sowohl um das Verhalten der Schülerinnen und Schüler zu Hause als auch auf »der Gasse« zu kümmern hätten und dass sie die Kinder vor allem auch »auf der Gasse« ansprechen und sie zu ihrem Tun befragen sollten, um sie "an die göttliche Gegenwart und Allwissenheit « zu erinnern. ${ }^{47}$ Der erziehende Aspekt des Schulmeisterdaseins, von dem Strafen ein Teil war, er-

len hier diskutierten Handreichungen umsetzte. Es werden nicht nur die verschiedenen Stufen der Strafen - von den Ermahnungen über die Warnungen, Drohungen, Verheissungen bis hin zu den eigentlichen Strafen - minutiös beschrieben, sondern es wird auch zu jeder Strafform genau aufgezeigt, bei welchem Vergehen konkret welche Strafe wie umzusetzen war.

43 Ebd., S. 456.

44 Ebd., S. 457.

45 Ebd.

46 Merian 1779, S. 52.

47 Ebd. 
streckte sich damit ausdrücklich nicht nur auf die Schule, sondern war Teil des lokalen Kontextes, der dem Schulmeister eine zentrale Rolle zusprach.

Einig waren sich die verschiedenen Autoren darin, dass Fehler, die schon wiederholt angemahnt worden waren, zu bestrafen seien. Dazu zählte Felbiger konkret die Verletzung der Schulgesetze, »Unehrerbietigkeit, Widerspänstigkeit, Ungehorsam gegen die Vorgesetzten«, »Sünden« und »sündhafte Gewohnheiten, wodurch Gott beleidiget « werde - Lügen, üble Nachrede, Fluchen, Schwören, Versäumen des Gottesdienstes oder grober Mutwillen - und vor allem auch »Fehler, woran das Herz Theil nimmt «. ${ }^{48}$ Ebenfalls zu bestrafen war die »Verharrung in dem Bösen«, vor allem auch, wenn damit die Gefahr verbunden war, andere Schüler zu diesem Verhalten zu motivieren oder wenn sie von diesem Verhalten betroffen waren.

Während Felbiger bei den körperlichen Strafen und mündlichen Ermahnungen ähnliche Überlegungen formulierte, wie sie schon bei Brünings und Merian $\mathrm{zu}$ lesen gewesen waren, unterschied sich seine Einschätzung der Scham als mögliche Strafe ${ }^{49}$ "Alle Beschimpfungen und ehrenrührische Beschämungen « waren auch für Felbiger nicht akzeptabel. ${ }^{50}$ "Dagegen sind in Schulen gewisse Beschämungen nicht nur erlaubt, sondern auch nothwendig: solche nämlich, die auf ein Vergehen so zu sagen ganz natürlich passen.$^{51}$ Die Beschämung als Strafpraxis war demnach dann legitim, wenn auch das Fehlverhalten Scham zur Folge hatte und in alttestamentarischer Manier Gleiches mit Gleichem vergolten werden konnte.

Wieder in Übereinstimmung mit den Anleitungen von Brünings und Merian waren auch für Felbiger das Strafen im Affekt und das Strafen während der Unterrichtszeit zu vermeiden. Im Unterschied zu den (protestantischen) Anleitungen vertrat Felbiger allerdings das Prinzip der Reue, das nicht nur zur Einsicht in begangene Fehler führe und helfe, diese in Zukunft zu vermeiden. Reue konnte für Felbiger auch ein Grund darstellen, eine Bestrafung nicht nur auf später $\mathrm{zu}$ verschieben, sondern ganz darauf zu verzichten. Dabei war darauf zu achten, dass das Nachsehen einer Strafe oder deren Minderung den »Strafwürdigen, als auch einer ganzen Schule den größten Schaden « zufügen könne. ${ }^{52}$ »Bitten, Weinen, und Heulen eines Strafwürdigen « galten deshalb niemals als hinreichender Grund, eine Strafe aufzuschieben oder gar auszusetzen. Auch wenn der Lehrer »in Gefahr stünde durch die Erlassung der Strafe« sein Ansehen an der Schule zu

\footnotetext{
48 Felbiger 1775, S. 459.

49 Vgl. Frevert 2017, S. 84ff.

50 Felbiger 1775, S. 461.

51 Ebd., S. 462.

52 Ebd., S. 464.
} 
verlieren, durfte auf die Strafe nicht verzichtet werden. ${ }^{53}$ Strafverzicht war nur dann möglich, wenn der Fehler erstmalig aufgetreten war.

In Felbigers Augen besonders gefährlich war zudem die Tendenz der Schulmeister, bei besonders fähigen, fleissigen und begabten Schülern gelegentlich auf eine eigentlich angemessene Bestrafung zu verzichten, wobei dieses Verhalten umso öfter auftrete, je »besser« die schulischen Leistungen des Schülers seien. Diesen Lehrern legte er nochmals die Berücksichtigung seiner Strafgrundsätze nahe und betonte, dass das eben beschriebene Verhalten nicht nur für den einzelnen, nicht bestraften Schüler, längerfristig nachteilig sei, sondern dass es sich dabei vor allem auch um eine »Ungerechtigkeit" handle, die er als das "wahre Verderben solcher Kinder« bezeichnete..$^{54}$ Für Felbiger war damit nicht nur das Strafen an sich anleitungsbedürftig, sondern auch der Verzicht auf eine Strafe erforderte klare Kriterien. Sowohl die Ausübung als auch das Aussetzen einer Handlung hatten Folgen für Einstellungen und Verhalten, die gemäss den Ansprüchen, welche diese Anleitungen zu erfüllen versprachen, möglichst in eine kausale Beziehung zu bringen waren. Strafen war für Felbiger nicht nur eine konkrete Tätigkeit, die überlegt, mit dem notwendigen Sachverstand und mit Augenmass auszuführen war, sondern sie war auch eine pädagogische Handlung, deren Unterlassung problematisch werden konnte, weil durch das Nichtausführen falsche Anreize geschaffen und unerwünschten Normvorstellungen Vorschub geleistet wurde. Strafen war aber auch eine Tätigkeit, die nicht von persönlichen Gefühlen beeinflusst werden durfte, die ausschliesslich auf Verhaltensänderungen zielte und die im Fall des Schulmeisters auf die Zeit und den Ort der Schule und des Unterrichts beschränkt zu bleiben hatte.

Den Felbiger'schen Vorgaben folgte auch Crauers Methodenbuch (1786) weitgehend, auch wenn Crauer seine Bemerkungen zur Schulzucht wesentlich knapper formulierte. Was hingegen bei Crauer nicht $\mathrm{zu}$ finden ist, sind Ausführungen zur Reue und zur Möglichkeit, Strafen aufzuschieben oder ganz auszusetzen. Inwiefern diese Abweichungen der Nähe zum protestantischen Kontext geschuldet waren - Crauer war 1765 ins Kloster St. Urban eingetreten, das im Grenzgebiet zum protestantischen Oberaargau liegt -, kann nur vermutet werden. Die erfolgreiche Verbreitung der im 19. Jahrhundert in der Lehrerbildung verwendeten Geschichten der Erziehung zeigt allerdings, dass sich in protestantisch geprägten pädagogischen Kontexten bestimmte pädagogische Handlungsformen und Ausbildungstraditionen herausbildeten, die auch im katholischen Kontext als "richtig« und »weiterführend« angesehen wurden, weil die damit verbundene Intention nicht als konfessionell, sondern als pädagogisch konnotiert verstanden wurde. Für die Geschichten der Pädagogik bedeutet das, dass das in ihnen

53 Ebd.

54 Ebd., S. 465. 
vertretene Modell der beispielhaften Erzieher, an deren Vorbildfunktion sich die angehenden Lehrpersonen moralisch bilden konnten, sich auch in katholischen Kontexten durchsetzte - einfach mit katholischen Erzieherfiguren anstelle der protestantischen Klassiker. ${ }^{55}$ Reue und Strafverzicht könnten demnach als "nichtpädagogische« Handlung verstanden worden sein und deshalb keine Handlungsoption darstellen.

Auch die Stufeneinteilung der Fehler fiel bei Crauer knapper aus. Detailliertere Ausführungen und Überlegungen fehlen, Strafen wurden vielmehr als Fakt diskutiert, deren grundsätzliche Berechtigung nicht infrage zu stellen war. Aber auch hier wird deutlich: »Der Schullehrer muss bey dem Strafen nichts anders vor Augen haben, als die Besserung der Schüler, und er muss sich dabey gerecht zeigen, und die Strafe niemals im Zorne vollziehen $"{ }^{56}$ Strafen war auch bei Crauer eine sehr ernsthafte Angelegenheit, die nicht gedankenlos auszuführen war, sondern in der entsprechenden Gesinnung und mit der richtigen Absicht sollte das mit ihr verbundene Ziel erreicht werden können.

\section{Johannes Büels Bemerkungen für Landschullehrer}

Während die bisher vorgestellten Anleitungen die Themen Strafe und Schulzucht immer in eigenen Kapiteln diskutierten, sind in Büels Bemerkungen für Landschullehrer (1792) die entsprechenden Ausführungen über die ganze Publikation verstreut, wobei Büel seine Abschnitte nicht mit Titeln versah, sondern durchnummerierte. Dieses Handbuch erweckt deshalb eher den Eindruck einer assoziativ gereihten Sammlung von ausformulierten Merksätzen, die dem Schulmeister konkrete Handlungsanweisungen vermitteln, ohne ihn mit allzu ausführlichen Begründungen oder theoretischen Erklärungen zu »belasten«. Ergänzt wurden diese insgesamt 129 Abschnitte mit »ein paar Worten über Aufklärung " ${ }^{57}$ sowie einem Anhang, bestehend aus Auszügen von Johann Georg Hamanns Fünf Hirtenbriefen das Schuldrama betreffend (1763) und Adolph Freiherr Knigges Über den Umgang mit Menschen (1788). Abgesehen von diesem Anhang sei seine Schrift, so Büel in der Vorrede, »keine Compilation aus andern Erziehungsschriften, sondern einzig die Frucht meiner Aufmerksamkeit und meines Nachdenkens ${ }^{58}$ das nicht durch die Lektüre anderer Schriften behindert worden sei, habe er sich doch »des Lesens aller Schriften über Erziehung und Schulen so lange gänzlich [...] enthalten, bis ich den Charakter der Kinder und die Beschaffenheit meines Berufs

55 Tröhler 2013, S. $21 \mathrm{ff}$.

56 Crauer1786, S. 60.

57 Büel 1792, S. 107f.

58 Ebd., S. 6. 
selbst hinreichend [...] studiert « habe. ${ }^{59}$ Seine Ausführungen beruhten demnach vollständig auf seiner eigenen Erfahrung bzw. seiner schulmeisterlichen Tätigkeit. »Seit mehr als einem Jahr«, so Büel dann allerdings weiter, »lese ich alle Erziehungsschriften«. Dabei habe er nicht nur gemerkt, »wie viel schon gesagtes ich wieder sagte « und was er alles ausgelassen habe. Er habe beispielsweise auch gelernt, dass es einen Unterschied zwischen öffentlicher und privater Erziehung gebe, dass Erziehung auf dem Land und in der Stadt nicht identisch seien und »dass die ganze Erziehungskunst auf gewissen allgemeinen Grundsäzen beruhe, aus welchen ein verständiger Lehrer das besondre und lokale sich abstrahieren müsse.$^{60}$ Es gibt in Büels Einschätzung also durchaus so etwas wie eine »Theorie« der Erziehung, die allerdings auf die lokalen Bedingungen anzupassen sei. Seine Ausführungen zum Entstehungsprozess seiner Handreichung machen aber vor allem auch die Einteilung des Textes in nummerierte Abschnitte nachvollziehbar, die nicht einen durchgehenden, systematisch aufgebauten Text bilden, der sich an einer bestimmten Reihenfolge von Themen orientiert, sondern sich eher als Gedankensammlung auf der Basis einer bestimmten Erziehungs- und Unterrichtspraxis präsentiert, die weder einer Systematik folgt noch Allgemeingültigkeit beansprucht, die über die Darstellung der eigenen Erfahrung hinausreicht.

Auf den ersten 30 Seiten seiner Bemerkungen formulierte Büel Beobachtungen und Empfehlungen, die auf das Verhalten des Schulmeisters gegenüber Schülern, Eltern und Behörden zielten. Anschliessend beschäftigte er sich mit grundsätzlichen Überlegungen zum unterrichtlichen Handwerk und thematisierte das Verhalten der Schüler, bevor er in der 38. Bemerkung explizit auf das Thema Strafen und auf den Charakter des Schulmeisters zu sprechen kommt. ${ }^{61}$ Strafen wird von Büel nicht als Handlung oder Tätigkeit gesehen, die in bestimmten Situationen auszuüben oder zu unterlassen sei. Strafen wird vielmehr als moralisches Problem diskutiert, das mit der anthropologischen Frage verbunden wird, ob das Kind "gut« sei. ${ }^{62}$ Von der Antwort auf diese Frage unabhängig ging auch er davon aus, dass »Strafen [...] in einer Schule seyn« müssen, »so lange man in derselben Fehler und Vergehungen der Schüler antrefen wird. In der physischen und moralischen Welt sind Strafen mit Vergehungen immer in Verbindung; so sey es auch in der Schule!.$^{63}$ Fehler und Strafen waren für Büel reale Tatsachen, an

59 Ebd., S.7.

60 Ebd., S. 8.

61 In der vorhergehenden Bemerkung weist Büel darauf hin, dass »der Verfasser von Lienhard und Gertrud«, Johann Heinrich Pestalozzi, über Landschulen viel »Wahres und Trefendes« sage, »aber auch hie und da etwas, das Ideal ist und bleiben wird« (ebd., S. 31). Inwiefern diese Bemerkung einen Zusammenhang zum nachfolgenden Abschnitt hat, der sich dem Thema Strafen widmet, bleibt unklar.

62 Ebd., S. 57.

63 Ebd., S. 31. 
deren Existenz auf keine Weise etwas zu ändern oder die gar anzuzweifeln war, sondern mit denen umgegangen werden musste, wofür er die Lehrer durch seine Handreichung befähigen wollte.

Wie die bisher diskutierten Handreichungen unterschied auch Büel verschiedene Fehler und Strafen, betonte die graduelle Angemessenheit der Strafe und warnte vor Bestrafungen im Zorn. ${ }^{64}$ Die konkrete Strafhandlung war zudem in der Regel nicht eine körperliche Bestrafung, sondern fand vielmehr auf der moralischen Ebene statt. Auch hier zeigen sich keine Unterschiede zwischen seinen Überlegungen und den Ausführungen in den anderen Handreichungen. Strafen ging in der Regel mit Begriffen wie Ehre und Schande einher, und der zu Bestrafende wurde beschämt oder an seiner Ehre gepackt. Büel behauptete sogar, dass er, "seit dem ich Schule halte«, sich nur »ein einzigesmal genöthiget« gesehen habe, »einen Schüler zu schlagen «. ${ }^{65}$ Die körperliche Strafe, das wird auch bei Büel deutlich, war zwar eine existierende Strafpraxis. Die Autoren der verschiedenen Handbücher stellten sich aber auch auf den Standpunkt, dass es sich dabei um eine Massnahme handle, deren Anwendung nur sehr zurückhaltend zu empfehlen sei, wobei diese Zurückhaltung nicht explizit als normative Vorgabe, sondern vielmehr implizit formuliert wurde, indem die eigene Strafpraxis, die vornehmlich ohne Körperstrafe auskomme, als Norm setzende Praktik vorgestellt wurde.

Auf die moralische Dimension des Strafens zielte auch Büels Hinweis, dass die Schüler mit Blicken zu den erwünschten Verhaltensformen geführt werden sollten bzw. konnten. ${ }^{66}$ Es sei zudem darauf zu achten, dass die Strafen die persönliche Beziehung des Schülers zum Schulmeister nicht beeinträchtigen würden, ${ }^{67}$ weshalb eine Strafe nicht einfach nur auszuführen war, sondern jeweils auf die positiven und negativen Folgen der zu bestrafenden Handlung hinzuweisen sei. Um die Bedeutung der persönlichen Beziehung zu betonen bzw. als Hinweis auf die Qualität der damit verbundenen Strafpraxis, wies Büel darauf hin, dass seine Schüler ihn sogar darauf aufmerksam machen würden, wenn sie ihre Hausaufgaben nicht erledigt hätten, ein »Fehler«, der normalerweise eine Bestrafung nach sich ziehe und deshalb eher verschwiegen werde. Aber: „Warum sollte das Kind lügen, wenn das Geständniß der Wahrheit ihm keine harten Verweise, keine Strafe zuzieht? «. ${ }^{68}$ Für ihn war zudem unklar, ob eher »Böses« zu bestrafen oder »Gutes« zu fördern sei. ${ }^{69}$ »Wenn es nothwendig ist, dass ein Lehrer mit Klugheit strafe, so ist es gewiss nicht weniger nothwendig, dass er mit Klugheit lobe und

\footnotetext{
64 Ebd., S. $31 f$.

65 Ebd., S. 32.

66 Ebd., S. 51.

67 Ebd., S. 93.

68 Ebd., S. 77.

69 Ebd., S. 96.
} 
belohne ${ }^{70}$ Strafe - und das ist bei Büel im Vergleich zu den bisherigen Handreichungen ein neues Argument - wurde in einem grösseren Kontext der Herstellung von moralisch richtigem Verhalten verortet, dessen Praxis zwischen Lob und Strafe oszillierte.

Unabhängig von den verschiedenen inhaltlichen Schwerpunktsetzungen der einzelnen Handreichungen kann als durchgängiges Thema festgehalten werden, dass es sich bei der Beschreibung und bei der praktischen Bearbeitung von Fehlern und Strafen um ein Handlungsfeld handelte, das in einem Bereich stattfand, der als zwischen den Tätigkeitsbereichen der Eltern und Schulmeister liegend zu bezeichnen ist, wobei für die protestantischen Autoren, so auch für Büel, feststand, dass die Aufgabe des Lehrers über den Ort und die Zeit des Unterrichts hinausweise. Deshalb sei darauf zu achten, dass es nicht zu Konflikten mit den Eltern komme ${ }^{71}$ wobei die Frage der Abgrenzung nicht nur die Strafpraxis betraf, sondern sämtliche Tätigkeiten des Schulmeisters, die auf das Verhalten und die normative, sittliche und moralische Orientierung des Schülers zielten. In diesem Sinn war die Beschreibung der Strafpraxis auch Teil einer Praktik, welche die verschiedenen institutionellen Einflusssphären von Familie und Schule gegeneinander abzugrenzen suchte.

\section{Strafen in der Stapfer-Enquête}

Die in den Anleitungen und Handreichungen formulierten Überlegungen zu Fehlern und der damit verbundenen Strafen legen die Vermutung nahe, dass das Thema "Strafe« auch in der Schweizer Schulumfrage von 1799 präsent ist. Diese Erwartung wird allerdings enttäuscht, was zumindest teilweise mit dem Aufbau des Fragebogens erklärt werden kann, der nach den "Lokalverhältnissen«, dem »Unterricht«, den »Personalverhältnissen« und den »ökonomischen Verhältnissen« fragte und damit auf die »äußere« und »formale« Organisation und Gestaltung von Schule und Unterricht zielte und weniger die moralisch-normativen Seiten des Unterrichtens und des Lehrerseins in den Blick nahm. Die Äusserungen zu Strafen und Fehlern finden sich denn auch ausschliesslich in den ergänzenden »Bemerkungen", bei denen die antwortenden Lehrerinnen und Lehrer die Möglichkeit hatten, eigene Themen und Wünsche zu notieren sowie Vorschläge zur Reform und Verbesserung der Schule anzufügen. Die weitgehende Nichtberücksichtigung des Themenfelds von Fehlern und Strafe kann allerdings auch als Hinweis darauf gelesen werden, dass aus der Sicht der Schulmeister hier kein grosser Reform- bzw. Handlungsbedarf bestand oder zumindest kein Diskussionsbedarf

70 Ebd., S. 115.

71 Ebd., S. 61. 
darüber mit der helvetischen Regierung, das heisst mit der politischen Behörde. Möglicherweise waren Fehler und Strafen für die Schulmeister um 1800 aber auch im Vergleich $\mathrm{zu}$ anderen in den Bemerkungen angesprochenen Sachverhalten nicht das dominante Thema ihrer schulischen Praxis. ${ }^{72}$ Nur insgesamt sieben Lehrer - von insgesamt 918 Personen, die Bemerkungen formuliert hatten äusserten sich zu diesem Themenfeld. ${ }^{73}$ Von sehr viel höherem Interesse für die Schulmeister waren etwa der unregelmässige Unterrichtsbesuch, der Umgang mit ihren weiteren Pflichten neben dem Schulehalten, die ökonomischen Verhältnisse - hier vor allem die bescheidene Bezahlung und der ungenügende Zustand des Schulhauses ${ }^{74}$ - sowie institutionell-organisatorische Themen wie die Dauer des Schuljahres, die Organisation der Schülerinnen und Schüler in Klassen oder die fehlenden oder zumindest ungenügenden Ausbildungsmöglichkeiten für Lehrpersonen. ${ }^{75}$

Die Kontexte, in denen Fehler und Strafen trotz diesen einschränkenden Vorbemerkungen dennoch thematisiert wurden, sind sehr unterschiedlich. Der 26-jährige Thomas Ganginer beispielsweise, Priester und Lehrer an der katholischen Schule von Lachen im Kanton Linth, merkte an, dass alle Bemühungen, die Schulen zu verbessern und diese »nüzliche Einrichtung [...] allen Kindern [...] teilhaft zu machen«, nur dann erreicht werden könnten, wenn die Regierung die Schulmeister »jn Betreff anwendbaren Straffen unterstüzung leisten«, für die »stets müßigen Gaßenbetleren andere Einrichtung trefen«, auf die Durchsetzung

72 Vgl. Fuchs 2015, S. 165. Ein ähnliches Bild-das Nichtthematisieren eines erwarteten Themaswird bei der Erwähnung bzw. Nichterwähnung des Namens Pestalozzi in der Stapfer-Enquête sichtbar. Entgegen der historischen Erzählung, die Pestalozzi zu einer der entscheidenden Figuren der helvetischen Reformbewegung und der Schulgeschichte stilisiert, wird er in der Stapfer-Enquête - wie eigentlich sämtliche, am Ende des Ancien Regimes verfügbaren pädagogischen Theorieangebote -, nicht oder kaum diskutiert (Fuchs 2015, S. 225f.; vgl. Horlacher 2014).

73 Eine Abfrage der Datenbank mit den Stichworten »Strafe« und »bestrafen « ergibt acht Treffer. Die französischsprachigen Texte wurden hier nicht berücksichtigt, da die diskutierten Anleitungen und Handreichungen auf das deutschsprachige Publikum gerichtet waren. Einer der Treffer, Lehrer Peter Badertscher aus dem bernischen Ebnit, spricht nicht die Strafpraxis im Unterricht an, sondern die finanziellen Folgen für die Schule, wenn die Eltern dafür bestraft werden, dass sie ihre Kinder nicht regelmässig zur Schule schickten. Das Problem sah Badertscher darin, dass die Kinder in diesem Fall überhaupt nicht mehr zur Schule gingen und er auf das entsprechende Schulgeld verzichten müsse (Stapfer-Enquête, Nr. 705). Das Thema Strafe in einem weiteren Verständnis wurde natürlich auch ohne die Verwendung dieser beiden Stichworte diskutiert, dies vor allem im Zusammenhang mit Disziplin. Da hier allerdings die Straf- und Fehlerpraktik im Zentrum steht, wurde ausschliesslich auf Nennungen fokussiert, die explizit die Strafe bzw. deren konkrete Anwendung ansprechen. 
der Schulpflicht bei den Eltern geachtet werde und Bemühungen unternommen würden, »gutte Schuhl Männer zu bekommen « ${ }^{76}$ Für Ganginer war die obrigkeitliche Unterstützung als formale Absicherung des "zulässigen« oder »angemessenen« Strafens eine der vier Hauptforderungen auf dem Weg zu einer Verbesserung des Schulwesens. Dass diese Forderung nicht nur an erster Stelle formuliert, sondern auch neben die Forderung nach qualitativ »besseren « Lehrpersonen gestellt wurde - eines der Hauptanliegen aller mit der Reform und Verbesserung des Schulwesens beteiligten Akteure -, unterstreicht die Bedeutung, welche das Strafen zumindest für den Schulmeister Ganginer in seiner alltäglichen Handlungsweise hatte.

Teilweise ähnliche Überlegungen formulierte auch Christoph Sulzer, Pfarrer und Lehrer in Brunnadern, Kanton Säntis, der wünschte, dass »zwekmäßige Belohnungen, u. Straffen da« seien. Während Belohnungen und Ermunterungen vollständig fehlten - Sulzer dachte hier konkret an Bücherprämien, schönes Schreibpapier oder Lobsprüche -, würden Fehler ausschließlich mit Schlägen bestraft. In seinen Augen sollten Strafen »beschämend« und Belohnungen »ermunternd« sein. ${ }^{77}$ Ähnlich äusserte sich auch Bendicht Hofer aus Heimiswil, Kanton Bern, der sich »schikliche Belohnungen, und Straffen für Elteren und Kinder « wünschte. ${ }^{78}$ Diese Bemerkungen lassen eine im Vergleich zu den verschiedenen Anleitungen und Handreichungen unterschiedliche Strafpraxis sichtbar werden. Während die Autoren der Handreichungen körperliche Strafen eher als nur selten anzuwendendes Strafmittel propagierten, beschreibt Sulzer diese eher als übliche Handlungen, was nochmals darauf hinweist, dass die Beschreibung der eigenen Strafpraxis in den Anleitungen und Handreichungen auch als normgebende Praktik zu verstehen ist, da sie nicht nur eine reale oder erwünschte Strafpraxis beschreiben, sondern in und durch diese Beschreibung eine Praxis verändern wollten.

Jacob Grundlehner hingegen, 38 Jahre alt, Vater von sieben Kindern und seit 19 Jahren Lehrer in Amriswil, Kanton Thurgau, sprach das Thema Strafen nur ganz kurz und eher beiläufig an, als er sich zu den für einen guten Lehrer notwendigen Charaktereigenschaften äusserte. Die Schulmeister sollten nicht nur »eine gutte Erziehung genoßen« haben, sondern in dieser »Kunst auch selbst geübt« sein sowie eine "sanfte Gemüths-Art besizen, damit sie bey der Bestraffung der Boosheiten, und Lasterhaften Vergehungen der Kinder bedachtsam zu werke gehen«. Das sei besonders deshalb wichtig, um »nicht im Zorn und Hize einem Kinde einen gefährlichen Streich « zu versetzen, der dann bedauert werde. ${ }^{79}$ Der

\footnotetext{
76 Stapfer-Enquête, Nr. 448.

77 Ebd., Nr. 1181.

78 Ebd., Nr. 1374.

79 Ebd., Nr. 85.
} 
Lehrer sollte also nicht nur über eine gute Ausbildung verfügen, sondern vor allem auch Geduld und Augenmass haben. Wie schon in den verschiedenen Anleitungsbüchern warnte auch Grundlehner vor Affekthandlungen, die - so kann zumindest die häufige Warnung davor interpretiert werden - wenn auch nicht an der Tagesordnung, so doch eine einigermassen häufige Praxis waren; durchaus auch mit gravierenden körperlichen Folgen, sicher aber mit Gewissensbissen seitens der Schulmeister.

Die wohl ausführlichsten Überlegungen zu Strafen und Fehlern formulierte der Lehrer der reformierten Schule in Glarus Jacob Steinmüller und Vater von Johann Rudolf Steinmüller (1773-1835), zu dieser Zeit Erziehungsrat des Kantons Säntis. Steinmüllers Bemerkungen am Ende des Fragebogens waren vollständig der Bestrafung der »Fehler meiner Zöglinge« gewidmet, wobei auch er »Stecken und Rute (welch leztere [sic!] mir unerträglich wäre) [...] noch immer aus meiner Schule verbannet« habe. Anstelle der körperlichen Bestrafung versuche er, seine "Kinder theils durch Liebe zugewinnen theils durch Ehrbegierde zum Rechtthun anzufachen«. Auch Steinmüller bezog seine Strafpraxis auf die moralische Ebene. Die Herstellung der inneren Einsicht ins richtige Tun stand im Zentrum sowie die Frage, welche Hilfsmittel diesen Prozess der Einsicht am wirksamsten unterstützten. Dazu passt, dass durch "Scham« bestraft wurde, dass Strafen auf den folgenden Tag verschoben werden konnten, um wegen der damit verbundenen Wartezeit die Wirksamkeit der Strafe zu erhöhen, was sich insgesamt als erfolgreicher gezeigt habe als »derbe Schläge«. Um zu verhindern, dass »keine vergehungen ungeahndet vorbey gehen «, hatte Steinmüller zudem ein System von Aufsehern eingerichtet, die in seinem Auftrag bzw. in seinem Namen das Tun und Verhalten der Schüler beobachteten und Fehlverhalten meldeten, damit dieses bestraft werden konnte. Die Steinmüller'sche Strafpraxis war damit durchaus umfassend..$^{80}$

Vergleichbar zu den Handreichungen unterschied auch Steinmüller zwischen Fehlern aus »Unwissenheit« und Fehlern aus »vorsezlicher Bosheit«, wobei in seinen Augen erschwerend hinzukomme, dass die Schüler aus ganz unterschiedlichen Familien stammten und deshalb auch "von so verschiedener Erziechung" seien. ${ }^{81}$ Umso mehr sei darauf zu achten, dass den Schülern »die Schul zu keinem Joch« gemacht, sondern dass sie gern zur Schule gehen würden, was Steinmüller

80 Ebd., Nr. 559.

81 Die unterschiedliche Bestrafung von Fehlern war auch bei Bendicht Arn aus Kappelen, Kanton Bern, Thema, wobei es Fehler gebe wie »augenscheinlicher Mutwillen, Lügen und Verführung der kleineren«, die zwingend zu bestrafen seien. Gedächtnisfehler hingegen, »kindliche Flatterhaftigkeit oder auch der Versaümniße deren die Eltern Schuld haben «seien nicht zu bestrafen, da dies kontraproduktiv wirke. Zudem sei »die öfftere Einschärfung der Cerechtigkeit und Treü, und der Tadel deß Müßiggangs und eines schlechten unedlen Betragens [...] sehr heilsam« (ebd., Nr. 829). 
seine Schüler auch immer wieder explizit fragte. "Schon oft sezte ich sie auch auf die Prob, ob sie lieber Feyrtag halten, oder in die Schul kommen wollen? und mit vergnügen, wählten sie lezteres « ${ }^{82}$

Steinmüllers ausführliche Bemerkungen zu seiner Strafpraxis und den sie leitenden Überzeugungen decken sich weitgehend mit den in den verschiedenen Anleitungen sichtbar gewordenen Strafpraktiken. Steinmüllers Bemerkungen können auch in dem Sinne als Praktik verstanden werden, als sie eine erfolgreiche Praxis beschreiben, die in ihrer Verschriftlichung Vorbildfunktion zugesprochen wurde, wenn auch nicht für den praktisch tätigen Schulmeister, so doch für die, für die Schulen politisch Verantwortlichen. In dem Sinne hatte Steinmüllers Beschreibung seiner Strafpraxis einen anderen Adressatenkreis im Blick als die Anleitungen und Handreichungen für Schulmeister, die damit verbundene Praktik Normsetzung durch die Beschreibung der eigenen praktischen Erfahrung - war hingegen identisch.

\section{Die Praxis des Strafens als soziale Praktik}

Der Fokus auf Fehler und Strafen und die damit verbundenen Handlungen in den verschiedenen Anleitungen und Handreichungen für Schulmeister sowie in der Stapfer-Enquête hat eine durchaus vielfältige Strafpraxis in Schule und Unterricht zutage gefördert. Es liessen sich Themenbereiche und Handlungsformen identifizieren, die in allen Publikationen mehr oder weniger identisch diskutiert wurden, unabhängig davon, ob es sich um einen Leitfaden protestantischer oder katholischer Provenienz handelte und auch unabhängig davon, ob die Erfahrungen des Autors aus der Alten Eidgenossenschaft, dem Alten Reich oder dem Habsburgerreich stammten. Auch wenn die konfessionelle Herkunft der Leitfäden möglicherweise unterschiedliche Vorstellungen von Fehler und Strafen präformierte - vor allem der Hinweis auf Reue ist in diesem Zusammenhang ein auffälliger Unterschied -, so hatte die politische oder geografische Situierung der Fehler- und Strafpraxis doch darüber hinaus keine weitreichende Bedeutung für die hier diskutierte Fragestellung. Der Umgang mit körperlichen Strafen, die Frage nach der Angemessenheit der Bestrafung, der erzieherische Aspekt der Strafhandlung sowie die richtige Haltung sowohl der Strafenden als auch der zu bestrafenden Person stellten sich als die immer wiederkehrenden Themen der Diskussionen um Fehler und Strafe heraus.

Die verschiedenen Handreichungen und Anleitungen haben sich zudem in unterschiedlicher Detailliertheit darum bemüht, möglichst direkte Handlungsanleitungen oder -leitlinien zu formulieren, auf welche die Schulmeister bei Be- 
darf zurückgreifen konnten. Es ist auch deutlich geworden, dass die Anleitungen und Handreichungen das Thema Fehler und Strafen kaum auf der explizit normativen Ebene diskutierten, sondern vor allem auf der Ebene der Praxisanleitung, was mit der Textgattung und den damit verbundenen Ansprüchen der Autoren zusammenhängt. In sämtlichen Anleitungen wurde zudem mehr oder weniger explizit darauf hingewiesen, dass diese Publikationen keine theoretischen Abhandlungen, sondern aus der Praxis und für die Praxis entstanden seien, wobei die konkrete Beschreibung der strafenden Handlungen nicht als Abbild einer bestimmten Realität, sondern eher als absichtsvolle Formulierung der zugrundeliegenden Überzeugungen oder eben als Praktik zu verstehen ist. Auf welcher Basis oder aufgrund welcher Überlegungen die einzelnen Autoren bestimmte Strafformen ausübten und damit als sinnvoll oder effektiv empfahlen, wird in diesen Anleitungen und Handreichungen höchstens marginal diskutiert, in der Regel aber einfach mit dem »what worked«-Argument legitimiert. Die eigenen Erfahrungen und die als erfolgreich erlebte und beschriebene Praxis wurden als Modell gesetzt, wobei die Dignität der praktischen Erfahrung nicht zur Diskussion stand.

Trotz zahlreichen, seit dem 18. Jahrhundert immer wieder sichtbar werdenden Bemühungen, die Legitimität der eigenen Erfahrung für generelle Aussagen oder zur Theoriebildung in Zweifel zu ziehen bzw. deren Grenzen aufzuzeigen, ${ }^{83}$ hat diese Praktik nichts von ihrer Faszination und Wirksamkeit verloren. Eine Forschungsperspektive, welche Praktiken in den Blick nimmt, hat sich damit auch als interessanter Fokus erwiesen, einen Zugang zur Frage nach der anhaltenden Bedeutung von Ratgeberliteratur zu eröffnen. Die Beschreibungen der verschiedenen Strafpraxen und Strafpraktiken in den Anleitungen, Handbüchern und in den Bemerkungen der Stapfer-Enquête haben aber auch gezeigt, dass auch eine auf Praxis und Praktik fokussierte Perspektive keine historische Realität zu rekonstruieren vermag, sondern dass es auch hier im Wesentlichen darum geht, so gut wie möglich zu rekonstruieren, was gemeint war, wenn etwas gesagt bzw. getan wurde. Dieses Tun-als-Sagen kann allerdings sehr wohl als Teil von Praktiken untersucht werden, weil so auch Tätigkeiten und Wirkmechanismen in den Blick genommen werden können, die mit einer andern methodologischen Perspektive weniger oder überhaupt nicht sichtbar gemacht werden können. In dem Sinn ist eine auf Praktiken fokussierte Perspektive genauso fruchtbar und »nützlich" wie jede andere methodologische Perspektive, da es auch hier primär darum geht, Fragestellung, Quellen und Methoden in eine produktive Übereinstimmung zu

83 Die Grenzen einer auf der persönlichen Erfahrung beruhenden Ratgeberliteratur wurde nur wenige Jahre später von Johann Friedrich Herbart in seiner Allgemeinen Pädagogik (1806) kritisch diskutiert. Herbart wies darauf hin, dass die Erfahrungen einer einzelnen Person immer nur einen beschränkten Einblick in potenzielle Handlungsmöglichkeiten biete, weshalb er sich mit der Frage beschäftigte, wie diese empirischen Erfahrungen systematisch bearbeitet werden können (S. 7f.). 
bringen, wobei der Entscheid für den einen und damit auch gegen einen anderen Zugang immer auch eine Frage der subjektiven Präferenz ist. ${ }^{84}$

Der Entscheid für einen Zugang ist allerdings unabhängig von der subjektiven Präferenz davon abhängig, welche methodologischen Perspektiven mit welchen Fragestellungen und welchen Quellen interessante im Sinne von die Diskussion anregende oder weiterführende Ergebnisse hervorbringen können. Ein Fokus auf Praktiken ist im bildungshistorischen Kontext durchaus weiterführend, hilft er doch, Bildungsgeschichte von ihrer traditionellen Fokussiertheit auf Personen, Institutionen und politische Rahmenbedingungen zu lösen und eine kulturgeschichtlich orientierte Perspektive zu stärken, die Phänomene von Erziehung und Bildung in ihrer gesamten Breite wohl besser im Sinn von adäquater in den Blick zu nehmen vermag. Dies soll aber nicht als Plädoyer für einen Foucault'schen Diskursbegriff verstanden werden, der vollständig auf Subjekte in der Bildungsgeschichte verzichtet. Vielmehr ist es ein Hinweis darauf - und das sollte der Beitrag zeigen -, dass Personen, Institutionen und politische Rahmenbedingungen durchaus eine Rolle spielen, dass diese aber nicht als zentrale Akteure zu verstehen sind, um die herum Bildungsgeschichte zu erzählen ist, sondern dass sie Texte und Kontexte für eine Bildungsgeschichte darstellen, die inhaltlich bestimmte Fragen stellt und auf dieser Basis historische Sachverhalte in den Blick nimmt und damit danach fragt, was Phänomene und Ereignisse in der Zeit und für die Zeit bedeute(te)n.

\section{Quellen und Literatur}

\section{Quellen}

Büel, Johannes (1792): Bemerkungen für Landschullehrer und für Freunde derselben. Nürnberg.

Brünings, Gottfried Christian (1778): Anleitung zu fruchtbarer Lehrart in den niedern Schulen. Mannheim.

Crauer, Nivard (1786): Methodenbuch für die Lehrer der Normal-Stadt- und Landschulen in der Republik Solothurn. O.O.

Ephemeriden der Menschheit, oder Bibliothek der Sittenlehre, der Politik und der Gesezgebung, Erster Band (1780). Leipzig.

Felbiger, Johann Ignaz von (1775): Methodenbuch für Lehrer der deutschen Schulen in den kaiserlich-königlichen Erblanden. Wien.

Herbart, Johann Friedrich (1806): Allgemeine Pädagogik aus dem Zweck der Erziehung abgeleitet. Göttingen.

84 Pohlig 2008. 
[Merian, Emanuel] (1779): Anleitung für die Landschulmeister. Basel. Schulordnung (1766): Der Stadt Basel Schulordnung. O.O.

Stapfer-Enquête (1799): Edition der helvetischen Schulumfrage von 1799; www. stapferenquete.ch

\section{Literatur}

Alkemeyer, Thomas/Buschmann, Nikolaus/Michaeler, Matthias (2015): Kritik der Praxis. Plädoyer für eine subjektivierungstheoretische Erweiterung der Praxistheorien. In: Ders./Volker Schürmann/Jörg Volbers (Hg.): Praxis denken. Konzepte und Kritik. Wiesbaden, S. 25-50.

Benner, Dietrich (1987): Allgemeine Pädagogik. Eine systematisch-problemgeschichtliche Einführung in die Grundstruktur pädagogischen Denkens und Handelns. Weinheim, Basel.

Brühwiler, Ingrid (2014): Finanzierung des Bildungswesens in der Helvetischen Republik. Vielfalt - Entwicklungen - Herausforderungen. Bad Heilbrunn.

Carr, Edward Hallett (1961): What is history? Cambridge (UK).

Chartier, Roger (1992): Einleitung: Kulturgeschichte zwischen Repräsentationen und Praktiken. In: Chartier, Roger: Die unvollendete Vergangenheit. Geschichte und die Macht der Weltauslegung. Frankfurt a.M., S. 7-23.

Cuban, Larry (1984): How teachers taught: Constancy and change in American classrooms, 1880-1990. New York.

Derbolav, Josef (1975): Pädagogik und Politik. Eine systematisch-kritische Analyse ihrer Beziehungen: mit einem Anhang zur »Praxeologie«. Stuttgart.

Depaepe, Marc (2000a): Introduction. In: Ders. (Hg.): Order in progress. Everyday educational practice in Primary Schools Belgium, 1880-1970. Leuven, S. 9-17.

Depaepe, Marc (2000b): Developing a theoretical framework for the history of educational reality in the classroom. In: Ders. (Hg.): Order in progress. Everyday educational practice in Primary Schools Belgium, 1880-1970. Leuven, S. 19-53.

Dinges, Martin (1997): Normsetzung als Praxis? Oder: Warum werden die Normen zur Sachkultur und zum Verhalten so häufig wiederholt und was bedeutet dies für den Prozess der »Sozialdisziplinierung«? In: Gerhard Jaritz (Hg.): Norm und Praxis im Alltag des Mittelalters und der Frühen Neuzeit. Wien, S. 39-53.

Dinges, Martin (2002): Neue Kulturgeschichte. In: Joachim Eibach/Günther Lottes (Hg.): Kompass der Geschichtswissenschaft: ein Handbuch. Göttingen, S. 179-192.

Dross, Fritz (2006): Normale Praxis: Von neuen Konzepten in der Armenpflege, angestrengten Bemühungen zweier Medizinalräte und der erfolgreichen 
Nicht-Gründung eines Krankenhauses. In: Sebastian Schmidt/Jens Aspelmeier (Hg.): Norm und Praxis der Armenfürsorge in Spätmittelalter und früher Neuzeit. Stuttgart, S. 219-233.

Frevert, Ute (2017): Die Politik der Demütigung. Schauplätze von Macht und Ohnmacht. Frankfurt a.M.

Fuchs, Markus (2015): Lehrerinnen- und Lehrerperspektiven in der Helvetischen Republik. Bad Heilbrunn.

Herman, Frederik/Depaepe, Marc/Simon, Frank/Van Gorp, Angelo: Punishment as educational technology: A form of pedagogical inertia in schools? In: Paul Smeyers/Marc Depaepe (Hg.): Educational Research: Networks and Technologies. Dordrecht, S. 203-219.

Holenstein, André (2014): Reform und Rationalität. Die Enquêten in der Wissensund Verwaltungsgeschichte der Helvetischen Republik. In: Daniel Tröhler (Hg.): Volksschule um 1800. Studien im Umfeld der helvetischen Stapfer-Enquête 1799. Bad Heilbrunn, S. 13-32.

Horlacher, Rebekka (2014): Pestalozzi und die Lehrer um 1800. In: Daniel Tröhler (Hg.): Volksschule um 1800. Studien im Umfeld der Helvetischen Stapfer-Enquête 1799. Bad Heilbrunn, S. 135-148.

Horlacher, Rebekka (2018): Religion als Ausdruck kultureller Erwartungen an Schule. Religionsunterricht an Solothurner Schulen um 1800. In: Schweizerische Zeitschrift für Geschichte 2018, H. 3, S. 437-458.

Jaritz, Gerhard (1997): Norm und Praxis in Alltag und Sachkultur des Spätmittelalters: »Widerspruch« und »Entsprechung«. In: Ders. (Hg.): Norm und Praxis im Alltag des Mittelalters und der frühen Neuzeit. Wien, S. 7-19.

Mitterauer, Michael/Saurer, Edith (1993): Editorial. In: Historische Anthropologie. Kultur-Gesellschaft-Alltag 1, H. 1, S. 1-3.

Müller, Max (1995): Pädagogik und Erziehungswissenschaft. Der praxeologische Übergang bei Derbolav. Bern.

Pohlig, Matthias (2008): Geschmack und Urteilskraft. Historiker und die Theorie. In: Jens Hacke/Ders. (Hg.): Theorie in der Geschichtswissenschaft. Einblicke in die Praxis des historischen Forschens. Frankfurt a.M., New York, S. 25-39.

Popkewitz, Thomas S./Yates, Lyn/McCulloch, Gary/Westberg, Johannes/Piattoeva, Nelli/Cappelli, Gabriele/Head, Randolph C. (2018): The cult of facts, romanticizing the archive, and ignoring styles of reasoning: Delusive technologies of conducting historical research. In: Bildungsgeschichte. International Journal for the Historiography of Education 8, H. 2, S. 191-220.

Priem, Karin/König, Gudrun M./Casale, Rita (Hg.) (2012): Die Materialität der Erziehung. Kulturelle und soziale Aspekte pädagogischer Objekte. Weinheim, Basel. 
Schmidt, Sebastian/Aspelmeier, Jens (2006): Vorwort. In: Diess. (Hg.): Norm und Praxis der Armenfürsorge in Spätmittelalter und früher Neuzeit. Stuttgart, S. 7-14.

Skinner, Quentin (2002): Meaning and understanding in the history of ideas (1969). In: Ders.: Visions of Politics. Bd. I: Regarding Method. Cambridge (UK), S. 57-89.

Tröhler, Daniel (2013): Languages of Education. Protestant Legacies, National Identities, and Global Aspiration. New York. 


\title{
"Da ist die Frage, ob man's steuern kann, seinen Körper" \\ Praxeologische Betrachtungen des Kindergartenalltags
}

Anja Sieber Egger/Gisela Unterweger

\begin{abstract}
Wenn man als »kleinste Einheit« des Sozialen nicht ein Normensystem oder ein Symbolsystem, nicht »Diskurs « oder »Kommunikation« und auch nicht die »Interaktion «, sondern die »Praktik«annimmt, dann ist diese kleinste Einheit des Sozialen in einem routinisierten »nexus of doings and sayings « (Schatzki) zu suchen, welches durch ein implizites Verstehen zusammengehalten wird. [...] Es sind zwei >materielle Instanzen, die die Existenz einer Praktik ermöglichen [...]: die menschlichen »Körper« und die »Artefakte ${ }^{1}$
\end{abstract}

In diesem inzwischen vielzitierten Ausschnitt des für die Diskussionen rund um die Praxistheorie wichtigen Artikels von Andreas Reckwitz ${ }^{2}$ wird zentral angesprochen, was der nachfolgende Beitrag zum Ziel hat: Es soll die Vollzugswirklichkeit von Praktiken im schweizerischen Kindergarten über das Sprechen, die Körperbewegungen und den Einbezug von Artefakten erfasst und darüber hinaus diskutiert werden, was diese >materiellen Instanzen für die Positionierungen von Subjekten für Bedeutungen haben.

Doch wie wird Praxis, wie werden Praktiken überhaupt verstanden und diskutiert? Wenn wir Praktiken mit dem Soziologen Stefan Hirschauer in der saloppsten möglichen Form als das »unentwegte Gebrabbel von Körpern « ${ }^{3}$ definieren oder vom selben Autor, etwas genauer formuliert, als »Formen des kör-

Reckwitz 2003, S. 290.

2 Ebd.

3 Hirschauer 2017, S. 95. 
perlichen Vollzugs sozialer Phänomene «, ${ }^{4}$ dann wird mit der zweimaligen Erwähnung von Körperlichkeit der von Reckwitz bereits angesprochene wichtige Aspekt eines sozial- und kulturwissenschaftlichen Praktikenbegriffs deutlich, der nicht nur vom »practice turn «, 5 sondern auch stark vom »body turn « ${ }^{6}$ geprägt ist. Diese Überlegung fliesst nachfolgend in die Diskussion rund um die beschriebenen und analysierten Praktiken mit ein. Ebenso fliesst ein, dass neben der körperlichen Dimension wie eingangs angesprochen auch der Einbezug von Dingen oder Artefakten wichtig ist, die in ihrer Wechselwirkung mit menschlichen Aktivitäten betrachtet werden sollen. Die in jüngster Zeit formulierte Forderung, die »Materialität als materiell-diskursive Dimension von Praktiken ${ }^{7}$ in sozialwissenschaftliche und kindheitstheoretische Überlegungen einzubeziehen, soll anhand empirischer Ausführungen im Beitrag ebenfalls aufgenommen werden mit der Frage, wie die »Positionierung von Subjekten [...] gerade in der Befolgung unterschiedlicher normativer Erwartungen an den Gebrauch der Dinge ${ }^{8}$ in Alltagspraktiken im Kindergarten erkennbar wird. Darüber hinaus wird die Sinnhaftigkeit von Praktiken in einer spezifischen Art und Weise gefasst, nämlich als implizites, routinisiertes, wiederum körpergebundenes Wissen, als `knowing how ‘; ${ }^{9}$ dies in Abgrenzung zu einem klassischen Handlungsbegriff, der stärker mit einem intentional-rationalen Verständnis von Handlung ${ }^{10}$ einhergeht. Praktiken kommen in einem praxistheoretischen Verständnis »nicht als diskrete, individuelle und punktuelle Exemplare« vor - wie in einem sozialwissenschaftlich traditionelleren Verständnis von Handlung -, sondern sie sind eingebettet in eine "umfassendere, sozial geteilte und durch ein implizites, methodisches und interpretatives Wissen zusammengehaltene Praktik als ein typisiertes, routinisiertes und sozial verstehbares Bündel von Aktivitäten. «11

Die hier in aller Kürze aufgeführten drei Aspekte - Körperlichkeit, Dinge und sozial geteilte Sinnhaftigkeit - werden im nachfolgenden Beitrag auf der theoretischen Grundlage von Pierre Bourdieus Praxeologie ${ }^{12}$ (Abschnitt 1) und auf

\footnotetext{
4 Ebd., S. 91.

5 Vgl. Schatzki/Knorr-Cetina/Savigny 2001.

6 Vgl. Gugutzer 2015.

7 Rabenstein 2018, S. 15.

8 Ebd., S. 24.

9 Reckwitz 2003, S. 289.

10 Ebd., S. 291-294.

11 Ebd., S. 289.

12 Vgl. Bourdieu 2012.
} 
der empirischen Grundlage des Forschungsprojekts `Kinder, die auffallen $\aleph^{13}(\mathrm{Ab}-$ schnitt 2) diskutiert.

In unserem Forschungsprojekt, ebenso wie für den vorliegenden Beitrag, legen wir einen Fokus auf Praktiken der Anerkennung und Adressierung (Abschnitt 2). Wir betrachten mit einem ethnologisch-(schul-)ethnografischen Zugang ${ }^{14}$ den alltäglichen Vollzug solcher Praktiken, welche uns im Hinblick auf Prozesse der Subjektivierung und der Positionierung von Kindergartenkindern interessieren. Subjektivierung verstehen wir mit Butler (2001) als einen Prozess der Einpassung in (oder Unterwerfung unter) diskursiv zur Verfügung gestellte Subjektpositionen, welche über Adressierungen in Interaktionen vermittelt werden. Nach Sabine Reh und Norbert Ricken kann Adressiertheit als eine "Dimension interaktiver Praktiken $\ll^{15}$ verstanden werden, welche nicht nur "sprachlich, sondern auf verschiedenen Ebenen, in verschiedenen Modi erzeugt wird. ${ }^{16}$ Eine so gedachte Adressierung einer Person, also das Ansprechen als jemand (als freches Mädchen, als ordentliches Kind ...), führt zu deren sozialer Positionierung zumindest für die Zeitspanne der Interaktion, oft aber auch darüber hinaus. Das Konzept der Adressiertheit dient der in Abschnitt 3 vorgenommenen Interpretation der interessierenden Vollzugswirklichkeiten als analytische Heuristik. Leitend für die Analyse ist dabei die Frage, wie Kinder durch die Lehrpersonen angeleitet werden, situativ angemessene Praktiken des Kindergartenfeldes zu inkorporieren. Über die Frage dieser Inkorporierung von Praktiken hinaus widmen wir uns damit zusammenhängend auch der Frage nach den Anerkennungsverhältnissen bzw. dem Subjektivierungsgeschehen im Kindergarten. Resümierend (Abschnitt 4) fassen wir die Spezifik des Umgangs mit dem Kinderkörper und mit Artefakten im Kindergarten zusammen und beachten dabei vor allem die Aspekte der Habitualisierung und der Normativität der Praktiken.

13 SNF-Projekt (Nr. 159328): Kinder, die auffallen. Eine Ethnographie von Anerkennungsverhältnissen im Kindergarten. Geleitet von Anja Sieber Egger und Gisela Unterweger, unter Mitarbeit von Christoph Maeder, Ursina Jaeger und Fabienne Kaiser. Mitarbeit bis Ende 2018: Fränzi Buser, bis Mitte 2017: Alex Knoll. Laufzeit 2016-2019. Weitere Informationen online unter http://p3.snf.ch/project-159328 (Zugriff: 15.04.2020). Vgl. Sieber Egger/Unterweger 2018.

15 Reh/Ricken 2012, S. 43.

16 Ebd., S. 43. 


\section{Ethnologische Lesarten von Praxis und Pierre Bourdieus Praxeologie}

Die ethnologische Erforschung von Alltag und Kultur in den unterschiedlichsten Gesellschaften und Gemeinschaften hat von Beginn weg Praktiken in den Blick genommen und dazu die Feldforschung mit ihrer Kernmethode der langfristigen teilnehmenden Beobachtung eingesetzt. Marcel Mauss beispielsweise beschrieb in Soziologie und Anthropologie 2, ${ }^{17}$ ausgehend von Alltagsbeobachtungen, wie bestimmte körperliche Praktiken von Erziehung und Sozialisation geprägt sind. So gibt es nach Mauss kaum `natürliche`Arten zu gehen, sondern diese stellen soziale Eigenheiten dar. Er wählte als Bezeichnung für solche körperlichen, sozial verankerten Gewohnheiten den lateinischen Begriff »habitus«, den er im folgenden Ausschnitt der Verständlichkeit halber mit »habitudes« umschreibt:

Ces »habitudes « varient non pas simplement avec les individus et leurs imitations, elles varient surtout avec les sociétés, les éducations, les convenances et les modes, les prestiges. Il faut y voir des techniques et l'ouvrage de la raison pratique collective et individuelle, là où on ne voit d'ordinaire que l'âme et ses facultés de répétition. ${ }^{18}$

Wir meinen, dass man den von Mauss umschriebenen Habitus heute wohl eher mit dem Begriff >Praktiken bezeichnen würde. Praktiken, wie sie seit dem "practice turn « in unterschiedlichen Disziplinen theoretisiert werden, wurden in der Ethnologie insofern auch ohne eine so benannte praxeologische Programmatik spraktisch< erforscht. Die Beschreibung konkreter Praktiken konnte und kann als Ausgangspunkt für die Rekonstruktion von kulturellen Eigenlogiken eingesetzt werden. Dies alleine reicht jedoch nicht aus; eine Hinwendung zu theoretischen Überlegungen ist unumgänglich im Sinne einer Explizierung des eingesetzten Praktikenbegriffs. In diesem Zusammenhang setzen wir uns mit der einflussreichen Praxeologie von Pierre Bourdieu auseinander, einer Theorie, die darauf abzielt, das praxeologische Verständnis des Sozialen herauszuarbeiten, und die der frühe und damals noch stark ethnologisch ausgerichtete Bourdieu mittels Feldforschung bei den algerischen Kabylen erarbeitet hat. ${ }^{19}$

Mit seinem praxeologischen Ansatz konnte Pierre Bourdieu aufzeigen, warum Menschen Handlungsgewohnheiten haben und auch Handlungsbeschränkungen zeigen respektive, und hier geht Bourdieu über andere Sozialtheorien hinaus, mit welchen ihnen meist verborgenen Prinzipien Menschen handeln.

\footnotetext{
17 Mauss 1975, S. $201 \mathrm{ff}$.

18 Ebd. 1985, S. 368.

19 Vgl. Bourdieu 2012.
} 
Bourdieu setzte bekanntlich ebenfalls den Habitusbegriff ein - im Vergleich zu Mauss in einem stark erweiterten Bedeutungsumfang. In Bourdieus Verständnis fasst Habitus den leiblichen Charakter von Praxis, den Prozess zwischen einverleibten und objektiven Strukturen, denn in den Körper "gehen Strukturen ein und strukturieren ihn, sodass er wiederum die Praxis strukturierend wirken kann«. ${ }^{20}$ Mit seinen praxeologischen Überlegungen ging es Bourdieu darum, aufzuzeigen, dass der Habitus

als Produkt der Ceschichte [...] individuelle und kollektive Praktiken [produziert], [...] er gewährleistet die aktive Präsenz früherer Erfahrungen, die sich in jedem Organismus in Cestalt von Wahrnehmungs-, Denk- und Handlungsschemata niederschlagen und die Übereinstimmung und Konstantheit der Praktiken im Zeitverlauf viel sicherer als alle formalen Regeln und expliziten Normen zu gewährleisten suchen. ${ }^{21}$

Für den Vollzug der Praxis gilt bei Bourdieu, dass der Mensch sowohl ein innen- als auch aussengeleiteter Akteur mit einem Körper ist. Dieser Körper ist ein Gedächtnis, das jegliche praktische Erfahrung bis hin zu Bewegungsabläufen sammelt, speichert und bei Bedarf ausführt. In diesem andauernden Sammlungsund Speicherungsprozess ist der Mensch immer sozial eingebunden: Individuell selbstverständliche Handlungsschemata, um mit Bourdieu zu sprechen, verlangen nach kollektiver und sozialer Verständlichkeit und Anschlussfähigkeit, nach Anerkennungsmomenten sozusagen. Am Beispiel Schule führen Reh und Rabenstein diesen Gedanken folgendermassen weiter:

»Praktischen Erfordernissen« zu folgen, »Verhaltensregelmäßigkeiten« zu zeigen, indem man an Praktiken teilnimmt, ist also immer schon auch durch die Androhung von Sanktionen - nämlich der Nicht-Anerkennung, hier etwa der Nicht-Anerkennung als Schüler oder Schülerin - begleitet. $^{22}$

Der von Bourdieu eingesetzte Begriff der Praxis umfasst auch mehr als >nur das Handeln, verstanden als »Aktionen, Interaktionen, Sprechakte oder Spielzüge ${ }^{23}$ folgende weitere zwei Aspekte machen den Bourdieu'schen Praxisbegriff ebenso aus: `Arbeit< wie auch das >Herstellen/Hervorbringen «. Arbeit wird von Bourdieu weit gefasst: ${ }^{24}$ von der >schweren Plackereiく bis hin zu leichten >Tätigkeiten (wie

\footnotetext{
20 Fröhlich/Rehbein 2014, S. 197.

21 Bourdieu 1993, S. 101.

22 Reh/Rabenstein 2012, S. 229.

23 Fröhlich/Rehbein 2014, S. 199.

24 Ebd.
} 
bspw. in der Verwaltung), das Herstellen und das Hervorbringen betrifft Gegenstände wie auch Vollzugsmomente. Damit macht Bourdieu deutlich, dass Praxis mehr als nur >Handlung ist.

Der im Lauf der individuellen Biografie angeeignete Habitus stattet die einzelnen Personen mit einem praktischen Sinn für das Feld aus, in welchem sie sich aktiv bewegen. Dieser praktische Sinn ${ }^{25}$ lässt in bestimmten Situationen bestimmte Handlungsweisen als naheliegend oder gar zwingend erscheinen und schliesst andere aus. Er ist nicht bewusst und folgt keiner konventionellen Logik, sondern eben einer praktischen Logik, wie Bourdieu ausführt:

Die Idee der praktischen Logik als einer Logik an sich, ohne bewusste Überlegung oder logische Nachprüfung, ist ein Widerspruch in sich, der der logischen Logik trotzt. Genau nach dieser paradoxen Logik richtet sich jede Praxis, jeder praktische Sinn: gefangen von dem, um was es geht, völlig gegenwärtig in der Cegenwart und in den praktischen Funktionen, die sie in dieser in Cestalt objektiver Möglichkeiten entdeckt, schließt die Praxis den Rekurs auf sich selbst (d.h. auf die Vergangenheit) aus, da sie nichts von den sie beherrschenden Prinzipien und den Möglichkeiten weiß, die sie in sich trägt und nur entdecken kann, indem sie sie ausagiert, d.h. in der Zeit entfaltet. ${ }^{26}$

Das $>$ Wie $<$ einer Praktik - das $>$ Knowing how $<$ ist inkorporiert und so selbstverständlich, dass es schwer in Worte gefasst werden kann, und das `Wozu ist in Bourdieus Ausführungen den Akteuren sogar noch stärker verschleiert. So gesehen eröffnet Bourdieu den Zugang zum Impliziten: über die Beobachtung und Analyse von Praktiken. Der praktische Sinn, mit welchem der Habitus die Akteure ausstattet, erschliesst sich dabei erst über eine "Global- und Langzeitanalyse «, ${ }^{27}$ und im Mittelpunkt einer solchen Analyse stehen die Aktionen der Körper. Dies möchten wir anhand eines Ausschnitts aus unserem Forschungsprojekt aufzeigen. Interessant ist das Datenmaterial insbesondere auch deshalb, weil die darin vorkommenden Kinder Praktiken erst erlernen, weil sie angeleitet werden, situative und angemessene Praktiken körperlich zu verinnerlichen. Sie müssen den praktischen Sinn des Kindergarten- oder des Schulfeldes erst erschliessen und verinnerlichen, und in diesem Prozess wird Wissen, das später implizit und routinisiert vorhanden ist, erst einmal expliziert. In diesem Prozess bildet sich der

25 Vgl. Bourdieu 1993. Die deutsche Übersetzung des Buchtitels als >sozialer Sinn< ist unserer Ansicht nach verwirrend - wir sprechen daher auch im Deutschen von einem spraktischen Sinns.

26 Bourdieu 1993, S. 167 (Hervorhebung im Original).

27 Fröhlich/Rehbein 2014, S. 198. 
schulische Habitus vor dem Hintergrund der institutionellen Anforderungen erst heraus.

\section{Praktiken der Anerkennung und Adressierung im Kindergarten im Blick - das ethnografische Forschungsprojekt}

Das Forschungsprojekt »Kinder, die auffallen. Eine Ethnographie von Anerkennungsverhältnissen im Kindergarten« hat die Praxis der integrativen Schule auf der ersten Schulstufe zum Untersuchungsgegenstand - in der Schweiz gehört der zweijährige Kindergarten zur obligatorischen Schulzeit, die Kinder treten nach ihrem vierten Geburtstag in diese Institution ein. ${ }^{28}$ Seit der Einführung dieses Kindergarten-Obligatoriums ${ }^{29}$ wie auch des integrativen Modells beschulen Schweizer Kindergärten praktisch alle Kinder eines Schuljahrgangs. ${ }^{30}$ Der $>U m-$ gang mit einer heterogenen Schülerschaft im Kindergartenalltag entwickelt sich entsprechend immer stärker zu einer Kernanforderung pädagogischen Handelns. Im Fokus des Forschungsvorhabens steht dieser pädagogische Umgang mit Heterogenität, wobei Heterogenität nicht als eine gegebene und an den Kindergarten von aussen herangetragene Tatsache, sondern als situativ verhandelte Herstellung von Differenz verstanden wird. Es wird aus einer sozialkonstruktivistischen Perspektive darauf geblickt, wie Lehrpersonen in alltäglichen Praktiken zwischen Kindern unterscheiden, oder anders: wie es dazu kommt, dass Kinder auffallen, und welche Differenzlinien beziehungsweise Differenzkategorien ${ }^{31}$ dabei relevant gesetzt und in den Vordergrund gerückt werden.

Mit der Frage der impliziten und expliziten Unterscheidungspraktiken verbunden ist die Frage, wie Kinder in Anerkennungsprozessen positioniert und wie Normalitätsgrenzen ausgehandelt werden. Für das Projekt stehen sowohl die pädagogischen Praktiken der Lehrpersonen im sintegrativen Kindergarten, also ganz zu Beginn der Bildungslaufbahnen der Kinder, im Vordergrund als auch die Normalitätsvorstellungen der Lehrpersonen, wenn sie Kinder beobachten und unterscheiden. Es interessiert, wie die Aushandlung von Normen genau vonstatten geht. Diese Aushandlungen sind nicht nur verknüpft mit gesellschaftlichen und institutionellen Vorstellungen von normalem und abweichendem Verhalten,

28 Vgl. EDK 2007.

29 Dieses Kindergarten-Obligatorium war nicht nur ausschlaggebend für die Tertiarisierung der Lehrerinnen- und Lehrerausbildung für diese Stufe, es schlägt sich auch in der Benennung der Personen nieder, die auf dieser Stufe unterrichten: In der Schweiz wird von Kindergartenlehrpersonen gesprochen und nicht wie in Deutschland von Betreuerinnen und Betreuern.

Bildungsdirektion 2008, S. 5.

Vgl. West/Fenstermaker 1995. 
sondern damit zusammenhängend mit Prozessen der Anerkennung und der Subjektivierung der Kinder als Kindergartenkinder. Mit diesem zweiten Schritt wird der sozialkonstruktivistische Zugang, der nach der Herstellung von Wirklichkeit fragt, um einen poststrukturalistischen Ansatz erweitert, der das Wirken von diskursiv verankerten Normen (der Anerkennbarkeit) ergründet. Wir beziehen uns dazu auf die Überlegungen von Judith Butler. ${ }^{32}$ Butler setzt voraus, dass die Subjektwerdung über Prozesse der Anerkennung erfolgt und dabei gesellschaftliche Normen der Anerkennbarkeit wirksam werden. Anerkennung wird in diesem Sinne nicht als moralische Anforderung an die pädagogische Praxis verstanden, sondern primär als Ausgangsbedingung für die Subjektivierung von Kindern als Schülerinnen und Schüler.

Die Prozesse der Subjektivierung bei Kindergartenkindern werden anhand des Blicks auf die Adressiertheit von Praktiken erschlossen. Um Prozesse der Subjektivierung respektive der Anerkennung zu fassen und methodisch umsetzen zu können, sind die Überlegungen der Erziehungswissenschaftlerin Sabine Reh und des Erziehungswissenschaftlers Norbert Ricken ${ }^{33}$ hilfreich. Sie halten fest, dass Adressiertheit als eine »Dimension interaktiver Praktiken [...] verstanden werden kann, welche nicht nur sprachlich, sondern auf verschiedenen Ebenen, in verschiedenen Modi ${ }^{34}$ erzeugt wird. Die Adressiertheit von Praktiken konstituiert ein Verhältnis zwischen dem Agierenden und dem Angesprochenen, eine relationale Positionierung, auf welche der Angesprochene wiederum mit Readressierungen reagieren kann. Reh und Ricken schlagen vor, die Adressiertheit von Praktiken in ihrer Sequenzialität zu untersuchen, und stellen eine Heuristik von Fragen vor, welche eine Rekonstruktion solcher Sequenzen erlauben. In dieser Heuristik werden zuerst die Situationsdefinitionen und die normativen Horizonte (1) erkundet. Die Frage nach den Normen berührt verschiedene Ebenen: von konkreten Verhaltenserwartungen und Regeln bis $\mathrm{zu}$ »Formen der Intelligibilität $\aleph^{35}$ und insbesondere Normen der Anerkennbarkeit. Danach geht es um die Positionierungen der Akteure im Sinn einer Figuration (2) nach Elias: ${ }^{36}$ Die Frage nach dem Verhältnis zwischen den Positionierungen und ihren Interdependenzen wird ins Zentrum gestellt. Wie und als wer wird also jemand angesprochen und damit positioniert, und wie und als wer positioniert sich die sprechende Person selbst? In einem dritten Schritt wird nach den performativen Effekten der Adressierungssequenz gefragt, also nach der (vorläufig) erfolgten Positionierung

\footnotetext{
32 Vgl. Butler 2001; Butler 2014.

33 Vgl. Reh/Ricken 2012.

34 Ebd., S. 43.

35 Ebd., S. 44.

36 Vgl. Elias 2018.
} 
der angesprochenen Person. Auch hier wird dann noch einmal nach dem in der Adressierung gültig gemachten normativen Horizont gefragt. ${ }^{37}$

Wir folgen im nächsten Abschnitt diesem Dreischritt am Beispiel eines Beobachtungsprotokolls aus dem Kindergartenalltag. Das Datenmaterial für das Forschungsprojekt wurde während gut zwei Jahren von einer fünfköpfigen Forschungsgruppe im Rahmen einer Team-Ethnografie ${ }^{38}$ in drei sozioökonomisch unterschiedlich situierten Kindergärten in einer Schweizer Grossstadt erhoben; in diesem Beitrag steht einer dieser Kindergärten im Fokus. ${ }^{39}$ Es ist der Kindergarten Sonnwies, der von Kindern aus wohlhabenden Familien besucht wird. Mit Ausnahme einer Familie verfügen die Eltern, mehrheitlich sowohl Väter als auch Mütter, über eine akademische Ausbildung und sind in prestigeträchtigen Berufen positioniert (Akademie, Kunst, Beratung und Recht, global tätigen Konzernen und Organisationen, Bildungsbereich). Die rfeinen Unterschiede ${ }^{40}$ innerhalb dieses gut situierten Milieus fehlen allerdings nicht. Die unterschiedliche Positionierung der Familien lässt sich zum einen mit der Etablierten-AussenseiterFiguration von Elias und Scotson ${ }^{41}$ treffend umschreiben. Es gibt alteingesessene Familien, die seit Generationen im Quartier leben und clanähnliche Strukturen aufweisen. Hinzu kommen neu zugezogene Familien, häufig sogenannte Expats, ${ }^{42}$ und es gibt auch ein Kind, das aus einer >klassischen Arbeitsmigrationsfamilie aus dem Süden stammt. Die Familiensprachen der Kinder spannen sich von Schweizerdeutsch über Deutsch, Russisch und Englisch bis Kroatisch. Im nun folgenden Ausschnitt richten wir unseren Blick auf mehrere Kinder dieser Kindergartenklasse, welche an diesem Morgen in zwei Halbklassen aufgeteilt wurde. Die Szene spielt sich zu Beginn des Schuljahres ab.

37 Reh/Ricken 2012, S. 44f.

38 Für eine kritische Betrachtung der angewandten Methode vgl. Sieber Egger/Unterweger/ Maeder 2019 und Unterweger/Sieber Egger/Maeder 2018.

39 Für Einblicke in die beiden anderen Forschungsorte resp. in kontrastierende Diskussionen der drei Felder verweisen wir auf Knoll/Jaeger 2020; Maeder 2018; Maeder/Knoll 2019; Sieber Egger/Unterweger 2019; Sieber Egger/Unterweger/Maeder 2019; Unterweger/Sieber Egger/ Maeder 2018.

Vgl. Bourdieu 1982.

41 Vgl. Elias/Scotson 1993.

42 Der Begriff »Expat« steht für 〉Expatriateく. Damit werden (weisse) gut ausgebildete Menschen bezeichnet, die für eine bestimmte oder auch unbestimmte Zeit in anderen Ländern arbeiten (vgl. www.theguardian.com/global-development-professionals-network/2015/ mar/13/white-people-expats-immigrants-migration [Zugriff: 15.04.2020]). 


\title{
3 »Bleib auf dem Teppich!« oder das Adressierungsgeschehen rund um die Einführung der "Sandwanne"
}

\begin{abstract}
Henry wird aufgefordert, ganz sachte (»fiin«) über den Sand zu rollen und wird von der Kindergartenlehrerin gelobt: »Wunderbar machst du das.« Sie weist auf die feine Spur hin, die Henry nun gemacht habe, obwohl er den wallholzähnlichen Spurenmacher hatte. Wenn man nicht zu viel Kraft einsetzen würde, gäbe es auch bei denen ganz schöne, feine Spuren. Nikolaus sagt: »Mein kleiner Bruder könnte das sicher nicht machen. Kindergartenlehrerin: »]a, deshalb ist er ja auch noch nicht im Kindergarten, gell.« Nikolaus: »Der ist so stark.«Die Kindergartenlehrerin wendet ein: »]a, aber weisst du, auch starke Leute können sachte sein. Da ist die Frage, ob man's steuern kann, seinen Körper.«
\end{abstract}

Diese kurze Szene spricht einige der Punkte an, die bereits ausgeführt wurden: Es geht um Bedeutungen der körperlich vollzogenen Praktiken und um die damit verbundenen Normen. Wir können anhand dieser Szene auch bereits den ersten Fragenkomplex der oben genannten Heuristik heranziehen. Als normativer Horizont wird die Körperbeherrschung der Kinder eingeführt: Körperkraft soll gezielt und dosiert eingesetzt werden können. Die Kindergartenkinder sollten diesbezüglich schon gewisse Fähigkeiten unter Beweis stellen, die sie offenbar, so die Annahme der Lehrerin, erst ab einem gewissen Alter mitbringen. Gleichzeitig ist die Situation aber gerahmt als eine Lernsituation, in welcher die Kindergartenlehrerin den Kindern bis ins Detail körperlich zeigt und vormacht, wie sie ihren Körper für den Gebrauch der Sandwanne einsetzen sollen. Neben dieser Demonstration instruiert die Kindergartenlehrerin die Kinder auch verbal. Sie kommentiert jeweils auch die Art und Weise, wie die Kinder ihre Instruktionen umsetzen.

Zur Einbettung der beobachteten Szene: Die Kindergartenklasse wurde vor der oben skizzierten Situation in zwei jahrgangsgemischte Gruppen eingeteilt. Das von der Lehrerin zuvor gegenüber den Ethnografinnen formulierte Ziel war die Einführung der Regeln rund um die besagte Sandwanne, die seit Schulbeginn noch nicht zum Einsatz gekommen war. Dementsprechend gespannt schienen die Kinder auf die Spielmöglichkeit. Die Sandwanne ist mit sehr feinem, hellem Sand gefüllt, und zur Wanne gehören verschiedene Gerätschaften aus Holz und Kunststoff - die sogenannten Spurenmacher. Eröffnet wurde die Szene im Stuhlkreis. Im Beobachtungsprotokoll wird diese Eröffnung folgendermassen beschrieben:

Frau Stäubli legt nun vor jedes im Stuhlkreis sitzende Kind grau-grüne Filzteppiche hin. Alle Kinder schauen ruhig und gespannt zu, bis auf Ava. Sie springt auf und rückt einen Teppich zurecht, der etwas schief gelegen hatte. Frau Stäubli greift sofort ein, sie würde schon zum Rechten schauen, und schiebt Ava zurück auf ihren Stuhl. Frau Stäubli fragt die Kinder, was sie mit den Teppichen für eine Form gelegt 
hätte. Einige meinen ein Zick-Zack, andere wiederum nennen einen Stern. Frau Stäubli scheint mit diesen Antworten nicht zufrieden zu sein. Sie zeichnet mit den Armen einen großen Kreis in die Luft und fragt nach, was das sei. Nina meldet sich: das sei eine Sonne. Frau Stäubli bestätigt, fragt aber weiter, was die Sonne für eine Form hätte. Hugo meldet sich und wird von Frau Stäubli aufgerufen. Er antwortet: »Ein Kreis«. Frau Stäubli: »Ganz genau Hugo, danke. Ich habe einen Kreis gemacht mit Teppichen, einen Teppichkreis. Und dieser ist für die Gruppe gedacht, die mit mir die Sandwanne anschauen kann.«(Kindergarten Sonnwies, 2.9.2016)

In diesem Kreis aus ca. $50 \mathrm{~cm}$ x $50 \mathrm{~cm}$ grossen Filzteppichstücken sollen die Kinder nun also an den Gebrauch der Sandwanne herangeführt werden. Die Lehrerin, Frau Stäubli, widmet sich relativ lange der Frage, welche Form sie mit den ausgelegten Teppichen geschaffen habe - eine Frage, welche viele Kinder offensichtlich nicht auf Anhieb beantworten können. Als das von ihr gesuchte Stichwort »Kreis« fällt, schliesst sie die Sequenz ab mit dem Hinweis auf die Funktion des Kreises. Die Körper der Kinder werden mit den durch die Lehrperson ausgelegten Teppichstücken räumlich-materiell angeordnet und zum Nichtbewegen auf kleinstem Raum angeleitet, oder um mit Foucault zu sprechen: »Die Aufmerksamkeit [gilt] dem Körper, den man manipuliert, formiert und dressiert, der gehorcht, antwortet, gewandt wird. ${ }^{43}$ Die Lehrerin dirigiert die Kinderkörper in eine bestimmte Ordnung. Die vorhandenen Dinge, vornehmlich die Teppichstücke, aber auch die Sandwanne und die dazu gehörenden Gerätschaften nehmen in diesem Geschehen eine ebenso wichtige Rolle ein wie die Lehrperson als »Dirigentin« der Kindergruppe. Die Kinder wurden angewiesen, auf ihren Filzstücken im Kreis sitzen zu bleiben und dabei Abstand zu halten zur Sandwanne, aber auch zum benachbarten Filzstück resp. dem darauf platzierten Kind - eine Praxis, die auch im späteren (Schul-)Leben der Kinder zentral sein wird und welche die Kinder nicht nur räumlich-örtlich, sondern auch sozial positioniert als voneinander abgrenzbare Gleiche unter Gleichen. Auch Frau Stäubli kniet auf einem Teppichstück, in direkter Reichweite der Sandwanne. Die Teppichstücke treten in der ganzen Sequenz dominant in Erscheinung und werden so nach Rabenstein ${ }^{44} \mathrm{zu}$ kopräsenten Akteuren, die für die Diskussion des eingangs gestellten Anliegens nachfolgend ebenfalls in den Blick gerückt werden sollen. Um noch einmal darauf zurückzukommen: Ziel des Beitrags ist es, die Vollzugswirklichkeit von Praktiken über das Sprechen, die Körperbewegungen und den Einbezug von Artefakten zu erfassen. Davon ausgehend soll diskutiert werden, was diese >materiellen Instanzen für die Positionierungen von Subjekten für Bedeutungen haben. Einen Hinweis auf die

43 Foucault 2014, S. 174.

44 Rabenstein 2018, S. 19. 
Bedeutung der Teppichstücke gibt eine Interaktion zwischen Lehrerin und Kindergartenkindern gleich zu Beginn:

Frau Stäubli weist ]immy, der näher [an die Sandwanne] kommen wollte an, auf seinem Teppich zu bleiben. Sie nimmt den Deckel der Sandwanne weg und weist auf dessen Gewicht hin. Wieder sagt sie den Kindern, sie sollen auf den Teppichen sitzen bleiben.

Frau Stäubli fungiert als Bewacherin der Sandwanne. Sie reguliert den Zugang, sie verteilt die unterschiedlichen »Spurenmacher«. Obwohl ebenfalls im Kreis positioniert, ist sie damit sozial anders positioniert als die Kinder, nämlich als tonangebende und bestimmende Person der Gruppe. Dies deutet auf ein generationales Ordnen ${ }^{45}$ und auf eine spezifische Kompetenzordnung der Organisation Schule hin: Die Lehrerin als erwachsene Person und in ihrer organisationalen Rolle ist mit besonderem Wissen und Hierarchie ausgestattet, während die Kinder in der Situation als unwissend konstruiert werden. Die neugierig wirkenden Kinder sitzen auf ihren Teppichen, und eins nach dem anderen wird der Reihe nach aufgefordert, mit ausgewählten Gerätschaften Spuren in den Sand zu zeichnen. Alle Kinder agieren erkennbar sorgfältig und zeigen sich bemüht, die Regeln zu befolgen, auch wenn nicht allen alles gelingt.

Dieser Aufriss der Gesamtsituation soll die Bedeutung der körperlichen Praktiken wie auch der in diese Praktiken involvierten materialen Objekte veranschaulichen. Dabei können wir unterscheiden zwischen den Praktiken der Lehrperson, welche ihren Körper und Artefakte einsetzt, um die Körper der Kinder zu steuern, und den noch einzuübenden Körperpraktiken der Kinder, welche offensichtlich noch nicht alle über das notwendige implizite und inkorporierte Wissen zur Ausführung dieser Praktiken verfügen. Gerade diese Krisenhaftigkeit einer noch nicht etablierten Praxis ist interessant, da sie den Prozess der Inkorporierung von Praktiken sichtbar werden lässt. Nachfolgend soll nun der Fokus auf die Dimension der Adressierung gelegt werden. Es interessiert, wie bzw. als was und wer die Kinder im Kindergarten mittels der vollzogenen (Körper-)Praktiken adressiert werden, welche Subjektpositionen dadurch eröffnet bzw. verschlossen werden und welche (vorläufigen) Subjektivierungen dadurch erfolgen. Um dies analytisch zugänglich zu machen, setzen wir die oben beschriebene Frageheuristik nach Reh und Ricken ${ }^{46}$ ein.

45 Alanen 2005, S. 79.

46 Vgl. Reh/Ricken 2012. 


\section{Normative Horizonte und Situationsdeutungen}

Als Erstes soll hier die Frage nach der Situationsdeutung und nach dem in der Situation aufgespannten normativen Horizont aufgegriffen werden. Die Eröffnung der Situation erfolgte über das Auslegen von Teppichstücken im Stuhlkreis durch die Lehrerin. Als Ava ein Teppichstück zurechtrücken wollte, macht die Lehrerin nonverbal und verbal deutlich, dass sie die Hoheit über die Gestaltung der Situation beansprucht. Mit der Frage nach der mit den Teppichstücken ausgelegten Form, welche sie ebenso verbal und nonverbal zum Ausdruck bringt, rahmt sie ihre soeben vorgenommene Handlung als eine Lernsituation. Die ausgelegten Teppichstücke werden von der Lehrerin als »Teppichkreis« benannt, und dieser Kreis innerhalb des Stuhlkreises wiederum dient einem speziellen Zweck: dem "Anschauen« der sogenannten Sandwanne. Dieses "Anschauen« geschieht in einer Halbgruppe mit enger Begleitung der Lehrerin und kann so wiederum als eine weitere, spezifische Lernsituation interpretiert werden.

Die Halbierung der Gruppe und die Platzierung in einem Kreis weisen auf eine besonders intensiv didaktisierte und pädagogisierte Form hin, denn der Kreis ist im Kindergarten eine räumliche Standardanordnung, unter anderem für das kollektive Erarbeiten von Lerninhalten. Die Kindergartenlehrerin schafft mit dem Kreis eine, wie das Magyar-Haas und Kuhn basierend auf Heinzel ausführen, "Sozialisationssituation, die der Vergemeinschaftung und der Einübung in normgerechtes Verhalten dient und in diesem Sinne >Anpassung und Integration< [...] in die Institution und in ihre spezifischen Ordnungsverhältnisse und Regularien zum Ziel hat «. ${ }^{47}$ Der Kreis kann so nach Berdelmann und Reh und unter Bezugnahme auf Schatzki als >Platz für etwas`verstanden werden: »Plätze werden als Plätze für etwas ausgewiesen sowie identifizierbar durch ihren geregelten Einbezug in Aktivitäten innerhalb von Praktiken. ${ }^{48}$ Der Kreis hat als solcher Platz spezifische Funktionen: So ist z.B. die Blickrichtung aller Personen im Kreis durch die Positionierung auf den Teppichstücken in die Kreismitte gerichtet, dort steht auch die Sandwanne, das Objekt der Begierde sozusagen. Die im Kreis versammelten Kinder und die Lehrerin befinden sich in einer gegenseitigen Beobachtbarkeit, alle können alle und alles kontrollieren. Der Kreis ermöglicht somit bestimmte Handlungsweisen, zugleich schränkt er andere aber auch ein oder verhindert sie.

Als normativer Horizont scheint im Ausschnitt die kompetitive Gefügigkeit ${ }^{49}$ der Kinder auf: Das richtige, kompetente Mitmachen wird verbal belohnt, ein offenbar als übereifrig und übergriffig erfahrenes Handeln wie dasjenige von Ava

47 Magyar-Haas/Kuhn 2011, S. 22.

48 Berdelmann/Reh 2015, S. 188.

49 Bühler-Niederberger 2011, S. $202 \mathrm{ff}$. 
weist die Kindergartenlehrerin umgehend zurück. Das individuelle Handeln von Ava entspricht nicht den Anforderungen an die kompetente Gefügigkeit und wird entsprechend von der Lehrerin bearbeitet.

Etwas später, die Halbklassen sind nun getrennt, setzt sich die Szene folgendermassen fort:

Frau Stäubli, die noch steht, fordert die sitzenden Kinder auf, zusammenzurutschen, näher zur Sandwanne zu rutschen. Dann sagt sie: »]immy, was machst du da?« Jimmy hatte nach einem Teppich gegriffen, der ohne Besitzer war, und war damit aufgestanden. Frau Stäubli: »Ich brauche auch einen Platz! Ich will auch einen Teppich.« [...]

Dann wendet sie sich an Max, der an seinem Teppich herumnestelt: »Max, du probierst jetzt diesen Teppich in Ruhe zu lassen. Cell, das üben wir jetzt. Der bleibt einfach am Boden. N Nun wendet sich Frau Stäubli, auf ihrem Teppichstück sitzend, der Sandwanne zu. Sie sagt: »]etzt schaut ihr einmal einfach nur, es sind alle auf ihrem Teppich. Alle sind auf ihrem Teppich.« [...] Jimmy will näher rutschen und wird von Frau Stäubli ermahnt, auf seinem Teppich zu bleiben. Dann nimmt sie den Deckel der Sandwanne weg und weist auf dessen Gewicht hin - wenn er herunterfalle, könne das weh tun. Wieder sagt sie den Kindern, sie sollen auf den Teppichen sitzen bleiben [...].

Der zuvor als »kompetente Gefügigkeit der Kinder« umschriebene normative Horizont lässt sich anhand dieses Ausschnitts noch einmal bekräftigen: Es geht um das Einüben einer Sitzpraktik, welche aufs Engste an das Teppichstück gekoppelt ist. Es scheint die vordringliche Aufgabe der Kinder zu sein, ruhig im ad hoc hergestellten Kreis auf ihren Teppichen zu sitzen, ohne diese zu manipulieren, wie es Max getan hatte. Diese Anforderung hat offenbar deshalb eine spezielle Dringlichkeit, weil von der Sandwanne eine grosse Anziehung ausgeht - darauf verweist etwa, dass Jimmy näher an die Wanne rutschen will. Unter dem Strich sind es Praktiken der Selbst- und Körperbeherrschung und damit auch der Nichtbewegung, welche normativ als Verhaltenserwartungen an die Kinder herangetragen werden. Einige Kinder nehmen diese Erwartungen an, andere wiederum durchkreuzen »eigensinnig « diese Erwartungen, formen sie um oder verhalten sich widerspenstig. Den konkreten Positionierungen der Kinder möchten wir nun im Folgenden unter Beizug der zweiten Adressierungsheuristik nachgehen.

\section{Die Positionierungen der Kinder und das Ins-Verhältnis-Setzen}

Durch die verlangte Sitzpraktik auf den Teppichstücken im Kreis werden die Kinder implizit adressiert als $\mathrm{zu}$ disziplinierende, $\mathrm{zu}$ ordnende und in ihrer Aufmerksamkeit zu lenkende Akteure innerhalb der generationalen Ordnung. 
Gleichzeitig wird ihnen Neugier, Interesse und Impulsivität zugesprochen, denn ohne die entsprechenden Anweisungen, so die nicht ausgesprochene Unterstellung, würden sich wohl alle Kinder direkt auf die Sandwanne stürzen, sich von der Anziehungskraft des neuen Objekts überwältigen lassen. Erst einmal sollen sie aber "nur schauen«. Damit werden sie als passive Lernende positioniert. Diese verlangte Praktik der körperlichen Zurückhaltung bei gleichzeitiger Aufmerksamkeit für das Geschehen ist offenbar noch keine Selbstverständlichkeit, und die Lehrerin will hier zu einer Aktivität innerhalb einer bestimmten Lernsituation (dem »Zeigen im Kreis«) anleiten. Sie positioniert sich dabei selbst als souveräne Herrscherin über die Sandwanne. Sie sitzt nahe bei ihr, sie darf sie berühren und aktionsbereit machen, indem sie den Deckel hebt. Die Position der Lehrerin als machtvolle und bestimmende Akteurin wird von den Kindern bis jetzt nicht infrage gestellt.

Hier interessiert, welche weiteren Positionen in der Situation und über das Adressierungsgeschehen hergestellt werden. Die Positionierungen sind, wie oben nach Reh und Ricken ${ }^{50}$ ausgeführt, als ein Ins-Verhältnis-Setzen der beteiligten Akteure zu verstehen. Ganz grundsätzlich betrachtet, erfolgt die Positionierung der Kinder und der Lehrperson innerhalb der generationalen Ordnung des Kindergartens bzw. wird diese Ordnung laufend durch die Adressierungen und Positionierungen der beteiligten Akteure hergestellt. Explizit deutlich wird dies im ersten Protokollausschnitt mit dem Hinweis auf den kleinen Bruder eines Kindergartenkindes. Dieser ist in der generationalen Ordnung noch tiefer positioniert als die Kindergartenkinder, er könnte laut Lehrerin und Bruder noch nicht an dieselbe Aufgabe herangeführt werden, welche jetzt den anwesenden Kindern gestellt wird. Aber auch die Kinder adressieren umgekehrt mit ihrer meist stillen kompetenten Gefügigkeit die Lehrerin als generational »Andere«, als bestimmende und wissende Erwachsene.

Neben der Position des kompetent gefügigen Kindes scheinen in der Situation noch andere Positionierungen auf. So bei Ava in der Einstiegssequenz, die von einer selbst gewählten aktiv-unterstützenden Handlungsposition wieder auf diejenige des kompetent gefügigen, ruhigen Kindes eingeschränkt wird. Auch Jimmy, der Junge, welcher ein Teppichstück gegriffen hatte und zur Seite legen wollte, hatte eine aktiv-hilfsbereite Position eingenommen. Die Ethnografin interpretierte die Situation so, dass Jimmy das Teppichstück - auf dem die Lehrerin noch nicht Platz genommen hatte - als überzählig eingeschätzt hatte und es deshalb aus dem Kreis befördern wollte. Er hätte in dieser Lesart zur räumlichen Ordnung des Kreises beigetragen, wurde von der Lehrerin aber ebenfalls dazu aufgerufen, keine vorschnelle Eigeninitiative walten zu lassen. Schliesslich gibt es Max, der sein Teppichstück in die Hände nahm, damit spielte und es nicht wie geheissen 
auf dem Boden liegen liess, um sich daraufzusetzen. Er verwendete das Teppichstück in einem uns nicht erschliessbaren eigenen, spielerischen Sinn, der aber offensichtlich nicht in den normativen Horizont des kompetent gefügigen Kindes passte. An dieser Stelle eröffnet sich ein Spannungsfeld, wenn wir den Praktikenbegriff anwenden wollen. Wie sich in diesen und den nachfolgenden Beispielen zeigt, sind zu diesem Zeitpunkt im Schuljahr bei den Kindergartenkindern die von der Kindergartenlehrperson erwünschten Praktiken (noch) nicht im eigentlichen Sinn etabliert: Die Aktivitäten sind noch nicht routiniert und verinnerlicht, das Geschehen zeigt sich im Gegenteil als krisenhaft und störungsanfällig. In dieser Krisenhaftigkeit lässt sich der Eigensinn der Kinder deutlich erkennen, zugleich aber auch die konstanten Versuche der Lehrerin, in dieser Lernsituation die erwünschte kollektive Praktik zu etablieren und zu verstetigen.

Anhand eines nächsten Materialausschnitts können wir noch weitere Positionierungen herausarbeiten:

Frau Stäubli fragt: »Was macht man dann mit dem Sand? Ist der zum `sändele (mit Sand spielen) in diesem Sandkasten drin? «Von den Kindern kommt ein zögerliches Nein. Sie ruft Alexander auf, aber der sagt nichts (oder vielleicht leise »Oh doch!«), dann Johanna. Die beginnt längere Ausführungen: Das sei so zum Spuren machen, so wie ein Künstler. Sie erzählt auch, mit welchen Geräten und Werkzeugen man da Spuren machen könne, bis Frau Stäubli sie unterbricht: »Johanna, du musst noch nicht alles erklären. Ich habe - du weißt noch alles ganz genau, hmm?« Alexander ergänzt nun unaufgefordert, man solle nicht dreinsitzen. Frau Stäubli fasst zusammen: Man sitze nicht rein und man mache Spuren.

An der Reaktion und den Antworten von Alexander zeigt sich eine Positionierung, die wir als subtil widerspenstig interpretieren, denn sie kann als Infragestellung der Hierarchie der generationalen Ordnung vor versammeltem Publikum verstanden werden. Mit seiner Bemerkung, man dürfe nicht in der Sandwanne sitzen, erzeugt er ein absurdes Bild: mit einer Grösse von ca. $70 \mathrm{~cm}$ auf $50 \mathrm{~cm}$, einem Tischmodell gleichend, wäre ein Hineinsitzen in die Sandwanne für die körperlich schon dem Kleinkindalter entwachsenen Kindergartenkinder erstens schwierig und zweitens dem gerade von Johanna eingeführten (pädagogischen) Sinn des Objekts offensichtlich zuwiderlaufend. Alexander nimmt in dieser Situation zwar den aufgespannten normativen Horizont der Lehrerin auf, indem er eine Verhaltensanforderung formuliert. Er nennt eine Regel im Umgang mit der Sandwanne, welche von der Lehrerin nicht negiert werden kann. Er fordert diesen normativen Horizont und damit einhergehend auch die Lehrerin aber heraus, weil seine Aussage auf ein Verhalten verweist, von dem wohl alle Kinder in der Runde wissen, dass es die Grenzen der Konformität nicht nur subtil, sondern sehr deutlich überschreiten würde. Damit spielt er mit den gesetzten Regeln, 
führt sie ad absurdum und nimmt sich zugleich die Bühne, sich als kompetenter Teilnehmer am Geschehen zu profilieren. Diese Interpretation von Alexanders Intervention - es wären nur auf der Grundlage dieses Ausschnittes auch andere möglich - gründet im ethnografischen Kontextwissen zu Alexander, das über die lange Beobachtungszeit aufgebaut werden konnte. Die Lehrerin schliesslich ignoriert das widerspenstige Potenzial von Alexanders Beitrag und integriert diesen in eine bestätigende Zusammenfassung. Damit stellt sie wieder eine Positionierung von Alexander als kompetent gefügiges und in der generationalen Ordnung positioniertes Kind her; sie lässt ihn sozusagen ins Leere laufen.

Am Geschehen rund um Johanna lässt sich eine weitere Positionierung herauslesen. Johanna beantwortet die Frage der Lehrerin pflichtbewusst und ist sichtlich bemüht, ihre Sache gut zu machen. Dazu muss man wissen, dass Johanna das zweite Kindergartenjahr besucht. Sie ist quasi das grosse Mädchen, dem in bestimmten Situationen von der Lehrerin geradezu eine Vorbildrolle zugesprochen wird. In dieser Situation hier wird sie in dieser Position bestätigt, allerdings gleichzeitig auch in die Schranken gewiesen - die Lehrerin möchte die didaktische Hoheit über die Situation bewahren.

Interessant erscheint die Sequenz bis hierhin, weil die Kinder ihre beinahe schwebende Positionierung als teils Wissende, teils Unwissende, vor allem aber als lernende Körper fortwährend handelnd bestätigen müssen. Dies wird besonders deutlich in einem weiteren Ausschnitt, welche die Regel aufgreift, dass der Sand unter allen Umständen in der Sandwanne bleiben muss und auf keinen Fall auf den Boden geraten darf. Ein Mädchen stützt sich gegen Schluss der Sandwanneneinführung beim Reinigen ihres »Spurenmachers« mit dem Handballen auf dem Sand ab. Das wird von der Kindergartenlehrerin sofort registriert und als Problem benannt. Die Lehrerin dramatisiert diesen Moment, indem sie die Reaktion des Mädchens als exemplarischen Test für das richtige Verhalten darstellt:

»]etzt hat Nina Sand an der Hand. Was macht sie jetzt, die Nina?« Nina klopft und reibt daraufhin ihre Hände über der Sandwanne frei vom Sand, worauf sie von der Kindergartenlehrerin gelobt wird: »Siehst du, jetzt musste ich gar nichts mehr sagen, du hast das so gut vorgezeigt.»

Das Mädchen Nina führt nach der entsprechenden Frage der Lehrerin stumm die situativ verlangte Aktivität vor. Sie zeigt damit, dass sie bereits gelernt hat, was in diesem Fall zu lernen war. Dieses »Zeigen« kann unabhängig vom konkreten Inhalt selbst als wichtige Praktik von Schülerinnen und Schülern interpretiert werden, komplementär zum "Zeigen, was zu lernen ist« der Lehrpersonen. Die Lehrerin wiederum bestätigt das Handeln des Mädchens, indem sie es als Vorbild adressiert und es so als aus der Gruppe herausgehoben positioniert: Es war so gut, dass sich eine weitere sprachliche Erläuterung und Instruktion der Lehrerin er- 
übrigt. Gleichzeitig positioniert sich die Lehrerin einmal mehr als Instanz, welche in der Situation das Handeln der Kinder kontrolliert und bewertet.

\section{Der Fall Jimmy}

Für die Erwähnung einer letzten Positionierung wollen wir noch einmal aufJimmy zurückkommen, der bereits oben zum Thema wurde. An seinem Beispiel möchten wir die Frage der Positionierung in Bezug auf ein Kind, das auffällt, vertiefend aufgreifen. Auch Jimmy ist während der 30-minütigen Szene aufmerksam und offenkundig willig mit dabei. Er wird als Erster aufgefordert, mit seinem Spurenmacher eine Spur in den Sand zu ziehen, und tut wie geheissen, sorgfältig und langsam. Danach demonstriert die Lehrerin den Einsatz des sogenannten Flachmachers - eines Geräts, mit dem der Sand geglättet und die Spuren getilgt werden können. Sie weist auch darauf hin, dass man "absanden « müsse, das heisst den Sand von den jeweiligen Instrumenten wieder gut abklopfen, und macht es auch gleich vor. Unmittelbar darauf ereignet sich folgende Situation:

Dann folgt Julian mit seiner Spur. Jimmy kommt ihm etwas in die Quere, hält sein Instrument auch wieder über den Sand. Die Kindergartenlehrerin will ihn zurückhalten. Dann merkt sie, dass er offenbar sabsanden « wollte, wie sie es vorher vorgezeigt hatte. Da lobt sie ihn: »Ah, wolltest du auch noch absanden? Macht er es gerade gleich wie ich, sehr gut. Das hast du dann gut geschaut, Jimmy. Super.

Die erste und unmittelbare Reaktion auf Jimmy ist körperliche Abwehr. Erst in einem zweiten Schritt vermutet die Kindergartenlehrerin, dass der Junge eigentlich gerade Regeltreue unter Beweis stellen wollte, und lobt ihn daraufhin mehrfach. Gerade dieses beinahe überdeutliche Lob lässt die Sonderposition anklingen, in welcher Jimmy sich im Kindergarten befindet. Jimmy erscheint, neben Max, als Kind, das vonseiten der Lehrpersonen intensiver bearbeitet wird als andere - er wird zu einem Kind, das auffällt. Diese Sonderposition zeigte sich den Autorinnen mittels der Analyse vielfältiger Felddokumente und -protokolle, welche in einem Zeitraum von beinahe zwei Jahren entstanden sind. Besonders deutlich lässt sie sich in Kreissequenzen erkennen. Der Raum des Kreises wird für Jimmy zu einem Vorführraum: Er wird häufig ermahnt und an Verhaltensregeln erinnert, auch in der hier präsentierten Situation. Im Kreis kann Jimmy keinem Blick entgehen, durch die wiederholten individuellen Adressierungen wird er zum "geschauten Mittelpunkt ${ }^{51}{ }^{51}$ vor allem auch in Relation zu den anderen Kindern. Dieses Beobachtetsein und -werden hat zur Folge, dass Jimmy sich in der Situation keinen Fauxpas leisten kann, ansonsten wird er sofort gerügt - oder

51 Magyar-Haas/Kuhn 2011, S. 28. 
anders: Jimmy wird sofort als Kind, das auffällt, adressiert. Jimmys Reaktion und Readressierung auf diese Positionierung scheint ein sichtliches Bemühen, das situativ Richtige zu tun - beispielsweise, wie oben gesehen, einen Teppich, der aufgrund der anwesenden Kinder als überzählig erscheint, zurückzulegen oder das verpasste $>$ Absanden noch schnell nachzuholen.

Eine sehr ähnliche Situation ereignete sich am Schluss der Sandwannensequenz: Jimmy hatte den Zeitpunkt verpasst, seinen Spurenmacher in die entsprechende Kiste zurückzulegen. Er war gerade mit seiner eigenen körperlichen Positionierung beschäftigt gewesen und hatte offenbar bemerkt, dass er etwas von seinem Teppichstück abgekommen war. Mehr zu sich selbst hatte er gesagt: »Oh, ich muss auf meinen Pelz."Gleichzeitig war auch noch sein bester Freund aus der anderen Gruppe kurz im Kreis aufgetaucht, und so ging die Kiste mit den Gerätschaften an ihm vorbei. Kaum merkte Jimmy das, wollte er die Kiste zurückholen und versuchte, sie einem anderen Kind zu entreissen. Die Kindergartenlehrerin intervenierte unmittelbar: »jimmy, du musst gar niemandem das Zeug wegreißen. Wenn du die Sachen vergisst, musst du halt noch schnell hintennach. Aber nicht einander das Zeug wegreißen. Können wir das abmachen?« Trotz seinen Bemühungen um kompetentes Handeln scheint ihm ein solches selten richtig zu gelingen, und er wird auch entsprechend immer wieder als inkompetent adressiert und damit als Kind, das auffällt positioniert. Gerade diese Wiederholungen, die sich praktisch in jedem einzelnen Beobachtungsprotokoll der ganzen Feldforschung zeigen, erscheinen in Hinblick auf die Subjektivierung als Kindergartenkind von Belang. Praxistheoretisch betrachtet, zeigt sich bei Jimmy, dass seine Beteiligung an den im Kindergarten eingeforderten Praktiken immer wieder infrage gestellt ist und er die gefragten Aktivitäten noch nicht verinnerlicht hat.

\section{Performative Effekte: vorläufige Subjektivierungen}

Den dritten Schritt der Frageheuristik, die Frage nach den performativen Effekten in der Abfolge von Adressierungen, möchten wir ebenfalls am Beispiel von Jimmy aufgreifen. Jimmy wird von den Lehrerinnen als Kind wahrgenommen, das gerne in den Kindergarten geht und interessiert bei der Sache sein kann. Aber er wird auch als Junge beschrieben, der Mühe hat mit dem Regulieren von Nähe und Distanz, als Kind, das anderen auch mal wehtut und eine Tendenz zum Dreinfahren zeigt, kurz: Er beherrscht seinen Körper nicht immer so, wie es im Kindergarten verlangt wird. Auch die Eltern beschreiben den Jungen im Elterngespräch auf diese Art und Weise. Insgesamt sind im betreffenden Ausschnitt des Beobachtungsprotokolls zur Sandwanneneinführung sechs Ermahnungen an Jimmy beschrieben und drei an je andere Kinder. Das Beobachtungsprotokoll ist kein Messinstrument - die Aussage reflektiert aber die allgemeine Erfahrung der Ethnografinnen, dass Jimmy häufiger als andere Kinder ermahnt und an Verhal- 
tensregeln erinnert wird. Wie oben bereits angesprochen ist Jimmy insofern ein Kind, das auffällt und das punkto Normierung und Justierung seiner Aktivitäten intensiver bearbeitet wird als andere.

Unser Fokus liegt nun auf der Frage, wie Jimmy auf die an ihn gerichteten Adressierungen, die allesamt normierte Handlungsanweisungen beinhalten, reagiert. Jimmy wurde in der Sandwanneneinführung durch körperliches Eingreifen und verbale Ermahnungen von der Kindergartenlehrerin mehrfach als inkompetentes Kind adressiert, das die angemessenen schulischen Praktiken noch nicht oder nicht genügend verinnerlicht hat. Seine Reaktionen lassen darauf schliessen, dass Jimmy selbst eine solche Positionierung nicht stehen lassen wollte. In den beiden Situationen, wo er sozusagen zum falschen Zeitpunkt das Richtige tat, stellte er das Befolgen der situativ aktuellen Regel (Absanden oder Gerät zurücklegen) über allgemeinere Regeln des sozialen Umgangs (andere nicht unterbrechen und stören). Er positionierte sich damit, so könnte man interpretieren, geradezu als übereifriger Lerner in Bezug auf die konkrete Lernsituation rund um die Sandwanne. Eine solche Positionierung schien aber kaum Anerkennung $\mathrm{zu}$ finden, denn die Lehrerin rügte ihn durchgehend wegen der Missachtung allgemeiner Verhaltensnormen und adressierte ihn so auf einer übergreifenden Ebene als inkompetentes Kindergartenkind; oder eben als Kind, das auffällt. Denn, um mit Bourdieu zu sprechen: Jimmy fehlt in diesen Situationen der praktische Sinn, um im Kindergarten im richtigen Moment das Richtige zu tun, er lässt das knowing how in Bezug auf das erwartete Verhalten (noch) vermissen. Er lässt sich zwar auf das Geschehen ein und macht den Willen deutlich, die in der spezifischen Lernsituation eingeforderten Aktivitäten zu lernen und zu vollziehen. Dass er es aber nicht schafft, gleichzeitig die übergeordneten Verhaltensnormen des sozialen Umgangs zu berücksichtigen, lässt ihn im Rahmen der sozialen Ordnung des Kindergartens als defizitär erscheinen. In der Summe der vielen, immer wiederkehrenden Positionierungen als inkompetentes Kindergartenkind wird er damit zu einem vulnerablen Kind. Es ist eine Subjektposition, der sich Jimmy nicht entziehen kann, die auch von seinen Eltern getragen wird und die schliesslich in einer medizinischen Abklärung und einer ADHS-Diagnose mündet. Wie Jimmy mit dieser Subjektivierung umgeht, erschliesst sich in der Forschung nur indirekt. Seine wiederkehrenden Bemühungen um die srichtige Beteiligung an den verlangten Praktiken des Kindergartens lassen es plausibel erscheinen, dass er dieser Subjektposition, die ihm zwar besondere Aufmerksamkeit, aber wenig (schulische) Anerkennung einträgt, entgegenwirken möchte. 


\section{Fazit}

Alltägliche Praktiken im Kindergarten und das mit ihnen verbundene »Knowhow« können über einen Beobachtungsfokus auf den Körper und über die Analyse der Verwendung von Artefakten analytisch zugänglich gemacht werden. Mit dem gewählten Protokollausschnitt zur Einführung der Sandwanne konnte aufgezeigt werden, dass Kinder im Kindergarten als Lernende von schulischen Praktiken und als zu Erziehende adressiert werden, was in Anbetracht der Aufgabe des Kindergartens nicht weiter erstaunlich ist. Im Kindergarten werden gesellschaftliche Normen zu guter Kindheit enaktiert und gelebt, wie eben die Norm der >Lernkindheit ${ }^{52}$ Auffallend ist jedoch die spezifische Art und Weise: Die Kinder werden in einem hohen Mass als lernende Körper, welche das zu erlernende Wissen über bestimmte Praktiken und den mit diesen Praktiken verbundenen Umgang mit Artefakten inkorporieren sollen, adressiert. Wir gehen mit Claudia Machold davon aus, »dass gesellschaftliche Normen, Konventionen und Diskurse regulieren, was in einem bestimmten gesellschaftlichen Kontext als anerkennbare Subjektform gilt« ${ }^{53}$ Mit unserer Analyse können wir deutlich machen, dass diese Normen und Konventionen in Praktiken enaktiert werden, welche im Kindergarten einen sehr prominenten Zugriff auf den kindlichen Körper beinhalten. So wird das übereifrige Mädchen an den Schultern geführt, um das normgerechte Verhalten zu bewirken, und der verträumte Junge, der an seinem Teppichstück herumnestelt, wird auf den >richtigen Umgang mit dem Artefakt angesprochen. Diese Einsicht bedeutet auch, dass im Umgang mit dem Kinderkörper andere Normen wirksam werden als im Umgang mit erwachsenen Körpern.

Der Fokus auf den Körper und seinen praktischen Umgang mit Dingen und spezifischen (handwerklichen und feinmotorischen) Arbeiten, ist ein Merkmal des Kindergartens, welches wir während der Feldforschung als besonders auffallend empfunden haben. Implizites und routinisiertes Körperwissen, das bei Erwachsenen als verinnerlichte Praxis spielt - beispielsweise setzen wir uns im Kino auf den zugewiesenen Platz und bleiben bis zum Ende des Films sitzen -, wird bei den Kindern vermutlich in solchen Szenen wie der Sandwanneneinführung und anderen Situationen, die wir beobachten konnten, erlernt. Wissen wird in solchen Situationen also als Körperwissen verinnerlicht und so habitualisiert. ${ }^{54}$ Bourdieu wurde dafür kritisiert, ${ }^{55}$ dass er den genauen Erzeugungsmodus des Habitus offen lässt und nur das Wirken einer >stillen Pädagogik a andeutet. Im Kindergarten aber, so lassen unsere Ausführungen vermuten, werden wir Zeugen der gezielten

\footnotetext{
52 Vgl. Schulz 2016.

53 Vgl. Machold 2018.

54 Vgl. Bourdieu 1993.

55 Turner 1994, S. 44.
} 
Herausbildung eines schulischen Habitus, der gerade auf der körperlichen Ebene viel verlangt und der über den Körper eingeübt wird. Sowohl über das körperliche Vorzeigen, das Berühren der Körper wie über explizite Erläuterungen und Adressierungen werden die Kinder mit einem praktischen Sinn ausgestattet, der ihnen einen Orientierungsrahmen gibt, wie sie sich im Feld >Kindergarten und Schule $<\mathrm{zu}$ bewegen haben. Damit einher geht auch das Erlernen des Wissens, welche Praktiken, und damit die Kinder als Ausführende, sozial anerkannt werden und welche nicht. Im Rahmen dieser (schulischen und gesellschaftlichen) Normen von Anerkennbarkeit werden bestimmte Subjektpositionen möglich, während andere verschlossen bleiben. So lassen die Hinweise auf die Hervorbringung von Körperlichkeit und Leiblichkeit der Kinder und auf ihre entsprechende Adressierung

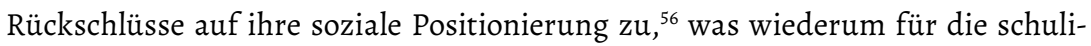
sche Sozialisation von Bedeutung ist.

Am Fall von Jimmy wird deutlich, dass schulische Normen von Anerkennbarkeit auf verschiedenen Dimensionen angesiedelt sind. So gibt es einerseits Normen in den geschaffenen Lernsituationen, welche auf die kompetente Ausführung von zu erlernenden spezifischen Praktiken zielen. Es gibt viele solcher Normen, welche im Kindergarten explizit und oft mit einigem didaktischem Aufwand vermittelt werden. Ein gutes Beispiel hierfür sind gestalterische Prozesse, Interaktionen im Kreis, bestimmte Spiele wie Regelspiele, Ausflüge etc. Zugleich gibt es normative Anforderungen, welche als selbstverständlich vorausgesetzt werden. Diese umfassen die Dimension der - nicht nur schulspezifischen, sondern wohl auch milieuspezifischen ${ }^{57}$ - Regeln des sozialen Umgangs. ${ }^{58}$ Erst Verstösse gegen solche Verhaltensnormen führen dazu, dass diese expliziert werden: Man schubst nicht, man lässt sich ausreden, man schlägt nicht, man hält seine Emotionen in Interaktionen im Zaum usw. usf. Ein Kindergartenkind befindet sich also in einem Geflecht normativer Anforderungen und damit Normen von Anerkennung, von denen die einen erklärt und unter Anleitung eingeübt werden und von denen es die anderen bereits mehr oder weniger beherrschen sollte. Ein wiederholtes Versagen sowohl im einen wie im anderen Bereich führt zu einer Positionierung als inkompetentes Kindergartenkind und damit vor dem Hintergrund des herrschenden Diskurses zu einer Subjektivierung als Risikokind, ${ }^{59}$ das, wie im Fall Jimmy, weiterer Abklärung, Betreuung und Förderung bedarf. Die Be-

56 Neumann u.a. 2017, S. 5.

57 Verschiedene ethnografische Untersuchungen arbeiten solche milieuspezifischen Muster, die mit schulischen Anforderungen kollidieren können, heraus. Zum Einsatz körperlicher Gewalt siehe Lareau 2011, S. 226; zu Interaktionsstilen im englischen Arbeitermilieu vgl. Willis 2013; zu Passungsfragen allgemein vgl. Betz 2009. 
urteilung, ob ein Kind zu einem Kind wird, das auffällt, geschieht vorrangig über die Beurteilung seines Vollzugs von Praktiken.

Die von uns rekonstruierten Praktiken im Kindergarten erlangen nie eine endgültige Form, es gibt keine Praktik, die in ihrem Vollzug gänzlich identisch ist mit einer zuvor ausgeführten. Wie Butler ${ }^{60}$ herausstreicht, lässt gerade der Zwang zur Aufführung - und damit zur Wiederholung - von (normierten) Praktiken immer auch einen Spielraum, die Praktik leicht verändert zu vollziehen und damit die normative Bedeutung der Praktik zu verschieben. Bei Butler ist dieser Vollzug, die Aufführung, unter dem Stichwort >Performativität‘ gefasst. Sie hat sich vor allem mit der Performativität von Geschlecht befasst oder wie Hannelore Bublitz festhält:

Der springende Punkt dabei ist, dass die Performativität des Ceschlechts sich nicht auf etwas Gegebenes bezieht, sondern in der Wiederholung, in der Zitatförmigkeit immer wieder aktiv hervorgebracht wird. [...] In dieser zitatförmigen, wiederholenden und reartikulierenden Praxis ist die Widersetzung verortet. [...] Die Performanz des Ceschlechts birgt die Verschiebung der Normen in sich; die Normen werden nie auf die gleiche Weise zitiert. ${ }^{61}$

Was hier für die Aufführung von Geschlecht gesagt wird, gilt auch für die Aufführung von >Kindergartenkindk. Verschiebungen von Normen sieht man in unserem Material beispielsweise deutlich bei den Handlungen von Alexander oder Johanna. Während Alexander einerseits die Norm zitiert, indem er einen formal korrekten Beitrag auf eine Frage der Kindergärtnerin formuliert, verschiebt er sie gleichzeitig, indem er einen inhaltlich absurden Vorschlag unterbreitet. Johanna auf der anderen Seite zitiert ebenfalls die Norm, indem sie formal korrekt und in der richtigen Interaktionsabfolge die Frage der Kindergärtnerin beantwortet. Sie verschiebt die Norm aber, indem sie ihre Antwort sehr vertieft und ausführlich darlegt. Auch Jimmys Interventionen, so haben wir dargelegt, zitieren Normen des Kindergartens, allerdings auf Kosten der Performanz von anderen, übergeordneten Normen. Auffällig scheint uns hier, dass dieser Spielraum der Normverschiebung in den von uns untersuchten Kindergärten mit viel Aufwand ausgesprochen eng gehalten wird. Ein nicht kleiner Anteil der Arbeit der Kindergartenlehrperson besteht darin, fortwährend den kindlichen Vollzug der Praktiken zu prüfen, zu beurteilen und nötigenfalls, bei der Einschätzung einer massgeblichen Abweichung, zu sanktionieren. Dies geschieht hochgradig routinisiert und ist ein Praxiskomplex für sich: die Praxis des viel zitierten `Umgangs mit Heterogenität،. Die Normen werden dabei nicht - wie es das oben angeführte Foucault'sche Zitat na-

60 Butler 2018, S. 213-215.

61 Bublitz 2013, S. 75. 
helegt - im Sinne einer Dressierung in die Körper geleitet, sondern es gibt vonseiten der Kinder neben aller kompetenten Gefügigkeit auch Eigensinn und Widerstand, was mit dem Butler'schen Blick auf die Performativität deutlich gemacht werden kann. Die Kinder sind keine passiven »Empfängerinnen und Empfänger« in diesem Geschehen, sondern haben einen aktiv handelnden Anteil.

\section{Literatur}

Alanen, Leena (2005): Kindheit als generationales Konzept. In: Heinz Hengst/Helga Zeiher (Hg.): Kindheit soziologisch. Wiesbaden, S. 66-82.

Berdelmann, Kathrin/Reh, Sabine (2015): Adressierung durch den Raum - (Lieblings-)Plätze in der Schule. Eine fotoethnographische Exploration. In: Thomas Alkemeyer/Herbert Kalthoff/Markus Rieger-Ladich (Hg.): Bildungspraxis. Körper Räume Objekte. Weilerswist, S. 183-205.

Betz, Tanja (2009): Kindheitsmuster und Milieus. In: Aus Politik und Zeitgeschichte 17, S. 14-20.

Betz, Tanja/Bischoff, Stefanie (2013): Risikokind und Risiko Kind. Konstruktionen von Risiken in politischen Berichten. In: Helga Kelle/Johanna Mierendorff (Hg.): Normierung und Normalisierung der Kindheit. Weinheim, S. 60-81.

Bildungsdirektion (2008): Lehrplan für die Kindergartenstufe des Kantons Zürich. Zürich: Lehrmittelverlag.

Bourdieu, Pierre (1982): Die feinen Unterschiede. Kritik der gesellschaftlichen Urteilskraft. 1. Aufl. Frankfurt a.M.

Bourdieu, Pierre (1993): Sozialer Sinn: Kritik der theoretischen Vernunft. 9. Aufl. Frankfurt a.M.

Bourdieu, Pierre (2012): Entwurf einer Theorie der Praxis. Auf der ethnologischen Grundlage der kabylischen Gesellschaft. 3. Aufl. Frankfurt a.M.

Bublitz, Hannelore (2013): Judith Butler zur Einführung. 4., erg. Aufl. Hamburg. Bühler-Niederberger, Doris (2011): Lebensphase Kindheit. Theoretische Ansätze, Akteure und Handlungsräume. Weinheim.

Butler, Judith (2001): Psyche der Macht: das Subjekt der Unterwerfung. Deutsche Erstausg. Frankfurt a.M.

Butler, Judith (2014): Epilog. In: Bettina Kleiner/Nadine Rose (Hg.): (Re-)Produktion von Ungleichheiten im Schulalltag: Judith Butlers Konzept der Subjektivation in der erziehungswissenschaftlichen Forschung. Opladen, S. 181-187.

Butler, Judith (2018): Das Unbehagen der Geschlechter. Deutsche Erstausg. 19. Aufl. Frankfurt a.M.

EDK (2007): Interkantonale Vereinbarung über die Harmonisierung der obligatorischen Schule (HarmoS-Konkordat). Bern: Schweizerische Konferenz der 
kantonalen Erziehungsdirektoren (EDK), online unter http://edudoc.ch/rec ord/24711/files/HarmoS_d.pdf (Zugriff: 15.04.2020).

Elias, Norbert (2018): Figuration. In: Johannes Kopp/Anja Steinbach (Hg.): Grundbegriffe der Soziologie. Wiesbaden, S. 115-117.

Elias, Norbert/Scotson, John L. (1993): Etablierte und Aussenseiter. Frankfurt a.M. Foucault, Michel (2014): Überwachen und Strafen. Die Geburt des Gefängnisses. 14. Aufl. Frankfurt a.M.

Fröhlich, Gerhard/Rehbein, Boike (Hg.) (2014): Bourdieu Handbuch. Leben - Werk - Wirkung. Sonderausgabe. Stuttgart, Weimar.

Gilliam, Laura/Gulløv, Eva (2014): Making children sociak: Civilising institutions in the Danish welfare state. In: Human Figurations 3, H 1. http://hdl.handle. net/2027/spo.11217607.0003.103 (Zugriff: 15.04.2020)

Gugutzer, Robert (2015): Soziologie des Körpers. 5., vollst. überarb. Aufl. Bielefeld. Hirschauer, Stefan (2017): Praxis und Praktiken. In: Robert Gugutzer (Hg.): Handbuch Körpersoziologie. Wiesbaden, S. 91-96.

Knoll, Alex/Jaeger, Ursina (2020): Lost in diglossia? (Un-)doing difference by dealing with language variations in Swiss kindergartens. In: Ethnography and Education 15, H. 2, S. 238-253.

Lareau, Annette (2011): Unequal Childhoods. Class, Race, and Family Life. Berkeley.

Machold, Claudia (2018): Kinder positionieren. In: Christine Thon/Margarete Menz/Miriam Mai/Luisa Abdessadok (Hg.): Kindheiten zwischen Familie und Kindertagesstätte. Wiesbaden, S. 133-149.

Maeder, Christoph (2018): »Die Lego sind heute nicht offen.« Die wissensmässige Belegung des Raums als ein Gesellschaftsdispositiv im Kindergarten. In: Michaela Pfadenhauer/Angelika Poferl (Hg.): Wissensrelationen. 2. Sektionskongress der Wissenssoziologie. Weinheim, S. 421-429.

Maeder, Christoph/Knoll, Alex (2020):»Wir machen das so.«Zur sozialen Organisation des Kindergartens. In: Michaela Pfadenhauer/Elisabeth Scheibelhofer (Hg.): Interpretative Sozialforschung: die Entwicklung in Wien. Methodologie, Methoden und empirische Beiträge zur Organisationssoziologie. Wien, S. 330-349.

Magyar-Haas, Veronika/Kuhn, Melanie (2011): Die Quadratur des Kreises? Formierungen von Gruppen und Machtverhältnissen in pädagogisch arrangierten Kreissituationen. In: neue praxis 1, S. 19-34.

Mauss, Marcel (1975): Soziologie und Anthropologie. Bd. 2. München.

Mauss, Marcel (1985): Les techniques du corps. In: Ders. (Hg.): Sociologie et anthropologie. Paris, S. 365-386.

Neumann, Sascha/Betz, Tanja/Bollig, Sabine/Joos, Magdalena (2017): Kinderkörper. Leibliche, pädagogische und gesellschaftliche Produktionen von Körper- 
lichkeit im Kindesalter. In: Zeitschrift für Soziologie der Erziehung und Sozialisation 37, H. 1, S. 3-9.

Rabenstein, Kerstin (2018): Wie schaffen Dinge Unterschiede? Methodologische Überlegungen zur Materialität von Subjektivationsprozessen im Unterricht. In: Anja Tervooren/Robert Kreitz (Hg.): Dinge und Raum in der qualitativen Bildungs- und Biographieforschung. Leverkusen, S. 15-35.

Reckwitz, Andreas (2003): Grundelemente einer Theorie sozialer Praktiken. Eine sozialtheoretische Perspektive. In: Zeitschrift für Soziologie 32, H. 4, S. 282301.

Reh, Sabine/Rabenstein, Kerstin (2012): Normen der Anerkennbarkeit in pädagogischen Ordnungen. In: Norbert Ricken/Nicole Balzer (Hg.): Judith Butler: Pädagogische Lektüren. Wiesbaden, S. 225-246.

Reh, Sabine/Ricken, Norbert (2012): Das Konzept der Adressierung. Zur Methodologie einer qualitativ-empirischen Erforschung von Subjektivation. In: Ingrid Miethe/Hans-Rüdiger Müller (Hg.): Qualitative Bildungsforschung und Bildungstheorie. Opladen, S. 35-56.

Schatzki, Theodore R./Knorr-Cetina, Karin/Savigny, Eike von (Hg.) (2001): The practice turn in contemporary theory. New York.

Schulz, Marc (2016): Die Pädagogizität des genauen Beobachtens. Aufmerksame Körper, pädagogische Optiken und >Lernkindheit<. In: Friederike Schmidt/ Marc Schulz/Gunther Graßhoff (Hg.): Pädagogische Blicke. Weinheim, S. 7288.

Sieber Egger, Anja/Unterweger, Gisela (2018): Ethnographic Research in Schools. Historical Roots and Developments with a Focus on Germany and Switzerland. In: Dennis Beach/Carl Bagley/Sofia Marquez da Silva (Hg.): The Wiley Handbook of the Ethnography of Education. Hoboken (NJ), S. 233-256.

Sieber Egger, Anja/Unterweger, Gisela (2019): »Jetzt gilt's richtig ernst«. Eine ethnographische Perspektive auf die Inszenierung des Schulbeginns. In: Judith Hangartner et al. (Hg.): Kindheit(en) in formalen, nonformalen und informellen Bildungskontexten: Ethnografische Beiträge aus der Schweiz. Wiesbaden, S. 153-174.

Sieber Egger, Anja/Unterweger, Gisela/Maeder, Christoph (2019): Relational Dilemmas in Producing and Sharing Knowledge with a Research Field. Chapter 4. In: Marit Hoveid/Angelika Paseka/Sofia Marquez da Silva (Hg.): Doing Educational Research: Overcoming Challenges in Practice. London u.a., S. 72-88.

Turner, Stephen (1994): The social theory of practices: tradition, tacit knowledge and presuppositions. Oxford.

Unterweger, Gisela/Sieber Egger, Anja/Maeder, Christoph (2018): Vertrautheit und Distanz in der Ethnographie. Überlegungen zur Beziehungsgestaltung und Wissensproduktion im pädagogischen Feld. In: Fallarchiv Kindheitspä- 
dagogische Forschung. Online-Zeitschrift zu Qualitativen Methoden in Forschung und Lehre 1, online unter DOI: 10.18442/006 (Zugriff: 15.04.2020).

West, Candace/Fenstermaker, Sarah (1995): Doing Difference. In: Gender and Society 9, H. 1, S. 8-37.

Willis, Paul E. (2013): Learning to labour: Spaß am Widerstand. 1. Aufl., aktual. Neuausg. Hamburg. 



\section{Konzeptionelle Reflexionen und theoretische Ausblicke}





\section{Registrieren oder Verstehen? Überlegungen zur Rekonstruktion sozialer Wirklichkeit mittels sozialer Handlung und/oder als Praxis}

Christoph Maeder

Im Text Die Zeiten des Historikers und die Zeiten des Soziologen. Der Streit zwischen Braudel und Gurvitch - wiederbetrachtet wird von Alain Maillard eine wissenschaftshistorische Debatte aus Frankreich beschrieben. ${ }^{1}$ Es geht dabei um gegensätzliche Konzeptionen der Zeit, deren Bedeutung für die Sozialwissenschaften verhandelt wird. Rückblickend erkennen wir darin die Ereignisgeschichte als eine chronologische Registratur von Ereignissen, die im Gegensatz zu der »longue durée« steht. Letztere wird nicht als eine Reihenfolge, sondern als die sinnhafte Entfaltung von Geschichte in der Abfolge von Verbindungen von bedeutsamen Vorgängen über einen relevanten längeren Zeitabschnitt konzipiert. Ereignisgeschichte und »longue durée« stehen so verstanden für das einfache Registrieren von Ereignissen in der Zeit und das Verstehen von Zusammenhängen des Registrierten mit seiner Chronologie auf der anderen Seite.

Anhand zweier bedeutender Gelehrter und ihrer Disziplinen wird damit eine Gegenüberstellung gemacht, welche die Soziologie vereinfacht als eine positivistische und die Geschichte als eine hermeneutische Wissenschaft darstellt. Doch angesichts einer starken und langen interpretativ-verstehenden Tradition in der Soziologie lässt sich heute eine solche disziplinäre Bipolarität nicht mehr als ein gültiges Unterscheidungsraster aufrechterhalten. Was aber bleibt, ist eine Arbeitskategorie zur Unterscheidung von wissenschaftlichen Ansätzen, die uns Hinweise darauf gibt, wie mit der Sinndimension des Sozialen verfahren wird. Dabei ist $\mathrm{zu}$ fragen, wie mit dem Gegensatzpaar von Registrieren versus Verstehen in den Geschichts- und den Sozialwissenschaften umgegangen werden kann, ohne sich notwendigerweise immer gleich an einem Ende des Kontinuums verorten zu müssen. Eine solche Möglichkeit von Registrieren und Verstehen als Verbindung für die Analyse des Sozialen bietet meines Erachtens die Wissenssoziologie und die darin enthaltene symbolisch-interaktionistisch geführte Handlungstheorie. ${ }^{2}$

1 Vgl. Maillard 2011.

2 Vgl. Blumer 2013. 
Hier wird die gelebte und die praktische soziale Wirklichkeit als das Fundament der Gesellschaft betrachtet. Dabei werden die Aspekte von positiver Ereignishaftigkeit und interpretativer Konstruktion von Ereignissen als Dinge im Alltag produktiv zu Institutionen und daraus entstehenden Sozialstrukturen zusammengefügt. ${ }^{3}$ Dergestalt wird Gesellschaft oder soziale Ordnung theoretisch als eine kontinuierliche Permutation von Handlungsverkettungen verstanden, in der die sozialen Situationen und deren Interpretation uno actu von kommunizierenden Menschen erzeugt und in der »Konversationsmaschine « als Alltagswelt wirk- und bedeutsam gemacht und im strengen Wortsinn genommen verwirklicht werden. ${ }^{4}$ Oder anders formuliert: Das Gefüge der sozialen Wirklichkeitskonstruktion lässt sich so in seiner Dinglichkeit und Interpretiertheit erkennen.

In meinem hier als eine Suchbewegung in diesem Spannungsfeld von Registratur und Verstehen verstandenen Beitrag zwischen Praxis- und Handlungstheorien möchte ich erkunden, wie denn derartige Handlungsverkettungen als Praktiken konzipiert und verstanden werden können, ohne mich dabei in die Weiten der vielen Facetten aktueller Praxistheorien hinein verlieren zu wollen. ${ }^{5}$ Dies scheint mir gerade deshalb umso berechtigter zu sein, je mehr sich der Komplex dessen, was unter dem Begriff »Praxistheorien « verhandelt wird, ausdehnt und dabei unübersichtlicher und in sich selber auch widersprüchlich wird. ${ }^{6}$ Ein gemeinsamer Fluchtpunkt aller Praxistheorien liegt fast durchgängig in der Auflösung des Subjekts als eines Handlungsträgers des Sozialen. Es erfolgt in den meisten Praxistheorien - in einer hier bewusst zugespitzten Diktion - der Ersatz des Subjekts als eines handelnden Wesens durch eine situative Mimesis von Körpern und Dingen. Praxis in den Praxistheorien bedeutet - und das ist zentral - dabei genau nicht ein Gemenge von sozialen Handlungen im Sinne von Max Weber und ein sinnhaft strukturiertes Tun und Wirken in der sozialen Welt nach Alfred Schütz, sondern erfasst wird die Emergenz von Ordnung durch eine Verschränkung von inkorporierten und materialisierten Ordnungsroutinen von Menschen und ihren Dingen in ihren Bewegungen. ${ }^{7}$

Damit verschwinden die planenden, leidenden, denkenden, interpretierenden und sonst wie in der Welt stehenden Handelnden als Akteure oder Figuren der Gesellschaft. Sie werden von durch habitualisierte Routinen gesteuerte Assemblagen von Menschen und Dingen in ihren Bewegungen und in ihrem Zusammenspiel ersetzt. Die Verflüssigung des Subjekts durch die rezenten Praxistheo-

3 Vgl. Berger/Luckmann 1969.

4 Vgl. Strauss 1993; Berger/Luckmann 1969, S. 163 f.

5 Vgl. Reckwitz 2003.

6 Vgl. Reichertz 2016, S. 830-848.

7 Der locus classicus für den Ausgangspunkt der Weber'schen Handlungstheorie: Weber 1972; zur Sinnhaftigkeit des Sozialen Schütz 1974. 
rien ist meines Erachtens ein Ergebnis dessen, was sich heute unter dem Label einer weiteren angeblichen Wende in den Sozialwissenschaften, dem sogenannten "practice turn « versammelt hat. ${ }^{8}$ Dass eine solche Entsubjektivierung nicht zwangsläufig aus der Konzeption von Praktiken heraus geschehen muss, das versuche ich im Folgenden nachzuzeichnen. Ich knüpfe dafür beim Locus classicus zu den Praktiken in der Soziologie an, dort wo der Begriff und das Konzept von Praktiken in Ergänzung zum Subjekt zum ersten Mal nachhaltig in die Soziologie eingeführt worden ist, der Ethnomethodologie. Nach der Darlegung dieses salten Praxisverständnisses aus der heutigen Sicht will ich mich dann fragen, was dies für eine rekonstruktiv-interpretative und mit qualitativen Methoden operierende Sozialforschung bedeuten kann.

\section{Die ethnomethodologische Sicht auf Praktiken}

Die zentrale Wurzel in der interpretativen Soziologie für die Entwicklung der Theorie des alltäglich-praktischen sozialen Handelns in der Form sogenannter Praktiken ist in den Studies in Ethnomethodology zu finden. ${ }^{9}$ Diese gelten immer noch als der Schlüsseltext für die Entwicklung von weiteren Forschungsansätzen, die davon ausgehen, dass zu Praktiken geronnene Handlungsroutinen in Rede und Interaktion, aber auch im Umgang mit Artefakten fundamental sind für die Entstehung und Aufrechterhaltung von sozialer Ordnung. Im Kern geht es dabei darum, nachvollziehen und verstehen zu können, wie sich Menschen mit ihren Aktivitäten sich selbst und anderen ihr Handeln verstehbar (»accountable«) machen. Dieser grundsätzliche Ansatz, nicht mehr nur den bewussten Absichten (= Intentionen) der Subjekte nachzuspüren, sondern stattdessen auf deren tatsächliche und konkrete Sprechhandlungen, und zwar selbst die kleinsten und scheinbar unbedeutendsten, $\mathrm{zu}$ fokussieren, ist später von einigen Schülern Garfinkels (z.B. Harvey Sacks, Gail Jefferson etc.) zur Konversationsanalyse ausgebaut worden. ${ }^{10}$ In der Originalformulierung liest sich dies so:

The activities whereby members produce and manage settings of organized everyday affairs are identical with members' procedures for making those settings saccountables. [...] When I speak of accountable my interests are directed to such mat-

8 Vgl. dazu beispielhaft die Besprechung einer einschlägigen Schrift Schulz-Schaeffer 2017, S. 286-291.

9 Vgl. Garfinkel 1967.

10 Vgl. für einen Überblick Eberle 2007, S. 139-160. 
ters as the following. I mean observable-and-reportable, i.e. available to members as situated practices of looking-and-telling. ${ }^{11}$

Was hier auffällt, ist, dass Sprechen und Tun als organisierte Alltagstätigkeiten enthalten sind und dass nicht von Praktiken, sondern von Aktivitäten, die verstehbar gemacht werden, die Rede ist. Und weiter werden kompetent handelnde Mitglieder einer Kultur mit ihrem praktischen Wissen zum Schauen und Reden auf diese Aktivitäten eingeführt, welche im Sinn einer positiven Wissenschaft als beobacht- und beschreibbar gelten sollen. Hier geht es gerade nicht nur um die zeitliche und räumliche Abfolge von Aktivitätssequenzen ohne Handlungssinn, wie dies in den aktuellen Praxistheorien weitestgehend konsensuell unterstellt wird. ${ }^{12}$ Im Gegenteil: Der Handlungssinn in der Interaktion als einem kommunikativen Ereignis ist sozusagen in Routinen geronnen und im praktischen überindividuellen Aktivitätsvollzug mitsituiert. Die Konstitution und Rekonstruktion von Handlungssinn und dessen Strukturierung ist dieser ersten Theorie der Praxis deshalb gerade nicht fremd, wie dies z.B. Warren Handel in seinem bekannten Buchtitel Ethnomethodolgy. How people make sense ${ }^{13}$ auch schon früh zum Ausdruck gebracht hat. Auch wenn die Aktivitätsroutinen einen fast selbstläufigen Maschinencharakter haben für die Beobachtenden, so gehören sie doch zum gesellschaftlich erzeugten Vorrat von Handlungssinn, weil sie ohne diesen gar nie hätten entstehen können. Das Erkenntnisinteresse dieser Perspektive ist damit auf zwei Aspekte einer routinisierten sozialen Handlungspraxis gerichtet: eine genaue Analyse der formalen Strukturen von praktischen Handlungen und auf die Prozeduren, die den jeweils situativen Sinn erzeugen. Eine Konzeption von Sinn durch Handelnde in der Praxis wird jedoch in den späteren Praxistheorien gerade abgelehnt und durch eine sinnentleerte routinisierte Synchronisation von Abläufen zwischen Menschen und Menschen und Dingen ersetzt. ${ }^{14}$

Wenn wir uns nun fragen, welches denn die formalen Eigenschaften solcher Praktiken sind, die eine Wirklichkeitskonstruktion durch eine im Subjekt verankerte, aber gemeinsam geleistete Sinnkonstitution ermöglichen, dann stossen wir auf die theoretisch-methodologischen Begriffe von Indexikalität, Sequenzialität, Reflexivität und Reziprozität. Sie bilden zusammen das Bündel, welches jedes alltäglich-praktische Tun umfasst und es so als ein sinnhaftes Tun für die Emergenz von Gesellschaft auszeichnet.

11 Vgl. Garfinkel 1967, S. 1 u. 9.

12 Vgl. Reichertz 2016, S. 832.

13 Vgl. Handel 1982.

14 Vgl. Reichertz 2016, S. 834. 


\section{Formale Strukturen von praktischen Handlungen}

Ein Beispiel soll das Argument illustrieren. Wenn ich den Satz höre, der lautet: »In welcher Klasse sind Sie?«, so höre ich einen vollständigen und vernünftigen Satz in der Form einer Frage. Und für diesen Satz als eine praktische Äusserung gilt gemäss der Ethnomethodologie die Regel von Garfinkel und Sacks, wonach die interaktive Brauchbarkeit dieses Satzes auf bestimmten formalen Strukturen beruht. Damit sind die folgenden vier miteinander verknüpften formalen Ebenen von praktischen Handlungen (hier am Beispiel einer Sprechhandlung) adressiert: Indexikalität, Sequenzialität, Reflexivität und Reziprozität. ${ }^{15}$

Die Indexikalität eines jeden Zeichensystems bedeutet das Folgende: Wir können den Satz S zwar als eine Frage korrekt identifizieren, doch ohne Handlungskontext wissen wir dennoch nicht, was gemeint ist und was die Frage überhaupt bedeuten könnte. Die Frage bleibt, obwohl formal richtig als Frage erkannt, dennoch sinnlos. Wir können sie nur dann verstehen, d.h. mit gehaltvoller Bedeutung auffüllen, wenn wir einen weiteren Kontext jenseits der von Syntax und Grammatik dazu haben.

Wenn S in einer Schule auftaucht, dann könnte die Frage - je nachdem, wem sie gestellt wird - idealtypisch zweierlei bedeuten. Bei einer Lehrperson wird gefragt, wo und welcher Klasse diese unterrichtet, für wen sie zuständig ist, mit wem sie arbeitet usw. Wenn sie einer Schülerin oder einem Schüler gestellt wird, dann bedeutet die Frage die Abklärung einer organisatorischen und vermutlich altersmässigen Zuteilung einer Person zu einer Gruppe, die wir in diesem Kontext als Schulklasse bezeichnen usw.

Wenn S aber auf einem Bahnhof in der Schweiz zwischen zwei oder mehreren Personen auf dem Bahnsteig fällt, dann erhalten wir eine weitere und deutlich andere Bedeutung, nämlich die Unterscheidung von 1. und 2. Bahnklasse und deren Attribuierung zu Personen, die als Reisende eine klassenmässige Zugehörigkeit infolge eines Fahrscheinkaufs haben. Und wenn genau derselbe S im soziologischen Seminar über Theorien sozialer Ungleichheit fällt, dann werden wir auf die marxistische Klassentheorie verwiesen. Da es mir hier um das Prinzip der formalen Struktur alltäglicher Handlungen am Beispiel einer Sprechhandlung geht, verzichte ich hier jetzt auf die Nennung weiterer möglicher Kontexte der Verwendung von $S$ und dessen situativ jeweils angezeigter Interpretation.

Entscheidend ist die Feststellung, dass praktische Aktivitäten wie die exemplarische Äusserung von S immer einen Index in der Form des Kontextes als einer speziellen Auszeichnung (ein sindexical particulars) der Verwendung mitführen müssen, um als saccount (= Hervorbringung) überhaupt verstanden werden $\mathrm{zu}$ können. Eine reine Mimesis als handlungsstrukturierendes Agens und gesell- 
schaftskonstruierende Emergenz kann es so gesehen, d.h. unabhängig von den Subjekten und ihren Kontexten nicht geben. Und alle Zeichensysteme unterliegen im Gebrauch, wie wir seit Umberto Eco alle wissen, dem Phänomen einer unbegrenzten Semiosis, die immer wieder nur durch indexikale Kontextualität und routinemässige Konsensualität eingeschränkt und beherrschbar gemacht werden kann. ${ }^{16}$

Die Sequenzialität als nächste formale Eigenschaft von praktischen Handlungen verweist darauf, dass jede indexikale Hervorbringung, um verstanden werden zu können, auch strikt sequenziell erzeugt werden muss und auch so geordnet ist. Dies kann anhand von sogenannten Redezugwechseln oder den »turn taking systems« mit den »adjeciency pairs« der Konversationsanalyse leicht nachvollzogen werden. Es gelten hier die Regelstrukturen von Frage und Antwort, Gruss und Gegengruss usw. ${ }^{17}$

Die Reflexivität praktischer Handlungen als drittes Merkmal von praktischem Tun besagt, dass in der Verschränkung von Entäusserung, Interpretation und Reaktion eine Handlungssequenz entsteht, welche das, was als wirklich unterstellt wird, gerade auch durch diese Interaktion herstellt. Was demnach als äussere soziale Wirklichkeit wahrgenommen wird, wird in der Praxis der Handelnden gerade als Gemeinsames referenziert und hergestellt. Auf die Bedeutung einer so verstandenen Handlungspraxis für die Sozialwissenschaft können wir mit den Worten von Giddens ausgedrückt an dieser Stelle nur hinweisen: "All social systems, no matter how grand or far-flung, both express and are expressed in the routines of daily social life. ${ }^{18}$ Die Reflexivität praktischer Handlungen wird in ihrer Konstruktion oft dahingehend missverstanden, wonach hier völlig Freiheit bestehe. Es würde demnach keine Rolle mehr spielen, ob z.B. zwischen sozialer und physikalischer Wirklichkeit unterscheiden wird, weil ja ohnehin salles« sozial konstruiert sei. Dieser Fehlschluss übersieht, dass Natur und Kultur beides gelegentlich auch für handelnde Subjekte tödliche Domänen sein können. Nichts liegt demnach der hier von mir vertretenen Sichtweise ferner als eine übertrieben voluntaristische Gesellschaftskonzeption, die unterstellt, das Prinzipielle (die Konstruktion) würde dem handelnden Subjekt in freier Beliebigkeit für die Anwendung und Ausgestaltung anheimgestellt. Die objektive, d.h. vom Willen des Subjekts unabhängige soziale und natürliche Welt ist jedenfalls ganz in einem

16 Vgl. Eco 1994. Eine lesenswerte Anwendung dieser Konzeption findet sich im Buch Das Foucaultsche Pendel (Eco 1993, S. 338f.), wo dieser Zwang zur Kontextualisierung von Sinn anhand des Cebrauchs von Zahlen durchgespielt wird.

17 Vgl. dazu umfassend Silverman 1998.

18 Vgl. Giddens 1984, S. 36. 
Durkheim'schen Sinn genauso wirklich wie der einzelne Handelnde und seine Aspirationen. ${ }^{19}$

Reziprozität und darin eingeschlossen die Taken-for-Grantedness sind schliesslich die vierte formale Eigenschaft von praktischen Handlungen. Damit ist indiziert, dass in der Handlung mit anderen die von Schütz formulierte >Generalthesis des alter ego < gilt, wonach im menschlichen Gegenüber routinemässig das Gleiche wie in mir, aber ein Nicht-Ich unterstellt wird. Dies ist die ethnomethodologische Koppelung an die Handlungstheorie von Max Weber, mit welcher soziales Handeln vom reinem Verhalten genau dadurch unterschieden wird, als dass im Handlungsentwurf der Handlungspraxis ein konkreter oder generalisierter anderer miteinbezogen wird. ${ }^{20}$ Die Taken-for-Grantedness bedeutet demnach, dass die Handelnden dies alles als natürlich und normal unterstellen und eben gerade nicht auf die Idee der aktiven Konstruiertheit von sozialer Ordnung durch ihre Handlungspraktiken kommen. Diese Absenz ist für das Gelingen von Gesellschaft zentral, denn sobald diese in der Lebenswelt fraglos gegebene Unterstellung wegfällt, zerbricht die soziale Ordnung - wie die Krisenexperimente von Garfinkel gezeigt haben. Eine weitere Konsequenz der Taken-for-Grantedness-Unterstellung in sozialen Situationen ist die Annahme der Handelnden, dass das, was jetzt geschieht, immer wieder geschehen könne. Diese Fraglosigkeit des unterstellen simmer wieder ist der Anschluss an das von Schütz formulierte soziokulturelle Apriori der Lebenswelt. ${ }^{21}$

Die formalen Strukturen praktischer Handlungen - Indexikalität, Sequenzialität, Reflexivität und Reziprozität - gilt es nun, gemäss der ethnomethodologischen Praxistheorie in der empirischen Forschung zu rekonstruieren und in der Situiertheit von sozialen Situationen zu analysieren. Die Fraggestellungen lauten dann: Welches sind die Zeichensysteme und deren Indizes, die in welchen praktischen Handlungen von kompetenten Mitgliedern einer Gemeinschaft, einer Gruppe, eines Berufs usw. gebraucht werden? Auf welche Kontexte verweisen sie routinemässig und in welchen Sequenzen sind die praktischen Handlungen organisiert, wie überhaupt verstehbar und bedeutsam? Welche Reflexivität wohnt diesen indexikalen, sequenziell ablaufenden Handlungen mit ihren Zeichensystemen überhaupt inne? Und welche Reziprozitäten oder Beziehungen (auch zu Dingen und Körpern) spielen dabei eine Rolle und werden für gelingende Interaktionen vorausgesetzt? Es ist selbstredend klar, dass die Bearbeitung solcher Fragenbündel auf anspruchsvolle, oftmals multimodale Datentechnologien und vielschichtige theoretische Grundlagen zurückgreifen muss.

19 Die Regel von Durkheim (1984), wonach Soziales mit Sozialem zu erklären sei, lässt sich jedenfalls nicht aufheben.

Vgl. Weber 1972, S. 1.

21

Vgl. Schütz/Luckmann 1994b u. 1994a. 


\section{$3 \quad$ Schlussfolgerung}

Das Konzept von Praktiken, so wie es für die interpretative Soziologie mit der Ethnomethodologie eingeführt wurde, hat für die Sozialforschung weitreichende Folgen gehabt. Damit hat sich nicht nur der Blick auf die Gesellschaft per se erweitert und verändert, sondern in der Tat wurden die Soziologie und die mit ihren Methoden und Theorien forschenden weiteren Sozialwissenschaften von der funktionalistischen Mikro-Makro-Unterscheidung der Gesellschaft gelöst. Es rückten damit die Praktiken des Handelns ins Zentrum, die auch die Weber'sche Ausgangsposition vom idealtypisch verstehend Handelnden in die Theorien der Lebenswelt hinein wesentlich erweitert haben. Und davon angeleitet sind in den sogenannten Laborstudien später auch die Grundlagen für die Science, Technology and Society Studies (STS-Studien) gelegt worden, aus denen später wegen des Materialitätsargumentes die Akteur-Netzwerk-Theorie von Latour hervorgegangen ist. ${ }^{22}$ Dabei ist aber nun zentral zu beachten, dass diese späteren Praxistheorien die Ethnomethodologie durchgängig ohne die Dimension des sozialen Sinns rezipiert haben. Ihr Kerngehalt besteht aus mimetisch produktiven Verkettungen von inkorporierten und/oder materialisierten Routinewissensbeständen in Auseinandersetzung mit der materiellen Welt als Gesellschaft. ${ }^{23}$ Damit verabschieden diese Praxistheorien genau jene Form der Beschreibung von Geschichte und Gesellschaft, wie sie für eine Rekonstruktion der »longue durée« in historischer oder der Sinnhaftigkeit menschlichen Tuns in soziologisch-interpretativen Sicht angestrebt werden. Dieser Reduktionismus des Sozialen durch eine präzise Auslassung in an sich hochkomplexen und detailverliebten Theorien verdient es meines Erachtens kritisch weiterverhandelt und in seinen Folgen für die Sozialwissenschaften bedacht zu werden. In diesem Sinn wäre ich auch vorsichtig und würde nicht unterstellen wollen, dass das vorgängige handlungstheoretische Konzept der Soziologie einfach durch die praxistheoretischen Ansätze ersetzt werden kann. Vielmehr wäre es verdienstvoll, einer Theorievergessenheit vorzubeugen und wieder nach dem Ertrag der einen oder anderen Denktradition im Hinblick auf die Erklärung der Erzeugung von sozialen Ordnungen anhand konkreter Fälle zu fragen.

Für die Interpretation im Kontext von historisch angelegten Unternehmungen ist dabei meines Erachtens mindestens zweierlei bedeutsam. Erstens haben die sogenannten Praxistheorien, so wie sie in einem zum Locus classicus gewordenen einschlägigen Text zusammengetragen wurden, durchaus von ihm ausgelas-

22 Als berühmt gewordener Ausgangspunkt gilt hier die ethnografische Untersuchung eines naturwissenschaftlichen Labors; vgl. Latour/Woolgar 1979. Für die Akteur-Netzwerk-Theorie sei verwiesen auf Latour 2010. 
sene, elaborierte und für das Verständnis von Gesellschaft bedeutsame Vorgänger. ${ }^{24}$ Diese nicht, nur selektiv oder gar als überwunden zu bedenken, ist meines Erachtens riskant für die empirische Rekonstruktion sozialer Ordnungen. Dies insbesondere wegen der unaufhebbaren Verankerung und Verschränkung der formalen Eigenschaften von praktischen Handlungen in der Interaktionssphäre. Empirisch robuste datenmässige Dokumentationen zu den praxistheoretischen beschreib- und analysierbaren Gegenständen jenseits der Texte gibt es ja erst seit dem Aufkommen der Audio-, Film- und Videotechnologien. Was zeitlich dahinter oder sonst wie ausserhalb liegt, das kann jedenfalls nur mit grossem argumentativem Aufwand praxistheoretisch in der Linie der neueren Praxistheorien erschlossen werden, wenn überhaupt. Der Nodus von Handlungssinn und praxeologisch angelegter Empirie ist jedenfalls anspruchsvoll und sollte nicht einfach ausgeblendet werden. Und zweitens ist es gerade in einem theoriebewussten historischen Umfeld selbstverständlich gut $\mathrm{zu}$ wissen, dass man sich beim Gebrauch von Begriffen wie dem der Praxis oder der praxeologischen Rekonstruktion durchaus auf den Schultern von Riesen und weniger am Beginn eines neuen Durchbruchs, einer Innovation oder an einer Weggabelung befindet. ${ }^{25}$

\section{Literatur}

Berger, Peter L./Luckmann, Thomas (1969): Die gesellschaftliche Konstruktion der Wirklichkeit. Frankfurt a.M.

Blumer, Herbert (2013): Symbolischer Interaktionismus: Aufsätze zu einer Wissenschaft der Interpretation. Berlin.

Durkheim, Emile (1984): Die Regeln der soziologischen Methode. Frankfurt a.M.

Eberle, Thomas S. (2007): Ethnomethodologie und Konversationsanalyse. In: Rainer Schützeichel (Hg.): Handbuch Wissenssoziologie und Wissensforschung. Konstanz, S. 139-160.

Eco, Umberto (1993): Das Foucault'sche Pendel. München.

Eco, Umberto (1994): Einführung in die Semiotik. München.

Garfinkel, Harold (1967): Studies in Ethnomethodology. Englewood Cliffs.

Garfinkel, Harold/Sacks, Harvey (1976): Über formale Strukturen praktischer Handlungen. In: Elmar Weingarten/Fritz Sack/Jim Schenkein (Hg.): Ethnomethodologie. Beiträge zu einer Soziologie des Alltagshandelns. Frankfurt a.M., S. 130-176.

Giddens, Anthony (1984): The constitution of society. Outline of the theory of structuration. Cambridge.

24 Vgl. in vielen Arbeiten als Referenzpunkt zitiert Reckwitz 2003.

25 Vgl. Merton 1983. 
Handel, Warren (1982): How People Make Sense. Englewood Cliffs.

Latour, Bruno (2010): Eine neue Soziologie für eine neue Gesellschaft. Einführung in die Akteur-Netzwerk-Theorie. Frankfurt a.M.

Latour, Bruno/Woolgar, Steve (1979): Laboratory Life. The Social Construction of Scientific Facts. Beverly Hills, London.

Law, John/Singleton, Vicky (2004): Object Lessons, online unter www.hetero geneities.net/publications/LawSingleton2004ObjectLessons.pdf (Zugriff: 15.04.2020).

Maillard, Alain (2011): Die Zeiten des Historikers und die Zeiten des Soziologen. Der Streit zwischen Braudel und Gurvitch - wiederbetrachtet. In: Trivium. Revue franco-allemande de sciences humaines et sociales - Deutsch-französische Zeitschrift für Geistes- und Sozialwissenschaften 9, online unter http:// journals.openedition.org/trivium/4048 (Zugriff: 15.04.2020).

Merton, Robert K. (1983): Auf den Schultern von Riesen. Ein Leitfaden durch das Labyrinth der Gelehrsamkeit. Frankfurt a.M.

Reckwitz, Andreas (2003): Grundelemente einer Theorie sozialer Praktiken: Eine sozialtheoretische Perspektive. In: Zeitschrift für Soziologie 32, H. 4, S. 282301.

Reichertz, Jo (2016): Braucht die qualitative Sozialforschung die Praxistheorie oder: Was gewinnt man, wenn auf das Mentale verzichtet? In: Jürgen Raab/ Reiner Keller (Hg.): Wissensforschung - Forschungswissen: Beiträge und Debatten zum 1. Sektionskongress der Wissenssoziologie. Weinheim, S. 830-848. Schulz-Schaeffer, Ingo (2017): Rez. »Hilmar Schäfer (Hg.), Praxistheorie. Ein soziologisches Forschungsprogramm. Bielefeld: transcript 2016«. In: Soziologische Revue 40, H. 2, S. 286-291.

Schütz, Alfred (1974): Der sinnhafte Aufbau der sozialen Welt. Frankfurt a.M.

Schütz, Alfred/Luckmann, Thomas (1994a): Strukturen der Lebenswelt. Bd 2. Frankfurt a.M.

Schütz, Alfred/Luckmann, Thomas (1994b): Strukturen der Lebenswelt. Bd 1. Frankfurt a.M.

Silverman, David (1998): Harvey Sacks. Social Science \& Conversational Analysis. New York.

Strauss, Anselm L. (1993): Continual Permutations of Action. New York.

Weber, Max (1972): Wirtschaft und Gesellschaft: Grundriss der verstehenden Soziologie [1922]. 5. Aufl. Tübingen. 


\section{Die normative Kraft des Praktischen Bildungstheoretische Reflexion von zentralen Elementen der Buchbeiträge}

Tomas Bascio

Am Ende wird - basierend auf den versammelten Buchbeiträgen, aber mit einem zusätzlichen Schwerpunkt - der Versuch unternommen, auf ein zentrales Element zu fokussieren, nämlich auf das normative Fundament von Praktiken. Dabei beinhaltet der angekündigte Vergleich bereits die These, dass Praktiken, wie sie hier beschrieben wurden, im Wesentlichen auf (impliziten oder explizit gemachten) normativen Prämissen gründen, aber auch durch ebendiese hervorgebracht werden. Ähnlich wie ein Ölgemälde erst durch eine - teilweise auch mehrschichtige und aufwendige - Grundierung wesentlich zu seiner Farbigkeit und Langlebigkeit kommt, scheinen Praktiken erst durch ihr normatives Fundament, das analog zum Ölgemälde auch als normative Grundierung bezeichnet werden könnte, als Praktiken überhaupt wahrnehmbar zu sein. Und so wie ein Gemälde in seiner fertigen Ausführung die Grundierung höchstens noch erahnen lässt, sind die Werte und Normen, die einer Praktik zugrunde liegen, auf den ersten Blick möglicherweise verborgen. Um der Grundierung eines Bildes auf den Grund zu gehen, müssten die Farbschichten mit Skalpell und Schaber weggeschnitten und weggekratzt werden. Wie in den Beiträgen beispielhaft gezeigt wurde, waren für die Sichtbarmachung des normativen Fundaments bzw. der normativen Grundierung der Praktiken ebenfalls Eingriffe nötig, auch wenn es sich methodisch nicht um gemäldechirurgische, sondern um historische und ethnografische Ansätze handelt.

In diesem abschliessenden Beitrag soll also der Blick auf die Praktiken als normierende Ordnungen ${ }^{1}$ in den Mittelpunkt gerückt werden, so wie sie sich der Annahme nach in den Buchbeiträgen präsentieren (1). Zusätzlich soll gezeigt werden, wie Praktiken durch meist nichtintendierte, sprachliche Ordnungen der Autoren und Autorinnen in den Beiträgen lesbar gemacht bzw. wie in den untersuchten Beispielen Praktiken durch verschiedene Akteure sprachlich geordnet werden (2)

1 Dabei wird »Ordnung« nicht - wie heute in den Sozialwissenschaften üblich - ausschliesslich als diskursanalytischer Begriff verstanden, sondern ebenso im praxeologischen Verständnis. 
und wie es methodisch offensichtlich anspruchsvoll ist, die normative Fundierung bzw. die normative Grundierung sichtbar zu machen (3).

Zuvor soll noch einleitend eine handlungstheoretische Reflexionsschlaufe durchlaufen werden: Nach dem Lesen der Buchbeiträge könnte nämlich einer Leserin oder einem Leser ein unschärferelationales Gefühl beschleichen. Analog zur These der Quantenphysik, wonach im subatomaren Bereich keine genauen Messungen durchführbar seien, scheint es nicht möglich zu sein, Praxis bzw. Praktiken genau zu erfassen oder zumindest einheitlich zu beschreiben. Auf die begriffliche Unschärfe des Praktikenbegriffs ${ }^{2}$ oder auf dessen ausschliessliche Existenz in Zusammenhang mit Abläufen und Relationen ${ }^{3}$ wird in verschiedenen Texten verwiesen. Alle in diesem Band versammelten Untersuchungen setzen Praktiken in Beziehung zu einer bestimmten Forschungsperspektive und fokussieren - unabhängig davon, ob mit historisch- oder ethnografisch-methodischem Zugang gearbeitet wird - auf eine bestimmte, menschliche Praxis. ${ }^{4}$ Dass die Praktiken unterschiedlich definiert und beschrieben werden, könnte zur (vorschnellen) Annahme führen, es wäre besser, den Praktikenbegriff möglichst zu vermeiden, ${ }^{5}$ dass Praktiken die Grenzen der eigenen Forschungsrichtung sichtbar machen ${ }^{6}$ oder dass es Praktiken zwar geben möge, dass sie aber nur ungenau und sehr disparat erfasst werden können und deshalb keine vernünftigen Aussagen über Praktiken - auch nicht nach dem Lesen der hier versammelten Artikel - möglich seien. Ein solches Urteil ginge beispielsweise von der Prämisse aus, dass Praktiken in irgendeiner Form ein Bündel von Handlungen beschreiben, und wenn die zugrundeliegenden Handlungen nicht genau festgemacht, wenn die Ursachen einer Handlung nicht genannt werden können, dann sind letzten Endes auch die Praktiken, die auf ebendiesen Handlungen aufbauen, nicht sinnvoll beschreibbar. Ein solches Urteil wäre gemäss dem Sprach- und Handlungsphilosophen Donald Davidson aber verfrüht und falsch. Denn die Beschreibung und die Erklärung von Handlungen -

2 De Vincenti in diesem Band (i.d.Bd.), S. 116.

3 Ebd., S. 117.

4 Dabei ist es nicht unerheblich, dass die hier untersuchten menschlichen Aktivitäten in ihren verschiedenen Auffassungen und Kontexten aristotelisch gesprochen praktisch und nicht etwa poietisch oder theoretisch gedeutet werden. Das heisst, weder die handwerklichen Fertigkeiten (Poiesis) noch die Einsichten in obere Prinzipien (Theoria) interessieren hier, sondern (zwischen-)menschliche Aktionen und Interaktionen, die in Praktiken ihren Ausdruck finden (vgl. Gigon 1973, S. 65f.).

5 So etwa Philipp Felsch: »Offen gestanden, versuche ich, das Wort >Praktiken< inzwischen möglichst selten zu verwenden. Denn bei den letzten Malen zerfiel es mir manchmal wie ein modriger Pilz im Mund « (2016, S. 255).

6 So fragt sich beispielsweise ]ürgen Budde, »was denn das spezifisch Ethnographische an der Ethnographie ist, wenn sie mit grosser methodischer Breite, methodologischer Vielfältigkeit sowie einem unscharfen Praktikenbegriff ausgestattet ist« (2015, S. 8). 
und damit weitergedacht: auch von Praktiken - sind ohne genaue Kenntnisse der inhärenten Kausalgesetze sehr wohl möglich: »Es ist ein Irrtum zu glauben, es sei keine Erklärung gegeben worden, solange kein Gesetz genannt worden ist. « ${ }^{7} \mathrm{Er}$ klärungen (für Ereignisse) werden auch gegeben, wenn kein Gesetz dafür genannt wird. Und - deshalb diese sprachanalytische Schlaufe - es ist sogar sehr wahrscheinlich, dass die für die Erklärungen verwendeten Begriffe die gleichen wie für die vielleicht später folgenden (Kausal-)Gesetze sind, auch wenn die Begriffe in Gesetzen bereits eine erweiterte oder umgekehrt auch eine eingeschränkte Bedeutung haben. Auf die Praktiken gemünzt, könnte daraus geschlossen werden: Auch wenn Praktiken ursächliche Gründe haben, die aber (noch) nicht bekannt sind, sind vernünftige, sinnvolle Aussagen über ebendiese Praktiken möglich, auch wenn der Begriff der Praktiken auf den ersten Blick heterogen und uneinheitlich verwendet wird. Tatsache ist, dass er (unterschiedlich) verwendet wird, um bestimmte Ereignisse zu beschreiben, und dass diese Aussagen sprachlich auch bedeutungsvoll sind, wenn auch die verwendeten Begriffe uneinheitlich sind.

\section{Die normierende Ordnungskraft der Praktiken}

Was über das Beschreiben von Praktiken bei allen Artikeln als übergeordnete, gemeinsame Klammer bezeichnet werden kann, ist die Deutung von Praktiken als normierende Ordnungen - trotz unterschiedlichen Themen, Schwerpunktsetzungen, analysierten Zeiten und ausgesuchten Methoden. Unabhängig davon, ob mit Praktiken »Tätigkeiten, deren Beschreibungen, Begründungen und Legitimationen « verstanden werden, ${ }^{8}$ womit eine moralische, normative Ebene explizit mitgemeint ist, oder ob Praktiken implizit Wert- und Normvorstellungen transportieren, wie beispielsweise bei der Beschreibung der Praxis des Mitschreibens, bei welcher Texte kommentiert, bezweifelt, gestrichen oder ergänzt werden: ${ }^{9}$ Den Praktiken scheint eine moralisch-normative Komponente innezuwohnen.

Viele der hier dargestellten Praktiken sind als normative Handlungsmuster gerade wegen ihrer pädagogischen Einbettung erkennbar. So sind Praktiken des Strafens als "Beschreibung der Strafpraxis ${ }^{10}$ immer auch (normative) Begründungspraktiken. Als sprachlich gefasste Handlungen, mit denen gemäss den meisten Autoren und Autorinnen auch ein Handlungsäquivalent in den sprachlich formulierten Tätigkeiten korrespondiert, kommen Strafpraktiken in fast allen hier versammelten Texten vor: So sind Strafpraktiken auch bei den Hauswarten be-

\footnotetext{
7 Davidson 1998, S. 39.

8 Horlacher i.d.Bd., S. 244.

9 Reh/Klingeri.d.Bd., S. 229.

10 Horlacher i.d.Bd., S. 246.
} 
obachtbar, die als Vollstrecker die Strafverhängung der Lehrpersonen umsetzen mussten. ${ }^{11}$ Bei den Studentenverbindungen wurden in Zusammenhang mit dem Trinken Praktiken des "Strafens oder Ahndens von Vergehen $\aleph^{12}$ ausgesprochen, unter anderem auch die Höchststrafe eines Seminarausschlusses, wie sie auch die Analyse des Romans Unterm Rad gezeigt hat, ${ }^{13}$ in Schaffners Johannes-Roman werden zudem Kollektiv- oder Prügelstrafen ausgemacht. ${ }^{14}$ Eine eigentliche Strafpraktik ist auf den ersten Blick in den Eignungsabklärungen vermutlich nicht ersichtlich, bedenkt man allerdings die normative Kraft der Eignungsabklärungen, die über Zulassung oder Nichtzulassung zu einem Lehramtsstudium entscheiden konnten, ${ }^{15}$ so könnten auch hier Strafpraktiken gesehen werden. Zumindest können diese Abklärungen als normative Praktiken gesehen werden, da die gute, ideale Lehrperson als normative Orientierung diente. Auch in der Studie der Kindergartenkinder werden Strafen nicht explizit genannt, doch könnte die ausgesprochene Rüge der Kindergartenlehrerin wegen der Missachtung einer Verhaltensnorm durchaus als Strafe bezeichnet werden, nämlich - wenn die Zurechtweisung in Gegenwart der anderen Kinder geschieht - als öffentliche Blossstellung oder allgemein als soziale Sanktion, je nachdem, wie, in welchem Tonfall, mit welchem Blick etc. die Lehrperson das Kind anspricht. ${ }^{16}$ Dass in Nachrufen bisweilen dem Verstorbenen gegenüber auch (negative) Kritik geäussert wurde, ist etwas überraschend: Naturgemäss nicht mehr für den Verstorbenen, aber für die Hinterbliebenen oder all jene, die den Nachruf hörten oder lasen, könnten solche genannten »Fehler« einer verstorbenen Lehrperson oder eines Schülers leicht als strafende, in böser Absicht ausgesprochene Abrechnung (miss-)verstanden worden sein. ${ }^{17}$ Und wenn in Kollegheften »Ungenauigkeiten und Fehler beklagt ${ }^{18}{ }^{8}$ wurden, so könnten diese Rekonstruktionspraktiken von Studierenden in ihrem normativen Gehalt auch als strafendes Urteil gegenüber einem Professor oder einem Dozenten bezeichnet worden sein.

Die obengenannten Beispiele zu den Strafpraktiken scheinen eines gemeinsam zu haben: Sie gehen mit einer bestimmten Annahme einher, wie Menschen

11 Juen i.d.Bd., S. 68, 76.

12 De Vincenti i.d.Bd., S. 132.

13 Grube i.d.Bd., S. 153.

14 Ebd., S. 152.

15 Hoffmann-Ocon i.d.Bd., S. 184.

16 Sieber Egger/Unterweger i.d.Bd., S. 281. Vom Kind könnte es umgekehrt gar als Erfolg taxiert werden, wenn es derart angesprochen wird, das ändert aber nichts daran, dass die Interaktion auch ein normativ-strafendes Element aufweist. Es wäre zudem auch denkbar, dass das Kind zunächst die Aufmerksamkeit und das Getadeltwerden als Erfolg verbucht, es später aber als Bestrafung begreift (vgl. später zum Thema Eigensinn).

Burri i.d.Bd., S. 98. 
handeln, weshalb sie so und nicht anders handeln und vor allem auch: wie sie anders hätten handeln müssen. In Verbindung mit Donald Davidsons Handlungstheorie könnten die Strafpraktiken so begriffen werden, dass diese nicht - wie umgangssprachlich üblich - Fehlverhalten, sondern eigentliche Fehlhandlungen sanktionieren sollten. Dabei geht die strafende Seite meist davon aus, dass die fehlbare Person - auch wenn diese nicht absichtlich die strafbare Handlung vollzieht - trotzdem als Verursacher/-in des sanktionswürdigen Ereignisses gilt, weshalb sie wiederum als Verantwortliche gesehen und auch als solche bestraft werden kann. ${ }^{19}$

Oft sind Strafpraktiken im pädagogisch-erzieherischen Kontext die auffälligeren Praktiken, aber es werden in den Texten zuhauf auch andere, alltägliche oder »dezentere« Praktiken beschrieben, die im jeweiligen Kontext eine normative Komponente haben bzw. überhaupt erst durch das Normative verständlich sind. Praktiken werden - wie es De Vincenti formuliert - durch nichts konstituiert, »ausser durch sich selbst respektive durch benachbarte Praktiken «. ${ }^{20}$ Aber um über die Praktiken zu schreiben und um zu verstehen, welcher normative Gehalt in den beschriebenen Praktiken enthalten ist, wird immer auch über das Beschreiben der eigentlichen Praxis hinaus versucht, mit überzeitlichen, dekontextualisierten, quasi transzendental-sprachpragmatischen Begriffen und Kategorien zu arbeiten. Und so wie Horlacher nach der Analyse der Handbücher und Leitfäden konstatiert, »dass auch eine auf Praxis und Praktik fokussierte Perspektive keine historische Realität zu rekonstruieren vermag, sondern dass es auch hier im Wesentlichen [sic!] darum geht, so gut wie möglich zu rekonstruieren, was gemeint war, wenn etwas gesagt bzw. getan wurde «, ${ }^{21}$ könnte weiter gefragt werden: Wie könnten Praktiken anders als mit allgemeinen, überzeitlichen Begriffen verständlich gemacht werden? Die praxeologische Perspektive hilft, Praktiken überhaupt erst ans Tageslicht zu heben, normative Ordnungen werden erst in der Analyse der Praktiken gesehen und stehen nicht schon von Anfang an fest, aber welche analytische Aussagekraft, welche Bedeutung hätten "Strafen« oder »Trinken«, wenn sie nicht auch überzeitlich verstanden werden könnten? Das Strafen als sozialnormative Praktik oder die Praktik des Trinkens als sozialer Akt scheinen zwar überhaupt erst durch ihre Kontextualisierungen und in Bezug auf die Materialität greifbar zu sein, aber in der Interpretation sind sie auch deshalb bedeutungsvoll, weil wir aus heutiger Sicht verstehen, weshalb Strafen und Trinken überhaupt mit Moral und Sitte in Verbindung gebracht werden können, welchen normativen Gehalt Strafen und Trinken (über die blosse Flüssigkeitsaufnahme hinaus) haben können: Studentisches Kneipen erhält erst seinen Sinn, wenn die Vorstellung jugendlichen

\footnotetext{
19 Vgl. Davidson 1998, S. $73 \mathrm{ff}$.

20 De Vincenti i.d.Bd., S. 121.

21 Horlacheri.d.Bd., S. 264.
} 
Trinkens als moralisches Problem denkbar ist, Abstinenz als moralische Tugend ist erst als normative Praktik verständlich, ${ }^{22}$ weil Abstinenz als Begriff, Haltung und Praktik auch ausserhalb des seminaristischen Kontextes verständlich ist. Gemeinsinnpflege oder Solidarität ${ }^{23}$ entfalten sich zwar erst durch einen Kontext wie denjenigen des beschriebenen Trinkens und der Trinkpraktiken vollends, doch dass die Pflege des Gemeinsinns und der Solidarität überhaupt als moralischer Topos verstanden werden, hat damit zu tun, dass wir die Pflege nicht als eine Art sachliche oder botanische Pflege deuten, sondern als moralische Tugend (heute würde wohl eher von Haltung gesprochen werden). So gehen wir beispielsweise auch davon aus, dass es beim »Einüben einer Sitzpraktik « ${ }^{24}$ nicht bloss um das psychomotorische Sitzenlernen geht, sondern auch um das Erlernen einer als normal und konsensuell gesehenen Art, wie ein Kind im Kindergartenkontext $\mathrm{zu}$ sitzen hat. Dabei geht eine Kindergartenlehrperson nicht wissenschaftlich oder empirisch vor, indem sie zuerst prüft, ob ihre Aufforderungen tatsächlich als normal wahrgenommen werden oder einen gesellschaftlichen Konsens darstellen, sondern sie geht eher von einer impliziten, unreflektierten, immer aber auch normativen Annahme aus, wie eine Tätigkeit, eine Praxis im Allgemeinen richtig zu sein hat. Ähnlich ist es bei den Hauswartspraktiken: Deren Alltagshandlungen scheinen per se nur im historischen Kontext verständlich und nicht überzeitlich zu sein. In den beschriebenen Fällen bestanden die habituellen Tätigkeiten der Hauswarte aus Heizen, Reparieren, aber auch aus Kontrollieren und Aufsichtsaufgaben, sodass auch durch sie der Schulalltag reglementiert, geordnet und organisiert wurde. ${ }^{25}$ Gerade der Aspekt des Kontrollierens scheint überhaupt erst in der eingehenderen Analyse der Hauswartspraktiken auf, aber das Verständnis davon, was im gesellschaftlichen Kontext Kontrollieren bedeuten mag, geht über die Hauswartstätigkeiten hinaus, weil wir ein Wissen, eine Kategorie davon haben müssen, was mit Kontrollieren gemeint sein könnte (und zwar nicht nur im Kontext des Seminars). Die Hauswarte übten nicht bloss einen Beruf aus, sondern waren auch Teil der jeweiligen »landscape «, ${ }^{26}$ Teil der Schulkultur. Ihre Berufspraktiken vermischten sich mit erzieherischen und somit auch normativen Praktiken des Aufpassens, Kontrollierens, Meldens, Intervenierens usw. Ihre Praxis als Hauswart war also immer auch Teil der Seminarpraxis und von dieser nicht zu trennen. ${ }^{27}$ In Bezug auf den normativen Gehalt der beschriebenen Praktiken liesse sich bei allen ande-

22

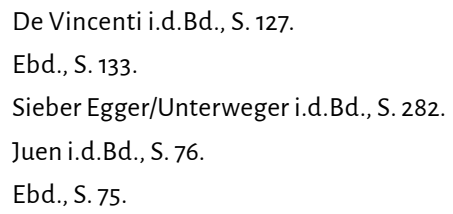
und was eine Schulkultur sein könnte, auch wenn diese Begriffe nicht näher definiert werden. 
ren behandelten Themen Ähnliches sagen. In Zusammenhang mit Erinnerungspraktiken werden von den Nachrufsakteuren »Erinnerung « und »Gemeinschaft» hergestellt, ${ }^{28}$ bei den Eignungsabklärungen - so Hoffmann-Ocon - wurde mit oftmals »normativen Ansprüchen ${ }^{29}$ nach der »Eignung« (Originalbegriff) eines jungen Menschen zum Lehrerberuf gefragt, von Reh/Klinger werden aus einem Studentenführer die Vorzüge des akademischen Vortrags dahingehend zitiert, dass damit »die intellektuellen Kräfte« und der "wissenschaftliche Geist« geweckt und der »Fortschritt der Wissenschaft" vorangebracht werden sollten. ${ }^{30}$ In diesen historischen Beispielen wurden mit Metaphern normative Angaben gemacht, die in Zusammenhang mit den beschriebenen Praktiken, aber auch darüber hinaus verständlich sind. Angelehnt an Hans Blumenbergs Metapherntheorie könnten metaphorische Begriffe wie »Gemeinschaft«, »(Berufs-)Eignung«, »Fortschritt« oder »Geist« als »absolute Metaphern« bezeichnet werden in dem Sinne, dass sie zwar auch als historische Begriffe angesehen werden müssen, aber auch, dass »sie sich gegenüber dem terminologischen Anspruch als resistent erweisen, nicht in Begrifflichkeit aufgelöst werden können. « $^{31}$ Auch wenn Blumenberg eher an allumfassende Phänomene wie »Zeit«, »Welt« und »Leben« denkt, könnten darunter genauso gut Begriffe wie »Geist« oder »Gemeinschaft«, die mitunter ebenso abstrakt und wenig fassbar sind, subsumiert werden. Metaphern werden neben ihrer kommunikativen Funktion auch wegen ihrer hermeneutischen (abstrakte Sachverhalte plastisch veranschaulichenden), ihrer heuristischen (zur Theoriebildung) oder appellativ-argumentativen (überzeugen wollenden) Funktion eingesetzt. ${ }^{32}$ Die hermeneutische und heuristische Funktion der Sprache und im Speziellen der Metaphern erlaubt es, implizite oder explizite Muster, Kategorien, Typologisierungen in den Beschreibungen der Praktiken herauszudestillieren, unabhängig davon, ob die (wissenschaftlichen) Autoren und Autorinnen oder die historisch oder ethnografisch untersuchten Akteure der beschriebenen Fälle sich diesen Mustern oder Kategorisierungen bewusst waren oder nicht.

28 Burri i.d.Bd., S. 87.

29 Hoffmann-Ocon i.d.Bd., S. 187.

30 Reh/Klingeri.d.Bd., S. 218.

31 Blumenberg 2015, S. 12. »Gemeinschaft« erschliesst sich auf den ersten Blick möglicherweise als Metapher weniger als andere, wird aber auch in soziologischen Arbeiten als Metapher beschrieben (allerdings ohne auf Blumenberg Bezug zu nehmen): »Cemeinschaft ist nicht greifbar und soll doch gespürt werden können. Gemeinschaft ist eine Imagination, sie ist ein Bild und beruht auf der Übertragung von etwas auf ein anderes. Gemeinschaft ist Metapher und greift zugleich auf weitere Metaphern zu, um zur Anschauung gelangen zu können« (Niekrenz 2001, S. 15). 


\section{Sichtbarmachen von Praktiken durch sprachliche Ordnungen und komplexitätsreduzierende Ordnungsmuster}

In den Buchbeiträgen werden sprachliche Ordnungen in zweifacher Hinsicht gemacht:

1. Einerseits auf einer analytischen Ebene: Die Autoren und Autorinnen benutzen - meist implizite, manchmal explizit gemachte - sprachliche Ordnungen, um die in den Texten vorgefundenen normativen Ordnungen herauszudestillieren. Sprachliche Ordnungen helfen dabei, die analysierten komplexen, normativen Ordnungen, die normativen Fundierungen in epistemologischer und ontologischer Hinsicht verständlich zu machen.

2. Andererseits auf der beschriebenen, praktischen Ebene: Die Praktiken erscheinen zwar erst durch die Präsentation und Auswahl durch die Autoren und Autorinnen, aber in der Beschreibung erscheint eine zusätzliche, praxeologische Ebene, die zumindest vom Anspruch der Wissenschaftlerinnen und Wissenschaftler her die Praktiken in actu zeigt, wenngleich es nicht Abbilder einer »Realität« sind, so doch exemplifizierte Beispiele von (potenziell) beobachtbaren Praktiken. In diesen beschriebenen Praktiken finden sich ebenfalls sprachliche Ordnungen bzw. sprachliche Verallgemeinerungen, die von den in den herausgearbeiteten Untersuchungen dargestellten Akteuren gemacht werden und ihnen als Orientierungshilfe dienen, um für sich die normativen Praktiken sprachlich $\mathrm{zu}$ ordnen. Meistens ist dies ein alltagssprachlicher, unbewusster und nichtintentionaler Akt, sodass zwar von aussen betrachtet Ordnungen geschaffen werden, meist aber unsystematisch und nicht in analytischer oder ordnender Absicht. ${ }^{33}$

\section{Durch analytische sprachliche Ordnung die normierenden Ordnungen der Praktiken offenlegen}

Wenn Burri in ihrem Beitrag aufopfernde Lehrer als »in Nachrufen besonders gerne gesehener Charakter « und deswegen »als Topos « bezeichnet, ${ }^{34}$ so wird hier analytisch eine Art kategoriale Ordnung der »Nachrufsakteure« versucht. Bei den Seminartugenden soll es grundsätzlich auch »typische Tugenden $\aleph^{35}$ gegeben haben, und Lehrpersonen werden von Burri in geborene, individuelle oder verkannte Lehrertypen eingeteilt, die jeweils in den Nachrufen herauszulesen sind: ${ }^{36} \mathrm{Hier}$ wird mithilfe einer Typologisierung versucht, Ordnung in der Analyse herbeizu-

33 Für die methodische Nutzung von Typen vgl. beispielsweise die als qualitative Methode in der Biografie- und Bildungswissenschaften angewandte Typenbildung (Tippelt 2009). Burri i.d.Bd. S. 97. 
führen, was wiederum an bekannte Lehrertypologisierungsversuche erinnert. ${ }^{37}$ Oder wenn Grube den Roman Unterm Rad als »Prototyp« eines Internatsromans bezeichnet, so wird den darin verhandelten normativen Internatspraktiken ein gewisser Verallgemeinerungscharakter zugesprochen. Über mehrere Texte hinweg wird von Handlungs- oder Verhaltensmustern, von Alltagsroutinen oder von möglichen Wirkmechanismen in Zusammenhang mit analysierten Handlungen gesprochen, was wiederum nichts anderes als einen Versuch darstellt, Praktiken mit ihren Handlungen und Verhalten in Muster, Kategorien oder Typen zu denken: Praktiken werden als Handlungsmuster ${ }^{38}$ oder als »kollektive[] Handlungsmuster ${ }^{39}$ gesehen, im Seminaralltag wird nach »institutionalisierten Kontrollmustern ${ }^{40}$ in den untersuchten Romanen nach "Darstellungsmuster[n] über Alltagsabläufe und Ordnungsroutinen « gesucht. ${ }^{41}$ Bei den Eignungsabklärungen wird den Kandidaten ein musterhaftes Wissen unterstellt, mit deren Hilfe sie ihre eigene Eignungspraktik anpassen konnten. ${ }^{42}$ Ebenso wird die Selbststilisierung in den von den jungen Lehrpersonen verfassten Texten als Muster erkannt, ${ }^{43}$ wobei die Frage, inwiefern in den Texten, die sowohl schulfeldbeschreibend wie auch selbstreflexiv zu sein hatten, normative Ansprüche oder auch Muster, Regeln, gar Typen abzulesen sind, inwiefern die Texte als eher subversiv oder mehr adaptiv angesehen werden können, wohl dahingehend beantwortet werden müsste, dass jeweils alle genannten Aspekte in ihnen enthalten zu sein scheinen.

Die Praktik des Mitschreibens wird auch als »Ausdruck eines wirksam werdenden kulturellen Musters ${ }^{44}$ beurteilt, im systematischen Auswerten der Kolleghefte als serielle Quellen wird das Potenzial gesehen, »Hinweise auf übliche, typische oder aber auch variierende Rezeptionspraktiken « zu sehen. ${ }^{45}$ Im ethnografischen Beitrag wird ein wichtiger Unterschied zwischen den Kindergartengenerationen darin gesehen, dass die Kindergartenlehrpersonen verinnerlichte Praktiken als »implizites und routiniertes Körperwissen ${ }^{46}$ mit sich tragen, während die Kinder solche Routinen erst erlernen (müssen). Routinen können als

37 Es erinnert v.a. an die Unterscheidung des logotropen vom paidotropen Lehrertypen gemäss Christian T. Caselmann (Caselmann 1949), aber auch an andere psychologisch-idealisierte Typologisierungen (z.B. Kerschensteiner 1921 oder Spranger 1958).

38 Juen i.d.Bd., S. 57.

39 De Vincenti i.d.Bd., S. 119.

40 Grube i.d.Bd., S. 143.

41 Ebd., S. 144.

42 Hoffmann-Ocon i.d.Bd., S. 173.

43 Ebd., S. 194.

44 Reh/Klingeri.d.Bd., S. 231.

45 Ebd., S. 229.

46 Sieber Egger/Unterweger i.d.Bd., S. 289. 
Handlungsvollzüge ebenfalls typologisch und musterhaft verstanden werden. Schliesslich sieht Horlacher am Ende ihres Beitrags einen prospektiven Analyseschritt darin, mögliche »Wirkmechanismen $\aleph^{47}$ herauszuschälen, was auf eine Benennung und ev. auch Typologisierung oder Musterhaftigkeit potenzieller Handlungsursachen hinausliefe.

Eine aufschlussreiche Perspektive, das Agieren oder Reagieren einzelner Menschen in den dargestellten, meist normativen Praktiken zu verstehen, bietet die Deutungskategorie des Eigensinns, die als eigene Analysekategorie beschrieben werden könnte. Der Eigensinn bzw. die Eigensinnigkeit wird in einigen vorliegenden Texten teilweise explizit so genannt und charakterisiert, in anderen werden andere Ausdrücke benutzt, diese liessen sich aber ebenfalls mit dem Begriff des Eigensinns übersetzen. In den Texten von Grube oder Hoffmann-Ocon wird der Eigensinn in verschiedenen Ausformungen selber als eigensinnige Praktik beschrieben, "durch eine Perspektivverschiebung« könnten Akteure »als eigensinnige Figuren mit eigenen Routinen « gesehen werden. ${ }^{48}$ Oder - wie von Grube umschrieben - eigneten sich (Seminaristen) »den Umgang mit widerstreitenden Praktiken, unterschiedlichen Meinungsbildungen und Anerkennungserwartungen teilweise subtil eigensinnig an. ${ }^{49}$ Der Umgang mit seminaristischen Ordnungsregimen zeigt sich bei Grube - je nach Akteur und Kontext - in eigensinniger Weise als Trotz, Widerständigkeit, Renitenz oder wurde in Schmähgedichten oder Lesekreisen ausgelebt, Letztere »sorgten bei Seminaristen für eigensinnige Aneigung intellektuellen Wissens ${ }^{50}{ }^{50}$ Dass gewisse Praktiken von Studierenden oder von Schülerinnen und Schülern mit den Erziehungspraktiken der Dozierenden oder Lehrpersonen kollidieren (mussten), zeigt sich nicht nur bei angehenden Lehrpersonen, wenn sie selber noch auf der Schüler- bzw. Studentenseite sitzen, sondern auch bei den ganz Kleinen. Beim von Unterweger und Sieber Egger gezeigten Beispiel des Kindes Alexander zeige sich »eine Positionierung als subtil widerspenstig. ${ }{ }^{51}$ Der hier verwendete Begriff des Subtilen deutet an, dass die exemplifizierte Widerspenstigkeit - oder eben: Eigensinnigkeit - zu der von Grube gemachten Bestimmung von Eigensinn passt. Dieser »impliziere ein Mitmachen gegenüber institutionalisierten Regeln und Normen ebenso wie ein gleichzeitiges Distanzieren oder emotionale, inkonsistente Abweisung. ${ }^{52}$ In der von Unterweger und Sieber Egger analysierten Vignette stellt das Kind Alexander durch seine Bemerkung, man solle sich nicht in die Sandwanne setzen, nicht nur

47 Horlacheri.d.Bd., S. 264.

48 Hoffmann-Ocon i.d.Bd., S. 179.

49 Grube i.d.Bd., S. 164.

50 Ebd., S. 160.

51 Sieber Egger/Unterweger i.d.Bd., S. 284.

52 Grubei.d.Bd., S. 140. 
die als normal gesehene "Hierarchie der generationalen Ordnung vor versammeltem Publikum « in Frage, ${ }^{53}$ sondern zeigt auch eine neue Seite der Eigensinnigkeit, die beim Kind als aufmüpfig interpretiert werden ${ }^{54}$ könnte, aber nicht nur: Neben der Deutung des Widerspenstigen, Trotzigen oder Aufmüpfigen könnte die kindlichen Aussage als ernst gemeint oder auch als Ironie oder Humor gelesen werden. Die sprachliche Demonstration könnte zwar in frecher oder bewusst eine Autorität unterwandernder Intention vorgetragen worden sein, unabhängig davon transportiert sie einen ironischen, humorvollen Subtext, der im Kindergartenplenum und vor der Lehrerin vorgetragen vielleicht nicht die vom Kind erhoffte, aber irgendeine bzw. mehrere Reaktion(en) auslöst (vielleicht lachen andere Kinder, vielleicht auch die Lehrerin usw.). Die Situation scheint bei dieser Lehrperson nicht aus dem Ruder zu laufen, aber solche oder ähnliche Schülerreaktionen könnten einer (mutmasslich) souverän auftretenden Lehrperson ihre erzieherische Nichtsouveränität vor Augen führen, die für Erziehungssituationen typisch zu sein scheint..$^{55}$ Diese beschriebene Kindergartensituation könnte - in Anlehnung an den Phänomenologen Eugen Fink - auch so gedeutet werden, dass »das Wesentliche [...] die Co-Existenz von Freiheiten, nicht das Zusammenleben von naturhaften Lebewesen oder intelligenten Verstandeswesen $\aleph^{56}$ ist. Auf das Beispiel bezogen wären die koexistierenden Freiheiten bzw. die "nicht-souveräne[n] Freiheit[en]«, ${ }^{57}$ die Kindergartenlehrerin und das Kind, die - jede und jedes auf seine Art - praxeologisch versuchen, »Wesentliches« bzw. "Sinnhaftes« in einer bestimmten Situation zu erreichen. Die Lehrerin versucht durch normative Vorgaben, Ordnung zu wahren oder herzustellen, das Kind in normativ-eigensinniger Weise, (Eigen-)Sinn zu kreieren. An diesem kleinen Beispiel zeigt sich, dass die moralische Sitte nicht per se gegeben ist und den Menschen unwidersprochen einsichtig sein muss oder von allen gleich akzeptiert wird, sondern dass sie in einem ständigen Aushandeln von Werten entsteht, dass sie sich ständig produziert, auf einen Nenner gebracht: dass »die Sitte lebt.$^{58}$

\section{Sprachliche Ordnungen in den untersuchten Praktiken}

Nicht nur die hier rekonstruierten Kategorisierungen durch die Autorinnen und Autoren der Buchbeiträge sind von Interesse, sondern auch die Kategorisierungen, Musterhaftigkeiten und Typologisierungen, die sich in den analysierten Prakti-

\footnotetext{
53 Sieber Egger/Unterweger i.d.Bd., S. 284.

54 Ebd., S. $283 f$.

55 Reichenbach 2001; 2018.

56 Fink 1970, S. 217.

57 Reichenbach 2001, S. 37.

58 Fink 1970, S. 100.
} 
ken finden, beispielsweise wenn Seminaristen mit »Negativdarstellung[en] [...] diskursive Muster « aufgriffen, um ein Internat oder Seminar zu diskreditieren. ${ }^{59}$ Schmähgedichte, die sich auch an Lehrer richteten, ${ }^{60}$ erinnern in ihrer Eigensinnigkeit an die Typologisierung von Aristophanes über den Philosophen Sokrates. ${ }^{61}$ Solche Typologisierungen funktionieren, weil sie mit Karikaturen arbeiten, mit überspitzten Darstellungen, weil sie das Spiel mit dem (moralisch) Sagbaren und überhaupt das Ausloten moralischer, normativer Grenzen suchen.

Johann Eduard Erdmann ging in seiner Hodegetik, die er als Professor verfasste, von drei verschiedenen Vorlesungstypen aus, die sich auch in den von ihm - noch als Student - produzierten Mitschriften niedergeschlagen hätten. ${ }^{62}$ Seine Ordnung der Vorlesungstypen (diktierend-altersschwacher, schnellsprechender oder nach Worten ringender Dozent) schlug sich also in eigensinniger Weise auf eine Niederschriftstypologisierung nieder (parallel zu den vortragenden Dozenten: gelangweilter, stenografierender oder paraphrasierender Mitschreiber). Die Praktiken der Mitschriften standen - so Erdmann - also in enger Interdependenz zu den professoralen Vorträgen. Auf eine solche Art von Typologisierung bzw. kategorialer Ordnung wurde von den Akteuren in den beschriebenen Fällen zurückgegriffen, um in den normativen Praktiken (sprachliche) Ordnung zu schaffen. So auch beim Thema Strafen: Unterscheidung von angemessenem und weniger angemessenem Strafen (Pfarrer Brüning) oder Überlegungen zum richtigen Zeitpunkt des Strafens. ${ }^{63}$ Die unterschiedliche Bewertung des Alkoholkonsums beruhte letztlich auf einer Typologisierung des Trinkens. Je nachdem, wer in welchem Kontext trank: Bei den einen wurde das Trinken als Schärfung der patriotischen Gesinnung interpretiert, bei den anderen als ungebildeter Trinkexzess verurteilt. ${ }^{64}$ Auch bei den Praktikumsberichten scheinen (Stereo-)Typisierungen eine Rolle zu spielen: einerseits aufseiten der Studierenden, wenn sie z.B. Schulklassen und Kinder beschrieben (»Keine Musterkinder, doch eine lebendige, fröhliche, oft übermütige Schar«), ${ }^{65}$ aber auch die Direktoren und die Berichtsbeurteiler nutzten Stereotypisierungen (Schüler vom Land sollten gemäss Walter Zulliger etwa »nicht einfach in die Stadt gesteckt wer-

59 Grube i.d.Bd., S. 163.

60 Ebd., S. 159.

61 In Aristophanes' Komödie Die Wolken wurden sowohl Philosophen wie Sokrates als auch Philosophieschüler zum Gespött gemacht (vgl. Aristophanes 2014). Sehr viel später hat Gernot Böhme in Der Typ Sokrates (1992) - wie es der Titel schon vermuten lässt - Sokrates ebenfalls als Typen und nicht in erster Linie als historische Figur untersucht.

Reh/Klinger i.d.Bd., S. 222.

Horlacher i.d.Bd., S. 250.

64 De Vincenti i.d.Bd., S. 133.

65 Lehramtskandidatin zitiert in Hoffmann-Ocon i.d.Bd., S. 190. 
den «). ${ }^{66}$ Auch in den verschiedenen Korrespondenzen zwischen den Hauswarten und den Behörden wurde oft mit allgemeinen Begriffen, die sich oft stereotyper Bilder bedienten, argumentiert, wenn beispielsweise vom »Gesindel« die Rede war. ${ }^{67}$ Auch die in den Nachrufen aufgegriffenen Tugenden wie etwa »Treue, Gewissenhaftigkeit, Pflichtbewusstsein, Arbeitsamkeit, Bescheidenheit ${ }^{68}{ }^{68}$ die sich mit vorgefundenen pädagogischen Tugenden aus der Unterstrasser Hausordnung zu überschneiden scheinen, deuten auf eine gewisse Regelhaftigkeit, Typologisierung, Musterhaftigkeit hin: Schüler bzw. Studenten hatten bestimmte, idealisierte und in der Anzahl überschaubare Haltungen zu erlernen. Auffällig sind auch die idealtypischen Metaphern, die in der Nachrufpraxis benutzt wurden, insbesondere die Metapher der "Seminarfamilie« und daran angelehnte Begriffe: Da wurde dem "väterlichen Berater" gedacht oder es ist von »väterliche[r] Güte« oder schlicht vom »Familienvater« die Rede, allgemein von Familie, Hausmutter, Familienkreis oder vom »Stück Familie«. ${ }^{69}$ Solche »ontologischen Metaphern", wie George Lakoff und Mark Johnson sie nennen, helfen auch, Erfahrungen mit nichtpersonifizierten oder rollenspezifischen Entitäten wie diejenigen, die man mit einem Seminar oder einem Direktor haben kann, zu begreifen, indem solchen »Erfahrungen menschliche Motivationen, Merkmale und Tätigkeiten zugrunde « gelegt werden. ${ }^{70}$ Familien- oder familiennahe Metaphern finden sich auch in den autobiografischen Dokumenten, wo ein Anstaltsdirektor mit »Herr Vater«, dessen Frau entsprechend mit »Frau Mutter « angesprochen wurden oder von »väterliche[m] Freund« oder vom »eigenartige[n] väterliche[n] Wohlwollen « die Rede ist. ${ }^{71}$ Eine Typologisierung in der ethnografischen Studie erfolgt beispielsweise, wenn die Lehrerin fragt: "Was macht sie jetzt, die Nina? ${ }^{72}$ In diesem Fragestil wird nicht nur das Mädchen (Nina) direkt angesprochen (Die Lehrerin sagt nicht: "Was machst $d u$ jetzt? "), sondern indirekt auch die Klasse. Die eigentliche Frage ist an alle gerichtet: Was macht ein Kind normalerweise, im besten Fall in dieser Situation? Gemeint ist also irgendein Kind; das grammatikalisch scheinbar fehlplatzierte »die« bei »die Nina« betont und verallgemeinert bzw. typologisiert die eigentlich Angesprochene, sodass sie nicht nur als Nina, sondern als irgendeine Nina bzw. als irgendein Kind, als typisches Kind in einer solchen Situation angesprochen wird. Nina wird mit anderen Worten ebenfalls

66 Zulliger zitiert in ebd., S. 182.

67 Juen i.d.Bd., S. 68.

68 Burri i.d.Bd., S. 97.

69 Alle die genannten Begriffe sind Originalbegriffe, die in den analysierten Quellen von Burri zitiert werden (i.d.Bd., S. 90, 93, 100f.).

70 Lakoff/Johnson 2008, S. 44.

71 Originale Quellenbegriffe (Grube i.d.Bd., S. 150).

72 Sieber Egger/Unterweger i.d.Bd., S. 285. 
als Typ, in metaphorischer-ontologischer Hinsicht vom Subjekt zum Objekt gemacht. Ohne dass dies explizit gemacht würde, sind alle im Raum aufgefordert, mitzudenken. Da nicht das Mädchen direkt adressiert wird, könnte - falls Nina nicht $\mathrm{zu}$ antworten weiss - jemand aus der Klasse stellvertretend für Nina, die hauptsächlich gemeint ist, antworten, da ja alle indirekt angesprochen wurden. Das "Verschwinden" der Individualität erinnert an den »individuellen Lehrer", der meistens in den Nekrologen beschrieben wurde: Dieser wurde zwar als Individuum dargestellt, gleichzeitig immer unter dem Gesichtspunkt seines Lebens in und für die Institution gezeichnet. Auch hier liesse sich sagen, dass das Individuum im Verlaufe des Nekrologentextes quasi verallgemeinert, das heisst letztlich typologisiert wurde.

Das analysierte Typische, das Herausdestillieren musterhafter Ordnungen oder kategorialer Reihen/Gruppierungen wird von den Beitragsautoren und -autorinnen oft zögerlich oder in Anführungszeichen geschrieben, ganz so, als sollte die nichtintendierte, aber im Ansatz vorhandene kategoriale, musterhafte oder typologisierte Reduktion vermieden werden. Sprachlich wird sie trotzdem oft vollzogen: Dann wird von »typische[n]< Merkmale[n] der zeitgenössischen Hygienebewegung ${ }^{133}$ gesprochen oder davon, dass das persönliche Verhältnis zwischen Seminaristen und Lehrer »fast musterhaft für zahlreiche schulliterarische Romane $\aleph^{74}$ konstatiert werden könne.

\section{Methodisches Erfassen von Praktiken - eine Schlussbetrachtung}

Zum Schluss soll unter Einbezug einiger Überlegungen zu den gewählten Methoden die Frage erläutert werden, inwiefern die normierenden Ordnungen und das Musterhafte bzw. das Kategorisierende aus den Praktiken herausdestilliert werden.

Die Feststellung, dass bei historisch-praxeologischen Forschungen »keine direkte Beobachtung einer vergangenen Praxis ${ }^{75}$ möglich sei, während bei der ethnografischen Erforschung von Praktiken die Datensammlung durch die teilnehmende Beobachtung unmittelbarer gegeben sei, suggeriert, dass die ethnografische Herangehensweise "näher" an der »Praxis-Realität» sei. Prima facie scheint sich die ethnografische Herangehensweise tatsächlich stark von der historischen abzugrenzen, bei genauerem Hinsehen fallen jedoch mehr Gemeinsamkeiten als Differenzen auf: So sind die wichtigsten und grundsätzlichen

\footnotetext{
73 Juen i.d.Bd., S. 77.

74 Grube i.d.Bd., S. 150.

75 Reh/Klinger i.d.Bd., S. 209.
} 
Untersuchungsmaterialien sowohl in der historischen Forschung wie auch in der Ethnografie Texte: Briefe, Seminarprotokolle, Ego-Dokumente, Hausordnungen. Mitschriften aus vergangenen Tagen unterscheiden sich in vielerlei Hinsicht sehr von zeitgenössischen Beobachtungs- und Feldprotokollen, in einem wesentlichen Aspekt aber überhaupt nicht: Es sind schriftliche Quellen, sie werden als schriftliche Dokumente analysiert, und sie bleiben in ihrer Schriftlichkeit auch für Dritte, für spätere Forschergenerationen die wichtigste Datenauswertungsgrundlage. Sowohl in der Historiografie wie auch in der Ethnografie (und vielen anderen Wissenschaften) werden mittels einer wie auch immer gearteten Rekonstruktionsmethode bestimmte Ereignisse, Prozesse oder Ergebnisse untersucht. Wenn »die Welt als Text ${ }^{76}$ apostrophiert wird oder in jedweden menschlichen Produkten potenziell »Quellen, Quellen, Quellen ...«" ${ }^{77}$ gesehen werden, scheinen sich sozialwissenschaftliche von historischen Herangehensweisen weniger weit $\mathrm{zu}$ unterscheiden, als es die unterschiedlichen disziplinären Situierungen suggerieren. Verschiedene Autoren und Autorinnen gehen davon aus, dass Materialität für das Verständnis von Praktiken wichtig sind, ${ }^{78}$ noch wichtiger scheint für die Untersuchung und das Erfassen von Praktiken aber ein anderer Sachverhalt zu sein: Das Reden bzw. das Schreiben über die Praktiken bleibt der eigentliche Untersuchungsgegenstand, Texte und die dazugehörigen Kontexte bleiben zentrale Referenzen für die Analyse der Praktiken. ${ }^{79}$

Bekannte >Gefahren<, die in den historischen Wissenschaften diskutiert werden, gelten auch für die Ethnografie und für andere Wissenschaften: dass bei der Rekonstruktion einer Praxis bzw. von Praktiken aus Quellen/Datenmaterialien die Quellen/Daten als Abbilder »der« Realität genommen werden, oder zugespitzter formuliert, dass die analysierten Quellen überhaupt als Abbild einer kohärenten Realität gesehen werden. ${ }^{80}$

Bei den hier dargestellten Texten fällt auf, dass in vielen von ihnen auf dieselben Theorieansätze Bezug genommen wird und dass die Praxeologie nicht als dogmatisches Forschungsprogramm benutzt werden soll, sondern dass diese

76 Garz/Kraimer 1994.

77 Budde 2008.

78 »Praktiken hinterlassen ihre Spuren im Material. Die Betrachtung von Artefakten, aber auch der materiellen Seite von Text- und Bildquellen stellt demnach eine wichtige Ergänzung textlich-oder bildlich-symbolischer Überlieferungen dar«(Reh/Klinger i.d.Bd., S. 212). Allerdingsnimmt man Wittgensteins Verständnis von Lebensformen als Grundlage - sind viele Lebensformen bzw. Praktiken eben nicht materiell grundiert (Grüssen, Beten, Fluchen u.v.a.m.; ausser man wollte auch den menschlichen Körper immer auch als Material bezeichnen, dann stellt sich allerdings die Frage, was nicht materiell zu bezeichnen wäre; vgl. dazu Fussnoten 79f.).

79 Vgl. Horlacher i.d.Bd., S. 243.

80 Vgl. Grube i.d.Bd., S. 144. 
einen Blick auf (vermeintlich) bekannte Phänomene oder Themen neu justieren kann, nämlich beispielsweise auch auf die Frage, inwiefern Praktiken normativ grundiert sind. ${ }^{81}$

Zwei Aspekte sollen zum Schluss nochmals bedacht werden:

1. Auch wenn Quellen nicht »von sich aus sprechen«, ist der sprachlich-textliche Anteil an den Praktiken beträchtlich, ist das Element der Sprache und des Erzählens zentral: Das Sprechen und Schreiben über das Strafen, über das Trinken, die Hauswartsaufgaben, die Eignung zum Lehrberuf usw. sind auf einer ersten Ebene sprachliche Attribute, die auf einer zweiten Ebene - unabhängig davon, ob mit historischer oder ethnografischer Herangehensweise - immer auch sprachanalytisch $\mathrm{zu}$ fassen versucht werden. Deshalb ist bei der in den Beiträgen vielfach formulierten praxeologischen Perspektive $\mathrm{zu}$ fragen, was genau die zu analysierenden Quellen sind, wer die Quellen erzeugt hat, mit welcher Absicht, in welchem Kontext. Aber auch, weshalb diese (und nicht andere) Quellen heute interessant sind, wer sie analysiert und zu deuten versucht, für welches Problem einer bestimmten praxeologischen Frage gewisse Quellen überhaupt von Interesse sind und weitere Fragen sind unhintergehbare Aspekte, die es praxeologisch immer zu bedenken gilt. Zudem bleibt die Frage, inwiefern eine bestimmte Praxis erst durch eine gewählte Forschungsperspektive erzeugt wird, auch immer zentral. Was zum zweiten Punkt führt:

2. Angeblich ahistorische Dokumente werden historisch analysiert, mit einer gewissen Distanznahme wird versucht, bei der teilnehmenden Beobachtung möglichst nahe am Geschehen zu sein: Die untersuchten Dokumente - ob historische Quellen oder Beobachtungsprotokolle - werden bei der Analyse selber Elemente im Geschehen, werden zu Akteuren, ${ }^{82}$ was Burri als radikale Historisierung

81 Die je unterschiedlichen theoretisch-konzeptionellen Bezugnahmen innerhalb der praxeologischen Forschung haben auch Auswirkungen auf die Art, wie mit Datenmaterial und Quellen gearbeitet wird, wie diese situiert und gedeutet werden. Beispielsweise ist mit dem mehrfachen Verweis auf Rahel Jaeggis Lebensformen eine bestimmte Art von Lebensformen gemeint, die sich sowohl von ethischen, naturalistischen unterscheidet, aber auch von sprachlich-analytischen im Sinne Ludwig Wittgensteins. Mit Lebensform beschreibt er die Übereinstimmung der Menschen in der Sprache. Das Sprechen einer Sprache, das von ihm bezeichnete Sprachspiel, ist Teil einer Lebensform (vgl. Wittgenstein 1984, 250 [\$23]). Jaeggi fragt»nach Lebensform im Plural, also den verschiedenen kulturellen Formen, die das menschliche Leben annehmen kann « (Jaeggi 2014, S. 21), weshalb bei ihr auch nicht der logische bzw. biologische Cattungsbegriff nach Aristoteles grundlegend ist (vgl. Aristoteles 1995, S. 5 [Topik I 5, 102a]). Will man Lebensformen als »Ensemble lebendiger Praktiken« untersuchen, stellt sich erst mal also die Frage, wie Lebensformen - oder Praktiken - als »überpersönlich geprägte Ausdrucksformen mit öffentlicher Relevanz« (Jaeggi 2014, S. 22) untersucht werden können.

82 Bruno Latour würde wohl von Aktanten bzw. von Hybriden sprechen. Die Hybridität der vielschichtig postulierten Hybride ist selbst Cegenstand einer intensiven soziologischen Debatte 
apostrophiert: »Es gäbe kein Handeln, wären die Nachrufe nicht da, d.h. würden vorgetragen, gedruckt, verteilt, gelesen, aufbewahrt usw. Sie werden damit zu wesentlichen Elementen im Handlungsgefüge « ${ }^{83}$ Der zusätzliche Aspekt müsste noch hinzugefügt werden: Würden Praktiken nicht so analysiert, wie sie heute untersucht werden, gäbe es zwar (in einem vergangenen seminaristischen Gefüge oder in einem zeitgenössischen Kindergarten) Tätigkeiten, Handlungen, Praxisgefüge, die aber erst durch den heutigen Blick, durch die heutigen Fragestellungen zu dem werden, was wir »Praktiken«nennen. Die Frage ist allerdings, wie in analysierten - vergangenen oder zeitnahen - Handlungskonstellationen Praktiken von Nichtpraktiken unterschieden werden, wenn - kaum thematisiert man menschliches Tun in Handlungskontexten - Praktiken als Analysebasis gegeben sind: Was wäre das Gegenteil einer menschlichen Praxis, die Differenzierung innerhalb von Praktiken? Die Gefahr einer »begrifflichen Nivellierung, einer Veralltäglichung des Begriffs der Praktik einerseits und einer >Übertheoretisierung andererseits « ${ }^{84}$ könnte durchaus bestehen. Aber - um auf den Anfang zurückzukehren: Praktiken sind als heuristische Denkkategorie durchaus zielführend, um normative Grundlegungen von Handlungen, Handlungskomplexen überhaupt erst an die Oberfläche zu heben, um sie sichtbar und denkbar zu machen.

\section{Literatur}

Aristophanes (2014): Die Wolken. Stuttgart.

Aristoteles (1995): Philosophische Schriften. Bd. 2: Topik - Sophistische Widerlegungen. Hamburg.

Blumenberg, Hans (2015): Paradigmen zu einer Metaphorologie. 6. Aufl. Frankfurt a.M.

Budde, Gunilla (2008): Quellen, Quellen, Quellen ... In: Gunilla Budde/Dagmar Freist/Hilke Günther-Arndt (Hg.): Geschichte: Studium - Wissenschaft - Beruf. Berlin, S. 52-69.

geworden (vgl. Kron 2015). Die Annahme von Hybriden, d.h. von sozialen, kulturellen, dinghaften Vermischungen bzw. von Mischfiguren, setzt voraus, dass auch Nichthybride denkbar sind, also im Cegensatz zu Nichteindeutigem etwas Eindeutiges. Doch was sollen genau die Distinktionsmerkmale sein? Der Soziologe Athanasios Karafillidis vertritt die These, »dass die ontogenetische Grundlage von Hybridität die Operation der Unterscheidung ist, von der man sich aus theoretischen, politischen oder ideologischen Gründen so gerne distanziert« (Karafillidis 2015, S. 20). Die These impliziert, dass aus der Praxis des Unterscheidens sowohl Empirisches wie auch Essentialistisches als Resultat herausspringen kann und dass diese auch parallel existieren können.

83 Burri i.d.Bd., S. 106.

84 Füssel zitiert in Reh/Klinger i.d.Bd., S. 209. 
Budde, Jürgen (2015): Reflexionen zur Bedeutung von Handlung und Praktik in der Ethnographie. In: Zeitschrift für Qualitative Forschung 16, H. 1, S. 7-24.

Caselmann, Christian T. (1949): Wesensformen des Lehrers. Versuch einer Typenlehre. Stuttgart.

Davidson, Donald (1998): Handlung und Ereignis. Frankfurt a.M.

Fink, Eugen (1970): Erziehungswissenschaft und Lebenslehre. Freiburg i.Br.

Felsch, Philipp (2016): Die Arbeit der Intellektuellen. Zur Vorgeschichte des practical turn. Nach Feierabend. Zürcher Jahrbuch für Wissensgeschichte 12. Wissen, ca. 1980, 255-262. Zürich/Berlin.

Garz, Detlef/Kraimer, Klaus (1994): Die Welt als Text. Theorie, Kritik und Praxis der objektiven Hermeneutik. Frankfurt a.M.

Gigon, Olof (1973): Theorie und Praxis bei Platon und Aristoteles. In: Museum Helveticum 30 , H. 2, S. 65-87.

Guski, Alexandra (2007): Metaphern der Pädagogik. Metaphorische Konzepte von Schule, schulischem Lernen und Lehren in pädagogischen Texten von Comenius bis zur Gegenwart. Bern.

Jaeggi, Rahel (2014): Kritik von Lebensformen. Berlin.

Karafillidis, Athanasios (2015): Formale Bedingungen von Hybridität und nichtmoderne Beobachter. In: Thomas Kron (Hg.): Hybride Sozialität - soziale Hybridität. Weilerswist, S. 17-47.

Kerschensteiner, Georg (1921): Die Seele des Erziehers und das Problem der Lehrerbildung. München.

Kron, Thomas (Hg.) (2015): Hybride Sozialität - soziale Hybridität. Weilerswist.

Lakoff, George/Johnson, Mark (2008): Leben in Metaphern. Konstruktion und Gebrauch von Sprachbildern. 6. Aufl. Heidelberg.

Niekrenz, Yvonne (2011): Gemeinschaft als Metapher. Das Imaginäre als Ordnungsschema. In: Matthias Junge (Hg.): Metaphern und Gesellschaft. Die Bedeutung der Orientierung durch Metaphern. Wiesbaden, S. 15-30.

Reichenbach, Roland (2001): Demokratisches Selbst und dilettantisches Subjekt. Demokratische Bildung und Erziehung in der Spätmoderne. Münster.

Reichenbach, Roland (2018): Ethik der Bildung und Erziehung. Essays zur Pädagogischen Ethik. Paderborn.

Spranger, Eduard (1958): Der geborene Erzieher. Heidelberg.

Tippelt, Rudolf (2009): Idealtypen konstruieren und Realtypen verstehen - Merkmale der Typenbildung. In: Jutta Ecarius/Burkhard Schäffer (Hg.): Typenbildung und Theoriegenerierung. Methoden und Methodologien qualitativer Biographie- und Bildungsforschung. Opladen, S. 115-126.

Wittgenstein, Ludwig (1984): Werkausgabe 1: Tractatus logico-philosophicus. Tagebücher 1914-1916. Philosophische Untersuchungen. Frankfurt a.M. 


\section{Verzeichnis der Autorinnen und Autoren}

Bascio, Tomas, lic. phil., Pädagogische Hochschule Zürich, Zentrum für Schulgeschichte, Lagerstrasse 2, 8090 Zürich

tomas.bascio@phzh.ch

Burri, Jennifer, MA, Universität Basel, Departement Geschichte, Hirschgässlein 21, 4051 Basel

jennifer.burri@unibas.ch

De Vincenti, Andrea, Dr., Pädagogische Hochschule Zürich, Zentrum für Schulgeschichte, Lagerstrasse 2, 8090 Zürich

andrea.devincenti@phzh.ch

Grube, Norbert, Prof. Dr., Pädagogische Hochschule Zürich, Zentrum für Schulgeschichte, Lagerstrasse 2, 8090 Zürich

norbert.grube@phzh.ch

Hoffmann-Ocon, Andreas, Prof. Dr., Pädagogische Hochschule Zürich, Zentrum für Schulgeschichte, Lagerstrasse 2, 8090 Zürich

a.hoffmann-ocon@phzh.ch

Horlacher, Rebekka, Dr., Pädagogische Hochschule Zürich, Zentrum für Schulgeschichte, Lagerstrasse 2, 8090 Zürich

rebekka.horlacher@phzh.ch

Juen, Adrian, MA, Pädagogische Hochschule Zürich, Zentrum für Schulgeschichte, Lagerstrasse 2, 8090 Zürich

adrian.juen@phzh.ch

Klinger, Kerrin, Dr., Humboldt-Universität zu Berlin, Institut für Erziehungswissenschaften, Abteilung Historische Bildungsforschung, Unter den Linden 6, 10099 Berlin

kerrin.klinger@hu-berlin.de 
Maeder, Christoph, Prof. Dr., Pädagogische Hochschule Zürich, Zentrum Kindheiten in Schule und Gesellschaft, Lagerstrasse 2, 8090 Zürich christoph.maeder@phzh.ch

Reh, Sabine, Prof. Dr., Bibliothek für Bildungsgeschichtliche Forschung (BBF) des DIPF, Leibniz-Instituts für Bildungsforschung und Bildungsinformation, Warschauer Strasse 34-38, 10243 Berlin sabine.reh@dipf.de

Sieber Egger, Anja, Prof. Dr., Pädagogische Hochschule Zürich, Zentrum Kindheiten in Schule und Gesellschaft, Lagerstrasse 2, 8090 Zürich anja.sieber@phzh.ch

Unterweger, Gisela, Dr., Pädagogische Hochschule Zürich, Zentrum Kindheiten in Schule und Gesellschaft, Lagerstrasse 2, 8090 Zürich gisela.unterweger@phzh.ch 


\section{Pädagogik}

Kay Biesel,

Felix Brandhorst,

Regina Rätz,

Hans-Ullrich Krause

Deutschland

schützt

seine Kinder!

Eine Streitschrift

zum Kinderschutz

[ranempt] $\times r: \times r \mathrm{C}$
Kay Biesel, Felix Brandhorst, Regina Rätz, Hans-Ullrich Krause Deutschland schützt seine Kinder!

Eine Streitschrift zum Kinderschutz

2019, 242 S., kart., 1 SW-Abbildung

$22,99 €(D E), 978-3-8376-4248-3$

E-Book: 20,99 € (DE), ISBN 978-3-8394-4248-7

EPUB: $20,99 €$ (DE), ISBN 978-3-7328-4248-3
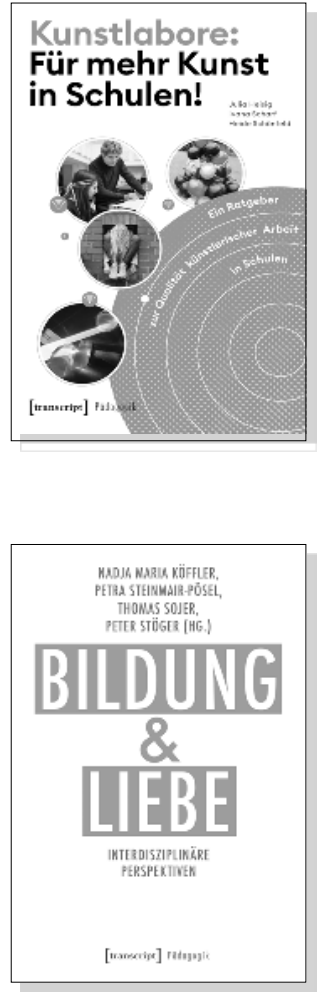

Julia Heisig, Ivana Scharf, Heide Schönfeld

\section{Kunstlabore: Für mehr Kunst in Schulen!}

Ein Ratgeber zur Qualität künstlerischer Arbeit in Schulen

Februar 2020, 216 S., französische Broschur, durchgängig vierfarbig 27,99€ (DE), 978-3-8376-4985-7

E-Book: kostenlos erhältlich als Open-Access-Publikation, ISBN 978-3-8394-4985-1
Nadja Köffler, Petra Steinmair-Pösel, Thomas Sojer, Peter Stöger (Hg.)

\section{Bildung und Liebe}

Interdisziplinäre Perspektiven

2018, 412 S., kart., 11 SW-Abbildungen

39,99€ (DE), 978-3-8376-4359-6

E-Book: 39,99 € (DE), ISBN 978-3-8394-4359-0 


\section{Pädagogik}
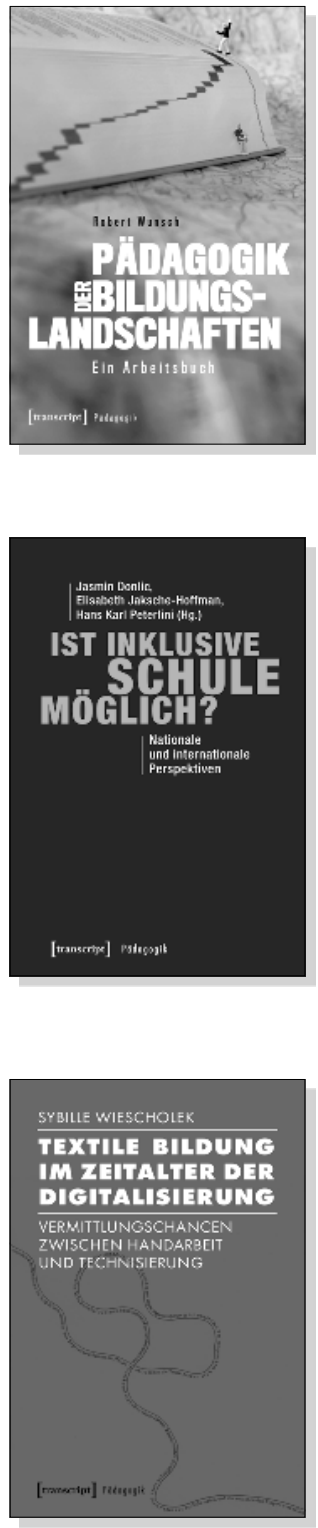

Robert Wunsch

\section{Pädagogik der Bildungslandschaften}

Ein Arbeitsbuch

Januar 2020, 210 S., kart., Dispersionsbindung, 1 SW-Abbildung 29,99€ (DE), 978-3-8376-5119-5

E-Book: 26,99 € (DE), ISBN 978-3-8394-5119-9
Jasmin Donlic, Elisabeth Jaksche-Hoffman,

Hans Karl Peterlini (Hg.)

\section{Ist inklusive Schule möglich?}

Nationale und internationale Perspektiven

2019, 312 S., kart., Dispersionsbindung, 11 SW-Abbildungen 29,99 € (DE), 978-3-8376-4312-1

E-Book: 26,99 € (DE), ISBN 978-3-8394-4312-5
Sybille Wiescholek

\section{Textile Bildung im Zeitalter der Digitalisierung} Vermittlungschancen zwischen Handarbeit und Technisierung

2019, 258 S., kart., Dispersionsbindung, 53 SW-Abbildungen 39,99€ (DE), 978-3-8376-4687-0

E-Book: 39,99 € (DE), ISBN 978-3-8394-4687-4 